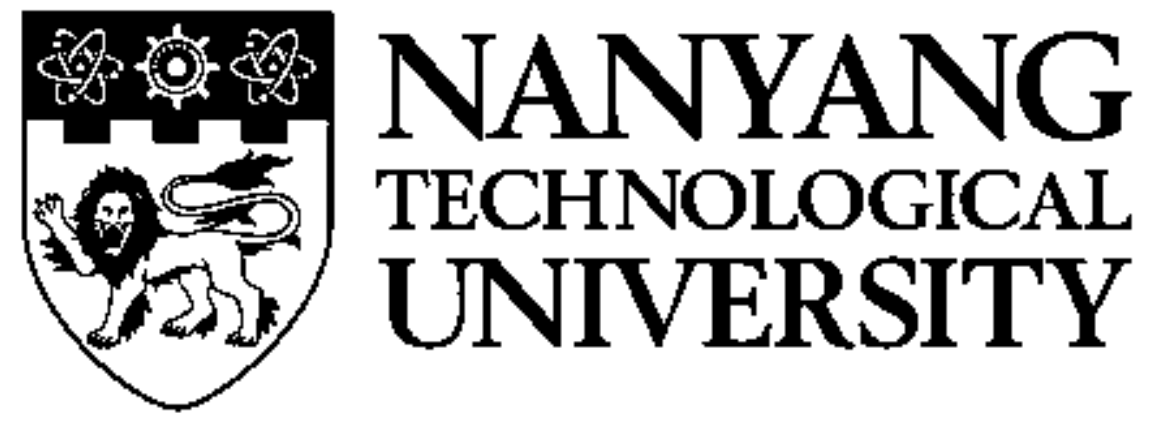

\title{
THE ROAD TO FEDERALISM \\ FINDING THE MIDDLE GROUND IN NEPAL, MYANMAR AND SRI LANKA
}

\author{
MICHAEL G BREEN \\ SCHOOL OF SOCIAL SCIENCES \\ 2017
}


[This page is intentionally left blank] 


\title{
THE ROAD TO FEDERALISM FINDING THE MIDDLE GROUND IN NEPAL, MYANMAR AND SRI LANKA
}

\author{
MICHAEL G BREEN
}

School of Social Sciences

A dissertation submitted in partial

fulfillment of the requirements for the degree of

Doctor of Philosophy

2017 
[This page is intentionally left blank] 


\section{Acknowledgements and declaration}

This thesis would not have been possible without the access, participation and advice from those activists, academics and political leaders who are involved in federalism debates in Nepal, Myanmar and Sri Lanka, and I thank them for contributing their valuable time to my endeavours.

I would like to thank in particular those organizations and individuals that hosted or assisted me substantially in my endeavours, including the United Nations Development Programme, Support to Participatory Constitution Building in Nepal; the Enabling State Programme, Nepal; Tampada Institute, Myanmar; Ethnic Peace and Resources Centre, Myanmar; and the Centre for Policy Alternatives in Sri Lanka. I would also like to thank those individuals in country who helped me to meet the range of people I have been lucky enough to meet, as well as sharing their own insights and helping to make fond memories. This includes, but is by no means limited to, Rohan Edrisinha, Budhi Karki, Yagya Shahi, Ruwendi Wakwella; Lionel Guruge; Alan Smith, and Khin Zaw Win.

This work has proceeded as part of a research project on federalism in Asia, which has allowed me to develop knowledge of other Asian federal systems and test my ideas with others more broadly. I acknowledge the funding of the Singapore Government and I especially thank my supervisors, Baogang He and Brian Galligan, Laura Allison-Reuman, Donald Horowitz, Chou Meng-Hsuan, Francis Hutchinson and all those who have been involved in our federalism in Asia workshops. I also acknowledge the mapping services provided to me Kirke Narusk and permission to publish.

Finally, I declare that this thesis comprises my own original work. 
[This page is intentionally left blank] 


\section{Contents}

Acknowledgements and declaration ...................................................................... 5

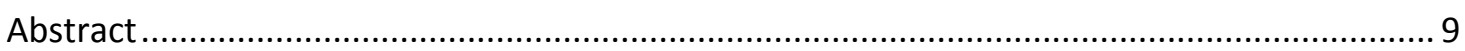

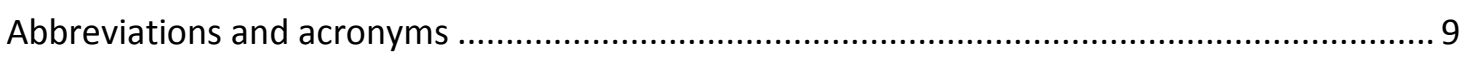

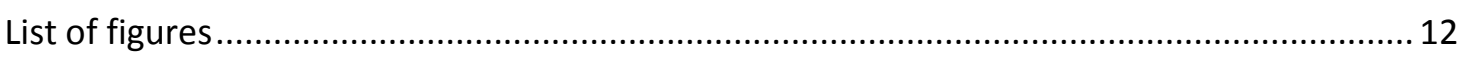

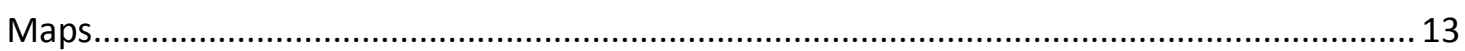

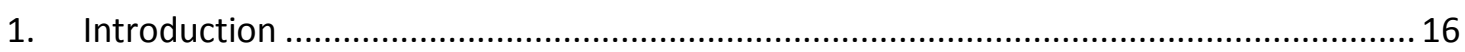

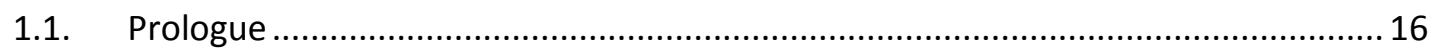

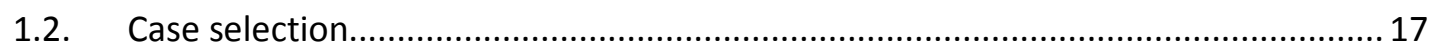

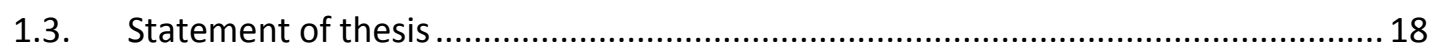

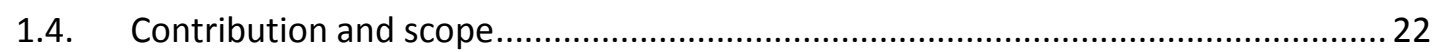

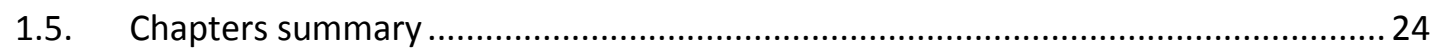

2. Methodology and conceptual framework ......................................................... 27

2.1. New institutionalism ........................................................................ 27

2.2. The federalization process ..................................................................... 34

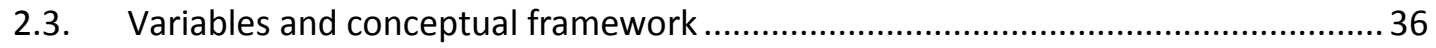

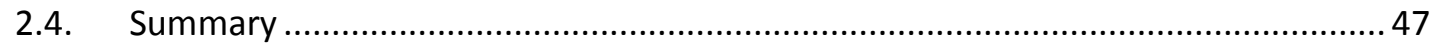

3. Federalism, accommodation and Asia .......................................................... 48

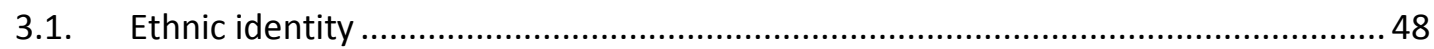

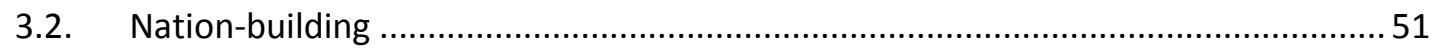

3.3. Constitutional settlements..................................................................... 52

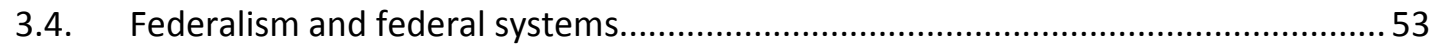

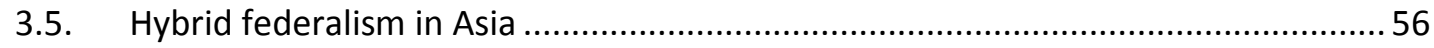

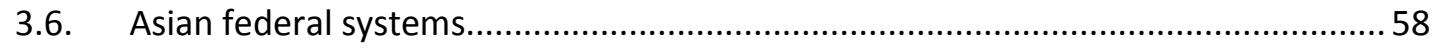

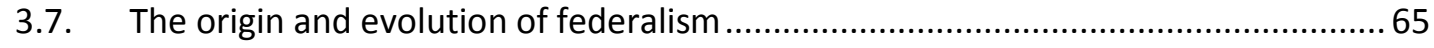

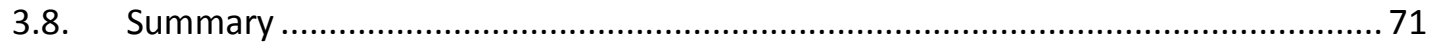

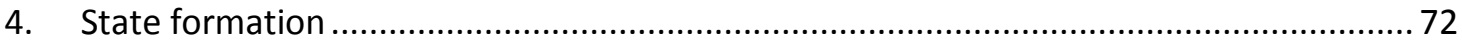

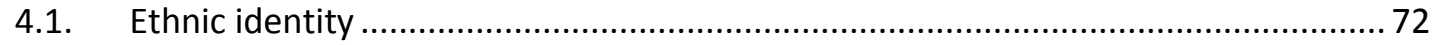

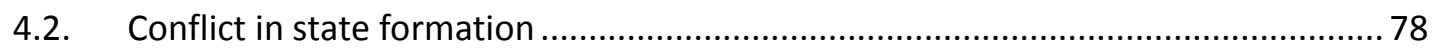

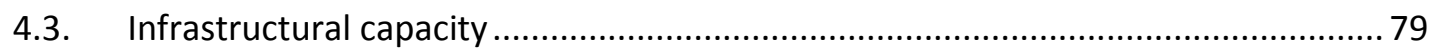

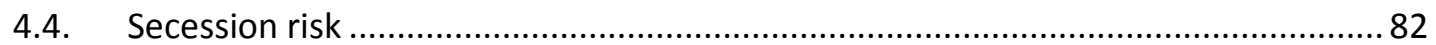

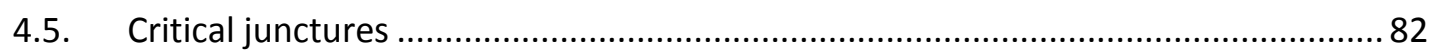

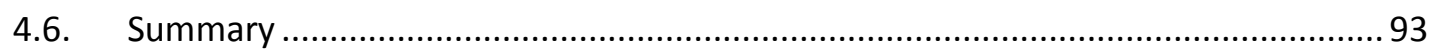

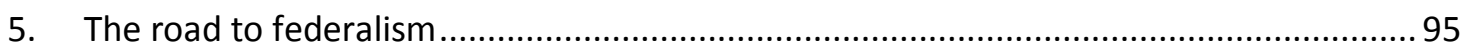

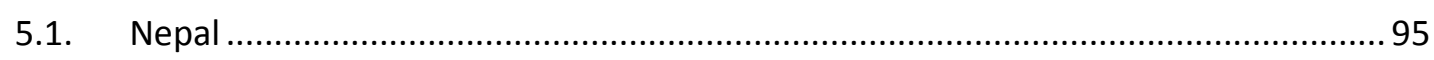




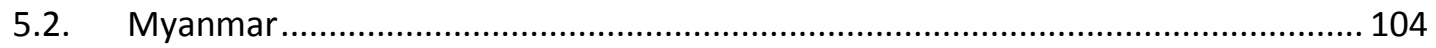

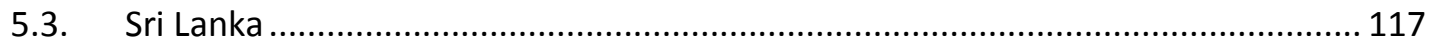

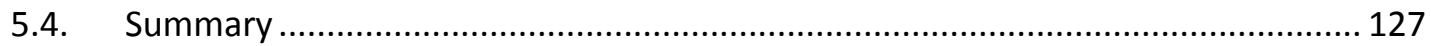

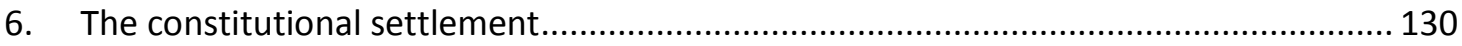

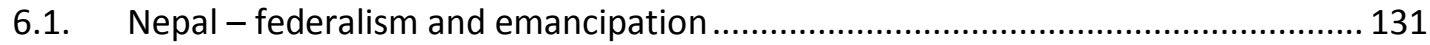

6.2. Myanmar's long-awaited restitution .................................................................... 139

6.3. Sri Lanka - 'maximum devolution within a unitary state' .................................... 147

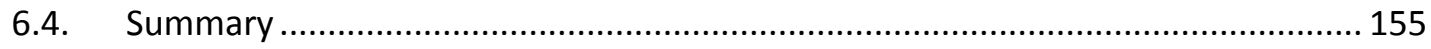

7. Accommodation and moderation - federal design issues.............................................. 157

7.1. The effectiveness of federalism in Asia ............................................................... 158

7.2. Ethnic or territorial federalism .......................................................................... 162

7.3. Power sharing and political inclusion ................................................................ 167

7.4. Deliberative democracy and divided societies ..................................................... 177

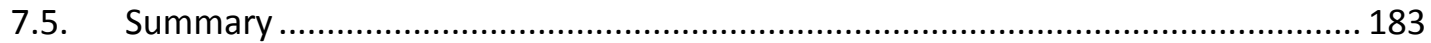

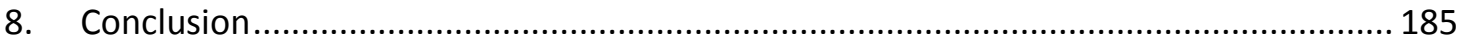

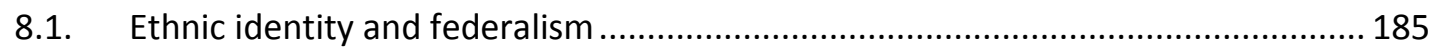

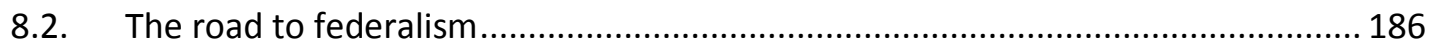

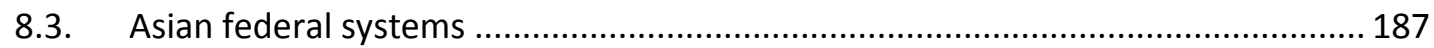

8.4. Federal design issues - accommodation and moderation .................................... 188

8.5. Prospects for federalism in Nepal, Myanmar and Sri Lanka .................................. 193

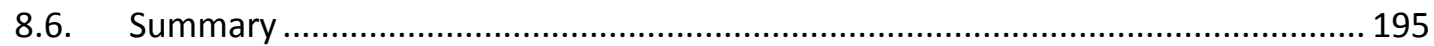

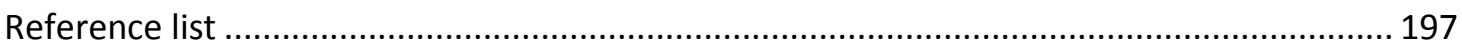

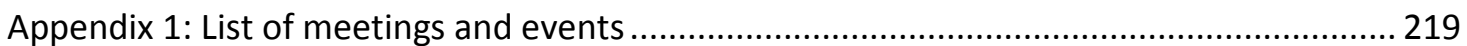

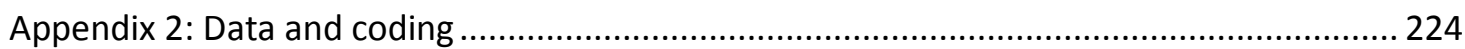

Appendix 3: Media data from Nepal's federalism debate ..................................................... 286

Appendix 4 - Quantitative analysis for variable selection ..................................................... 294 


\section{Abstract}

Following the establishment of post-World War II modern nation-states, many Asian countries including Nepal, Myanmar and Sri Lanka sought to nation-build on the basis of their dominant ethnic group's identity, to the exclusion of smaller ethnic groups. There was substantial resistance, leading to civil war and poor development. Minority ethnic groups have demanded federalism and the recognition of their political equality, lest they pursue a secessionist agenda. It is not known why Asian states have been reluctant to institutionalize federalism, nor what causes it to be established in these holding together situations, let alone what type of federalism is more likely to be conducive to establishing political equality and bringing an end to conflict and authoritarianism. This thesis addresses these questions and dissects the lessons and innovations of the institutional responses of Nepal, Myanmar and Sri Lanka to their diversity based challenges.

Using a historical institutional methodology and analyzing the critical junctures and intervening path dependencies, I demonstrate the importance of secession risk and infrastructural capacity variables to the establishment of holding together federalism, building on the theories of Riker (1964) and Ziblatt $(2004,2006)$. I show how the initial nation-building mechanism, as a tool of power reproduction by the dominant ethnic group, kick started a simultaneous reactive sequence leading to centralization, concession and ultimately, a federal compromise. In particular, when the secession risk is moderate, and when minority ethnic groups have a demonstrable infrastructural capacity, there are incentives for regime change agents from the dominant ethnic group to align with minority ethnic groups to pursue mutual goals of federalism and democratic reform.

Further, although federalism may be agreed as part of such a constitutional settlement, there remain many issues to resolve, primarily the demarcation of units, the division of powers, power-sharing and proportionality. An ethnic federal system is likely to have a narrower and less secure set of powers for units with any shortcomings in ethnic autonomy addressed by inclusion, non-territorial arrangements, local government and personal laws.

Accommodation of diversity is a just goal, but without moderation, accommodation can lead to extremism and undermine political equality. Nepal, Myanmar and Sri Lanka are finding a middle ground whereby deliberative and moderating institutions are combined with accommodating ones to balance centrifugal and centripetal forces. Based on their experiences, I hypothesize that a federal system that encourages, if not requires, multiethnic political parties at the center, and ethnic parties in the units and sub-units provides a range 
of cross-ethnic, accountable, multilevel and semi-detached forums that incentivize moderation through deliberation, while accepting the validity and justice of ethnic autonomy and other accommodating institutions. 


\section{Abbreviations and acronyms}

\begin{tabular}{|l|l|}
\hline AFPFL & Anti-Fascist People's Freedom League \\
\hline BIA & Burma Independence Army \\
\hline BSPP & Burma Socialist Programme Party \\
\hline CPA & Centre for Policy Alternatives \\
\hline CPB & Communist Party of Burma \\
\hline CPN & Communist Party of Nepal \\
\hline CRSDSP & $\begin{array}{l}\text { Committee for the Restructuring of the State and the Distribution of State } \\
\text { Power }\end{array}$ \\
\hline FPTP & First past the post \\
\hline ITAK & Illankai Tamil Arasu Kachchi \\
\hline JVP & Janathā Vimukthi Peramuna \\
\hline LSSP & Lanka Sama Samaja Party \\
\hline LTTE & Liberation Tigers of Tamil Eelam \\
\hline MP & Member of Parliament \\
\hline MMP & Mixed-Member Proportional \\
\hline NCCT & National Ceasefire Coordination Team \\
\hline NLD & National League for Democracy \\
\hline PM & Prime Minister \\
\hline PRCCR & Public Representations Committee for Constitutional Reform \\
\hline SAA & Self-Administered Areas \\
\hline SLFP & Sri Lanka Freedom Party \\
\hline SLORC & State Law and Order Council \\
\hline STVPR & Standard Transferable Vote Proportional Representation \\
\hline TNA & Tamil National Alliance \\
\hline UML & Communist Party of Nepal (United Marxist-Leninist) \\
\hline UNFC & United Nationalities Federalism Council \\
\hline UNP & United National Party \\
\hline USDP & Union Solidarity and Development Party \\
\hline WWII & World War II \\
\hline
\end{tabular}




\section{List of figures}

Diagram 1: Converging self-reinforcing and reactive paths and the road to federalism ......... 35

Diagram 2: Conceptual model on the origins of holding together federalism in Asia ............. 37

Diagram 3: Federalism, quasi-federalism and Asian federal systems ................................ 55

Diagram 4: The assimilation, integration and accommodation continuum .......................... 63

Diagram 5: Nepal - elements of accommodation 1948-2015............................................99

Diagram 6: Nepal - institutional accommodation 1946-2016 .......................................... 102

Diagram 7: Nepal - accommodation, secession risk and infrastructural capacity 1948-2015 103

Diagram 8: Nepal - accommodation and democratization 1948-2015 .............................. 104

Diagram 9: Myanmar - elements of accommodation 1948-2015 ..................................... 112

Diagram 10: Myanmar - accommodation, secession risk and infrastructural capacity 1948-

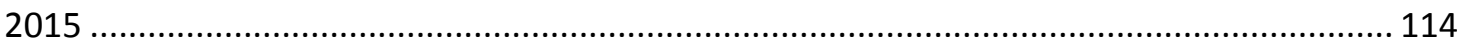

Diagram 11: Myanmar - institutional accommodation 1946-2016 .................................... 116

Diagram 12: Myanmar - accommodation and democratization 1948-2015 ........................ 117

Diagram 13: Sri Lanka - elements of accommodation 1948-2015.................................... 122

Diagram 14: Sri Lanka - accommodation and democratization 1948-2015 ........................ 124

Diagram 15: Sri Lanka - institutional accommodation 1946-2016 ..................................... 125

Diagram 16: Sri Lanka - accommodation, secession risk and infrastructural capacity 1948-

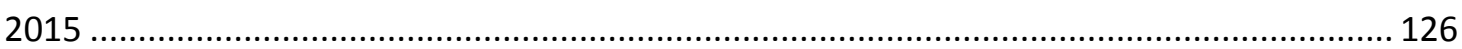

Diagram 17: Institutional accommodation in Nepal, Myanmar and Sri Lanka, 1946-2016.... 128

Diagram 18: Sequences and path dependency to federalism in Asia.................................. 129

Diagram 19: Support for territorial federalism during Nepal's constitution-making process 179

Box 1: Measuring an Asian federal system and interpreting results

Table 1: Summary of key variables per Nepal, Myanmar and Sri Lanka. 41

Table 2: Definition and operationalization of variables, conditions and mechanisms............ 42

Table 3: Federal systems in Nepal, Sri Lanka and Myanmar ...............................................45

Table 4: Summary of demographic, unit demarcation and autonomy relationships ............ 163

Table 5: Summary of secession risk and autonomy relationship ....................................... 164

Table 6: Comparison of 2013 election outcomes on a party versus ethnic basis.................. 170

Table 7: Proposed criteria for assessing deliberative conditions in federal systems ............ 183 


\section{Maps}

Map 1: Federal map of Nepal, including ethnic distribution

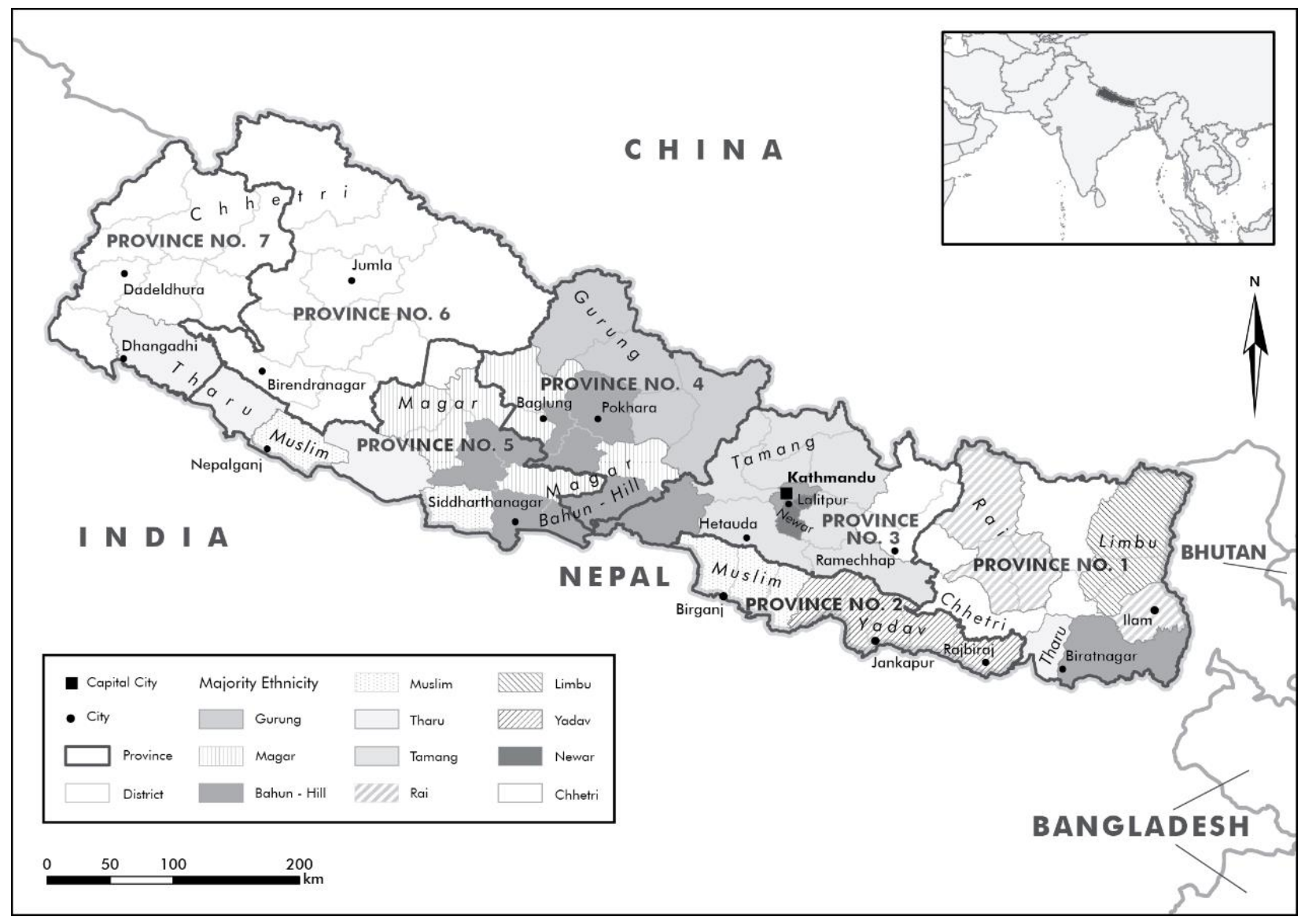

(Ethnic distribution based on majority ethnic group per district, as per Nepal Census (Central Bureau of Statistics 2014)) 
Map 2: Federal map of Myanmar, including ethnic distribution

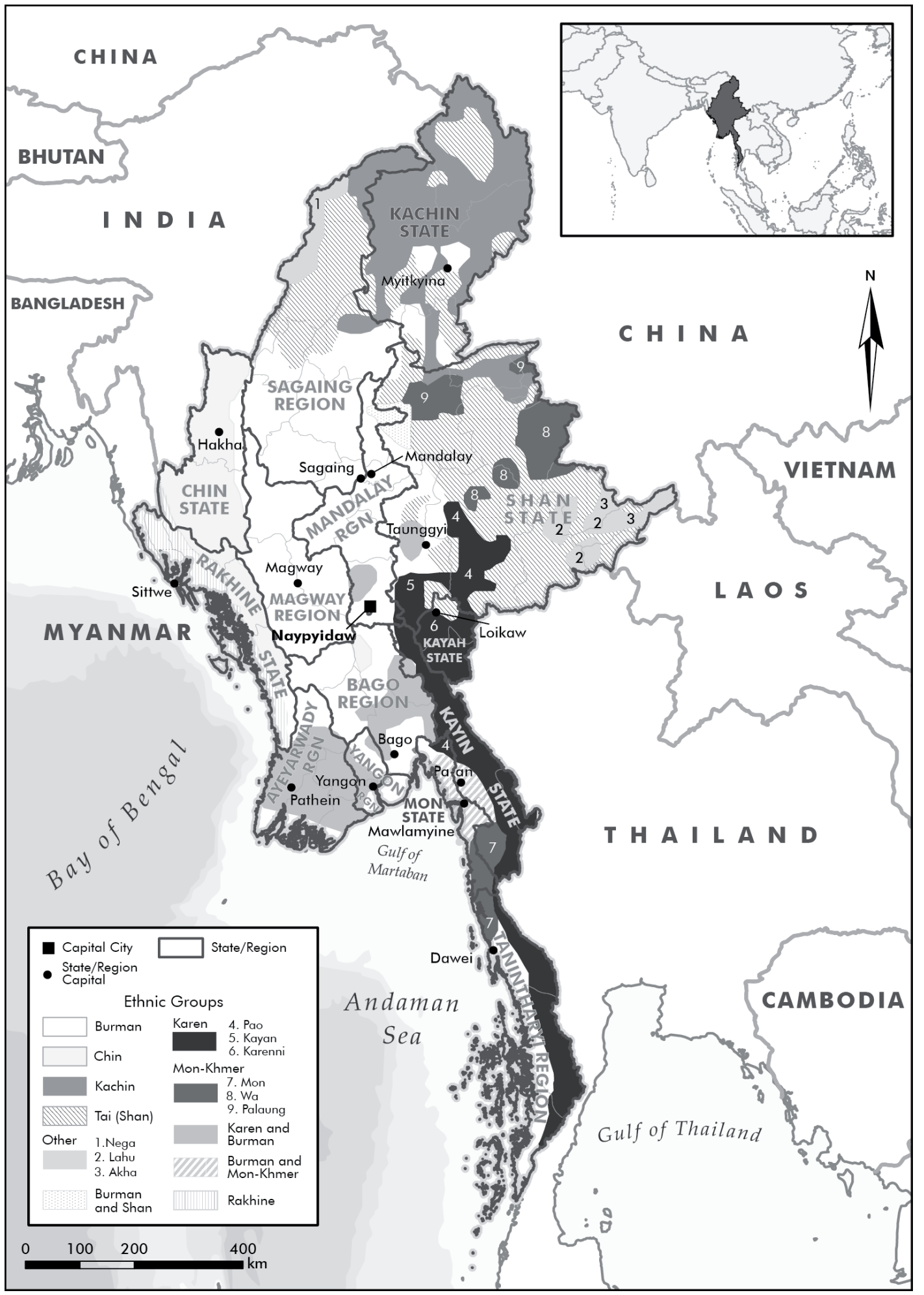

(Ethnic distribution based on data from Smith 1991) 
Map 3: Federal map of Sri Lanka, including ethnic distribution

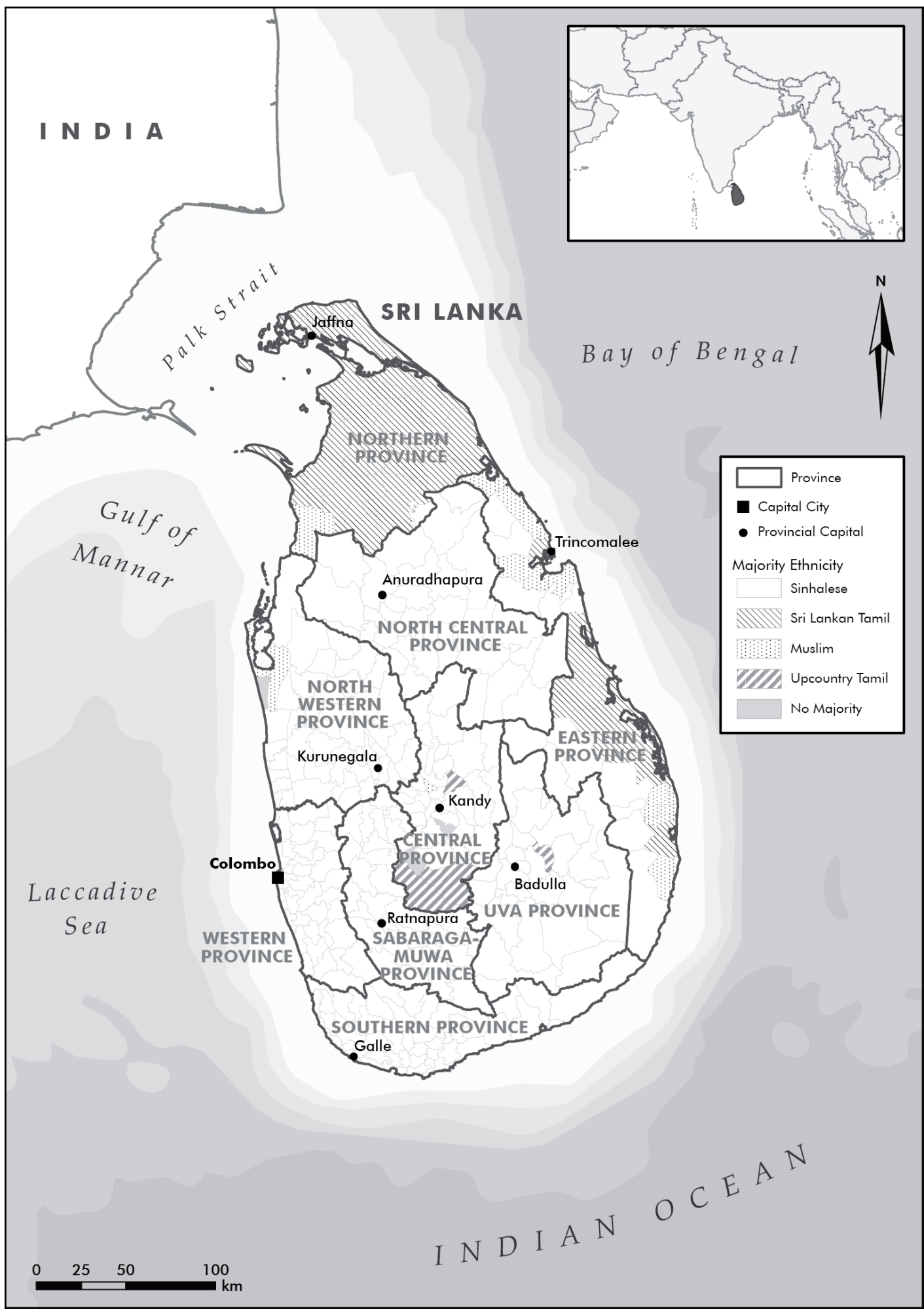

(Ethnic distribution data from Sri Lanka census (Department of Census and Statistics 2015)) 


\section{Introduction}

\subsection{Prologue}

Nations built on exclusion and assimilation, decades of civil war, widespread poverty, authoritarianism and the decline of democracy. Nepal, Myanmar and Sri Lanka are travelling a road to federalism. Institutions and ethnic identity have interacted to privilege some and marginalize others. But when the right conditions prevail, political equality can be restored.

Seventy years ago, a new world order was emerging from the aftermath of World War II (WWII) and the decolonization of large parts of the developing world. Nepal, Myanmar and Sri Lanka, ethnically diverse and highly religious countries, made formative decisions about whether and how the majority ethnic, caste and religious groups would relate institutionally to the smaller groups located within their borders. In the following years, the consequences of those choices and the institutional advantage that they embedded played out in patterns of power production and reproduction and reaction and counter-reaction, culminating in new opportunities for transformative change.

The conditions are now in place for minority ethnic groups in Nepal, Myanmar and Sri Lanka to take their legitimate space in the state and determine their own futures. 2015-16 were watershed years. Nepal enacted its new federal democratic constitution, Myanmar commenced a process towards changing its constitution to a democratic federal union, and Sri Lanka turned its parliament into a constitutional assembly tasked with finding a solution to 'the national issue'.

When problems, like conflict and poor development, are based in the political suppression of ethnic diversity, federalism would seem an obvious solution. It can accommodate ethnic diversity by enabling self-rule by ethnic minorities and inclusion in central institutions. However, as in other countries in Asia, federalism has been strongly resisted, and minorities have suffered. Many fear that federalism will lead to secession and national disintegration, and that new minorities will be created and marginalized.

With accommodation, should come moderation, lest the worst effects of intra-ethnic competition come to play. Nepal, Myanmar and Sri Lanka are finding a middle ground, where the rights of minority ethnic groups are affirmed and given institutional substance, and the risks of federalization are mitigated by creating deliberative conditions across multiple levels to establish a new path towards peace, development and democracy. 
It is not known why these countries, among others in Asia, have been resistant to federalism, even in the face of protracted conflict, and why it is that each is now arriving at federalism. It is a necessity that they address the challenges associated with nation-building in ethnically diverse societies, and the conditions that have led to exclusion and discrimination. Is there a middle way which can avoid the oscillation between extremes, or the emphasis on assimilation or integration which has beset the evolution of their modern states? Unless Nepal, Myanmar and Sri Lanka adequately accommodate their minority ethnic groups, and moderate their extremes, they may continue to suffer the consequential impacts and their governments may continue to be unable to deliver on their peoples' aspirations for peace, development and democracy.

This thesis finds answers to these questions, by tracing the evolution of federalism and other institutions for the accommodation, integration and assimilation of ethnic diversity. It shows how the exclusionary basis of nation-building encapsulated a simultaneously reproductive and reactionary sequence that foreshadowed many of the problems that would be experienced in Nepal, Myanmar and Sri Lanka, but at the same time, precipitated a shift towards an accommodating federalism that would become an end in itself. In exploring the debates, the institutions and the interaction of prevailing conditions, the thesis also extracts lessons for federal design and new innovations to be explored and applied over the coming years.

\subsection{Case selection}

This thesis focuses on the road to federalism in Nepal, Myanmar ${ }^{1}$ and Sri Lanka ${ }^{2}$. There are many good reasons to study federalism and ethnic accommodation by comparing the cases of Nepal, Myanmar and Sri Lanka. Each country's political history as a modern state has been punctuated by the politics of identity, eventually arriving at federalism as an outcome of civil war, as part of a 'third generation' of federalism in Asia (see Chapter 3.7.1) and, after a long period of internal debate about whether and how to accommodate minorities. Ethnic identity and the management of the associated political cleavages are a challenge in common to Nepal, Myanmar and Sri Lanka.

\footnotetext{
${ }^{1}$ Known as Burma at independence until 1989 when it was renamed the Union of Myanmar by the then military junta. Although not yet recognized by the US, this name is now commonly accepted and so I exclusively use the name Myanmar.

${ }^{2}$ Sri Lanka was formerly known as Ceylon. Its name was changed to Sri Lanka in 1972, which was identified with the majority Sinhalese. It is referred to throughout this thesis as Sri Lanka.
} 
Prior to and following the establishment of their post-WWII modern nation-state, each sought to nation-build on the basis of the dominant group's identity, to the exclusion smaller ethnic groups. After a tumultuous political trajectory including reversions to authoritarianism, elites and civil society have recognized the necessity of managing, rather than suppressing, ethnic identity and cultural diversity. Minority ethnic groups in each case have demanded federalism to overcome the legacies of historical discrimination and exclusion, which have been perpetuated by unitary and quasi-federal systems, and authoritarian and democratic regimes. This is discussed further in Chapter 3.2 (see also Lawoti 2005; Bhattachan 2008; Bennett et al. 2006a; DeVotta 2004; Smith 1991; Taylor 2009).

The contextual situations are also similar - regionally, socially and economically - allowing particular variables to be controlled, while important differences in matters like regime type and the mode of state formation allow rival theories to be assessed. Ethnic identity varies within and across cases and each country has been at a critical juncture over recent years enabling real time observation of the decision-making processes and debates determining the types and features of their federal systems, and the relationships between them. Most particularly, it is these institutional differences and their evolutionary paths that are compared. These similarities and differences are elaborated in Chapter 2.3.

I have not chosen to focus on the first-generation federal countries, India, Pakistan and Malaysia, all of which have been well researched and whose federal systems are more clearly associated with the decolonization processes. Other countries in Asia are facing the federal challenge, such as the Philippines, but without the array of past institutional responses nor the widespread conflict that has precipitated the contemporary settlement processes.

\subsection{Statement of thesis}

Federalism is regularly promoted as a potential solution to such 'minority problems' (e.g. Kymlicka 2007; Anderson 2013; Ghai 2000; Lawoti 2010; Stepan, Linz \& Yadav 2011; Stepan 1999) and is the preferred means of accommodation by minority ethnic groups in Nepal, Myanmar and Sri Lanka. However, it has been the major issue preventing a modern constitutional settlement in those countries.

Federalism as a term is itself contested, with dubious connotation in the region, due in large part to the experience of Pakistan and Bangladesh, which split after a bloody war and external intervention. Federalism is most often used to refer to a specific type of state 
structure, being two or more levels of government, each with constitutionally-based powers and a direct relationship to the people ${ }^{3}$, but it has also been given an ideological connotation, focusing on systems for 'unity in diversity' and 'shared and self-rule' (see discussion in Chapter 3.4). There are many types of federalism, some overlapping. Minority ethnic groups often seek ethnic federalism, where unit boundaries are drawn to account for and empower ethnic groups (Kymlicka 1995; Kymlicka 2007), as compared to territorial federalism, where boundaries and laws are blind to ethnicity and cultural difference (Ghai \& Cottrell 2007; Brown 2007). In Nepal, Myanmar and Sri Lanka, they also distinguish between genuine federalism, meaning a democratic federation with equality between units and the center, and quasi-federalism, as encompassing other forms of government that incorporate federal features, including a constitutional division of powers, but the units are subordinate to the center.

Despite federalism's apparent popularity as a tool to manage diversity and resolve conflict, there has been relatively little analysis in the literature of Asia and its varied and still evolving hybrid approaches, which have not been well conceptualized or evaluated. The emergence of federalism in particular is under-theorized, especially in the Asian region and with respect to 'holding together federalism' (where federalism was introduced to prevent the break-up of a country, rather than via the 'coming together' of previously independent units) (Stepan 1999). This is a gap which my research addresses. I develop a concept of Asian federal systems to guide my research and develop a coherent theory on their origins and evolution. These may be further developed and improved with more explicit consideration of the experience of other Asian countries and the implementation of federalism in Nepal, Myanmar and Sri Lanka.

There are no known overarching causes or necessary and sufficient conditions that explain why a state in Asia chooses to accommodate, nor how genuine or effective measures will be (Bertrand \& Laliberte 2010). A variety of requisite or determinative causes or conditions has been considered including democratization (Bertrand \& Laliberte 2010; Galligan 2007); the method or mode of state formation, especially violence (Reid 2007); minority' commitment to human rights (Kymlicka 2007); religion (He 2007; Walton 2013; Raghavan 2013); and the role of international actors (Kymlicka 2007; Bertrand \& Laliberte 2010).

\footnotetext{
${ }^{3}$ Each is selected and acting directly on its constituents; possessing legislative and executive powers derived from a constitution; and, able raise revenue and allocate resources (Watts 1999; Riker 1964; Elazar 1987). Conversely, a unitary system, where sovereignty is held or vested (by the people) in a central level of government, may have administrative units, bicameral parliaments and even local government elections, but those units are not constitutionally protected and the center may unilaterally alter, revoke or create units and powers.
} 
I use these elements as control variables and rival theories and instead build upon the theories of William Riker (1964) and Daniel Ziblatt $(2004 ; 2006)$ regarding the origins of federalism, which I find are still most pertinent. I expand their focus from the conditions and mechanisms of coming together federalism, to the holding together systems of Asia. I distinguish between those processes that are essentially unilateral and concessionary, which bought only quasi-federalism often in an authoritarian or presidential context, and those under which a democratic federalism is the most viable option. I use a historical institutionalism based methodology, mapping path dependencies and the interaction of selfreinforcing and reactive sequences, and analyzing critical junctures and federalism debates.

My key proposition is that holding together federalism in Asia is established following an alliance of excluded minorities and regime change forces from the dominant group. I argue that necessary and sufficient conditions for the establishment of federalism are ethnic diversity, associated infrastructural capacity and a moderate secession risk. This applies whether the alliance seeks to overturn a colonial administration, such as occurred in India and Myanmar, or an indigenous ruler, such as occurred in Nepal. I demonstrate that Nepal, Myanmar and Sri Lanka are on a road to federalism, triggered by the identity-based nation-building that gave rise to a simultaneously self-reinforcing and reactive sequence. I also show why federalism does not arise under democratic conditions, unless as part of a transition involving regime change.

Further, by tracing the evolution of institutions of accommodation and integration, and their relative impacts, I draw important lessons for the balancing of centrifugal and centripetal forces, which often compete to the detriment of stability and the development and inclusion of minorities. I develop a new hypothesis and argue that accommodation needs to be accompanied by moderation to mitigate the risks of secession and minority oppression, which are the most common concerns accompanying federalization. Deliberative settings, incorporating inclusive representation and accountability, embedded in a competitive multilayered system with a degree of semi-detachment, provide the incentives for accommodating institutions to contribute to achieving just outcomes.

I argue that the experiences of Nepal, Myanmar and Sri Lanka show that a federalism designed to embed deliberative conditions and encourage multiethnic institutions, particularly political parties, at the center while leaving space for ethnic parties and lowerlevel group autonomy at the unit levels, is able to balance the centrifugal forces associated with ethnic federalism and the moderating centripetal forces associated with integration and 
electoral incentivization. That is, it contributes to justice as a political equality that combines accommodation and moderation and provides space for all groups and individuals to have access to and participate in political deliberation and decision-making. The cases of Nepal, Myanmar and Sri Lanka entail a rejection of the consociational paradigm (see Chapter 3.6.2), as a consensus government has only appeared at times of transition, and even then, with an oppositional element. The minority ethnic groups in these countries are seeking accommodation via autonomy and inclusion, with little regard for the role of the group in the center.

Hybrid systems have been developed to find a middle ground. State-wide multiethnic, and unit based ethnic political parties are more likely to emerge under hybrid federal systems and multiethnic political parties pursue more moderate policies than those that are based on ethnicity. Mixed, sovereign and multilevel institutions, in combination with proportionality, incentivize reciprocity and accountability. Such hybridizations are evident in these cases and suggest the beginnings of a new paradigm for federalism in ethnically diverse countries. Further, the cases show an empirical relationship between the extent that ethnicity is used as a basis of federal delineation with accommodation via proportionality and inclusion, and the security and powers of the units (i.e. ethnic federalism tends to be more centralized than territorial federalism, on account of the potential for secession and marginalization of new minorities). These matters comprise new hypotheses for testing and further development in the future.

In developing and testing this thesis, I undertook field work: in Nepal in September-October 2014, which supplemented my previous research and professional activities in that country between 2007 and 2010 (which focussed on federalism and the political rights of marginalized communities); in Myanmar in November-December 2014 and again in August 2016; and in Sri Lanka in November-December 2015. During these periods, I had more than fifty meetings with senior political leaders (including former prime ministers and current and former chief ministers), insurgents (current and former), government representatives and civil society about the key issues, processes, options and relationships regarding federalism and ethnic accommodation. Many of these people are, or have been, closely involved in the constitution-making processes (for example, Dr Jayampathy Wickramaratne, an MP who is leading the drafting of the new Sri Lankan constitution), or instrumental in the negotiation of peace agreements and federal compromises (such as former Nepali Maoist leader $\mathrm{Dr}$ Baburam Bhattarai). Conclusions drawn have been verified using additional or alternative sources and referenced accordingly. I also observed and participated in more than twenty 
meetings and events related to constitution-making and federalism in Nepal, Myanmar and Sri Lanka, and tested and presented ideas directly. Key events and discussions are listed in Appendix 1 . These included seminars and workshops that I led and which were attended by Members of Parliament (MPs), political parties and civil societies representatives.

\subsection{Contribution and scope}

I make a contribution in two key areas, the origins of federalism and in constitutional design for divided societies. In doing so, I make methodological advances regarding path dependence and introduce new ways of understanding Asian federal systems, which some scholars may find useful. Specifically:

- I alter and test Ziblatt's (2004; 2006) improvement on Riker's (1964) theory on the origins of federalism in the context of modern holding together federal systems in Asia. I alter the necessary condition / variable of 'external threat' to instead consider 'secession risk', demonstrate that variable's causal relationship to key federal design outcomes, and further detail the pertinent causal mechanism;

- I identify particular federal institutional configurations that appear most conducive to blending accommodation and moderation in a divided society, and in doing so, develop an additional hypothesis regarding the means by which consociationalism's emphasis on the empowerment of ethnic actors, and centripetalism's emphasis on incentivizing moderation by cutting across cleavages, may be reconciled (see summary of debate in Chapter 3.6.2);

- I show that, contrary to conventional historical institutionalism theory, path dependencies may be simultaneously reproductive and reactive (see Chapter 5 for details). In doing so, I demonstrate the sequence by which post-WWII Asian federalism arises, which is different to the sequence that Burgess (2013) argues precipitates federalism (see Chapter 3.5).

- I offer a new way to conceptualize and measure federalism that is aimed towards the management of diversity, develop an index for measuring the extent to which a state system accommodates, and propose a new concept of an Asian federal system.

I expect that these provide a useful contribution to the literature and further opportunity for refinement, elaboration and application. I do not make an argument that Asian federal systems are ideal approaches or normatively based. Further, the study does not test my thesis on all holding together federal systems, which would require a separate piece of work. 
Also, there are shortcomings in the availability of information across all three cases, due in part to their sometimes insular past and internal suppression of debate, and the results of my study may be improved should further data become available.

I do not investigate matters like the causes of ethnic conflict or democratic transitions or the effects of decolonization, except to the extent that they concern my cases specifically and link with my main research focus. The focus of my research is on the institutions associated with the accommodation of minority or excluded ethnic groups, most especially federalism along with consociational and centripetal institutional design options. I do not consider the full range of institutions and agreements that might be involved in a constitutional settlement arising from post-conflict situations, such as security sector reform (e.g. 'consociation plus'). Furthermore, the focus of the research is on the post WWII era. Prior events, social structures and institutional configurations are understood as creating or comprising antecedent conditions, some of which are critical and some of which are not.

Further, with some exceptions, I do not consider the potential impact of future international events, or the impact on the international arena of developments in these countries, which are beyond the scope of this thesis. I do consider the role of international actors as contributing to secession risk, or playing a role or intervening in critical internal decisionmaking processes. Further, I note that an important cause of conflict, de-democratization and poor development is the lack of justice provided to minority ethnic groups (as discussed in Chapter 3.1 and 3.2), and so institutions that maximize justice (as discussed in Chapter 7) are likely to increase the resilience of those institutions to withstand external shocks.

There have been highly significant developments occurring in each country during the writing of this thesis, including shortly after commencing. These include the commitments to reform the constitutions in Myanmar and Sri Lanka, and the finalization of Nepal's new constitution. The thesis and its findings address these developments, which has necessitated some methodological adaptations and refocusing, in particular towards the origins and evolution of federalism, rather than the effects of different institutional arrangements. To this end, while I consider the effects of different institutional arrangements, it is limited to considering the incentive structures rather than outcomes, with some exceptions (e.g. the inclusivity of electoral outcomes). 


\subsection{Chapters summary}

My thesis is structured as follows. Firstly, I explain my methodology and conceptual framework. Chapter 2 outlines the reasons for applying historical institutionalism to my research and defines my use of key concepts like path dependency and critical junctures. I apply that framework to the federalization process, developing a conceptual model for the interaction of self-reinforcing and reactive paths along the road to federalism. I then develop my second conceptual model, which links antecedent conditions to federal outcomes, and detail my variables and their application in each of my cases.

Chapter 3 expands on the theoretical underpinning and logic of my thesis and main proposition. I outline the importance of ethnic identity and the justice inherent in its recognition and accommodation. I argue that the persistence of ethnic identity renders mute arguments about whether identities are constructed or primordial, and define the context and key terms used throughout the thesis. In particular, when the modern states of Asia attempted to consolidate their colonial boundaries via an identity-based nation-building agenda, conflict and instability resulted. With few exceptions, these modern borders masked substantial internal diversity which governments would come to accept as needing to be accommodated for peace and development. I then turn to federalism and federal systems, and their emergence in Asia. I distinguish between different types of federalism and define my use of terms.

Using this basic framework, I develop a concept of an Asian federal system for analytical purposes, incorporating the key institutions for achieving the federal purpose of 'unity in diversity', and outline a measurement approach along a continuum of assimilation, integration and accommodation. At the accommodation end of the spectrum are two rather distinct approaches, one which encourages centripetal forces and the other which empowers ethnic groups and is centrifugal. Expanding on the logic of my thesis, Chapter 3 explores the causes of federalism in the literature and in the Asian experience, concluding that the theories of William Riker and Daniel Ziblatt can be modified to apply to the holding together federal systems of Asia, which have emerged over three generations.

In Chapter 4, I turn specifically to the cases of Nepal, Myanmar and Sri Lanka and their formation as modern states. I first consolidate and overview the antecedent conditions and status of the key variables at this post WWII juncture and then undertake a specific analysis of how those conditions and variables influenced the key actors and the decisions that they took. In Nepal, federalism was of little interest to the key actors despite some ethnic groups 
advocating for such autonomy. With the battle for power amongst only the elite of the dominant group, a unitary state based on individual rights would become the preferred option of each key actor, irrespective of their other disagreements. In Myanmar, a volatile and finely balanced set of key actors allied to establish a federal system in order to secure independence from the British and prevent the breakdown of the colonial boundaries. But, with Bamar dominance entrenched, a highly centralized and hybridized version would be imposed by the major party at the time. In Sri Lanka, despite unique cultures, the absence of a secessionist threat and regional or identity-based infrastructural capacity meant federalism was not taken seriously and a liberal democracy based on individual rights was meant to provide for political equality, despite the concerns put to the constitutional architects at the time.

Chapter 5 focuses on the evolution of federal institutions and those which serve an assimilating, integrating or accommodating purpose more generally. In each case, the initial advantage of the dominant ethnic group is consolidated via further institutional change. However, these changes, taking the form of identity-based nation-building, triggered a reactive sequence that clashed with the simultaneous reproductive sequence of ethnic domination encapsulated by the nation-building and other related activities. The chapter explains the major institutional changes over the course of each case's modern history, maps them along an assimilation, integration and accommodation continuum and shows how those changes heightened the intensity of reactions and the strength of the minorities leading ultimately to instability and the necessity of federal reforms to better manage ethnic diversity. Finally, for each case, I discuss the interaction of this federalization process with democracy and the key variables and show how when those variables display certain characteristics, alliance formation and a fuller federalization follows. This takes us to the contemporary constitutional settlement.

Chapter 6 details the contemporary critical junctures, which are still evolving in some cases, using the federal debate to draw out the underpinnings of change and its parameters. It confirms the continued salience of secession risk and infrastructural capacity and expands in some detail on the alliances formed and necessary for achieving a genuine federalism, as compared to the quasi-federalism that each has institutionalized, without success, in the past. First, the chapter reformulates the key actors, as updated from the state formation stage and briefly details the relevant constitutional change processes around which that alliance operates. Although there is a modern-day emphasis on participatory processes, the processes of these countries are primarily elitist though involving ethnic elites and an 
important deliberative dimension in contrast to previous unsuccessful attempts at federal constitutional reform. Chapter 6 considers in more detail the way that secession risks and other fears around ethnic federalism are mitigated through institutional design and federal compromises, such as the trade-offs between autonomy and ethnicity, and the role of democracy and other control variables in framing the possible and prospective positions taken in each case. This leads into an exploration of the lessons that the federalization of Nepal, Myanmar and Sri Lanka provide.

Chapter 7 looks specifically at federal design issues and how they interact with electoral system design. I develop a criteria-based evaluation approach that focuses on political equality as blending accommodation with moderation through the creation of institutions and federal configurations that are conducive to deliberation, which I use to underpin a hypothesis for future testing that such arrangements are more likely than traditional federal structures to achieve political equality. I consolidate the lessons from the contemporary federal debates in Nepal, Myanmar and Sri Lanka, and how issues of power-sharing are addressed via electoral systems and proportionality requirements, rather than consociationalism's executive power-sharing institutions (e.g. a grand coalition), or federalism, especially bicameralism. I recount how electoral systems have operated in the countries and how recent changes are linked to increasingly moderate policies and electoral outcomes, while at the same time providing for accommodation through federalism. In particular, the moves of major political parties towards greater inclusivity has provided a semi-detached forum for cross-ethnic deliberation at the center, while reserving space for ethnic political parties at the unit and subunit level. Other institutional arrangements that encourage moderation together with accommodation include the emphasis on local government and multilevel autonomy and the use of a parliamentary system to increase accountability on the executive.

The final chapter summarizes my thesis and its key findings outlining the unique but path dependent nature of Asian federal systems and the lessons for blending accommodation and moderation in ethnically divided societies. I hypothesize that a multilevel federalism, hybridized in terms of multiethnic institutions at the center, and ethnic institutions at the unit and sub-unit levels, and supplemented by substantial proportionality requirements offers a better alternative to ethnic federalism, consociationalism or state neutrality as a means of promoting political equality and the development and democratization that should follow. 


\section{Methodology and conceptual framework}

This chapter outlines my methodology and the conceptual frameworks that I use to understand the origins and evolution of federalism in Nepal, Myanmar and Sri Lanka. It explains historical institutionalism and how its key concepts of path dependency and critical junctures are applied to the cases. The chapter then develops my conceptual models and details the conditions, variables, mechanisms, sequencing factors and actors, and their operationalization. At the same time, I explain further my choice of Nepal, Myanmar and Sri Lanka as cases on the basis of those variables and other elements, including the varieties of federal systems that have been in place over time in these countries.

\subsection{New institutionalism}

I approach my research into federalism, institutional change and accommodation through the application and modification of theories of path dependence within a new institutionalism methodological perspective. I develop and apply a concept of an Asian federal system to measure institutional arrangements and chart their evolution, their interaction with sequencing factors and social structures, and the role of key actors. I depart from more standard approaches by applying a critical juncture framework to contemporary developments and demonstrate how a path can be simultaneously self-reinforcing and reactive. Elaborating this path dependence provides a window to institutional change, the reasons institutions diverge and breakdown, and the forms of hybridization that emerge to address unique circumstances and trajectories - in short, a theory on the origin and evolution of federalism in Asia.

I choose to apply new institutionalism in preference to structural and behavioral approaches to my study. I do not apply structuralism or a sociological perspective because it does not adequately account for the mediating effects of institutional variables, while a quantitative study is, in the main, unsuitable given the number of cases and the nuances of actor preferences and institutional configurations over time. The design of institutions, especially at the constitutional level, has been shown to contribute substantially to the success or failure of particular federal systems or state structures more broadly ${ }^{4}$, while institutional

\footnotetext{
${ }^{4}$ For example, Ronald Watts (1999, pp. 110-112) notes institutional design factors as one of four that contribute to 'stress within federations, while Simeon and Conway (2001) settle on four minimum institutional design requirements for 'successful' multinational democracies. Hale (2004) shows just how much institutions matter, tracing federal failures to the institutional treatment of an 'ethnic core', such that federal systems with a dominant or bipolar ethnic core have not sustained. Horowitz (2000 [1985]) also argues that bipolar federal systems are unstable. The suitability of new institutionalism, which originated in the economics literature through luminaries such as Douglas North $(1994)$ and Ronald Coase $(1937 ; 1960)$, to such political institutions has been
} 
variables underpin existing theories on the origins of federalism. Institutions mediate social structures and outcomes - they are influenced by society, and society is influenced by institutions - neither can be understood in isolation (March \& Olsen 1984; March \& Olsen 2008; Peters 2011). I define institutions according to March and Olsen's (2008, p. 3) commonly accepted definition:

An institution is a relatively enduring collection of rules and organized practices, embedded in structures of meaning and resources that are relatively invariant in the face of turnover of individuals and relatively resilient to the idiosyncratic preferences and expectations of individuals and changing external circumstances.

There are three commonly accepted types of new institutionalism - rational choice institutionalism, historical institutionalism and sociological institutionalism. Each accepts the intervening role of institutions, but takes a different approach to their definition and the preferences of actors (among other things). Such choices are not ontological distinctions, but methodological conveniences dependent on the focus of the research and the theoretical model (Diermeier \& Krehbiel 2003). I use historical institutionalism in preference to sociological institutionalism because of the utility of applying a bounded conception of institutions and accounting for social structures as antecedent conditions ${ }^{5}$. Further, I reject rational choice institutionalism because it tends to assume and over-simplify actors' preferences and assume a trend to institutional equilibrium ${ }^{6}$. An emerging fourth type -

well articulated by Paul Pierson (2000; 2004), among others. I build on this to demonstrate simultaneous reactive and self-reinforcing path dependencies.

${ }^{5}$ The key feature of sociological institutionalism is its expansive definition of institutions. Here, institutions can be more informal and symbolic, encompassing culture and its institutions, such as family, religion and marriage. For sociological institutionalism, culture influences institutional design and institutions may be used to legitimise social values and are not necessarily based on rationality or instrumentality. Institutional norms are internalized through community-wide acceptance and so they both mould and mediate preferences (Hall \& Taylor 1996; Lane \& Errson 2000; Peters \& Pierre 2012; Jepperson 2001). However, sociological institutionalism has been criticised for its all-encompassing nature. It may be relevant to consider large social and cultural factors as institutions, but it is not necessarily helpful. Focusing on macro processes may lead practitioners to underplay or miss entirely the important interplay and power games between actors. Culture can still be conceptualized but understanding institutions as mediating between actors and cultures provides greater explanatory potential when considering different political outcomes under similar conditions (Schmidt 2008; Steinmo \& Thelen 1992, p. 11; Hall \& Taylor 1996, p. 954).

${ }^{6}$ According to rational choice institutionalism, individual actors are taken to be strategic and self-interested, with fixed preferences, and institutions are designed for a 'calculated purpose' and are geared towards optimising outcomes - or equilibrium. However, rational choice approaches are often unable to adequately explain suboptimal outcomes, inefficient institutional arrangements or institutional origins, because it assumes purposive instrumental choices and self-interested rational actors (Hall \& Taylor 1996; Schmidt 2008). Indeed, "political systems are never in general equilibrium" (Baumgartner \& Jones 2010, p. 15). Historical institutionalism differs from rational choice institutionalism in two key respects, the extent to which routine and rules define behaviours, and the extent to which actors' preferences are influenced by institutional arrangements, the latter of which forms 'part of the puzzle' (Steinmo \& Thelen 1992, pp. 8-9). Historical institutionalism sees political outcomes as partly the result of conflict between (interest) groups and partly as a result of the structural interplay between and across institutions and their parts. Institutions and their configuration thus influence the outcomes of 
discursive or constructivist institutionalism - focusses on the role of (path dependent) ideas, policy paradigms, and the explanatory power of discourse analysis (Schmidt 2008; Hay 2008). I incorporate its insights as part of my analysis of federalism debates in Chapter 6 and analyze the federalism discourse in the Nepal federalism debate in Chapter 7.4. However, the approaches advocated by its proponents can be accommodated within historical institutionalism ${ }^{7}$. In particular, discourse analysis is informative as to the effect and prominence of the explanatory variables, while processes like agenda setting or reframing are more usefully considered as causal mechanisms (see Baumgartner \& Jones 2010; Falleti \& Lynch 2009 for example).

Further, I do incorporate some sociological elements by problematizing actors' preferences and conceptualizing ethnic identity as an antecedent condition, and I compile and analyze quantitative data through the measurement of federal institutional change within and across cases. In particular, I detail the evolution of the institutions of interest, and illustrate their interaction with a range of other factors, from conflict and economic crises, to regime types and the behaviors of central governments. These quantitative elements are elaborated below in relation to sequencing, in Box 1 and Chapter 3.6 as part of the discussion on the concept of Asian federal systems, and in Appendix 2. This data source and measurement system contributes to the literature and may be of use to other scholars researching in similar fields.

My measurement approach also incorporates informal institutions. I make a distinction between institutions as formal rules and as organized practices (which may be informal) and consider the extent to which the latter may or may not be in conformance with the formal rules and their intent ${ }^{8}$. While most studies of federalism have tended to focus on the analysis

conflicts. Historical institutionalism also emphasizes asymmetries of power, path dependent institutional development and the integration of institutions with other (complex) causal factors (Hall \& Taylor 1996, pp. 937942; Peters \& Pierre 2012).

${ }^{7}$ Although practitioners of new institutionalism tend to divide themselves according to their particular approach, it is argued that they should be seen as complementary and a blended approach is more likely to provide a complete picture of the structures and actors that influence political processes and outcomes (Peters 2011). Discursive institutionalism has been one attempt to 'build bridges' between the different schools (see Schmidt 2008; Peters 2011; Hay 2008), while March and Olsen (2008, p. 4) imply one new institutionalism, suggesting that the others are simply variants of the 'rational actor perspective' and the 'cultural community perspective'. Indeed, March and Olsen are variously taken to be normative (e.g. Peters 2011, p. 20) and historical (e.g. Hall \& Taylor 1996, pp. 939-942), while normative institutionalism is often equated with sociological institutionalism (though it is argued by some that sociological varieties stress cognitive rather than normative elements) (Hay 2008; Lecours 2005, p. 17). Furthermore, the idea of 'policy paradigms' and associated period of 'normal' and 'exceptional policy-making' taken up by constructivist or discursive institutionalists was initially proposed and incorporated within the historical institutional perspective (i.e. Hall 1993).

8 Historical institutionalism's theory of gradual institutional change also concludes that institutions are more flexible than their rules might suggest and uses compliance as a variable (Mahoney \& Thelen 2010). 
of formal institutions, analyses of federalism in practice reveals important insights into the mechanisms of change and the role of actors, as well as the concept of federalism itself (see for example Riker 1964; Erk 2008; Zheng 2007). Similarly, a growing number of scholars have been applying new institutionalism to the study of federalism in order to better understand the formal and informal elements of federalism and federal institutional change ${ }^{9}$.

Historical institutionalism has been criticized, however, for a perceived inability to explain change. The most commonly applied framework involves critical junctures and path dependencies (see in particular Krasner 1984; Collier \& Collier 1991; Mahoney 2000; 2010). Schmidt's (2008) discursive institutionalism builds on historical institutionalism and considers institutional change endogenously. Schmidt applies the information from the 'traditional' new institutionalist schools as background information and seeks explanation for change in the interplay of ideas and discourse. Broschek (2013) focuses on incremental change as an explanation for the new federal systems of Europe, applying to an extent the theory of gradual institutional change (see Mahoney \& Thelen 2010). I argue that incremental shifts that sum up to fundamental change may be relevant to some federal systems, but not those in Asia that arose from more fundamental transformations during a critical juncture, even if that critical juncture was a near inevitable outcome of the institutional path.

Tillin (2015) argues that as institutions are power distributing mechanisms, institutions change as a result of changes in the distribution of power, which may arise out of interactions of institutions and associated frictions, ideas and interests, or exogenous shocks. I agree and take a perspective that such institutional change is the other side of institutional stability. The reasons that institutions persist despite obvious shortcomings gives us a basis for understanding why they change. The persistence of the institutions favoring particular ethnic groups in Nepal, Myanmar and Sri Lanka can be explained as path dependence, whereby initial advantage, social norms and self-interest based preferences focus institutional reproduction towards perpetuation of ethnic identity and advantage. Diffusion informs options for change and provides a basis for hybridization, but is not causative. Change may be gradual, but if so, it remains within path and maintains an existing power

\footnotetext{
${ }^{9}$ Andre LeCours (2014) for example, provides a new institutional (discursive) approach to considering the reasons for the (then) 'federal failure' in Nepal, while Neil DeVotta's (2004) important analysis of the evolution and effect of language policies in Sri Lanka reveals a path dependency that aligns with historical institutionalism's concept thereof. Tillin (2015) applies a comparative historical institutionalist methodology to show that holding together federal systems are more flexible than coming together systems in terms of changes to the numbers and boundaries of units because the latter's units are embedded in central (and thus polity wide) decision making structures, meaning that changes have broader implications. See also Broschek $(2011 ; 2010)$ and Benz \& Broscheck (2013).
} 
balance. Federalism arises out of a path-breaking critical juncture, one that upends the existing path of dominant group power reproduction through its interaction with a reactive sequence. This has occurred in Nepal, where federalism was agreed at the same time as a rapid and transformative regime change, while each of Myanmar and Sri Lanka's current federalization processes has come along with regime change alliances.

\subsubsection{Path dependence and critical junctures}

Path dependency is defined as "those historical sequences in which contingent events set into motion institutional patterns or event chains that have deterministic properties" (Mahoney 2000, p. 507). Path dependencies can be: 'self-reinforcing' and driven by the reproduction of utilitarian (cost-benefit), power, function (specific or system wide consequences) or legitimation based outcomes; or, 'reactive sequences', where a contingent event triggers a series of relatively determined 'causally connected events' that can be characterized as 'backlash processes' (Mahoney 2000). While self-reinforcing path dependencies are the most commonly accepted interpretation (e.g. North 1994; Pierson 2000), my research shows that a path can be simultaneously self-reinforcing and reactive, most particularly when a self-reinforcing element is based on power reproduction mechanisms which almost inevitably invite a reaction from those excluded from that power source $^{10}$.

If an institution is insufficiently responsive towards excluded sectors of society, their reactions, and emerging ideas (like democracy), it is unlikely to be sustained over the long term, despite its reproductive capacity. Path dependencies are 'punctuated' by crises, cleavages and system collapses, where substantial change becomes possible, and uncertainty and contingency prevail (Krasner 1984; Collier \& Collier 1991, pp. 27-28; Sewell 2005; Sabel \& Zeitlin 2012). A combination of events can be especially transformative, for example where random events align with social upheavals, or, as Mahoney (2000) argues, when different paths converge. Agenda-setting and reframing may also precipitate 'dramatic change' and 'new points of stability' (Baumgartner \& Jones 2010, pp. 15-18). The choices made at such times are said to be especially critical, as once a new institutional arrangement is in place, they will preclude others from arising (by practicality or cost) and self-perpetuate its new

\footnotetext{
${ }^{10}$ For example, there are four distinct periods in Sri Lanka where the extent of domination (and power reproduction) and the intensity of reaction increased commensurately (Stokke \& Uyangoda 2012). These may be characterized as 'counter-reactions' (Pierson 2004) when they remain within-path, but should be considered as 'reactive sequences' when they concern causally-connected chains that lead to substantial change.
} 
functions (over a long period) (Krasner 1984). Such periods of contingency are known as critical junctures.

I adopt a definition proposed by Capoccia \& Kelemen (2007, p. 348) whereby critical junctures are "relatively short periods of time during which there is a substantially heightened probability that agents' choices will affect the outcome of interest", such that transformative change may not necessarily arise but there is opportunity ${ }^{11}$. Further, a critical juncture can be defined and identified in ways that align with the research question of interest $^{12}$. I focus on critical junctures for federalism and the accommodation of minority ethnic groups.

\subsubsection{Conditions, causal mechanisms and sequencing}

In applying a critical juncture framework, I focus on critical antecedent conditions, key actors and causal mechanisms, alongside variable based analyses. Critical antecedents are those conditions which influence and restrict the range of options available to actors during a critical juncture. They can be either 'conditioning causes' or 'causes of causes', where sequencing becomes important. Focusing on critical antecedents avoids infinite regress while grounding the research in a focused understanding of historical and contextual conditions. Other antecedent conditions are treated as control conditions or as providing descriptive context (Slater \& Simmons 2010).

I understand causal mechanisms to be relational concepts, rather than attributes or intervening variables. Mechanisms may be observed to occur at different levels of analysis and are abstract and portable, effecting change through their interaction with critical

\footnotetext{
${ }^{11}$ Collier \& Collier (1991, p. 29) define critical junctures as "a period of significant change, which typically occurs in distinct ways in different countries (or in other units of analysis) and which is hypothesized to produce distinct legacies". Building on this formative definition, Mahoney (2000), among others, emphasizes agency and contingency, while Pierson (2004) emphasizes divergence and the reproductive outcomes. However, there is never absolute contingency because the options or choices available during a critical juncture are affected by, and in some cases "deeply embedded in antecedent conditions" (Collier \& Collier 1991, p. 27; see also Slater \& Simmons 2010), or limited by 'the rules of the game' and bounded rationality, being the "cognitive and emotional constraints of actors" (Baumgartner \& Jones 2010, p. xxiii). Nor is there necessarily change, just the opportunity or 'substantially heightened probability' of choices effecting change. Accounting for such 'negative cases' can strengthen conclusions (Capoccia \& Kelemen 2007), and provides a useful opportunity for counter-factual analysis. Analysts of critical junctures (Capoccia \& Kelemen 2007; Mahoney 2000; Pierson 2000; 2004) also emphasize that outcomes arising out of critical junctures may also be caused by unexpected and small events that, due to contingency and prevailing uncertainty, are influential and result in lasting change (for example the royal massacre in Nepal). Conversely, moments of significant social upheaval or crises may not constitute a critical juncture when institutions remain unchallenged.

12 For example, Bush (2003) identifies six critical junctures in Sri Lanka over the last 60 years. However, these were continuations of the paths relating to institutional accommodation and federalism, even though some were transformative and diverging regarding regime type. At those times, the range of options regarding accommodation was not open and the reproduction of dominating institutions continued, albeit under a different regime.
} 
antecedent conditions, actors and institutions (Falleti \& Lynch 2009; Tilly 2001). Identifying causal mechanisms that may have different effects under different conditions is an alternative to searching for law like relationships (Tilly 2001), and so, although variable-based sequences form part of my explanation, I keep them separate.

The 'bargaining' intrinsic to Riker's (1964) theory about the origins of federalism (see Chapter 3 ) is an example of a causal mechanism. Ziblatt (2004) reformulates that mechanism, as a 'concession' (or in his words, when "the core concedes authority and periphery seeks autonomy when subunits have infrastructural capacity to deliver public goods of union" ( $p$ 77)). I argue that in a holding together context, a concession leads only to quasi-federalism. However, Riker's bargain is also misleading in these contexts, because the core is not necessarily part of the agreement, indeed its replacement is an impetus for alliance, and the bargain is premised on the idea of exchange, where each party trades-off something in order to gain from the other. An alliance will still involve bargaining, but for mutual benefit. Because of the relatively balanced power of actors in an alliance, versus those negotiating a coming together system, there will be a higher level of compromise than is observed in a concession. Hence, I distinguish between bargains that are concessions and bargains that are alliances. I define an alliance as a formal or informal association or agreement between two or more (collective) actors to pursue mutual objectives, which may or may not be shared (in this case regime change and federalization). A more complete list of important causal mechanisms is provided in Table 2.

Sequences concern recurring patterns of intervening variables. In my cases, the sequences are borne of the combined self-reinforcing and reactive path dependencies and so I identify those sequencing factors that are of interest to my thesis, and relevant rivals, and map accordingly. In the main these are variables. However, I do not assert that all sequencing factors are formative and should be considered as intervening variables or constitute reactive sequences, but I use the identification of recurring patterns to test my causal model. These sequencing factors are:

- Institutional - changes to institutions relating to the assimilation, integration or accommodation, such as through constitutional or legislative change;

- Conflict - violent responses by minority ethnic groups to institutional changes and other related government activities, such as riots or insurgent action;

- Regime - changes in the regime type, such as from a monarchy to a democracy;

- Economic - major economic changes, either positive or negative such as marketization, flotation of a currency and economic crises; 
- External - contingent or external events that affected the system and its function, legitimation or power bases, such as international security changes and natural disasters.

\subsection{The federalization process}

The sequences, institutional changes and critical junctures are key elements of the federalization process. In particular, I show how simultaneously self-reinforcing and reactive paths converge for fuller federalization. This conceptual model is illustrated in Diagram 1, described below and applied in Chapter 5. The self-reinforcing elements are associated mostly with the dominant ethnic group, and the reactive with the minority ethnic groups, although practically they are inseparable. Immediately following the state formation critical juncture, the dominant ethnic group embarks on a nation-building agenda, to consolidate and expand their initial institutional advantage, as part of the intra-group contest for power. This invites a reaction from minority groups, taking the form of resistance, conflict and eventually the building of a parallel infrastructural capacity, which are themselves power producing activities ${ }^{13}$. A concessionary form of quasi-federalism is established by the dominant ethnic group, in order to stabilize their position and assuage the claims of minorities. This may be effective for some time, but not sustainably so, and the establishment of a formal regional or identity-based infrastructural capacity combines with the parallel infrastructural capacity and associated conflict to keep the system vulnerable. When other factors converge, power is sought to be maintained by increasingly repressive activities, contributing to splits in the dominant group, to the extent that the support of the system itself is undermined, an alliance forms across groups and the paths converge. Around this point may be a change in regime type. Ideally, a middle ground is reached whether no ethnic group holds an unreasonable institutional advantage and each can reproduce its position and status in the broader state structure, and as part of a shared path.

\footnotetext{
${ }^{13}$ Rokkan and Urwin (1982) observed a similar process in Europe, where the 'first wave of centralizing state formation' was based on the dominant ethnic culture, but was met with resistance from peripheral groups who in turn mobilized and formed what he calls 'stateless nationalist and regionalist parties'. In the cases of Nepal, Myanmar and Sri Lanka, armed groups were also formed as exclusion and resistance to federalization became entrenched in the dominant elite.
} 
Diagram 1: Converging self-reinforcing and reactive paths and the road to federalism

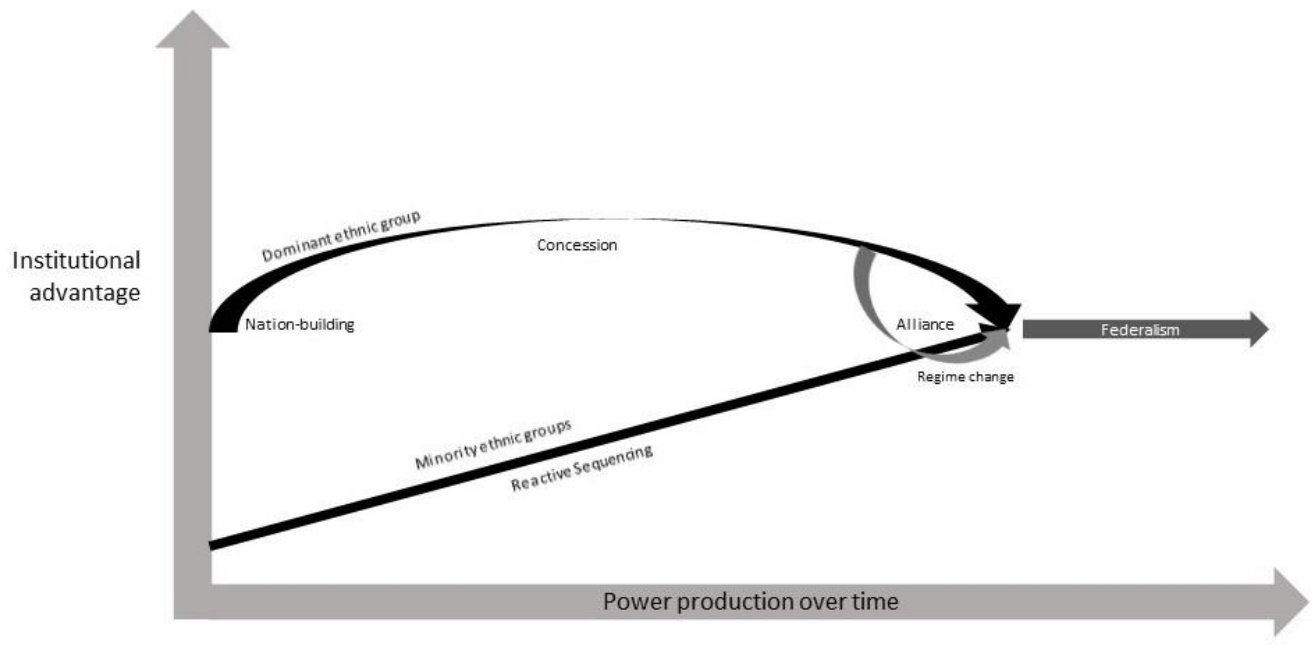

To establish this, I prepare and analyze sequence maps for each case, to identify recurring patterns, the basis and interplay of reproductive and reactive sequences and the impact of changing conditions on the institutional configurations. These sequence, or path dependency, maps are based around the creation of an index and tracking of institutional change as aligned with a conceptual differentiation between assimilation, integration and accommodation (discussed in Chapter 3.6.1) and incorporating the timing of the key sequencing factors introduced above. They illustrate the reasons that paths diverge and the mechanisms through which federalization occurs. Formal and behavioral factors of federal and consociational institutions were scored, along with regime type, conflict, economic and external shocks. Behavioral aspects also detail the party based composition of legislatures and executives, and recent years of ethnic proportionality. The data is provided in Appendix 2.

The critical juncture analyses stages focus on the decision-making processes and proceed primarily from review of primary and secondary sources from those junctures (such as meeting records, interviews, reports, media commentary etc.) and regarding key actors (e.g. political party platforms, participant observation), and through discussion with actors in country, to identify options, preferences and the mechanisms determining the selected outcomes. I identify the relevant positions of the key actors and the process by which constitutional change occurred or is occurring. I analyze the debate to confirm the influence of the key variables, and in the contemporary juncture, their relationship with more particular institutional outcomes, like the extent of accommodation in the system. The approach for analysing the institutions to which the options, preferences and mechanisms 
relate is based on the concept of Asian federal systems elaborated in Chapter 3.6 (see especially Box 1) and informing the institutional measurement approach outlined above.

With the decision-making processes and institutional trends identified, I link the institutions with political equality, from which other success factors (e.g. stability) can follow. I elaborate on the notion of political equality in this context below and in Chapter 6, where I consider criteria for blending moderation with accommodation as measured. Moderation is taken to follow from the establishment of institutional settings that are conducive to deliberation, incorporating multiethnic, multilevel, semi-detached, inclusive, reciprocal and accountable forums, where moderate outcomes, such as federal compromises and certain electoral outcomes are shown to occur. Further, the relationship between different aspects of accommodation are identified, such as between the extent or security of autonomy, and the extent of ethnicity afforded in the federal design. Key lessons from the experiences of Nepal, Myanmar and Sri Lanka are extracted, compared and consolidated. These institutional configurations are not pure or ideal options, but practical real options that account for what is politically possible in given conditions (e.g. some institutional elements may be inversely related, others are mutually reinforcing).

\subsection{Variables and conceptual framework}

This section outlines the conceptual model for my key proposition, and details the variables and their operationalization. My key proposition, regarding the formation and path of federalism in Asia, has the type of federal system as the dependent variable. As I have argued, federalism relies on the alliance of regime change forces from the dominant group and minorities seeking federalism, as the key mechanism for change. To reach this alliance, a substantial (regional or ethnic-based) infrastructural capacity and a moderate secession risk are required. These are the independent variables. My research applies to holding together federalism and rejects incremental change as its basis, while noting that quasi-federalism arises in such a manner. Diagram 2 illustrates my conceptual model. Bargaining, through either an alliance or concession, and repression are causal mechanisms, along with nationbuilding, by which conditions and variables are given an institutional manifestation. Ethnic diversity, when exposed to identity-based nation-building leads to conflict. These are the antecedent conditions. Depending on the values of the variables of infrastructural capacity and secession risk (under which the prevailing antecedent conditions are subsumed in this model), federalization will follow, mediated by any existing relevant institutions. 
Diagram 2: Conceptual model on the origins of holding together federalism in Asia

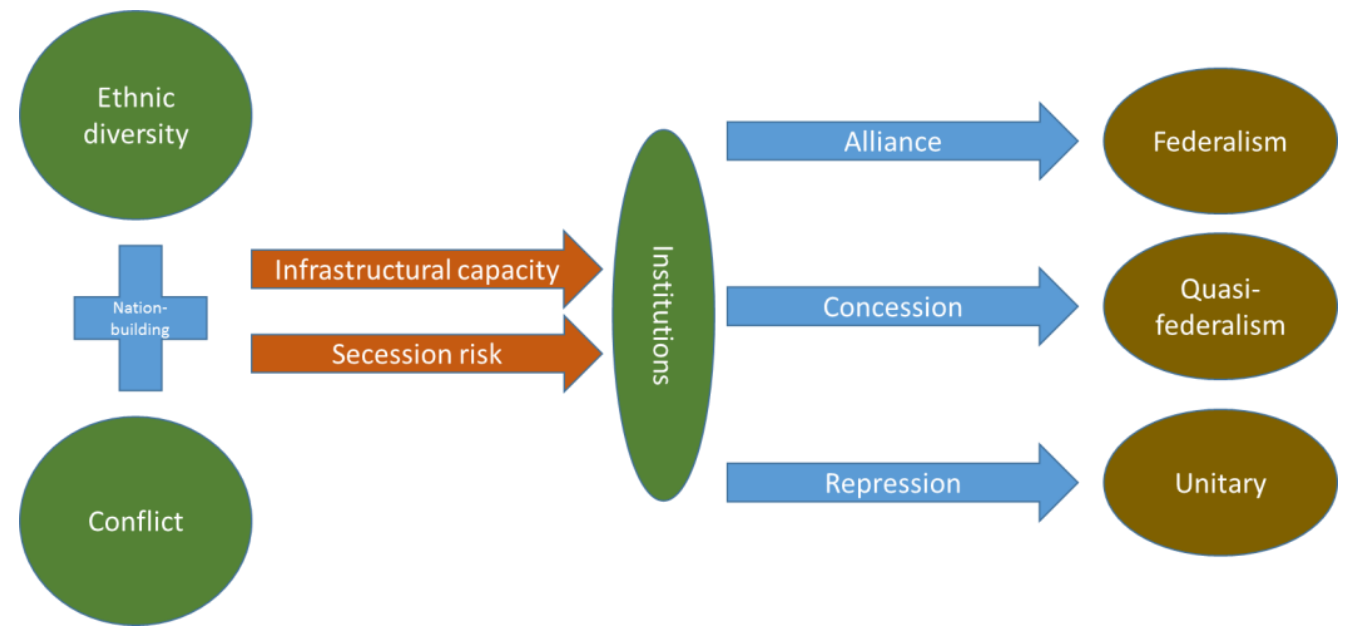

\subsubsection{Independent and control variables}

Infrastructural capacity is operationalized contextually, along administrative and negotiation dimensions. There are a number of ways a prospective federal unit can gain and hold infrastructural capacity, such as through decentralization, whether pre-existing colonial administrative architecture or under delegation from a central government; and through conflict, including the holding of territory, the development of parallel administrations and autonomy via ceasefire arrangements. Further, in modern times, political parties provide important elements of infrastructural capacity and credible negotiating partners, even if a broadly non-partisan forum might be preferred. This is a broader conception of infrastructural capacity than that taken by Ziblatt, who confines it to 'embedded parliamentary structures' (via a constitution) and 'well developed administrative structures' (2004, p. 78), as it does not assume the evolution of liberal democratic institutions. Ziblatt himself 'borrows' the concept of infrastructural capacity from Michael Mann's (1986; 1988) concept of infrastructural power, which relates to the political power of the core (rather than that of actors in the periphery as in Ziblatt) ${ }^{14}$.

Secession risk is equated with the external threat posited by Riker (1964) as being a necessary condition, except as working in reverse being a precipitator to holding together, rather than coming together federalism. It almost goes without saying that a holding

\footnotetext{
${ }^{14}$ Mann's theories on the autonomy and evolution of the state distinguish between despotic and infrastructural political power. Infrastructural power is defined as "the capacity of the state to actually penetrate civil society, and to implement logistically political decisions throughout the realm" (Mann 1988, p. 5). It is distinguishable from despotic power, which is exercisable without regard to civil society. Following Ziblatt (2006), I use the term infrastructural capacity in relation to the periphery, as distinct from the core's infrastructural power. I adapt the advice of Soifler (2008) who recommends operationalization of infrastructural power along three dimensions (state capabilities, weight of the state, subnational variation), and Ziblatt who distinguishes between negotiating and administrative capacity. I emphasize the negotiating party aspect of Ziblatt's definition, rather than the ability to deliver benefits, because it is a holding together context.
} 
together federal system would not exist without a secession risk, but it is here conceptualized as a necessary condition when at a moderate level, and an independent variable, affecting the form of federalism, as well as its establishment. It is operationalized by combining three factors - the homogeneity of the given areas; the breadth of non-state military power (i.e. areas under control of a rebel force); and the presence of a supportive international environment, most especially supportive neighbors (for discussion on factors affecting the strength of a secessionist movement, see Horowitz 2000 [1985], pp. 265-277). It incorporates the securitization of ethnicity that is argued by Kymlicka (2007) as being instrumental to the resistance to accommodation that has been observed in Asia.

The selection of ethnic identity (incorporating dimensions of diversity, religion and political culture) and conflict as critical antecedent conditions is based on quantitative analysis of accommodation in Asia, which showed that, among rival theories, ethnic diversity is the only statistically significant variable, while conflict appears to play a mediating role ${ }^{15}$. There is some correlation between the dominant religion of a country and accommodation, so I address this as a component of ethnic diversity. I also apply a basic typology for classifying political culture into one or more of egalitarian, hierarchical, individualist and fatalist, following Douglas' (1982) system of classification.

Other variables posited by rival theories are used as control variables. The exception is the mode of state formation, which is disaggregated into the most meaningful elements, being internal conflict (capturing whether there was a war of independence for example), and infrastructural capacity (which captures the colonial and traditional state structures and bureaucratization). Further, the role of international actors and diffusion have been argued as influential. International actors have been important at times, particularly India and the

\footnotetext{
${ }^{15}$ Selecting variables based on rival theories outlined in Chapters 1 and $3, I$ ran a series of regressions to test their relationship with degrees of accommodation (based on a composite index) in each Asian state, concluding that ethnic diversity is the only statistically significant factor (with a co-efficient of 0.797 and $P>|t|$ at 0.66 ). The model explained approximately $30 \%$ of the variance $(R 2=0.2956)$. On its own, a high degree of ethnic diversity does not determine whether or not federalism is pursued, or what type. Nevertheless, based on these results, it is apparent that while a state with high ethnic diversity may or may not substantially accommodate, a state with low diversity (such as Sri Lanka and Thailand) is more unlikely to. For one, conflict appears to mediate. Further, the dominant religion of each country appeared at face-value to correlate with the extent of accommodation, most particularly the low accommodation in Buddhist countries. A one-way ANOVA test was run using religion and five categories/factors (Buddhist, Confucian/Secular, Muslim, Hindu and Christian). Buddhism had the lowest mean at 3.23, followed by (in increasing order), Confucian/Secularism, Muslim, Christian and Hindu. The model appeared robust with higher mean squares across groups (16.84) as compared to within groups (5.68), a relatively uniform standard deviation (where population numbers allowed relevance) and $p<0.05$. This quantitative analysis also found that the level of democracy, the presence or not of political secularism and the mode of state formation (violent; peaceful; or pre-existing state) were not meaningfully correlated with the extent of accommodation. However, given that that the number of observations (22) is not sufficient to draw solid conclusions, and because there exist rival theories proposing those variables as the most meaningful in this context, they have been used as control variables throughout the study. Full details of the model and regression data are provided in Appendix 4.
} 
British at the state formation stage. However, the presence and type of federal system, once demanded, has been dictated by internal decision-makers in light of their perspectives on secession. For example, India's preferred approach to federalism in Sri Lanka (in 1987) and Nepal (in 2015) was either amended or ignored so as to reduce the viability of, or potential for, secession ${ }^{16}$. I incorporate international actors alongside domestic actors, when they play a key role. A similar approach is taken to the military ${ }^{17}$. Further, the international influence is operationalized as part of the secession risk variable (see Table 2).

In drawing lessons from the impacts and incentive structures created by the different federal institutional configurations, I focus on political equality as a goal, taken here to mean individual and group equality, rather than simple legal equality. Political equality is a proxy for justice and a structural necessity for ultimately achieving substantive equality. I consider the views of theorists (like Kymlicka 1995) and practitioners (like Sakhong 2010) who argue that ethnic federalism is the most just approach to structuring a multinational state; and opponents (like Brown 2007; Barry 2002) who argue that territorial federalism is best suited to managing diversity. I look at specific design features like the presence of supplementary or alternative representative arrangements, and the totality of a constitutional package regarding the accommodation (or not) of minorities via the conceptualization of Asian federal systems as the approach to the management of diversity. Deliberation is an important mechanism by which accommodation is moderated, contributing to political equality, and conducive conditions can be institutionalized. I return to this matter in Chapter 7.

In these cases, the political party system drives the extent of ethnic executive power-sharing. The party system is in part an output of the structure of the state and its electoral system, and otherwise derived from underlying the social structures. In the cases of Nepal, Myanmar and Sri Lanka, the political party systems arose largely independently from the electoral systems, even if only because an electoral system had not existed at the time of their formation or throughout much of their modern existence (e.g. due to authoritarianism). Nevertheless, a party system is influenced by electoral systems and federal institutional

\footnotetext{
${ }^{16}$ Sri Lanka did not devolve law and order powers despite agreeing to do so and amending its constitution accordingly, and Nepal did not agree to demarcate one or two Madheshi majority provinces abutting the Indian border, with the effect of limiting the potential for federal structures to be used as a vehicle for secession (see Chapter 6 for further details).

17 The role of the military is important in many cases where ethnic conflict has led to calls for federalism. The military has acted decisively in the case of Myanmar, where it has maintained a degree of autonomy. However, in Sri Lanka where federalism has been fiercely resisted, the military has remained subordinate to civilian government. Significantly, the military in each country has been dominated by the largest ethnic group, as opposed to the ethnic rivalries that are embodied by the opposing composition of government and the military in countries where military coups have been frequent and deleterious (for examples, see Horowitz 2000 [1985], pp. 443-559).
} 
design $^{18}$. Political parties themselves are conceptualized as actors, rather than variables, while the party system is a component part of a federal system.

The key differences and similarities between the variables across the cases are summarized in Table 1. Table 2 provides a definition of the variables, conditions and mechanisms, and their operationalization. Using three cases like this provides for different points of comparison and allows for the use of both methods of difference and agreement. For example, while each country has experienced significant internal conflict, only Sri Lanka experienced a peaceful mode of state formation, while Nepal is unique in being the only country which was not colonized by a western power. Each country has a prominent religious culture: Nepal is predominantly Hindu, while Myanmar and Sri Lanka are mostly Buddhist and their states are in many respects non-secular. Also, while each country has distinct ethnic nationalities and recent immigrant groups, Sri Lanka has only four significant ethnic groups and only two of those are especially active in competing over institutional arrangements. Nepal and Myanmar have a higher degree of ethnic diversity.

The regime type and its variation over time within and across cases is also an important point of difference, particularly given the theoretical preference for democratic federalism and the perception that absence of elections and rule of law belies the presence of federalism (see discussion in Chapter 3.4). Analyzing how federalism and the accommodation of minorities has changed and evolved in relation to democracy and regime type enables these rival theories to be explicitly considered.

\footnotetext{
${ }^{18}$ Sartori (1997, pp. 39-73) argues that the effect of electoral systems differs according to the conditions in which they are implemented. For example, a first past the post (plurality) system will cause a two-party system only if the party system is structured and there is 'cross-constituency dispersal'.
} 
Table 1: Summary of key variables per Nepal, Myanmar and Sri Lanka

\begin{tabular}{|c|c|c|c|}
\hline Variable & Nepal & Myanmar & Sri Lanka \\
\hline $\begin{array}{l}\text { Ethnic identity } \\
\text { a) Diversity } \\
\text { b) Religion } \\
\text { c) Political cultures } \\
\text { d) Social stratification }\end{array}$ & $\begin{array}{l}\text { a) } 18 \text { ethnic groups } \\
\text { more than } 1 \% \text { of } \\
\text { population; } \\
\text { dominant group at } \\
28.8 \% \text { of } \\
\text { population } \\
\text { b) Majority Hindu, } \\
\text { minority Buddhist, } \\
\text { Muslim } \\
\text { c) Hierarchical, } \\
\text { fatalist \& } \\
\text { consensus-based } \\
\text { d) Rigid but } \\
\text { weakening system } \\
\text { of ranking ethnic } \\
\text { groups }\end{array}$ & $\begin{array}{l}\text { a) ethnic groups } \\
\text { more than 1\% of } \\
\text { population; } \\
\text { dominant group at } \\
68 \% \text { of population } \\
\text { b) Majority Buddhist, } \\
\text { minority Christian, } \\
\text { Muslim, Hindu } \\
\text { c) Individualistic, } \\
\text { egalitarian and } \\
\text { consensus-based } \\
\text { d) No formal } \\
\text { stratification }\end{array}$ & $\begin{array}{l}\text { a) ethnic groups } \\
\text { more than } 1 \% \text { of } \\
\text { population; } \\
\text { dominant group at } \\
75 \% \text { of population } \\
\text { b) Majority Buddhist, } \\
\text { minorities Hindu, } \\
\text { Muslim, Christian } \\
\text { c) Individualistic, } \\
\text { egalitarian and } \\
\text { consensus-based } \\
\text { d) Caste system with } \\
\text { waning influence }\end{array}$ \\
\hline $\begin{array}{l}\text { Conflict (internal) } \\
\text { a) Civil war } \\
\text { b) At state formation }\end{array}$ & $\begin{array}{l}\text { a) } 1996-2005 \text {, ended } \\
\text { in peace } \\
\text { agreement } \\
\text { b) Minor conflict at } \\
\text { state formation } \\
\text { stage, already } \\
\text { independent }\end{array}$ & $\begin{array}{l}\text { a) } 1947 \text { to current, } \\
\text { various ceasefires } \\
\text { b) Violent war of } \\
\text { independence }\end{array}$ & $\begin{array}{l}\text { a) } 1983 \text { to } 2009 \text {, state } \\
\text { military victory } \\
\text { b) Peaceful transition } \\
\text { to independence }\end{array}$ \\
\hline $\begin{array}{l}\text { Infrastructural capacity } \\
\text { (regional/identity- } \\
\text { based) }\end{array}$ & $\begin{array}{l}\text { Low infrastructural } \\
\text { capacity until } \\
\text { developed in parallel } \\
\text { under Maoists } \\
\text { insurgency during civil } \\
\text { war (1996-2005) }\end{array}$ & $\begin{array}{l}\text { Medium infrastructural } \\
\text { capacity existing before } \\
\text { independence and } \\
\text { continuing in various } \\
\text { sanctioned and } \\
\text { unsanctioned forms }\end{array}$ & $\begin{array}{l}\text { Low infrastructural } \\
\text { capacity at } \\
\text { independence, but } \\
\text { developed via } \\
\text { devolution and in } \\
\text { parallel by insurgency } \\
\text { (post 1983) }\end{array}$ \\
\hline Secession risk & $\begin{array}{l}\text { Low, but tending to } \\
\text { moderate at the time } \\
\text { of federalization }\end{array}$ & $\begin{array}{l}\text { High but trending to } \\
\text { moderate as state } \\
\text { democratizes }\end{array}$ & $\begin{array}{l}\text { Moderate, but formerly } \\
\text { high as LTTE fought for } \\
\text { independent state }\end{array}$ \\
\hline Regime type & $\begin{array}{l}\text { Transition to } \\
\text { democracy after long } \\
\text { period of authoritarian } \\
\text { rule (monarchy) }\end{array}$ & $\begin{array}{l}\text { Transition to democracy } \\
\text { after long period of } \\
\text { authoritarian rule } \\
\text { (military) }\end{array}$ & $\begin{array}{l}\text { Reinvigorating } \\
\text { democracy after } \\
\text { authoritarian-tending } \\
\text { president }\end{array}$ \\
\hline Federalism & See Table 3 & See Table 3 & See Table 3 \\
\hline
\end{tabular}


Table 2: Definition and operationalization of variables, conditions and mechanisms

\begin{tabular}{|c|c|c|c|}
\hline $\begin{array}{l}\text { Variable/condition } \\
\text { /mechanism }\end{array}$ & Type & Definition & Operationalization \\
\hline Ethnic identity & $\begin{array}{l}\text { Antecedent } \\
\text { condition }\end{array}$ & $\begin{array}{l}\text { A social structure based on a group of people sharing a } \\
\text { similar culture, language, religion or caste, which forms } \\
\text { a basis of social interaction and status and upon which } \\
\text { they distinguish themselves from others. Generally } \\
\text { formed at birth, based on kinship and relatively rigid }\end{array}$ & $\begin{array}{l}\text { - Number of ethnic groups (comprising more than } 1 \% \text { of the } \\
\text { - } \quad \text { Propulation) } \\
\text { - } \quad \text { Religious and political cultures of major ethnic groups } \\
\text { - } \quad \text { Social stratification within and across major ethnic groups }\end{array}$ \\
\hline Conflict (internal) & $\begin{array}{l}\text { Antecedent } \\
\text { condition / } \\
\text { sequencing }\end{array}$ & $\begin{array}{l}\text { Conflict between internal actors/groups, including } \\
\text { between local ethnic groups and colonialists, between } \\
\text { ethnic groups, and between state and non-state actors. } \\
\text { May include violent large-scale protests, insurgencies } \\
\text { and civil war }\end{array}$ & $\begin{array}{l}\text { - Length (years) and scope (measured in terms of proportion } \\
\text { of unit/provinces affected) }\end{array}$ \\
\hline Nation-building & Causal mechanism & $\begin{array}{l}\text { Actions by the state to consolidate borders and } \\
\text { reproduce power through the institutionalization of a } \\
\text { national identity }\end{array}$ & - $\quad$ (Dominant) identity-based, neutral, or multiethnic \\
\hline $\begin{array}{l}\text { Infrastructural } \\
\text { capacity }\end{array}$ & $\begin{array}{l}\text { Independent } \\
\text { variable }\end{array}$ & $\begin{array}{l}\text { Regional or identity-based institutionalized } \\
\text { administrative and political arrangements (including } \\
\text { political parties), which provide important services to } \\
\text { group members (e.g. education) or seek to protect and } \\
\text { further their rights through the political sphere }\end{array}$ & $\begin{array}{l}\text { - Strength of regional or identity-based administrative and } \\
\text { representative structures, along the following dimensions: } \\
\circ \quad \text { Existence and type of regional administration } \\
\circ \quad \text { Political / negotiating organization }\end{array}$ \\
\hline Secession risk & $\begin{array}{l}\text { Independent } \\
\text { variable }\end{array}$ & $\begin{array}{l}\text { The potential of a particular ethnic group or region to } \\
\text { mount a successful secessionist or irredentist } \\
\text { movement }\end{array}$ & $\begin{array}{l}\text { - The perceived likelihood of a group or region successfully } \\
\text { seceding, as a function of: } \\
\qquad \begin{aligned} & \text { O The areas subject to insurgent control } \\
& \circ \text { The ethnic heterogeneity of the given region } \\
& \circ \text { The extent of international support } \\
&\end{aligned}\end{array}$ \\
\hline Regime type & $\begin{array}{l}\text { Control / } \\
\text { sequencing }\end{array}$ & $\begin{array}{l}\text { The type of political regime existing at the central level, } \\
\text { understood as the overarching structures of the state } \\
\text { and in terms of democratic and authoritarian varieties }\end{array}$ & $\begin{array}{l}\text { - Democratic (free and fair elections, near universal suffrage), } \\
\text { or } \\
\text { - } \quad \begin{array}{l}\text { Authoritarian (a monarchy, military or single-party rule or } \\
\text { presidentialism without free and fair elections etc.) }\end{array}\end{array}$ \\
\hline
\end{tabular}




\begin{tabular}{|c|c|c|c|}
\hline $\begin{array}{l}\text { Variable/condition } \\
\text { /mechanism }\end{array}$ & Type & Definition & Operationalization \\
\hline External & $\begin{array}{l}\text { Control / } \\
\text { sequencing }\end{array}$ & $\begin{array}{l}\text { Exogenous and contingent events that impact on the } \\
\text { strength of the state and affect antecedent conditions }\end{array}$ & $\begin{array}{l}\text { - Natural disasters that are large scale in impact } \\
\text { - Shift in the international environment (e.g. end of the cold } \\
\text { war) }\end{array}$ \\
\hline Economic & $\begin{array}{l}\text { Control / } \\
\text { sequencing }\end{array}$ & $\begin{array}{l}\text { Economic events that impact on the functional } \\
\text { capacities of the state and the public's support }\end{array}$ & $\begin{array}{ll}- & \text { Major reforms to the economy (e.g. marketization) } \\
\text { - } & \text { Major economic crises (e.g. devaluation of currency) }\end{array}$ \\
\hline Concession (bargain) & Causal mechanism & $\begin{array}{l}\text { A largely imposed bargain where a dominant actor } \\
\text { provides a measure of that sought by a subordinate } \\
\text { group (e.g. autonomy), in order to institutionalize, } \\
\text { maintain or stabilize their relationship (e.g. via regime } \\
\text { continuation) }\end{array}$ & - As per definition \\
\hline Alliance (bargain) & Causal mechanism & $\begin{array}{l}\text { A formal or informal association or agreement between } \\
\text { two or more actors/groups to pursue mutual } \\
\text { objectives, which may or may not be shared, involving } \\
\text { bargaining but with substantially more compromise } \\
\text { than a concession }\end{array}$ & - $\quad$ As per definition \\
\hline $\begin{array}{l}\text { Asian federal } \\
\text { systems }\end{array}$ & $\begin{array}{l}\text { Dependent } \\
\text { variable }\end{array}$ & $\begin{array}{l}\text { A regional variety that is based around a purpose of } \\
\text { managing diversity and incorporating a range of } \\
\text { institutional tools that interact to effect this purpose. It } \\
\text { is characterized most particularly by mixed units, } \\
\text { centralization, special representation and cultural rights }\end{array}$ & $\begin{array}{l}\text { See Box } 1 \text {, summarized below: } \\
\text { - } \quad \text { Autonomy less centralization } \\
\text { - } \quad \text { Basis of units } \\
\text { - } \quad \text { Interdependence } \\
\text { - } \quad \text { Representation } \\
\text { - } \quad \text { Cultural rights } \\
\end{array}$ \\
\hline Political equality & $\mathrm{n} / \mathrm{a}$ & $\begin{array}{l}\text { Group and individual equality, (and a proxy for justice) } \\
\text { such that individuals and groups have the capacity and } \\
\text { opportunity to have a substantive say about key } \\
\text { decisions that affect them, and that the decisions of } \\
\text { other (groups and individuals) do not unreasonably } \\
\text { infringe up on their (individual and group) rights }\end{array}$ & $\begin{array}{l}\text { - Accommodation, measured according to the institutions } \\
\text { constituting Asian federal systems, particularly autonomy } \\
\text { and inclusion; plus } \\
\text { - Moderation, as encouraged via: } \\
\circ \quad \text { Electoral incentives to appeal across groups } \\
\circ \quad \text { Multiethnic institutions, especially parties } \\
\circ \quad \text { Accountability and reciprocity requirements } \\
\circ \quad \text { Multilevel forums for cross-ethnic deliberation } \\
\circ \quad \text { Semi-detached institutions }\end{array}$ \\
\hline
\end{tabular}




\subsubsection{Federalism}

There are also important differences in their federal systems across and within cases. In the case of Nepal, two federal systems have been institutionalized over the course of its modern history. Initially, a constitutionally and indigenously derived Panchayat system was created, comprising three levels of government with specified powers and a direct relationship to the people at the local level. This quasi-federalism failed to satisfy or mitigate the democratic demands of dominant ethnic group elites (being in an authoritarian environment) and in 2015 a new constitution enshrined a more conventional democratic federation with units based on both identity (ethnicity, language etc.) and viability (geography, economy etc.). Myanmar has had three federal systems in its modern history. Initially a highly asymmetrical and communally based union was developed, but the threat of secession led the military to intervene. On paper it was genuine federalism, but in practice highly centralized. In response to escalating ethnic conflict, a relatively symmetrical but tightly controlled twotiered system was introduced. Finally, with the military committed to a democratic transition, the new constitution of 2008 created a quasi-federal system, which remains subject to change as the democratic transition proceeds. Each of these has been a predominantly ethnic system, but in the latter two cases, the dominant group has been split across several units ('ethno-territorial'). In Sri Lanka, a long-standing democracy, only one federal system has been in place - a constitutional devolution to regions that are largely ethnically homogeneous - despite the ongoing discussions around arrangements that are more accommodating of ethnic minority groups. These federal systems are summarized and classified in Table 3, and discussed in some detail in Chapter 5. 
Table 3: Federal systems in Nepal, Sri Lanka and Myanmar

\begin{tabular}{|c|c|c|c|c|c|c|}
\hline & Nepal 1962 & Nepal 2015 & Sri Lanka 1987 & Myanmar 1947 & Myanmar 1974 & Myanmar 2008 \\
\hline $\begin{array}{l}\text { Central authority over } \\
\text { constituent units }\end{array}$ & $\begin{array}{l}\text { Center appoints, } \\
\text { approves, overrules }\end{array}$ & $\begin{array}{l}\text { Each level of government } \\
\text { is sovereign }\end{array}$ & $\begin{array}{l}\text { Center funds provinces, } \\
\text { appoints governors, } \\
\text { power devolved }\end{array}$ & $\begin{array}{l}\text { Center appoints, } \\
\text { approves \& funds units; }\end{array}$ & $\begin{array}{l}\text { Power centralized but } \\
\text { devolved to units }\end{array}$ & $\begin{array}{l}\text { Center appoints, can } \\
\text { overrule; military } \\
\text { intervention powers }\end{array}$ \\
\hline $\begin{array}{l}\text { Autonomy (scope) of } \\
\text { constituent units }\end{array}$ & Implementation only & $\begin{array}{l}\text { Legislative \& executive } \\
\text { Strong powers }\end{array}$ & $\begin{array}{l}\text { Legislative \& executive } \\
\text { Medium powers }\end{array}$ & $\begin{array}{l}\text { Legislative \& executive } \\
\text { Medium powers (plus a } \\
\text { secession right) }\end{array}$ & Implementation only & $\begin{array}{l}\text { Legislative \& executive } \\
\text { Narrow range of powers }\end{array}$ \\
\hline Constitutionalism & $\begin{array}{l}\text { Low, king can amend, } \\
\text { interpret and resolve } \\
\text { disputes }\end{array}$ & $\begin{array}{l}\text { Medium, rigid but } \\
\text { disputes resolvable by } \\
\text { panel with central } \\
\text { dominance }\end{array}$ & $\begin{array}{l}\text { Medium, supermajority } \\
\text { and court interpretation, } \\
\text { but lack of independence }\end{array}$ & $\begin{array}{l}\text { High, supermajorities } \\
\text { required and } \\
\text { independent court }\end{array}$ & $\begin{array}{l}\text { Low, party is supreme, } \\
\text { flexible constitution }\end{array}$ & $\begin{array}{l}\text { Medium, rigid with } \\
\text { tribunal to interpret but } \\
\text { center can resolve some } \\
\text { disputes }\end{array}$ \\
\hline Interdependence & $\begin{array}{l}\text { Nil } \\
\text { Authoritarian }\end{array}$ & $\begin{array}{l}\text { Bicameralism, } \\
\text { intergovernmental panel } \\
\text { Parliamentary }\end{array}$ & $\begin{array}{l}\text { Nil } \\
\text { Hybrid presidential }\end{array}$ & $\begin{array}{l}\text { Members of units drawn } \\
\text { from central parliament } \\
\text { Parliamentary }\end{array}$ & $\begin{array}{l}\text { Nil } \\
\text { Presidential }\end{array}$ & $\begin{array}{l}\text { Bicameralism, joint } \\
\text { committees }\end{array}$ \\
\hline Basis of units & $\begin{array}{l}\text { Territorial (village, town \& } \\
\text { districts), accounting for } \\
\text { clustered groups }\end{array}$ & $\begin{array}{l}\text { Mixed, balancing identity } \\
\text { and viability with an } \\
\text { emphasis on the latter }\end{array}$ & $\begin{array}{l}\text { Ostensibly territorial but } \\
\text { practically ethnic }\end{array}$ & Ethnic & $\begin{array}{l}\text { Ethnic (with majority } \\
\text { group split across a } \\
\text { number of units) }\end{array}$ & $\begin{array}{l}\text { Ethnic (with majority } \\
\text { group split across a } \\
\text { number of units) }\end{array}$ \\
\hline $\begin{array}{l}\text { Representative } \\
\text { mechanism }\end{array}$ & $\begin{array}{l}\text { Elections but candidates } \\
\text { vetted } \& \text { no } \\
\text { proportionality or parties }\end{array}$ & $\begin{array}{l}\text { Substantial proportional } \\
\text { representation element in } \\
\text { lower houses and parties, } \\
\text { plus appointment }\end{array}$ & $\begin{array}{l}\text { Proportional } \\
\text { representation but high } \\
\text { threshold }\end{array}$ & $\begin{array}{l}\text { Representation based on } \\
\text { nationalities and territory, } \\
\text { FPTP }\end{array}$ & $\begin{array}{l}\text { No proportionality, single } \\
\text { party system }\end{array}$ & $\begin{array}{l}\text { FPTP, but with provision } \\
\text { for representation of } \\
\text { 'national races' over } \\
\text { certain population }\end{array}$ \\
\hline Cultural rights & $\begin{array}{l}\text { Minority protections only. } \\
\text { Nepali national language } \\
\text { \& Hinduism state religion }\end{array}$ & $\begin{array}{l}\text { Recognizes multiethnic } \\
\text { and multilingual nature of } \\
\text { state, secular but with } \\
\text { preference to Hinduism }\end{array}$ & $\begin{array}{l}\text { Minority protections. } \\
\text { Tamil an official language } \\
\text { Buddhism has 'foremost } \\
\text { position' }\end{array}$ & $\begin{array}{l}\text { Minority protections. } \\
\text { Buddhism has 'special } \\
\text { place'. Burmese language }\end{array}$ & $\begin{array}{l}\text { Basic protections and } \\
\text { freedoms only }\end{array}$ & $\begin{array}{l}\text { Minority protections. } \\
\text { Buddhism has 'special } \\
\text { place'. Myanmar } \\
\text { language }\end{array}$ \\
\hline Classification & $\begin{array}{l}\text { Quasi-federalism } \\
\text { Mixed }\end{array}$ & $\begin{array}{l}\text { Federalism } \\
\text { Mixed / hybrid }\end{array}$ & $\begin{array}{l}\text { Quasi-federalism } \\
\text { Ethno-territorial }\end{array}$ & $\begin{array}{l}\text { Federalism } \\
\text { Ethnic }\end{array}$ & $\begin{array}{l}\text { Quasi-federalism } \\
\text { Ethno-territorial }\end{array}$ & $\begin{array}{l}\text { Quasi-federalism } \\
\text { Ethno-territorial }\end{array}$ \\
\hline (Regime) & Authoritarian & Democracy & Democracy & Democracy & Authoritarian & Democracy (military led) \\
\hline
\end{tabular}




\subsubsection{Actors}

Actors which are known to have played a key role in the particular cases, and which have been positioned by theory as important influences more generally in the extent of ethnic conflict and accommodation, are conceptualized for further investigation. The key actors identified are:

- Political parties - including internal and system dimensions such as whether they are ethnic, multiethnic or non-ethnic (as per Horowitz 2000 [1985]);

- Militaries and insurgencies - accounting for the significant overlap with political parties that is observable in the countries (see Horowitz 2000 [1985]; DeVotta 2004; Callahan 2007; Miller 2012);

- Executives - as relevant to the given political system, for example monarchs, presidents, cabinets and military dictators (accounting for overlap with the previous two categories);

In analyzing the mediating role of these actors, a democratically neutral approach is taken, whereby a party-less or single-party system can be considered as a non-ethnic, ethnic or multiethnic single party system, while an executive concentrated in an individual (or small group of individuals) is applicable to presidential systems, as well as dictatorships, monarchs and military juntas. At times, civil society has been influential, such as during the peoples' uprisings in Nepal and Myanmar and through religious organizations and international actors. However, these have not operated in any systematic manner, or have been supported by political parties or insurgencies (and so encapsulated elsewhere). Further, these actors have not been definitive or determinative of ultimate outcomes (the key decisions have resided in the three types of actors mentioned above).

International actors are particularly relevant during the state formation juncture, where India played a critical role in the transition in Nepal (see Whelpton 2005; Gellner 2005) and Britain in the constitutional design and independence of Sri Lanka and Myanmar (DeVotta 2011; Wikramasinghe 2006; Taylor 2009). India was also significant in the 1987 Sri Lankan constitutional amendments relating to devolution (the $13^{\text {th }}$ Amendment). They are included as key actors at the state formation critical juncture.

It is obvious but important to say that the key actors do not speak with one voice and in some cases, divisions are deep. For example, in Myanmar, even amongst the military aligned party, internal divisions are often laid bare, such as via the 2015 deposition of the then 
Speaker Thura Shwe Mann from the party chairmanship, while in Nepal, since the Constituent Assembly election the Maoists have split into three main offshoots and several other small units (though a core remains). At the group level, cohesion is even less likely. For example, Bush (2003) dissected the intra-group disharmony that contributed to the failures of the Sri Lankan state to find a successful accommodation, while Horowitz (2000 [1985], p. 583) makes clear that although some "purport to be leaders of whole ethnic groups, they are in fact leaders of ascendant parties or factions". Achieving a viable long-term solution requires the buy-in of a critical mass of key actors' constituent members, and the relevant ethnic group, but not necessarily unanimity or other form of consensus. This thesis does not consider such internal cohesion systematically nor as a variable, and it is a methodological convenience to theorize as though such key actors speak with one voice.

\subsection{Summary}

My methodology and conceptual framework is approached from a historical institutional perspective, whereby self-reinforcing and reactive path dependencies interact to converge at the point of federalism. Ethnic identity and conflict are critical antecedent conditions, while infrastructural capacity and secession risk are the independent variables interacting with the institutions and causal mechanisms including nation-building and bargaining (by concession or compromise). The different types of federal systems and the path dependencies observable in these cases' federalization processes provide fruitful ground for analyzing the origins and evolution of federalism in Asia. 


\section{Federalism, accommodation and Asia}

Federalism is the preferred means of accommodation by ethnic minority groups in Nepal, Myanmar and Sri Lanka. However, its origins in Asia are not well understood. I detail my proposition that holding together federalism follows from an alliance of ethnic minorities and excluded factions from the dominant group that is viable when there is supporting infrastructural capacity and a moderate secession risk. If the secession risk is too high, federalism is resisted.

I begin this chapter by outlining the importance and political salience of ethnic identity and briefly explain why Asia's post WWII nation-building agenda has led to conflict and demands for ethnic autonomy and federalism. I outline the need to accommodate diversity, and the justice inherent in that, and explain the major approaches that are promoted and debated. In particular, there are active debates about whether it is more effective to integrate or accommodate ethnic minorities, and, if pursuing accommodation, whether a consociational or centripetal approach is more likely to be effective.

Federalism is integral to most accommodation and many integration strategies and is seen by some as an end in itself. I establish a conceptual basis for analyzing and evaluating Asian federal systems, and consider how they have emerged. I show how the Asian experience of federalism, which has emerged over three generations and nine countries, is unique and provides a different perspective on prominent theories of the origins of federalism, from which I make my arguments about the origins of holding together federalism in Asia.

\subsection{Ethnic identity}

In the face of globalization's homogenizing tendencies, local, nationalistic and identity-based movements continue to reassert. Identity politics, which is seen by some as a dangerous modern-day scourge and by others as the path to emancipation, is now an inescapable feature of contemporary politics in many parts of the world, including Asia.

Identity politics is also in part an outcome of democratization. Democratization gives rights awareness to minorities and gives them the knowledge and opportunity to challenge elites' perception of national identity (He 2007), while system or regime changes give space for elites to rethink how to deal with longstanding separatist agendas (Miller 2012, p. 5). The modern states of Nepal, Myanmar and Sri Lanka, despite many differences, all share the primacy of identity to their political troubles and their resolution. As reported during Nepal's 
constitution-making process "the old hegemony is challenged and the politics of identity have taken central place" (United Nations Development Programme 2007, p. 3).

A person's identity is an integral part of their self, their sense of place and their structure of interaction and behavior. An individual and their group's freedom to practice culture, speak language and worship as they choose is fundamental to wellbeing and prosperity, supporting individual autonomy and self-respect (see Kymlicka 1995). Such freedoms are recognized as human rights (for example, the United Nations Declaration on the Rights of Indigenous Peoples (United United Nations 2008)) and often legally protected by the state. However, most states 'guaranteeing' cultural rights and freedoms tend to provide for them in a negative sense only, such as in a bill of rights, and there are comparatively few that provide positive rights and the institutions to give them effect, instead preferring to remain neutral and treat culture as a private matter outside the scope of government. Scholar's like Charles Taylor (1994), Will Kymlicka (1995) and Iris Young (2002) argue that there is an inherent injustice in this doctrine of liberal neutrality and that notions of justice and fairness demand that the state recognize identity and provide the institutional supports and groupdifferentiated rights that would support minorities to achieve substantive equality and a meaningful place in society.

A person will have multiple and overlapping identities. However, those that are based on ethnicity, religion or caste are often dominant, and mutually exclusive (Horowitz 2000 [1985], pp. 51-61). In Asia, such identities often form the basis of political organization (e.g. through ethnic parties) and underlie conflict. It has been argued that the salience of ethnic identities in Asia is an outcome of colonialists seeking to 'divide and rule' (e.g. Taylor 2009, pp. 150155, 285-286; Singh \& Kukreja 2016, pp. 67-68), and an entire constructivist school of thought has arisen around the ideas of Benedict Anderson (2006 [1983]), who argues that identities are fluid and 'imagined'. It would follow that identity should not be institutionalized in the public sphere. This perspective, however, diminishes their existence before and outside of colonial contexts and as the basis of colonial classification ${ }^{19}$, and their persistence across various social and political spheres. Irrespective of the extent to which

\footnotetext{
${ }^{19}$ Nira Wikramasinghe (2006) writes of the influence of the British in Sri Lanka in 'gelling' previously flexible and contextual identities (e.g. caste was previously the predominant identifier in place of ethnicity) (pp. 49-61), but ultimately concludes that " "in the last decades of British rule, a 'divide and rule' policy to suppress nationalism by fostering ethnic tensions was more mythical than real" (p. 150). Horowitz (2000 [1985]) argues that the colonial classifications provided a further basis for comparison and competition, but that those classification systems were built on pre-existing distinctions (see especially pp. 164-166). Walton (2013) discusses the solidification of ethnic identity as aided by the British obsession with categorization, but as based in relationships, locations and allegiances.
} 
identity has been used and misused as a source of mobilization, identities that are based on ethnicity are enduring and pervading. Prominent Nepal historian David Gellner (2005, p. 5) observes five 'common assumptions', that: 'everyone belongs to only one ethnic group; which they are born into; and cannot change; and [that] irrespective of size; they should all be treated equally'. Ethnic identities are a reality to be lived with, whether constructed or primordial.

Ethnic identities are reinforced by the convergence of multiple associated differences (e.g. religion, language and caste) and preferences, and are relational (Young 2002). For my purposes, I use the term ethnic group to denote groups based on one or a combination of ethnicity, language, religion or caste, depending on the prevalence accorded by social and political convention. For example, in Nepal, some caste distinctions are so socially divisive that a distinction is made between lower caste (Dalit) and upper caste members of the same ethnic group (Pahadi).

Kymlicka (1995) distinguishes between ethnic nationalities and immigrant groups, arguing that the former warrant a particular and more expansive form of recognition. Ethnic nationalities are taken to refer to groups that share common culture and language, and were present, self-governing and having institutions in the state prior to its 'founding'. An immigrant group is one with a more recent association. However, in Asia these categories intersect and overlap, and it is difficult to draw a line (see Bowen 2005). Nevertheless, state authorities can and do make such distinctions, often with deleterious consequences. In Nepal, Myanmar and Sri Lanka, particular groups have been defined as recent immigrants (Madheshis (Nepal), Rohingyas (Myanmar) and Upcountry Tamils (Sri Lanka)), on a sometimes highly questionable basis and have been disenfranchised and denied the opportunity for empowerment through the institutionalization of federalism ${ }^{20}$. Instead, I make a distinction between the dominant ethnic group and minority ethnic groups, whether or not there is disagreement about their status. I make a further distinction, following Barter (2015), between first and second order minorities. First order minorities are those groups who are a minority in the country, but may be a majority in a region, while second order minorities are those groups who are a minority in a particular region and who may or may not be a minority in the country as a whole.

\footnotetext{
20 In the case of Rohingyas, it has precipitated a refugee and humanitarian crises permeating across the region, while the Upcountry Tamils and many Madheshis remain in a position of relative poverty. Each state is neighbored by the far more populous states of India (and in the case of Myanmar, Bangladesh), and so their disenfranchisement may be related to the 'minority complex' that is often cited in relation the Sinhalese in Sri Lanka (see for example Oberst 1988, pp. 181, 189-90).
} 


\subsection{Nation-building}

International borders and the modern nation-state ideal were imposed in a context of high diversity and contested histories. These post WWII modern states were premised on the idea that each ethnic nationality would be encompassed within the borders of a single state a 'nation-state'. In the immediate aftermath of WWII, the maps of the world were redrawn with this in mind, and the principle of inviolable sovereignty was institutionalized through the international system of mutual recognition. In particular, the international boundaries of South and South East Asia were defined by the process of decolonization and externally imposed, whether or not a country was itself a former colony ${ }^{21}$ (Reid 2010a). With few exceptions, these new states hosted a variety of ethnic groups, recent and long-standing, hardly fitting the ideal of the single identity nation-state.

The legacy of these imposed borders reverberates today, and the identity-based nationbuilding which it spawned has been blamed for the exclusion, discrimination and conflict that has prevented peaceful consolidation of new national borders. With at least one exception (India), many of the new modern states failed to recognize and institutionalize their internal diversity and instead attempted to consolidate power by imposing a unitary identity, culture and language, known as 'nation-building', turning what were "reviled imposed borders into sacred national ones" (Reid 2010a, p. 12). This occurred in Nepal, Myanmar and Sri Lanka, where the symbols and structures of the state were imbued with the identity of the dominant ethnic group:

Nepal has been an ethnic state all along - only it was monoethnic. And all other languages, ethnicities were either silenced, or subsumed under one monoethnicnationalist umbrella or placed in a hierarchical order (Mishra 2009).

The root cause of the national conflict is Sri Lanka being a Sinhala-Buddhist Nation State - a State that is identified with a single nation and demos and has a hierarchical structure with the Sinhala Buddhist Nation that sits on the top of the hierarchy. This hierarchy is represented in the unitary character of the State (Tamil People's Council 2016, p. 5).

When such nation-building was based on the culture and language of the dominant ethnic group, it has been ineffective in places where there is a diversity of strong and distinct ethnic

\footnotetext{
21 Uncolonized countries, like Nepal and Thailand for example, were abutted by at least one colonial country.
} 
groups $^{22}$. This has led to increasing calls for accommodation through federalism or independence (Kymlicka \& He 2005; Amoretti \& Bermeo 2004; Bertrand \& Laliberte 2010). These places, where ethnic identities are politically salient, are known in the literature as divided societies. They are deeply divided when the segments are in an antagonistic, oppositional or even violent relationship, an important indicator of this is the nature of the political party system (see McCulloch 2014; Reilly 2001). Nepal, Sri Lanka and Myanmar are examples of countries that have attempted to build a single national identity-based on that of the most populous ethnic group, only to experience violent resistance, incidences of ethnic cleansing and a contrary trend towards a consolidation of traditional cultures (Lawoti 2005; Bhattachan 2008; Bennett et al. 2006b; DeVotta 2004; Smith 1991; Taylor 2009). Each is deeply divided and in transition.

\subsection{Constitutional settlements}

Constitutions and constitutional structure are the instruments through which reforms must be effected if ultimate improvements in patterns of political outcomes are to be expected (James Buchanan, cited in Gerring \& Thacker 2008, p. 157).

Federalism is the contemporary demand of minority ethnic groups in Nepal, Myanmar and Sri Lanka. It is seen as the way out of conflict and identity-based marginalization, and an end in itself, as articulated by Myanmar's Arakan National Party: "since whatever we do depends on the constitution, we need to work towards decentralization to share power to reach our ultimate goal: federalism", (Htoo May, Member of Parliament, Arakan National Party, Myanmar, quoted in Snaing 2016). Demands for federalism are being aired as part of Nepal's, Myanmar's and Sri Lanka's 'constitutional moment' (as in Ackerman 1993; Ackerman 2000). Federalism is embedded in, and derived from, a constitution and it is from this peak institution that substantial change can be driven.

Some say that constitutional development processes are as important as its contents. For deeply divided societies, like Nepal, Myanmar and Sri Lanka, participatory processes are advocated by international experts and academics, with the United Nations Development Programme, Nepal $(2007$, p. 1) going so far as to declare that "it is widely accepted today that the most important aspect of constitution making is the widest possible participation of

\footnotetext{
22 India, Indonesia and Singapore, among others, used a language that was not that of the dominant identity group which went some way to tempering the demands of minority ethnic groups and reducing perceptions of domination (He 2007).
} 
all the people and their communities and organizations". However, the merits of participatory processes (versus say an expert drafted constitution) are far from established ${ }^{23}$. Constitutional processes in the case of Nepal, Myanmar and Sri Lanka are primarily elitebased, notwithstanding the popular uprisings that triggered change and the engagement of the public in the change process. In such cases, constitutional settlement is an exercise in compromise and conflict resolution, arising out of shifts in the power balance across both elites and those whom they purport to represent (Kingsbury 2012; Coakley 2009; Lande 1999; Miller 2012). This means that central governments need to respond specifically to the demands of the minority groups that have taken up arms against the state, as compared to the popular outcomes of public participation, which are often contradictory and incoherent, and may serve to further marginalize minority groups. Today, federalism is fundamental to these minority groups' demands and "autonomy remains the prevalent model of dispute settlement..., in virtually all constitutional settlements to self-determination conflicts" (Weller \& Wolff 2005, p. 232).

\subsection{Federalism and federal systems}

As mentioned in Chapter 1, federalism as a term is contested, but most often used to refer to a specific type of federal system - a democratic federation, colloquially known as a 'genuine federalism'. However, federalism is inherently a hybrid. The American federal system is widely acknowledged as the standard form of federalism, but the proponents of that institutional design co-opted the term federalism in justifying the American hybrid that combined traditional federal elements of existing federal states/units with strong centralist institutions (Hamilton, Madison \& Jay 2003; Galligan 2007). Since that time other federal systems have arisen, each with their own unique hybridizations and effects.

I make a distinction between federalism, quasi-federalism and federal systems. While Hueglin \& Fenna $(2015$, p. 25$)$ distinguish between 'a commitment to federal principles', and 'complex federal arrangements', arguing that the existence of only one term - federalism covering both 'discourages a critical examination', there are separate terms for both, which

\footnotetext{
${ }^{23}$ Horowitz (1999) for example, warns of the dangers of participatory processes because the multiplicity and asymmetry of interests and objectives more often leads to compromised and theoretically incoherent results. More recently, Wallis (2014) sought to comparatively assess effectiveness, finding that "the higher the level of participation involved in constitution-making, the more likely it is that the resulting constitution and the institutions it creates will make sense to the societies they seek to govern" ( $p$ 14). However, her approach was limited to two cases, arguably similar outcomes can result if effective representative arrangements exist (e.g. a political party system) or can be put in place, and 'making sense' to locals can come at the expense of coherent and targeted outcomes possible under expert driven processes.
} 
are widely but not universally used. Federalism has been understood as an ideology, reflecting a 'balance' between otherwise competing preferences for centralism and decentralization (King 1982) and "based on the presumed value and validity of combining unity and diversity and of accommodating, preserving and promoting distinct identities" (Watts 1999, p. 6), sitting alongside its institutional manifestation, being a federal system. A federal system can then be classified according to a number of sub-categories (Watts builds on the system of classification created by Elazar (1987, pp. 38-64)). I argue that this ideology is better understood as a purpose of federalism, of which there may be others, and that federalism should be understood as an institutional arrangement.

Further, given the conventional connotations in the region, that is that genuine federalism is democratic and with sovereign levels of government, and the more standard definitions of federalism in political science (e.g. Bealey 1999, pp. 130-131), I reserve the term federalism for federal systems that have broadly equal and sovereign levels of government, and refer to other federal systems lacking sovereignty or guaranteed autonomy in the units as quasifederalism. I use federalism and quasi-federalism as referring to institutional arrangements federal systems - rather than ideologies. The key point of commonality is the presence of a constitutional division of powers. Federalism and quasi-federalism can be democratic or not although federalism tends to be most effective when democratic (Galligan 2007; Burgess 2013). I make no upfront judgement about the normative value of either, I merely adopt the distinction that is made in the region and by those debating issues of ethnic accommodation and state restructuring.

I use the term federalization to refer to the introduction or enhancement of a federal system, whether genuine or quasi, via institutional change. Further, I classify federal systems consistently with its purpose and so including those interacting elements like the system of representation. A visual representation is provided in Diagram 3, which illustrates the important inclusion dimension of Asian federal systems, which can coexist with federalism, quasi-federalism, other variations of the traditional federal form, and unitary systems. Asian federal systems are discussed further in the subsequent sections. 
Diagram 3: Federalism, quasi-federalism and Asian federal systems

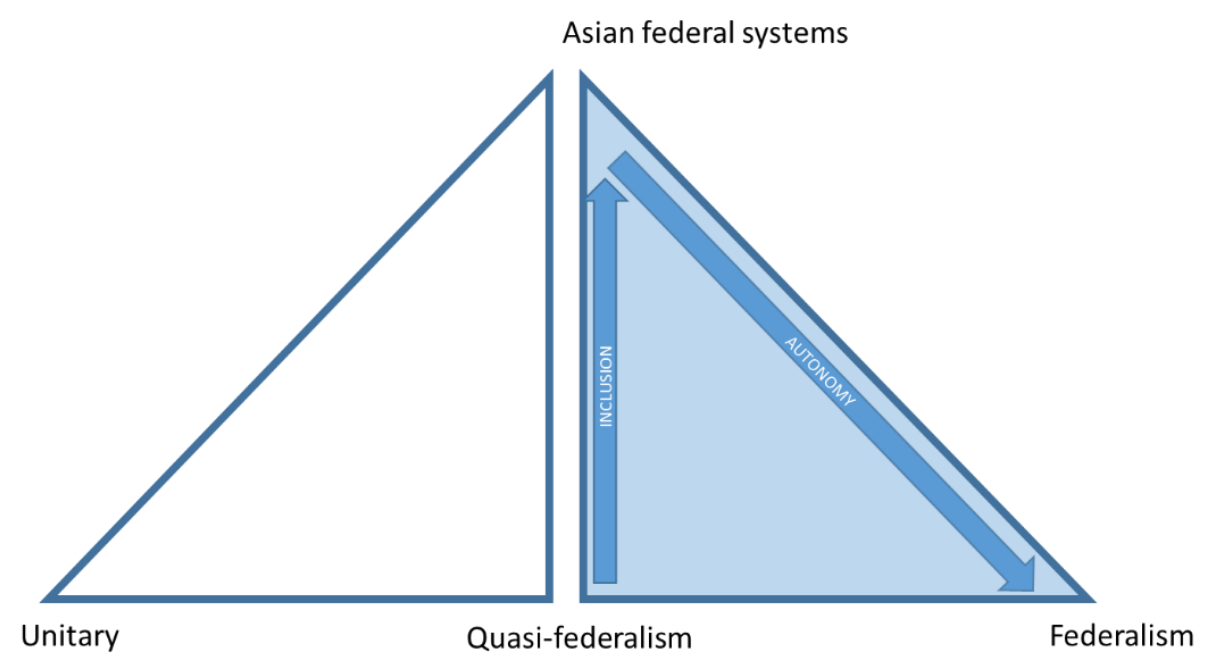

Federalism can have many types. Ethnic federalism, as discussed in Chapter 1, is commonly demanded by ethnic minority groups, but is not necessarily ideal. Liam Anderson (2014) makes a case that it is the 'least worst' institutional configuration for a deeply divided society because unitary approaches have been unsuccessful in terms of stability, democratization and development. I argue that in fact a more hybridized approach to federalism (neither ethnic nor territorial) is more likely to achieve the key aims of federalization and achieve political equality across deeply divided communities.

The main criticisms of ethnic federalism are that it increases the chance of conflict and secession; and potentially impacts negatively on second order minorities. It has been shown that conflict is more likely when an ethnic group has control of regional institutions, especially if they are also excluded at the center (Deiwiks, Cederman \& Gleditsch 2012). However, autonomy is often used as a means to defuse conflict and so, despite some correlation, autonomy has more often reduced the likelihood of conflict (see Anderson 2013; Miller 2012; Wolff 2009; Coakley 2001), even if it is only an interim measure (Weller \& Wolff 2005). Nevertheless, the fears of secession that affect federalization processes are present and must be addressed.

Further, it is not established that federalism makes second order minorities more vulnerable than they were or would be under a unitary state. Federalism provides more opportunities and points of intervention for rights protection and positive empowerment. Barter (2015), in summarizing a special issue focusing on second order minorities, highlights the actual and potential impacts on second order minorities from secessionist nation-building, which he sees as essentially replicating the exclusionary practices of the nation-state in its nation- 
building agenda. However, while the cases of Nepal, Sri Lanka and Myanmar may show how second order minorities are sometimes marginalized (sometimes violently) by nationalistic minorities (e.g. the Madhesh riots in Kapil Vastu, Nepal in 2007, or the expulsion of Muslims from Jaffna, Sri Lanka in 1990), it is less clear whether such marginalization is used more as a tool to support claims for autonomy, and less as an outcome. In any case, an institutional design that minimizes such risks is a desired and desirable outcome.

\subsection{Hybrid federalism in Asia}

There have been relatively few attempts to comparatively and systematically understand ethnic accommodation in Asia, which is varied (ideologically, institutionally and effectively) and hybridized. I focus on federalism, as the preferred solution, but incorporating the range of institutional elements that interact with federal structures and contribute substantively to 'unity and diversity' and 'the preservation and promotion of distinct identities' (Watts 1999, p. 6). That is, including other elements of accommodation strategies such as electoral systems, as well as by analyzing all federal systems, including those that are better described as quasi-federalism. In doing so, I develop a new approach to understanding and evaluating federalism in Asia, as a means of managing diversity and a potential middle ground between consociational and centripetal specifications (discussed below). I believe that there is little benefit in seeking to understand Asian federal systems without understanding these related aspects that form a package towards 'unity in diversity'.

Also, I do not take the perspective that a liberal or other form of democracy is a prerequisite of accommodation, however, it is clearly an aspiration of majority and minority ethnic groups in Nepal, Myanmar and Sri Lanka. Pertinently, many argue that accommodation of minorities is less likely to occur in undemocratic systems, or that a federal system cannot work in an authoritarian regime (e.g. Stepan 1999; Elazar 1987; Burgess 2013; Hueglin \& Fenna 2015). Michael Burgess (2013, p. 253) argues that federalization follows a sequence of "democracy to constitutional democracy to liberal democracy to federal democracy in a logical historical path"24.

\footnotetext{
${ }^{24}$ Burgess (2013), building on Elazar (1987) among others, sees liberal democracy and federalism as existing in a symbiotic relationship, and bases his work around the idea of federal democracy as a species of liberal democracy (p. 253). Burgess argues that practice has 'fused together' liberal democracy and federalism and that the federal claims of the Soviet Union, Czechoslovakia and Yugoslavia were 'counterfeit' and in practice centralized and authoritarian. Burgess categorizes Pakistan and Malaysia as 'flawed federal democracies' on account of a lack of federal practice (p. 273). There is also a well-established scholarship critiquing the now dissolved federal systems of Eastern Europe (in particular Bunce 1999).
} 
This downplays the significance of hybrid arrangements that have emerged in countries that the West would assert are not fully democratic, such as China and Malaysia (see for example Kymlicka \& He 2005). Further, Henders (2010) and Bertrand \& Laliberte (2010) note little difference across regime types in whether and how minorities are accommodated. Federal systems in Asia that are not fully democratic may be more accommodating and more sensitive to context because of the authoritarian elements of prior and existing political institutions and the predominance of group rights and communal modes of thinking and legislating ${ }^{25}$. A theory for accommodating ethnic groups in Asia needs to be situated within a framework of Asian cultures and political systems.

Although federalism has been regularly touted as a potential solution to 'minority problems', particularly ethnic federalism (e.g. Kymlicka 2007; Anderson 2013; Ghai 2000; Lawoti 2010), Asian hybridizations and their evolution have not been well researched. There has been considerable discussion on India and a growing literature on Malaysia and Pakistan (e.g. Adeney 2007; 2009; 2012; Singh \& Kukreja 2016; Hutchinson 2014; 2015; Bhattacharyya 2010; 2015), but this has often been in the context of traditional Western models and liberal democratic ideals, even in the cases of Pakistan and Malaysia where authoritarian tendencies are considered as informing the extent to which their federal practices are consistent with democracy (rather than considering the merits or otherwise of non-democratic varieties). Adeney (2009), however, argues that it is the lack of consociational features accompanying Pakistan's federal system that has largely caused its instability and conflict, rather than the democratic shortcomings per se, an insight on which I build.

Baogang He (2007) goes some way to developing a federal concept for Asia, through a comparative study of Asia (He, Galligan \& Inoguchi 2007) and this informs my conceptual framework. Additionally, given the fledgling literature on federalism in Asia, I systematically ${ }^{26}$ reviewed each post WWII constitution of a further six countries (India,

\footnotetext{
25 The Asian experience of federalism would suggest that federal principles and practices can work in the absence of democratic norms and practices and can contribute to stability and development, which are important generally applicable goals of the state. For example, Malaysia's federal system has been subjected to a continued 'centralization drive', but the units play an important role, for example delivering public services (Hutchinson 2014). That there has been a trend towards centralization or illiberalism does not preclude its classification as federal. Riker (1964) for example, noted many similar trends among established federal democracies, arguing that stability as a federal system comes from the inability of one level of government to completely overawe the other. While the Malaysian center has engineered certain political outcomes in units, it has never been unlimited in its control and has had to finely balance its prerogatives with the rights and interests of the units and their constituents, even if only to maintain control and prevent the rise of secessionist movements (Case 2007). Pakistan's federal system has peripheralized and become more inclusive, since 1973, even if it remains illiberal, authoritarian and, overall, centralized. The units still enjoy some measure of autonomy and maintain a direct relationship with the people (Singh \& Kukreja 2016; Adeney 2007).

${ }^{26}$ That is by extracting categorizing and comparing elements in accordance with the approach taken to analysing the constitutions of Nepal, Myanmar and Sri Lanka, which is elaborated in Box 1 and Appendix 2.
} 
Malaysia, Pakistan, China, Philippines and Indonesia). Generally, Asian variations on the traditional federal models include or incorporate:

- Mixed or ethno-territorial federalism, being a hybrid of ethnic and territorial federalism: creating multiple-identity (but not neutral) units, or accommodating ethnic groups' demands for autonomy in one or more geographic locations and dividing the dominant identity group across a number of other territorially defined units (as in Anderson 2013, pp. 164-218; Hale 2004);

- Asymmetrical autonomous regions, a hybrid of unitary with federal features: where one or a number of units have been granted (constitutional) functions or powers that are not provided, or are different to those provided, to other units (as in Henders 2010; Agranoff 1999; Wolff 2009; Miller 2012), such as Hong Kong and Aceh, or where units have a different stake or involvement in the governance of the center (O'Leary 2010), such as in Burma's first independence constitution;

- Consociational or other identity-based features, a hybrid of individual and group-based institutions. For example, the provision of cultural autonomy, allowances for personal laws, institution of free prior and informed consent or minority vetoes, and special representation arrangements (e.g. proportional representation and reservations). Such arrangements are often process-based and more dynamic and flexible than traditional forms of federalism (Lijphart 1977; 1985; 1996; Nimni 2005; Coakley 1994; Roepstorff 2013, pp. 118-124; Nohlen, Grotz \& Hartmann 2001a; 2001b).

Other approaches have classified federal systems from across the globe according to a long and varied typology, which has included hybrid arrangements in mostly separate, unique and prescriptive categories (Watts 1999, pp. 8-9; Elazar 1987). These are not considered useful for my exercise because of their focus on traditional federal structures and the narrow applicability of several categories. Hence, I develop my own concept of Asian federal systems.

\subsection{Asian federal systems}

Each of Asia's federal systems is highly hybridized with unique elements and common factors. My research addresses a gap in the literature and establishes, applies, tests and refines a new concept of Asian federal systems that aims to capture and theorize the common elements, and the unique features to understand their evolution and different mixtures of consociational, centripetal and deliberative features. 
As discussed above, taking a holistic approach to federalism in Asia requires that its purposes be considered when identifying what are the relevant features. Asian federal systems are primarily about the integration or accommodation of different ethnic groups. Hence, features that seek to achieve these ends should be incorporated into the concept and its dimensions where interacting with federal institutions and contributing to the aim of unity in diversity. This includes mechanisms for proportional representation and the recognition of cultural rights. Further, the concept should be democratically neutral. Democracy is shown to interact with the federalization process but is not a feature per se, and can be controlled through the comparative process.

The concept takes a family resemblance approach (see Gerring 1999), with four particularly pertinent features:

- the supremacy of the center - from the Indian center's ability to act in 'the national interest', to China's party-led constitution, Asian federal systems share this feature;

- $\quad$ units that are based on a mixture of ethnicity and territory - unlike the United States' purely territorial approach, or Switzerland's ethnic approach, all of the systems in question have at least some units that are based primarily on ethnicity and some that are based primarily on territory, or have units with a mixed basis;

- $\quad$ asymmetry - formal differences in the powers, status or representation of units is a common feature of Asian federal systems, from the special autonomy existing in places like Aceh to the special representation afforded to the ethnic nationalities in Myanmar's federal system;

- cultural rights - supplementing the special representation and unit demarcation are non-territorially based cultural rights, such as personal laws and language rights, which serve to protect the rights of small minorities and account for heterogeneity, and in some cases, particular rights for those classified as indigenous people.

Asian federal systems do not fit neatly into Watts' (1999) or others' federal typologies as they are substantial and modern day hybridizations. This is acknowledged as much by Watts' (1999, pp. 8-13) who creates a hybrid category that is effectively a collection of miscellaneous systems. However, as outlined above, Asian federal systems do reveal particular resemblances. There are uniquely shared features that warrant a new approach to understanding federal systems in Asia, if not elsewhere.

The explicit treatment of ethnic groups in institutional design gives Asian federal systems much of their character and warrants conceptualization. This concept can be considered a 
contribution to a greater understanding of Asian federalism, but does not purport to create a rival to Watts' (1999) or other conventional typologies, or position an ideal type, but a broader federal remit is in evidence and should be systematically accounted for. Box 1 provides a summary of the operationalized factors of the concept of an Asian federal system, with further details available in Appendix 2. The concept is used as a framework for identifying, measuring and analyzing options and approaches in each case (see Chapter 5 especially). 


\section{Box 1: Measuring an Asian federal system and interpreting results}

The Asian federal system concept focuses on the approach to the management of ethnic diversity and measures formal and informal institutions along a continuum from assimilation to accommodation. The higher the score, the more accommodating, or more federal, it is.

The elements have been subcategorized to enable comparison of component parts, in particular those that can be said to be consociational in character (relating to power-sharing), those that relate to traditional federal systems, and those that relate strictly to the extent of ethnicity afforded in the federal design.

The formal federal components and their operationalization are:

- Autonomy: the extent of centralization (e.g. intervention rights) offset against the extent of constitutional autonomy afforded to the units;

- Constitutionalism: concerning the constitutional change, interpretation and dispute resolution processes;

- Bicameralism: how units are represented in the center, such as whether there are two relatively equal houses of parliament, or whether units are formally represented in other central institutions;

The formal consociational components and their operationalization are:

- Legislative executive relations: particularly if the executive is drawn from and accountable to the legislature;

- Representation: how ethnic groups are represented in key institutions, particularly the legislature, including electoral systems; and,

- Cultural rights: the extent to which diverse cultural rights, such as those relating to language and religion, are positively protected or undermined.

The formal ethnicity in units component measures the proportion of units which are based primarily in a single ethnicity, mixed or territorially based.

Informal, or behavioral elements of an Asian federal system are recorded as acts implementing or not, or reinforcing or undermining, components as outlined above. Examples include: if a constitutional provision is not implemented within three years, its score is negated; each time a unit, or its legislature or executive is dissolved, or legislation is disallowed; the proportionality of electoral results; and the nature of executives such as whether minimum, oversized or consensus.

The scoring system is heavily informed by the approach of Lijphart (1999) but adapted. His approach is not replicable in these cases due to information unavailability and the inapplicability of certain assumptions (e.g. that party and ethnicity correlate). I have chosen to take a more nuanced approach to some elements, such as autonomy and centralization, and discount the salience of measures like central bank independence and the strength of civil society.

Additional to the Asian federal system scoring are the sequencing and other related factors. With the exception of democratization, and the use of Gallagher's Index (Lijphart 1999, p. 145), I have created my own measures because existing measures are either incomplete for Nepal, Myanmar or Sri Lanka or not sufficiently sensitive to the more detailed information requirements of analyzing a small number of cases. The sequencing factors are the extent of conflict, when regime type changes occur, when there is either major marketization or an economic crisis and when there is international intervention or other contingent event, like a natural disaster. Positive changes are scored as one, and negative changes as negative one, and are generally not cumulative. For comparing with democratization, I use the Polity Project's timeseries data (Marshall, Gurr \& Jaggers 2016). Further details and explanation are available in Appendix 2. 


\subsubsection{Assimilation, integration and accommodation}

I measure the Asian federal systems of Nepal, Myanmar and Sri Lanka along a continuum of assimilation to integration to accommodation. As discussed earlier, the assimilative practices of the past, often encompassed within a nation-building agenda, are ethically unsound and practically ineffective. Assimilation should be distinguished from, and contrasted with, integration and accommodation (McGarry, O'Leary \& Simeon 2008). Assimilation is taken to refer to an approach that aims to erode private and cultural differences, and build a common national identity ${ }^{27}$, while integration and accommodation both seek to respect cultural difference ${ }^{28}$.

Integration is defined as the "the privatization of national, ethnic and cultural differences" (McGarry, O'Leary \& Simeon 2008, pp. 41-44), and the predominance of individual rights and freedoms. This approach is a fundamental underpinning of (traditional) liberal democracy in the West and there are many advocates (e.g. Roeder \& Rothchild 2005; Brown 2007; Galligan 2007; Barry 2002). Integrationists argue that the state should be neutral and that private or civil society organizations are best placed to manage identity-based differences.

If it were accepted that an ethnic group in conflict over its demands for political rights would accept integration or a simple plural democracy, which seems unlikely given the choice ${ }^{29}$, there are bigger issues. In practice, liberal democracies are not culturally neutral and historical and social discrimination prevents many minority groups from achieving substantive freedoms and distributive justice (Kymlicka 1995; O'Flynn 2006). The continuing disadvantage, discrimination and cultural domination experienced by indigenous groups in otherwise wealthy countries like Australia, Canada and United States are important examples among many. Inevitably, a 'neutral' state will, via its institutions, reflect to some extent the cultural preferences and biases of its dominant ethnic group (for example through the language of instruction in education).

If it is not possible for a state to remain neutral, then it is just and necessary for a state to accommodate ethnic minorities in their policies and institutions (as argued for example by Kymlicka 1995; O'Flynn 2006; Young 2002; Taylor 1994). Accommodation entails recognition of cultural difference - recognition that the state compromises more than one ethnic

\footnotetext{
${ }^{27}$ Whether by fusion (creating a new culture) or acculturation (absorption by one into the other) (McGarry, O'Leary \& Simeon 2008, p. 42).

28 Some integrationists can be characterized as favoring voluntary assimilation, seeing integration as mere stepping stones to assimilation (McGarry, O'Leary \& Simeon 2008, pp. 41-44).

${ }^{29}$ The experiences of Nepal, Myanmar and Sri Lanka demonstrate that integration is not an acceptable solution to ethnic conflict or reconciliation.
} 
community and that its institutions should be designed in consideration of their interests. Assimilation, integration and accommodation can be considered along a continuum, depending on the treatment of cultural difference and ethnicity, as indicated in Diagram 4.

Diagram 4: The assimilation, integration and accommodation continuum

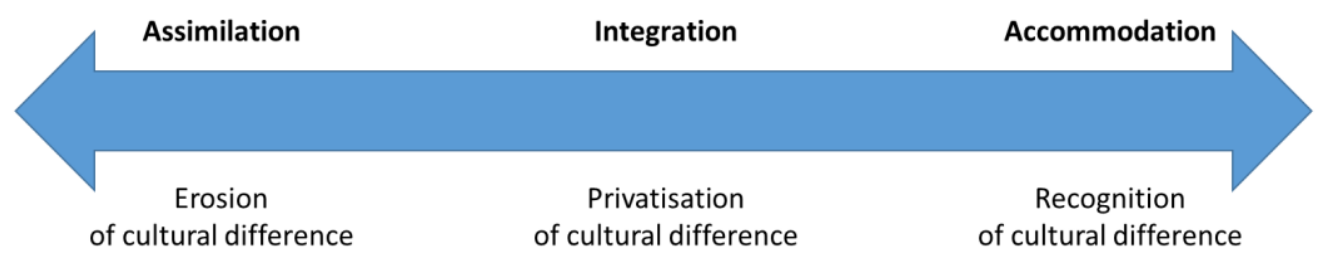

\subsubsection{Consociational or centripetal}

Among those who advocate accommodation, there are two main schools of thought centripetalism, associated with Donald Horowitz (2000 [1985]) and consociationalism, conceived by Arendt Lijphart $(1977 ; 1999)^{30}$. Both emphasize the argument that cleavages associated with ethnicity tend to reinforce each other and so liberal democratic approaches, including state neutrality and individual rights based institutions, in effect permanently marginalize minority ethnic groups in divided societies. However, they respond differently to this problem.

Lijphart's consociational solution is characterized by the coexistence of four features: power sharing arrangements among coalitions of the elite ('grand coalitions'); cultural / segmented autonomy (personal laws, educational and / or territorial); proportional representation; and, minority veto (Lijphart 1977; 1985; 1999). Consociationalism focuses on political processes and aims for consensus among ethnic groups. Lijphart stresses the elite driven nature of consociationalism, noting that it relies on their goodwill and the acceptance of such a system of government by 'the masses' ${ }^{31}$. Inevitably, such consociationalism cannot be a long-term solution for deeply divided societies, as the degradation of Malaysia's consociational

\footnotetext{
30 Other scholars incorporate a more specific but less conceptually clear typology of accommodation approaches. For example, Patten (2008) argues for a fourfold typology incorporating (on a scale of increased accommodation) disestablishment (neutrality); nation-building (identity-based); cultural preservation; and equality of status. However, this merely breaks into two each of integration and accommodation, without then including the full gamut of possible responses. Some eschew the term accommodation altogether, instead seeking to focus on empowerment. For example, Gagnon (2009) criticizes the conceptual framework promoted by McGarry, O'Leary and Simeon (2008) as preserving existing power relations and associated domination. However, Gagnon's 'empowerment' model proposes strategies that mirror many strategies proposed by accommodationists, namely the right to self-determination, legitimacy of recognition claims, seeking cultural preservation, and an accent on real rather than just formal equality. Gagnon argues that these can be effected through 'treaty federalism', which is similar to Burgess' (2013) partnership based approach to federalism, while also supporting centripetal style moderation. Regardless of the conceptual framework one wishes to apply to the integration and accommodation perspective, the range of tools overlap (e.g. federalism) and should be dissected before being considered as a package, in terms of their actual and possible application.

${ }^{31}$ Although Lijphart has since softened his criteria, the criticism remains valid.
} 
elements demonstrates (Kymlicka \& He 2005), but it may be particularly useful as a strategy during times of transition ${ }^{32}$.

Further, in the cases of Nepal, Myanmar and Sri Lanka, the conditions noted by Lijphart as being conducive to consociationalism do not exist because each is dominated by an effectively majority ethnic group (with no 'multiple balance of power'). This contributes to elites competing (intra- and inter-group) rather than cooperating to achieve their objectives. There is also no external threat (though times of crises more generally can be seen as conducive to consociationalism). However, consociationalism's emphasis on coalition governments and consensus-based politics can be observed in periods of transition in Myanmar, Nepal and Sri Lanka, where federalism is seen by many as the end. Indeed, leading federal scholar Daniel Elazar concluded "that consociationalism is even more likely than federalism to be a means rather than an end" (1985, p. 26).

Horowitz (2014) argues (along with Roeder \& Rothchild 2005) that empowering ethnic 'troublemakers' through consociational mechanisms leads to an increase in extreme demands and conflict, and leaves a system vulnerable to deadlock. Horowitz further argues against the viability of consociationalism in many contexts because of, inter alia, the very low likelihood of a politically dominant groups sharing substantive power. He is also concerned about the potential for immobilism or deadlock arising from minority veto.

Horowitz's preferred alternative - centripetalism - is based on incentivization. Centripetal approaches try to encourage moderate cross-ethnic policies and the development of interethnic coalitions in a pre-election bargain, thereby sidelining the extremes (that consociationalism would include as a means of conflict resolution). A key tool is the use of an alternative vote, which creates an incentive for political actors to seek the support of minorities, and moderate their policies accordingly (see also Reilly 2001). Horowitz also stresses coherence, arguing an inherent incompatibility of consociationalism and

\footnotetext{
32 Institutionalization of consociationalism does occur in some cases. McGarry and O'Leary (2007) building on consociational theory and its application in the context of constitutional settlements expand on the elements argued as necessary for achieving stability in a post-conflict divided society - known as 'consociation plus' (or 'complex consociations'). Consociation plus concerns security sector reform, refugee returns, language rights and prisoner management, in addition to Lijphart's four features. These additional matters, while certainly of importance in many countries including Nepal, Myanmar and Sri Lanka are beyond the scope of this thesis, as it focuses on institutional design, primarily federalism, and the accommodation of minorities. McGarry and O'Leary (2007) make a further conceptual distinction between corporate and liberal consociations. A corporate consociation is of the tradition envisaged by Lijphart whereby ethnic identities are essentially fixed, with representative guarantees etc. accorded to those ethnic groups, whereas a liberal consociation accepts a more fluid basis for identity, empowering salient elements as they arise through more organic processes and organizations, like electoral outcomes and political parties.
} 
centripetalism and associated hybrids because consociationalism empowers extreme elements and eliminates or dilutes the oppositional element (which he sees as essential to a working democracy) - and is centrifugal - conflicting with and undermining the centripetal and moderating incentives intended to be built via the electoral system (Horowitz 2014).

There is only a small number of real world examples of centripetalism to evaluate. McCulloch (2014) examines the results of centripetal electoral institutions in eight deeply divided societies finding that in the majority of cases, including Sri Lanka, moderation 'did not pay' and that even in the few cases where a moderate candidate was elected, instability followed. Further, it was only successful in places that already had a moderate middle with significant existing support, and she argues that centripetal strategies are incapable of creating such support or moderation unless it already exists. These findings are generally consistent with those of Reilly (2002), who evaluated five cases of diverse but not necessarily divided societies. Importantly, Reilly concluded that more heterogenous societies are less likely to benefit from preferential voting as compared to a bipolar society (p. 168). Centripetalism as conceived appears unlikely to be effective in these cases, however, moderation as a goal should not be discarded.

Common to both centripetalism and consociationalism is an assumption that not only is there an electoral democracy and a predominantly ethnic party system, which is not the case in many places in Asia. While Sri Lanka has sustained, at least to an extent, a democracy, Nepal and Myanmar have fluctuated between democratic and authoritarian regimes all the while cognizant of ethnic identity and its institutional management. There are ethnic parties in each case, but there are also multiethnic parties emerging, while the institutions of authoritarian government (e.g. Myanmar's one-party system) have also, at times, been multiethnic. Federalism provides adequate space for both ethnic and multiethnic parties to develop and co-exist, balancing the opposing forces of centralization and peripheralization. This is explored further in Chapter 7.

\subsection{The origin and evolution of federalism}

As discussed, it is commonly accepted that the diverse and multinational status of many Asian states has resulted in considerable minority resistance to nation-building agendas. However, federalism has emerged in so few Asian countries, which begs the question of why has it been resisted, or what caused it to be adopted in the situations that it was? 
Daniel Ziblatt (2006, pp. 3-6) frames three standard approaches to explaining the origins of federalism - understood as democratic federations: ideational (e.g. Burgess 2013), where federalism is an outcome of the predominance of such ideas (which of course begs the question about the origin or basis of those ideas); cultural-historical (e.g. Erk 2008), where the relative distinctiveness of cultural groups drives federalization (which is overly deterministic), and social contract or bargaining theories. This latter theory, explained prominently by William Riker (1964) sees federalism as being a bargain between elites deriving from a desire to mitigate an external threat and expand territory - occurring only when the relative military capacity is such that the (prospective) center cannot subsume the units.

Ziblatt (2004; 2006) builds on Riker's idea and convincingly argues that federations emerge in situations where regional or ethnic groups have an infrastructural capacity already in place and upon which new federal arrangements can be built (providing a credible negotiating partner and the governance benefits sough through unification). Ziblatt shows that ideas and cultures as per theory might be necessary conditions, but they are not sufficient. However, he does this only in respect of coming together federal systems and his theories do not apply to holding together federalism.

Hueglin \& Fenna (2015, pp. 129-134) conceive of 'devolutionary federalism', as applying to the cases of Spain, Belgium and South Africa, but do not look further or theorize commonalities. More closely linked to my cases, Kingsbury (2012) argues that autonomy arises from conflict resolution via 'mediated compromise' to prevent state break-up and build legitimacy by better reflecting identity-based diversity in the structures of the state. However, these are isolated settlements. Benz \& Broschek (2013) argue that holding together systems "evolved from a rather incremental transformation of authority relationships" ( $p$ 101). This may account for the holding together systems of Europe (Belgium, Spain), but in Asia, it can only be said to apply to quasi-federalism. Genuine federalism in Asia (e.g. India, Nepal) arose through critical junctures and a fundamental transformation of authority relationships at central and unit levels. Those that were mediated (e.g. Sri Lanka in 1987) elicited a concession, rather than a fair compromise. But under what conditions?

\subsubsection{Three generations of federalism}

The period in which Asian federal countries federalized heavily influences their process of federalization, most particularly their origin. Federalism in Asia can be understood to be 
occurring over three generations. There are the three constitutionally federal countries in Asia - Malaysia, India and Pakistan. Each of these countries is part of the first generation of federalism in Asia, arising out of processes of decolonization and modern state-building. I note the conjecture about the 'federal credentials' of Malaysia and Pakistan, branded variously as 'flawed' (Burgess 2013), 'defunct' (Singh \& Kukreja 2016) and 'failed' (Bhattacharyya 2010), but subscribe to a position that, although sometimes subject to centralizing trends and undemocratic practices, each comprises the essential features of federalism constitutionally and in practice.

The second generation of federalism occurring after the establishment of their modern states concerns the incorporation of federal features in otherwise unitary states, namely China, Indonesia and the Philippines. Each of these has provided special autonomy for particular regions, and is substantially decentralized. The remaining three countries are part of the third generation of federalism, and are in many respects 'aspiring federations'. These are Nepal, which has recently federated, and Myanmar and Sri Lanka, which are subject to ongoing pressure for fuller federalization, and which are the subject of this research.

Notwithstanding their variation, Asian approaches to the accommodation of minority ethnic groups and federalism appear path dependent, following the critical junctures and upheavals in the post WWII and revolutionary period of modern-nation state building (Reid 2007; Reid 2010a; Bhattacharyya 2010). With some exceptions (which are discussed below), the form of state that was put in place at the origin of the modern state in Asia has been maintained. Indonesia had a very short lived federal system, which was never institutionalized, while Myanmar has fluctuated between unitary and federal type arrangements. Otherwise there has been no shift from unitary to federalism, or vice versa, up till Nepal established its federation some 65 years after the building of its modern state. This is despite the presence of hypothesized conditions mentioned above, such as a 'federal society/ideas', infrastructural capacity, democratization and the waning of international impediments (e.g. end of cold war). Further, if the case of Sri Lanka could teach us one thing, it would be that the prevalence of a federal idea and distinct pre-national cultures are not enough.

\subsubsection{Bargains, compromises and alliances}

The theory of the federal bargain, propounded by Riker (1964) is still the most prominent and pertinent. Riker's theory implies that when a prospective (or in this case existing) core can militarily overpower the periphery, it will, so the weaker the center the more likely 
federalism and vice versa ${ }^{33}$. This could explain the difference between Sri Lanka and Nepal for example. However, we know that federalization did not occur in Myanmar at times of near complete state collapse and that when the Sri Lankan state was weak it did not concede federalism and it is more likely now than in 1987 . So, what has changed and what else is important?

The presence of infrastructural capacity, in addition to a 'sociological federalism' - i.e. a deeply divided society characterized here as ethnic identity - is a necessary condition for the establishment of a federal system, but not sufficient. The first generation of federalism suggests that a state-building or decolonization process is formative, and since then incremental change has not led to anything other than highly centralized quasi-federalism. Although the extent of infrastructural capacity was in each case considerable with the British essentially administering each country, separately or jointly, as a federal system, on its own, such infrastructural capacity could have been transferred into a unitary state (e.g. Indonesia). However, the live secession risk, along with the drive to independence or change of regime type provided for a cross-ethnic alliance to form to pursue mutual objectives. Further each of these cases has a simultaneous shift to federalization and democratization, even if in each case some subordinated version of each pre-existed.

All post state-building (second and third generation) federal systems of Asia have arisen out of conflict to, at least in part, manage, minimize or eliminate a secession threat, but only in Nepal's case has federalism been established. None of the countries has adopted consociationalism and although some features are present, particularly during the transition stage, federalism has been the main desire of ethnic minorities. A pre-existing democracy or democratic culture does not appear to have played a role in federalization, with its relative absence in Nepal and presence in Sri Lanka.

In each second generation country, there was reasonable infrastructural capacity, and a secession risk, but neither was as embedded or widespread. For example, the secession threat in the Philippines relates only to Mindanao. Thus, the regime was not destabilized by federalist or secessionist movements and no useful alliance was able to be formed. The state / government, nonetheless seeking to mitigate conflict and secession risks, and reproduce its

\footnotetext{
33 The state building theories of Michael Mann (1986; 1988) offer a similar but more nuanced explanation for federalization, focussing instead on the relative strength of the periphery as a part of a dialectic between the core and an economic elite, albeit for a different era and region. His theories are not applicable to the evolution of my cases' modern states, because ethnic rather than economic interests predominate, and the relative strength of the minority ethnic groups is not an outcome of development, but of conflict. Nevertheless, the dialectic process can be broadly correlated with the interaction of self-reproducing and reactive sequences.
} 
own power, made concessions to those peoples involving decentralization and special autonomy. In each case, it mattered little whether the state was democratic or not, but what sets them apart is the relative absence of identity-based nation-building. Indonesia for example, chose a neutral language and the Philippines entrenched secularism and both were, in the main, ethnically inclusive (Kymlicka \& He 2005). The initial mechanism giving rise to the reactive sequencing, identity-based nation-building imposed under a condition of ethnic diversity, was missing even if the other variables were conducive.

Horowitz (2014) is pessimistic about the possibilities that accommodating policies will be adopted in deeply divided societies, unless and until the dominant group or the state is at a moment of weakness. That this can arise through conflict should be no surprise. Horowitz's pessimism is well placed under an assumption whereby a group in power is expected to share the power it currently (practically or nominally) enjoys. However, Nepal became a federation after a regime change that saw minorities and regime change forces from the dominant group in alliance, a process that can also be seen to be occurring in Myanmar and Sri Lanka. That is, 'zero-sum' views of power-sharing are inapplicable in such situations as each actor has something to gain, and the exclusion of the old power base from a new federal regime is not ethnically-based and thus impermanent.

In these holding together cases, it is an alliance between the periphery and a regime change faction, rather a bargain with the core, that is the operative mechanism. The difference between a holding together and coming together federalization process is that while the centre is still interested in a unified state, in the former from a perspective of what might be lost, and in the latter from a perspective of what can be gained. Thus, the calculus is different. The greater the practical control, militarily and administratively, of a minority over a prospective unit, the more there is to lose. This motivates the concession that Ziblatt demonstrates as precipitating coming together federalism, but in a holding together situation a concession does not lead to genuine federalism, rather a quasi-federal arrangement that maintains the formal institutional ability of the centre to 'overawe' the units. It remains within path. The calculus for the excluded members of the dominant group is different. With nothing to lose, an alliance with minorities can be mutually beneficial and lead to a fuller federalization.

There is a distinction here between concessions, which are largely one-sided or unilateral and imposed, and alliances, which are agreements between minorities and other dominant group factions and which force compromise. Concessions reproduce existing ethnic power 
balances, while alliances fundamentally alter the balance of power. They require alliance across not only minority groups, but also excluded majority factions together seeking regime change for democracy and localized autonomy (that is, each essentially agrees to take up the others' priorities for mutual benefit, even if the gain is indirect). Conditions conducive to such an alliance have not been available until relatively recently, due to the divisive and existential threat to the state imposed by the cold war and related internal battles for a new state ideology, which split potential inter and intra group alliances along a left right divide.

It is further argued that the key reason for resistance to accommodation has been fear of secession. International actors have been highly relevant at various stages, for example, India regarding the scheme of constitutional devolution enacted in Sri Lanka in 1987. However, the extent of institutional accommodation has been dictated by internal decisionmakers in light of their perspectives on secession. It is a definitional truism that there should be a secession risk for a holding together federal system, but it is not so simple. A credible secession threat has inhibited rather than contributed to a shift from unitary to federal state in Nepal, Myanmar and Sri Lanka but when sufficiently lowered, federalization has followed.

Further the lack of democracy is rejected as a substantive cause of resistance to accommodation, demonstrable through the contrasting approaches of Sri Lanka and Myanmar. However, its absence and peoples' aspirations for it, can help give rise to the conditions for an alliance for regime change, while factors like the concern for minorities' respect for human rights and religion are used to uphold existing power bases and mitigate imperatives for accommodation due to the secession risk.

I show in some detail in Chapters 4 and 5 that ethnic-based nation-building gives rise to a sequence towards federalism. Firstly, the secession risk arises in consequence of such nation-building (despite an initial accommodative turn at the state formation stage) and the response of the state is first and foremost, centralization and a shift towards authoritarianism. This is followed by a concessionary attempt to quell further conflict, incorporating weak accommodation or integration and a quasi-federalism. Such a concession is a temporary measure and further conflict combines with other conditions (as discussed above) to usher in a genuine democratic federalism. The state's attempts to reinforce power on behalf of a dominant elite through centralization and authoritarianism drive the different factions together making federalism the likely end of the road for such cases. 


\subsection{Summary}

The primacy of identity to the politics of Nepal, Myanmar and Sri Lanka, and indeed many other countries in the Asian region, is a symptom of the nation-building agenda and its focus on a common identity at the expense of the recognition of diversity. This has resulted in internal conflict, poor development outcomes and de-democratization. Although most would reject the assimilation practices of the past, many debate whether a state should privatize difference and pursue integration, or recognize difference and accommodate.

I have argued that accommodation is a just and necessary step. However, accommodation strategies can take one of two main forms, neither of which is inherently preferable. Consociationalism seeks to include and empower ethnic elements, especially elites, while centripetalism seeks to incentivize moderation and fair treatment. Federalism is an important tool applicable to each approach. However, it can have a variety of different meanings. I distinguish between federalism and quasi-federalism, each of which can also be described as a federal system, to provide for conceptual and analytic clarity. Using these concepts, I make an argument for further elaboration in subsequent chapters that federalism is established when there is an alliance of minority and majority ethnic groups, when there is a substantial infrastructural capacity and moderate secession risk. When there is no alliance, and the power balance allows, within path federalization occurs, resulting in quasi-federalism only. 


\section{State formation}

Nepal, Sri Lanka and Myanmar are diverse but fractured countries, living and recovering from long periods of civil war, which arose from the imposition of a dominant culture and related political and social exclusion. This domination can be traced back centuries, but in modern times, opportunities for transformative change arose at the post-WWII state formation stage. In each case an identity-based (ethnic) domination was institutionalized and perpetuated, but punctuated by a reactive sequence and predictable backlashes. For some groups, this juncture was merely a continuation of historical disadvantage, for others it constituted a change in their social and political positioning.

This chapter analyzes the critical junctures occurring during the post-WWII period of modern state-building. Each country experienced a major transformation and 'escaped the clutches' of unwanted rulers, whether colonialists or oligarchs. At that time, the key actors made a decision that would continue to play out for decades to come, being how to structure the state, and the means and extent to which ethnic minorities are accommodated, integrated or assimilated. The basis, or parameters, of these decisions can be found in the critical antecedent conditions, which are conceptualized as 'ethnic identity', including any associated social stratification and discernable religious and political culture, and recent internal conflict, which in this case consists mainly of conflict with colonialists. This section discusses the variables, infrastructural capacity and secession risk, and the key actors and their power and preferences. I then describe and analyze the decision-making processes and draw out the effects of the antecedent conditions and their interaction with the independent variables, most particularly the mechanisms by which certain approaches are accepted, and others rejected. I conclude that the secession risk and infrastructural capacity, influenced by ethnic identity, are the formative variables determining actors' preferences and the options considered and accepted during each critical juncture.

\subsection{Ethnic identity}

\subsubsection{Nepal}

\section{Ethnic diversity}

Nepal is highly diverse in its ethnic groups, each with relatively distinct identities. Nepal has around 118 different groups, some of which are based primarily on ethnic affiliation, others on caste, some on language and, in the case of Muslims, on religion. There is no numerical majority group, though high caste hill Hindus (Bahun and Chhetri 'Pahadis'), along with some 
Newari ${ }^{34}$, have been dominant, despite comprising only around $28 \%$ of the population. I refer to the non-dominant groups as minority ethnic groups.

There are seven large (over 1\%) and a further 52 ethnic groups claiming indigeneity ('ethnic nationalities'), known as Janajatis, while a significant proportion (around 20\%) identify as Madheshis, generally referring to Hindu caste groups from the plain areas ('the Terai'). Overall eighteen different ethnic groups comprise at least one per cent of the population (Central Bureau of Statistics 2014). The place of Madheshis in the Nepali state has been disputed and citizenship rules have been in place with the ulterior objective of restricting citizenship rights to those considered by many to be Indian, particularly those who are primarily Hindi speaking. The open border with India has exacerbated fears about an 'influx of Indians' overrunning the Terai, large expanses of which were until the $20^{\text {th }}$ century virtually uninhabitable due to the high levels of malaria ${ }^{35}$. The distinction between indigenous groups and immigrant groups is further complicated by the debated position of the Pahadis, who have been in Nepal for many centuries but are seen by Janajatis as internal colonizers.

Importantly, while certain groups are more clustered than others, there is significant intermingling and coexistence (Bhattachan 2008). In the more ethnically focused federal proposals made during the constitutional reform process of 2008-2015, unit delineation was made on the basis of 'traditional homelands' despite the significant internal diversity that meant no one group was able to form a majority in almost all of the proposed units (Hatlebakk \& Ringdal 2013; Centre for Constitutional Dialogue 2010d). This intermingling has made the use of Nepali language widespread but by no means universal. Indigenous groups have their own languages, while a number of languages are spoken across the southern plains, where comprehension of Nepali is particularly low. Nevertheless, the loss of Indigenous languages is continuing and dramatic (Gellner 2005).

\section{$\underline{\text { Religion and culture }}$}

Nepal was formally a Hindu state until 2008 and more than $80 \%$ of its population is recorded as Hindu. Buddhism is also common (at least 9\%), followed by Islam (4\%) and Kirat (3.5\%) (a traditional animist belief system) (Central Bureau of Statistics 2014). There is an alignment between ethnicity and religion, with Janajatis being predominantly Buddhist or animist or both, and it is they who remain most resistant to the imposition of a state religion as an

\footnotetext{
${ }^{34}$ Newaris are an indigenous (Janajati) group, who despite forming to an extent part of the hegemony of the upper caste hill-based Hindus, are incorporated statistically and qualitatively with other Janajati groups.

35 The indigenous Tharu people were nonetheless present in large numbers due to a natural resistance to Malaria.
} 
infringement on their identity (Bhattachan 2008). For many Nepalis, the line between different religions is somewhat blurred and Hindus are known to visit Buddhist temples and vice versa. The state also now provides public holidays for a variety of religions' holy days.

Nepal had a formal and rigid system of social stratification that persists in practice today, underpinned by centuries of discrimination and Hindu mythology. An 1845 Royal Decree that lasted until 1951 set out the hierarchy based on a combination of caste and ethnicity, and included separate laws and punishments for different groups (Chakravartty 2014, p. 65). The high-caste hill Hindus (Pahadis) almost entirely dominated the upper echelons of the state, society and the economy (Lawoti 2005; Ghai 2011; Malik et al. 2009: 379-380). Notwithstanding, embedded in Hindu political culture is the idea of village-based governance. This was embodied by the Panchayats that were said to be a revitalization of indigenous traditions and facilitative of bottom-up democracy (Smith 1967; Gellner 2005). Nepal social and political culture, which remained largely unchallenged due to the relatively poor development and education standards particularly outside of the major cities, has been famously characterized as 'hierarchical fatalism' (Bista 1991). This relates mostly to Hindu caste groups. In comparison, Janajati groups are said to be more egalitarian, but disempowered as the Pahadis' "traditional social habits, nourished by feudal culture were incongruous with egalitarian demands"(Verma 1981, p. 3). Nepali political culture is also influenced by strong communal sentiments, or loyalty to one's own kin, ethnic or caste group, and preference for consensus rather than competitive politics (Whelpton 2005, pp. 173-177). These communal social features have underpinned the push for a federal political arrangement, though as Bista (1991) warned some 25 years earlier, such forms of social organization may be positively or negatively harnessed.

\subsubsection{Myanmar}

\section{Ethnic diversity}

The government states that there are 135 ethnic groups in Myanmar, although these are commonly accepted to fall within eight major ethnic groups ${ }^{36}$. Some groups form majorities in particular areas, while others are more dispersed though having connections to a particular homeland. The Bamar ${ }^{37}$ are the majority comprising around two-thirds of the population. Some of the minority ethnic groups, particularly Chin, Karen and Shan have

\footnotetext{
36 There is conjecture about the basis and reasonableness of such groupings, with some claiming it is a military convenience and that the ethnic groupings are based on regionalism rather than other defining features like language or kinship (Sadan 2009).

37 In this essay Bamar refers to the ethnic group rather than the citizens of the country, to avoid confusion.
} 
substantial populations in neighboring countries, which contributes to fears of secession. There is no formal ranking of ethnic groups although, historically, hill based groups have been considered by Bamar as 'backward' (Walton 2013). Further, the Bamar have tended to dominate state institutions, such as the Burmese Independence Army (Taylor 2009, pp. 62, 92; Smith 1991).

The major ethnic groups in Myanmar object to the use of the term 'ethnic minority', which is considered to affirm a position of subordination to the Bamar majority, instead preferring 'ethnic nationality' (reflecting their history and in some cases local majorities). The premise is accepted, however, for the purpose of consistency with the other cases and related academic literature, and because they are nonetheless minorities in the demographics and politics of Myanmar as a whole, they are in this paper referred to as minority ethnic groups. In any case, all of these groups are accepted as being indigenous and fitting the criteria of an ethnic nationality defended by Kymlicka.

There are also around one million 'Rohingyas' who are a Muslim minority with a disputed heritage. Although there is evidence that the Rohingyas have been present in Myanmar for many centuries, they share culture and kinship with other Muslim communities from across the border and have been classified as immigrants by the Myanmar government and disenfranchised (as recently as 2015) (Kean \& Min 2015). The military aligned government refused to accept the term Rohingya, which is how they self-identity, instead referring to them as Bengalis on account of their supposed heritage in Bangladesh. The new government of 2016 found a middle ground referring to the group only as Muslims, avoiding making a call one way or the other. Some areas (especially Yangon) are also home to large numbers of immigrants from India, most of whom are Muslim, and ethnic Chinese, who have also been subject to discrimination. Muslims appear to be at the bottom of any informal social hierarchy (Matthews 2001; Walton \& Hayward 2014).

Myanmar (or Burmese) language is the official language of the state and is the language of instruction in schools and universities. Hence, most younger generation are capable in this language, although indigenous languages are still most prominent in many of the ethnic areas and there has been considerable pressure for greater official use of such languages and decentralization of education (Snaing 2015b). Many of the minority ethnic groups remain highly concentrated in their traditional homelands, forming local majorities. However, the 
extent of such is not known as the ethnic makeup of the units has never been released by the Myanmar government ${ }^{38}$.

\section{$\underline{\text { Religion and culture }}$}

Buddhism is the dominant religion in Myanmar and most ethnic groups, including the Bamar, are Buddhist. There is a common phrase equating the two - "to be Burman is to be Buddhist" (cited in Walton 2013, p. 7). The Myanmar form of Buddhism is Theravada, which is the oldest of the different schools. The Karen, Chin, Kayin and Kachin groups are predominantly Christian, while there are large numbers of Muslims (possibly up to 13\%, but officially less than 5\%). Buddhism has 'a special position' in the 2008 Myanmar constitution (Article 361, Constitution of the Republic of the Union of Myanmar 2008) and some of its laws and investment policies are heavily biased ${ }^{39}$ (Walton \& Hayward 2014; Matthews 2001; Silverstein 1977). Further, the state is active in building Buddhist shrines and temples across the state, including in areas that are predominantly Christian.

Theravada Buddhist societies are generally individualistic and egalitarian, but in Myanmar, the Bamar did not regard the minority ethnic groups as equals (Silverstein 1977, pp. 4-26). The prominence of Buddhism in social spheres is reflected in the political culture, where political leaders of all persuasions (from the military to Aung San Suu Kyi) have appealed to Buddhist ideals to legitimize rule or claims to rule (Walton 2012; McCarthy 2006). Although Buddhism carries with it ideals of tolerance, its political traditions were built around the edicts of King Asoka, and his model of an ideal king who is a Bodhisattva (has attained enlightenment), and would combine social and religious leadership ${ }^{40}$. Theravada Buddhism has thus become highly centralized across South and Southeast Asia (including Sri Lanka). Notwithstanding, Furnivall (1960, p. 21) identifies traditions of local autonomy as one of the few surviving features of Myanmar's political culture.

\footnotetext{
38 The data was collected for the 2014 census and is supposed to be released sometime in 2017.

${ }^{39}$ As recently as March 2015 its legislature passed a package of 'race and religion' Bills allegedly designed in part to "stop the Bengalis" (Muslim Rohingyas) and preserve the majority Bamar Buddhist identity (N. Zaw 2015). 40 While Asoka himself was tolerant of other religions and provided for local autonomy (which was a practical necessity given the size of his kingdom), this has manifested over time into an authoritarian and highly centralized tradition still practiced in the Theravada Buddhist countries of Southeast Asia (Albinski 1958; Cummiskey 2013; Wijeyeratne 2007).
} 


\subsubsection{Sri Lanka}

\section{Ethnic diversity}

Sri Lanka has a relatively small number of ethnic groups, although by other measures it is on a similar level to Myanmar and Nepal ${ }^{41}$. Sri Lanka is made up of three major ethnicities, the smaller of which is internally divided into two identity-based ethnic groups, Sri Lankan (Hindu) Tamils and Upcountry Tamils, who arrived from India during the British colonial period primarily to work on the tea plantations. Each major ethnic group is divided into castes, and there are also small numbers of Burghers (people of European heritage) and the indigenous Veddas (Malik et al. 2009, pp. 313-318). The Sinhalese comprise around three quarters of the population, with the Sri Lankan Tamil population recorded at 11\%, down from $12 \%$ prior to the war (1981). Other major groups are Muslims at $7.9 \%$ and the Upcountry Tamils at 5.5\% (Department of Census and Statistics 2015, Table A8).

Sri Lanka's largest city, Colombo, is mixed with large numbers of all ethnic identity groups, but otherwise, the north and east of the country is overwhelmingly Tamil (with many Muslims concentrated in the east), and the remainder of the country is populated mostly by Sinhalese (other than certain tea plantation districts which are populated by Upcountry Tamils). Upcountry Tamils are quite poor in comparison to other groups, while the impacts of the civil war have left the north and east of the country relatively underdeveloped.

English was the language of the elite around the time of decolonization and was the official language until the 'Sinhala only' policies of the 1950s (discussed later). It remains today as the official 'link' language, because for many Tamils (especially those from the north), Sinhalese is unintelligible. While Tamil has now been recognized as an official language, implementation of language equality policies has been poor (Nesiah 2012), and related concerns have been a key driver of the Sri Lankan Tamils' push for federalization.

\section{$\underline{\text { Religious and culture }}$}

Buddhism is given the 'foremost place' in the constitution (see Article 9) and the government has a special role in its protection and propagation. The state is active in fulfilling this role, for example via its Ministry for Buddhism, or through building Buddhist shrines in majority Tamil areas (Zuhair 2016, p. 20). Many Sinhalese Buddhists believe that the island is the

\footnotetext{
${ }^{41}$ Sri Lanka has less than 10 ethnic groups, whereas Myanmar and Nepal have more than 100 . However, according to the ethnic fractionalization index, its diversity is scored at 4.5, landing between Nepal (5.1) and Myanmar (4.0), on account of the relatively high proportion of its dominant group and some heavily intermixed regions (Alesina et al. 2003).
} 
sanctuary of Buddhism and that it is their responsibility to protect it as such (Raghavan 2013; Zuhair 2016, pp. 12-13). Around 69\% of the population is Buddhist (including most Sinhalese). Hinduism is the dominant religion of the Tamil ethnic groups (around 15\% of Sri Lanka). Muslims comprise around $7.6 \%$ of the population. Christianity is well represented at 7.5\%, due to the British legacy (Malik et al. 2009, pp. 313-318). Otherwise, there is near complete alignment of ethnicity and religions.

Sri Lankan political culture is influenced by this religious heritage and a comparatively long period under British colonial rule, which resulted in an English-speaking elite and strong bureaucratic capacity. As in Myanmar, the centralized and authoritarian traditions of Theravada Buddhism have been increasingly prominent. But in Sri Lanka, the impacts are compounded due to the mythology that places Sri Lanka as the repository of Buddhism. Muslims in Sri Lanka are not seen to have a specifically religiously grounded political culture, but do see themselves as a distinct ethnic group and a component of the communal Sri Lankan political makeup (Malik et al. 2009; Wikramasinghe 2006).

Sri Lanka has, in some respects, merged aspects of Hindu and Buddhist culture to create a caste system, although it is internal to each group and castes are clustered, rather than pervading across the country and its people, as in Nepal. Now waning in influence, the caste system has been influential with all but one of Sri Lanka's prime ministers coming from one caste group (Goyigama). Otherwise, there is no formal division between ethnic and religious groups despite the practical discrimination against minorities. Each group has its own elite generally participating in the functions of the state and there is a strong egalitarian culture that is reflected in the political sphere (Malik et al. 2009, pp. 312-316, 336; DeVotta 2010).

\subsection{Conflict in state formation}

Nepali people are proud of the fact that their country has never been colonized by a western power, but that does not mean that its transition to a modern nation-state was without incident. While the modern Nepali state is said to have commenced around 250 years ago with the Gorkhali conquest of the Kathmandu Valley (1768-69), since that time and up until 1951, it was under the authoritarian rule of a monarch or a hereditary oligarchy (the 'Ranas', who are high caste Pahadis) and maintained a feudalistic system. An anti-Rana movement emerged post WWII and when, in 1947, a democratic party - the Nepali National Congress was formed (in India in exile), the movement gained pace. The Congress, with support from other minor parties launched an insurgency in 1950 that, although mainly confined to border areas, led to the Indian brokered Delhi Accord by which ultimate authority was restored to 
the King. Included in the Accord was a commitment to hold democratic elections, which eventually occurred in 1959 (Hachettu \& Gellner 2010; Whelpton 2005, pp. 35-85; Smith 1967). Nepal is characterized as a mildly violent transition from an oligarchic dictatorship to a modern (democratic) state.

In Myanmar, after three wars and the progressive gaining of territory, the British consolidated their rule in 1886. Initially it was administered by Britain as a province of India, but became a separate colony in 1937. Myanmar did not gain independence from the British until 1948 following a bloody and treacherous war of independence that pitted its ethnic groups against one another and involved Bamar collaboration with the invading Japanese army. Britain agreed to independence in its rush to withdraw from the region on condition of cooperation among the Bamar and minority ethnic groups, though there was much rebuilding of relations to be done. The Karen, who banked on special treatment from the British in return for its loyalty, had been particularly opposed to the Bamar during the conflict (Smith 1991, pp. 60-87; Taylor 2009, pp. 219-250). Myanmar is characterized as a violent and transformational shift from a colonial to a modern state.

Sri Lanka was also a British colony (and before that a Portuguese and Dutch colony), and it had been prepared for independence through gradual democratization and self-rule measures instituted by the British since 1931. In particular, a political party based agitation for independence led to a series of reforms - the Donoughmore Commission reforms followed by the Soulbury Commission recommendations. It became independent in 1948, following an election in the preceding year, through which power passed to a multiethnic but Sinhala dominated elite (Wickramasinghe 2010, pp. 308-366; Malik et al. 2009). Sri Lanka's mode of state formation is characterized as a peaceful and incremental transition from colonial to modern state.

\subsection{Infrastructural capacity}

Nepal has been a unitary state since around 1769 . However, actual governance has not had practical reach to the entire country, nor succeeded in gaining the loyalty of its disparate indigenous people. Many of its minority ethnic groups continued to live a traditional lifestyle beyond the reach of the modern and pre-modern state and have maintained a distinct identity and sense of nationhood (Lawoti 2007; Bhattachan 2008). Some groups were able to formalize some level of local rule, for example the Limbu chieftains of eastern Nepal, though remained subordinate to the state (Whelpton 2005, p. 51). Others practiced village-based democracy immune to the presence of the central state and organized around traditional 
forms of leadership (Lecomte-Tilouine 2004, pp. 115-116; Bhattachan 2003). Religion also remained an important form of social organization, particularly in the Terai.

At the time of state formation, only one political party had formed, the Nepali National Congress, which comprised high caste Pahadis and still exists today as the Nepali Congress. Even though it succeeded in bringing-down the Rana regime, it replaced it with yet more high caste Pahadis (Smith 1967). Although other political parties quickly emerged, such as a communist party in 1949, they too were dominated by high caste Pahadis, with the only exception being the Nepal Tarai Congress (1951), which was mostly Madheshi and demanded an autonomous Terai region (Bhattachan 2003: 11). However, at that stage, there was little infrastructural capacity to support that claim. As the modern state evolved, the role of the state in the lives of its minority ethnic groups substantially increased but its effective reach remained limited. Nepal is characterized as having had an ethnically and regionally divided society, but a formally unitary system of government, with low infrastructural capacity.

Myanmar has formally and practically an ambiguous status. Prior to British colonization, the Bamar kings professed to rule much of the country, though were primarily restricted to the plains (Taylor 2009, pp. 15-66). The hilly and mountainous regions of Myanmar were under the traditional leadership of a variety of minority ethnic groups, and the Bamar kings had only an indirect relationship with them. The British were able to subdue some, reach agreements with others, and avoid the remainder ${ }^{42}$. They governed the country as two sectors, each internally divided - Burma Proper/ Ministerial Burma (incorporating four divisions) and the Frontier Areas, comprising the Shan, Chin and Kachin areas. The latter areas were excluded from legislative application and were comparatively neglected with little built infrastructure and without any direct authority by the British. Some parts of the Frontier Areas were entirely off-limits to the British (His Majesty's Government 1956 [1945]; Taylor 2009, pp. 67-292; Smith 1991, pp. 40-52).

At the time of the critical juncture (and for some time afterwards), there was really only one local political party to speak of, the Anti-Fascist People's Freedom League (AFPFL), described

\footnotetext{
42 Former colonial senior public servant, J.S. Furnivall (1960, pp. 8-12) writes that while seeking to centralize control over the Burmese plains, the British maintained by necessity the approach of the Burmese kings to the hills. They sought indirect rule arrangements with tribal headmen, who formed circles of closely related communities, to effectively act as local governments. In time, the British bought these headmen under their control as far as practical, through appointment and patronage, such that "local government was merely an extension of central government" (p. 9), despite its limited reach. This was particularly the case in Shan State, where the people were deemed to be relatively advanced, as compared to the 'backward areas', where administrative structures and institutions were at the discretion of the Governor. In Burma Proper, there was considerable local government presence, although its remit was minimal.
} 
as a "loose coalition of numerous groups united only in their common opposition to foreign rule" (Furnivall 1960, p. 55), including communist and liberal elements. However, it operated as a single party, dominating political discourse and independence negotiations. The Communist Party was expelled and launched an insurgency soon after independence, while ethnic parties emerged later, but were still under the umbrella of the AFPFL (Taylor 2009, pp. 243-249). Because the British system had relied on communal representation, there was little impetus to form political parties. Other large scale indigenous (Bamar) organizations were affiliated with the AFPFL, or were religious ${ }^{43}$, such that until the AFPFL split in 1957, Myanmar was effectively under single party-rule (Furnivall 1960, pp. 55-62), or in the words of then British Governor Rance, the "AFPFL is the only horse to back" (cited in Smith 1991, p. 78). Myanmar can be characterized having had an ethnically and regionally divided society and system of governance, with a moderate infrastructural capacity in the periphery.

Sri Lanka is socially segmented in four relatively distinct and large ethnic groups who live in relatively clustered locations. However, the British governed the country as a unitary state and provided equal rights to all citizens from 1931 (up until then there had been some forms of communal representation) (Wickramasinghe 2010). Prior to British unification, the island was a conglomerate of separate warring kingdoms, rather than divided along the present cleavages. Although it is claimed that the entire island once belonged to the Sinhalese, this is not a contemporary reality and does not have its basis in historical fact (McConnell 2008). One of the four main groups, Upcountry Tamils, were bought to the country by the British in the $19^{\text {th }}$ century and have not integrated with the Sri Lankan Tamils or others (Malik et al. 2009, p. 315).

Despite the absence of meaningful ethnic or regional institutional infrastructure, Sri Lanka did have a political party system that included separate organization for Tamils - the Tamil National Congress -which at that stage also purported to represent Muslims. Both the Ceylon National Congress and United National Party (UNP) (formed in 1946) had some Muslims and Tamils, but were dominated by Sinhalese. In 1951, the party of future president and one time federalist SWRD Bandaranaike, the Sri Lanka Freedom Party, which was a "virulently Sinhalese nationalist organization" (Wickramasinghe 2010, p. 44), split off from the UNP. Sri Lanka is characterized as an ethnically and regionally divided society, but with low infrastructural capacity.

\footnotetext{
${ }^{43}$ The All-Muslim Burma Congress helped establish the AFPFL but was disassociated on account of its religious affiliation and the early insistence that the AFPFL should be secular (Furnivall 1960, p. 62).
} 


\subsection{Secession risk}

Nepal, Myanmar and Sri Lanka have faced what is effectively a secession risk even prior to post-colonial independence. With low or absent conflict and little regional infrastructural capacity at the time of modern state formation, the secession risk in Sri Lanka and Nepal was low. In Sri Lanka, there were no known or credible calls for separate states for Tamils and Sinhalese. Even if there were, there were no armed forces available to back it up, and the international actors at the time, the UK and India, supported an independent and unitary Sri Lanka. Without these centrifugal forces, it follows that the unitary form was essentially unchallenged and the need to manage a secession risk did not come on the agenda until much later.

In Nepal, the calls for independence were also muted, and without this risk to manage, the peripheral demands for federalism were easily disregarded or dampened down. Besides the military, the only armed force in Nepal at the time of modern state formation was associated with the Nepali National Congress and its movement for democracy, which was unrelated to any ethnic, regional or separatist movement. Further, unlike Sri Lanka, Nepal does not have any particularly ethnically homogenous areas and the current claims for autonomy are based more in historical entitlement than contemporary demographic realities.

Myanmar's initial federal union can be correlated with the comparatively higher secession risk. With a number of viable permutations, from joining Myanmar to India, to creating independent states for Kachin (including part of India), the Karen and the Shan, the makeup of states in that region was relatively open. The British, through pragmatism and idealism, wished for the Bamar to reach agreement with the minority ethnic groups. The actors were armed and ready to defend their claims, following from the war of independence and there was a high degree of ethnic homogeneity in given regions. Furthermore, the international environment was volatile and there were opportunities, which would be taken subsequently, for ethnic groups to align with cross-border forces and seek the active or passive support of a sympathetic neighbor, notably China and Thailand.

\subsection{Critical junctures}

\subsubsection{Nepal}

In Nepal, the impending independence of India and the growing democratic ideology, in combination with the King's and people's dissatisfaction with the Rana oligarchy, provided the space for significant change. The key actors can be classified as: 
- The Rana oligarchy, who had power in 1947 but were losing support and unable to sustain their rule in the face of resistance from multiple sectors, preferred continuation of the status quo;

- The Nepali National Congress political party, which sought to transform the country to democratic rule and was willing to employ violence to do so;

- The King, who sought to restore his position of authority that had been usurped by the Ranas some hundred years ago; and,

- India, which had an interest in stability over the border, but also sympathized with the democratic ideals of the Nepali National Congress.

(see Whelpton 2005; Malik et al. 2009; Hachettu \& Gellner 2010).

There are two stages at which constitution-making for the new modern state structure was particularly relevant. In 1948, the Rana regime tried to shore up its support with a new constitution empowering other levels of government (Panchayats) (see Part IV, Government of Nepal Act 1948), and sharing executive power with the King and Nepali National Congress. The Ranas sought to underpin their power by appealing to, and reinforcing, Pahadi hegemony, including by characterizing opposition movements as being conspiracies against the Pahadi identity and nation (Whelpton 2005: 84-85). However, this attempt to co-opt central and regional elites was not acceptable to the increasingly democratic-leaning elites, nor the King, and it was never implemented.

Within two years, oppositional movements began to align and worked with India to remove the Ranas from power altogether and establish a new constitution starting from 1951 . The retitled Nepali Congress party, based out of India, launched an insurgency and captured several major centers in the Terai as well as some hill locations. The then King fled to India, where the Delhi Accord was brokered. This alliance, important for regime change, was inconsequential for federalism, being an alliance of Kathmandu-centric Pahadi elites. In any case, a unitary state was the option preferred by all the key actors. While the influence of India in the process meant that federalism was a known alternative, it was only the King that considered it, and never particularly seriously. In the south, a Madheshi political party had formed and demanded an autonomous region, but they were not part of the negotiations and failed to gain public support (winning less than $2 \%$ of the vote in the 1959 election) (Mabuhang 2014, p. 7; Khanal 2009). The Madheshis, like the Limbus who had planned a declaration of independence and other dissident ethnic groups (Whelpton 2005, p. 83), were of insufficient influence and did not have infrastructural capacity on which to claim 
autonomy, even if the historical bases of their claims were sound. So federal and hybrid options were not pursued.

Leaving aside India, all of the key actors in the critical juncture were high caste Pahadi (and male) and the struggle for authority was within, rather than across, ethnic groups. Each sought to produce power for his own by framing a claim to rule on the basis of either a historical right and a need for stability (the King and the Ranas), or an emerging democratic idea. Senior Maoist Khimlal Devkota (2012) characterized the Delhi Accord as, "in essence, a compromise between feudal, and bureaucratic and comprador bourgeois classes for share in the state-power in the interest of monopoly capitalism. That was a serious deception and betrayal to genuine need and aspirations of the people" ( $p$ 125). That is, it reproduced the existing dominant position of the high caste Pahadis, and perpetuated the marginalization of others. The romantic notions of the democratic elite would lead them to see the solutions in the institutionalization of a democratic system, and so for them federal institutions or other forms of institutional accommodation would not be necessary.

The Accord gave two of the three key domestic actors a slice of power, with ultimate authority in the King, and executive power otherwise shared with a Nepali Congress dominated Cabinet, including some independents, with a promise of a future election (Interim Government of Nepal Act 1951; Whelpton 2005, pp. 61-85; Hachettu \& Gellner 2010; Verma 1981, pp. 4-5). Importantly, while social stratification remained an organized practice sanctioned by Hindu mythology, the Royal decree that gave formal status to ethnic and caste discrimination was abolished and the new constitution established legal equality and non-discrimination (see Articles 14-16 Interim Government of Nepal Act 1951).

Nepal's ethnic identity-based social stratification placed all negotiating power and resources in the hands of members of a single ethnic group. The demographic elements of the ethnic identity social structure, in this case that a single ethnic identity group could not form a majority and there was considerable heterogeneity, was negated by this social stratification. Would some kind of group-based equality emerge via democracy? Unfortunately, there was little opportunity for this to be tested although it is apparent (as discussed in Chapters 5 and 6) that the emergence of powerful ideas for federalism did not occur until such ranking systems began to substantively erode and more inclusive and non-majoritarian institutions were introduced into the state structure.

There is no evidence that religion played any particular role in the decision-making process, other than by influencing the actors in the same way as the broader ethnic identity group 
social structure. The idea that it was a Hindu state may have influenced actors towards the rejection of the Limbu's claim for autonomy (being primarily Buddhist), but not in the case of the Madheshis, whose claims are resisted to this day. Hinduism has traditions that allow for autonomy and celebrate diversity (see for example Ghandi 1962) so, ideologically, there would seem to be no barriers. India, which is also a Hindu majority state, chose to institutionalize federalism following independence and is heralded as one of the most successful multination democracies in the world.

\subsubsection{Myanmar}

Burmans had to decide also how far authority should be centralized and how far it could be delegated on the principle of local autonomy. From British rule, they inherited a strongly centralized system; this was the type of administration to which they were accustomed and which the officials knew how to work. Even so far as Burmans preferred local autonomy, the immediate situation demanded strong central authority for the restoration of order (Furnivall 1960, p. 24).

In Myanmar, the critical juncture was much more divisive and how the new state was structured, and what territories it constituted, hung in the balance. Four sets of key actors are defined here:

- The Anti-Fascist Peoples' Freedom League (AFPFL) political party, together with the Burma Independence Army (BIA) from which it arose were the most powerful actors at the time, and, through its charismatic leader Aung San, took the role of negotiating independence with Britain in 'consultation' with ethnic elites. It included a multiethnic element but mostly comprised and represented the Bamar ethnic group (Tawnghmung 2010, p. 139).

- Three major minority ethnic groups, the Shan, Chin and Kachin, had particular status on account of their separate Frontier Areas under the British administration. These groups wavered between joining the union or pursuing independence.

- Four other large minority ethnic groups most prominently the Karen, had an important role in the British administration and army, but did not have special status. They believed they would receive preferred treatment by the departing British, and independence (the BIA fought with the Japanese against the British and allied ethnic groups including the Karen).

- The British, wanted to 'offload' Myanmar (following their weak position and broader regional policy in the aftermath of WWII), but had some concern for the minority ethnic 
groups, especially those who had stayed loyal to them during the war. As a result, it made the consent of the ethnic minorities to a union with the Bamar a condition of their agreement to independence.

These positions were formalized in an agreement between the then British Prime Minister C.R. Atlee and Aung San (1956 [1947]), on behalf of the Bamar:

It is agreed that the objective of both His Majesty's Government and the Burmese Delegates [is] to achieve the early unification of the Frontier Areas and Ministerial Burma with the free consent of the inhabitants of those areas.

With these mutual objectives, and despite periods of brutal war that divided the country's ethnic groups, a major proportion was able to come together and reach agreement to work together for the restoration of independence. In 1947, the 'Panglong Agreement' between Aung San and representatives from Shan, Kachin and Chin groups, agreed to a federal system. Unfortunately, the agreement was vague and not inclusive. It included just nine points and the structures envisaged were subject to the resolution of a future constituent assembly. It is often stated that it included a right to secession (e.g. Walton 2008, p. 896). This was not mentioned in the agreement, but it was a demand of the ethnic nationalities and may have formed a side agreement (Smith 1991, p. 79).

Notably, the Karen and other groups outside the Frontier Areas were not part of this agreement. The Karen had been advocating for an independent state and so conceding to an autonomy arrangement within a Bamar led state would be a retrograde step. However, the British would receive advice from its Burma office that an independent Karen state would be unviable, and likely to either "involve too much expropriation of land to which the Karens have no claim," or not adequately accommodate them (Smith 1983 [1946], p. 736). It then tried to dissuade them from pressing independence claims to avert civil war, even advising that the British could no longer provide them with financial assistance, but to no avail (Hare 1998).

The British meanwhile ran their own commission of enquiry to elicit the views of ethnic minority groups on the specifics of a new constitution in light of the Panglong Agreement and its lack of inclusivity ('The Frontier Areas Committee of Enquiry'). However, there were misunderstandings between commissioners and certain representations, and their recommendations were not adequately reflected in the final constitution (Sakhong 2012), even if reflecting substantially the intent of the Panglong Agreement (Smith 1991, p. 84). 
Important points permeated, such as the demands by 'a majority of witnesses' for a right to secession (point 5, p. 20), and the continued subordination of certain groups (e.g. the Wa and Nagas), who were deemed not yet fit to take on administrative responsibilities (point 8, p.

21) (Frontier Areas Committee of Enquiry 1947), but the ideal of equality among ethnic groups did not.

Further, some of the Burman elite preferred a unitary structure, which would become apparent in the coming years. Aung San took the Panglong deal to England where he struck an agreement with the British, after initially being rejected on account of the lack of consent from the ethnic minority groups. However, after preparing a draft constitution and convening a constituent assembly, he was assassinated along with other allied members of his Cabinet. His successor, $\mathrm{U} \mathrm{Nu}$, took a less accommodating approach to minority ethnic groups (discussed in Chapter 5.2).

The Aung San led draft was prepared along federal lines, including for example, a Bamar state and strong revenue and taxation powers. However, following the change in AFPFL leadership significant revisions were made, including the removal of dedicated unit legislatures (replaced with 'State Councils') and an asymmetrical and majority rule based upper house weighted in favor of Bamar (Lian 2012, pp. 11-14). The Constituent Assembly that was formed to debate the proposed new constitution worked quickly, requiring only three sessions, and concluding with a unanimous vote. It adopted the set of principles articulated by Aung San in the first session of the Assembly ${ }^{44}$. As overwhelming winners of the election for the Assembly, the AFPFL had prepared the constitution in advance, in accordance with its own convention's resolutions, and with confidence for its passage. Burma Proper had 210 representatives, as compared to just 43 for the minority ethnic groups (noting that the 210 included 26 Karens and four Anglos) (Maung 1956, pp. 108-113; Furnivall 1960, pp. 95-98). Further, despite the Karen having reserved seats, the Karen National Union (then a recent conglomeration of Karen organizations) boycotted the elections, and so most Karen did not participate (Smith 1991, p. 85). Hence the passage of the constitution through the Constituent Assembly was a fait accompli.

\footnotetext{
44 'That Burma should be an 'independent sovereign republic' to be known as the Union of Burma; that the Union should consist of specified autonomous units; that all powers of the State should be derived from the people; there should be constitutional guarantees for the fundamental rights of the citizens; that there shall be adequate safeguards for minorities; that the sovereignty of the Union shall be maintained according to justice and international law; that the Union shall be dedicated to the idea of peace and friendly relations with nations" (cited in Maung 1956, p. 109).
} 
The groups that were not part of the Panglong Agreement were not satisfied. The Karen in particular, who like the Chin were granted a 'special division' (semi-autonomous unit) with the prospect of upgrading into a state, almost immediately took up arms against the government. Other groups followed in the coming years, including communists who also felt they had been excluded (despite also taking part in the Assembly 'in a vocal' manner and voting to adopt the constitution as proposed) (Smith 1991, pp. 62-92; Smith 2007; Taylor 2009, pp. 219-292; Walton 2008; Sakhong 2010; Silverstein 1977, pp. 15-21; Maung 1956, pp. 124-136). Arguments still rage about 'the spirit of Panglong' and what was envisaged, but it is clear that this Panglong alliance was formative in terms of the decision to federalize, and discussion of its spirit continues today as the bases for further federalization ${ }^{45}$.

During the juncture, each group sought to produce and maintain power through the new structure for their specific group - the Bamar through a centralized structure (with the possible exception of Aung San and allies), and each ethnic group through autonomy provisions (if not independence). The Bamar played on a claimed historic right to rule based on the history of Buddhist kings, while others asserted their independent nationhood (Taylor 2009, pp. 234-252; Silverstein 1977, pp. 15-21). Ultimately, the structure was a compromise just enough power sharing from the Bamar to enable the independence project to get through, but not too much so as to provide autonomy to groups that did not already have such status or the ability to claim it (e.g. the Mons), nor to undermine its potential appeal to the Bamar dominated Constituent Assembly. The right to secession was added after initial publication of the constitution, in order to assuage ethnic opponents (Sadan 2009, p. 161). In assessing specifically the role of the antecedent conditions and other key variables it is certainly apparent that the key actors (other than Britain of course) were representing the interests of their ethnic group and saw that those interests could be best protected and enhanced by either holding together the Burman state (AFPFL (Bamar)) or through autonomy arrangements (minority ethnic groups). The social stratification that overlaid the ethnic identity structure of Nepal did not exist in a systematic or universal sense. Unlike Nepal though, the Bamar ethnic group could hold a clear majority, which was of course also known

\footnotetext{
45 For example, it was a key point of discussion at the $21^{\text {st }}$ century Panglong Conference in 2016 (discussed in Chapter 6) and addressed directly by the daughter of Aung San, fellow democracy icon and leader of the governing National League for Democracy: "People ask what I mean by using the word "Panglong" for the Union Peace Conference? Does it mean it should be based on its original spirit, agreement and promises? What I would like to say is it's not going to be based on the Panglong Agreement, which was concluded in order to achieve independence. On the contrary, I believe it must be based on the spirit of Panglong, which upholds Unity in Diversity" (Aung San Suu Kyi, speaking to signatories of the National Ceasefire Agreement, cited in Khuensai 2016).
} 
by the British. Further, the military was at that time essentially a Bamar army, and this carried latent power, which affected inter-group relations.

Countervailing the potential Bamar dominance was the pre-existing state segmentation in the form of both an infrastructural capacity and ethnic armies. The minority ethnic groups and the Bamar served together in the British army, but were organized into ethnic brigades, so for example, when the Karen chose to battle with the state after independence, a coherent military unit could be withdrawn and stand alone. The infrastructural capacity included traditional hereditary structures with village headmen and Shan Sabhas (royals) commanding political allegiance and basic administrative functions (e.g. justice, land). These provided a barrier against Bamar domination and a basis for the new state structure. It was these traditional Shan royals who attended and concluded the Panglong Agreement and participated in the Constituent Assembly (Walton 2008; Maung 1956, pp. 124-136).

The direct relationship between federalization and infrastructural capacity is evidenced not just by the comparison with Nepal and Sri Lanka, but also within case at the subunit level by the preferable constitutional and negotiating treatment afforded to those groups that were in Frontier Areas under the British administration, and those that were subsumed into Burma Proper. That the Karen did not receive a special unit in the initial constitution is attributable to the lesser infrastructural capacity on account of being split between Burma Proper/Ministerial Burma and the Frontier Areas. Similarly, those groups that were not administratively separate (part of the Frontier Areas) from the Bamar received no special concessions at the time of initial federalization.

If we look to religion for an answer, given the claims about a Buddhist resistance to federalism, there is some evidence that it was a factor. Aung San was an avowed secularist, but U Nu was quite different, once revealing that "in the marrow of my bones is a belief that government should enter into the sphere of religion" (cited in Sakhong 2010, pp. 46-47). As discussed above, Aung San agreed to federalism's institutionalization, while U Nu resisted. The source of resistance is unlikely to be found in the traditions of the religion, which like Hinduism has traditions of autonomy. However, if the Burmese state was to be religious, as preferred by $\mathrm{U} \mathrm{Nu}$, then there was no room for autonomy by Christian groups. This issue would play out in the following years, but is not causal. 


\subsubsection{Sri Lanka}

The abolition of communal representation and the adherence to the principle of equality between individuals signified - in effect - Sinhalese rule (Wickramasinghe 2010, p. 42).

In Sri Lanka, federalism had been an option for more than twenty years prior to independence, but it never quite got the hearing it deserved, due to the early and definitive work of the Sinhalese political elite. The key actors were:

- The Sinhala political elite, most especially D.S. Senanayake, initially as part of the Board of Ministers, and then forming the major political parties including the United National Party (UNP), which led the first independence government. Their preferences are reflected in the constitution of 1946-47 being a unitary state.

- The Tamil political elite, most prominently the Tamil Congress, who sought equal group status with the Sinhala, through special legislative and representative status. The Tamils were especially concerned about the potential for marginalization given the numerical dominance of the Sinhalese and sought counter-measures. However, it did not want federalism.

- The British, most especially the Soulbury Commission, which drafted the first constitution following consultations across the county. The British were withdrawing from the region and seeking to hand over control to domestic actors.

(Wikramasinghe 2006; Wickramasinghe 2010; Choudhry 2010; Edrisinha 2005; The Soulbury Commission 2008 [1945])

There were no insurgencies or independence armies operating in Sri Lanka. The Sinhala political elite were the most powerful actors, and they successfully co-opted some Tamil support through appointment to their Board of Ministers. The British Soulbury Commission played the role of mediator and arbiter, but was not decisive. Although the 1946-47 constitution was based on its report, their report was based in turn on a draft constitution prepared in 1944 by the Sinhalese led Board of Ministers. In fact, the Board of Ministers was upset at the Commission for consulting with minority ethnic groups rather than focusing solely on its report, and ultimately, the Commission had little choice but to follow the lead of the Board of Ministers because its support was necessary for enactment (Edrisinha et al. 2008a, pp. 128-135). The proposed new constitution was ultimately adopted by the Sri Lankan people through a majority vote in a referendum, which itself demonstrates how 
without safeguards the demographics of Sri Lanka enables the preferences and concerns of Tamils to be disregarded if and when in Sinhalese' interests (Wickramasinghe 2010).

Despite federalism being a longstanding option ${ }^{46}$, by the time of impending independence it was put only by a relatively weak group of Sinhalese, representing the Kandy Sinhalese, who were perceived as seeking to protect hereditary rights, and leftist parties, while the Tamil Congress sought electoral concessions for all minorities to provide an equal balance of power (50/50 representation) (Keuneman 2008 [1944]; Choudhry 2010, p. 107). The Board of Ministers was cognizant of Tamil rights, recommending an additional weightage based on geography in the design of the electoral constituencies, with the effect of increasing Tamil representation in the legislature, and a special majority requirement on certain matters (Edrisinha et al. 2008a, p. 130). The Soulbury Commission instead recommended basic minority protections and some multi-member districts, but ultimately accepted a western liberal approach that gave formal equal rights but practical Sinhalese dominance, with the institutionalization of majoritarian politics (The Soulbury Commission 2008 [1945]; Choudhry 2010). In time, those minority protections would count for little, and the conclusion of the chapter on discrimination in the Soulbury Commission Report was optimistic, but ominous:

A careful review of the evidence submitted to us provides no substantial indication of a general policy on the part of the Government of Ceylon of discrimination against minor communities. But when a minority, rightly or wrongly, feels itself to be forever debarred from attaining an adequate share of the responsibilities of government, it becomes particularly apprehensive of the actions of what it regards as a permanent and unassailable opposition.....We do not consider these apprehensions to be justified...[and] we are satisfied that the Government of Ceylon is fully aware that the contentment of the minorities is essential, not only to their own well-being but to the well-being of the Island as a whole. If it were otherwise, no safeguards that we could devise in the long run would be of much avail (Item 177-178 The Soulbury Commission 2008 [1945], p. 176).

As with Nepal and Myanmar, it is easy to see the process as a battle for power. However, with a largely coherent Sinhalese elite, and the mediation role of the British, compromise was not necessary and the minority protections were enough to have the new constitution

\footnotetext{
${ }^{46}$ Sinhalese politician and future president SWRD Bandaranaike proposed federalism in a series of letters and speeches in 1926, even contemplating a union of states including India. Bandaranaike premised his proposal on mainly security grounds but acknowledged the different communities and the three historical kingdoms (Bandaranaike 2008 [1926]).
} 
passed by the required proportion of voters. There was no ethnic or regional infrastructural capacity with the exception of the Tamil Congress and a Tamil presence within the central bureaucracy and the administrative divisions, and there were no armed groups advocating independence or autonomy. Without these factors, there was little reason for anyone in Sri Lanka to think they needed to create a holding together federal system, and that instead non-territorial means of accounting for minorities would be sufficient (i.e. communal representation or liberal neutrality with discrimination protections).

However, following independence, power was passed to an elected coalition government unencumbered by either communal or federal safeguards. Although multiethnic, it was a British educated elite dominated by the Sinhalese (Wickramasinghe 2010). And, as in Nepal, the competition was intra-group, which ultimately led to the Sinhalese political parties appealing to the extreme elements for electoral support, undermining the minority protections that did exist, and institutionalizing Sinhala dominance above and beyond the numerical majority they initially enjoyed (see DeVotta 2004). These changes were rapid and far reaching, as is discussed in the following chapter.

Religion does not appear to be a factor in the initial state formation decisions. Many of the Sinhalese and Tamil elite were Christian and the idea of Sri Lanka being a protectorate of the Buddhist religion was not prominent until used for electoral convenience in subsequent years. The traditions of Theravada Buddhism and its belief in the ideal king were certainly not a factor, as the chosen democratic structures demonstrate. Like Myanmar and Nepal, Sri Lanka chose a parliamentary democracy, which Lijphart (1999) argues is more appropriate for ethnically diverse countries, but in practice contributed to the democratic dysfunction that led each to centralize political authority in a single executive (albeit at different times in their history) and appeal to ethnic extremes for electoral purposes.

Further, the power balance existing among Sri Lankans during colonial years contrasted with the numerical domination of the Sinhala elite. The Tamils had benefited under the British administration and were comparatively over-represented in the public service, military and other important institutions (Horowitz 1980). This affected the views of the British and the Sinhalese towards the Tamils who believed any communal or federal concessions were not necessary or warranted, as outlined above.

Securitization, which has been posited by Kymlicka (2005) among others as a reason for resistance to federalism, contributes but does not explain the different decision made by Nepal, Myanmar and Sri Lanka. Out of the three cases, secession was a live and real threat in 
Myanmar only, and it had the most vexed relationships with its neighbors (for example, parts of Myanmar were claimed by China for many years post-independence (Smith 1991, p. 39)). However, it was this state only that started federal and has maintained a federal system over a considerable portion of its subsequent history. The right to secession was part of a compromise made in order to ensure agreement of minorities and uphold their alliance with the Bamar against the British. Federalization is more like a secession risk mitigation strategy, necessitated by pre-existing infrastructural capacity and conflict, rather than a reason not to federalize in the first place.

Finally, the mode of state formation, being a peaceful and incremental shift would theoretically mitigate resistance to federalism. But, in contrast to the arguments made by Reid $(2007 ; 2010 b)$, the violent mode of state formation in Myanmar did not prevent the emergence of federal institutional arrangements, indeed it facilitated it. The strength of arms in minority hands, the international environment and the relatively homogenous homelands underpinned the serious secessionist (independence) claims that necessitated a holding together solution. That there was infrastructural capacity reinforced the viability of a federal option.

Further, without any serious push for federalism from key actors in Nepal and Sri Lanka, whether or not the mode of state formation was peaceful or violent was irrelevant. It is more significant that there was no regional infrastructural capacity and no secession risk. Not only did this minimize the negotiating position and power base of minority ethnic groups, it contributed to the subdued calls for federalism. Minority ethnic groups did not have any institutions carrying their ethnic identity and they did not need them, in their view at that time, in order to protect their interests. It is no coincidence that the main proponents of federalism at the time of Sri Lanka's independence were advocating on behalf of the group that had the most recent and residual infrastructural capacity, and the memories of nationhood that go along with it ${ }^{47}$. But with low secession risk and an insignificant infrastructural capacity, their claims were paid little more than lip service.

\subsection{Summary}

The analysis of the critical juncture expands on Ziblatt's conclusion that it is the pre-existing infrastructural capacity that largely determines whether or not a federal system will emerge.

\footnotetext{
${ }^{47}$ Prior to colonization, Sri Lanka was three separate kingdoms and it was not until the British were able to defeat the Sinhalese Kandy kingdom, that the country was actually unified. Early colonialists had been unable to subdue their resistance.
} 
This capacity provides the basis and the power source upon which elites of a particular ethnic group can demand autonomy and give effect to its provision. Further, the presence of a secession risk, or independence movement, creates the impetus to hold together. A structuralist assessment of ethnic diversity would lead to different conclusions regarding Nepal and Myanmar, suggesting for example that Nepal would have become federal (with no group commanding a majority) and Myanmar not (given the overwhelming Burman majority). Power is derived here from access to institutional resources, buffered by numerical strength and relative position in any existing social stratification - and linked to a realistic and militarily supportable secession threat.

Religion plays a role in preference formation as part of ethnic identity-based interests, but was not a significant factor until later years. International actors are influential to the extent that they are supported, or supportable, by powerful local decision-makers. The mode of state formation and the regime type cannot be said in these cases to have significantly contributed to the nature of the initial decisions with regard to federalism and other means of accommodation. It is significant that in only the Myanmar case were any multiethnic alliances formed in relation to independence and state structuring, which is discussed further in subsequent chapters. 


\section{The road to federalism}

This chapter traces and maps the evolution of federal institutions along an assimilation, integration and accommodation continuum, and identifies relationships, patterns and sequences. It analyzes the various federal systems that were established over time and considers in particular their relationship to democracy and the underlying reactive sequence that is punctuated by conflict. The analytical framework outlined in Chapters 2 and 3 is used to map institutional change, coded alongside internal conflict, regime changes and external or contingent events. Further, secession risk and infrastructural capacity have been tracked and compared. I also assess rival theories and identify the sequence leading to varieties of federal approaches in Asia.

The path dependent nature of the outcomes which perpetuated, restored and in some cases expanded the domination of an existing identity-based elite can be seen as a direct outcome of the institutionalization of initial advantage, even when highly contested as in the case of Myanmar. This has allowed power to be gradually reproduced by and for the dominant ethnic elite, even when swapping from one faction to another. However, in each case, those policies and programs aimed a reproducing power - including via identity-based nationbuilding - have led to backlashes and reactive processes which have eventually combined to lead to federalization. Regime crises brought about by the reactions to institutional reproduction of power and ethnic advantage were initially mitigated via centralization, followed by quasi-federal concessions that gave some, but limited and often undemocratic forms of, autonomy. Genuine federalism requires fundamental transformation of powerrelations, which is now occurring in each case.

\subsection{Nepal}

\subsubsection{Initial advantage}

Nepal's initial 1951 institutional arrangement was a power sharing arrangement amongst factions of the existing Pahadi elite that reinforced and further propagated the ethnic identity of the state that existed prior to WWII, being the Nepali speaking Hindu Pahadi culture. Although the royal decree that formalized caste and ethnic discrimination was formally abolished, discrimination persisted in practice because it was embedded in the identity-based social structure. Democratic forces would seem to have been the victor in the power struggles that followed WWII and regional upheavals, but the 1951 constitution gave the King supreme authority and this initial advantage was exercised and exploited on many occasions in order to maintain power and the ethnic basis to the state. 
Each key actor at the state formation critical juncture subscribed to the view that Nepal was a state of and for Pahadis and that the institutions of the state should reflect and build upon their culture and its symbolism. The political parties did little for the accommodation of minority ethnic groups when given the opportunity, but it was the King who most enthusiastically promoted the exclusionary Nepali national identity. The period immediately following the dissolution of Parliament in 1959 was, in particular, one of 'remarkable growth' in nationalism and the propagation of the symbols of Nepali national identity (Verma 1981, p. 7). This nation-building took many forms, such as privileging Nepali language and Hindu religion, citizenship rules that required the wearing of traditional Nepali/Pahadi headwear for identity card photographs, and the slogan "ek desh, ek bhesh, ek bhasa" ["one country, one dress, one language"] (International Crisis Group 2007, p. 3). The ethnic identity of the state was also enshrined in constitutional clauses, for example:

United by the common bond of allegiance to the Crown... (Article 2(1)), Nepal is an independent, indivisible and sovereign monarchical Hindu state (Article 3(1))... [and the King is an] adherent of the Aryan culture and Hindu religion (Article 20(1)) (The Constitution of Nepal 1962).

Even so, the initial modern arrangement was more accommodating than its pre-war institutional arrangement, which was at the assimilation end of the continuum. It provided for broad-based representation, constitutional decentralization and took account of identity, but still within an overall framework of central control. That is, there was some recognition of minority ethnic groups, but only as subordinated to Pahadi identity. The competing powers could and would maintain this basic framework and continued to nation-build in the hope of maintaining a unified country in the face of regionally and ethnically derived centrifugal forces. It is this identity-based nation-building that was the main mechanism of power reproduction and legitimation. However, it also caused many of the conflicts and the reactive backlashes that strengthened infrastructural capacity and secession risks in the regions and ultimately caused system instability and path divergence. Functional outcomes were directed mostly to the benefit of the elite of the dominant ethnic group, and so there would be little buffer for minority ethnic groups when the economic fortunes of the state turned, nor for the elite when its legitimacy was undermined.

\subsubsection{Institutional changes}

There are three main institutional manifestations that are of particular interest over the course of Nepal's evolution to federalism in 2015. Irrespective of the place or commitments 
to democracy existing in early constitutions (1948, 1951 and 1962), the Panchayat system of ground-up decentralization was enshrined. Panchayats, or people's assemblies, existed at a number of levels and were nominally based on territory, but the deliberate and constitutionally based clustering of ethnic groups into single Panchayats meant that there was an important ethnic dimension. In some constitutions Panchayats had defined responsibilities, in others principles for operation and electoral procedures that accounted for diversity. The system served to enable participation in governance and administration in disparate and culturally diverse villages and regions, but subject to central control. It was said to be an indigenous solution to the problems of modern governance, though it left no place for political parties and other non-sanctioned forms of association that were actively sought by the people (Gellner 2005; Smith 1967; Kumar 1980). In other words, it was a means by which the King could negate 'rival claims of parties' (Verma 1981, p. 7).

At no time did these early arrangements cross into an accommodation space and the center remained supreme. While there was stability for almost 30 years, the Panchayat system cannot be termed a success. Its establishment was unilateral and used to underpin power via patronage and provide increased legitimation through nation-building, in the absence of democratic or broad functional means of legitimation. It "made practically no difference to the people" (Verma 1981, p. 32) as in practice Nepal's political and administrative systems remained highly centralized. For example, despite at the time having only three percent of the population of Nepal, Kathmandu provided more than half of the civil service, and housed over $80 \%$, while all major political and investment decisions were made in the center (Verma 1981, pp. 97-102, 164-168).

In response to the armed insurgencies that arose in 1961, the King introduced further changes to improve the Panchayat system, but never in a way to share real power with minorities or even democratic reformists. In 1967 the constitution was amended to add principles of the Panchayat system and non-political association, and in 1980, following a referendum, further amendments were made to increase the democratic components of the Panchayats (being direct elections to the National Assembly, universal franchise, appointment of the prime minister on its recommendation, and accountability of the Council of Ministers (such that it was essentially a parliamentary system but without political parties)). However, as argued by Verma (1981, p. 10) even though "the form was different; the evils persisted; and the substance remained very much the same". 
The 1980 referendum was held in response to violent protests and economic crises (the convergence of a reactive element and an external or contingent event) as a way of keeping political parties subdued (Gellner 2005; Kumar 1980). The demonization by the regime of political parties continued through the election process and beyond, with a justification that partisan politics were themselves a threat to national unity (Verma 1981, pp. 43-53). Nominees for the Panchayat elections needed to be approved as the 'consensus candidate' by an external committee which effectively vetted candidates and ensured loyalty to the King. This loyalty was repaid with positive campaigning in the regions for the referendum outcome desired by the King. That these changes followed immediately after internal conflict and violent widespread protests (centering on the Terai, where the secession threat was highest), indicates the concessionary nature of the changes and their ulterior motives.

Given the serious secessionist threat rearing in the Terai, stoked by a reported 1975 plan by the then Indian prime minister to annex the Terai ${ }^{48}$, the changes brought forward by the King had to balance threat minimization with accommodation by firmly controlling the latter. The Panchayats were so weak and so beholden to the King, that they failed to engender an infrastructural capacity that could stand alone or exist without the patronage of the King (see Kumar 1980). Similarly, the democratic forces while remaining a vehicle of the dominant ethnic group, were unable to force regime change even with the convergence of an economic crisis, and the concessions were sufficient to stabilize the state in the medium term.

The second important set of institutional arrangements was put in place in 1990. These were democratic, but unitary and still perpetuating the dominant ethnic identity as the basis of the nation-state (see Lawoti 2008). Although the new constitution mentioned local authorities and the multiethnic nature of the state, the identity-based nation-building agenda remained enshrined, for example Hinduism as the state religion, Nepali as the national language and restrictive citizenship rules (see Articles 46(1)(c), 4(1), 6 \& 9 The Constitution of Nepal 1990 respectively). On the one hand the Nepali state introduced accommodating institutions (like proportional representation in an upper house) and a fundamental rights regime. On the other hand, it maintained its hold on the ethnic character of the state and its assimilating and integrating elements.

Further, while the push for democracy was widespread, it was largely confined to the urban middle class, which in effect meant the high caste Pahadis. In fact, there was less

\footnotetext{
48 In a similar way to its incorporation of Sikkim. The alleged plan still stokes secessionist fears today (see for example Subedi 2007), and was even raised with me by a former prime minister.
} 
representation of minority ethnic groups in this new democratic system, even if only because in the past the King had 'co-opted' ethnic elites (International Crisis Group 2007, p. 4). The 1990 version of democracy remained highly centralized. In 2000 just $18 \%$ of the budget was allocated to district level programs (Thapa \& Sijipati 2004: 60-64), while in 1999, 95.2\% of the public sector and police were high caste Pahadis or Newars, despite comprising only a third of the population (Malik et al. 2009, p. 431). There was little democratic push for accommodation from within the system, as its political parties were also captured in the main by the Pahadi elite. That an uprising eventuated should come as no surprise.

Diagram 5 illustrates the key institutional changes, disaggregated into federal, consociational and ethnicity in units' elements over time, according to the scoring approach embedded in my Asian federal system concept. The diagram combines the formal constitutional changes and behavioral elements. The trends over time clearly show that despite an initial accommodating turn at the overthrow of the Rana regime in 1951, a reversion quickly occurred. It was not until the King, in 1962, established quasi-federalism that key elements of accommodation shifted again, this time from an assimilating range to a more stable but integrating approach. From 1990, when democracy was reintroduced, consociational means of accommodation were also implemented, but federalism was absent. Then, as federalism was introduced, consociationalism was reduced. How this was a result of a reactive sequence is discussed in the following section.

Diagram 5: Nepal - elements of accommodation 1948-2015

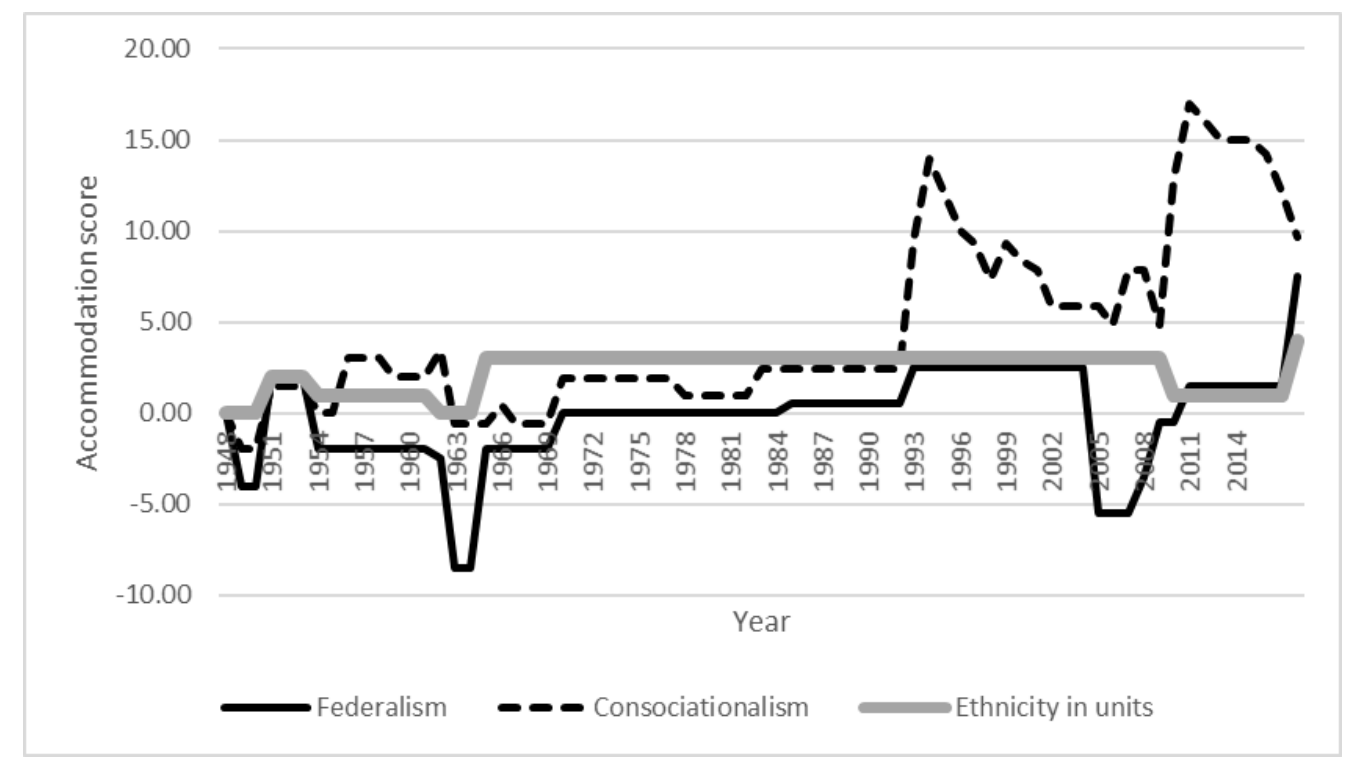




\subsubsection{Democracy and reactive sequencing}

The repeated failures of democracy in Nepal can be attributed to the lack of accommodation of minority ethnic groups (see especially Lawoti 2005; Ghai 2011). There were some consociational means of accommodation, but no federalism (see Diagram 5). Democracy without federalism was tried, and failed. Observing the dysfunction of high caste democracy, two communist parties joined forces, and demanded from the government a constituent assembly to produce a new secular republican constitution. When refused, they became 'the Maoists'49 and 'took to the jungle' to commence the insurgency that would eventually fundamentally change the conditions that had existed and persisted through the state formation stage and beyond (Devkota 2012). The Maoists gave voice and power to the excluded minority ethnic groups, created regional and ethnically based infrastructural capacity, and made major inroads to removing the persisting hierarchy embedded in ethnic identity and the caste system particularly. With these changed conditions, some kind of federalization seemed inevitable.

The initial opening of channels of access to power (circa 1950) caused intragroup infighting but without serious challenge to nation-building agenda. However, as post 1990 democracy meant, for the minorities, continued exclusion and power consolidation of the Pahadi elite, a further reaction was inevitable. The state's response was further repression, as the prior concessions were not repeatable under the new regime, which ultimately weakened the state such that once the reactive elements converged with external or contingent events - in this case the loss of identity-based legitimation via the royal massacre ${ }^{50}$ - the regime was able to be overturned.

Critically there were now two alternate and temporally excluded power sources - the democratic forces, and the Maoist insurgency representing the minorities and marginalized peoples. Although it can be argued that the Maoists were a class organization and were not formed to represent minority ethnic groups, the alignment of ethnicity with exclusion renders this argument mute. Further, it was an explicit objective of the movement to take on the interests of the minority ethnic groups and incorporate them into their 'struggle' (Devkota 2012, p. 22), and their 40-point demand issued to the government in 1996 prior to

\footnotetext{
${ }^{49}$ The Maoists eventually become a political party and subsequently underwent various splits and name changes. Most often, the main party has been called the United Communist Party of Nepal (Maoists). I continue to refer to the main Maoist party as simply 'the Maoists' for continuity and ease of understanding. 50 The majority of the royal family was murdered in 2001 . The crime was officially blamed on the then Crown Prince who also died in the incident. However, it is widely believed that the then King's brother, who subsequently became King, was responsible because he, his wife and his son were not present or harmed during the incident. This undermined his legitimacy as the new monarch.
} 
launching its insurgency explicitly and directly called for autonomy for ethnic groups (see point 20 Bhattarai 2004 [1996]). As one of the founding members of the Maoists told me, the push for federalism came up because of the domination of caste and ethnic groups, and it was always the intention to 'emancipate' these groups through autonomy. Similarly, Lawoti (2014, pp. 131-132) argues that "what undergirded that rebellion-and has thrown the constitution-making process into disarray - is less the politics of socioeconomic class per se than the politics of identity more broadly understood... underlying [poverty and inequality] were widespread and deep-seated patterns of exclusion based on ethnic, caste, religious, and regional identities".

Ultimately, the minority ethnic groups and factions of the dominant group aligned. In 2005, the Maoists and the seven main political parties signed an agreement to work together to overthrow the King, which set the stage for Jana Andolan II (the People's Uprising) of April 2006, which paralyzed the state until the King ceded power. Following the return of civilian government, the Maoists signed the Comprehensive Peace Agreement with the seven major political parties. This agreement required the election of a constituent assembly to lead a participatory process for the development of a new and inclusive constitution. The democratic forces agreed to a range of accommodating strategies (federalism, secularism), while the Maoists, and the minorities, supported a multi-party democratic regime, which they had previously opposed. This alliance, encapsulated in the Comprehensive Peace Agreement and its requirements for state restructuring, continued to guide the new constitution-making process:

To carry out an inclusive, democratic and progressive restructuring of the state by ending the current centralized and unitary form of the state in order to address the problems related to women, Dalit, indigenous people, Janajatis, Madheshi, oppressed, neglected and minority communities and backward regions by ending discrimination based on class, caste, language, gender, culture, religion, and region (Item 3.5, Comprehensive Peace Agreement, Government of Nepal \& Communist Party of Nepal (Maoist) 2006).

These major institutional changes and the extent which the system as a whole was accommodating is mapped out below in Diagram 6. This diagram shows that notwithstanding the overall upwards trend in accommodation, the convergence of regime and external factors, such as economic crises, interacted with the institutional evolution to determine the timing of change. The most significant institutional changes came when a 
destabilizing conflict converged with regime, external and economic events. As conflict was resolved, accommodation increased.

Diagram 6: Nepal - institutional accommodation 1946-2016

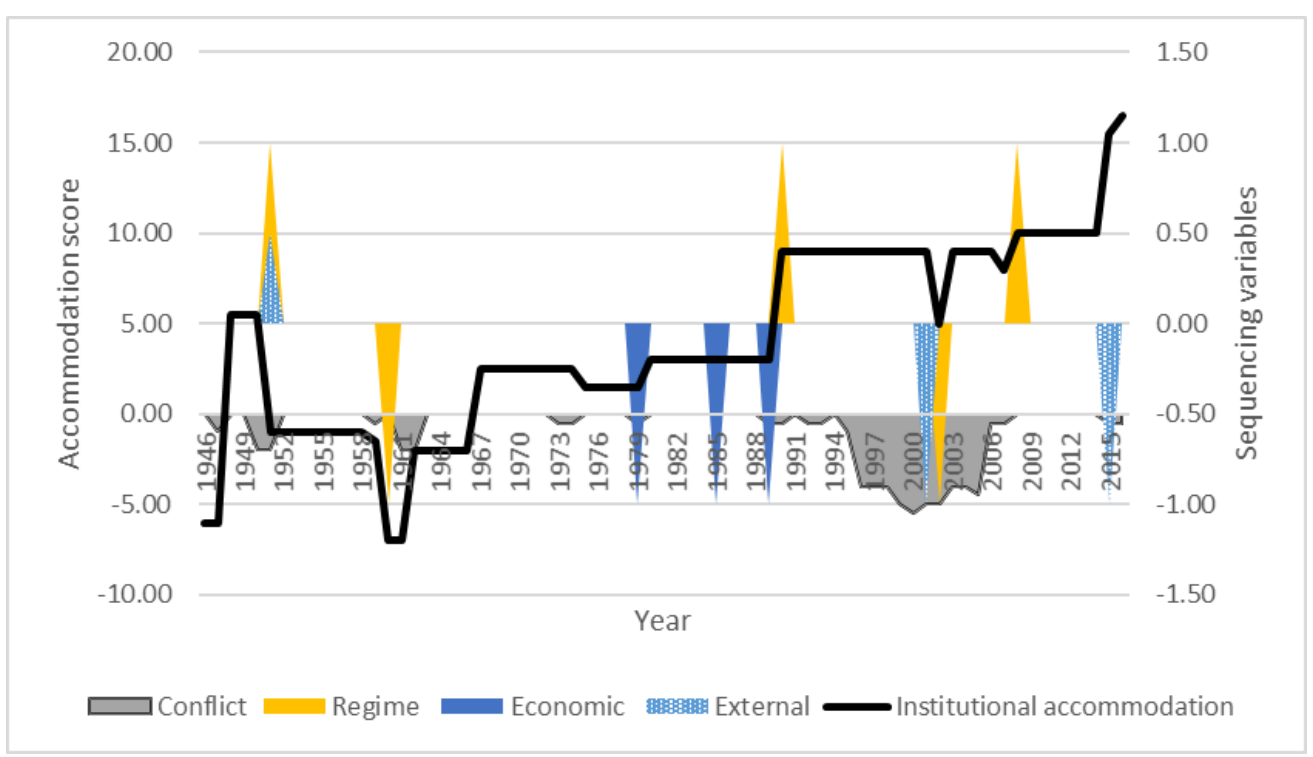

The argument for the salience of infrastructural capacity for federalization and as a means of affecting the power balance is demonstrated in the Nepal case. To get to this point, the Maoists developed parallel state structures as a system of regional autonomy, including courts, administrative systems, taxation, representative bodies and public services like health, during the civil war, and sought international recognition of these state structures as an additional form of legitimation. The Maoists were filling a void left by the absence of substantive local government, and executing part of their strategy to take state power. Starting in three districts in the west, and Gorhka district, by 1998 the Maoists had established parallel governments in 25 of 75 districts, and by January 2003, spread to 68 districts (Thapa \& Sijipati 2004, pp. 56-59, 156; Devkota 2012, p. 48). Even after the Constituent Assembly elections in 2008, the Maoists continued this approach, unilaterally declaring twelve autonomous regions complete with boundaries, capitals and ethnicallybased names (THT Online 2009). But ultimately, it was the secession risk that created an imperative to hold together, which together with infrastructural capacity, guides the approach taken to its mitigation.

A Madheshi uprising occurred over 2006-07 where secession was openly canvassed. It was led by an alliance of Madheshi parties and armed groups that were in the main offshoots of the Maoists (International Crisis Group 2007). Almost 50\% of the country's population live in the Terai, and its distinct cultures and geographical features lend credibility to the 
secessionist movement. The rise of armed groups and new ethnic parties, gave form to the fear of 'disintegration' that permeated the federalism debate in Nepal, and the threats were direct and numerous. For example, the leader of Madheshi Janadhikar Forum, Upendra Yadav, made clear that Madheshis "would like to govern ourselves now...[but] if the government does not respect our demands, we will be forced to divide the Terai region from Nepal” (cited in Miklian 2009, p. 6).

Diagram 7 relates the degree of formal accommodation, as per the Asian federal system concept, to the secession risk and infrastructural capacity. There is a clear upward trend in the degree of accommodation once the secession risk began to drop. This supports the argument that the introduction of federalism followed from the increase in infrastructural capacity, only once the related secession risk was at a moderate level.

Diagram 7: Nepal - accommodation, secession risk and infrastructural capacity 1948-2015

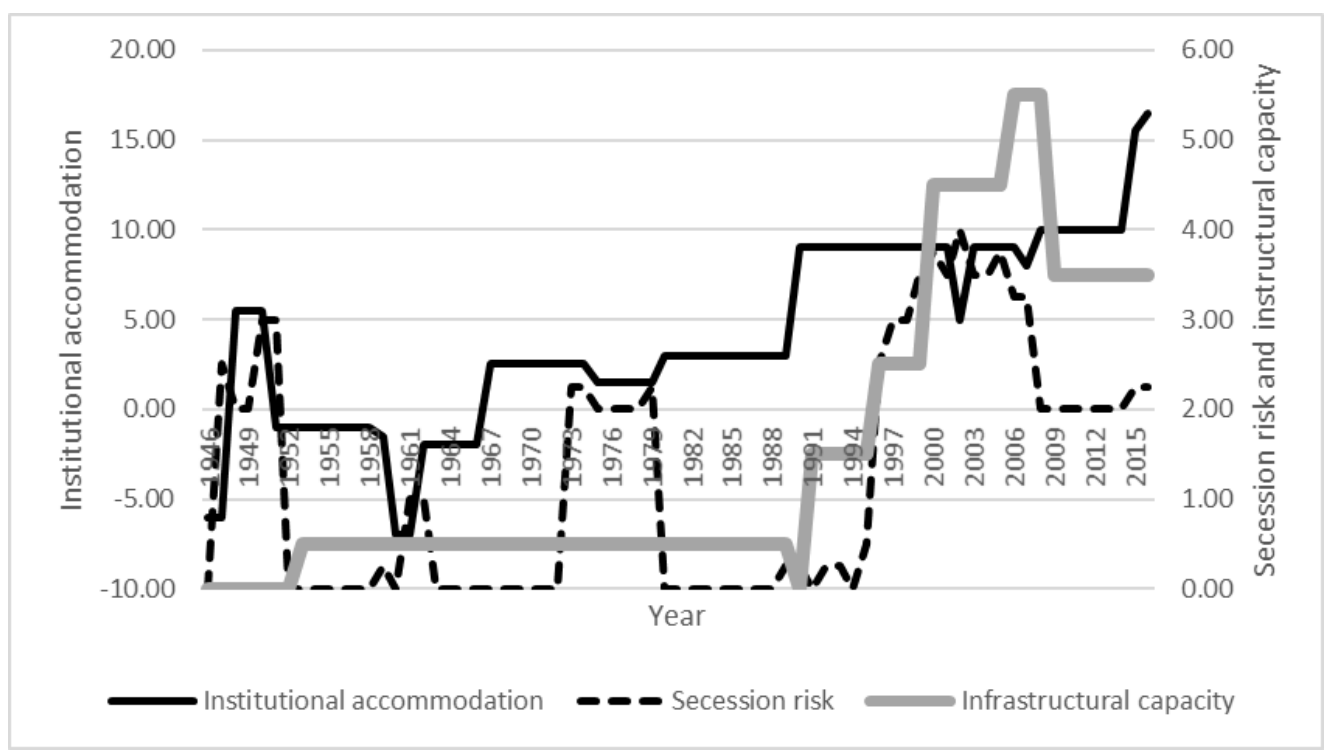

Democratic transition provided an opportunity for federal change that would otherwise not have occurred had democracy been maintained, because electorally speaking, federalism would not have been the popular choice, even if it is potentially more widely beneficial. For example, a 2007 study comparing the Constituent Assembly members and the general public highlighted that $93 \%$ of Assembly members supported federalism compared with just $42 \%$ of the general public (Hachettu, Kumar \& Subedi 2008: 87). Although the ethnic parties accused the government of "suppressing people's aspiration by majoritarian politics" (BK Gachhadhar, Chairperson Madheshi Janaadhikar Forum (Loktantric), cited in Post Report 2014a), the difference between popular minority ethnic and dominant group opinion regarding federalism was small (Sharma 2013). Diagram 8, which displays the extent of 
accommodation and democratization, shows that while there is a correlation between the two, federalization followed a decline in democracy, which created the opportunity for excluded groups to pursue mutual benefit, and for minorities to be included in the reform process.

Diagram 8: Nepal - accommodation and democratization 1948-2015

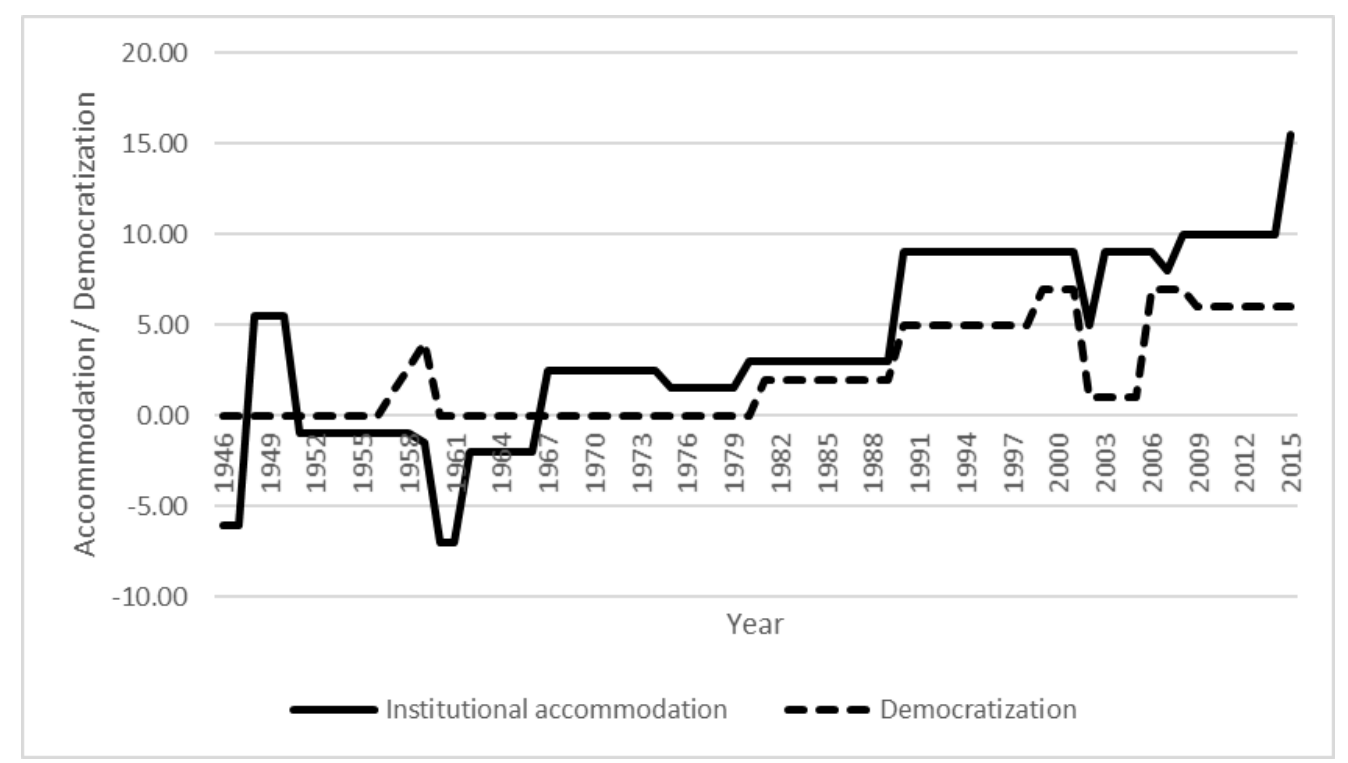

Whether the regime change and minorities' alliance was necessarily related to democratic reform, or any kind of change in regime type is a matter to be explored with respect to the other cases, as in Nepal, the type of regime seems incidental and the infrastructural capacity, secession risk and regime change are far more significant. Nepal had fluctuated between democracy and monarchy, but until the most recent transition, the dominance of its elite was never seriously undermined. Nepal's path has taken it to genuine federalism - in this case a democratic federation. Although the path taken by Myanmar and Sri Lanka would appear at face value different to Nepal's, striking commonalities in sequencing and overall trajectories are apparent, as are the convergence of hypothesized necessary and sufficient conditions. I discuss these below.

\subsection{Myanmar}

\subsubsection{Initial advantage}

In Myanmar, the initial situation was more tumultuous but bore many similarities to the intra-group battle to consolidate power that occurred in Nepal. The initial institutional arrangements were, despite the backtracking on the Panglong Agreement, quite accommodating in comparison to other states in the region, or future incarnations in Myanmar itself. Certain ethnic groups had dedicated units, and guaranteed representation in 
the center, but they did not have a proper distinction from the center, as the units' heads of state and council members were simultaneously members of the union government (see $\mathrm{Ch}$ IX, The Constitution of the Union of Burma 1947). Further, the powers of the ethnic units were asymmetrical, with the Shan State keeping greater financial powers and having a dedicated civil service (Furnivall 1960, pp. 93-108). Only the Shan, Chin, Karenni and Kachin groups could be said to have benefited under the new constitution, and then only arguably so. Others, including the second most populous minority, the Karen, were mostly subsumed into a large majority Bamar area that combined the functions of the center and a unit.

Representation of minority ethnic groups in the center was highly unequal, and subordinated. In the upper house (Chamber of Nationalities), the Shan had 25 seats allocated to traditional headmen, while the Kayah had just three. In the lower house, ethnic parties competed with other parties in mostly two-member constituencies. However, almost all the ethnic parties were aligned with the AFPFL, which continued to operate as a one-party system until its split. For example, in 1956, 60 candidates from four ethnic parties competed for 25 seats in Shan State, but only two winners were in opposition to the AFPFL (Furnivall 1960, pp. 102-103). Thus, while the system was asymmetrical and benefited some more than others, it was heavily weighted towards Bamar initial advantage.

Sentiments of unfairness were aggravated by the gap between expectation and outcome. The promise of founding father Aung San at the Panglong Conference, that "if Burma gets one Kyat [of currency] then you will get one Kyat" (cited in Walton 2008, p. 897), is commonly mentioned today as a basis for restructuring the state and understood by many as meaning one for the Bamar, one for the Shan, one for the Karen, and so on, irrespective of population. Instead, the allocation of seats in the upper house was based on population, which undermined this principle of equality (Sakhong 2005, pp. 18-19), and most resources were retained by the Bamar core. As conceded by its author $U$ Than $U$, the "constitution was federal in theory, but unitary in practice" (cited in Lian 2012, p. 12).

The Bamar initial institutional advantage meant that its culture and power could be progressively imposed via identity-based nation-building. However, the units did not come under central leadership, most particularly the Shan State, because of practical constraints and shortcomings in the ability of the center to properly implement the new institutional arrangements (Win, Han \& Hlaing 2011, p. 129). Local government administration was virtually absented following independence creating a vacuum which could be filled by nonstate actors (Taylor 2009, pp. 229-230, 264-270). The minority ethnic groups could continue 
to hold and build their infrastructural capacity, increasing secession risk and imperiling the Bamar nation-building agenda, but not coalescing into a coherent force on its own. Over time, the trajectory of accommodation in Myanmar fluctuated from one extreme to another as different groups battled for prominence in the new state. However, after the dust of independence settled, a particular trend became apparent.

\subsubsection{Institutional changes}

The first sign of power consolidation bears unfortunate similarities to the treatment of those classified in Nepal and Sri Lanka as immigrant groups. That is, via restrictive citizenship laws that were intended to disenfranchise Muslim minorities, who were deemed incompatible with national identity, and a threat to the state's Buddhist heritage. This occurred within around one year of independence. Further, conflict with dissatisfied minority ethnic groups (but not the Panglong signatories) commenced almost immediately on promulgation of the constitution. Even if the first constitution is construed as accommodating (as I have), it was only as such for particular minority ethnic groups, with the remainder expected to be integrated or assimilated into the Bamar core (or the Shan ethnic group, for example). Although the first major constitutional change was towards accommodation, being the creation in 1951 of a unit for the Karen, it was rejected as insufficient and fighting continued. Other early changes worked to consolidate initial Bamar advantage, and invite resistance. For example, in 1954, Buddhism was given a special place in the constitution, despite this earlier being rejected by the Constituent Assembly (Win, Han \& Hlaing 2011, p. 65).

With $\mathrm{U}$ Nu as prime minister, and an institutional arrangement that facilitated Bamar domination, further moves towards centralization should have been expected. U Nu had openly expressed concerns about the capacity of the state to manage a federal system:

The Shan, Chin, Kachin and Kayah nationals have each set up their own state. It has come to our knowledge that the Rakhine, Mon and Kayahs have similar aspirations for setting up separate states. I wish to state positively our policy on the matter of setting up separate states... The population of the union is rather sparse and thus in the interests of economy or defence, we cannot afford to divide the union into many heterogeneous segments. To state my candid personal opinion, I do not even fully savour the current fragmentation of the union into Shan, Kachin and Kayah states, let alone further dismemberment. Instead of this separation, I would rather have the Shan, Kachin, Chin and Kayah nationalities govern the union, because the current 
need of the union is unity and not disaggregation ( $U$ Nu, Prime Minister of Burma, 1948, cited in Win, Han \& Hlaing 2011, p. 124).

In time, democratic dysfunction combined with the communist threat to prompt $\mathrm{U} \mathrm{Nu}$ in 1958 to put the military in charge as a caretaker government for two years, in what would become an ominous sign of things to come. The secession risk continued to grow until it became, at least in the eyes of some, unacceptably high.

By 1960, change was afoot in several respects. U Nu was persisting with his aim of making Myanmar a Buddhist state; Mons, Arakanese and Kayah were advocating for a unit (state) of their own; and the Shan had led an agreement with the other empowered minority ethnic groups to reform the existing federal system (the Taunggyi agreement), lest they exercise their right to secession. The confluence of these events concerned almost all in one respect or another ${ }^{51}$. While $U$ Nu sought to use the situation to his advantage seeking to trade-off agreements regarding federalism with his Buddhist reforms, others saw the creation of new units at a time of possible federal reform as too risky and wished for them to be sequenced (Win, Han \& Hlaing 2011, pp. 60-163). Ultimately, this mattered little, as in 1962, in direct response to the secession risk, the military took over and abolished the ethnic councils and ministries and banned political parties.

A period of absolutist rule followed, as the military built a one-party system, encouraged grassroots participation albeit in a subordinated manner, and removed the prior communal or identity-based rights that had existed up until then. The new party, the Burma State Socialist Party (BSSP) was ostensibly non-ethnic in ideology and multiethnic in membership ${ }^{52}$ (which apparently reached more than two million by the 1980s), but in practice dominated by Bamar. For example, the BSSP's political agenda 'the Burmese Way to Socialism' detailed most specifically in 'The System of Correlation of Man and His Environment', purported to be blind to ethnicity, but in reality it was underpinned and permeated by Bamar Buddhist ideologies and bases for legitimation (see point 4 for example, Burma Socialist Programme Party 1964). Further, the military government established Burmese as the language of instruction in schools, disadvantaging minorities and propagating Bamar identity (Walton

\footnotetext{
${ }^{51} \mathrm{U}$ Nu was on the verge of progressing outcomes from the Taunggyi conference of 1961, where minority ethnic groups agreed a series of federal reforms, highlighting their discontent with the centralizing elements of the 1948 constitution. Changes sought included: the creation of a Bamar unit; equal representation (and equal powers) in the upper house; creation of new ethnic nationality units; the introduction of dedicated legislatures and other institutions (e.g. judiciary) in the units; and, improvements in the revenue arrangements (Sakhong 2012, pp. 1223).

${ }^{52}$ Even with single-party candidate vetting, elections returned a considerable number of ethnic candidates in the periphery (Taylor 2009, pp. 300-326).
} 
2013, pp. 14-15). As put by Sakhong (2005, pp. 24-25), U Nu tried to create a homogenous society via Buddhism, while the head of the military, Ne Win, focused on assimilation through language policies.

Eventually, in 1974, as conflict continued and periodically erupted, the BSSP introduced a new quasi-federal constitution (The Constitution of the Union of Burma 1974). Seven ethnic units were created, along with seven Bamar units. It addressed the high degree of asymmetry that is said to have contributed to the downfall of the initial federal structures (e.g. Tawnghmung 2010). The units had constitutionally guaranteed powers, including for revenue and natural resources, though they were generally weak and subject to the whim of the center, who could use intervention powers (e.g. Article 40A and 411) and resolve disputes unilaterally (Article 226). The new constitution firmly established a hierarchy such that "local autonomy under central leadership is the structure of the State" (Article 28).

Most significantly, the president would nominate the chief minister (and the units could not refuse to appoint) (Article 261) and the chief minister would remain responsible to the president, rather than the unit's constituents (Article 261(I)). The units were all represented in the center (Council of State (Article 64)), but Bamar nationalism remained prominent via language in education and other institutions (Articles 102; 152). That this constitution would be unsatisfactory to the minority ethnic groups, leaving aside any aspirations for democracy, is plain to see. Even though there were significant opportunities for local level input during the process of constitutional development ${ }^{53}$, the constitution was unilaterally imposed and reinforced existing powers and regime. It did little to dampen down conflict and the integration of minorities in the name of nation-building continued.

Little substantive institutional change occurred following the enactment of that constitution, despite the seemingly intractable conflicts. In 1982, restrictive citizenship laws again came to the fore, specifically targeted at excluding Rohingyas, but otherwise there was a period of relative stability. The resistance of the minority ethnic groups was insufficient for substantial change. As Taylor (2009, pp. 335-336) writes, the ethnic armed groups could not agree amongst themselves and so did not threaten seriously the state, however, they remained a security issue and prevented the state exercising full control. But, by 1984, all the armed groups had dropped demands for secession / independence (Smith 1991, p. 386). This, combined with the end of the cold war, economic crises and 1988's democratic uprising

\footnotetext{
${ }^{53}$ For example, Taylor (2009, p. 308) writes of the formation of almost 17,000 local task groups, meetings with more than 100,000 people and more than 5000 submissions.
} 
would have appeared to have cumulatively bridged a threshold for combined regime change, and federalization. Instead, the military dug in.

The details of the 1988 peoples' uprising, its brutal repression, and the subsequently dishonored election results do not need detailed here, although it is important to briefly recount the process that led to the 2008 constitution. Following the 1988 uprising, the military seized power from the BSSP and pledged to hold an election for a new government. The election took place in 1990, and the National League for Democracy (NLD), led by Aung San Suu Kyi, the charismatic daughter of the independence hero Aung San, won an overwhelming victory. However, instead of assuming power, the NLD were relegated by the military regime to participants in a constitution drafting process, on the basis that they could not take over until a new constitution was in place ${ }^{54}$. A constitutional convention ('National Convention') was established for this purpose.

In the lead up to the election, the military's State Law and Order Council (SLORC) claimed that elected representatives would write the new constitution: "neither the Defence Forces nor the SLORC will draw up a new constitution. The elected representatives are to draw up the constitution. If the people approve that constitution, we will transfer power as soon as possible to the government which emerged according to that constitution" (State Law and Order Council spokesperson, cited in Tonkin 2004, pp. 6-7). However, in contrast to the election outcomes, the National Convention was numerically and practically dominated by the military and its political party. The convention was established in 1993 and suspended just three years later, not reconvening again until 2004. Initially, it comprised 702 delegates, of which only 99 were elected members of the legislature. The NLD had won more than $80 \%$ of the seats available at the 1990 election, but received only $11 \%$ of the representation at the Convention (ALTSEAN Burma 2007).

By the time the National Convention was reconvened, its democratic legitimacy was almost entirely eradicated. Delegates had increased in number to 1081 , and were by invite only, leaving just $1 \%$ of the 1990 election winners with a seat. However, some of the undemocratic aspects of the convention membership and processes are justifiable in a postconflict ethnically divided society, bearing in mind the transitionary and conflict-resolution context within which it operates, and the use of consociationalism as a transition strategy. That is, we know that democratic outcomes in deeply divided societies can permanently

\footnotetext{
${ }^{54}$ A condition which was "made abundantly clear" by the military in the lead up to the election, who stated that the objective of the elected legislature was to draft a new constitution (Tonkin 2004).
} 
marginalize minorities and so mechanisms that ensure that ethnic minority groups have a voice are warranted. From this perspective, that almost $60 \%$ (645 of 1081) of delegates at the reconvened convention were 'representatives of national races' (rather than political parties per se) is positive (figures from ALTSEAN Burma 2007).

However, the process was tightly controlled by the military, so that the outcome could also be controlled. Perhaps most significant was the imposition of a set of six objectives for the new constitution, three related to federalism ${ }^{55}$ and one provided for 'participation by the Defense Services in a national political leadership role' (see Item 2). Over time, the Convention adopted more than 100 other basic principles, including the elements of the federal system ${ }^{56}$ (National Convention 1995). Meanwhile, the military criminalized dissent (including about the process), barred delegates from raising particular issues or debating sensitive topics and limited delegates contacts with those whom they were purported to be representing (ALTSEAN Burma 2007). This led to many democratic and ethnic forces boycotting, but with limited impact. For example, the Kachin Independence Organisation boycotted the initial sessions (1993-1996), but participated in the second incarnation (200407) eventually instructing its members to support the new constitution (Jones 2014, p. 795). The final step in the process was a referendum, which itself was highly controversial. It was held in the immediate aftermath of the devastating Cyclone Nargis and officially passed with a $92.4 \%$ majority.

The quasi-federal constitution of 2008 was a unilateral concession, aimed in the main at maintaining regime power and resolving conflict. Notwithstanding the accommodating elements discussed below, the units and minority ethnic groups remain subordinate to the center, most particularly indicated by the presidential control over the appointment of unit chief ministers (Article 261, Constitution of the Republic of the Union of Myanmar 2008). As acknowledged by the Chair of the Karen National Union, Saw Mutu Sae Po, the 2008 constitution does enact a federal system, but its 'essence is weak' (Myanmar News Agency 2016b).

\footnotetext{
55 1. Non-disintegration of the Union; 2. Non-disintegration of national unity; and, 3. Perpetuation of national sovereignty (Item 2, National Convention 1995).

56 Including the boundaries and names of the units (which would prove the most contentious issue in Nepal), that the system would be symmetrical (Item 3, Chapter II), and the division of powers (Item 38, Chapter IV), (National Convention 1995).
} 
The 2008 constitution continues many of the features of the 1974 constitution, including the division of the country into seven ethnic states and seven divisions (Article 9, Constitution of the Republic of the Union of Myanmar 2008). It of course differs in fundamental areas associated with the 'managed transition' to democracy and a multi-party system, and the provision for a continued role for the military in the governance of the state is a subject of much controversy (e.g. Article 17(b)). Other important differences are the creation of institutions for smaller and second order minorities. Ethnic groups of a certain size have a right to participate in the legislatures (Article 15) and have dedicated ethnic affairs ministries (e.g. Article 7(3)). Self-administered areas, which are a type of autonomous region for smaller groups, with a dedicated division of powers, are also established. There are five selfadministered zones, plus one larger division for the Wa group (Article 56). The states, regions and self-administered areas have only a weak division of powers, lacking substantive taxation and revenue, natural resources, law and order and education responsibilities, and the members of the self-administered areas' legislatures are drawn from the membership of the relevant state (unit) parliaments (see Schedules 2 and 3 and Article 276).

Diagram 9 illustrates the key institutional changes, disaggregated into federal, consociational and ethnicity in units' elements over time, as per Diagram 5 for Nepal. Starting with a very accommodating system meant that its decline was rapid and strongly resisted. Although it has mostly maintained units based on ethnicity, consociational elements have been almost entirely absent until 2008 when the democratic transition took hold. The federal system was reinstated much earlier - 1974 - with improvements coming as consociational elements declined. That is, like Nepal, consociational arrangements have been part of a transitional process towards federalism. Further federalization should be expected, as discussed in chapters 6 and 8 . 


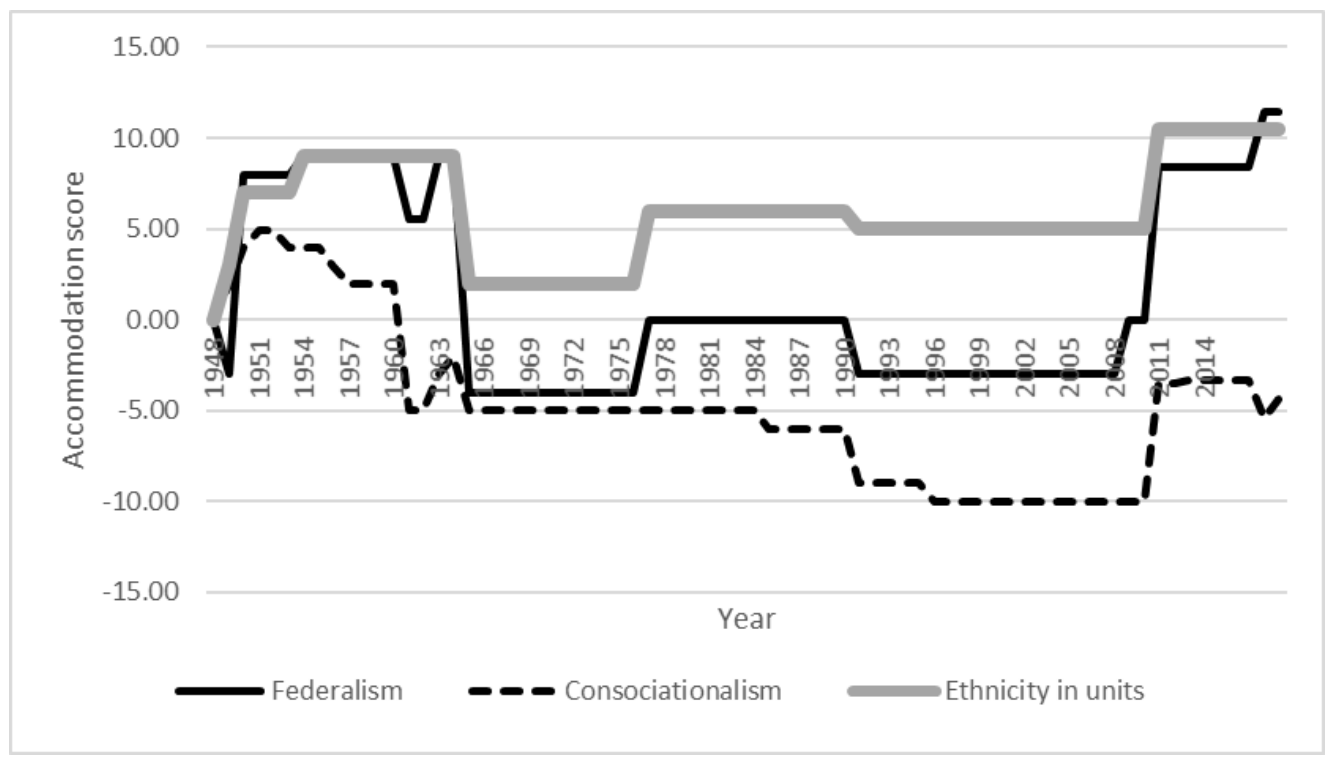

\subsubsection{Democracy and reactive sequences}

The balance of power emanating from the state formation critical juncture was not all one sided and so the ability of the minority ethnic groups to resist and react was commensurately higher (compare Nepal for example). The gap between the ideal of federalism, enshrined in the Panglong Agreement and referred to today as 'the spirit of Panglong', combined with the reaction to the nation-building agenda to lead to an entrenched civil war and democratic repression ${ }^{57}$.

Key elements of the above mentioned institutional changes illustrate the self-reinforcing elements coexisting with reactive sequences. The process leading to the breakdown of the initial federal system is most pertinent. Coming into the elections of 1960, the commitment

57 The key elements of conflict in Myanmar deserve special mention because of their breadth and complexity and so are summarized. Major protests, riots and military offensives are also included (e.g. anti-Muslim riots, the Saffron Revolution) in the conflict mapping but not mentioned below. (Key sources are Taylor 2009; Smith 1991; Burma News International 2014; Lintner 1999; Transnational Institute 2011; Kivimaki \& Pasch 2009)

- $\quad$ 1947-49 - insurgencies commence in Karen, Karenni, Arakan and Mon areas, as well as with the Communist Party of Burma (CPB)

- 1961-64 - further insurgencies commence within Shan and Kachin states, including merging of multiple Shan groups into the Shan State Army (SSA) (1964)

- 1965-70 - four cuts program intensifies conflict, mostly within Karen state, and with the CPB, but also following failed peace talks with Shan, Kachin etc.

- $\quad$ 1989-91 - CPB breaks up and remnants, including the United Wa State Army, along with SSA and Kachin Independence Army (KIA), sign ceasefires. The government seeks to establish a Border Guard Force with varying levels of take-up

- 1994-2000 - intense fighting and displacement in Karen, Karenni and Shan states especially

- 1995-96 - other (major) National Democratic Force group members sign ceasefires (including New Mon State Party (NMSP), Kachin Independence Army \& Karenni National Progressive Party), following change of Thai government policy \& pressure, talks with Karen National Union (KNU) breakdown.

- 2011-15 - further ceasefires with KNU, NMSP, SSA and others, as well as a National Ceasefire Agreement (2015) though limited in scope. Fighting recommences in Kachin and Shan states. 
by $\mathrm{U}$ Nu to make Buddhism the state religion heightened the ethnic nationalities' dissatisfaction with the institutional arrangements, and some threatened to secede. The response by the head of the military, Ne Win, was specific to the secession threat posed by ethnic federalism. He immediately abolished the regional / ethnic institutions, including their legislatures, stating that "federalism is impossible, it will destroy the union" (cited in Smith 1991, p. 196). This led to more ethnic groups launching insurgencies, which in turn led to $\mathrm{Ne}$ Win progressively reinforcing power through the consolidation of Bamar dominance, most notably through institutional changes that established formal equal rights thus removing special rights for ethnic groups (Taylor 2009, pp. 303-305). Eventually, in the face of increasing backlashes and an inability to suppress them via further centralization and military power, he re-introduced a federal system, entailing only quasi-federalism.

The initial compromise and the power balance therein had meant that ethnic domination could not be consolidated to the extent it was in Nepal and Sri Lanka. Conversely, the minority ethnic groups were never powerful enough to break the overall trend, despite the number of concessions their forceful reactions were able to elicit. To ask why it is that the 2008 constitution makes little progress in terms of federalization is informative as to how the conditions and alliances that exist now provide a basis for a genuine federalism. As mentioned, it was a unilateral concession. The infrastructural capacity that had existed via the administrative arrangements in place since 1974, and via the parallel administrations run by ethnic armed groups and their political wings, continued in place. Indeed, many armed groups had agreed ceasefires with the state that gave them a more secure autonomy. For example, the United Wa State Army has, since its 1989 ceasefire, self-administered a large territory to the exclusion of the military and other official state apparatus (Callahan 2007), while the leaders of the Mongla rebel group claim that they "run a complete system of government", and have constructed hydroelectric dams, hotels, casino, schools and hospitals (cited in Weng 2015). If anything, the infrastructural capacity has grown and continues to grow:

In spite of the internal and external situations, we continue to maintain our state, Kawthoolei, administered by our own Kawthoolei Government since 1950, under the banner of the Karen National Union, and the well trained and disciplined Karen National Liberation Army, which were formed in that same year. We desire Kawthoolei to be a Karen State with the right to self-determination (Karen National Union 2014). 
The secession risk has also existed since initial (and failed) federalization in 1948, and although armed groups had renounced secessionism for federalism since the early 1980s, it was a fear front and center in the minds of the military who had imposed the basic principles on the new constitution that would 'prevent disintegration'. Today, this fear is subsiding as it becomes increasingly clear that the minority ethnic groups no longer seek secession, and there is little support available to ethnic insurgents from neighbors and the international community more generally. Indeed, all ethnic minority groups representatives that I met with advised that their organization had renounced secession. Further, the government is now led by the NLD, which is not military-aligned and does not appear to fear secessionism (which was confirmed in discussion with me). Thus, while the risk of secession remains, it is now no longer high enough to prevent federalism. This can be seen in Diagram 10, which relates the level of institutional accommodation with the secession risk and minority ethnic groups' infrastructural capacity. Although the infrastructural capacity has been higher in the past, it was usually associated with a high secession risk that meant that it was not recognized or incorporated for fear of the consequences.

Diagram 10: Myanmar - accommodation, secession risk and infrastructural capacity 1948-2015

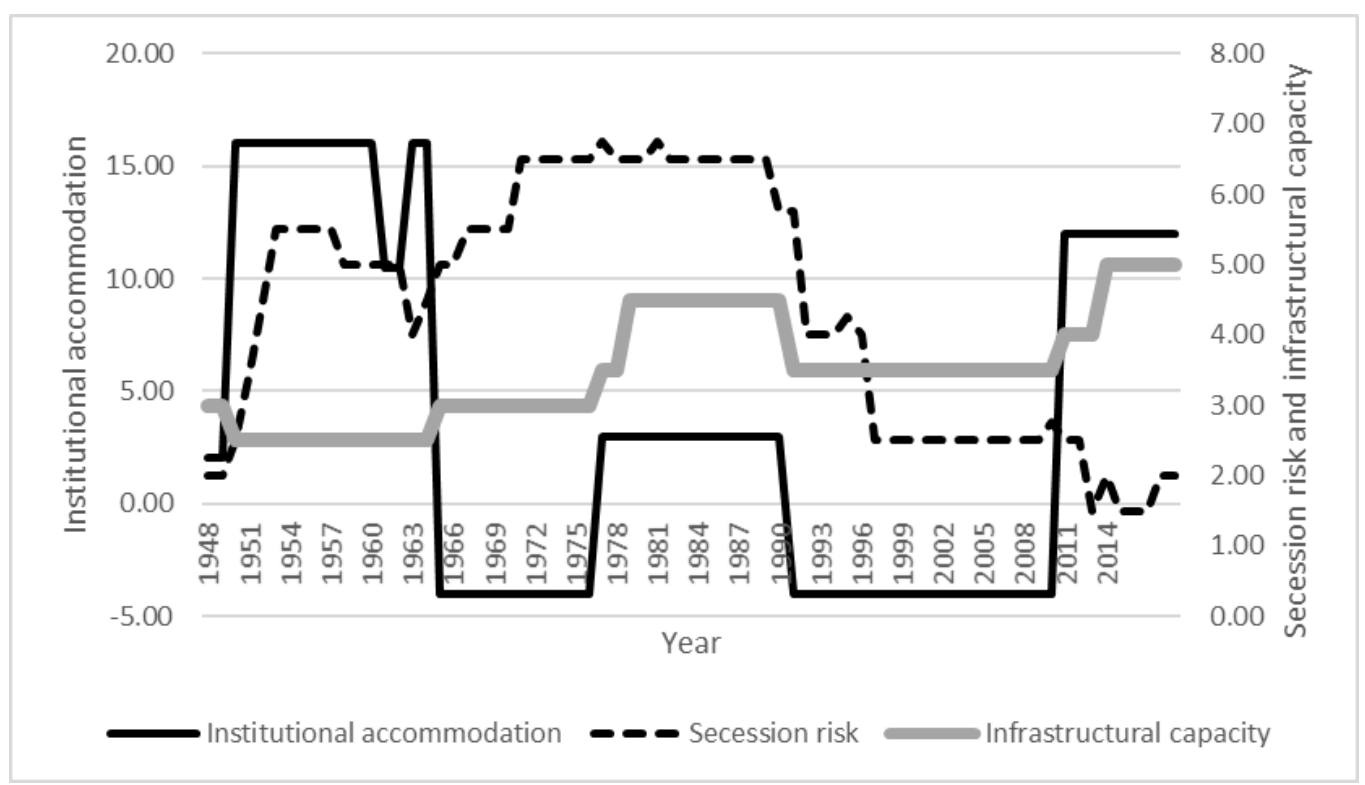

Further, while ethnic groups have found it difficult to form and maintain alliances amongst themselves, they are cooperating perhaps more than ever (notwithstanding that fighting continues between some groups (e.g. T'ang National Army and Shan State Army (South)). Past alliances placed ethnic groups in one of two camps, either as part of a democratic or a 
communist alliance ${ }^{58}$. Groups have now crossed that ideological divide, establishing for example the United Nationalities Federalism Council (UNFC) to lobby the state for a federal solution (Linn 2011). They recognize the imperative to work together. Indeed, one ethnic party admitted to me that it did not want a 'federal army', but agreed to support it so as to have a harmonious position with the ethnic armed groups. However, while cooperation among ethnic groups may be important, they are already in broad agreement about the need for federalism ${ }^{59}$. It is the alliance between dominant and minority ethnic groups that is critical to overturning the ethnic hegemony that has beset consolidation of the state of Myanmar.

Signs were encouraging when following the 1990 election, the NLD and ethnic parties (namely the United Nationalities League for Democracy) signed a memorandum of understanding to mutually commit to pursuing a 'genuine federal union' (Lian 2012, p. 22). They were to undertake tripartite discussions with the military, but the NLD was reluctant to commit to fixed positions $s^{60}$, which bred mistrust and a fear that there would be continued 'burmanization' (Smith 1991, pp. 438-439). Nevertheless, there was an important and observable recognition by opposition democratic forces "that a mere democracy without federal arrangement[s] in a divided society like Burma will not work" (Lian 2012, p. 23), and the ethnic parties and their constituents began to align behind a democratic future. Although elections were again held in 2010, the NLD boycotted and the military's political party dominated, with some ethnic parties also winning seats (Smith 2010; Skidmore \& Cheesman 2012). The NLD participated in 2012 by-elections, with great success.

In the lead up to and following the 2015 election, the NLD and minority ethnic groups both confirmed commitment to the priorities of both federalization and democratization. The NLD has stated that "the constitution needs to be one that will give birth to a genuine, federal democratic union" NLD leader Aung San Suu Kyi, (cited in Win \& Khine 2016). The UNFC proposed an agreement for a democratic federation, "based on democratic rights and ethnicbased states, with full national equality and self-determination" (cited in Nyein 2015). The

\footnotetext{
58 Smith (1991, p. 10) noted that in 1988, out of 25 armed groups, about half were allied with communist forces, and half with (ethnic) democratic forces - the National Democratic front.

${ }^{59}$ Even the United Wa State Army has unified behind a call for federalism (including a state of equal status to the other ethnic states), although their democratic credential remain in question - "In order to avoid complications, we will not allow any party, except for the UWSP, to set up office and be active in our state" Bao Youxiang, Secretary General of United Wa State Party; Commander-in-Chief, United Wa State Army; and Chairman, Wa State People's Government (cited in Shan Herald 2015).

60 NLD had agreed to the 'Panglong Sprit' and equality of units, freedom of religion and languages, and rights of self-determination and self-administration, but to be addressed through a nationalities consultative convention (like a second Panglong) (Smith 1991, pp. 438-439). This is now occurring.
} 
NLD has also made formal agreements to pursue federalism, such as the Kalay Declaration in 2011 (Walton 2013, p. 17), and has held the first in a series of ' $21^{\text {st }}$ century Panglong' dialogues (August 2016) (see Chapter 6 for further detail). Although, most ethnic parties that I spoke to said they did not have a very good relationship with the NLD and were distrustful, they needed to work together to get the changes that they wanted. This alliance formation, following the Nepal experience, is the formative mechanism linking the variables to a genuinely federal outcome, in accordance with a particular sequence (see Chapter 5.4 for detail).

Diagram 11, which shows the overall institutional accommodation trends, as set against important regime, economic, conflict and external elements further shows how the impact of the reactive sequence on the power reproduction has placed Myanmar on a road to federalism. Each new institutional configuration was a direct response to the outcome of the one which it replaced, as Bamar elites sought to consolidate power in the face of widespread resistance, and the impacts of exogenous shocks, like economic crises, natural disasters and the prevailing international environment. Further, if you discount the first 10-15 years of intra-group destabilization (as you might in Nepal also), the trajectories are near identical across cases.

Diagram 11: Myanmar - institutional accommodation 1946-2016

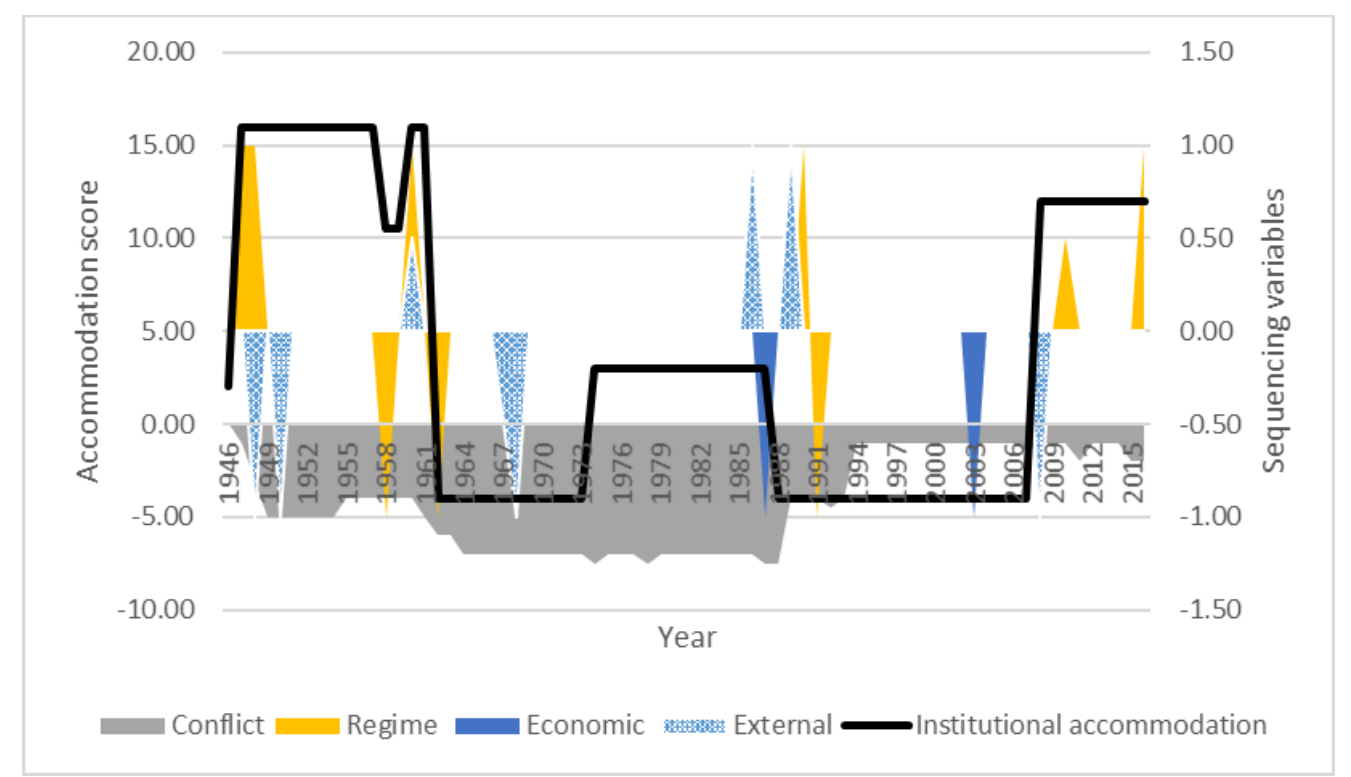

Further, despite the current federalization and democratization processes coinciding, fluctuations in federalism and accommodation have not correlated with changes in democracy, as indicated in Diagram 12, which contrasts the degree of accommodation with the degree of democratization. Although not reaching similar levels, the degree of 
accommodation afforded by authoritarian governments has at least trended upwards (once in place), as compared to the downward trend following independence and the institutionalization of a parliamentary democracy.

Diagram 12: Myanmar - accommodation and democratization 1948-2015

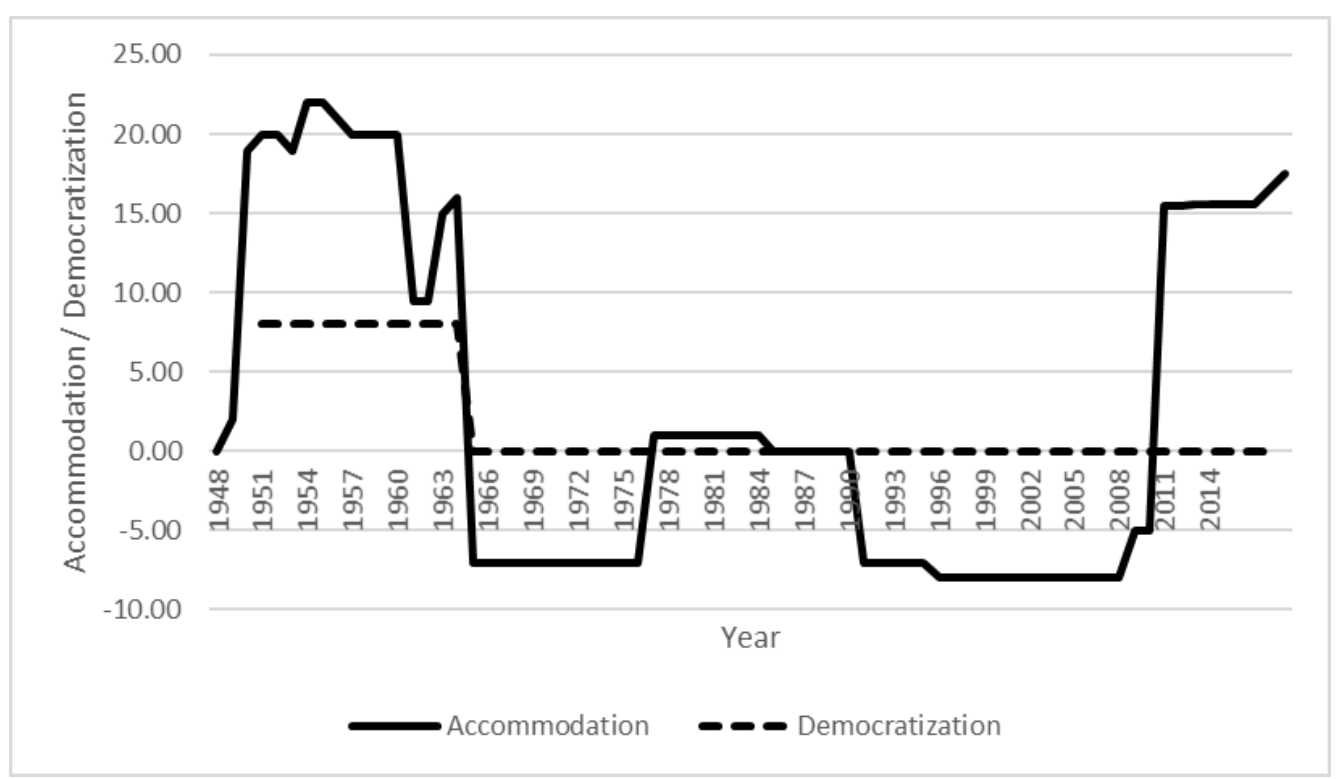

Finally, it is important to distinguish the role of the international community. As discussed earlier, securitization of demands for autonomy led to resistance to federalism, but only when the secession risk was at a particularly high level. Here, the international community has been influential, not through the exertion of pressure on state actors, but through actions leading to a reduction in the secession threat. By 2009, bordering states were no longer tolerant of insurgents' presence in their territory, or instability in the border regions more generally, and this has heavily influenced the ethnic armed groups to come to the negotiating table (Smith 2010; Steinberg 2012).

\subsection{Sri Lanka}

\subsubsection{Initial advantage}

The initial advantage of the Sinhala elite and their apparent desire to assert their culture, religion and language was more pronounced than in the other cases, and so their initial actions were more decisive and effective. The essentially individualistic majoritarian style of democracy with no institutions for minority voice, meant that power reproduction could be relatively unbridled. A parliamentary system was put in place, but the demographics of Sri Lanka were such that it served only to institutionalize Sinhalese dominance (Tamil parliamentarians were only elected in districts where they were numerically concentrated 
and the Sinhalese parties did not need to enter a coalition with them to secure a majority). Upcountry Tamils remained entirely unrepresented between 1952 and 1977 (Malik et al. 2009, p. 325).

Under the British, communal representation had existed until abolished by the Donoughmore Constitution of 1931. The Donoughmore Commission did not believe that it had delivered 'fair representation' nor 'promoted unity', instead having 'the opposite effect' and stoking inter-ethnic tensions (Special Commission on the Ceylon Constitution 2008 [1928], p. 66). For Donoughmore, communal representation "had exercised an influence on society wholly pernicious in that it has created an ever widening breach between communities and has tended to obscure the national interests in the clash of rival races or religions.... It is our aim ...to promote the assimilation of different races" (Special Commission on the Ceylon Constitution 2008 [1928], p. 79). This aim persisted through to the Soulbury Commission and subsequent constitutions.

The initial institutions provided minority protections in only two ways - a clause that would invalidate any law that disadvantaged a particular community or religion (see Article 29(2)\&(3), Ceylon Constitution Order in Council 1946), and a two thirds majority for constitutional change, a requirement which the Sinhalese alone at that time could not muster. Arguably, the electoral delineation clauses also provided some protections by allowing scattered communities to be represented via weightage to area as well as population (Wickramasinghe 2010, p. 45). But legislative freedom was otherwise largely unbounded, and the British confidence that the fears of minority ethnic groups were exaggerated would be shown otherwise. The constitution did not include basic rights protections, such as a Bill of Rights, but the democratic system itself should have meant such protections were not necessary, such as in the ethnically neutral parliamentary systems of Australia and the UK, for example.

\subsubsection{Institutional changes}

One of the first institutional changes by the new Sinhala led government (with support of some Tamils) meant the disenfranchisement of around one million Upcountry Tamils. This consolidated Sinhala dominance to the extent that constitutional change was now possible even in the face of united opposition from all minorities (Choudhry 2010, p. 117; Citizenship Act 1948; Ceylon Parliamentary Elections Amendment Act 1949). Tellingly, these actions "shattered any possibility of stronger interethnic and class alliances" (Wickramasinghe 2010, p. 48). This was followed by the formalization of Sinhala as the only official language and the 
beginning of the reactive sequences, as Tamils protested in response, and Sinhalese rioted and violently repressed the resistance (DeVotta 2004, pp. 109-120). It was a pattern that would continue in an increasingly pronounced manner, even after concessions were made ${ }^{61}$.

1972 saw a new constitution bring a range of institutional changes that symbolically and practically marginalized Tamils and other minority ethnic groups (Constitution of the Republic of Sri Lanka (Ceylon) 1972). Firstly, the name of the country was changed from Ceylon to Sri Lanka, a Sinhalese denomination, while their religion - Buddhism - was given the 'foremost place', and it would be 'the duty of the state to protect and foster' (see Article 6). Most significantly, the state was declared a unitary state (Article 2), a decision that would continue to have ramifications through for example the minimal ability and effect of devolution reforms given High Court review ${ }^{62}$. Provinces, which had been used by the British, were mentioned albeit in an incidental manner and with no real purpose or power (Article 78(2)). Electoral districts were able to be delineated accounting for identity, enabling minority representation to be assured (Article 78(4)), but otherwise the institutions were Sinhala centric, including language (Article 7). Further, the minority protection article of 1946 (Article 29(2)) was removed altogether. By 1976, the situation had deteriorated to the extent that almost all Tamil political parties sought an independent state, and were willing to use violence to achieve it (Welhengama \& Pillay 2013, p. 274).

The next substantial institutional change was incidental in relation to the place of minorities, but practically significant. Presented as a response to unstable democratic governance, a new constitution creating an executive presidency was enacted (The Constitution of the Democratic Socialist Republic of Sri Lanka 1978). This diminished the potential for central power sharing and increased the potential for abuses of power. As with the 1972 constitution, the legacy on the 1987 amendments was significant, as it meant different regime types at the center and the units and a practice of presidential control over provinces. A proportional representation electoral system was introduced, but with a cut-off of $12 \%$ serving to prevent the rise of minor parties, and largely clustered ethnic groups who would be likely to perform electorally well through a first past the post system, it did not provide any real value to minorities. As Tamil unrest escalated, further institutional changes aimed at

\footnotetext{
${ }^{61}$ For example, although Tamil became an official language, implementation of the official languages policies has been substandard. A 2011 official languages audit found many key issues remained unaddressed, such as the requirements for police and public services to be available in the Tamil language (Nesiah 2012).

62 Following the enactment of the $13^{\text {th }}$ Amendment to the 1978 Constitution, the Supreme Court with a split decision decided that the devolution arrangements comprised within that amendment were consistent with a unitary state, but only if one feature was deleted (Edrisinha 2005)
} 
suppression entrenched Sinhala dominance. An anti-terrorism law (Prevention of Terrorism (Temporary Provisions) Act 1979) resulted in the arbitrary arrest of Tamil dissidents, and an anti-secessionist clause was added in 1983 with the aim and effect of eliminating Tamil participation in parliament (Welhengama \& Pillay 2013, p. 275). It is generally accepted that up to that time, the Tamil's sought to use democratic forums to protect their rights and pursue their interests, only reluctantly adopting violence (McConnell 2008).

Further institutionalization of Sinhalese dominance, or power reproduction, had led to further reaction, which led to further repression followed by further institutionalization and the cycle continued (DeVotta 2004). The creation of development councils in 1980 was an attempt to break this cycle, but it did not go far enough. It created what some described as quasi-federalism (although it lacked constitutional protections) and was similar to Myanmar initial federal system, establishing what is effectively a chief minister, an executive and a legislature in the regions, but with these positions drawn from parliament at the center, rather than being dedicated to, and accountable for, district business (Horowitz 2000 [1985], pp. 616-617). That the expulsion of Tamils from the central parliament followed is demonstrative of its inadequacy.

The crescendo came in 1983 in circumstances that were abominable from any perspective. A deadly ambush by Tamil insurgents was followed by anti-Tamil riots that left thousands dead and led to the onset of a full scale civil war. It was not until India intervened and brokered an agreement (the Indo-Lanka Accord) that there was any important concession by the Sinhala dominated government (Bush 2003, pp. 118-155). This saw the formal institutionalization of quasi-federalism, via amendment to the constitution (Thirteenth Amendment to the Constitution of the Republic of Sri Lanka 1987). It was modeled on India's constitution and is similar to that in place in Myanmar but with less emphasis on special representation and no upper house. While it did include a strong set of powers for the units, these were rendered virtually meaningless by the wide-reaching potential for the center to override and intervene and the lack of implementation. It was not satisfactory to the dominant Tamil armed group ${ }^{63}$, immediately undermined and never properly implemented in the areas where it was most needed (Edrisinha 2005; Choudhry 2010).

The perceived and evident fear of many Sinhalese was secession. The Sinhala Commission tasked with investigating federalism proclaimed it "to be the biggest threat faced by Sri Lanka

\footnotetext{
${ }^{63}$ All the major insurgent groups, except for the LTTE, accepted the agreement and disarmed (Uyangoda 2010a, p. 294).
} 
in its entire history of more than 2500 years" (Sinhala Commission 2008, p. 594). The secession risk, although necessary for holding together federalism, was so high as to lead to mitigation strategies that would render its form virtually unworkable, and its purpose nullified. The system of devolution had accommodating institutions such as the constitutional division of powers that included important revenue sources, law and order and land (see Schedule 8), and the directly elected provincial councils (see Article 154P). However, the governor of the provinces would be a direct appointment of, and have direct responsibility to, the president (see Article 154B(2)). The constitution states that the governor 'should' act on the advice of a chief minister, but this did not become convention, and in potentially hostile areas (i.e. the North and East), the governor was usually an exmilitary person acting in the interests of the center.

Subsequently, the units' powers were diluted even further - devolution of law and order functions never occurred, contrary to the constitution; other powers, such as land and revenue were not fully devolved; the public service remained with the center and the governors were further empowered to consent to all Bills with financial implications and exercise control over provincial public service and state land alienation (Gurupan 2013; Centre for Policy Alternatives 2010; Saravanamuttu 2013; Welikala 2004). There have already been several dissolutions of provincial councils and there is distinct lack of constitutionalism. Amendments are regular and it is even possible to make legislation that would otherwise be unconstitutional, by two thirds majority vote (see Article 84). Many Tamil and civil society leaders that I met with believed that the government deliberately made provincial councils unworkable so that they could be later abolished.

While the 1988 merging of the Northern and Eastern Provinces was meant to be to the benefit of the Tamils, it lasted little more than two years. The then chief minister found it to be unworkable and, in the face of threats from the LTTE and the Sri Lankan military, had the council dissolved via the effect of a declaration of independence and fled the country. In any case, the Supreme Court ruled in 2006 that the merging was unconstitutional and the provinces remain separate today. Elected representatives were only returned to the Eastern Provincial Council in 2008, and the Northern Provincial Council in 2014, prior to which they were under the executive rule of the governor. As summed up by former president Kumaratunga, the then "President Jayawardene did not give a cent to the originally formed North and East Provinces, thereby making them redundant. After that, Prabhakaran [LTTE leader] did the remaining things to destroy them" (Kumaratunga 2013, p. 40). 
Diagram 13 illustrates these key institutional changes, disaggregated into federal, consociational and ethnicity in units' elements over time. It is clear that there was a longterm and steep decline in the degree of accommodation, until the intervention by India. As the consociational elements decreased, subsumed in a nation-building agenda, the demands for federalism increased until ultimately that aspect also improved, however short-lived. When compared with the other cases, we can see how consociational elements, or their absence, can be important contributors to the institutionalization of a federal system, especially as a transition strategy, and that without an inclusive approach to federalization, sustainability is bought into question. These relationships and their interaction with other variables, are discussed below.

Diagram 13: Sri Lanka - elements of accommodation 1948-2015

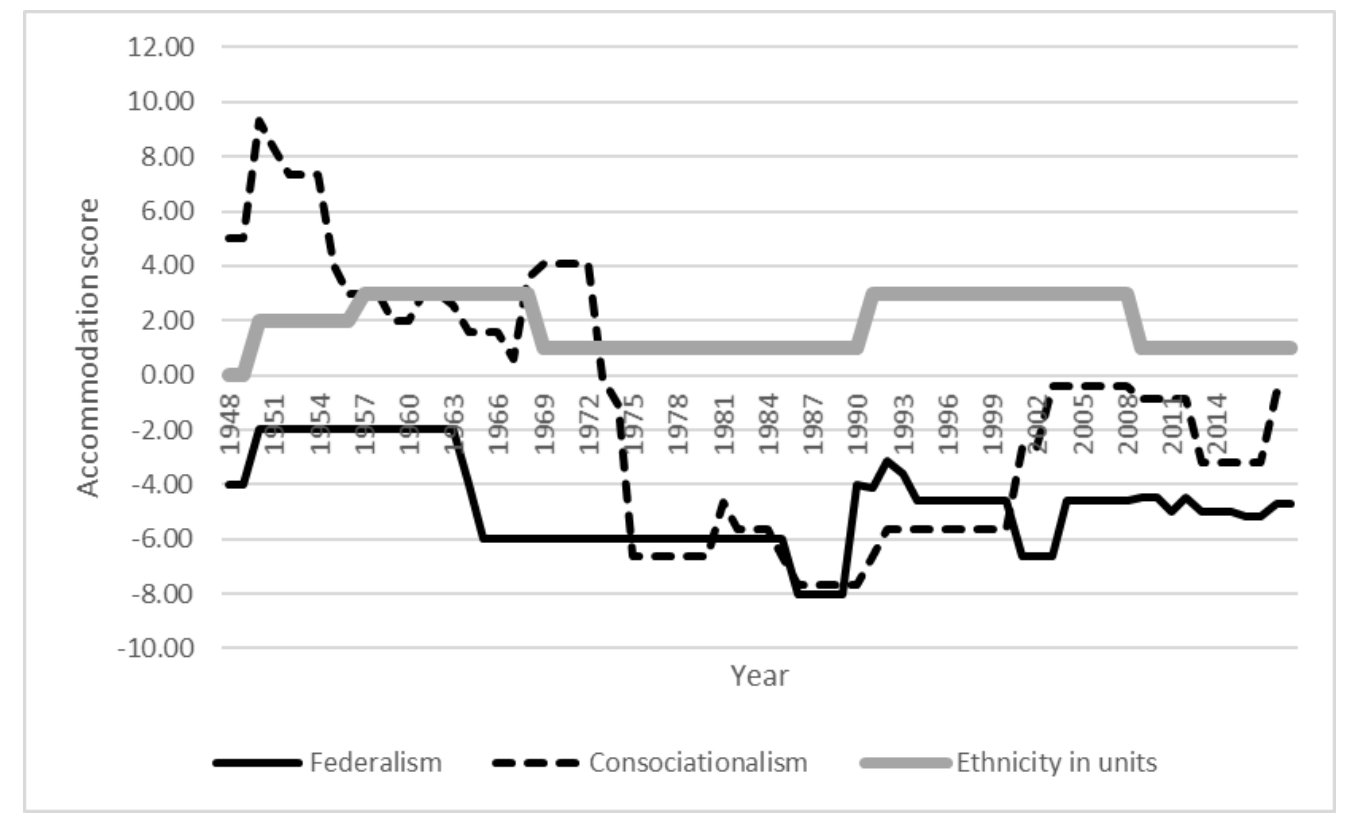

\subsubsection{Democracy and reactive sequencing}

Identity-based power reproduction in the modern Sri Lankan state has been most pronounced, as might be predicted from the lopsided power balance emanating from the critical juncture. However, this path interacted with the reactive elements to lead to a series of concessions and ultimately the beginnings of an alliance between ethnic minorities and factions of the dominant group. Concessions made before the complete breakdown of ethnic relations, namely the 1957 B-C Pact (between SWRD Bandaranaike and SJV Chelvanayakam) and 1965 D-C Pact (between Dudley Senanayake and Chelvanayakam) may have arrested the sequence, but were never implemented. The 1987 amendments were 
more comprehensive and largely implemented. However, they too were undermined and ultimately could not achieve the key objective, which was in any case to end conflict rather than provide genuine autonomy for the Tamils. The management of diversity was based on integration, rather than accommodation. Throughout, the balance of power remained with the Sinhalese and it was not until recently that minority votes were required (more on this later).

The differences to Myanmar can be explained in part by the lower levels of infrastructural capacity outside of the center, and the absence of conflict at the state formation stage. There was little other than the historical claim to draw out or underpin claims for autonomy and a negotiating position. Historical claims (for indigenous rights for example) in these contexts are a reason that autonomy and other claims are made, but not a basis of resolution or, it would seem, a particularly useful bargaining chip. More beneficial arrangements came after the Tamils had amassed both an armed force and a parallel administrative structure, providing the necessary infrastructural capacity for federalism and creating or promoting a secession risk to be managed. Later, once the secessionist goal was renounced in favor of federalism, the fear remained, no doubt assisted by things like the statements of former Tamil leader Chelvanayakam, who saw it as a 'stepping stone to secession' (Bandarage 2012, p. 108), and the conspiracy theories of sections of the Sinhala nationalist elite (which I was regularly regaled with during my stay).

Democracy in Sri Lanka, while persisting, was not a conducive institution for initiating federalization because of the minority status of those groups which were seeking to benefit from its introduction. Each time that Sri Lanka came close to federalizing, with the exception of 1987 when an intervention and extreme conflict situation forced their hand, democratic pressures led to the literal tearing up, even burning of proposals for federal accommodation (Edrisinha 2005). This can be clearly seen in Diagram 14, which maps the change in accommodation with that in democratization and shows that despite a consistently high level of democracy, the extent accommodation has trended sharply down. 
Diagram 14: Sri Lanka - accommodation and democratization 1948-2015

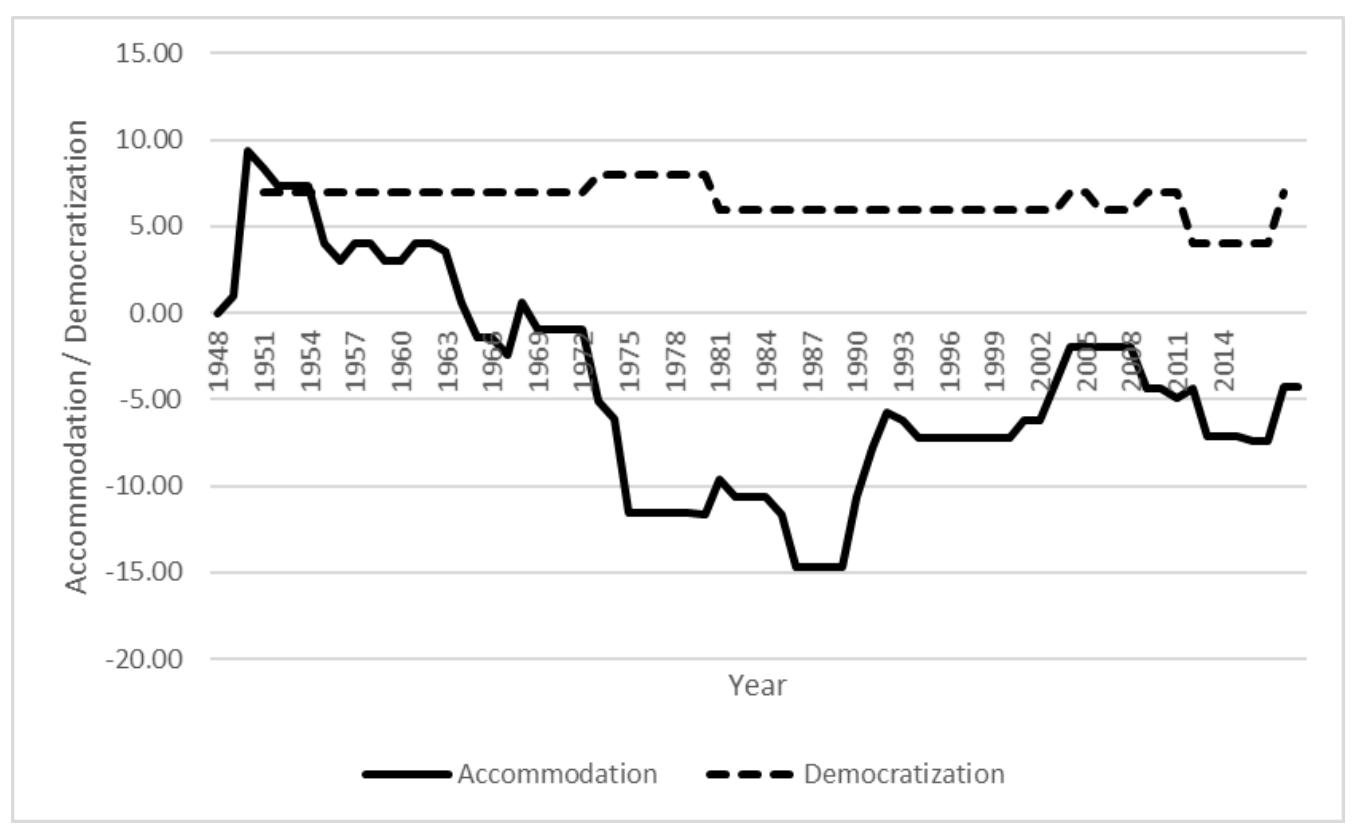

Otherwise, similarities with the coexisting reactive and reproductive sequence can be discerned as, an initial accommodation at the moment of state formation, followed by a dominant identity-based nation-building agenda, leading to reactions and counter centralization. Instability continued (as the causes of resistance were not addressed) and eventually a concessionary devolution of power was implemented in order to arrest conflict. Such unilateral concessions are a temporary dilution of resistance only, and so the stateweakening effects of the marginalized peoples' reactions eventually combine with other state weakening events, and or external changes that mean regime change becomes possible and desirable for not just the ethnic minorities, but also the disaffected faction of the dominant ethnic identity group. Diagram 15 shows the overall institutional accommodation trends, as set against important regime, economic, conflict and external elements. It is notable that no substantial accommodation moves were made until the height of conflict, and with the convergence of external events, including the influence of India. 
Diagram 15: Sri Lanka - institutional accommodation 1946-2016

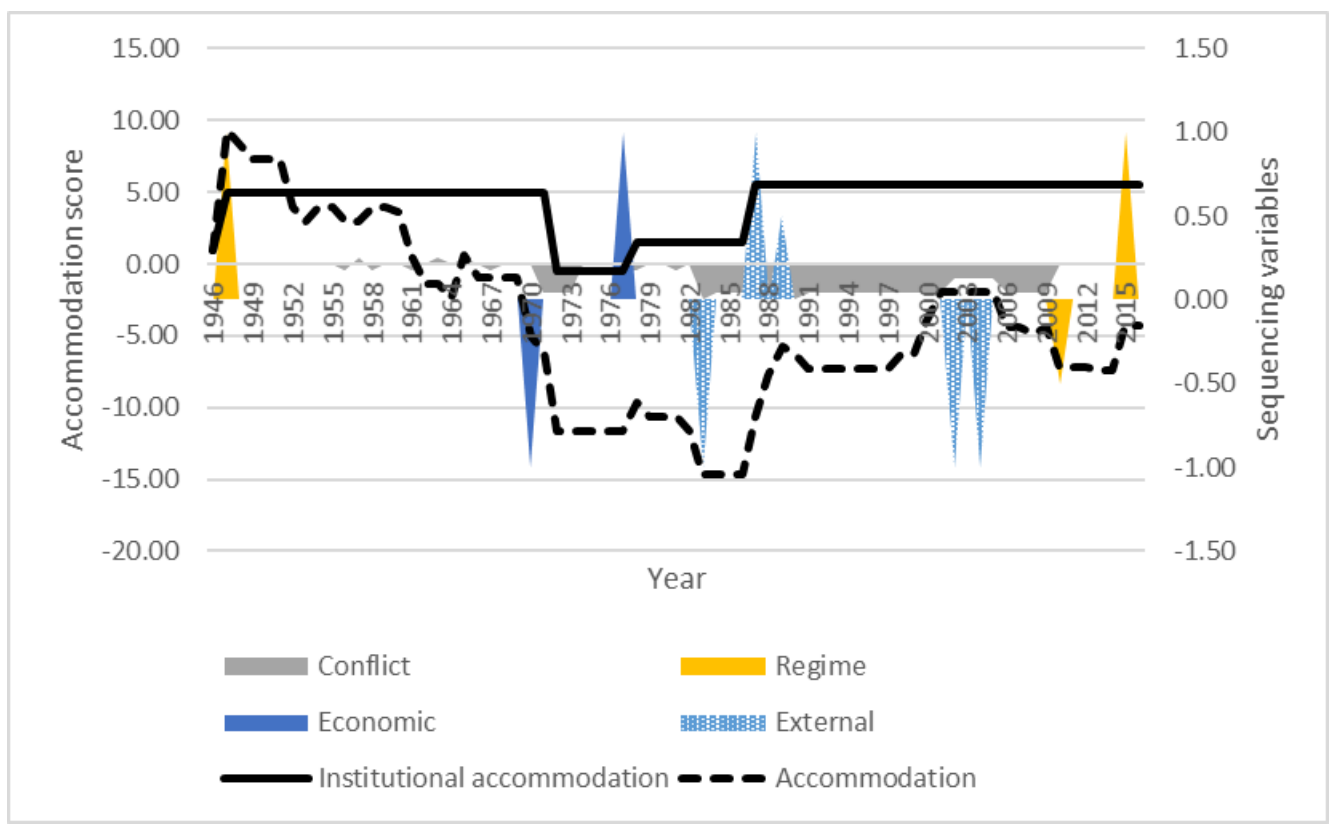

More specifically, while observing the prior two cases of Nepal and Myanmar, the 2004 tsunami might be thought to be the event that bought about a new critical juncture, especially since it came at a time where there were externally mediated settlement negotiations underway, and a mutual commitment to explore federalism. Prominent Sri Lankan academic Jayadeva Uyangoda (2005) argued at the time that the recovery process had highlighted questions about power sharing and regional autonomy by exposing the 'limits of State capacity', and that recovery should be linked to a deep federalization. But the Tsunami had more impact on the insurgents than on the state system and did not fundamentally undermine the legitimacy or functional bases of the state. The power balance was not substantively altered, other than through its consolidation at the center. The LTTE meanwhile overplayed its hand, unilaterally withdrawing from settlement negotiations and making a proposal for an Interim Self-Governing Authority, which has been described as confederal, or essentially a two-state solution (Uyangoda 2010a, p. 296).

A year later, the 2002 ceasefire began to breakdown, and by 2009 the Sri Lankan government was taking decisive action to end the insurgency by military means. The military victory led to unprecedented popularity but increasingly dictatorial governance by the then president. Ultimately this undermined the legitimacy of the office, and minorities rallied against the excesses of the government during latter years of the civil war and afterwards, and an unexpected election result ensued in early 2015 (Stone 2014; DeVotta 2011; Farook 2015). From this emerged an alliance seeking mutually supportive change. For the Sinhalese democratic reformists, led by the common candidate Maithripala Sirisena, the priority is the 
abolishment of the executive presidency, while for the Tamil activists and politicians, a 'solution to the national issue' is paramount.

There is now an alliance and the conditions for compromise, being a present but moderate secession risk and an infrastructural capacity. The major parties now need Tamil and Muslim support to form government, even if most are not part of the coalition, and Tamils and Muslims are included in the constitution drafting process. To the extent to which this alliance of shared and committed objectives lasts, the outcome of constitutional reform will be federalism, even if it is not named as such. The drop in the secession risk has made alliance and federalization more likely and encouraged a moderation of attitudes at the local and elite level, notwithstanding continuing fearmongering by sections of the elite. Diagram 16 shows how it was not until a moderate secession risk, and a substantive infrastructural capacity co-existed, that the parties together turned to federalism.

Diagram 16: Sri Lanka - accommodation, secession risk and infrastructural capacity 1948-2015

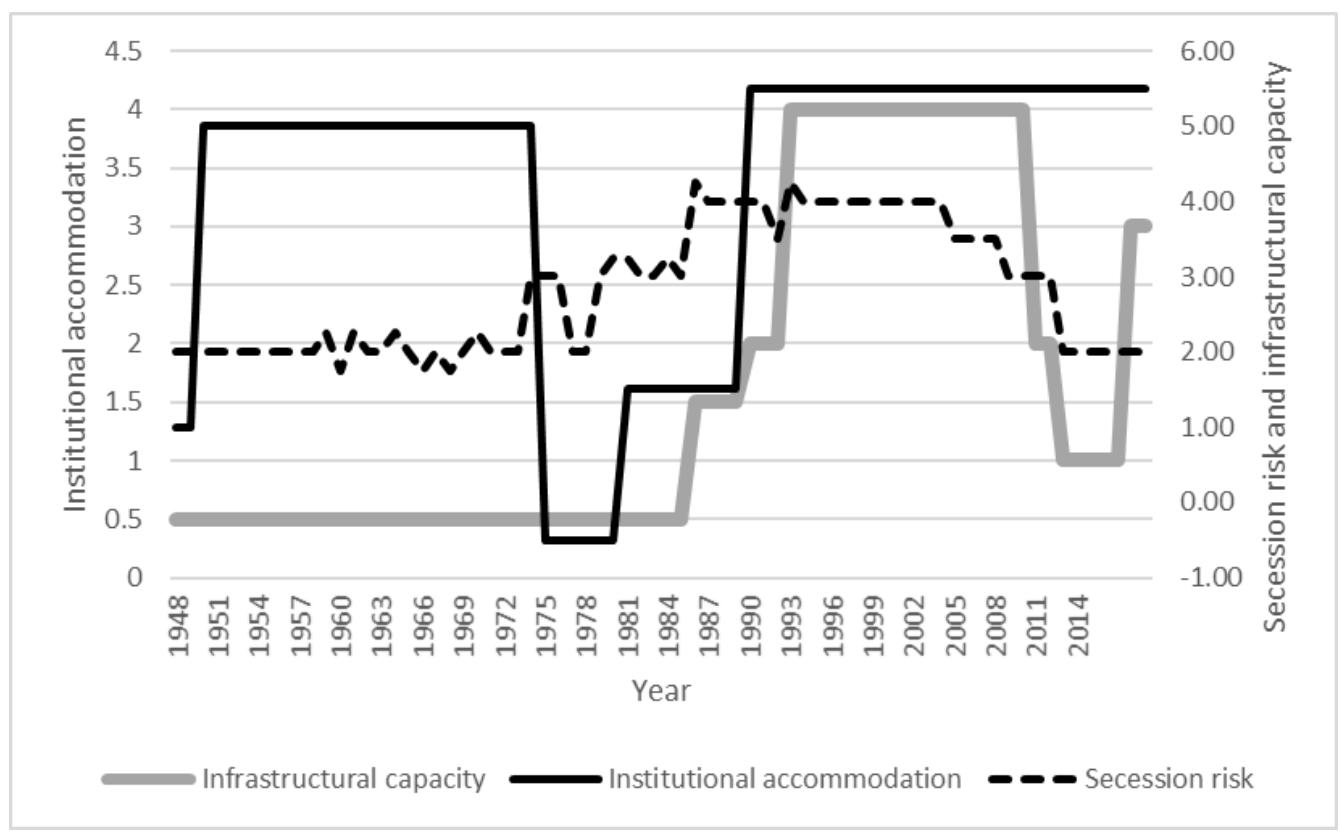

There were major intervening opportunities to arrest this sequence, particularly between 1987 and 2009 while the Tamils held an infrastructural capacity. Reasons given for breakdown are many and varied (see for example Edrisinha 2005; Uyangoda 2010a) but it was always a negotiation between the state and the Tamils (whether or not the LTTE were representative) and there was never an alliance made with or outside of that frame. With the state itself in little danger of collapse, as compared to 1987, no viable regime change alliances were available for the minorities, and federalization was seen as a zero-sum game by the participants. Infrastructural capacity and a moderate secession threat may be 
necessary conditions for the formation of federalism, but it is unlikely to occur without the formation of a regime change / federalism alliance.

\subsection{Summary}

The modern-states of Nepal, Myanmar and Sri Lanka have had a tumultuous existence. Their diversity has not been matched by accommodating state structures and associated institutions. A single dominant ethnic group, at the modern state formation stage, used their initial advantage to consolidate and reproduce power through the creation of exclusive and impositional institutions. Their initial advantage and the range of possible options was defined by the pre-existing regional/ethnic-based infrastructural capacity and the secession (independence) risk, which both continued to play a role in how the state responded to minority interests. These cases do not support rival theories, as although each country was transitioning to a democracy they took different routes while the role of international actors was important, especially in how it influenced the secession risk, but not decisive.

In each case, the creation and consolidation of initial advantage unleashed reactive sequences. The differences in the relative power between the minority ethnic groups and the dominant ethnic group, correlated with the time it took for major violent reactions to eventuate. A more evenly balanced Myanmar erupted almost immediately, while a progressively increasing intensity of reaction and counter reaction eventually led to full scale civil war in Sri Lanka. In Nepal, where the minorities were most marginalized, an uprising took decades to occur as 'the oppressed classes' did not seek to claim their rights through violent means until the mid-1990s (galvanized in fact by leaders from the dominant group). It was not until infrastructural capacity was built in the periphery that these groups could effectively demand their rights. The making of historical claims carried little weight without such practical support. Further, it was not until the impacts of their efforts, including armed struggle, converged with other events to weaken the state and encourage a regime-change alliance with dominant ethnic group members, that a genuine federalism would become a reality. If the risk, however, that one of those ethnic minority groups will secede is too high, the alliance will not form and federalism will be resisted. A high secession risk is one that has a degree of international support, is backed by armed forces and concerns an area that is substantively populated by one particular ethnic group. 


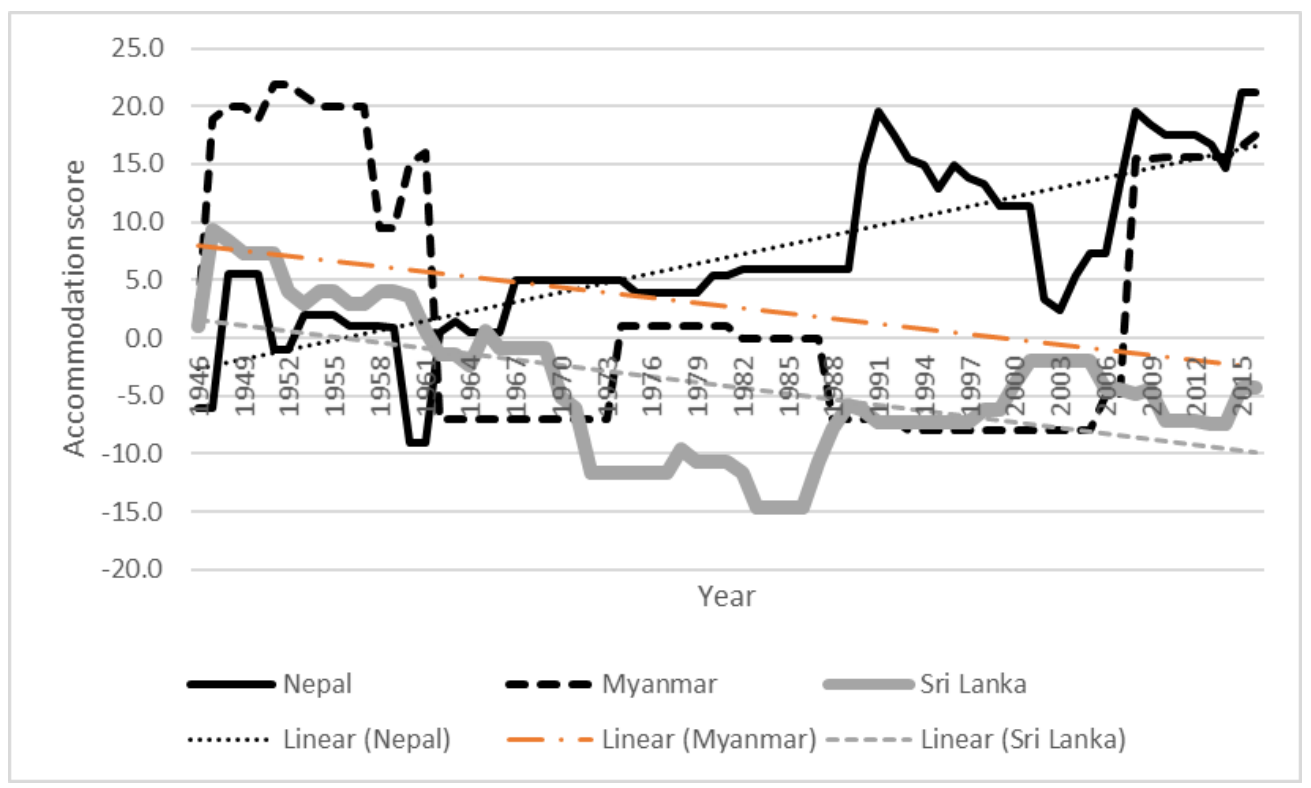

Diagram 17 compares the degree of formal and informal accommodation in each case, and includes a trend line. While only Nepal is on an upward trend, partially explaining its shift to federalism, the others linger in quasi arrangements. However, Myanmar and Sri Lanka also display upward trends when discounting the first 10-15 years when the battle for power was particularly intense and, at least in Myanmar's case, there was considerable fluctuation.

Further, the cases would seem to confirm the hypothesized sequence, which can be considered in terms of responses to reactions - whether repression, concession or an alliance. Quasi-federalism arises from a concessionary move by a dominant elite, to head off dissent and conflict, whereas more compromise would lead to a genuine federalism where the necessary alliances formed and the locus of power shifts. It is logical and apparent. The involvement of a third party may lead to a concession being more accommodating than it otherwise might have been. An idealized representation is illustrated in Diagram 18, that is, the conceptual model illustrated in Chapter 2, Diagram 1, with a basic idealized accommodation trend line overlaid. This pattern can be seen in each case, with differing time periods across each phase. 
Diagram 18: Sequences and path dependency to federalism in Asia

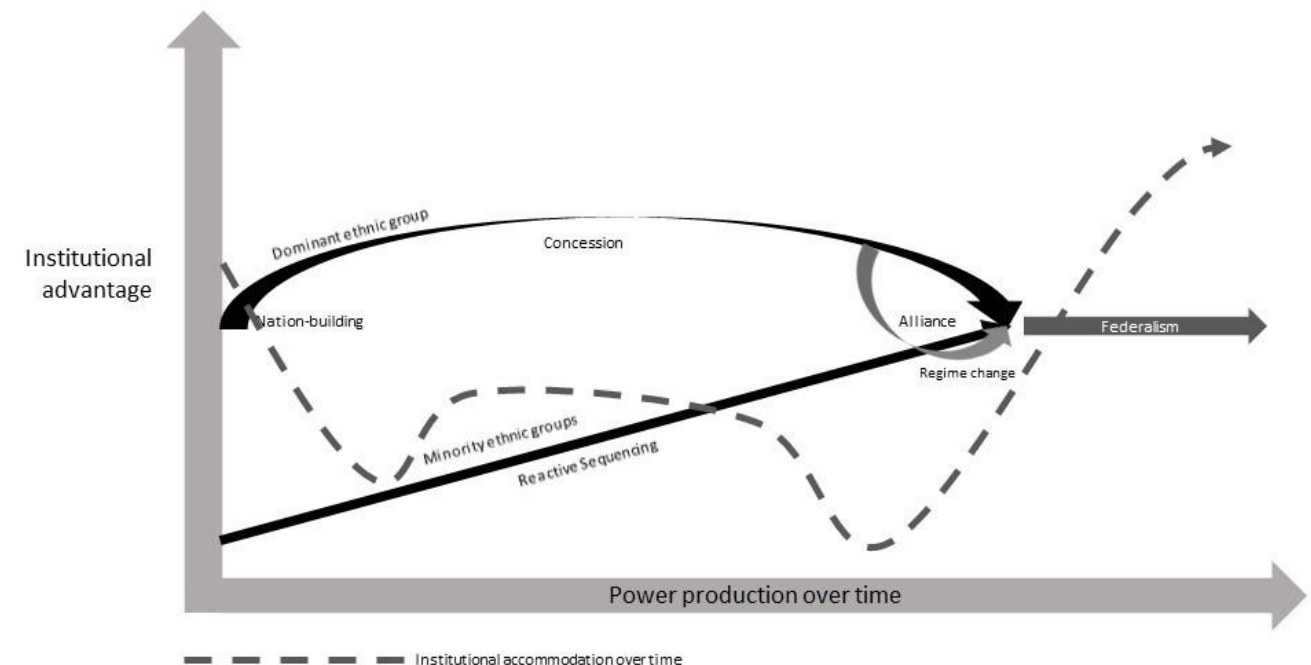

In summary, infrastructural capacity combined with secession risk and features of ethnic identity to define the power balance and the range of options that portend the road to federalism. Path dependencies were underpinned by power reproduction for the elite of the dominant ethnic group, which unleashed concurrent reactive sequences that strengthened the infrastructural capacity of the minority ethnic groups, affected the secession risk and weakened the system making it vulnerable to collapse at convergence with other significant events or crises. Such confluence provided the opportunity and incentive for alliances to build, from which new structures of the state and institutional arrangements can be built, through a constitutional settlement. 


\section{The constitutional settlement}

The decisions taken in Nepal, Myanmar and Sri Lanka to pursue major constitutional reform towards federalism are momentous but not without controversy. This chapter outlines the contemporary phase of their road to federalism - the constitutional settlement of identitybased grievances through simultaneous federalization and democratization - and the debates and design features emerging from their balancing of ethnic diversity and the desire to hold together.

I have shown that since the formation of the modern state Nepali, Myanmar and Sri Lankan efforts at identity-based national building have not been successful and have led to conflict. On their road to federalism, each took a different journey. Sri Lanka tried democracy without federalism, while Myanmar tried a federal system without democracy. Nepal, despite the apparent late awakening of identity politics, tried both combinations. Each approach failed to prevent or arrest conflict based on self-determination, or provide political equality for minority ethnic groups.

Nepal, Myanmar and Sri Lanka are now combining democracy with an Asian federal system, in line with the aspirations of the people for democracy and accommodation. There is alignment of anti-regime elements belonging to the dominant ethnic group with minority ethnic groups to make a constitutional settlement of the minorities' claims and the associated ethnic conflicts, while ushering in a new inclusive and democratic regime. The objectives of the two are mutually supportive in terms of reaching agreement on the need for a federal system and democratic reforms, but not necessarily the key issues of federalization itself, such as how to divide powers.

This chapter commences with a summary of the current constitutional processes in each country, the key actors and their interests, and the decision to accommodate via federalism. I then more specifically isolate the conditions, variables and causal mechanisms that affect particular institutional design outcomes, showing especially the continued salience of the secession risk and its twin perceived fear that second order minorities will be marginalized. In practice, if a single ethnic group forms the basis of a unit's boundaries, then the autonomy of those units is minimized to mitigate secession risk and the fears of second order minority oppression. However, mixed units mean a greater emphasis on moderation. This can be effected via a range of strategies, which I take up in the Chapter 7. 
It is these two elements of federalism - the basis of the demarcation of units and the division of powers - that dominate debate on federalism. Power-sharing elements, such as bicameralism, are of relatively little interest and subsumed to a contest over the extent and basis of self-rule. Although minority ethnic groups will tend to focus on their supposed historical entitlement, practical considerations and methods of agreement making are more formative.

\subsection{Nepal - federalism and emancipation}

The new constitution is meant not only to establish Nepal as an inclusive, secular and federal state, but also to provide clear avenues for conflict transformation, restorative justice, reconciliation, development and efficient leadership (first President of Nepal, Ram Baran Yadav 2010, p. 2).

Although the push for federalism came relatively late to Nepal, all the major political parties supported federalism in their election campaigns for the first Constituent Assembly and through the near unanimous declaration by the Assembly in its first sitting. Despite these consensual beginnings, the Constituent Assembly did not agree on the type of federalism until some seven years after its election, with the promulgation of the new constitution in September 2015. Federalism had been promoted as a remedy to the exclusion, subordination and poor development experienced by many minority ethnic groups and its institutionalization was of particular importance to them: "federalization will ...steadily end the present poverty, lack of education, unemployment, external dependence, and other factors hurting the self-respect and sense of sovereignty of the Nepali people," claimed Bhim Rawal, the then UML Vice-President (cited in Shrestha 2014b).

However, there remained a general scepticism about the real intentions of the major democratic parties, who were branded 'reluctant federalists' and 'status quoists' by political rivals. Opponents of federalism remained vocal, raising fears about secession and 'the disintegration' of the country. The growth of ethnic political parties had bought fears about federalism front and centre, and they were exploited, especially in the Terai and among Madheshi peoples. With protests blockading cities and trade routes and armed groups masquerading as political groups, a climate of fear and lawlessness was permeating the Terai and spreading to the east where Limbu and Khumbu parties demanded autonomy, and threatened a "bloody agitation" if their demands were not met (Kantipur Report 2010). It is 
this backdrop that informed the Assembly's approach to federal design and the deadlock on the demarcation of federal units.

\subsubsection{Key actors and processes}

The Maoist party is the main protagonist of this story. It had altered the power balance through violent conflict and seized the opportunity to consolidate once other factors converged. In doing so, the king was wholly removed from any position of influence. Although the Maoists' senior leaders are almost exclusively from the dominant ethnic group, it seeks to overturn the dominance of the existing elite and empower the excluded groups, which formed the basis of its insurgency, as discussed in Chapter 5. Over time, the Maoists transformed themselves into a political party and gained the most seats (229 or 38\%) in the 2008 Constituent Assembly election (Appendix 2, Table A6), giving it the box seat in the drafting of the new constitution.

The two other major political parties, longstanding participants in the push for democracy in Nepal, are dominated by the Pahadi high caste elite but making substantial moves towards greater inclusion. The Nepali Congress, who won 115 seats in the 2008 Assembly, seeks "a plural democracy with liberal values", economic freedoms and a strong state in the social sector (Nepali Congress 2014). The Communist Party of Nepal (United Marxist-Leninist) ('UML'), who won 108 seats, are social democrats and have in the past been strong supporters of federalism. These two parties, along with five other minor parties, negotiated with the Maoists to bring an end to the civil war.

The Constituent Assembly election process also saw the emergence of a fourth political force, the Madheshi parties, who together won almost 90 seats. The Madheshi peoples have been socially, politically and economically excluded and many were formerly aligned to the Maoists. There are policy differences between Madheshi parties, but on federalism, they remained closely aligned, demanding one or two autonomous units along the Terai. A number of minor and ethnic political parties were also represented in the Constituent Assembly. The former king and the military had no role and very little influence over the proceedings.

The first Constituent Assembly (for reasons that are explored below) could not conclude the drafting process and a second election was required. By this time, the people had given the Maoists their chance and, as admitted to me by a number of senior leaders, they 'squandered the whole thing'. The second election, on 19 November 2013, resulted in a new balance of power, with Nepali Congress (196 seats) and UML (175 seats) becoming the 
largest parties and able to form a two-thirds majority (with some minor parties). Other changes included a major decline in the representation of the Maoists' party (from 229 in 2008 to 80 ), and a surge in the vote for the royalist parties (34 seats combined, up from 12), campaigning on a return to a Hindu state (Appendix 2, Table A6).

Unlike the previous constitutions, the 2015 constitution was developed through a participatory process. However, it was dominated by the political parties. The Assembly was required to pass every aspect of the new constitution through consensus, only resorting to a two thirds majority vote where best efforts for consensus had failed (Centre for Constitutional Dialogue 2009). It comprised more than 600 members, many elected on a basis of proportional representation with others nominated to address identity-based representative gaps. It included unprecedented and largely proportional levels of Janajati, Dalit, Madheshi and other minority ethnic groups, and 25 political parties, making it the most inclusive institution in Nepal's history (Appendix 2, Table A7; Lawoti 2014, pp. 134-136; International IDEA 2015, pp. 11-12). However, participation of minority ethnic groups in the proceedings of the Assembly itself were low (Tamang 2011, p. 12), and it was through other forums that most key decisions were made.

The Assembly established eleven thematic committees and three procedural committees, comprising 43 members each. The thematic committees were tasked with preparing preliminary drafts of particular aspects of the constitution (e.g. state restructuring and distribution of power), while the procedural committees were responsible for engaging the general public (Centre for Constitutional Dialogue 2009). To inform their views, Assembly members consulted widely, distributing questionnaires, holding around 2000 meetings and receiving over half a million returned questionnaires from individuals and organizations in their local areas (Khanal \& Kushiyait 2010, p. 5). The thematic committees were able to deliberate and decide by consensus a majority of issues. While partisan interests were present, ethnic interests cut across parties and compromise approaches were able to be found on almost all issues of constitutional design. The key exceptions being the design of federalism, the electoral system and a presidential or parliamentary system.

The Committee on Restructuring of the State and the Distribution of State Power (CRSDSP) was by far the most contentious. This committee was tasked with developing the new federal system, including defining the number, boundaries and powers of the units ('provinces'). Although the CRSDSP found consensus on critical aspects like the division of powers and fiscal arrangements, there was an unbendable divergence about the basis of the 
demarcation of the units and the rights of the historically oppressed minority groups. It was a divergence that seemed to mirror a polarization in society, based on a public debate about the nature of federalism and an apparent choice between ethnic federalism, where units would be based on identity, and territorial federalism, based on viability ${ }^{64}$.

The CRSDSP released a majority report proposing a separate unit (province) for each major ethnic group, with political prerogatives for the named ethnic group and other structures, including non-territorial federalism, to accommodate smaller or scattered ethnic groups. However, none of the provinces could deliver a majority of the targeted ethnic group in their respective province (Centre for Constitutional Dialogue 2010d; Committee on the Restructuring of the State and Distribution of State Power 2010), and the recommendations remained highly controversial. The long-promised State Restructuring Commission comprising experts was then formed amongst much controversy to give another opinion, but it too failed to reach a consensus.

In time, deliberation gave way to negotiation as the debate moved behind closed doors. As the extended tenure of the Constituent Assembly drew to a close, the leaders of the major parties agreed on an eleven-province model with strong emphasis on ethnicity in demarcation, though without any preferential rights. But within days, both the Maoists and the Madheshi alliance, unable to convince their own parties of the merits of the deal, reneged (Republica 2012), and a second election became the only option. Deliberation across parties had resolved most issues, but not the most contentious ones. Most essential to their resolution and the final deal between parties was the outcome of deliberations within party.

\subsubsection{Federal compromises}

Following the second Constituent Assembly election, the dynamics of the debate began to change. Whether or not the results were a new mandate regarding federalism are unclear, but it is clear the UML and Nepali Congress took it this way, holding firm to a position that would appear to deny those who sought ethnic federalism. They cited viability as the key concern all the while stoking fears of secession and the oppression of second order minorities. For example, the UML pushed a new position that Nepal "could not sustain

\footnotetext{
${ }^{64}$ Identity was taken to comprise: "ethnicity; language; culture; geographical and regional continuity; and history", while viability meant: "economic interrelationships and capability; status and potential for infrastructure development; availability of natural resources; and administrative feasibility" (Item 5, Committee on the Restructuring of the State and Distribution of State Power 2010).
} 
administrative management of more than six provinces", while warning of a potential 'ethnic uprising' if an ethnic federal system was implemented (Iswor Pokhrel, UML General Secretary, cited in Post Report 2014c). One political leader told me he was apprehensive about the south as it was 'too close to India'. Further, the United Nations' Charter's right to self-determination (Article 1 ) is regularly discussed, but often used as a reason to deny autonomy because the right to self-determination is equated with a right to secession.

The Maoists began to compromise and a series of hybrid and more territorially focused options began to emerge. Instead of seeking to privilege one part of society over the other (to reverse the prior relation of domination) the Maoists began to seek balance, withdrawing their claim for political prerogatives for ethnic groups, while the ethnic elite, perhaps sensing what was on the line, began to claim they 'never asked for ethnic federalism', only recognition of identity and historical continuity (Kumal 2014). The Madheshi parties suggested they 'could live with' two states along the southern plains. On the face of it, the parties had come together, but as the Maoist parties and others representing the excluded groups moderated, just as quickly, UML and Nepali Congress moved back (Paudyal, 2015). As articulated by the Chair of the first Constituent Assembly Subas Nembang, "consensus hasn't been forged, not because they can't but they are not willing to" (Ekantipur Report 2015).

Following the earthquakes of mid-2015, the leaders finally demonstrated a willingness to finish the constitution and provide the base from which to rebuild (Upadhyay 2015). They finalized a draft, with some last minute bargaining (Nepali Times 2015; Shrestha 2014a), and released it for a hasty public consultation. Six provinces were proposed - without names or boundaries, which were to be determined by a subsequent federal commission and new provincial parliaments. Through the course of gathering public opinion on the draft, overwhelmingly the public sought for the federal provinces to be demarcated and a model was hastily drawn up and released to the public.

The reaction was swift and considerable with protests launched across the Terai and in the far west where the people of the remote and underdeveloped Karnali region sought their own province (despite the low population and weak economy). Protests quickly became violent and around forty people were killed. Subsequently, the demands of the Karnali peoples (who are predominantly Pahadi) were accepted by the political elite, while the demands of the historically marginalized Madheshis (who comprise around $20 \%$ of the population) and indigenous Tharus were denied (International IDEA 2015, pp. 26-28). There 
was compromise with groups within party, but those groups advocating rights from outside the major multiethnic parties were not afforded any further changes.

In September 2015, the new constitution was promulgated. It now included seven provinces based on a mixture of ethnicity and territory (or identity and viability). Large ethnic groups recognized as indigenous were mainly co-located with two or more of those large groups in each province and only Madheshis and two major Janajati groups - Tharu and Magars - were substantially split (see Map 1). Viability (territorial) bases were emphasized ${ }^{65}$ and identity was addressed by other features of the constitution. Proportionality was enshrined in a number of areas and was the subject of the first amendment in 2016, and there is a mixed (parallel) electoral system incorporating proportional representation and first past the post (Article 84). Other layers of government, with great potential for accommodating ethnicity, are included. There is a provision to allow the establishment of autonomous regions and special structures for marginalized groups (Article 56(5)), a range of identity-based commissions that provide a measure of non-territorial rights to scattered communities (Part 7), and a constitutionally empowered local government with powers including police, local taxes, school education and basic health (see Schedule 8, Constitution of Nepal 2015).

However, because the Madheshi peoples were not granted their dedicated units, protests continued in the Terai for many months, while longtime Maoist leader and former prime minister Baburam Bhattarai declared "half of the nation's population is unsatisfied with the new constitution. Hence it is not an occasion for celebration" (cited in Post Report 2014b). Understanding the basis of this response and the evolution of the debate on unit demarcation is critical here. It is not a viability based decision. The Far Western Region, which was split into two provinces, has an extremely low revenue basis, contributing less than $1 \%$ of the total revenue of the state in $2006 / 07$ (Table 6, Srivastava 2011, p. 24). The demarcation appears an ethnically biased reproduction of historical and existing domination (i.e. path dependent power reproduction), which would have been expected according to prominent Janajati scholar Mahendra Lawoti (2014) who claimed that the Pahadi elite's "repeated displays of contempt for democracy made the elected Assembly's truly representative character meaningless and laid bare the chasm that yawned between party leaders' pro-democratic rhetoric and the reality of their actions" (p. 137) ${ }^{66}$.

65 One leader of major party told me that 'hilly people are more civilized' and so the states should be mixed so as to promote development, while at the same time reiterating his view that giving ethnic rights via federalism will lead to the oppression of other groups in the region.

${ }^{66} \mathrm{He}$ cites the refusal to accept the recommendations of the State Restructuring Commission, their decision to avoid a vote of the Assembly and instead resolve issues 'in-confidence', a 'biased' media, and the elites' approach 
I do not disagree with Lawoti's assessment but note that it came at a time of great disappointment after the dissolution of the first Assembly, and prior to the second. Instead I would emphasize the magnitude of the decision to establish a democratic federation, a goal pursued without success by many other country's minority ethnic groups not least those in Myanmar and Sri Lanka. Federalism should have benefits for minority ethnic groups who will have greater access to power and greater say, notwithstanding the mixed make-up of the state. As reported following a broad reaching federalism conference in 2008 , it is not so much whether the minority ethnic groups are specifically empowered or become majorities in new provinces, but whether or not the high caste Pahadis remain so. That is, "unless the dominance of the Bahun, Chhetris and Newars is broken, federalism will not help much" (United Nations Development Programme 2008, p. 47).

Furthermore, I argue that it is a decision that accepts a mixed and territorially weighted basis for state demarcation, rather than a strict ethnic basis, consistent with the deliberated outcomes and popular opinion. By $2015,80 \%$ of the public were opposed to ethnic federalism (according to one long-running opinion poll) (Rai 2015), compared to a near 50/50 split earlier, and the calls for single-identity-based states was becoming increasingly confined to small ethnic parties operating out of the periphery. The major parties including the Maoists, which were becoming more multiethnic, moderated their policies as the federalism deliberations continued, consistent with the trend observed in the media and the public more generally, especially with less partisan lower level deliberation. This is discussed further in Chapter 7.4.

Critically, the decisions of provincial demarcation also signify a refusal to concede to the demands of the Madheshi parties for a single or even two single-identity-based units, which minimized the risk of a polarized federation, given that around $50 \%$ of the population reside in the Terai, and markedly reduced risks of secession and the marginalization of second order minorities. If the Pahadis (high caste groups) were more populous, the potential threats of becoming a local minority, losing out to the Madheshis in a battle for control of the federation, would be largely negated. The government went so far as to detain prominent Madheshi independence activist CK Raut for anti-national activities in the midst of the federal debate (Shah 2014). Whether or not the fear of secession is legitimate or not is beside the point, as reported by the International Crisis Group: "Although it is not openly discussed, there is a fear, in particular among hill origin Nepalis, that India in the long run will take 
control over Terai. We believe that this is an imagined threat, but even imagined threats can have real consequences, and combined hill-terai provinces may counter this fear" (Hatlebakk \& Ringdal 2013, p. 1).

The breakup and mixing of the Madheshi peoples across more than one unit, which was part of all official drafts, meant that the secession risk was sufficiently small such that the elites could be relatively unconcerned about the units' powers being misused as a basis for a secessionist movement. Further, the mixing of the groups in the units meant that oppression of second order minorities is less likely and the retention by the center of particularly strong intervention powers was deemed unnecessary. Making the units viable became a greater priority, and for that, strong powers and revenue sources were required. In fact, there was little change to the division of powers proposed in the initial committee reports and the final constitution. The units are strong in comparison to other Asian federal systems, most particularly Sri Lanka's and Myanmar's. They have substantive taxation and revenue powers, controls over land and natural resources, responsibilities for language and education and for law and order (see Schedule 6, Constitution of Nepal 2015). The units will also have a dedicated legislature. Bicameralism and the proportionality requirements are discussed in the next chapter.

Religion continued to play a role in symbolizing the extent to which the state preferences one ethnic group over another but has itself played little to no role in the federalization process itself. Nepal may have needed a secular turn to align with the broader multiethnic ideology underpinning the current constitution, but the abandonment of religion as an important social and political influence has not been institutionalized. Whether or not the state should be secular was one of the key issues raised by the public on release of the draft constitution with most preferring to recognize the state's religious heritage. This is a position reinforced by the improved electoral performance of the royalist Hindu parties. In response, the Constituent Assembly agreed to recognize the importance of 'traditional religion', which is taken to mean Hinduism, and ban religious conversion (Post Report 2015). However, this approach is now in a context where other cultural rights are given greater standing such that giving prominence to the Hindu religion no longer has a substantial subordinating effect.

Finally, Lawoti (2014) laments the sidelining of democratic processes as part of the federalization process. This is not only a commonality observed in the cases of many divided societies broaching constitutional settlements, as outlined in Chapter 3 , it is an apparent necessity as a change strategy in bringing equality to divided societies where one group has a 
numerical advantage over others. However, democratic processes were not abrogated, they were adapted and incorporated with the elite-based settlement processes associated with conflict resolution. In doing so, Nepal has not only been able to find a middle ground between ethnic and territorial federalism, but also between individual and group based representative processes, which should carry over into the institutionalization of federalism in the years to come.

\subsection{Myanmar's long-awaited restitution}

In Myanmar, the 2015 election has heralded a new era - not just a democratic future, but a federal one. There is a mutual commitment by the National League for Democracy (NLD) and the minority ethnic groups to reform the 2008 constitution's quasi-federalism and little viable alternative. However, the military and its political party remain powerful through the current constitutional reform process and the design features of a new federal system will be colored by its concern for 'national unity' (i.e. the prevention of secession) and the infrastructural capacity of the minority ethnic groups existing in the periphery today. Even though federal reforms have not yet been agreed - this could take many years - the threshold that has been crossed and the debates over design features reinforce the lessons from the Nepal case.

\subsubsection{Key actors and processes}

The 2015 election rebalanced the distribution of power across the three major forces - the minority ethnic groups (represented by political parties and armed groups); the democratic reformists, largely encapsulated by the NLD; and the military, including the Union Solidarity and Development Party (USDP), which is dominated by former military leaders. Prior to the election, the military and the USDP together held considerable power and were able to impose their preferences. The military possessed coercive powers, limited only by the ability of the ethnic armed groups to defend themselves, while the USDP commanded democratic power, however illegitimate, wielding a huge majority in both central and regional parliaments. The 2015 election surprised with the extent of the NLD victory. At the central level, the NLD won 135 seats, up from four as compared to the USDP's eleven, down from 124 (Appendix 2, Table A15). The ethnic political parties performed poorly. At the regional level, only the Shan and Arakan States had strongly performing ethnic parties, preventing the NLD from gaining a majority in those state parliaments.

As discussed in Chapter 5, the ethnic armed groups are by no means unified, but are all supportive of genuine federalism. They hold substantial infrastructural capacity and military power, alongside their representation in the democratic institutions mentioned above. They 
are generally dismissive of the current system, complaining about aspects like the presidential appointment of the chief minister, natural resource sharing and the continued role for the military. However, they differ on important design alternatives, which are discussed below, and whether or not there should be a federal $a r m y^{67}$ to prevent future coups. Further, many ethnic armed groups stand to lose under a democratic future, with ceasefire agreements providing more substantial autonomy and revenue than would be possible via democratic federalism.

The military, as evidenced by their roadmap to democracy and the basic principles imposed on the earlier constitutional convention prioritize matters like 'national sovereignty' and the 'indivisibility of the union'. Further, federalism properly implemented would remove lucrative revenue sources from the military and its cronies. The military continues to hold considerable powers on account of its arms, existing agreements and constitutional provisions guaranteeing control over key ministries, its budget and parliamentary seats. It remains autonomous and difficult for the government to rein in.

The NLD is rhetorically committed to federalism, but gives no detail on what this would mean. For the NLD, federalism is a commitment of founding father, Aung San, but its wish to pursue federalism via democratic means once all people have a chance to participate had undermined the minority ethnic groups' confidence. As I have argued, federalism does not arise via democracy but as part of a transition, and minority ethnic groups are right to be skeptical or concerned about the wherewithal of the NLD to implement federalism following the institutionalization of democracy. The Bamar vastly outnumber other ethnic groups, and without some countermeasure, majoritarian anti-federal outcomes might be anticipated. Indeed, one of its first actions was to appoint its own party members as chief ministers in all states including those where it did not win a majority ${ }^{68}$ (Nom 2016). It also assembled a 'national reconciliation' Cabinet comprising representatives from the main opposition, the USDP, but including only one ethnic party (Appendix 2, Tables A17 \& A18).

Constitutional change is an outcome expected by the ethnic armed groups through the peace process that the NLD have pledged to progress. Amendment of the constitution would need

\footnotetext{
${ }^{67}$ The idea of a federal army is a legacy of the mistrust in the Myanmar military. The proponents accept that there should be one military force but that it should be structured into discreet units consistent with the federal design of the country and incorporating the ethnic armies as "state security forces", dividing military power to prevent central military tyranny (Nai Hong Sar, leader of the National Ceasefire Coordination Team, (cited in Kha 2015))

${ }^{68}$ Notwithstanding, the leaders appointed to chief ministerships in the ethnic states were from the associated ethnic group, with the exception of Shan State, which is itself subject to more competing claims.
} 
to be progressed by the legislature, which is dominated by the NLD. However, effecting change is made difficult by the greater than $75 \%$ legislative majority required and the $25 \%$ of seats that are reserved for the military, which votes as a bloc and has traditionally been opposed to federalism. Further, fundamental changes to the state structure (e.g. creating new units) require a referendum (see Article 436, Constitution of the Republic of the Union of Myanmar 2008). But, contrary to its earlier assertions and the constitutional requirements, the NLD and other actors are progressing constitutional reform outside of the democratic institutions to ensure the inclusivity and agreement of the minority ethnic groups, whether political parties or armed groups (or both).

Most relevant has been the first in a series of ' $21^{\text {st }}$ century Panglong conferences', with almost all significant ethnic parties and armed groups participating by invitation in a forum of more than 1000 . The conferences are intended to provide a safe and inclusive space for democratic deliberation towards a suitable federal structure ${ }^{69}$. It is expected that these conferences will continue for three to five years and the first tranche, parts of which are discussed below, was productive in enabling a mutual and transparent airing of the aspirations and concerns of each of the main actors. The peace process provides further forums for deliberation towards constitutional change. They include the National Ceasefire Coordination Team (NCCT), and the UNFC. The NCCT comprises representatives of the government and major ethnic armed groups who signed a national ceasefire agreement in November 2015, just prior to the election. Ethnic armed groups that are not part of the national ceasefire process are represented in the UNFC, which has drafted a proposed new federal constitution and presented it to the $21^{\text {st }}$ century Panglong conference (Nyein 2016a).

\subsubsection{Federalism compromises}

Up until very recently, debate about federalism has been suppressed, and only flourished in areas outside of the military's control. The military asserts that federalism is inconsistent with the constitution and argued that debate about ethnic rights and autonomy should take place within this framework (see for example Pwint 2015). It has acknowledged the federal features inherent to its 2008 constitution, but still argues that "only when the government is vested with power will it be able to have control over the people and only when the government can have influence over other organizations will sovereignty prevail" (Col Min Oo, cited in Myanmar News Agency 2016c).

\footnotetext{
69 Unfortunately, the most powerful ethnic armed force, the United Wa State Army, walked out on the first day, citing inequality (Nyein 2016b).
} 
In the exile community, debate about, and advocacy for, federalism flourished and many of these people are now returning and working with both state and non-state actors to provide the technical supports necessary given the years of insularity (see for example Slow 2016). Minority ethnic groups claim rights based on their longstanding practical independence and indirect relationships with the center, and the commitments to "full autonomy in internal administration" made by the British and Aung San as part of the Panglong Agreement (Item 5, Burmese Government et al. 1947). The 'spirit of Panglong' remains an often referred, but weakly defined, underpinning for the future federal system as demanded by ethnic nationalities (Walton 2008). As discussed in Chapter 4, it is taken to mean equality between the minority ethnic groups and the Bamar, but there are many interpretations of what this should mean in practice. Further, given the internal migration and substantial numerical dominance of the Bamar, it is practically difficult to achieve institutionally.

As in Nepal, there has been a considerable emphasis on terminology. But instead of debating ethnic or territorial federalism, disagreement turned on the strength of the units and their relative autonomy with minority ethnic groups preferring to advocate for federalism and government forces preferring a 'union' (Jiratticorn 2014). The idea of a union is associated with the 1947 constitution and consistent with the idea of group rights' being protected mostly via the center rather than through autonomy, while federalism is associated with the more secure and segmented federations of the US and Canada, for example. However, this divergence has been largely overcome and by the third day of the first $21^{\text {st }}$ Century Panglong, one of the chairs opened proceeding by acknowledging that all participants now agree that there should be a federal union (Myanmar News Agency 2016c).

Sustainable peace relies on further federalization and it is not something that minority ethnic groups will concede on account of democratization, especially given their prior experiences ${ }^{70}$ and the substantial parallel infrastructural capacity that they continue to hold. But with the military remaining as 'reluctant' federalists, the alliance between democratic reformists and federalists is formative, as argued by NLD leader Aung San Suu Kyi: "[All parties should] help build a genuine federal democratic union that grants safety and freedom. This cannot be achieved by one side alone", (cited in Zaw \& Naing 2016). So what is holding back change? The lack of coherence within and across ethnic groups was a commonly put forward as one of the reasons that federalism had not yet been established. However, I did not speak to

\footnotetext{
70 Especially between 1947 and 1962, where despite the existence of a democratic system, Bamar led political parties dominated to the exclusion of the minority ethnic groups and their interests.
} 
anyone who believed that federalism would not be established - it was only a question of when. Myanmar government advisors suggested to me that federalization would come once the minority ethnic groups grew more capable of managing their own affairs. For example, one advised that although there are 42 areas available for legislation, the Kachin had used most with 16 areas legislated, while the Chin had used only five or six.

More obviously, it is the fear of secession that still pervades. Many minority ethnic groups still seek a right to secession in the constitution, as a safeguard not because they wish to act on it. The ethnic groups I spoke to all said they were not interested in secession, rather resource sharing and land rights. However, the military remain concerned enough to stress the 2008 constitutional provisions banning secession to the participants of the $21^{\text {st }}$ century Panglong conference, and to stress its continued salience (Myanmar News Agency 2016c). Certainly, the fear of secession was a common theme in my discussions with Bamar actors, but was not a concern of the NLD. Further, the NLD is opposed to a secession right, even though there is acceptance for the concept in its heritage: "Secession was part of the promise given at Panglong. Some people are worried and have asked whether I would allow secession. My answer is when the decision is made to establish a union, it must be with the determination that we would make it an enduring one" (Aung San Suu Kyi, cited in Khuensai 2016).

Although there is now near consensus (outside of the military) on the need for federalism there is a variety of views about the type and its features. When compared with Nepal, the debate over unit demarcation is relatively subdued. This is because it was previously imposed via the federal system in the military led regime's constitution of 1974, and the military could concede ethnically-based units and the institutionalization of local minority status for the Bamar in those ethnic states because of the general position of the Bamar in the state structures as a whole. Further, the military regime retained practical control over the new units, via intervention and direction powers and the one-party system, meaning that the twin threats of secession and marginalization at the local level could be managed. Ethnic political parties and armed groups that I met with were reluctant to talk about changing boundaries but expressed a certain dissatisfaction with, and a sense of inevitability about, the current set up.

The potential for marginalization of second order minorities is also mitigated by the use of ethnic affairs ministries, which are allocated to a community that is a minority in a unit, including for Bamar in ethnic states (Article 262, Constitution of the Republic of the Union of 
Myanmar 2008). In March 2016, 29 ethnic affairs Ministers were appointed (Kyaw 2016). Their role, to advocate for and protect the interests of these second order minorities goes some way to addressing the risks and perceptions of ethnic federalism, given its inevitable mixed make-up in the Asian context. There is also a process, which is already being utilized, whereby a community can demonstrate via survey that it has the requisite population to have an ethnic affairs minister appointed to act on its behalf (Zaw 2016).

Two very important boundary issues remain disputed, however, with more than a third of the ethnic organizations seeking an eight-state solution (i.e. seven ethnic states and one Bamar state (as compared with the seven and seven split currently), and others still demanding their own states instead of special administrative zones (Nyein 2016b; Jolliffe 2015, p. 89, Table 12). The debate about whether there should be one Bamar unit or seven harks back to the much cited 1947 promise of equality by then Bamar leader Aung San. However, there is little chance that the NLD, including its Bamar and non-Bamar leaders, would compromise on this matter and there remains considerable disagreement on the point amongst the minority ethnic groups themselves. The eight state solution would create an essentially bipolar federation, a kind that has proven to be unstable in the past, including in Myanmar (Hale 2004). This position is on the extremist end of the demands of the minority ethnic groups, and would fail to pass the test of an inter-ethnic deliberation, such as has occurred through the NLD, and at the National Convention.

A more tempered proposal is the merging of three Bamar units to form one, with other Bamar units to become multi-nationality units (Weng 2016). However, most ethnic armed groups and political parties have a certain inevitability about the maintenance of the existing fourteen-unit system, and concern themselves with other more pressing concerns, particularly the division of powers and the role of the military. Recently one minority ethnic group made public claims to an area of another ethnic state based on historical entitlement, which was condemned by other minority ethnic groups as a retrograde step given the current circumstances and the need for a unified front to achieve other more critical goals (Aung 2016).

The second boundary issue, which is more pressing, is the number of groups seeking their own unit. The $21^{\text {st }}$ century Panglong conference has seen a cavalcade of groups making claims for recognition, whether by upgrading their current status, or by the creation of a new ethnic state or self-administered area (Myanmar News Agency 2016c; Myanmar News Agency 2016a). These are of course not all new claims. There were sixteen groups that 
applied for a self-administered area during the constitutional development process for the 2008 constitution, but only six were accepted, and these were tied to generous ceasefire agreements (Crouch 2016). From some perspectives, self-administered areas are about empowering minority ethnic groups, but from others, motivations are more ulterior. One government advisor admitted for example, that the only way to prevent the Wa from seceding is to give them autonomy, but giving too many smaller groups autonomy undermines the role of the states and regions. Nevertheless, the ethnic minority groups with their own state seemed unconcerned with the prospect of further self-administered areas. The federal system will continue to have a high degree of ethnicity embedded in its design but the names and number of units should not be considered fixed.

The division of powers and security of autonomy is then the most critical part of the debate. In particular, control over land and resources and the associated revenue is pivotal to the disputes between Bamar centralists, such as the military, and minority ethnic groups (see for example Aye Maung in H.N. Zaw 2015). The focus on resources and revenue has embedded in it the self-interest of individuals and organizations that have formal or effective control over lucrative natural resources in this war economy. As argued by the military, "excessive demands on the part of the armed organizations for political assurances and preconditions as well as for recognition of unlawfully obtained management, administration and economic opportunities are the main obstructions that delay the peace process" (Lt-Col Zaw Oo cited in Myanmar News Agency 2016c). However, while the military blames the ethnic armed groups, the independent Myanmar Peace Monitor project found that that 'the key hindrance' to political reform is the power of the military over the economy, and its economic interests (Myanmar Peace Monitor 2013). NLD is the only key actor that does not stand to lose economically from a democratic federal compromise.

Myanmar's units lack substantial taxation, land, revenue and natural resource power ${ }^{71}$. Even prior to the 2015 election, the Parliament considered amendments to the division of powers, including over taxation and natural resource revenue, and other important determinants of autonomy, including to the provision that allows the president to appoint unit chief ministers. However, with the military voting as a block, they failed to get the requisite $75 \%$

\footnotetext{
71 In 2012-13, half the units derived around 50\%, up to 82\%, of their revenue from the center and the units differed by up to almost 2000 per cent in terms of total expenditure (Yangon/Kayah units) (Annex IV, Nixon et al. 2013, p. 91). Populations varying from a few hundred thousand to more than seven million (Ayeyarwaddy, Mandalay/Kayah) (p. 10). Compare with Nepal's new units, which were based more on viability rather than ethnicity and display greater spread of revenue raising abilities, natural resources and population, however, the two western units (which were split to appease protests) are the most resource poor (Devkota 2015).
} 
plus one, despite a majority of elected lawmakers voting in favor of critical aspects (Snaing 2015a). Natural resource powers are most contentious and were raised by numerus ethnic speakers at the $21^{\text {st }}$ century Panglong, alongside other powers like land, education, language and law and order (Myanmar News Agency 2016a; Myanmar News Agency 2016b; Myanmar News Agency 2016c).

These types of powers are associated with culture and historical entitlement - they would recognize traditional and indigenous rights to land and resources and give positive empowerment to the use of ethnic languages in education and other official purposes. While law and order is claimed in the context of civil war and the idea of a federal army, it will be decided according to a secession risk management approach and in a way that protects the rights of second order minorities. Historical entitlement is accepted as a premise, but not the basis of reform, while the protection of self-interest may be a hindrance but it is not preventative. To be sure, there are always countless issues that impact on decisions about whether and how federal design progresses, but none more so than the infrastructural status of the minority ethnic groups, and the perceived risk of secession.

Religion and secularism has been a tangential element of the federal debate, and is most controversial in relation to the treatment of Muslims rather than federalism. The political movement $\mathrm{Ma} \mathrm{Ba}$ Tha, which has recently lost its political patronage, is far more concerned with (there not being) citizenship rights for the Rohingya, rather than self-determination for minority ethnic groups even where those minorities are majority Christian such as in Chin and Karen states. There is little discussion about making the constitution secular or not and the emphasis remains on the self-rule elements of federalism. For example, the proposed draft constitution for the Karen State (Kawthoolei) would have the Karen State as based on secular principles, rather than the overarching Myanmar state (see Section 3, Karen State Constitution Drafting Committee 2006), although a Christian Karen State would be a possibility. Otherwise, federalism has an ambiguous relationship with the treatment of religious minorities. In Rakhine state, the nationalist Arakan National Party won the most seats increasing the potential from this federal outcome for marginalization of second order minorities. However, the NLD appointed one of its own as chief minister, and the center provides an additional check against discrimination by an extremist state/regional government (and potentially vice versa). Religious diversity and the status of Buddhism in the state complicates, but does not otherwise inhibit, the process of federalization. 
The role of democracy in these federal decisions deserves reiteration. Federalism has not come to Myanmar or Nepal via democracy. It is only when democratic processes are partially bypassed that federalization has occurred, and, it is only when democratic regime change coincides with federalization that federalism follows. The largely undemocratic convention process discussed in Chapter 5 led to a quasi-federal constitution, reforming part of the 1974 federal system that developed out of a one-party system. The processes for constitutional reform - a $21^{\text {st }}$ century Panglong, the UNFC and the NCCT - are all partially democratic, or undemocratic, while the legislative process for constitutional amendment is also only partly democratic given the military veto right. However, because these processes are inclusive using consociational elements to support a transition towards federalism, and built around a committed alliance of change agents - federalism is an outcome to be expected.

\subsection{Sri Lanka - 'maximum devolution within a unitary state'}

People of the south are scared of the word 'federal'. People of the north are scared of the word 'unitary'. What we should do is not fight over these two words. We should come up with a formula that is acceptable to all. It takes maturity to understand devolution. We cannot satisfy the extremist elements either in the north or in the south. We have to do what is good for, and acceptable to, the majority of the people (President Maithripala Sirisena, cited in Srinivasan 2016).

\subsubsection{Key actors and processes}

Sri Lanka's constitutional moment shares the conditions of the other third generation federal countries in Asia, including a moderate secession risk, infrastructural capacity and the formation of a regime change alliance. But with a weakened bargaining position following the end of the conflict, the strength and utility of the alliance between minority ethnic groups and the major parties is tenuous, yet critical. The key actors in the case of Sri Lanka's current critical juncture can be considered as three forces, similarly to Myanmar, although they are of course not always unified in the preferences and positioning. In contrast with Myanmar, there is now no substantive military involvement or power in Sri Lanka and its minority ethnic groups have been disarmed and can no longer position themselves via coercive power. The three forces are the Tamil political elite and the two factions of the Sinhalese political elite, here labelled as the coalition government (led by the United National Party (UNP) and Sri Lanka Freedom Party (SLFP)), and the Rajapaksa faction.

The Tamil political elite is represented in the main by the Tamil National Alliance (TNA), which comprises the four main Tamil parties and, for the first time, the opposition leader. It 
still campaigns and advocates the 'Thimpu principles', which were negotiated in 1985 and are in essence demands for federalism and a merged Northern and Eastern Province, on the basis of historical entitlement (Krishnaswamy 2015). There are also some Upcountry Tamil political parties with representation in Parliament and Cabinet. They are not aligned with the TNA nor a particularly powerful force. Though there are some aspirations for autonomous zones, special representation arrangements and non-territorial federalism, development is their priority (Ramakrishnan 2016).

The coalition government, which gained power on a good governance agenda, represents the moderate and pro-regime change faction of the dominant ethnic group. The UNP and the SLFP have been traditional rivals. Each is dominated by Sinhalese people though their governing coalition, which includes two Muslim parties and two Upcountry Tamil parties, but no Tamil parties (Appendix 2, Tables A25 \& A25). Each supports a unitary state, but has been open to discussion of further devolution through the present constitutional reform process (discussed below).

The Rajapaksa faction of the SLFP, which was removed from power at the election of 2015, represent Sinhala Buddhist nationalists. Rajapaksa was anything but magnanimous to the Tamils since their military defeat (see DeVotta 2011; Stone 2014 for examples), and increasingly authoritarian more generally, even changing the constitution to further empower the executive presidency, which he held. Rajapaksa and his faction still hold considerable influence over many rural Sinhalese and in the Parliament: "Rajapaksa presides over a coalition of hard-line Sinhalese nationalist parties opposed to any measure of regional autonomy for the Tamils. They are committed to preserving Sri Lanka's unitary and centralized state" (Uyangoda 2010b, p. 109).

Religious actors are important but experience has shown that, in political terms, they are reliant on patronage for major influence. The Rajapaksa regime actively supported extremist Buddhist nationalists, including a political party (Bodu Bala Sena), but their influence has drastically waned following its defeat. Similarly, international actors have been important at times, particularly India, and some Tamil actors I spoke to remain hopeful that India will intervene. However, we can see, for example through the failed Norwegian mediation attempt (2002-05), that decision-making power is well and truly with the Sri Lankan political elite and international actors are relatively minor.

The Muslim communities have two political parties with national representation, most prominently the Sri Lankan Muslim Congress, which is a member of the good governance 
coalition. However, the Muslim community is numerically small and significantly divided in federal policy terms, with some wanting autonomous regions, or even a province, and others derisive of such 'segregation' (Colombo Gazette 2016; Nathaniel 2016b). Muslim actors more often focus on inclusion and integration rather than special autonomy, as argued by Nizam Kariapper, Deputy General Secretary of the Sri Lankan Muslim Congress and Mayor of Kalmunai: "our objective is to achieve all the appointments based on merit and establishing a Sri Lanka identity going beyond ethnicity" (cited in Nathaniel 2016a). Further, Muslims are relatively well represented in the UNP and SLFP and the Muslim parties generally gain a small portion of the Muslim vote (see Appendix 2, Table A14). I was advised that most Muslims try to work with or within the major parties, and believe that this is the best way to achieve their goals, only withdrawing when there is a conflict of interest or as a way of holding the major parties to account for failing to heed Muslims' voices.

The power distribution across those three forces is tenuous but nonetheless heavily weighted towards Sinhala advantage. Despite running a parallel administration, holding land and military power and garnering the sympathies of its giant neighbor throughout much of the 1980s and 1990s, the Sri Lankan Tamils were not able to turn this to their favor in negotiating or goading a federal outcome. The LTTE became increasingly fanatical in its pursuit of independence, increasingly unpopular with the Tamil populace, and unwilling to compromise in favor of an all or nothing approach. Further, the Sinhalese dominate Tamils in population $74 \%$ to $11 \%$, which finds practical reflection in the make-up of key institutions, and the military, while under government control, is almost entirely Sinhalese (DeVotta 2010). The prior major reform proposals (1987, 1994-6, 2000 and 2002-05) were all undertaken in the context of conflict and with the backing of Tamil military power and territorial control. Political leaders of various persuasions now reject these proposals as the product of a different time, implying that minority concessions need no longer be made (Arudpragasam 2013). Even the president at the time of the 1990 s and 2000 proposals, Chandrika Kumaratunga cautions against pursuing a federal constitution today - "In 2000, the country was still at war whereas today, there are more stable conditions. The draft constitution of 2000 [which was federal] goes further than what we can do now" (cited in Gunasekera 2016).

Sri Lanka's new critical juncture must also be understood in the context of the inadequacies of the process that led to the $13^{\text {th }}$ Amendment to the constitution and the system of provincial councils that exists today. As discussed in Chapter 5, the 1987 amendments came with the intervention of India, and without the involvement of the Tamil minority for whom 
the amendments were intended to benefit. Not only did the lack of involvement mean the amendments were rejected in principle, it also meant that the new provincial council system was not an outcome of compromise between different constituent groups of the state - a constitutional settlement - but an imposition by the majority group on the minority, even if at the behest of India. It should not be a surprise that the $13^{\text {th }}$ Amendment fell well short of Tamil aspirations. Nor should it be a surprise that implementation was so vastly inadequate.

To draft the new constitution, an initially short timeframe of around six months was proposed. The rationale being that not only is the alliance fragile, with Rajapaksa 'lurking in the shadows' (as one MP told me), but the options and issues have been discussed for many years. Further, each of the previous constitutions are identifiable with the particular architect, and never fully embraced by oppositional elements as the acceptable framework to work within ${ }^{72}$. Now is the only time in Sri Lanka's history where the two major parties have agreed to work together and form a coalition, or to seek and incorporate the views of the public on such matters. The timeframe has now been extended and the process may take years. This constitutes a risk that this constitutional moment may pass before the commitments and alliances can be consolidated, as argued by prominent constitutional architect and MP Jayampathy Wickramaratne: "it is essential that the two main parties, the [Tamil National Alliance] and the smaller parties representing the Muslims and the hill country Tamils come together and agree and that they will all be flexible enough since this is not an opportunity that we will get for a very long time" (cited in De Silva 2016). But the moderating potential of the widespread and multilevel deliberative process that necessitated the extension in timeframe may be pivotal, as the outcomes of Nepal's deliberative processes suggest.

The forum for progressing constitutional change is the legislature. In March 2016, after some controversy, aborted debates and amendments, the Parliament unanimously resolved to turn itself into a constitutional assembly (as distinct from a constituent assembly) and establish a committee structure (Parliament of Sri Lanka 2016). Key elements of the resolution include that seven deputy chairman would be elected to each head a committee with specific thematic based tasks, for example the Public Representations Committee on Constitutional Reforms (PRCCR) was established to seek the views of the public, and a steering committee chaired by the Prime Minister was established to consolidate outcomes.

\footnotetext{
${ }^{72}$ For example, the independence constitution is known as the Soulbury Constitution, after the British author; the 1972 constitution was the Bandaranaike constitution; and the 1978 constitution was the Jayewardene constitution. None was accepted by the breadth of the populace as their own constitution.
} 
The Prime Minister assured that the "new constitution... won't be a government or partydrafted constitution" (cited in Perera 2016) and the drafting structures are more inclusive than those of the past. There are four Tamils (including two from the TNA and one from the ruling coalition) and one Muslim represented on the Steering Committee out of 20, one of the seven deputy chairman is a Tamil from the TNA and another is Muslim (Hemmathagama 2016). Notwithstanding, the TNA has, at times, demanded that the government only talk with it about a 'political solution for the Tamils' and then take that consensus to other parties (cited in Rutnam 2016a).

\subsubsection{Federal compromises}

As in Myanmar, the federalism debate in Sri Lanka focuses on the division of powers and their security, rather than dwelling on questions of ethnicity in unit design, as in the Nepal case. However, many are still concerned for terminology because of the history of the debate and associated fears, such that moderates prefer to avoid the use of terms like federalism and unitary altogether. Hence, whether the constitution enacts federalism, quasifederalism or some unitary arrangement will not be found by looking at any such statements in isolation. The Prime Minister has stated that there is "an emerging consensus to work within the structure of the $13^{\text {th }}$ Amendment", with more security to the provincial council in terms of their powers, and a devolution of additional powers to local government (Prime Minister, Wickremesinghe 2015$)^{73}$, which amounts to federalism.

The Chief Minister of the Northern Province, while on the one hand advocating for federalism, makes the point that "the classical distinction between federal and unitary state is giving way to more complex forms of the nation states... Thus we cannot limit us to look at the problem of devolution from a binary reasoning standpoint of unitary or federal only" (Wigneswaran 2016). Similarly, the country's most prominent political NGO asserts that “unhelpful debates about formalistic classifications as between 'unitary' and 'federal' are best avoided, but CPA firmly believes that the new constitution's normative foundations and structural architecture must ensure extensive devolution and power-sharing unhampered by majoritarian principles such as the unitary state, while guaranteeing the unity and territorial integrity of a new form of democracy in the Sri Lankan state within which pluralism and

\footnotetext{
73 Of course Sinhalese nationalists want it weakened or abolished, arguing that it has been a failure and should never have been agreed in the first place. For example, Dr Dayan Jayatilleke, former diplomat and Rajapaksa loyalist, rejects the $13^{\text {th }}$ Amendment, the Indo-Lanka Accord and its 'imposition' entirely - "There isn't a single vestige ...that makes it a benign or acceptable formula for all the peoples of Sri Lanka to come together. It is an Indian solution to an Indian problem. It is divisive, corrosive and destructive" (Jayatilleka 2013, p. 13). However, with the 'emerging consensus' amongst moderates, which now hold power, that devolution is fair and necessary, reform can be expected.
} 
multilevel governance can flourish" (Saravanamuttu 2016, p. 2). The constitutional change process instead refers to relatively vague notions of 'the national issue' and 'reconciliation', alongside specific institutions like the electoral system (see for example preamble in, Parliament of Sri Lanka 2016).

The federal unitary debate cannot be avoided entirely, however, and party leaders are wellversed in the electoral politics of nationalism. Both the President and the Prime Minister have been defensive of their traditional constituents, with the President stating that the "unitary character of the constitution would be retained" (cited in Tamil Civil Society Forum 2016; Perera 2016), and the Prime Minister going so far as to give that guarantee an ethnic basis: "as a Buddhist, Sinhalese and a Sri Lankan, I will not break up the country" (cited in Balachandran 2016). Such statements are designed to dissuade the Rajapaksa led joint-opposition from making political gains through fearmongering in Sinhalese communities. Indeed, although the establishment of federalism relies on compromise, the joint-opposition shows no such willingness. It released its one-page submission to the Constitutional Assembly entitled 'Uncompromising Principles of the Constitution', with the first point - 'Unitary State' direct and unambiguous (Joint Opposition 2016).

Unit demarcation is relatively settled, compared to the other cases, given the longstanding existence of the provinces as administrative divisions (dating back to colonial times), and the mixing of Tamil and Sinhalese majority areas to manage such secession risks is not really an option. However, different perspectives persist. The Constitutional Assembly's Report of the PRCCR (2016, pp. 48-50) summarized fourteen distinct approaches to demarcating units suggested by the public during consultations on a new constitution. Some prominent Tamils have called for 2-5 units, reflecting historical kingdoms (see for example Bandara \& Perera 2015; Mudalige 2016b), though there is no serious discussion on these possibilities.

The question of whether the Northern and Eastern Provinces should be merged is most pertinent and controversial. The merging of these provinces is meant to recognize and reflect the historical Tamil kingdom, but has been strongly resisted by the Muslim community in the east (who would see their proportion of the provincial population reduced from $33 \%$ in the east to $17 \%$ in a merged province) and by 'most' Sinhalese who see "it as a step to granting Tamil people the right to establish a separate state" (Public Representations Committee on Constitutional Reform 2016, p. 50; Nathaniel 2016b). A Muslim leader advised me that the SLMC was established in direct response to the merging of those provinces in 1988. The suggested Muslim autonomous zones in the Eastern (or North Eastern) province 
would go some way to addressing the concerns of Muslims. But as the PRCCR (2016) points out, it is clear that there is a fear that minorities will be oppressed by a majority, but it is also "very clear that who constitutes a minority is not fixed and that it shifts according to many factors" (p. 21).

Instead, local government is seen as an avenue to accommodate the range of minorities, account for fluctuating priorities and manage the secession risk. It is promoted in order to improve peoples' access and participation in governance, increase accountability and counter the potential negative impacts of provincial demarcation. Local governance, taken the village level and linked via delegated representatives through the provincial and to the national levels was one of the few issues on which the PRCCR could reach consensus (2016, pp. 6979). Stronger local government can specifically empower those clustered communities that are minorities in their provinces, which would apply to communities from each of the state's major ethnic groups (Jayampathy Wickramaratne in Moramudali \& Kuruwita 2016; SubCommittee on Centre-Periphery Relations 2016, p. 5). Even the once militant and leftist Janathā Vimukthi Peramuna party seeks empowerment of the local level, rather than the units, to prevent secessionism and build a bottom-up democracy (Ramakrishnan 2015). Further, the indigenous Veddas, who receive little official recognition, are clustered in 62 villages scattered across Sri Lanka (Wijeratne 2016), and local government is the only level of government that can provide them with autonomy and positive cultural rights. It is true that strong local government has sometimes been recommended in order to weaken the units, but it was almost universally advocated by key actors that I met in Sri Lanka and elsewhere.

The debate on the powers of the units is the most vehement. As per Myanmar, the existing Sri Lankan unit boundaries were unilaterally conceded with a strong ethnic basis. While the territory controlled by the LTTE at the time of the 1987 amendments was substantial and could not be circumvented (particularly with the intervention of India), the overall position of the Sinhalese in the state was not under threat. They have substantial numerical domination, and the strong 'safeguards' that were placed in the constitution via the $13^{\text {th }}$ Amendment, protected the interests of the Sinhalese people in the north and east and prevented secession.

The non-implementation of important powers allocated to the units via the 1987 amendments, most particularly law and order and land, along with the erosion of financial powers further reduced the potential effectiveness and autonomy of the provincial councils provided for under the 1987 amendments. The provinces are over-reliant on the center, in 
part as a result of the scaling back of constitutionally guaranteed revenue sources (Welikala 2004), leaving little scope for them to determine their own priorities. Further, it is claimed that the division of powers is too ambiguous and overlapping, such that the concurrent list is used by the center to usurp the powers of the provinces (see for example Public Representations Committee on Constitutional Reform 2016, p. 54). Without strong and secure power, the autonomy of the Tamils in the north means little. However, without a fundamental reorganization of the units, the division of powers remains the area where Sinhala elite can best mitigate the secession risk (in the absence of shared rule and multiethnic institutions as is discussed in the next chapter). Most fundamental to the fear of secession is the coercive capacity of the units.

The PRCCR (2016, pp. 53-63) recorded that the communities' views were 'divergent' regarding law and order (police) powers and land powers. Nevertheless, the Constitutional Assembly's Sub-Committee on Centre-Periphery Relations has recommended that they are securely devolved to the provinces alongside more autonomous financial arrangements and a removal of the concurrent list and the center's power to make national policy on any matter (Sub-Committee on Centre-Periphery Relations 2016). Arguments for provincial law and order responsibilities revolve around the underlying necessity of law and order to the performance of other functions of the province. Arguments against can quite simply be summed up as revealing the persisting fear of secession in the minds of many Sinhalese. Advocates for devolved land power link ethnic and traditional rights to land rights, and express concern about the 'colonization' of Tamil and Muslim areas by Sinhalese, while opponents question these supposed historical rights and assert their right to development and access to land that 'might otherwise be monopolized by a minority'. The Committee, unsurprisingly, did not reach consensus on a recommended approach regarding most controversial matters, but did reach a moderate middle in relation to most others.

These ongoing debates bely the real reasoning behind the non-implementation of already allocated powers under the Sri Lankan constitution, being the prevention of the accumulation of capacities that might be considered necessary to effect a secessionist movement. For example, discussion with members of the anti-federal Rajapaksa faction oscillate between the position that the technical shortcomings of the $13^{\text {th }}$ Amendment mean it should not be implemented to a supposed imperative to prevent the creation of an unchecked coercive capacity (in the units), and the position of the Sinhalese elite that they have a right and a responsibility to oversight the activities of the Tamils for the cohesion of the Sri Lankan state. This supposed right to control is well captured by Manohara De Silva, 
Law Commissioner and President's Counsel, who argues that, according to the current constitution:

the Provincial Police Force cadre is determined without any control of the president or the cabinet of ministers. Even if a National Police Unit is in operation in a province, they [sic] will function under the chief minister. If a serious rioting or an ethnic clash occurs in a provincial village or town the National Police cannot immediately rush to the area to ensure law and order without the permission of the provincial [Deputy Inspector General] under the chief minister's control (cited in Perera 2015).

Religion gives a basis to much of the nationalist rhetoric, but has an otherwise ambiguous role in Sri Lanka's contemporary federalization process. Initially harnessed as a force against federalism, by then president Rajapaksa and prominent Buddhist monks most especially as the radical nationalist political party Bodu Bala Sena, religion's role grew to the extent of government impunity for attacks against religious and ethnic minorities. However, it was a religious figure, the late Venerable Maduluwawe Sobitha Thera, who spearheaded the formation of the good governance alliance that ousted the Rajapaksa regime on a promise of constitutional reform and a change in the regime type (Zuhair 2016, pp. 18-25). Buddhism has been adaptable to serve purposes for and against federalism and cannot be said to be inherently supportive of one approach over the other. Indeed, despite the near complete alignment of religion and ethnicity and the acknowledged impact on the 'psyche' of the Sinhalese, no Tamil or Muslim political actor I spoke to countenanced removing the privileging of Buddhism from the constitution, choosing to focus instead on federalism and devolution (for which they consider the executive presidency to be incompatible).

\subsection{Summary}

The constitutional reform processes of Nepal, Myanmar and Sri Lanka can be characterized as their constitutional moment, following from popular uprisings and the resolution of conflict. In Nepal, a participatory process was implemented, even though the elites took a key role, while the Myanmar constitutional reform process is entering a second stage following the conclusion of its tightly controlled National Convention. In Sri Lanka, the process involves a coming together of the different sides of politics for the first time since independence, and a deliberate outreach to identify and incorporate community views. Although terminology remains sensitive, in all cases there is a critical mass of key actors supporting federalization. 
The new conditions that enable these federalization processes to occur are common to each of Nepal, Myanmar and Sri Lanka, namely the establishment or growth of a regional or ethnic infrastructural capacity, and the presence of more moderate secession risk. Further, there has been an authoritarian-leaning government in place immediately prior, instigating a movement for regime change that has found a natural ally in movements for federalism. Unlike the zero-sum game of past concessions, compromise solutions in this context can produce win-win outcomes for those pursuing mutual objectives. However, the actors involved in the federalization process are by no means unified on the issues around the type of federalism.

The demands of the ethnic minority groups are based primarily on the idea of historical entitlement, traditional ownership and self-rule. This means that the way that units are demarcated (e.g. 'homelands') and the powers that are allocated to such units' self-rule are critical to the extent to which such demands can be met. However, the perception of federalism as a precursor to secession must also be addressed and deliberation can only take this so far, even if the fears are exaggerated. The fears about the marginalization of second order minorities are also regularly raised and should be accounted for in the federal design. From such perspectives, the unit demarcation and the division of powers are critical, as the secession risk can be mitigated by creating heterogeneous states, through the creation of a centralized division of powers, or via effective shared rule institutions. Local government may also play a role.

How the key actors have balanced these matters in federal institutional design provides important lessons. It is meaningful that these issues can and are addressed by federal design methods. However, while the issue of power-sharing may be downplayed in debates and demands, it is integral to how ethnic minority groups are accommodated and how the ethnic extremes are moderated, which is discussed in the next chapter. 


\section{Accommodation and moderation - federal design issues}

We want federalism that is identity-inclusive, so towards that end, our demand has always been a constitution that will bring peace and the only way to do this is to recognize identity. Federalism is not just about taking governance to the villages; it is about recognizing that there are certain marginalized elements in those villages that need representation, inclusion and need to have their voices heard. Our understanding is that only identity-inclusive federalism can do this. This kind of federalism would also ensure long-term peace in the country. We are not about taking away any community's rights but rather, ensuring that all communities have equal access and are ensured their rights (Nagendra Kumal (2014), Secretary, Nepal Federation of Indigenous Nationalities).

The road to federalism as taken by Nepal, Myanmar and Sri Lanka raises important issues and offers potential lessons for divided societies and for the accommodation of minority ethnic groups through federalism and associated institutional design. Based on these, I develop a hypothesis for future testing that a type of federalism that encourages multiethnic institutions, including multiethnic political parties, at the macro-scale combined with lower level but constitutionally empowered ethnically sensitive institutions, is more likely to achieve political equality than traditional federal designs aimed to emphasize state neutrality or ethnic rights. It is here I take a normative turn.

Firstly, I develop an approach to considering success in federal systems according to an ideal of political equality that blends moderation and accommodation, and explore the potential for deliberative democracy to facilitate moderation in a divided society and bridge the divide between consociational and centripetal approaches. The federalism debates in Nepal, Myanmar and Sri Lanka have highlighted the continuing influence of secession risk and infrastructural capacity and demonstrated how secure autonomy is in effect traded off against the recognition of ethnicity in unit demarcation to minimize secession risk and fears about the oppression of second order minorities. The accommodation of minority ethnic groups is also balanced with other moderating institutions, such as mixed or multiethnic institutions at the center, electoral incentivization to create conditions conducive to deliberation and local government, with the effect that a relative emphasis on territorial factors in unit delineation is supplemented by an ethnic emphasis in electoral design and at the sub-unit level. 
The cases show how the process of constitutional settlement acts in itself as a moderating mechanism by providing a deliberative forum for deeply divided ethnic groups to come together, and to engage with the dominant group in inclusive and accountable settings. Deliberative conditions, particularly inclusivity, multilevel engagement, semi-detachment and accountability, can blend with party-based competitive democracies to balance otherwise competing objectives of centripetal and consociational approaches to governance in a deeply divided society. In particular, tenets of competitive liberal democracies are temporarily superseded or bypassed to arrive at federalism via deliberative consensus-based processes that give extra weight to traditionally excluded groups. Once agreed, competitive democracy is reasserted, but in a more diffuse and inclusive setting that remains sensitive to cultural preferences for consensus via deliberation.

These cases do not have or need grand coalitions to manage diversity once federalism is in place; instead a system that encourages multiethnic political parties at the national level is hypothesized to be the most effective way of maintaining cross-ethnic deliberation in an accountable setting. Coalitions have not made the difference but multiethnic parties have. Rules that encourage the major parties at the center to become more multiethnic have an important moderating effect that can combine with the self-rule elements of federalism, with ethnic parties at the periphery, without the need for power-sharing or specific consociational forms of inter-ethnic exchange and empowerment. Horowitz and Lijphart agree that once ethnic parties emerge, their spread is near inevitable. This does not mean that multiethnic parties are altogether absent, although "it remains to be seen whether, in a deeply divided society, multiethnic parties and coalitions can put back together what ethnic parties have helped pull apart" (Horowitz 2000 [1985], p. 364). This is a question to which I now turn.

\subsection{The effectiveness of federalism in Asia}

In Chapter 3, I argued that the institutionalization of liberal democratic ideals, including the principle of state neutrality, along with a federal system is not what success turns on. David Steinberg (2012, p. 34) argues similarly that for Myanmar, "the essential issue remains not primarily the future of some form of democracy in that country, however important that is, but rather some indigenous solution to the problem of the distribution of power among ethnicities". In Sri Lanka, democracy has hindered and not assisted parties to reach accommodation, as ethnic based parties 'outbid' each other leading to ever more increasing exclusion and democratic decay (DeVotta 2011; DeVotta 2004). 
Democratic ethnic federalism and consociationalism (a consensus-based democracy) have been argued as the alternative to state neutrality in divided societies, but are opposed by those who argue moderation within a majoritarian competitive democracy is pivotal. In addition to secessionist fears, citizens of diverse countries like Nepal, Myanmar and Sri Lanka fear the impact that ethnic federalism might have on second order minorities, hence the emphasis on moderation. However, I have argued that there is an inherent injustice in the denial of substantive group autonomy, whether via a unitary or purely territorial federal state structure, particularly when the overarching state identity is imbued with the symbolism of the dominant group, as has been the case in Nepal, Myanmar and Sri Lanka. Therefore, accommodation must be blended with moderation.

Further, the design of the units cannot be understood without reference to the electoral or other representative systems as both are means of increasing the participation of different ethnic groups, as per my concept of Asian federal systems. A country may incorporate less ethnicity into its units (e.g. Nepal) but compensate via proportional electoral requirements, whereas a country (like Myanmar) that has a high degree of ethnicity in its federal units may see little need for proportionality in its electoral system. Neither approach is inherently more or less accommodating, but a hybrid system would appear to better balance between group and individual rights, or blend accommodation and moderation.

As mentioned in Chapter 1, the experiences of Nepal, Myanmar and Sri Lanka also entail a rejection of the consociational paradigm, except as part of a transition, and the formalization or use of a minority veto is rare and confined. In addition, Nepal and Myanmar have increasingly multiethnic political parties, operating at the central level alongside ethnic parties, which belies theoretical assumptions underpinning conflicting consociational and centripetal approaches. The minority ethnic groups in these countries are seeking accommodation via autonomy and inclusion, and remain relatively unconcerned about their role in the center. That is, a structure that empowers ethnic elements at the unit and subunit level, even extreme ones, while moderating via inclusion and deliberation at the center, including multiethnic political parties, is emerging.

\subsubsection{Federalism and success}

To consider the extent to which different federal systems are more or less successful, or likely to be more or less successful, I look to political equality. Most tend to evaluate federalism according to its contribution to stability, but if its purpose in Asia is the management of diversity, then evaluation should be aligned with its ability to deliver this in a 
fair and equitable manner. That is, does federalism contribute to just outcomes for minority ethnic groups?

Franck (1968), in an influential book on 'why federations fail' takes failure as the break-up of a federation (and argues for four hypotheses to explain such failure ${ }^{74}$ ), while Hueglin \& Fenna (2015, pp. 4-6) argue that the success of federalism can be understood simply in terms of the absence of existence of an 'existential conflict'. McCulloch (2014, pp. 6-9) also focuses on 'political stability', ranking countries in terms of stability, instability or imposed stability, which follows Lijphart's (1977, p. 4) conception of system maintenance, civil order, legitimacy and effectiveness. Henders (2010) in a comparative study of special autonomy in authoritarian and democratic contexts develops a broader approach to identifying success, settling on stability (understood on a spectrum); and justice, which is understood as an inclusive citizenship that achieves formal and substantive equality.

I build on Henders' approach, and accept the normative perspective of Kymlicka (1995) that success should be understood in terms of what institutional arrangements are most able to contribute to justice. I treat justice as fairness, not in a neutral individualistic Rawlsian sense, but in way that accounts for the different and underpinning value systems that can be observed in divided societies, including for example communitarian loyalties that influence decision-making and political posturing (see for example O'Flynn 2007; Sandel 2009, pp. 208244). The challenge in such societies is to achieve political equality - that is, an equality by which all sectors of society have the opportunity to participate in political decision-making, and to have their voices heard, rather than a classical liberal sense as legal equality and state neutrality. In a divided society, this means both individual and group equality.

Myanmar's United Nationalities Federal Council is advocating for exactly that. Its Position Statement (2011) asserts that the "lack of equality is the crucial problem underlying the politics of Burma" (Point 1), and that "instead of resolving the problems by political means, use of the military might for suppression or regional development after ceasefire, by the regimes in power is an attempt to break up the struggle of the nationalities for "Political

\footnotetext{
${ }^{74}$ That the presence of commonality (secondary factors) may be a necessary but not sufficient condition; absence of ideological commitment to federalism 'as an end in itself', makes success improbable or impossible; if political commitments are based on short term goals (e.g. to end conflict) then federal institutions last only as long as those goals are important; and, creation of federal institutions with federal ideologies will not resolve or transform issues.
} 
Equality" by trickery and so the country has been driven away from peace for more than 60 years" (Point 2).

McGann (2006) argues that political equality implies proportionality and that proportionality and majority rule offer the best protection for minorities and encourage consensus.

However, his arguments do not adequately account for the circumstances of divided societies and the permanent marginalization that occurs because of converging cleavages, let alone the power reproduction tendencies of institutions. Further, equality should not mean strict legal equality but incorporate special treatment for those in need, which may be at an individual or group level (e.g. Sandel 2005), while proportionality on its own is not sufficient because if there are groups that are so small or so scattered so as to be rendered voiceless, then special measures are required to provide a meaningful opportunity for group autonomy or participation more generally.

Accommodation, comprising inclusion and autonomy, can be said to provide one dimension of political equality, being the group dimension. However, the highest theoretical level of accommodation is not necessarily the most likely to create political equality (it might be too accommodating and compromise other rights) and there are trade-offs made. In particular, the aforementioned potential effect of ethnic federalism on second order minorities, and the potential for new conflict are valid concerns. This motivates Horowitz's call for moderation and underpins O'Flynn's (2006) argument that political equality should be understood as inclusion and moderation.

Following O'Flynn (2006) (and to an extent Horowitz 2000 [1985]; McGann 2006), I argue that moderation can bridge these two potentially conflicting ideals - individualism and communalism ${ }^{75}$. However, I expand $\mathrm{O}^{\prime}$ Flynn's inclusion to accommodation, in accordance with my conceptualization of Asian federal systems. Moderation can occur via at least two particular mechanisms - electoral incentivization and deliberation. For the former, vesting executive authority in a president who is elected via a system that requires appealing to other ethnic groups is rejected for the reasons discussed above, and the cases are looked to for more innovative options. For the latter, O'Flynn (2006) argues that institutional design

\footnotetext{
${ }^{75}$ Kymlicka (1995) famously sought to reconcile group and individual rights via the idea of external protections and internal restrictions. However, his framework is most suitable to situations where indigeneity is clear cut and not widespread (i.e. post--colonial countries, like the US, Canada and Australia) and is difficult, if not impossible to implement in Asia where the diversity is such that homogenous homelands can rarely be drawn, the status of particular groups is hotly disputed (e.g. the Rohingya in Myanmar), the state is openly not neutral, and there are numerous competing claims to natural resources, for example. Further, individual rights protections regimes are not prominent in this region.
} 
should encourage reciprocity (such as through mutual non-use of a veto right), and publicity (such as via requiring representatives to engage with community-level deliberative forums). I adapt the idea of publicity and reciprocity to focus on accountability as these requirements encourage participants to account and be accountable for the impact of their policy preferences (and how they are advocated) on other ethnic groups and individuals. As O’Flynn summarizes:

Once ethnic groups agree to deliberate with one another, they will no longer be able to justify their claims simply by appealing to their own interests. Instead, if they want their claims to succeed, they will have to begin to think about how those claims will impact on others (O'Flynn 2006, pp. 56-57).

Importantly, these 'success factors' are neutral to presence or type of democracy, which is itself still evolving to suit the Asian context and may not turn towards traditional Western liberal democracies. In particular, developing a deliberative rather than competitive liberal democracy may be more conducive to moderation and a successful federalism. I return to this matter later this in this chapter, after first considering the extent to which federal unit design and electoral mechanisms may effectively blend accommodation and moderation in the cases of Nepal, Myanmar and Sri Lanka.

\subsection{Ethnic or territorial federalism}

In Nepal, Myanmar and Sri Lanka, the units are demarcated with a degree of ethnicity incorporated into their design. However, there is a far greater extent of ethnic homogeneity in the units in Myanmar and Sri Lanka. The dominant ethnic group in both Myanmar and Sri Lanka has a relatively secure position at the center, each comprising more than two thirds of the population. Hence, greater ethnicity can be afforded in the units as the risks of localized marginalization are lower and the position in the center can be maintained as a counterweight to the potential consolidation of ethnic power in a unit, and potential for secession. This is why the debate over the division of powers is more contentious in Sri Lanka and Myanmar than in Nepal. Further, each is an ethno-territorial federal systems, rather than a strictly ethnic federal system, because the dominant group is split across several units. This hybridity creates a more balanced system, but in practice makes it more likely that the units remain subordinate to the center.

In Nepal, no one group can nation-build and dominate the new structures and so the rights of second order minorities are more secure and the risks of secession are inherently lower. The 
higher the number of groups, the more power can be afforded to units because it is more diffuse, most especially when the processes for designing federalism are inclusive and deliberated. The more minority ethnic groups have infrastructural capacity to bolster their position and make alliance more attractive, the deeper the federalization is likely to be. These relationships are illustrated in Table 4, where it is shown that the extent of autonomy is inversely related to the relative size of the dominant group, taking account of the number of major minority ethnic groups, measured here as groups comprising more than $1 \%$ of the population and the degree to which a single ethnicity is the basis of the units. The scores for basis of units and autonomy are components of the Asian federal systems concept and scored according to the system detailed in Appendix 2. A higher score equates to more ethnically based units, or more autonomy, as applicable.

Table 4: Summary of demographic, unit demarcation and autonomy relationships

\begin{tabular}{|l|l|l|l|l|r|}
\hline & $\begin{array}{l}\text { Number of } \\
\text { ethnic } \\
\text { groups }\end{array}$ & $\begin{array}{l}\text { Number of } \\
\text { groups over } \\
\text { 1\% of } \\
\text { population }\end{array}$ & $\begin{array}{l}\text { Dominant } \\
\text { group } \\
\text { percentage of } \\
\text { population }\end{array}$ & $\begin{array}{l}\text { Basis of } \\
\text { units score } \\
\mathbf{( 2 0 1 5 )}\end{array}$ & $\begin{array}{l}\text { Autonomy } \\
\text { score (2015) }\end{array}$ \\
\hline Nepal & 118 & 18 & 28.8 & 1 & 2 \\
\hline Myanmar & 135 & 7 & 69 & 3 & -0.5 \\
\hline Sri Lanka & 6 & 4 & 74 & 2 & -1.2 \\
\hline
\end{tabular}

(Sources: Table 1 and Appendix 2, Summary Tables)

Accounting for the added effect of a high secession risk takes the relationship a step further. Table 5 gives a range of examples across the federal systems of the three cases, adjusting statewide data to a sub-unit level. Conflict, ethnic homogeneity and the international influence are the three components of the secession risk. The examples show that control was most centralized where the secession risk was high, and autonomy strongest when that secession risk was low. This contributes to an apparent diffusion explanation for federalization because the international security environment contributes to the extent to which a realistic secession threat is viable. However, the secession risk is more pertinently explained by domestic factors. 
Table 5: Summary of secession risk and autonomy relationship

\begin{tabular}{|l|r|r|r|r|r|}
\hline Country: Unit(s) & \multicolumn{1}{|l|}{ Conflict } & \multicolumn{1}{|l|}{$\begin{array}{l}\text { Ethnic } \\
\text { homogeneity }\end{array}$} & $\begin{array}{l}\text { International } \\
\text { influence }\end{array}$ & $\begin{array}{l}\text { Secession } \\
\text { Risk }\end{array}$ & \multicolumn{2}{l|}{$\begin{array}{l}\text { Autonomy } \\
\text { score }\end{array}$} \\
\hline $\begin{array}{l}\text { Nepal: Madhesh } \\
\text { (2015) }\end{array}$ & 1 & 0 & 0 & 1 & 2 \\
\hline $\begin{array}{l}\text { Myanmar: Shan } \\
(2015)\end{array}$ & 0.5 & 1 & 0 & 1.5 & -0.5 \\
\hline $\begin{array}{l}\text { Myanmar: Karen } \\
\text { (2015) }\end{array}$ & 0 & 0.5 & 0 & 0.5 & -0.5 \\
\hline $\begin{array}{l}\text { Myanmar: Kachin } \\
\text { (2015) }\end{array}$ & 1 & 1 & 0 & 2 & -0.5 \\
\hline $\begin{array}{l}\text { Myanmar: Karen } \\
\text { (1974) }\end{array}$ & 3.75 & 0.5 & 2 & 6.25 & -2 \\
\hline $\begin{array}{l}\text { Sri Lanka (2016): } \\
\text { Northern }\end{array}$ & 0 & 2 & 0 & 2 & TBC \\
\hline $\begin{array}{l}\text { Sri Lanka (1989): } \\
\text { Northern/Eastern }\end{array}$ & 1 & 2 & 2 & 5 & -1 \\
\hline
\end{tabular}

(Based on Appendix 2 Summary Tables adjusted to a sub-unit level)

These federal systems are inherently mixed, balancing autonomy and ethnicity and creating mixed or ethno-territorial responses to diversity. Similar patterns are apparent elsewhere in Asia. India is the celebrated federal system of the region, supporting a vibrant democracy. At face value, India's experience might suggest that there is a positive relationship between the extent of ethnicity in the units and their autonomy. However, at the time of India's federalization, the units were territorial and it was not until later that they were reorganized along language grounds, with the continual addition of ethnicity into the system (Bhattacharyya 2010; Singh \& Kukreja 2016). Malaysia has a largely mixed system (its units were deliberately designed to cut across ethnic groups (Case 2007)) and secure autonomy, even if the extent of powers is low. It was not until after initial federalization that the extent of ethnicity in the units was increased (via the additions of Sabah and Sarawak). In Pakistan, a system with strong autonomy and a strong ethnic dimension was initially agreed in 1956 but lasted just two years replaced with the 'one-unit plan' which consolidated West Pakistan provinces into one, largely negating the ethnic dimension. It wasn't until 1970 that the original four western provinces were re-established, with the Federally Administered Tribal Areas added later (Adeney 2007). Alternatively, an argument might be made that as the ethnic groups prove themselves - or self-administer their units and make legislation - a more fulsome autonomy can gradually proceed. However, such incremental approaches to federalization are not practiced and basic structures are locked in until such time that substantial change becomes possible. Incremental ethnicization of a pre-existing federal system is more common (such as in India), and so arguably, units should start strong. 
Hybridity manifests in other spheres, most notably the political party system. Federalism provides the space for ethnic institutions to thrive in the units, but not necessarily in the center. It seems obvious that ethnic parties would be more prominent in the units, but making the distinction is important because the place of ethnic parties at the center is an assumed part of a consociational approach, but not necessary in a federal system if the parties at the center are multiethnic (this is discussed further in the next section). For example, in Myanmar in 2010, ethnic parties held around 25\% and more of the seats in five of the seven ethnic state parliaments, whereas at the center they held just ten percent of the seats (Transnational Institute 2010; Appendix 2, Table A15). Similarly, in Sri Lanka, the most recent Northern Province elections were dominated by ethnic parties winning more than 90\% of the seats (Department of Elections 2013), compared to around ten percent of seats in the center (Appendix 2, Table A23).

Multiethnic parties may be contrasted with non-ethnic parties, which are supposed as neutral but in these cases reflect the preferences of the dominant ethnic group. A multiethnic party accepts that members will bring ethnic preferences to the table, but to be addressed in a more collegiate fashion, rather than via inter-party competition. If combined with a secure existence for ethnic parties at the periphery there is less incentive for those ethnic agendas to be bargained at the center, which can be more safely de-ethnicized without a corresponding loss of the ethnic autonomy demanded by minority groups. The problem in Nepal, Myanmar and Sri Lanka has been the ethnocratic center, not ethnic rights in the periphery.

Also, an emphasis on local government and smaller autonomous zones can be seen in each of the cases, and Asia more generally. In Myanmar and Nepal, three levels of government are given constitutional status and powers, and a similar outcome is likely in Sri Lanka. Not only does this recognize South Asian traditions of village based government, it further mitigates the risks associated with secessionism, creating alternate (co-located) power sources, and the marginalization of second order minorities. It avoids an elitist consociational solution whereby access to power is held amongst a privileged few. As much is laid out by Pradip Gyanwali, Secretary of the UML who explained that the public "do not think that citizens will be strong if the current powers of the center are redistributed to elites in federal states. So providing rights to local people should be our first priority" (cited in D. Karki 2014).

Strong local government is considered to be appropriate in these cases because they have such high diversity and it is not possible for provincial level units to be demarcated with a 
high degree of homogeneity, except in rare cases such as the Northern Province of Sri Lanka. In this way, group autonomy can be enacted more precisely and broadly, while avoiding to a large extent the concerns that ethnic federalism gives rise to. A mixed basis to provincial level units is consistent with ethnic accommodation because it means stronger units and so indirectly more empowered ethnic minorities, with local level units providing autonomy to smaller groups. Further, it does not contribute to deadlock or negatively impact governability because power relates to self-rule and the proliferation of veto-points can be avoided. Personal laws can be used to further protect the rights of small and scattered minorities and positively empower them. Personal law systems, mostly relating to family law, are used extensively in Sri Lanka, and while Nepal and Myanmar do not have formal personal law systems, there is observation and acceptance of different family law principles. These personal law systems predate the modern state and were used to help maintain stability in the British empire (Ahmed 2010; Ghosh 2007; Aung 2015).

Further, autonomous zones and local government may be an appropriate middle ground for addressing the concerns relating to those groups who are of a somewhat ambiguous 'national' status - that is, those groups who are neither longstanding ethnic nationalities or recent immigrant groups and whose place in the state has been disputed. Specifically, Rohingyas in Myanmar, Upcountry Tamils in Sri Lanka and possibly Muslims in Nepal. Upcountry Tamils have canvassed such an approach while non-territorial federalism has been considered for Muslims in Nepal. Rohingyas have not claimed rights for an ethnic state in Myanmar, but there have also been ongoing problems between Arakanese and Rohingyas to the extent that the communities have been segregated.

However, all of these matters relate to self-rule. Federalism is a way of institutionalizing selfrule and shared rule. As discussed in Chapter 6, a role in the center is of comparatively little interest to the minority ethnic groups and barely debated. Indeed, I found it difficult to engage key actors in discussion about this issue, as they were almost entirely focused on selfrule. Bicameralism is accepted as a feature of federalism, but not prioritized. Legislatures representing unit interests often vote along party lines, rather than on a per unit basis, and so its impact as a mechanism of federal power-sharing is limited. Both Nepal and Myanmar have two houses of parliament, accepted with little debate, and Sri Lanka does not. It is advocated by some in Sri Lanka, but more as a means of improving democratic accountability and protecting against the majoritarian tendencies of the center by including underrepresented minorities and experts, in addition to representatives of the units (see Chapter 8, Public Representations Committee on Constitutional Reform 2016). Instead, the 
role of ethnic minority groups in the center is mostly given effect by the political party system and electoral mechanisms, which are fundamental to how a federal system manages diversity. The following section briefly recounts the political party and electoral systems to discern and attenuate lessons in the context of other federal design issues.

\subsection{Power sharing and political inclusion}

Political party systems have long been acknowledged as integral to the functioning of federal systems and the regulation of ethnic conflict. Riker (1964, p. 136) argued that political parties are the key institutional variable determining whether federal systems are sustained and whether they are centralized or decentralized. Rokkan and Urwin (1982) demonstrated that in Europe, regional and ethnic parties emerged in response to centralization while Horowitz (2000 [1985], pp. 291-349) argued that ethnic parties foster conflict, and that once they emerge, their rise is near unstoppable. Horowitz contrasts the depth of conflict evident when there are only ethnic parties and highlights the moderating effects of two-party systems and multiethnic parties and coalitions. Benjamin Reilly (2006, p. 814) goes further, citing a "weight of empirical evidence in favour of aggregative party systems in general, and the bleak assessment of ethnic parties in particular".

Reilly (2006) surveys four approaches to centripetal political engineering that are aimed at developing multiethnic political parties or coalitions - direct intervention, constraining ethnic parties, using electoral incentives and top-down approaches - but at the expense of ethnic and regional parties. There are downsides, as acknowledged (p. 824-825), including that some ethnic groups may get locked out of access to power, and that without such access ethnic groups may resort to other means (e.g. violence) to pursue their goals or express their grievances. This simply recreates many of the problems we are trying to address. However, as discussed in Chapter 3, their advice is contrary to those of consociational theorists who would prescribe a political system that enshrines an integral role for ethnic parties.

Hence, the question becomes, can the rise of ethnic parties be accepted but with extremities mitigated by the introduction or evolution of multiethnic parties at the center, and in larger heterogeneous units? Horowitz (2000 [1985], pp. 362-364) notes that the development of a multiethnic dimension is one of three directions that an ethnic party system can take, and certainly the most desirable one ${ }^{76}$. However, he also makes the case that in a deeply divided

\footnotetext{
${ }^{76}$ The other two, to a single party system or a military regime, are directions that have been taken in Myanmar, without sustained success, while only one of Reilly's approaches - electoral incentivization - is suitable for developing party systems that blend ethnic and multiethnic parties.
} 
society, "there is room for only one multiethnic party or alliance" (p. 410) because competitor parties are left with little option but to appeal to ethnic interests and extremes, and that there is a risk that such a party will resort to undemocratic means to maintain power (p. 429-437).

The cases of Nepal, Myanmar and Sri Lanka show that it is possible to have more than one multiethnic party as viable contestants for power, while at the same time accommodating ethnic parties. Engineering such dual outcomes is a worthy option in deeply divided societies where ethnic parties have come to prominence, especially when compared with the salience and effectiveness of coalition government as recommended by Lijphart (1999), or the more draconian interventions canvassed by Reilly (such as banning ethnic parties).

\subsubsection{Electoral and political party systems}

The range of electoral systems tried in each country over the past seventy years is substantial. From Sri Lanka's fully proportional electoral system to Myanmar's first past the post system (FPTP), supplemented by reservations, to Nepal's innovative mixed system, all take markedly different approaches. Nevertheless, at their most recent elections, Nepal (2014), Myanmar (2015) and Sri Lanka (2015) all returned moderate elements in what has been characterized as "a race to the centre...not to the wings, because people do not want to instigate any further antagonism" (Byrne \& Klem 2015, p. 9, writing about Sri Lanka and Nepal). This can be attributed, in part, to a war weariness, but also I would argue that this is an outcome of the increasingly multiethnic character of political institutions, most particularly political parties and coalitions. It is not an outcome of the electoral system directly. Sri Lanka's proportional representation (PR) system has entrenched a two-party system alongside ethnic extremism, contrary to the outcomes predicted by theory, while Myanmar's FPTP system sees parties proliferating, but only moderates being rewarded (with one exception being the Arakan National Party in Rakhine State).

Proportionality and inclusion were of critical importance to Nepal's transformation. Nepal had failed experiments with democracy in the 1950s and 1990s, as well as a partyless variant, all of which had FPTP electoral systems with additional appointed members, though not specifically for ethnic groups. In each case, minorities were poorly represented, and democracy failed. Except for one Madheshi party, no minority ethnic party gained a seat in parliament until the Constituent Assembly election of 2008, and the major non-ethnic parties were dominated by upper caste Hindus and were in effect the ethnic parties of the dominant ethnic group (for example the UML's central committee included only $13 \%$ minorities 
compared to a population proportion of more than 70\%) (Malik et al. 2009, pp. 406-7). It was not until the electoral system was reformed that both ethnic and multiethnic political parties became commonplace, to great effect.

Firstly, an ethnically-based proportionality component was introduced, with closed list proportional representation in a nation-wide constituency, and secondly, there was a requirement that "the political parties also shall ensure the proportional representation of women, Dalits, oppressed communities/indigenous groups, backward regions, Madheshis and other groups" (Article 63(4), Interim Constitution of Nepal 2063 (2007)). This was supported with legislation requiring parties to put up candidates at a mix of $13 \%$ Dalit, $37.8 \%$ Janajatis (indigenous), 31.2\% Madheshis, plus others (International IDEA 2015, p. 12). Parties below a certain size (a list with candidates running in $30 \%$ or less of available seats) were not required to have proportionality, and there was $10 \%$ flexibility for others. The work of incentivizing moderation was thus done at two levels - one for political parties to appeal across the electorate to gain reserved or proportional system seats and second to internally become multiethnic. The 2015 constitution retained provisions requiring major parties to be multiethnic (Article 176(6), Constitution of Nepal 2015).

The electoral system did result in inclusive outcomes and the effects on parties extends beyond the proportional representation list component (see Appendix 2, Tables A6, A7 \& A8, and Vollen 2008; Nepali 2008). Conventional approaches to analyzing proportionality (e.g. Lijphart) would correlate party type with ethnic representation, assuming the mono-ethnic nature of political parties in deeply divided societies. If this assumption held, then the outcome of the FPTP component of the 2013 Constituent Assembly election would have returned no Janajatis (indigenous), no Dalits and twelve Madheshis. Instead, FPTP voting returned 59 Janajatis (25\%), ten Dalits (4\%) and 45 Madheshis (19\%) (see table 6 below). While these numbers are not in proportion to the general population, they are nevertheless a marked improvement on a history where positions of power and political parties were traditionally dominated by one ethnic group. Indeed, almost $50 \%$ of the major party FPTP winners were from minority ethnic groups. Further, the electoral system is parallel, rather than mixed-member proportional and so these FPTP minority ethnic group seats are additional to their guaranteed share under the proportional component. 
Table 6: Comparison of 2013 election outcomes on a party versus ethnic basis

\begin{tabular}{|l|l|l|}
\hline & $\begin{array}{l}\text { First past the post seats by party } \\
\text { type }\end{array}$ & $\begin{array}{l}\text { First past the post seats by } \\
\text { ethnicity }\end{array}$ \\
\hline Non-ethnic* & 226 & 126 \\
\hline Ethnic & 0 & 59 \\
\hline Madheshi & 12 & 45 \\
\hline Dalit & 0 & 10 \\
\hline Other & 2 & - \\
\hline TOTAL & 240 & 240 \\
\hline
\end{tabular}

Data source: (Citizens Committee for Clean Election 2014)

* Non-ethnic is equated with high caste Pahadi and ethnic with minority ethnic groups, other than Madheshis and Dalits, who have their own category.

Multiethnic parties and specific efforts and rules requiring within party inclusion have meant that a grand coalition is not necessary, and some of the problems noted by Horowitz among others, such as deadlock, can be avoided. Further, a grand coalition is not actually desired by the parties ${ }^{77}$. Even though there were consociational style transitional arrangements, such as a national consensus government, it is the nature of the political party system that is determining how power at the center is shared amongst different ethnic groups and the people expect the composition of government to be decided by electoral means ${ }^{78}$. As put by the Sri Lankan Constitutional Assembly's Subcommittee on Centre-Periphery Relations "a healthy opposition is essential to the sound working of a democracy" $(2016$, p. 8).

There is a risk that within a multiethnic party, which is not transparent, existing relations of power between ethnic groups will be reproduced. For example, Nepal's post Constituent Assembly II Cabinet was still dominated by upper caste Pahadis, comprising more than three quarters of the Cabinet but less than 30\% of the population (Lawoti 2014: 142). However, the composition of the Cabinet was more inclusive in ethnic terms than under any previous incarnation of democracy or autocratic rule by the then king. The 2016 first post constitution Cabinet included Janajatis, Dalits, Muslims and other Madheshis all drawn from a mixture of multiethnic and ethnic political parties (Appendix 2, Table A10). Ethnic minorities that find themselves sidelined in major parties can and do start their own competitors adding an additional element of accountability to the internal party processes. As confided with me by

\footnotetext{
77 For example, according to Baburam Bhattarai, the then Maoist Vice Chairman "the Maoists, Madhesis, and Janajati forces have an issue-centered cooperation among them for constitution writing, which will remain until the statute is written" (cited in Upadhyay \& Bhattarai 2014), while the Madheshi parties, advised that they “instantly rejected the UML's proposal of national unity government. We will not even utter the letter 'G' of government until a constitution is drafted," Chairman of Sabhavana Party, Rajendra Mahato, (cited in Kantipur Report 2014).

${ }^{78}$ Claims that power-sharing negotiations were holding up the constitution process were firmly dismissed by the then UML General Secretary, Pradeep Gyanwali "Quite a few commentators have opined that the current deadlock has more to do with post-constitution power sharing. As someone who has been involved in talks and who has closely observed the political process, I can safely say that the issue of power sharing has not come up strongly and it has not affected the constitution-drafting process," (cited in Sharma \& Kharel 2015).
} 
one Janajati member of the UML, although it had been difficult to convince others of his groups' position, minorities have more influence working from within the major parties than from protesting or starting their own ethnic party.

The case of Myanmar also reinforces the importance of the political party system to proportionality, power sharing and moderation. The NLD has established a multi-party government of national reconciliation, but ethnic representation most substantially comes via its own members. It has appointed from its own party ethnic speakers in both houses of parliament, an ethnic vice president, and ethnic chief ministers to six of the seven ethnic states (Lwin \& Lone 2016). The national reconciliation government is inclusive of members of the military (as required under the constitution) and the military aligned USDP, but most ethnic parties, including the powerful and ideologically aligned Shan Nationalities League for Democracy declined to participate (Myint 2016). Even the USDP has become multiethnic. In the 2010 election, which the USDP won comprehensively, 64\% of the legislature's elected ethnic minority representatives were from major Bamar-led parties, with the remainder provided by ethnic parties (Appendix 2, Table A15).

The coalition present in Myanmar in 2016 is a coalition of parties, whether ethnic or not. But it is multiethnic because of the increasingly mixed status of the NLD and USDP, more so than the systematic inclusion of different ethnic parties, let alone meeting criteria of equal representation in a grand coalition. The oppositional element is important to the functioning of democracy, especially outside of times of transition, and arguably the accountability does more for moderation than a purer reciprocity as envisaged by a consensus-based approach. Further, the multiethnic status of major central political parties gives confidence to ethnic parties to collaborate and stand on an equal footing. This is encapsulated by the newly elected Ta'ang National Party MP, Daw Nan Moe, joining the Parliament for the first time: "Today I feel excited, because I have to start a great job for my ethnic people. We are a small group but there are also a lot of ethnic people in the NLD so I am hopeful we can work together" (cited in MacGregor 2016).

Myanmar has never had a proportional or mixed (parallel) electoral system. Proposals to move to a proportional representation system, at least in the Bamar dominated units, was debated in Parliament in 2014 and rejected by the lower house, after being recommended by the upper house. The NLD and ethnic parties believed that they would fare better under an entirely FPTP system, and that the proposed changes were a ploy by the military aligned USDP to bolster its electoral outcomes (Nyein 2014). The ethnic parties performed poorly at 
the 2015 election, however, and may seek for this to be revisited. The NLD successfully put forward ethnic candidates to run against ethnic parties. The ethnic parties relative failure has been blamed on vote splitting given their recent proliferation, however, this is not supported by evidence (International Crisis Group 2015, p. 7). The main reason is that a strong central alternative to the military party was seen as required for democratic transformation and the people saw NLD leader Aung San Suu Kyi as the best person to deliver that (see for example MacGregor 2016). This was acknowledged by the ethnic parties themselves: "the National League for Democracy is the only party, among the big ones, that could bring about change on a national scale. And there's only [one] Daw Aung San Suu Kyi. That's why everyone voted for them" (Dr Tu Ja, former leader of the Kachin Independence Organization, cited in Win 2016).

Otherwise, Myanmar's electoral outcomes are reasonably proportional and inclusive because the ethnic parties are often overrepresented, due to the clustering of their candidates and key constituents, balancing against the underrepresentation of the smaller nation-wide parties that fail to gain majorities in many constituencies (see Appendix 2, Table A15). So, while the NLD is a majority Bamar party, it is increasingly multiethnic and seen by ethnic groups as the preferred option at least at the national level to achieve democratic reform and reconciliation. It has adopted a moderate stance towards minority ethnic groups and committed to pursue federalism as part of the democratic transition. Moderation has come via the multiethnic nature of the major parties, rather than the electoral system. But accommodation should not be forgotten.

The most successful ethnic party in the 2015 election, the Arakan National Party, followed a specific policy of urging constituents to vote for the NLD at the central level, and for the ethnic parties at the local level (Win 2016). This is a potential inherent in the federal system that was successfully exploited in that unit and would appear to have value elsewhere. Not only does the dual nature of a party system in such federal systems create more proportional outcomes, it also facilitates inclusion by providing two avenues for minority ethnic groups to be represented, in multiethnic and ethnic parties, and reserving ethnic issues to the unit and local level. Myanmar has also had elections under a one-party system, which was multiethnic but Bamar dominated, for example in 1981 the party was $28 \%$ ethnic, which is close to a proportional level (Taylor 2009, p. 320). However, with power consolidated in the party, no incentive for the party to appeal to ethnic minority groups for votes, no real accountability to the electorate and no semi-detachment, a one-party system fails to incentivize moderation, even if deliberative practices prevail within party. 
Sri Lanka is also using a national reconciliation approach to its government formation, with political leaders compiling the good governance coalition that includes members of both major (Sinhalese) political parties, Upcountry Tamil parties and Muslim parties. However, it falls short of any kind of grand coalition status on account of the non-participation of the major Tamil political movement - the Tamil National Alliance. The major parties are including Tamils and Muslims among their ranks, but they are still Sinhalese dominated and ethnically biased in policy. In the most recent 2015 parliamentary election, just one major party candidate won a seat in the north and there is much closer alignment between the number of ethnic party seats and the number of ethnic representatives, especially of Tamils, when compared with Nepal and Myanmar (see Appendix 2, Tables A23 \& A24, compared with Tables A6 \& A7, and A15 \& 16). The Tamil National Alliance could have been a part of the coalition government, but considers that it is better able to further its objectives from opposition.

Encouraging or requiring proportionality within-party and in key constitutional reform institutions, such as in Nepal, may be more beneficial to Sri Lanka than a consociational approach to power-sharing. However, there is much to be done before those parties can be considered multiethnic or deliberative. One meeting of civil society leaders I attended was side-tracked by a lengthy discussion on party discipline, with some advocates seeking a ban on MPs crossing the floor or changing parties in return for a cabinet position. Similarly, most political and civil society leaders that I spoke too lamented the state of intra-party democracy, labelling it hierarchical, dynastic and centralized. However, many also asserted that the 'battle' between extremists and moderates was not between but within-parties and that it was from this venue that substantial change would be driven.

Sri Lanka's electoral system is supposed to encourage moderation via the use of an alternative vote when electing its president and preferential voting in its proportional representation system, both in place since 1978. However, they have failed to prevent the rise of extremists (e.g. Rajapaksa) in part because of the boycotting by, or banning of, Tamil participants, but also because the demographics of Sri Lanka are such that Tamil support is not really necessary for a candidate to be successful as there are still more votes available by appealing to extremist elements and there were not alliances among the minority groups. Furthermore, once in power, there is little scope for that person to be held accountable to minority groups. It was not until the then president Rajapaksa began to alienate many Sinhalese with his corruption and authoritarianism that the centripetal electoral design paid dividends. 
Prior to that Sri Lanka had a parliamentary system with FPTP. All of Sri Lanka's electoral systems have returned reasonably proportional outcomes in terms of ethnic group representation. However, there has been overrepresentation of Tamils and underrepresentation of Muslims, due to the latter's residence in more heterogeneous communities (see Appendix 2, Table A23 and The Island 2015). The 1978 shift to proportional voting had such a high threshold $(12 \%)$ that it only served to consolidate advantage in the existing major parties. The cut-off has since been reduced and the proportionality of outcomes has improved (Appendix 2, Table A23). However, because Sri Lanka has many homogenous areas, proportional systems do not necessarily improve proportionality of outcomes for ethnic groups, nor incentivize parties to appeal across ethnic groups. Moderation has not been a feature of Sri Lankan politics until recently and the system of preferential voting "led to an unacceptable degree of hyper-competition, corruption and violence" (Saravanamuttu 2016, p. 3). A mixed member proportional (MMP) system is now preferred by some (e.g. Saravanamuttu 2016; Tamil Civil Society Forum 2016; Tamil People's Council 2016), with others seeking a parallel system (similar to Nepal's) comprising 40\% proportional representation and 60\% FPTP (Rutnam 2016b).

The experience of each of the cases shows that traditional perceptions about the competitive requirement of democracy remain, and that a grand coalition approach to the management of diversity is not a major factor outside of the constitutional settlement process itself. As argued by former UML prime minister, Sher Bahadur Deuba in Nepal: "we have to remain in opposition to strengthen the democracy. We need to take democratic values to the grassroots level. In democracy, it is not good to have an all-party government" (cited in Bhattarai 2016). Further, they show that federalism provides the structures that enable a hybridization of political party systems, and the inclusivity of all ethnic groups at each level.

Proportionality and political inclusion, rather than power-sharing, are a critical element to federal accommodation in Asia. Their general absence in state institutions at one time or another has been one of the primary reasons that minority ethnic groups have revolted against majority rule and demanded autonomy. In Nepal for example, the redress of systemic exclusion of minority ethnic groups is one of the primary reasons for, and purposes of, federalism in Nepal. If Nepal's state structures had been inclusive of such groups, the demand for federalism, let alone the civil war would have been unlikely to arise. Similarly, in Sri Lanka, the federalism debate and the civil war are both responses to systemic exclusion and discrimination, rather than a longstanding demand of the Tamils. But after decades of 
ethnocracy and identity-based nation-building, political inclusion is not enough to overcome historical disadvantage, and positive group-specific institutions are necessary.

It might be argued that reservations or proportionality requirements that are identity-based unreasonably lock in and make primordial ethnicity, but we should not forget that these are multination states and the identities are present and persistent. The official and organic distinctions are in place and have been for a long time - longer than any of the world's existing constitutions. This is embedded to the extent that Myanmar citizenship cards incorporate a person's ethnic identity (Sadan 2009, p. 167). Further, those who (may) choose not to identify, or who do not fit within a reservation category, can be represented in an unallocated portion, which could also be filled by ethnic groups once their respective category is full, such as occurred in Nepal. Proportionality can be determined at the relevant level of government so that ethnic parties can still take a legitimately focused approach at the unit or local government level (or run for seats in areas most populated by their given ethnicity).

Andrew Reynolds (2000) proposes a similar framework to establish a middle-way of consociational and centripetal institutions, which he calls 'integrative consensual powersharing'. His model relies on the standard transferable vote proportional representation (STVPR) in mixed-member districts, rather than party list proportional representation, advocated by Lijphart. Reynolds argues that the STVPR system incentivizes parties to account for those who are outside of their particular ethnic group, on account of the benefits of securing preferences. However, he concludes that his integrative consensus type is appropriate where there are, or is potential for, cross-cutting cleavages. Further, the evidence that vote transfers across ethnic groups occur in divided societies is mixed (Reilly 2001; McCulloch 2014; May, Wheen \& Haley 2013; Coakley \& Fraenkel 2014). Nevertheless, the incorporation of preferential voting into a system like Nepal's would further facilitate moderation as parties would have greater incentive to appeal to voters from across other parties including ethnic parties, as well as across ethnic groups irrespective of party affiliation. Sri Lanka's experience suggests closed-list arrangements. The appeal across groups would happen at the electoral and party leadership level. If it were to use multi-member districts (rather than a nationwide constituency) meaningful heterogeneity in units would be required, otherwise the incentivization potential of a transferrable vote is not applied to ethnicity per se. 
I note that the experience of Nepal, Myanmar and Sri Lanka runs counter to conventional theory that proportional electoral systems are more suitable for divided societies because they tend to result in more proportional representation and multiparty governments, as well as supporting the emergence of a plethora of political parties, as compared to FPTP systems (Lijphart 1999). The actual outcomes of an electoral system are so intertwined with demographics that such generalizations cannot be shown to apply in the cases. Although party proportionality is higher where a PR system exists (Appendix 2, Tables A15 \& A23), ethnic proportionality outcomes are not necessarily so (Appendix 2, Tables A7, A16 \& A24). Myanmar has the highest ethnic proportionality (correlation between percentage of seats in the legislature and percentage of the population), but it has an entirely FPTP system, while Nepal with a mixed system has a comparatively lower degree of ethnic proportionality in outcome. Further, comparing Nepal's 1999 results, which were entirely FTPP, and the 2008 and 2013 results, when it used a mixed (parallel) system, demonstrates how FPTP may be most appropriate when minority ethnic groups are clustered. Madheshis and Janajatis were only marginally better off under the mixed system as compared to under the FPTP system, while Dalits, who are a scattered community benefited substantially (see Appendix 2, Table A6). Further, the change in electoral systems in Sri Lanka had no substantive effect on the number of parties represented in the government (see Appendix 2, Table A25). These outcomes reinforce the conclusions reached by Reilly (2002), who also observed the effect of the 'social context' on predicted outcomes.

However, developments in these three countries and South Asia more generally are contrary to other arguments put by Reilly (2007) that an Asian model of electoral democracy is emerging comprising FPTP systems and political party system engineering that encourages national parties and restricts regional or ethnic parties. The differences are partly due to their federalization, but also the very character of their societies, being highly diverse and divided. Indeed, the outliers in key aspects of Reilly's arguments, which are restricted to East and South-East Asia and the Pacific, are the Philippines and Indonesia which are the only highly diverse and significantly decentralized countries that he considers. I would argue that it is legitimate that such countries have regional and ethnic parties and aim towards within party inclusion at the center to avoid the permanent marginalization that can otherwise result. 


\subsection{Deliberative democracy and divided societies}

A political party system that incentivizes deliberation can be an effective mechanism for moderating extremes. Deliberative democracy, defined by the application of reasoned, informed and non-partisan (or dispassionate) argument to decision-making, is arguably more in keeping with traditional Asian political cultures and their emphasis on consensus ${ }^{79}$. As Whelpton, writing about the introduction of electoral politics to Nepal in the 1950s, observed, "many were unhappy with the kind of public conflict involved in competitive elections or in Panchayats themselves making decision by majority vote... there was a preference to seek consensus" (2005, p. 177).

Whether or not deliberative processes aim towards consensus, they facilitate and encourage interchange across sectors of society, and aim to ensure the proportional inclusion and political equality of participants. I adopt a definition defended by Dryzek (2000, pp. 1-2), who argues that authentic deliberative democracy can "be said to exist to the degree that reflective preferences influence collective outcomes". Some question deliberation's efficacy in deeply divided societies given the potential for increased polarization and emotive valuebased debates that are not conducive to reasoned analysis and compromise (see Dryzek 2005, pp. 219-222; Ugarriza \& Caluwaerts 2014, pp. 2-3). Therefore, I ask a further question - can deliberative democracy help find a middle ground between consociational and centripetal approaches to bring political equality to deeply divided societies by moderating extremes?

Dryzek (2005) argues that deliberation should occur in a 'semi-detached' sphere and not be associated with issues of identity and national sovereignty, because deliberation attached to decision-making results in people (most especially elites) being unlikely to change their minds and instead polarizing. However, this minimizes its impact, and civil society is not a strong actor in most deeply divided Asian countries, with some exceptions. Indeed, civil society has been repressed in many Asian developmental states, including Myanmar. I agree

\footnotetext{
79 The 1990s debate on Asian values, leaving aside the extent to which it was used to serve individual leaders' ends and simplifies an extensive internal diversity, identified a variety of differences with the West that go some way to explaining regime types and ways that equality and democracy are understood. In seeking 'good government' and a 'good society', many in Asia are more influenced by collectivist thinking and willing to tradeoff, or at least find a better balance between, individual rights and freedoms, and stability (Mauzy 1997; Meijknecht \& de Vries 2010). There is greater emphasis on hierarchy, and democracy may be better approached as a process of consultation, deliberation and consensus, rather than the adversarial and majoritarian approach that is taken in the West. Religion also continues to play a prominent role in many Asian states, where there is often no strict separation, or at least a blurring of the line that is strictly asserted in the West, and there is a clear correlation (which some argue to be a cause) between Buddhist states and resistance to federalism (Walton 2013; Raghavan 2013; Steinberg 2010; Tikekar 2009).
} 
nevertheless that deliberation should occur at a range of levels and with the general public, but contend that these institutions would be most effective if formalized, and multilevel federalism provides this opportunity. Further, I argue that political parties can and do provide important avenues for deliberation and moderation, fulfilling criteria of semidetachment but with firm links to the institutionalized political process.

Nepal's constitutional reform process demonstrates that deliberation can deal with difficult questions of ethnic and national identity. It created multilevel institutions that were linked, inclusive and accountable. Local level discussions were particularly deliberative because they were more easily divorced from the partisan and ethnic interests that often become entrenched at the elite level. Participants were more easily able to influence each other and find consensus, which could then be fed up to the elite level and decision-makers (see Centre for Constitutional Dialogue 2010a; Centre for Constitutional Dialogue 2010b; Centre for Constitutional Dialogue 2010c).

To establish this, I undertook a discourse analysis of the federalism debate in Nepal, identifying an increasing convergence between local level perspectives and those of elite decision-making bodies. Using media data (available in Appendix 3 ) and publicly available survey data I tracked the change in discourse that began with a polarization between ethnic and territorial federalism and converged to a broad agreement on mixed criteria that emphasized viability over identity, while still making room for both. Diagram 19 uses preferences for territorial federalism as an indicator of the change in local level discourse and the number of units (provinces) agreed by decision-making bodies as an indicator of the change in elite level discourse, whereby a smaller number of provinces indicates an increasing preference for solutions that emphasize viability (or territorial federalism). There is a clear correspondence. Further, as explained in detail in Chapter 6, the elite discourse changed in substance during this period as leading advocates of ethnic federalism gradually changed its meaning, dropping its association with political prerogatives and instead advocating an 'identity inclusive' federalism that was relatively moderate and more palatable to the general public. 
Diagram 19: Support for territorial federalism during Nepal's constitution-making process ${ }^{80}$

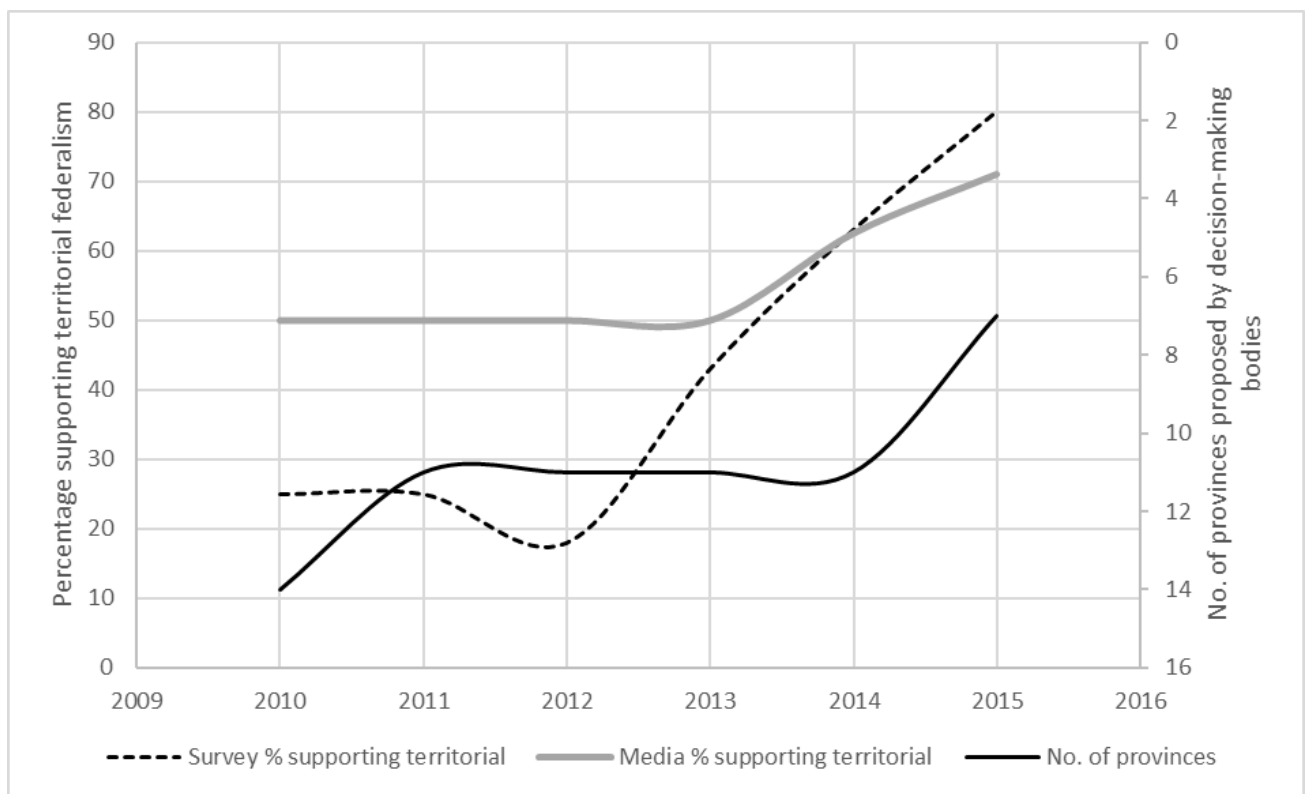

The Sri Lankan constitutional change process also demonstrates that local level deliberation can moderate views regarding federalism and fundamental questions of national identity. Former president Kumaratunga led a basic deliberative polling exercise that resulted in an increase in support amongst Sinhalese for devolution from 23\% to 68\% (Jabbar 2015). Absent from Myanmar constitutional convention process, its initial Constituent Assembly, and Sri Lanka's previous constitutional reform processes were these formal lower level arrangements for deliberating issues and feeding the results up to the elite level. From this perspective, Sri Lanka's current process has promise, while Myanmar's process lacks the grassroots level input (at this stage). Not that these are necessarily preventative, as the very commitment to an inclusive constitutional settlement process can signal a willingness to deliberate.

Others confirm the ability of deliberative mechanisms to moderate deeply divided societies. O'Flynn (2006) directly tackles the reconciliation of inclusion and moderation, as mentioned, arguing that political equality can be institutionalized through proportional representation in a legislature, but not necessarily in the executive as it reduces the potential accountability function of oppositional government and the requirement to publicly justify decisions. Two empirical studies (Luskin et al. 2014; He 2010a) using deliberative polling demonstrate that the seemingly intractable issues of identity and national sovereignty can be moderated via

\footnotetext{
80 Sources - survey data (Dixit 2010; Shakya 2015; Sharma 2015; Sharma \& Khadka 2011); media data: Appendix 3 (note insufficient data for 2011 \& 2012); decision-making data - (Committee on the Restructuring of the State and Distribution of State Power 2010; Constitution of Nepal 2015; Constitution of Nepal - Preliminary Draft 2015; International IDEA 2015).
} 
deliberation, and that civil and reasoned discussion can take place, at least at the local level. Further, He $(2013 ; 2010 b)$ identifies the potential of deliberative democracy to provide democratic legitimacy to self-determination claims based on historical arguments, as well the potential for deliberation in authoritarian settings, such as China, to facilitate democratization more broadly. Empirical studies of specific institutional tools to moderate the politics of deeply divided societies are also informative ${ }^{81}$.

In practice, development and peace-building professionals make a distinction between dialogue, deliberation and decision-making. 'Democratic dialogue' is a specific mechanism used in transitions to democracy as a prelude to deliberation, and ultimately decisionmaking. Although incorporating many features of what democratic deliberation would entail (e.g. sharing and seeking to understand others' perspectives), a conceptual distinction is made between the two. Democratic dialogues are intended to build trust, shared meaning and generally open up space for constructive cross-group (cross-ethnic) interaction.

According to this approach, dialogue should be followed by deliberation and 'examination of possible solutions', followed by decision-making that may involve negotiation and consensus building (Pruitt \& Thomas 2014). Although such a process is designed with peace-building in mind, institutionalization of multilayered and gradated means of decision-making is a viable approach to encouraging moderation in centrifugal and divided states.

These important steps have demonstrated that deliberative democracy can moderate extremes in deeply divided societies, and offered a selection of tools, or argued for the utility of certain conditions. Indeed, it doesn't necessarily rely on the presence of moderate leaders because people do change their minds under such conditions and through such processes. However, there is still a considerable gap at both the theoretical and empirical level. I consider the potential of federalism and the constitutional settlement process to contribute to a deliberative democracy that moderates consociational (centrifugal) elements, and show how the experience of Nepal, Myanmar and Sri Lanka exemplify options for their combination.

\footnotetext{
${ }^{81}$ Drake \& McCulloch (2011) argue that deliberative and consociational democracy overlap and can be effective regarding significant (rather than only local and small-scale practical) issues by instigating a two-stage process, the first of which relaxes deliberation's requirement for public reason to 'avoid pre-emptive exclusions', and the second which incorporates decision-making. Ugarriza \& Caluwaerts (2014) edit a series of case studies about the practice of 'democratic deliberation in deeply divided societies', including a proposed approach to 'federalist deliberative democracy' using the case of Nigeria. Akinola (2014) proposes that 'deliberative days' and polls be formally institutionalized and that the (traditional) federal institutions (e.g. legislatures) be "constitutionally mandated to ensure that elected representatives periodically meet citizens at a local level at public hearings or town hall meetings where representatives openly debate and discuss issues relating to national and state legislature activities" (p. 120).
} 


\subsubsection{Deliberative conditions and institutions}

Based on the arguments and outcomes described above, and the theoretical underpinning of deliberative democracy, I hypothesize that federal systems with well-designed electoral mechanisms can be both accommodating and moderating, if they institutionalize deliberative conditions. That is, when they are inclusive and representative, accountable, multilevel and semidetached. If we accept an argument about consensus-based cultures, but then emphasize competitive democracy, deliberation is required to find the middle ground.

At face value, the legislature that has substantive minority representation is a more suitable venue for deliberation than an executive, because it is transparent and more conducive to inclusivity. Further, if there is a parliamentary system, then the need for minority ethnic group involvement in the executive is lesser as the parliament plays a role in holding the executive accountable. Such sentiments are reflected by the traditionalist Nepali Congress: "looking at all of the parties' stances, it seems that we all want to ensure inclusion...the best way to do this is through a parliamentary system and a council of ministers that is answerable to the parliament" (KP Sitaula, Nepali Congress General Secretary and Chair of the Constitution Drafting Committee, cited in Rana 2014). A parliamentary committee structure also provides avenues to influence policy and reduce the incentive to sit in Cabinet (Lijphart 1999, p. 91). In Sri Lanka, a committee system is recommended to provide the multiparty element to executive governance, while still maintaining the oppositional element that is seen as necessary to ensuring democratic accountability (Sub-Committee on CentrePeriphery Relations 2016, p. 7; Prime Minister Wickremasinghe in The Sunday Leader 2016). I would add that it is not necessary that a system be parliamentary in a liberal democratic/Westminster sense merely that the body tasked with legislation is also the body from which the executive is drawn and held accountable. The hybrid arrangements of Myanmar and Sri Lanka fit this to an extent.

Multilevel federalism is argued to be more conducive to moderation and accommodation than a more traditional two-tiered structure. It provides more opportunities for meaningful group autonomy and the emergence of multiethnic and ethnic forms of political organization. Multilevel federalism is a feature present in Nepal and Myanmar currently and historically. The village-level governance of the Nepali Panchayat era, the autonomous zones of Myanmar and the multilevel state structures specified in constitutions (e.g. village, town, city and region) provide several opportunities for clustered communities to be given some effective self-governance and to engage with other ethnic groups at other levels (as compared to Sri Lanka's two-level system in the context of relatively low diversity). Even Myanmar's military 
has belatedly acknowledged the important place that local level autonomy can play in managing diversity, given that 'eight major races' masks the considerable diversity present across its 135 subcategories (Steinberg 2001, pp. 57-58), even if it may also be used as a strategy of weakening the units by empowering local levels (as suggested by Steinburg). A similar argument has been made that local level autonomy in Sri Lanka should be preferred to creating 'monolithic' and elitist ethnic organizations (Bandarage 2012). The Sri Lankan Constitutional Assembly's Sub-Committee on Centre-Periphery Relations has recommended not only listing powers of local government in the constitution, but also institutionalizing a local level deliberative aspect of this third tier of government - 'the Gram Rajya Concept' to ensure that villagers are able to participate, advise and hold their local authorities accountable (Item 2, Sub-Committee on Centre-Periphery Relations 2016, p. 7).

There are trade-offs present here as well. First is the secession risk factor which tends to limit the autonomy of highly ethnic units, and second is that the requirement of reciprocity would better be met from within heterogeneous institutions. Thus a federal system that has high unit heterogeneity is most conducive to deliberation. However, if it is too heterogeneous, there is not meaningful group autonomy. A hybrid federal system that has mixed or ethno-territorial bases would still incorporate an extent of heterogeneity and group autonomy. Shortfalls in territorially-based powers vested in an ethnic group via federalism have been supplemented, such as in Nepal, by non-territorial structures such as commissions for marginalized communities, parliamentary committees or via the use of personal laws, which are prevalent in the region. The potential negative impacts on second order minorities can be similarly mitigated by such approaches, as well as through the extra intergovernmental checks inherent in a federal system.

Finally, political parties add the extra layer of semi-detached deliberation advocated by Dryzek (2005) as a means of moderating ethnic extremities, with modifications. Semidetachment, in this context refers to a 'decoupling of deliberation and decision-making'. Although Dryzek and others argue for deliberation to be transparent and to occur in the public sphere, which is valuable in many respects, multiethnic political parties provide a forum that can facilitate cross-ethnic exchange in a way that is once removed from decisionmaking while still retaining an important measure of accountability. At the party level, there are three requirements that incentivize deliberation and thus moderation. First, there is a requirement to reach a decision in a cross ethnic setting free from partisan interests (within party); second there is a semi-detachment to, and accountability for, that decision, because it is not final and still subject to both executive and inter-party review (e.g. in parliament); and 
thirdly; the external tests or accountabilities of any such decisions also occur in a cross-ethnic setting, when external (non-party) institutions, including electoral systems, are also inclusive. Further, without the direct public gaze, they are more likely to be willing to change their minds. That multiethnic parties tend to be more centrist and moderating has been well established by Horowitz, Reilly and others, however, further work needs to be done on how the parties actually operate in practice, as although the outcomes may be moderate, the inner workings of different types of parties are not yet well known.

I propose a hypothesis for future testing that a hybrid form of ethnic and territorial federalism, that encourages ethnicity at the lower levels and multiethnicity at the center, replete with deliberative settings of multilevel forums, semi-detachment through multiethnic parties, inclusivity, accountable parliamentary settings and reciprocal electoral incentives is more likely than other types of federalism to maximize political equality. I propose deliberative conditions as criteria (see Table 7) for considering the incentive structure for federal institutional design that would encourage moderation within an overall accommodating structure, and which reinforces the potential of recent constitutional innovations in Nepal, Myanmar and Sri Lanka to effectively balance centripetal and consociational strategies. It is beyond the scope of this thesis to test the outcomes of such combinations, especially given their relative infancy in Nepal, Myanmar and Sri Lanka, but there is ground for optimism. An initial assessment is included in Appendix 2 (see summary tables).

Table 7: Proposed criteria for assessing deliberative conditions in federal systems

\begin{tabular}{|l|l|}
\hline Criteria & Description \\
\hline Accountability & $\begin{array}{l}\text { Executive is accountable to the legislature, which includes } \\
\text { a multiparty committee system }\end{array}$ \\
\hline Semi-detachment & $\begin{array}{l}\text { Multiethnic political parties provide a semi-detached } \\
\text { forum for cross-ethnic exchange }\end{array}$ \\
\hline Multilevel & $\begin{array}{l}\text { Local government is constitutionally empowered (there are } \\
\text { three or four levels of government) }\end{array}$ \\
\hline Inclusivity & $\begin{array}{l}\text { Inclusivity in central institutions is a requirement (e.g. } \\
\text { proportionality plus special representation) }\end{array}$ \\
\hline Reciprocal & $\begin{array}{l}\text { There are electoral incentives to appeal across ethnic } \\
\text { groups (e.g. a transferable vote) }\end{array}$ \\
\hline
\end{tabular}

\subsection{Summary}

A successful federal system should maximize political equality. This requires a blending of accommodation (autonomy, inclusion) and moderation. While Myanmar has fluctuated 
between accommodation, integration and assimilation, it has only recently begun to establish the institutions that would bring moderation and enable alliances to sustain and grow. These are the national level multiethnic political parties, proportionality and the more inclusive approach to constitutional change and national reconciliation. Sri Lanka, despite a presidential voting system designed to bring moderation and a proportional electoral system, has a demographic disadvantage. With clustered communities, no major multiethnic parties and weak units, an ethnocracy emerged. The success of Nepal in agreeing on a system that better meets criteria for blending accommodation and moderation can be in large part credited to its emphasis on inclusion and incentivization of moderation through proportionality requirements imposed at both the legislature and political party levels.

Proportional electoral systems are one way of encouraging inclusion, but may disadvantage clustered or small communities. For this purpose, an electoral system should be designed in context and with supplementary mechanisms such as reservations. These are multinational states and the institutionalization of identity-based representation recognizes the persistence of ethnic identity and its ongoing role in structuring preferences and social relations. Further, the electoral system influences the composition of the legislature but may or may not influences the type of executive. Power-sharing in these cases is not effected through a grand-coalition, unless at times of transition, but is instead effected within party. Multiethnic political parties are argued to be important venues for democratic deliberation and enable the blending of competitive and consensus based politics. Multiethnic political parties provide a semidetached and accountable forum for depoliticized cross ethnic exchange and are especially effective if part of a federal system that empowers ethnic groups in the periphery while encouraging moderation across the system via the multiplication of access points and accountability mechanisms. A multilevel federal system also provides more avenues for group autonomy and inclusion while reducing the secession risk and likelihood of marginalization of second order minorities. Multiethnic parties can be encouraged or mandated at the center, without restricting the role of ethnic parties in the periphery. 


\section{Conclusion}

\subsection{Ethnic identity and federalism}

Ethnic identity is increasingly salient in modern politics. While identities may be overlapping and fluid, ethnic identity is relatively rigid and persistent. The modern state was premised on the idea of a nation-state, comprising one dominant ethnic group. The end of World War II caused great upheavals across the globe, not least in the Asian region where the withdrawal of colonial powers left behind a legacy of state boundaries that a new political elite sought to protect via a nation-building agenda. In most cases, the new states comprised a diversity of ethnic groups, which posed a challenge to nation-builders. In cases where the new states promulgated a national identity-based on the dominant ethnic group's identity, conflict, poor development outcomes and reversions to authoritarianism have resulted. Many countries now accept the fallacy of such assimilation and are grappling with the best way to manage diversity.

Approaches to the management of ethnic diversity in deeply divided societies can be classified along a continuum from assimilation to integration to accommodation. Integration, however, can be seen as a stepping stone to assimilation, and is not a just response to the claims of indigenous ethnic groups and others in deeply divided societies, especially when the overarching state has its own ethnic identity. While many scholars agree that accommodation is an appropriate response to diversity, they disagree on the best approach. Consociationalism seeks to recognize and empower ethnic groups, while centripetalism seeks to incentivize moderation across ethnic groups.

Federalism can play an integral role in either approach. It can be used as a tool of integration or accommodation, and it remains the focus of the minority ethnic groups' demands.

Federalism can be understood as an ideology embracing 'unity in diversity' but is more conventionally a reference to a specific institutional configuration. In practice, there is a range of federal systems that are more or less federal and more or less unitary, but generally, people understand a genuine federalism to be a democratic federation. Other federal systems are described as 'quasi' lacking key features of broadly equal and sovereign levels of government. However, federalism is in essence a hybrid form of governance and so a wide approach to understanding the federal systems of Asia is suitable for analytical purposes.

Federalism can also be described as ethnic or territorial, or some mixture thereof, and as coming together or holding together. Ethnic federalism is a key demand of minority ethnic 
groups in Asia and Asian federal systems are all mostly holding together systems. When compared to Western federal systems, those in Asia evolved under substantially different conditions. Firstly, the notion of individualistic competitive democracy is challenged by consensus-based cultures and the search for a more deliberative approach. Secondly, the diversity, social stratification and colonial history of Asia means that simple divisions of ethnic nationalities and immigrants are impractical and problematic in effect.

\subsection{The road to federalism}

The (re)formation of modern Asian states necessitated the (re)establishment of initial state structures. These initial decisions set in train the road to federalism, one of which has been travelled over three generations. Each generation has followed a specific sequence, using causal mechanisms that are influenced as much by temporal elements as by contextual factor. The first generation are the federations that were established out of decolonization and built on a colonial tradition of democracy, alongside pre-colonial traditions of autonomy and self-rule. In these cases, democracy and federalism coincided with the formation of the modern state. The second generation regards the federal features in the unitary states of China, Philippines and Indonesia. These cases of federalization were precipitated by isolated, longstanding internal conflict and were aimed at regime continuity. The third generation, Nepal, Myanmar and Sri Lanka, is the subject of this thesis, and exemplifies a new way of understanding path dependence.

The third generation of federalism in Asia is characterized by path dependence where powerbased mechanisms of reproduction have enabled assimilating or integrating institutions to persist despite pressure for accommodation. The state formation stage institutionalized an initial advantage for a particular ethnic group, which was self-reinforcing. However, because of the reactive consequences simultaneously acting to destabilize the mechanisms of reproduction (as from some perspectives, these are mechanisms of exclusion and discrimination), they are vulnerable to transformative change when the effects of reactive sequencing converge with other external and contingent events to weaken the state, strengthen the hand of the minority ethnic groups, and make an alliance across ethnic groups and excluded factions mutually beneficial. The reactive sequence operates on both perspectives - there is ethnic-based nation-building by the dominant group, a violent response by minority ethnic groups, and centralization rather than accommodation. With centralization unable to mitigate conflict, a quasi-federal concession is made, with a view to maintaining the regime. This recognizes or seeks to co-opt the parallel infrastructural 
capacity that is developed by minority ethnic groups, but in a subordinated manner. Conflict continues, or restarts, and eventually transformative change becomes inevitable as the path's elements converge, meeting at the point of federalism.

\subsection{Asian federal systems}

In each case, unique and hybridized approaches to federalism and the accommodation of diversity have been pursued. An Asian federal system, a concept designed to reflect the salient common features, has been operationalized to provide a framework for analysis built around this purpose of diversity management. Nepal, Myanmar and Sri Lanka, like other Asian federal systems, are centralized, incorporate ethnicity into unit design and are supplemented with special representation mechanisms or proportionality and non-territorial elements such as personal laws. However, they do not have consociationalism, lacking the key ingredient of grand coalitions (unless delivered in an indirect manner through multiethnic parties), veto rights and system wide mechanisms of proportional representation.

The federal systems of Nepal, Myanmar and Sri Lanka were not established in the same way as those in the West, which are predominantly coming together federal systems. I alter Riker's (1964) prominent theory on the origins of federalism and show that holding together federalism is established in Asia when there is a regime change alliance involving minority ethnic groups and a faction of the dominant ethnic group, at a time when there is an infrastructural capacity, especially a parallel one, and a moderate secession risk. When there is only a unilateral concession, occurring while the dominant group remains as such, a quasifederalism is more likely to be established. An alliance will not form if the secession risk is too high, and is most beneficial and effective when the ethnic minority groups can bring an infrastructural capacity to the table.

An alliance is willing to pursue power-sharing because each group stands to gain, having already being largely excluded from the regime whether by way of minority status or political persuasion. Rather than being seen as a zero-sum game, in these cases alliances achieve mutual gain only conceding potential rather than actual (aspects of) autonomy. This is notwithstanding that in each case, federalism and quasi-federalism follow the establishment of an infrastructural capacity and are in response to a secession risk. Infrastructural capacity creates a practical necessity and a strategic advantage in alliance, as well as a solid position from which to negotiate. 
The third generation of federalism in Asia comprises those countries that are arriving at federalism out of regime change and conflict resolution. In these cases, democratization and federalization are simultaneous and only occurring once there is an effective alliance. They result in compromise (rather than concession). Minority ethnic groups on their own cannot secure genuine federalism. Further, the cases of Nepal, Myanmar and Sri Lanka suggest that democracy without federalism in deeply divided Asian societies is not sustainable because it does not deliver or meaningfully contribute to political equality. Conversely, federalism without democracy is inherently 'quasi', as power is concentrated in single authorities that have proven unwilling to recognize equals.

The secession risk, as perceived by dominant group forces, has been the major reason for resistance to federalization in Nepal, Myanmar and Sri Lanka. Whether bound up in a regime protecting its 'war economy' bounty (as may be the case in Myanmar), or an ideological responsibility to maintain a unified country (e.g. Sri Lanka), is beside the point. Genuine federalism - democratic and with sovereign levels of government - is established only when that secession risk is perceived as moderate, whereas a quasi-federalism is preferred to mitigate a high secession risk and maintain the position of the present regime. Without a secession risk, a unitary state will remain as such.

Whether or not these conclusions hold true in other regions is yet to be tested. In Africa, federalism was agreed to hold together Sudan despite a high secession risk. However, a referendum on secession was one of the conditions of the agreement, and the secession of the South followed shortly thereafter. Holding together federalism was also established in Iraq in 2005. However, there was little international appetite for secession and the risk appears, at face-value, moderate. Nevertheless, it may be that a moderate secession risk is a necessary condition in Asia only, or that a high secession risk can lead to federalism when there is international intervention (particularly armed intervention), or that federalism established in the face of a high secession risk is more simply a precursor to secession itself. These questions are beyond the scope of this study.

\subsection{Federal design issues - accommodation and moderation}

Through analysis of the institutional arrangements for accommodation, and the process of constitutional settlement itself, I draw out lessons and make an additional hypothesis for testing. Accommodating state structures as a goal of a federal system is not appropriate on its own, because ethnic accommodation can increase the risk of secession and the marginalization of second order minorities, and there are practical difficulties. Hence, I argue 
that political equality, understood in a group and individual sense, should be an evaluative factor, and specifically that moderation needs to be combined with accommodation for political equality. The cases reinforce the importance of institutional design, and its mediating function.

Deliberative democracy has been shown to have potential to moderate extremes, including in deeply divided societies, and certain features can be seen in the approaches of Nepal, Myanmar and Sri Lanka to constitutional settlement, and appear significant. These features institutionalize conditions that encourage deliberation such as semi-detachment (from decision-making), inclusivity, accountability and grassroots level deliberation. Indeed, the constitutional settlement process itself can moderate extreme positions, and carryover into the new set of institutions. Certainly, this was the case in Nepal whereby a deliberative and participatory process contributed to the alignment of elite and local perspectives, the building of trust across groups and the identification of cross-cutting cleavages.

I hypothesize, based on the debates and experience in Nepal, Myanmar and Sri Lanka, that political equality is best served by a hybridization of ethnic and multiethnic institutions at the local and macro-scales. That is, at the lower levels, ethnically-based institutions are encouraged and provide a degree of accommodation, but at the central level, multiethnic institutions, especially political parties have moderating effects. Such institutions can be explicitly required via institutional design. Further, because federalization is in part a secession risk mitigation strategy, ethnicity in units may be traded off against autonomy, and when the latter is prioritized, electoral and other institutions that encourage inclusivity are supplemented. The important point is not that accommodation should be restrained, but that it should be provided equally, and different configurations are possible. I would argue that an institutional arrangement should be neutral in the sense that it does not institutionalize an advantage for one group over another. This means some unequal treatment (such as special representation) might be warranted.

The decision to federalize opens the door for the next range of issues to be debated. This is particularly true during a transformative change (or constitutional moment), as there are broader and more varied options available. Nevertheless, there is still an existing institutional setting which benefits some more than others and narrows the parameters of possible outcomes. During this contest of ideas, some matters will be resolved relatively easily via deliberation, while others will become contentious issues. Across the cases, though to different degrees in each, three key issues stand out. The basis of unit demarcation - that 
is whether units should be based on ethnic identity or territory; the division of powers - how autonomous should the units be; and, proportionality and power-sharing - how should electoral systems be designed or inclusive institutions otherwise assured.

The way that the division of powers and the unit demarcation are dealt with is inter-related and partially derivative of the demography of the state. The extent to which ethnicity is reflected in unit demarcation - with a view to empowering a single ethnic group - is inversely related the strength and security of the autonomy provisions, but this relationship is mediated by the secession risk. Essentially, ethnic federalism raises the perceived secession risk, and so by design, the risk is mitigated by a weaker division of powers or less security of power, to prevent the consolidation of resources that might enable independence. In other words, states' hold together by retaining intervention rights in the center and minimizing the involvement of units in that center, rather than via the strength of some common identity or attachment that is posited by others as a necessary condition for a sustainable peace (e.g. Roeder \& Rothchild 2005). The alternative approach to reaching an accommodative arrangement is via hybridity in unit demarcation which removes (perceptual) barriers to the empowerment of those units. In such cases, inclusivity and proportionality can be supplemented to provide for identity-based rights and representations.

Proportionality, inclusion and power-sharing are closely related to the political party system, which can be manipulated to create the shared rule associated with a genuine federalism. The minority ethnic groups do not typically ask for a shared role in the center and, so quite simply, it is not institutionalized (other than through bicameralism which itself manifests in party rather than unit solidarity). Consociational and consensus-based politics are often advocated but are only present in a piecemeal fashion, and most prominently at the transition stage as different sectors of society work towards achieving a lasting constitutional settlement. Features of consociationalism do have great value at the transitional stage for a constitutional settlement and national reconciliation, including the design of a new political system, but consociationalism does not usually and ideally should not persist in Asia as the criticisms meted including deadlock, inflexibility and the empowerment of extremist elements are valid. Instead, it is through the political party system that an ethnically-based yet moderate power-sharing arrangement can be institutionalized.

The cases indicate that the best approach to proportionality and ethnic power-sharing is likely to be within-party. By best, I mean most likely to maximize 'justice as equality' by blending accommodation and moderation. We can forget about a need for grand coalitions 
if the parties are multiethnic. The strength of multiethnic parties is a feature of Asian politics, most apparent in Myanmar and Nepal, and is related to their positive moves regarding ethnic accommodation. In Nepal, the three major parties are now all multiethnic, while in Myanmar, the two largest parties are increasingly so. These multiethnic parties effectively replace ethnic or non-ethnic parties that are representative of the dominant group. Ethnic parties are only in place to represent minorities, and mostly at the unit or subunit level. Ethnic-based parties that secure a place in the center can really only hope to be part of government in a coalition, where they would be subordinate, or choose to pursue their interests from opposition.

I agree with Horowitz and others that centripetal incentives are necessary in deeply divided societies, but am of the view that electoral incentives for moderate majoritarian outcomes undermine inclusion, which is an important principle underpinning political equality and justice, and may not be effective where most needed (see McCulloch 2014). Creating the right environment for deliberation can moderate extremes and balance the potential for centrifugal forces to take center-stage. This means inclusive representation, accountability, multilevel and semi-detached platforms for reasoned debate, with a practical and reciprocal incentive for compromise.

There are incentives within multiethnic parties for moderation, besides via electoral engineering. A transferrable vote or proportional representation can both support inclusion in certain situations, but not in others. Sri Lanka is a case where they have been a failure as they instead empowered majoritarian extremists and incentivized bitter intra-party competition and corruption. The Myanmar case shows how proportional representation electoral reforms have been resisted by minorities because they deny them prominent representation in areas where groups are particularly clustered. Each society may require a different electoral system to achieve goals of inclusion and proportionality depending on its demographics and political party system.

Multiethnic parties provide a semi-detached, accountable and inclusive forum for deliberation, which has been shown to have moderating effects and to help de-ethnicize the politics of the center, reserving ethnic concerns for a unit or local level of government. Not only do multiethnic parties encourage deliberation and moderation, they also will create cross-cutting cleavages. The case of Nepal is demonstrative in its two-pronged strategy for political inclusion at the center including most pertinently a range of proportionality requirements for the political parties themselves. These moves helped to shift the 
composition of the parties from a minor to a substantive multiethnic element and a corresponding trend towards more moderate policies. Such action combines with ethnic proportionality existing at the electoral level that incentivizes political parties to appeal across ethnic groups, so that they can have their preferred candidates elected. The failure of Sri Lanka to resolve its national question up until now can be traced to not just the lack of alliance with minorities, but the inability of its major national level parties to become multiethnic. However, we do not want to lose sight of the ethnic rights demands that have led to the requirement for a constitutional settlement in the first place.

It might be argued that the relative success of each case is down to demographics, or realpolitik. Undoubtedly, the ethnic balance and distribution is important and Sri Lanka does have a disadvantage in the regard, being largely bipolar and with a very clustered northern Tamil community. However, as I demonstrate in Chapters 4 and 5, ethnic diversity contributes to, but does not dictate, the form and effect of the explanatory variables. Indeed, the extent to which a population is heterogenous has been reasonably stable, while the federal outcomes to which it relates are substantially different at different points in time.

Further, the suitability of multiethnic parties in bipolar societies, or other regions like Africa, may be called into question. However, the case of Burundi would suggest their prescription in other such contexts can be successful. Burundi is a largely bipolar society with one group comprising around $80 \%$ of the population. It has largely nullified 'ethnic outbidding' by requiring parties to put up inclusive lists that, alongside consociational guarantees, contributed to a peaceful post-conflict transition. A number of large multiethnic parties now co-exist with smaller ethnic parties. This can be contrasted with Rwanda, where ethnicity is 'officially ignored' with no corresponding reduction in ethnic tensions (see Reyntjens 2015 for details).

This is not to say that some places will have conditions more suitable for the prescription or emergence otherwise of multiethnic parties. The lack of a numerically dominant group, and the large number of groups in Nepal makes it particularly suitable for multiethnic parties to take hold, while ethnically heterogenous regions also provide a favorable condition. Others would argue that there should be an existing set of cross-cutting cleavages and moderate elites (e.g. Reilly 2001; Reynolds 2000). I contend that there is always potential for crosscutting cleavages and institutional design can bring these forward without undermining the importance of ethnic identity, while elites are more likely to moderate when incentivized by 
institutional designs and deliberative constitutional settlement processes. As has been shown, people do change their minds.

Federalism is well suited to facilitating both accommodation and moderation by providing space for both ethnic and multiethnic parties and by empowering multilayered institutions. Rather than having to choose between consociationalism and centripetalism, these cases are finding a middle ground via bottom-up deliberative democracy that serves to moderate a system of representation that is organically and deliberately incorporative of ethnic identities. Smaller communities that are independent, yet linked to other areas of decisionmaking which, by being inclusive and proportional, give voice to and across the different ethnic groups. The more identity-based matters are refocused towards the local level, the more likely it is that identity-based autonomy will be given practical relevance.

Such forms of hybrid federalism are the only genuine possibility for accommodating and moderating ethnic demands in Asia in all but a few cases, given the extensive diversity and histories of internal migration. In most macro-areas of Asian states, ethnic diversity is so substantial that the formation of federal units necessarily incorporates a variety of different groups and preferences, but groups become more and more clustered and concentrated as the units become smaller. The use of autonomous zones (as in Myanmar) or constitutionally empowered local government (as in Nepal) is more likely to be an effective vehicle for identity-based autonomy, than the creation of large ethnic-based federal units, so long as it is accompanied by mixed and inclusive institutions at the higher levels and a substantial diffusion of power.

\subsection{Prospects for federalism in Nepal, Myanmar and Sri Lanka}

Given the significance of design features, and the tumultuous trajectory of accommodation in Nepal, Myanmar and Sri Lanka, we can ask what are the prospects for federalism in Nepal, Myanmar and Sri Lanka following their contemporary critical juncture. Will federalism be properly implemented? Will it provide enough space for minority ethnic groups to participate equally in the governance of the state? Has a new path really been forged, and will it last? Although the evolution of institutions and the entrenchment of more inclusive and deliberative setting lead me to form an optimistic view about the prospects for establishing federalism in these countries, contingent factors and historical legacies may still derail their positive progress. I briefly discuss prospects below. 
In Nepal, although the new constitution was greeted with much celebration, it was also strongly opposed by many in the Madheshi and Tharu (Janajati) communities, who launched violent protests. It was a matter of mere months before the first amendment to its 2015 federal constitution was passed. The government is subject to continuing pressure to add an additional province (unit) in the Terai to better accommodate Madheshi and Tharu peoples, which was a course of action advocated by the Prime Minister (Post Report 2016). Although these controversies are hindering implementation of the new state structures, it is difficult to envisage a scenario where the Nepali state reneged on its federalism and its new and more inclusive secular identity. The civil war has been finished for more than ten years and participants are disarmed and part of regular political processes. The reform process has been deliberative and inclusive, even if some remain unhappy. Implementing federalism is a challenge in any context, even more so in a fledgling democracy. Its design features include many important accommodating and moderating mechanisms and incentives for success are present. Making federalism work is a challenge that Nepal must and will take on, as it forges a new path.

In Myanmar, internal conflict has increased since the 2015 election and formation of the NLD led civilian government, despite its commitment to a democratic federation (International Crisis Group 2016). Because the military remains autonomous, and some armed groups continue to rely on illicit sources of income, democratic change has not yet been able expand its tendrils into some of the most contentious aspects of Myanmar' politics. However, the movement, alliances and consensus for change are unprecedented, and similar to Nepal, there is little chance of a reversion to military rule. There is a great challenge for democratic reformists and ethnic groups to convince the military to support further federalization, and for each to participate economically. But there is a relative advantage as the basic features of federalism are already in place, and again, the extent of consensus is unprecedented. A process that is inclusive and a base on which to build make the prospects for federalism in Myanmar strong.

In Sri Lanka, it is certainly true that the state has come close to making major federal reforms in the past, drafting new constitutions and commissioning various reviews. However, this is the first time since the civil war concluded and the power balance shifted with the decline of creeping authoritarianism, and the first time that the major parties have worked together. The deep and tragic consequences of the civil war are obviously not something that any citizen wishes to see repeated, and making a fair place for minority ethnic groups in the state structure is broadly accepted as the only viable solution, despite the persisting 
fearmongering by associates of the former regime (see for example Udaya Gammanpila, cited in Jayawardhane 2016). Federalization, such as through bicameralism, more secure powers for provinces and a strong local level are broadly agreed, regardless of the label given, and it remains to see the process through (see for example Public Representations Committee on Constitutional Reform 2016; Jabbar 2016; Mudalige 2016a).

Notwithstanding, politics and its outcomes remain contingent. External actors have been able to influence outcomes in the past and may seek to do so again, while the "peace dividend' may improve development outcomes for minority ethnic groups and reduce pressure for federalism in the long-term. In any case, federalism does not negate the potential for extremism and the potential marginalization of second order minorities. Whether the electoral and deliberative conditions are sufficient to incentivize moderation in the face of institutionalized centrifugal forces remains to be seen. But the institutional measures are there, and the incentives for success are present, most especially in Nepal. Further, the demographics of Nepal make it more difficult for ethnic extremism to take hold. Sri Lanka is the most susceptible with only three or four major groups of which one is almost three quarters of the population. It also has the most entrenched ethnic party system, and its major parties are only nominally multiethnic. The extent to which the statewide major parties there and in Myanmar broaden their appeal to minority ethnic groups, rather than dominant group extremists, may be what their long-term success turns on.

\subsection{Summary}

Each of Nepal, Myanmar and Sri Lanka is travelling a road to federalism, one which is likely to resolve conflict and build political equality, as an important component of delivering on the peoples' aspirations for peace, development and democracy.

Federalism in Asia has received relatively little attention in the literature despite its varied and evolving institutions. Federalism has arrived in Asia in three generations - Nepal, Myanmar and Sri Lanka are part of the third generation. I have argued that Asian federal systems are a different species to the liberal democratic varieties of federalism in the West, and that its primary purpose is the management of ethnic diversity. Hence, analysis of Asian federal systems should look at the strategies interacting with federalism that achieve, more or less, this purpose, such as electoral systems. Asian systems should be measured according to the extent to which they are fit for this purpose, rather than via the mere presence or otherwise of particular federal features. 
Secondly, I have shown that the third generation of Asian federalism is path dependent with trends established at the state formation stage and in the following 10-15 years of consolidation. When there is regional and identity-based infrastructural capacity, and a moderate secession risk, federalization follows. Quasi-federalism arises unilaterally as a concession by the dominant group to stabilize the regime, but genuine federalism arises when an alliance forms between democratic change agents and minority ethnic groups. The latter form will tend to be more accommodating than those arising out of regime continuity.

The experiences of Nepal, Myanmar and Sri Lanka highlight important issues, available innovations and potential lessons for countries grappling with the best way to manage ethnic diversity. Federal design features are related to the interplay of demography (ethnic identity and its distribution) and the secession risk. Where units are ethnic in nature, the resulting degree of autonomy tends to be lower because of the imperative to manage the secession risk and protect second order minorities. Otherwise mixed states would be preferred and are more likely to be stronger and so still deliver an extent of group autonomy. Balancing the secession risk minimization imperative with the imperative to accommodate via autonomy based on historical association may in fact have other benefits, and can be supplemented by local level autonomy and non-territorial institutions.

Hybrid federal institutions build conditions that are more favorable for deliberation, as compared to the potential for deadlock and segregation that is inherent to consociational or ethnic federal institutions. Deliberation in a multilevel, cross-ethnic, inclusive, accountable and semi-detached setting encourages moderation. Moderation is the link between accommodation and political equality. Multiethnic parties at the central level are a critical institution for moderating the potential negative impacts of ethnic accommodation and it is hypothesized that they should be an integral part of bringing deliberation to deeply divided societies. Federalism provides space to facilitate, if not require, the growth of multiethnic national level political parties, which can exist alongside regional and local level ethnic parties. These are the challenges of constitutional settlement in Nepal, Myanmar and Sri Lanka, ones on which their successes will be built and their failures remedied. 


\section{Reference list}

Ackerman, BA 1993, We the People, Volume 1: Foundations, Harvard University Press. Ackerman, BA 2000, We the People, Volume 2: Transformations, Harvard University Press. Adeney, K 2007, 'Democracy and federalism in Pakistan', in B He, B Galligan \& T Inoguchi, (eds), Federalism in Asia, pp. 101-123. Edward Elgar, Cheltenham, UK.

Adeney, K 2009, 'The Limitations of Non-consociational Federalism: The Example of Pakistan', Ethnopolitics, vol. 8, no. 1, pp. 87-106.

Adeney, K 2012, 'A step towards inclusive federalism in Pakistan? the politics of the 18th amendment', Publius, vol. 63, no. 4, pp. 626-641.

Agranoff, R (ed) 1999, Accommodating diversity: asymmetry in federal states, Nomos, Baden Baden, Germany.

Ahmed, F 2010, 'Personal Autonomy and the Option of Religious Law', International Journal of Law, Policy and the Family, vol. 24, no. 2, pp. 222-244.

Akinola, O 2014, 'Federalist Deliberative Democracy in Nigeria: Challenges and Prospects', in JE Ugarriza \& D Caluwaerts, (eds), Democratic Deliberation in Deeply Divided Societies: from conflict to common ground, pp. 112-128. Palgrave Macmillan, London.

Albinski, HS 1958, 'The Place of Emperor Asoka in Ancient Indian Political Thought', Midwest Journal of Political Science, vol. 2, no. 1, pp. 62-75.

Alesina, A, Devleeschauwer, A, Easterly, W, Kurlat, S \& Wacziarg, R 2003, 'Fractionalization', Journal of Economic Growth, vol. 8, no. 2, pp. 155-194.

ALTSEAN Burma 2007, National Convention: Roadmap to Instability, 17 July 2007 Alternative ASEAN Network on Burma, Alternative ASEAN Network on Burma, Bangkok.

ALTSEAN Burma 2010, Election Results, Alternative ASEAN Network on Burma. Available from: http://www.altsean.org/Research/2010/Key\%20Facts/Results/Overall.php. [17 June].

Amoretti, UM \& Bermeo, NG (eds) 2004, Federalism and territorial cleavages, John Hopkins University Press, Baltimore and London.

Anderson, B 2006, Imagined Communities: Reflections on the Origin and Spread of Nationalism, Revised edn, Verso, London and New York.

Anderson, LD 2013, Federal solutions to ethnic problems: accommodating diversity, Routledge, Abingdon, Oxon.

Anderson, LD 2014, 'Ethnofederalism: The Worst Form of Institutional Arrangement...?', International Security, vol. 39, no. 1, p. 165.

Arudpragasam, A 2013, 'The APRC: A Forgotten Resolution', Peace Monitor, vol. 10, no. 2, pp. 54-57.

Attlee, CR \& Aung San 1956 [1947], 'Conclusions reached in the conversations between His Majesty's Government and the Delegation from the Executive Council of the Governor of Burma', in Maung Maung, (ed) Burma in the Family of Nations, pp. 185189. Djambatan International Publishing House, Amsterdam.

Aung, MT 2015, Current Legal Framework on Islamic Family Law in Myanmar, International Islamic University, Kuala Lumpur.

Aung, TT 2016, 'Paletwa territorial dispute reignited after Panglong summit', Myanmar Times, 8 August 2016, p. 5.

Balachandran, PK 2016, 'Wigneswaran Calls For Shared Sovereignty Within A United Lanka', The New Indian Express, 18 January 2016. Available from: http://www.newindianexpress.com/world/Wigneswaran-Calls-For-SharedSovereignty-Within-A-United. [20 January 2016].

Bandara, K \& Perera, Y 2015, 'Sampanthan proposes 3 to 5 regions', Daily Mirror, 23 September 2015. Available from: http://www.dailymirror.lk/85939/sampanthanproposes-3-to-5-regions. [10 November 2015]. 
Bandarage, A 2012, 'Towards Peace with Justice in Sri Lanka: An Alternative Perspective', India Quarterly: A Journal of International Affairs, vol. 68, no. 2, pp. 103-118.

Bandaranaike, SWRD 2008 [1926], 'Six Letters to the Ceylon Morning Leader and Lecture in Jaffna', in R Edrisinha, M Gomez, VT Thamilmaran \& A Welikala, (eds), Power-Sharing in Sri Lanka: Constitutional and Political Documents, 1926-2008, first edn, pp. 28-53. Centre for Policy Alternatives and Berghof Foundation for Peace Support, Colombo.

Barry, B 2002, Culture and Equality: An Egalitarian Critique of Multiculturalism, Harvard University Press, Harvard.

Barter, SJ 2015, 'Second-order' ethnic minorities in Asian secessionist conflicts: problems and prospects', Asian Ethnicity, vol. 16, no. 2, pp. 123-135.

Baumgartner, FR \& Jones, BD 2010, Agendas and Instability in American Politics, 2nd edn, University of Chicago Press, Chicago.

Bealey, F 1999, The Blackwell Dictionary of Political Science, Blackwell Publishers, Oxford.

Bennett, L, Tamang, S, Onta, P \& Thapa, M 2006a, Unequal citizens: Gender, caste and ethnic exclusion in Nepal, The World Bank and Department for International Development, Kathmandu.

Bennett, L, Tamang, S, Onta, P \& Thapa, M 2006b, Unequal citizens: Gender, caste and ethnic exclusion in Nepal, Kathmandu.

Benz, A \& Broschek, J (eds) 2013, Federal dynamics: continuity, change, and the varieties of federalism, Oxford University Press, Oxford.

Bertrand, J \& Laliberte, A (eds) 2010, Multination States in Asia, Cambridge University Press, Cambridge.

Bhattachan, K 2003, 'Expected Model and Process of Inclusive Democracy in Nepal', The Agenda of Transformation: Inclusion in Nepali Democracy, Social Science Baha, Kathmandu, 26 April 2003.

Bhattachan, K 2008, Minorities and Indigenous People of Nepal, National Coalition Against Racial Discrimination, Kathmandu.

Bhattacharyya, H 2010, Federalism in Asia: India, Pakistan and Malaysia, Routledge, London.

Bhattacharyya, H 2015, 'Indian Federalism and Democracy: The Growing Salience of Diversity-claims Over Equality-claims in Comparative and Indian Perspective', Regional and Federal Studies, vol. 25, no. 3, pp. 211-237.

Bhattarai, B 2004 [1996], 'The forty-point charter of demands', in D Thapa \& B Sijipanti, (eds), A Kingdom under Siege: Nepal's Maoists Insurgency, 1996-2004, 2nd edn, pp. 211216. The Printhouse, Kathmandu.

Bhattarai, KD 2016, 'Interview Sher Bahadur Deuba: 'NC will be an effective opposition if I am elected", The Kathmandu Post, 3 March 2016. Available from:

http://kathmandupost.ekantipur.com/news/2016-03-03/interview-sher-bahadurdeuba.html. [3 March 2016].

Bista, DB 1991, Fatalism and Development: Nepal's Struggle for Modernization, Orient Longman, Patna, India.

Bowen, JR 2005, 'Normative Pluralism in Indonesia: Regions, Religions, and Ethnicities', in W Kymlicka \& B He, (eds), Multiculturalism in Asia, pp. 152-169. Oxford University Press, Oxford.

Broschek, J 2010, 'Federalism and political change: Canada and Germany in historicalinstitutionalist perspective', Canadian Journal of Political Science, vol. 43, no. 1, pp. 124.

Broschek, J 2011, 'Conceptualizing and Theorizing Constitutional Change in Federal Systems: Insights from Historical Institutionalism', Regional \& Federal Studies, vol. 21, no. 4/5, p. 539.

Broschek, J 2013, 'Between path dependence and gradual change: Historical institutionalism and the study of federal dynamics', in A Benz \& J Broschek, (eds), Federal Dynamics: 
Continuity, Change, and the Varieties of Federalism, pp. 93-113. Oxford University Press, Oxford.

Brown, D 2007, 'Regionalist federalism: a critique of ethno-national federalism', in B He, B Galligan \& T Inoguchi, (eds), Federalism in Asia, pp. 57-81. Edward Elgar, Cheltenham, UK.

Bunce, V 1999, Subversive Institutions: The Design and the Destruction of Socialism and the State, Cambridge University Press, Cambridge.

Burgess, M 2013, In search of the federal spirit: new comparative empirical and theoretical perspectives, Oxford University Press, Oxford.

Burma News International 2014, Deciphering Myanmar's Peace Process: A Reference Guide 2014 Burma News International, Chiang Mai.

Burma Socialist Programme Party 1964, The System of Correlation of Man and His Environment, 3rd edn, The Burma Socialist Programme Party, Rangoon.

Burmese Government, Chin Committee, Kachin Committee \& Shan Committee 1947, Panglong Agreement, ibiblio.org, p. 3.

Bush, KD 2003, The Intra-Group Dimensions of Ethnic Conflict in Sri Lanka: Learning to Read Between the Lines Palgrave Macmillan UK, London.

Byrne, S \& Klem, B 2015, 'Constructing legitimacy in post-war transition: The return of 'normal' politics in Nepal and Sri Lanka?', Geoforum, no. 66, pp. 224-233.

Callahan, MP 2007, Political authority in Burma's ethnic minority states: devolution, occupation and coexistence, East-West Center, Washington DC.

Capoccia, G \& Kelemen, RD 2007, 'The Study of Critical Junctures: Theory, Narrative, and Counterfactuals in Historical Institutionalism', World Politics, vol. 59, no. 3, pp. 341369.

Case, W 2007, 'Semi-democracy and minimalist federalism in Malaysia', in B He, B Galligan \& T Inoguchi, (eds), Federalism in Asia, pp. 124-133. Edward Elgar, Cheltenham.

Central Bureau of Statistics 2014, Population Atlas of Nepal, 2014 Central Bureau of Statistics, CBo Statistics, Kathmandu.

Central Intelligence Agency 2007, The World Factbook, Central Intelligence Agency, Washington D.C. Available from: https://www.cia.gov/library/publications/theworld-factbook/index.html.

Centre for Constitutional Dialogue 2009, Participatory Constitution Making Process, vol. Participatory Constitution Building in Nepal, Booklet Series No. 10, Centre for Constitutional Dialogue, United Nations Development Programme Kathmandu.

Centre for Constitutional Dialogue 2010a, Federalism Dialogues: Proposed Jadan Province Centre for Constitutional Dialogue, United Nations Development Programme, Kathmandu.

Centre for Constitutional Dialogue 2010b, Federalism Dialogues: Proposed Kirant Province, 30 March - 1 April 2010 Centre for Constitutional Dialogue, United Nations Development Programme, Kathmandu.

Centre for Constitutional Dialogue 2010c, Federalism Dialogues: Proposed Limbuwan Province Centre for Constitutional Dialogue, United Nations Development Programme, Kathmandu.

Centre for Constitutional Dialogue 2010d, NEPAL - Proposed Federal Units Distribution of Major Caste/ Ethnicity, Centre for Constitutional Dialogue, United Nations Development Programme, Kathmandu.

Centre for Policy Alternatives 2010, Devolution in the Eastern Province: Implementation of the Thirteenth Amendment and Public Perceptions 2008-2010, Centre for Policy Alternatives \& Friedrich-Naumann-Stiftung, Colombo.

Centre for Poverty Analysis 2016, Peace and Conflict Timeline, Centre for Poverty Analysis. Available from: http://pact.lk/. [12 November]. 
Ceylon Constitution Order in Council 1946, Ceylon.

Ceylon Independence Act 1947, vol. Chapter 7, The National Archives, UK, Ceylon.

Ceylon Parliamentary Elections Amendment Act 1949, in 48, Ceylon.

Chakravartty, B 2014, 'Balancing Identity and Viability: Restructuring Nepal in a Workable Federal State', in B Karki \& R Edrisinha, (eds), The Federalism Debate in Nepal: Post Peace Agreement Constitution Making in Nepal, vol. II, pp. 55-76. Support to Participatory Constitution Building in Nepal, United Nations Development Programme, Kathmandu.

Choudhry, S 2010, 'Constitutional Politics and Crisis in Sri Lanka', in J Bertrand \& A Laliberté, (eds), Multination states in Asia: accommodation or resistance, pp. 103-136. Cambridge University Press, Cambridge.

Citizens Committee for Clean Election 2014, Nepal Constituent Assembly: Monitoring Report Informal Sector Service Centre, Informal Sector Service Centre, Kathmandu.

Citizenship Act 1948, Ceylon.

Coakley, J 1994, 'Approaches to the Resolution of Ethnic Conflict: The Strategy of NonTerritorial Autonomy', International Political Science Review, vol. 15, no. 3, pp. 297314.

Coakley, J 2001, Territorial Management of Ethnic Conflict, 2nd edn, Frank Cass, London. Coakley, J 2009, 'Ethnic Conflict Resolution: Routes Towards Settlement', Nationalism \& Ethnic Politics, vol. 15, no. 3/4, pp. 462-483.

Coakley, J \& Fraenkel, J 2014, 'Resolving conflict in bipolar societies: The fate of political settlements in Fiji and Northern Ireland', Political Science, vol. 66, no. 1, pp. 23-45.

Coase, R 1937, 'The Nature of the Firm', Economica, vol. 4, pp. 386-405.

Coase, R 1960, 'The Problem of Social Cost', Journal of Law and Economics, vol. 3, pp. 1-44.

Collier, RB \& Collier, D 1991, Shaping the political arena, University of Notre Dame Press, Notre Dame.

Colombo Gazette 2016, 'Muslims make push for separate Provincial Council', Colombo Gazette, 31 July 2016. Available from: http://colombogazette.com/2016/07/31/muslims-make-push-for-separateprovincial-council/. [2 August 2016].

Committee on the Restructuring of the State and Distribution of State Power 2010, Report on Concept Paper and Preliminary Draft Singha Durbar, Kathmandu.

Constitution of Nepal 1948, Nepal.

The Constitution of Nepal 1962, Nepal.

The Constitution of Nepal 1990, Nepal.

Constitution of Nepal 2015, Ministry of Law, Justice and Parliamentary Affairs, Nepal.

Constitution of Nepal - Preliminary Draft 2015, Constitution Drafting Committee, Constituent Assembly Secretariat.

The Constitution of the Democratic Socialist Republic of Sri Lanka 1978, Sri Lanka.

Constitution of the Kingdom of Nepal 1959, Nepal.

Constitution of the Republic of Sri Lanka (Ceylon) 1972, Sri Lanka.

Constitution of the Republic of the Union of Myanmar 2008, Ministry of Information, Myanmar.

The Constitution of the Union of Burma 1947, Burma.

The Constitution of the Union of Burma 1974, Burma.

Crouch, M 2016, The constitutional implications of Myanmar's peace process, International IDEA and Constitutionnet, Constitutionnet.org.

Cummiskey, D 2013, 'Comparative Reflections on Buddhist Political Thought: Aśoka, Shambhala, and the General Will', in SM Emmanuel, (ed) A Companion to Buddhist Philosophy, pp. 35-70. Wiley-Blackwell. 
De Silva, RT 2016, 'There is no draft', Daily Mirror, 20 January 2016. Available from: http://www.dailymirror.lk/103497/there-is-no-draft. [21 January 2016].

Deiwiks, C, Cederman, L-E \& Gleditsch, KS 2012, 'Inequality and conflict in federations', Journal of Peace Research, vol. 49, no. 2, pp. 289-304.

Department of Census and Statistics 2015, Population Tables: Census of Population and Housing - 2012: Sri Lanka Department of Census and Statistics, GoSL Department of Census and Statistics, Colombo.

Department of Elections 2013, Provincial Council elections 2013: Northern Province Department of Elections, Government of Sri Lanka, GoSL Department of Elections, Colombo.

Department of Elections 2016, Election Reports Department of Elections, GoSL Department of Elections, Sri Jayawardenepura Kotte.

Devkota, K 2012, A Perspective on the Maoist Movement in Nepal, D.R. Khanal, Kathmandu.

Devkota, K 2015, 'The truth about federal states', The Kathmandu Post, 21 September 2015. Available from: http://kathmandupost.ekantipur.com/news/2015-09-21/the-truthabout-federal-states-4.html. [21 September 2015].

DeVotta, N 2004, Blowback: linguistic nationalism, institutional decay, and ethnic conflict in Sri Lanka, Stanford University Press, Stanford, California.

DeVotta, N 2010, 'Politics and governance in post-independence Sri Lanka', in P Brass, (ed) Routledge Handbook of South Asian Politics: India, Pakistan, Bangladesh, Sri Lanka and Nepal, pp. 118-130. Routledge, London and New York.

DeVotta, N 2011, 'Sri Lanka: From Turmoil to Dynasty', Journal of Democracy, vol. 22, no. 2 , pp. 130-144.

Diermeier, D \& Krehbiel, K 2003, 'Institutionalism as Methodology', Journal of Theoretical Politics, vol. 15, no. 2, pp. 123-144.

Dixit, K 2010, 'An extended CA and a Maoist-led government', Nepali Times. Available from: http://nepalitimes.com.np/issue/2010/04/30/Nation/17034. [5 April 2010].

Douglas, M 1982, In the Active Voice, Routledge and Kegan Paul, London.

Drake, A \& McCulloch, A 2011, 'Deliberative consociationalism in deeply divided societies', Contemporary Political Theory, vol. 10, no. 3, pp. 372-392.

Dryzek, J 2000, Deliberative Democracy and Beyond, Oxford University Press, Oxford.

Dryzek, JS 2005, 'Deliberative Democracy in Divided Societies: Alternatives to Agonism and Analgesia', Political Theory, vol. 33, no. 2, pp. 218-242.

Economist Intelligence Unit 2013, Democracy Index 2013 The Economist, The Economist, London.

Edrisinha, R 2005, 'Multinational federalism and minority rights in Sri Lanka', in W Kymlicka \& B He, (eds), Multiculturalism in Asia. Oxford University Press, Oxon.

Edrisinha, R, Gomez, M, Thamilmaran, VT \& Welikala, A 2008a, 'Board of Ministers' Draft Constitution (1944), The Report of the Soulbury Commission (1945), and the Soulbury Constitution (1946-7)', in R Edrisinha, M Gomez, VT Thamilmaran \& A Welikala, (eds), Power-Sharing in Sri Lanka: Political and Constitutional Documents, 1926-2008, pp. 128-163. Centre for Policy Alternatives and Berghof Foundation for Peace Support, Colombo.

Edrisinha, R, Gomez, M, Thamilmaran, VT \& Welikala, A (eds) 2008b, Power Sharing in Sri Lanka: Constitutional and Political Documents 1926-2008, Centre for Policy Alternatives and Berghof Foundation for Peace Support, Colombo.

Egreteau, R 2014, 'Legislators in Myanmar's First “Post-Junta" National Parliament (20102015): A Sociological Analysis', Journal of Current Southeast Asian Affairs, vol. 33, no. 2, pp. 91-124.

Ekantipur Report 2014, 'PM Koirala expands Cabinet; 18 ministers sworn in', The Kathmandu Post, 25 February 2014. Available from: 
http://kathmandupost.ekantipur.com/news/2014-02-25/pm-koirala-expandscabinet-18-ministers-sworn-in.html. [26 February 2014].

Ekantipur Report 2015, 'CA will not wait until a consensus is forged: Nembang', eKantipur.com, 16 January 2015. Available from: http://www.ekantipur.com/2015/01/16/top-story/ca-will-not-wait-until-aconsensus-is-forged-nemabang/400444.html. [16 January 2015].

Elazar, DJ 1985, 'Federalism and Consociational Regimes', Publius, vol. 15, no. 2, pp. 17-34.

Elazar, DJ 1987, Exploring federalism, University of Alabama Press, Tuscaloosa.

Election Commission Nepal 2016, Election Reports, Singha Durbar, Nepal.

Erk, J 2008, Explaining federalism: State, Society and Congruence in Austria, Belgium, Canada, Germany and Switzerland, Routledge, Abingdon, Oxon.

Falleti, TG \& Lynch, JF 2009, 'Context and causal mechanisms in political analysis', Comparative Political Studies, vol. 42, no. 9, pp. 1143-1166.

Farook, L 2015, 'Why Muslims voted for Maithirapala', Colombo Telegraph, 2 February 2015. Available from: https://www.colombotelegraph.com/index.php/why-muslims-votedfor-maithiripala/. [3 February 2015].

Franck, T 1968, Why Federations Fail, New York University Press, New York.

Frontier Areas Committee of Enquiry 1947, Report of the Frontier Areas Committee of Enquiry, 1947 His Majesty's Government of the United Kingdom, Yangon.

Furnivall, JS 1960, The Governance of Modern Burma, 2nd edn, Institute of Pacific Relations, New York.

Gagnon, A-G 2009, The Case for Multinational Federalism: Beyond the all-encompassing nation, Routledge, Oxon.

Galligan, B 2007, 'Federalism and Asia', in B He, B Galligan \& T Inoguchi, (eds), Federalism in Asia, pp. 290-314. Edward Elgar, Cheltenham UK.

Gellner, DN 2005, 'Ethnic Rights and Politics in Nepal', Himalayan Journal of Anthropology and Sociology, vol. 2, pp. 1-17.

Gellner, DN 2007, Resistance and the state: Nepalese experiences, Revised edn, Berghahn Books, New York.

Gerring, J 1999, 'What Makes a Concept Good? A Criterial Framework for Understanding Concept Formation in the Social Sciences', Polity, vol. 31, no. 3, pp. 357-393.

Gerring, J \& Thacker, SC 2008, A Centripetal Theory of Democratic Governance, Cambridge University Press, Cambridge.

Ghai, Y 2000, Autonomy and ethnicity: negotiating competing claims in multi-ethnic states, Cambridge University Press, Cambridge.

Ghai, Y 2011, 'Ethnic Identity, Participation and Social Justice: A Constitution for New Nepal', International Journal on Minority and Group Rights, vol. 18, no. 3, pp. 309-334.

Ghai, Y \& Cottrell, J 2007, Federalism and State Restructuring in Nepal: The Challenge for the Constituent Assembly United Nations Development Programme, United Nations Development Programme, Kathmandu.

Ghandi, MK 1962, Village Swaraj, Navajivan Publishing House, Ahmedabad.

Ghosh, PS 2007, The Politics of Personal Law in South Asia: Identity, Nationalism and the Uniform Civil Code, Routledge, New Delhi.

Government of Burma Act 1935, Asian Legal Information Institute, Burma.

Government of Nepal \& Communist Party of Nepal (Maoist) 2006, Comprehensive Peace Agreement, Government of Nepal, Kathmandu.

Gunasekera, L 2016, 'Unity Govt must go full five years', Sunday Observer, 7 February 2016. Available from: http://www.sundayobserver.lk/2016/02/07/pol03.asp. [11 February 2016].

Gurupan, K 2013, 'No Starting Point to Resolution', Peace Monitor, vol. 10, no. 2, pp. 25-27. 
Hachettu, K \& Gellner, D 2010, 'Nepal: Trajectories of democracy and restructuring of the state', in PR Brass, (ed) Routledge handbook of South Asian politics: India, Pakistan, Bangladesh, Sri Lanka, and Nepal. Routledge, Abingdon, Oxon.

Hachettu, K, Kumar, S \& Subedi, J 2008, Nepal in Transition: A Study on the State of Democracy, DSA/Nepal Chapter and International IDEA, Kathmandu.

Hale, HE 2004, 'Divided We Stand: Institutional Sources of Ethnofederal State Survival and Collapse', World Politics, vol. 156, no. 2, pp. 165-193.

Hall, PA 1993, 'Policy Paradigms, Social Learning, and the State: The Case of Economic Policymaking in Britain', Comparative Politics, vol. 25, no. 3, pp. 275-296.

Hall, PA \& Taylor, RCR 1996, 'Political science and the three new institutionalisms', Political Studies, vol. 44, no. 5, pp. 936-957.

Hamilton, A, Madison, J \& Jay, J 2003, The Federalist Papers, New American Library, Penguin Group, New York.

Hare, WF 1998, Earl of Listowel Memoirs: Burma Independence 1947-1948, Pekhon University Press, London.

Hatlebakk, M \& Ringdal, C 2013, The economic and social basis for state restructuring in Nepal CHR Michelson Institute, CHR Michelsen Institute, Kathmandu.

Hay, C 2008, 'Constructivist Institutionalism', in SA Binder, RAW Rhodes \& BA Rockman, (eds), The Oxford Handbook of Political Institutions, pp. 56-74. Oxford University Press, Oxford.

He, B 2007, 'Democratization and federalization in Asia', in B He, B Galligan \& T Inoguchi, (eds), Federalism in Asia, pp. 1-32. Edward Elgar, Cheltenham, UK.

$\mathrm{He}, \mathrm{B} 2010 \mathrm{a}$, 'A Deliberative Approach to the Tibet Autonomy Issue', Asian Survey, vol. 50, no. 4, pp. 709-734.

He, B 2010b, 'Western Theories of Deliberative Democracy and the Chinese Practice of Complex Deliberative Governance', in EJ Leib \& B He, (eds), The Search for Deliberative Democracy in China, pp. 133-148. Palgrave Macmillan, London.

He, B 2013, 'Deliberative Democracies and Deliberative Conflict Resolution in the Divided Society', Taiwan Journal of Democracy, no. 63-65, pp. 63-86.

He, B, Galligan, B \& Inoguchi, T (eds) 2007, Federalism in Asia, Edward Elgar, Cheltenham, UK. Hemmathagama, A 2016, 'Constitutional Council Sits in Parliament', Daily Mirror, 6 April 2016. Available from: http://www.ft.lk/article/535264/Constitutional-Council-sits-inParliament\#sthash.QkQnU9WG.dpuf. [6 April 2016].

Henders, SJ 2010, Territoriality, asymmetry, and autonomy: Catalonia, Corsica, Hong Kong, and Tibet, Palgrave Macmillan, New York.

His Majesty's Government 1956 [1945], 'Burma Statement of Policy by His Majesty's Government, 1945', in Maung Maung, (ed) Burma in the Family of Nations, pp. 176184. Djambatan International Publishing House, Amsterdam.

Horowitz, DL 1980, Coup Theories and Officers' Motives, Princeton University Press, Princeton.

Horowitz, DL 1999, 'Constitutional Design: Proposals versus Processes', Kellogg Institute Conference, Constitutional Design 2000: Institutional Design, Conflict Management, and Democracy in the Late Twentieth Century, University of Notre Dame, 9-11 December 1999,p. 38.

Horowitz, DL 2000 [1985], Ethnic groups in conflict, 2nd edn, University of California Press, Berkeley, California.

Horowitz, DL 2014, 'Ethnic Power Sharing: Three Big Problems', Journal of Democracy, vol. 25, no. 2, pp. 5-20.

Hueglin, TO \& Fenna, A 2015, Comparative federalism: a systematic inquiry, 2nd edn, University of Toronto Press, Toronto. 
Hutchinson, FE 2014, 'Malaysia's Federal System: Overt and Covert Centralisation', Journal of Contemporary Asia, vol. 44, no. 3, pp. 422-442.

Hutchinson, FE 2015, (De)centralization and the Missing Middle in Malaysia and Indonesia Institute of South East Asian Studies - Yusof Ishak Institute, Institute of South East Asian Studies - Yusof Ishak Institute, Singapore.

Interim Constitution of Nepal 2063 (2007), United Nations Development Programme, Nepal. Interim Government of Nepal Act 1951, Consulate of Nepal, Nepal.

International Crisis Group 2007, Nepal's Troubled Terai Region, 9 July 2007 International Crisis Group, International Crisis Group, Kathmandu.

International Crisis Group 2015, The Myanmar Elections: Results and Implications, 9 December 2015 International Crisis Group, International Crisis Group, Yangon/Brussels.

International Crisis Group 2016, Myanmar's Peace Process: Getting to a Dialogue, 19 October 2016 International Crisis Group, International Crisis Group, Yangon/Brussels.

International IDEA 2015, Nepal's Constitution Building Process: 2006-2015 - Progress, Challenges, and Contributions of International Community International Institute for Democracy and Electoral Assistance, International IDEA, Kathmandu.

Jabbar, Z 2015, 'Sixty eight percent of Sinhalese for devolution - Chandrika', The Island, 9 December 2015. Available from: http://www.island.lk/index.php?page cat=articledetails\&page=article-details\&code title=136623. [8 December 2015].

Jabbar, Z 2016, 'SL to adopt electoral system of New Zealand with improvements: More powers to be devolved to province', The Island, 3 October 2016. Available from: http://www.island.lk/index.php?page cat=article-details\&page=articledetails\&code title=153145. [5 October 2010].

Jayakody, P 2015, 'The Comparison of Preferential Votes in 2015 \&amp; 2010', Daily Mirror, 8 August 2015. Available from: http://www.dailymirror.lk/85309/the-comparison-ofpreferential-votes-in-2015-2010. [27 March 2016].

Jayatilleka, D 2013, 'The Northern Provincial Council: Prudence Prevails for Now', Peace Monitor (The Challenge of Implementing the 13th Amendment), vol. 10, no. 2, pp. 1115.

Jayawardhane, K 2016, 'Federal experts in sub-committee: Threat to SL's unitary nature', Daily Mirror, 8 November 2016. Available from: http://www.dailymirror.Ik/article/Federal-experts-in-sub-committee-Threat-to-SL-sunitary-nature-118865.html. [9 November 2016].

Jepperson, RL 2001, The development and application of sociological neoinstitutionalism, Robert Schuman Centre, European University Institute, Florence.

Jiratticorn, A 2014, Myanmar's Long Road to Federalism: The Case of Shan State Institute for Southeast Asian Studies, Institute for Southeast Asian Studies, Singapore.

Joint Opposition 2016, Uncompromising Principles of the New Constitution, 25 October 2016 Joint Opposition, Constitutional Assembly of Sri Lanka, Colombo.

Jolliffe, K 2015, Ethnic Armed Conflict and Territorial Administration in Myanmar, July 2015 The Asia Foundation, TA Foundation, Yangon.

Jones, L 2014, 'Explaining Myanmar's regime transition: the periphery is central', Democratization, vol. 21, no. 5, pp. 780-802.

Kalambi, S 2015, Minorities in Parliament, 4 June 2015, Colombo Telegraph. Available from: https://www.colombotelegraph.com/wpcontent/uploads/2015/06/minorities parliament kelambi.pdf. [27 March].

Kantipur Report 2010, 'Limbuwan, Khumbuwan furious over federal provinces', eKantipur, 22 Jan 2010. Available from: http://www.ekantipur.com/2010/01/22/National/Limbuwan-Khumbuwan-furiousover-federal-provinces/306844/. [22 Jan 2010]. 
Kantipur Report 2014, 'UML invites Madhes-based parties to join govt', eKantipur, 1 December 2014. Available from: http://www.ekantipur.com/2014/12/01/topstory/uml-invites-madhes-based-parties-to-join-govt/398410.html. [1 December 2014].

Karen National Union 2014, The Karen National Union (KNU): Aims, Policy and Programme Karen National Union, Online.

Karen State Constitution Drafting Committee 2006, The Second Proposed Draft of the Future Constitution of Kawthoolei (Karen State), 8 August 2006 United National League for Democracy, United National League for Democracy Press, Myanmar.

Karki, B 2014, 'State Restructuring and Federalism Discourse in Nepal', in B Karki \& R Edrisinha, (eds), The Federalism Debate in Nepal: Post Peace Agreement Constitution Making in Nepal vol. II, pp. 1-23. United Nations Development Programme Support to Participatory Constitution Building Nepal, Kathmandu.

Karki, D 2014, 'If consensus fails, constitution should be put to vote: Interview Pradip Gyanwali', eKantipur.com, 1 September 2014. Available from: http://www.ekantipur.com/2014/09/01/interview/if-consensus-fails-constitutionshould-be-put-to-vote/394409.html. [15 September 2014].

Kean, T \& Min, AK 2015, 'President backtracks on white cards', The Myanmar Times, 13 February 2015. Available from: http://www.mmtimes.com/index.php/nationalnews/13106-president-backtracks-on-white-cards.html. [14 February 2015].

Keuneman, P 2008 [1944], 'Resolutions of the ceylon communist party 15 October 1944', in R Edrisinha, M Gomez, VT Thamilmaran \& A Welikala, (eds), Power-Sharing in Sri Lanka: Constitutional and Political Documents, 1926-2008, pp. 113-114. Centre for Policy Alternatives and Berghof Foundation for Peace Support, Colombo.

Kha, K 2015, 'Nai Hong Sar: 'If They Continue to Hold a Hard Line, Peace Will Be Difficult', The Irrawaddy, 3 July 2015. Available from: http://www.w3.org/TR/xhtml1/DTD/xhtml1transitional.dtd. [21 October 2015].

Khanal, K 2009, 'Democracy and Federalization of the Nepali State: Challenges and Opportunities', Sangam Journal, vol. 1, no. 1, pp. 1-14.

Khanal, K \& Kushiyait, BK 2010, A Review and Analysis of the 2009 Civil Society Public Submissions to the Constituent Assembly United Nations Development Programme, United Nations Development Programme, Kathmandu.

Khuensai, S 2016, 'State Counselor's words: Lost in transmission?', Shan Herald Agency for News, 18 July 2016. Available from: http://english.panglong.org/2016/07/18/statecounselors-words-lost-in-transmission/. [2 August 2016].

King, P 1982, Federalism and Federation, Croom Helm, London.

Kingsbury, D 2012, 'Mediated Constitutionality as a Solution to Separatism', in MA Miller, (ed) Autonomy and Armed Separatism in South and Southeast Asia. Institute of South East Asian Studies, Singapore.

Kivimaki, T \& Pasch, P 2009, The Dynamics of Conflict in the Multiethnic Union of Myanmar, October 2009 Friedrich Ebert Stiftung, Friedrich Ebert Stiftung, Berlin.

Kotelawala, H 2015, 'New Faces in Parliament', Sunday Times, 18 April 2010, p. 8. Available from: http://www.sundaytimes.lk/100418/News/page8.pdf. [27 March 2016].

Krasner, SD 1984, 'Approaches to the State: Alternative Conceptions and Historical Dynamics', Comparative Politics, vol. 16, no. 2, pp. 223-246.

Krishnaswamy, P 2015, 'North and East should be merged - Suresh', Sunday Observer, 19 July 2015. Available from: http://www.sundayobserver.lk/2015/07/19/pol04.asp. [21 July 2016].

Kumal, N 2014, That Janajati's want ethnic states is baseless propoganda in eKantipur, $\mathrm{S}$ Rana, Kantipur Publications, Kathmandu.

Kumar, DP 1980, Nepal: Year of Decision, Vikas Publishing House, New Delhi. 
Kumaratunga, CB 2013, Interview with Chandirka Bandaranayake Kumaratunga, L Guruge, Centre for Policy Alternatives, Colombo.

Kyaw, H 2016, Appointment of Region/State Ethnic Affairs Ministers (Order 7/2016) in (Order 7/2016), President's Office, Republic of the Union of Myanmar, Nay Pyi Taw.

Kymlicka, W 1995, Multicultural citizenship: A liberal theory of minority rights, Cambridge University Press, Cambridge.

Kymlicka, W 2007, 'Multi-nation federalism', in B He, B Galligan \& T Inoguchi, (eds), Federalism in Asia, pp. 33-56. Edward Elgar, Cheltenham, UK.

Kymlicka, W \& He, B (eds) 2005, Multiculturalism in Asia, Oxford University Press, Oxon.

Lande, CH 1999, 'Ethnic Conflict, Ethnic Accommodation, and Nation-Building in Southeast Asia', Studies in Comparative International Development, vol. 33, no. 4, p. 90.

Lane, J-E \& Errson, S 2000, The New Institutional Politics: Performance and Outcomes, Psychology Press, London and New York.

Lawoti, M 2005, Towards a democratic Nepal: Inclusive political institutions for a multicultural society, SAGE Publications, London, Los Angeles and New Delhi.

Lawoti, M 2007, Contentious politics and democratization in Nepal, SAGE Publications, London, Los Angeles, New Delhi, Singapore and Kathmandu.

Lawoti, M 2008, 'Exclusionary democratization in Nepal, 1990-2002', Democratization, vol. 15 , no. 2, pp. 363-385.

Lawoti, M 2010, Federal State Building: Challenges in framing the new Nepali constitution, Bhrikuti Academic Publications, Kathmandu.

Lawoti, M 2014, 'Reform and Resistance in Nepal', Journal of Democracy, vol. 25, no. 2, pp. 131-145.

Lecomte-Tilouine, M 2004, 'Ethnic Demands within Maoism', in M Hutt, (ed) Himalayan People's War: Nepal's Maoist Rebellion, pp. 166-191. Indiana University Press, Bloomington, Indiana.

Lecours, A 2005, New Institutionalism: Theory and Analysis, University of Toronto Press, Toronto.

Lecours, A 2014, 'The Question of Federalism in Nepal', Publius: The Journal of Federalism, vol. 44, no. 4, pp. 609-632.

Lian, Z 2012, Institutional Design for Divided Societies: A Blue-print for multi-ethnic Burma Burma Centre for Ethnic Studies, Chiang Mai.

Lijphart, A 1977, Democracy in plural societies: A comparative exploration, Yale University Press, New Haven.

Lijphart, A 1985, 'Non-Majoritarian Democracy: A Comparison of Federal and Consociational Theories', Publius, vol. 15, no. 2, pp. 3-15.

Lijphart, A 1996, 'The Puzzle of Indian Democracy: A Consociational Interpretation', The American Political Science Review, vol. 90, no. 2, pp. 258-268.

Lijphart, A 1999, Patterns of Democracy: Government Forms and Performance in Thirty-six Countries, Yale University Press, New Haven.

Linn, Z 2011, 'Burma's ethnic groups establish United Nationalities Federal Council', Asian Correspondent, 19 February 2011. Available from: http://asiancorrespondent.com/48722/burma\%E2\%80\%99s-ethnic-groupsestablished-united-nationalities-federal-council/. [22 November 2014].

Lintner, B 1999, Burma in Revolt: Opium and Insurgency Since 1948, 2nd edn, Silkworm Books, Chiang Mai.

Luskin, RC, O'Flynn, I, Fishkin, JS \& Russell, D 2014, 'Deliberating across Deep Divides', Political Studies, vol. 62, no. 1, pp. 116-135.

Lwin, EET \& Lone, W 2016, 'NLD control over chief ministers riles ethnic parties', The Myanmar Times, 29 March 2016. Available from: 
http://www.mmtimes.com/index.php/national-news/19694-nld-control-over-chiefministers-riles-ethnic-parties.html. [30 March 2016].

Mabuhang, B 2014, 'Autonomous Regions: Ethno-Demographic Analysis - A Question of Accommodation of Diversity', in BB Karki \& R Edrisinha, (eds), The Federalism Debate in Nepal: Post Peace Agreement Constitution Making in Nepal, vol. II, pp. 127-158. United Nations Development Programme, Support to Participatory Constitution Building in Nepal, Kathmandu.

MacGregor, F 2016, 'Day 1: NLD takes its parliamentary seats', Myanmar Times, 2 February 2016. Available from: http://www.mmtimes.com/index.php/national-news/nay-pyitaw/18763-day-1-nld-takes-its-parliamentary-seats.html. [2 February 2016].

Mahoney, J 2000, 'Path Dependence in Historical Sociology', Theory and Society, vol. 29, no. 4 , pp. 507-548.

Mahoney, J 2010, Colonialism and Postcolonial Development: Spanish America in Comparative Perspective, Cambridge University Press, Cambridge.

Mahoney, J \& Thelen, KA 2010, 'A theory of gradual institutional change', in KA Thelen \& J Mahoney, (eds), Explaining institutional change: ambiguity, agency, and power. Cambridge University Press, Cambridge.

Malik, Y, Kennedy, CH, Oberst, R, Kapur, A, Lawoti, M \& Rahman, S 2009, Government and Politics in South Asia, 6th edn, Westview Press, Boulder.

Mann, M 1986, The Sources of Social Power: Volume 1. A history of power from the beginning to A.D. 1760, Cambridge University Press, New York.

Mann, M 1988, States, War and Capitalism, Basil Blackwell, Oxford.

March, J \& Olsen, J 1984, 'The New Institutionalism: Organizational Factors in Political Life', American Political Science Review, vol. 78, no. 3, pp. 734-759.

March, J \& Olsen, J 2008, 'Elaborating the New Institutionalism', in SA Binder, RAW Rhodes \& BA Rockman, (eds), The Oxford Handbook of Political Institutions. Oxford University Press, Oxford.

Marshall, MG, Gurr, TR \& Jaggers, K 2016, Political Regime Characteristics and Transitions, 1800-2015, Centre for Systemic Peace.

Matthews, B 2001, Ethnic and Religious Diversity: Myanmar's Unfolding Nemisis Institute of Southeast Asian Studies, Institute of Southeast Asian Studies, Singapore.

Maung, M 1956, Burma in the Family of Nations, Djambatan International Educational Publishing House, Amsterdam.

Mauzy, DK 1997, 'The human rights and 'Asian values' debate in Southeast Asia: trying to clarify the key issues', The Pacific Review, vol. 10, no. 2, pp. 210-236.

May, RJ, Wheen, K \& Haley, N 2013, 'Assessing the Shift to Limited Preferential Voting', in RJ May, R Anere, N Haley \& K Wheen, (eds), Election 2007: The Shift to Limited Preferential Voting in Papua New Guinea, pp. 193-205. ANU Press, Canberra.

McCarthy, S 2006, The political theory of tyranny in Singapore and Burma: Aristotle and the rhetoric of benevolent despotism, Routledge, London and New York.

McConnell, D 2008, 'The Tamil people's right to self-determination', Cambridge Review of International Affairs, vol. 21, no. 1, pp. 59-76.

McCulloch, A 2014, Power-Sharing and Political Stability in Deeply Divided Societies, Routledge, Oxon.

McGann, AJ 2006, The Logic of Democracy: Reconciling Equality, Deliberation, and Minority Protection, University of Michigan Press, Ann Arbor, US.

McGarry, J \& O'Leary, B 2007, 'Iraq's Constitution of 2005: Liberal Consociation as Political Prescription', International Journal of Constitutional Law, vol. 5, no. 4, pp. 670-698.

McGarry, J, O'Leary, B \& Simeon, R 2008, 'Integration or accommodation? The enduring debate in conflict regulation', in S Choudhry, (ed) Constitutional Design for Divided Societies. Oxford University Press, Oxford. 
Meijknecht, A \& de Vries, BS 2010, 'Is there a place for minorities' and indigenous peoples' rights within ASEAN?: Asian values, ASEAN values and the protection of Southeast Asian minorities and indigenous peoples', International Journal on Minority and Group Rights, vol. 17, no. 1, pp. 75-110.

Miklian, J 2009, Nepal's Terai: Constructing an Ethnic Conflict, 20 July 2008 International Peace Research Institute, International Peace Research Institute, Oslo.

Miller, MA (ed) 2012, Autonomy and armed separatism in South and Southeast Asia, Institute of Southeast Asian Studies, Singapore.

Mishra, P 2009, 'Don't Gift Ethnic Federalism', The Kathmandu Post, 23 December 2009. Available from: http://www.ekantipur.com/2009/12/23/Oped/Dont-gift-ethnicfederalism/304979/. [24 December 2009].

Moramudali, U \& Kuruwita, R 2016, 'A Constitution supreme in all respects', Ceylon Today, 22 February 2016. Available from: http://www.ceylontoday.lk/89-118850-news-detail-aconstitution-supreme-in-all-respects.html. [23 February 2016].

Mudalige, D 2016a, 'Great Support for Second Chamber', Daily News, 26 September 2016. Available from: http://www.dailynews.lk/?q=2016/09/26/local/94115. [27 September 2016].

Mudalige, D 2016b, 'Wigneswaran wants two States', Daily News, 9 April 2016. Available from: http://www.dailynews.lk/?q=2016/04/09/political/78724. [10 April 2016].

Myanmar News Agency 2016a, 'Cries for federalism dominate second-day session of 21st Century Panglong Conference', Global New Light of Myanmar, 3 September 2016. Available from: http://www.globalnewlightofmyanmar.com/cries-for-federalismdominate-second-day-session-of-21st-century-panglong-conference/. [18 September 2016].

Myanmar News Agency 2016b, 'KNU Chairman Saw Mutu Sae Po addresses opening of Union Peace Conference-21st Century Panglong', Global New Light of Myanmar, 1 September 2016. Available from: http://www.globalnewlightofmyanmar.com/knuchairman-saw-mutu-sae-po-addresses-opening-of-union-peace-conference-21stcentury-panglong/. [18 September 2016].

Myanmar News Agency 2016c, 'VISIONS FOR FEDERAL UNION — UPC continues its third day session', Global New Light of Myanmar, 3 September 2016. Available from: http://www.globalnewlightofmyanmar.com/visions-for-federal-union-upc-continuesits-third-day-session/. [18 September 2016].

Myanmar Peace Monitor 2013, Economics of Peace and Conflict, September 2013 Burma News International, Chiang Mai.

Myanmarelections.org 2016, Data Reporting on Myanmar Elections Myanmarelections.org, Myanmarelections.org, Yangon.

Myint, M 2016, 'NLD's Inclusive Approach Yields Fissures as Well', The Irrawaddy, 12 April 2016. Available from: http://www.irrawaddy.com/burma/nlds-inclusive-approachyields-fissures-as-well.html. [12 April 2016].

Nathaniel, C 2016a, 'The Fundamental Is To Have Inclusive Democracy - Nizam Kariapper', The Sunday Leader, 11 January 2016. Available from: http://www.thesundayleader.Ik/2016/01/10/the-fundamental-is-to-have-inclusivedemocracy-nizam-kariapper. [11 January 2016].

Nathaniel, C 2016b, 'North-East Unification Would Be Rejected By Muslims - M.T. Hasen Ali', The Sunday Leader, 21 February 2016. Available from: http://www.thesundayleader.lk/2016/02/21/north-east-unification-would-berejected-by-muslims-m-t-hasen-ali/. [22 February 2016].

National Convention 1995, Fundamental Principles and Detailed Basic Principles, New Light of Myanmar, Yangon. 
Nepali, B 2008, CA Election Results - An Analysis Rights, Democracy and Inclusion Fund, Enabling State Programme, Kathmandu.

Nepali Congress 2014, Ideology and Values, Nepali Congress. Available from: http://www.nepalicongress.org/index.php?linkld=2. [28 November].

Nepali Times 2015, 'Map of federal Nepal', Nepali Times, August 8, 2015. Available from: http://www.nepalitimes.com/blogs/thebrief/2015/08/08/map-of-federal-nepal/. [10 August 2015].

Nesiah, D 2012, Tamil Language Rights in Sri Lanka, Centre for Policy Alternatives, Colombo. Nimni, E 2005, National cultural autonomy and its contemporary critics, Routledge, London. Nixon, H, Joelene, C, Saw, KPC, Linn, TA \& Arnold, M 2013, State and Region Governments in Myanmar, September 2013 MDRI CESD and The Asia Foundation, MDRI CESD and The Asia Foundation, Yangon.

Nohlen, D, Grotz, F \& Hartmann, C (eds) 2001a, Elections in Asia and the Pacific: A Data Handbook: Volume I: Middle East, Central Asia, and South Asia, Oxford University Press, Oxford.

Nohlen, D, Grotz, F \& Hartmann, C 2001b, Elections in Asia and the Pacific: A Data Handbook: Volume II: South East Asia, East Asia, and the South Pacific, Oxford University Press, Oxford.

Nom, NS 2016, 'Have Ethnic Groups Lost Faith in the NLD?', The Irrawaddy, 14 May 2016. Available from: http://www.irrawaddy.com/commentary/have-ethnic-groups-lostfaith-in-the-nld.html. [15 May 2016].

North, DC 1994, 'Economic Performance Through Time', The American Economic Review, vol. 84, no. 3, pp. 359-368.

Nyein, N 2014, 'NLD Reject USDP Plan for PR Voting System for Central Regions', The Irrawaddy, 29 October 2014. Available from: http://www.irrawaddy.org/burma/nldreject-usdp-plan-pr-voting-system-central-regions.html. [17 November 2014].

Nyein, N 2015, 'UNFC Calls for Agreement on Federalism to Mark Union Day', The Irrawaddy, 3 February 2015. Available from: http://www.irrawaddy.org/burma/ethnic-bloc-callsagreement-federalism-mark-union-day.html. [6 February 2015].

Nyein, N 2016a, 'Stakeholder Presentations at Peace Conference Reveal Contrasting Positions on Statehood and Security', The Irrawaddy, 2 September 2016. Available from: http://www.irrawaddy.com/burma/stakeholder-presentations-at-peace-conferencereveal-contrasting-positions-on-statehood-and-security.html. [4 September 2016].

Nyein, N 2016b, 'State Counselor Tells Peace Conference Participants Not to Dwell on the Past', The Irrawaddy, 3 September 2016. Available from:

http://www.irrawaddy.com/burma/state-counselor-tells-peace-conferenceparticipants-not-to-dwell-on-the-past.html. [4 September 2016].

O'Flynn, I 2006, Deliberative Democracy and Divided Societies, Edinburgh University Press, Edinburgh.

O'Flynn, I 2007, 'Review article: divided societies and deliberative democracy', British Journal of Political Science, vol. 37, no. 4, pp. 731-51.

O'Leary, B 2010, 'Thinking About Asymmetry and Symmetry in the Remaking of Iraq', in M Weller \& K Nobbs, (eds), Asymmetric Autonomy and the Settlement of Ethnic Conflicts, pp. 183-212. University of Pennsylvania Press, Philadelphia.

Oberst, RC 1988, 'Federalism and Ethnic Conflict in Sri Lanka', Publius, vol. 18, no. 3, pp. 175194.

Office of the Cabinet of Ministers 2016, List of Cabinet Ministers, Office of the Cabinet of Ministers, Sri Jayawardenepura Kotte.

Office of the Prime Minister and Council of Ministers 2016, Council of Ministers, Office of the Prime Minister and Council of Ministers. Available from: http://opmcm.gov.np/en/cabinet/. [1 August 2016]. 
Parliament of Sri Lanka 2016, Resolution for the appointment of the Constitutional Assembly, Parliament of Sri Lanka, Sri Jayawardenepura Kotte.

Patten, A 2008, 'Beyond the dichotomy of universalism and difference: four responses to cultural diversity', in S Choudhry, (ed) Constitutional Design for Divided Societies. Oxford University Press, Oxford.

Perera, J 2015, 'Abrogate the 13th Amendment - National Joint Committee', Sinhalanet, 27 February 2015. Available from: http://www.sinhalanet.net/abrogate-13thamendment-national-joint-committee. [19 November 2015].

Perera, Y 2016, 'New constitution in 2017: PM', Daily Mirror, 29 March 2016. Available from: http://www.dailymirror.lk/107566/New-constitution-in-PM. [30 March 2016].

Peters, BG 2011, Institutional Theory in Political Science: the 'New Institutionalism', The Continuum International Publishing Group, New York.

Peters, BG \& Pierre, J 2012, Institutionalism II, SAGE, Los Angeles.

Pew Templeton Global Religious Futures Project 2012, Rising Tide of Restrictions on Religion Pew Research Centre, Pew Research Centre, Washington D.C.

Pierson, P 2000, 'Increasing Returns, Path Dependence, and the Study of Politics', The American Political Science Review, vol. 94, no. 2, pp. 251-267.

Pierson, P 2004, Politics in Time: History, Institutions, and Social Analysis, Princeton University Press, Princeton.

Post Report 2014a, '22-party alliance appeals for consensus', eKantipur, 18 October 2014. Available from: http://kathmandupost.ekantipur.com/news/2014-10-18/22-partyalliance-appeals-for-consensus.html. [22 October 2014].

Post Report 2014b, 'Dahal lashes out at UML chief Oli', Kathmandu Post, 22 December 2014. Available from: http://www.ekantipur.com/2014/12/22/capital/dahal-lashes-out-atuml-chief-oli/399351.html. [22 December 2014].

Post Report 2014c, 'No need for more than six provinces: Pokhrel', eKantipur, 25 October 2014. Available from: http://www.ekantipur.com/2014/10/25/top-story/no-needfor-more-than-six-provinces-pokhrel/396808.html. [25 October 2014].

Post Report 2015, "Institutionalise secularism", Kathmandu Post, 7 September 2015. Available from: http://kathmandupost.ekantipur.com/news/2015-0907/institutionalise-secularism.html. [7 September 2015].

Post Report 2016, 'Split Province 5 and break impasse: PM', 18 November 2016. Available from: http://kathmandupost.ekantipur.com/news/2016-11-18/split-province-5-andbreak-impasse-pm.html. [19 November 2016].

President's Office 2016, Ministries, Government of Myanmar. Available from: http://www.president-office.gov.mm/en/?q=cabinet/ministries. [27 March].

Prevention of Terrorism (Temporary Provisions) Act 1979, Sri Lanka.

Pruitt, B \& Thomas, P 2014, Democratic Dialogue - A Handbook for Practitioners, International Idea \& United Nations Development Programme, Stromsborg, Sweden \& New York.

Public Representations Committee on Constitutional Reform 2016, Report of the Public Representations Committee on Constitutional Reform, May 2012 Government of Sri Lanka, Government of Sri Lanka, Colombo.

Pwint, H 2015, 'Disagreements delay talks on national ceasefire agreement', Mizzima News, 7 April 2015. Available from: http://www.mizzima.com/mizzima-news/ethnicissues/item/11074-disagreements-delay-talks-on-national-ceasefire-agreement. [27 April 2015].

Raghavan, S 2013, Defending Buddhism by Fighting Federalism; Ethnoreligious Nationalism of the Sinhala Sangha and Peacemaking in Sri Lanka: 1995-2010, thesis, University of Kent, Canterbury. 
Rai, OA 2015, 'Trust no one', Nepali Times, 21-27 August 2015. Available from: http://nepalitimes.com/article/nation/nepalis-opinion-on-leaders-federalism-andsecularism, 2528. [29 March 2016].

Ramakrishnan, P 2016, 'Hill-country Tamils don't want to be called 'Indian Tamils', The Hindu, 21 March 2016. Available from: http://www.thehindu.com/todays-paper/tpinternational/hillcountry-tamils-dont-want-to-be-called-indiantamils/article8378815.ece. [21 March 2016].

Ramakrishnan, T 2015, 'Devolution of power could lead to separatism: JVP', The Hindu, 23 July 2015. Available from: http://www.thehindu.com/news/international/ivpproposes-peoples-assemblies-instead-of-devolution-of-power/article7456720.ece. [26 July 2015].

Rana, PS 2014, 'Consensus will be sought till very end of constitution process', eKantipur, 8 September 2014. Available from: http://www.ekantipur.com/2014/09/08/interview/consensus-will-be-sought-tillvery-end-of-constitution-process/394740.html. [11 September 2014].

Reid, A 2007, 'Indonesia's post-revolutionary aversion to federalism', in B He, B Galligan \& T Inoguchi, (eds), Federalism in Asia, pp. 144-164. Edward Elgar, Cheltenham, UK.

Reid, A 2010a, Imperial alchemy: nationalism and political identity in Southeast Asia, Cambridge University Press, Cambridge.

Reid, A 2010b, 'Revolutionary State Formation and the Unitary Republic of Indonesia', in J Bertrand \& A Laliberté, (eds), Multination states in Asia: accommodation or resistance, pp. 29-50. Cambridge University Press, New York.

Reilly, B 2001, Democracy in Divided Societies: Electoral Engineering for Conflict Management, Cambridge University Press, Cambridge.

Reilly, B 2002, 'Electoral Systems for Divided Societies', Journal of Democracy, vol. 13, no. 2, pp. 156-170.

Reilly, B 2006, 'Political Engineering and Party Politics in Conflict-Prone Societies', Democratization, vol. 13, no. 5, pp. 811-827.

Reilly, B 2007, 'Democratization and electoral reform in the Asia-Pacific region: is there an 'Asian model' of democracy?', Comparative Political Studies, vol. 40, no. 11, pp. 13501371.

Republica 2012, 'Deal on 11-province model is preliminary: PM', Republica, 19 May 2012. Available from: http://www.myrepublica.com/feature-article/story/39846/deal-on11-province-model-is-preliminary-pm.html. [11 June 2012].

Reynolds, A 2000, 'Majoritarian or Power-Sharing Government', in MML Crepaz, TA Koelble \& D Wilsford, (eds), Democracy and Institutions: The Life Work of Arend Lijphart, pp. 155-196. University of Michigan Press, Ann Arbor, Michigan.

Reyntjens, F 2015, 'Burundi: Institutionalizing Ethnicity to Bridge the Ethnic Divide', in AJ Kuperman, (ed) Constitutions and Conflict Management in Africa: Preventing Civil War Through Institutional Design, pp. 27-50. University of Pennsylvania Press, Philadelphia.

Riker, WH 1964, Federalism: Origin, operation, significance, Little, Brown, Boston.

Roeder, PG \& Rothchild, DS 2005, 'Conclusion: Nation-State Stewardship and the Alternatives to Power Sharing', in PG Roeder \& DS Rothchild, (eds), Sustainable peace: Power and democracy after civil wars, pp. 319-346. Cornell University Press, Ithaca, New York.

Roepstorff, K 2013, The Politics of Self-Determination: Beyond the decolonisation process, Routledge, Oxon.

Rokkan, S \& Urwin, D 1982, 'Introduction: Centre and Peripheries in Western Europe', in S Rokkan \& D Urwin, (eds), The Politics of Territorial Identity. Sage, London. 
Rutnam, E 2016a, 'Proposed Constitution Loses The "New" Tag', The Sunday Leader, 3 March 2016. Available from: http://www.thesundayleader.lk/2016/02/28/proposedconstitution-loses-the-new-tag/. [3 March 2016].

Rutnam, E 2016b, 'Proposed Constitution: Division On Executive Presidency And 13A', Sunday Leader, 23 July 2016. Available from: http://www.thesundayleader.lk/2016/07/17/proposed-constitution-division-onexecutive-presidency-and-13a/. [23 July 2016].

Sabel, CF \& Zeitlin, J 2012, 'Experimentalism in the EU: Common ground and persistent differences', Regulation \& Governance, vol. 6, no. 3, p. 410.

Sadan, M 2009, 'Ethnic Minorities \& Political Governance: The Myanmar Situation', in L Ghosh, (ed) Minorities, Community Rights \& Political Governance: South \& S.E Asian Scenario, pp. 151-179. Routledge, London.

Sakhong, LH 2005, 'Federalism, Constitution Making and State Building in Burma', in DC Williams \& LH Sakhong, (eds), Designing Federalism in Burma. UNLD Press, Chiang Mai.

Sakhong, LH 2010, In defence of identity: the ethnic nationalities' struggle for democracy, human rights, and federalism in Burma, Orchid Press, Bangkok.

Sakhong, LH 2012, The Challenges of Ethnic Politics and Negotiated Settlement: From Ceasefire to Political Dialogue, February 2012 Burma Centre for Ethnic Studies, Peace and Reconciliation, Chiang Mai.

Samyak 2016, Prime Ministers and Cabinet of Ministers after the restoration of the democracy, Nepal Homepage. Available from: http://www.nepalhomepage.com/politics/cabinet. [15 May 2016].

Sandel, MJ 2009, Justice: What's the right thing to do?, Penguin Books, London.

Saravanamuttu, P 2013, 'Sustaining conflict through the devolution debate', Peace Monitor, vol. 10, no. 2, pp. 3-5.

Saravanamuttu, P 2016, Preliminary Submission by the Centre for Policy Alternatives (CPA) to the Public Representation Committee, 22 January 2016 Centre for Policy Alternatives, Colombo.

Sarkees, MR \& Wayman, F 2010, Resort to War: 1816 - 2007, CQ Press, Washington D.C.

Sartori, G 1997, Comparative Constitutional Engineering, 2nd edn, MacMillan Press Ltd, Houndsmills, Basingstoke, Hampshire and London.

Schmidt, VA 2008, 'Discursive Institutionalism: The Explanatory Power of Ideas and Discourse', Annual Review of Political Science, vol. 11, no. 1, pp. 303-326.

Sewell, WH 2005, Logics of history: social theory and social transformation, University of Chicago Press, Chicago.

Shah, S 2014, 'Limits of Liberty: CK Raut's arrest', Republica, 7 October 2014. Available from: http://www.myrepublica.com/portal/index.php?action=news details\&news id=843 29. [8 October 1978].

Shakya, A 2015, 'Himal Media Public Opinion Survey 2015', Nepali Times. Available from: http://nepalitimes.com/page/himal-media-public-opinion-survey-2015-outcome. [16 January 2015].

Shan Herald 2015, 'The Panghsang Summit: Excerpts from a journal', Shan Herald Agency for News, 20 May 2015. Available from:

http://panglongenglish.blogspot.com.au/2015/05/the-panghsang-summit-excerptsfrom.html. [15 May 2016].

Sharma, B \& Kharel, P 2015, 'NC-UML coalition will continue until the constitution is written', eKantipur, 12 January 2015. Available from:

http://www.ekantipur.com/2015/01/12/interview/nc-uml-coalition-will-continueuntil-the-constitution-is-written/400222.html. [12 January 2015]. 
Sharma, S 2013, 'Federalism and Public Opinion', New Spotlight News Magazine, 22 February 2013, vol. 6, no. 7,[1 May 2016].

Sharma, S 2015, Nepal Contemporary Political Situation Opinion Survey: Main Findings of NCPS XI \& Trends, Interdisciplinary Analysts, Kathmandu.

Sharma, S \& Khadka, BK 2011, Nepal Contemporary Political Situation - VI, VII \& VIII: Opinion Poll Report, Interdisciplinary Analysts, Kathmandu.

Shrestha, BK 2014a, 'Federal fundamentalism: Question the merits of federalism and you are accused of committing blasphemy ', Nepali Times, 22-28 August 2014. Available from: http://nepalitimes.com/regular-columns/Comment/questioning-the-merit-offederalism,348. [25 August 2014].

Shrestha, BK 2014b, 'Frivolous Federalism', Nepali Times, 14-20 November 2014. Available from: http://nepalitimes.com/regular-columns/GUEST-COLUMN/frivolousfederalism-nepal,392. [2 December 2014].

Silverstein, J 1977, Burma: military rule and the politics of stagnation, Cornell University Press, Ithaca, New York.

Simeon, R \& Conway, D-P 2001, 'Federalism and the Management of Conflict in Multinational Societies', in A-G Gagnon \& J Tully, (eds), Multinational Democracies, pp. 338-365. Cambridge University Press, Cambridge.

Singh, MP \& Kukreja, V 2016, Federalism in South Asia, Taylor \& Francis Group.

Sinhala Commission 2008, 'Interim Report on the Government's Proposals for Constitutional Reform', in R Edrisinha, M Gomez, VT Thamilmaran \& A Welikala, (eds), Powersharing in Sri Lanka: Constitutional and Political Documents 1926-2008, pp. 594-639. Centre for Policy Alternatives and Berghof Foundation for Peace Support, Colombo.

Skidmore, N \& Cheesman, N 2012, 'Interpreting the Transition in Myanmar', in N Skidmore, N Cheesman \& T Wilson, (eds), Myanmar's Transition. Institute of Southeast Asian Studies, Singapore.

Slater, D \& Simmons, E 2010, 'Informative Regress: Critical Antecedents in Comparative Politics', Comparative Political Studies, vol. 43, no. 7, pp. 886-917.

Slow, 0 2016, 'Aung Naing Oo, the patient peace activist', Frontier Myanmar, 29 February 2016, [18 March 2016].

Smith, A 2007, 'Ethnicity and federal prospect in Myanmar', in B He, B Galligan \& T Inoguchi, (eds), Federalism in Asia, pp. 188-212. Edward Elgar, Cheltenham, UK.

Smith, F 1983 [1946], 'Secretary of State for Burma to Governor of Burma', in H Tinker, (ed) Burma - The Struggle for Independence, 1944-48: From Military Occupation to Civil Government, January 1, 1944 to August 31, 1946, vol. 1, pp. 735-736. Stationary Office Books, London.

Smith, MJ 1991, Burma: Insurgency and the politics of ethnicity, Zed Books, London and New Jersey.

Smith, MJ 2010, 'Ethnic Politics in Myanmar: A Year of Tension and Anticipation', Southeast Asian Affairs, no. 1, p. 214.

Smith, TB 1967, The Ideology of Nepal's Panchayat Raj, thesis, University of Arizona, Tucson, Arizona, Faculty of Arts.

Snaing, Y 2015a, 'Constitution: Charter Push for Decentralization, Stronger Parliament Falters', The Irrawaddy, 9 July 2015. Available from: http://www.irrawaddy.org/election/news/charter-push-for-decentralizationstronger-parliament-falters. [11 October 2015].

Snaing, Y 2015b, 'Most Student Demands Unmet as MPs Pass Amended Education Law', The Irrawaddy, 19 June 2015. Available from: http://www.irrawaddy.org/burma/moststudent-demands-unmet-as-mps-pass-amended-education-law.html. [19 June 2015].

Snaing, Y 2016, 'On Eve of New Parliament, Incoming Lawmakers Eager to Get to Work', The Irrawaddy, 29 January 2016. Available from: http://m.irrawaddy.com/burma/on-eve- 
of-new-parliament-incoming-lawmakers-eager-to-get-to-work.html. [30 January 2016].

Soifer, H 2008, 'State Infrastructural Power: Approaches to Conceptualization and Measurement', Studies in Comparative International Development, no. 43, pp. 231251.

Special Commission on the Ceylon Constitution 2008 [1928], 'Donoughmore Report (1928) Extracts', in R Edrisinha, M Gomez, VT Thamilmaran \& A Welikala, (eds), PowerSharing in Sri Lanka: Constitutional and Political Documents, 1926-2008, pp. 60-97. Centre for Policy Alternatives and Berghof Foundation for Peace Support, Colombo.

Srinivasan, M 2016, 'Solving problems of Tamils is my obligation: Sirisena', The Hindu, 11 November 2016. Available from: http://www.thehindu.com/opinion/interview/interview-with-maithripalasirisena/article9330482.ece. [12 November 2016].

Srivastava, DK 2011, Key Elements of a New Fiscal Regime in Federal Nepal, Forum of Federations, Kathmandu.

Steinberg, DI 2001, Burma, the state of Myanmar, Georgetown University Press, Washington DC.

Steinberg, DI 2010, Burma/Myanmar: what everyone needs to know, Oxford University Press, Oxford.

Steinberg, DI 2012, 'The Problem of Democracy in the Republic of the Union of Myanmar: Neither Nation-State Nor State-Nation?', Southeast Asian Affairs, no. 1, pp. 220-237.

Steinmo, S \& Thelen, K 1992, 'Historical Institutionalism in Comparative Analysis', in S Steinmo, K Thelen \& F Longstreth, (eds), Structuring Politics: Historical Institutionalism in Comparative Analysis, pp. 1-32. Cambridge University Press, Cambridge.

Stepan, AC 1999, 'Federalism and democracy: Beyond the US model', Journal of Democracy, vol. 10, no. 4, pp. 19-34.

Stepan, AC, Linz, JJ \& Yadav, Y 2011, Crafting state-nations: India and other multinational democracies, John Hopkins University Press, Baltimore.

Stokke, K \& Uyangoda, J (eds) 2012, Liberal Peace in Question: Politics of State and Market Reform in Sri Lanka, Cambridge University Press, Cambridge.

Stone, J 2014, 'Sri Lanka's Postwar Descent', Journal of Democracy, vol. 25, no. 2, pp. 146157.

Sub-Committee on Centre-Periphery Relations 2016, Report of the Sub-Committee on CentrePeriphery Relations, 19 November 2016 Steering Committee of the Constitutional Assembly, Constitutional Assembly of Sri Lanka, Colombo.

Subedi, RR 2007, 'Madhesi Agitation Dispel Deepening', The Rising Nepal, 1 March 2007. Available from: http://therisingnepal.org.np/news/8426. [25 March 2015].

Szajkowski, B 2004, Revolutionary and Dissident Movements of the World, 4th edn, John Harper Publishing, London.

Tamang, S 2011, 'Exclusionary Processes and Constitution Building in Nepal', International Journal on Minority and Group Rights, vol. 18, no. 3, pp. 293-308.

Tamil Civil Society Forum 2016, Submission to the Public Representation Committee on Constitution Reform, 16 February 2016 Tamil Civil Society Forum, Tamil Civil Society Forum, Jaffna.

Tamil People's Council 2016, Tamil People's Council Final Proposals for Finding a Political Solution to the Tamil National Question Tamil People's Council, Tamil People's Council, Jaffna.

Tawnghmung, AM 2010, 'The Dilemmas of Burma's Multinational Society', in J Bertrand \& A Laliberté, (eds), Multination states in Asia: accommodation or resistance, pp. 136163. Cambridge University Press, Cambridge. 
Taylor, C 1994, 'The Politics of Recognition', in C Taylor \& A Gutmann, (eds), Multiculturalism: examining the politics of recognition, pp. 25-73. Princeton University Press, Princeton, New Jersey.

Taylor, RH 2009, The state in Myanmar, National University of Singapore Press, Singapore.

Thapa, D \& Sijipati, B 2004, A Kingdom Under Siege: Nepal's Maoist Insurgency, 1996-2004, 2nd edn, The Printhouse, Kathmandu.

The Island 2015, 'Allegation that minority representation will be affected baseless NUF: 'Next election must be under mixed system', The Island, 15 June 2015. Available from: http://www.island.lk/index.php?page cat=articledetails\&page=article-details\&code title=126606. [17 June 2015].

The Parliament of Sri Lanka 2016, Directory of Members, The Parliament of Sri Lanka, Sri Jayewardenepura Kotte.

The Soulbury Commission 2008 [1945], 'The Soulbury Commission Report (1945) - Extract', in R Edrisinha, M Gomez, VT Thamilmaran \& A Welikala, (eds), Power-Sharing in Sri Lanka: Constitutional and Political Documents, 1926-2008, pp. 164-181. Centre for Policy Alternatives and Berghof Foundation for Peace Support, Colombo.

The Sunday Leader 2016, 'UNP To Present New Constitution - Ranil', The Sunday Leader, 28 July 2016. [29 July 2016].

Thirteenth Amendment to the Constitution of the Republic of Sri Lanka 1987, Sri Lanka.

THT Online 2009, 'Maoists declare Newa, Tamsaling', The Himalayan Times, 16 December 2009. Available from: http://www.ekantipur.com/2009/12/16/top-stories/Maoistsdeclare-Newa-and-Tamsaling-states/304577/. [16 December 2009].

Tikekar, M 2009, 'Non-Muslims in an Islamic Republic: Religious Minorities in Pakistan', in L Ghosh, (ed) Political Governance and Minority Rights: The South and South-East Asian Scenario, pp. 121-150. Routledge, New York.

Tillin, L 2015, 'Explaining Territorial Change in Federal Democracies: A Comparative Historical Institutionalist Approach', Political Studies, vol. 63, no. 3, pp. 626-641.

Tilly, C 2001, 'Mechanisms in Political Processes', Annual Review of Political Science, vol. 4, no. 1, pp. 21-41.

Tonkin, D 2004, The 1990 Elections in Myanmar (Burma): Broken Promises or a Failure of Communications?, Ibiblio.org.

Transnational Institute 2010, A Changing Ethnic Landscape: Analysis of Burma's 2010 Polls Burma Centrum Nederland, Amsterdam.

Transnational Institute 2011, Ethnic Politics in Burma: The Time for Solutions, February 2011 Transnational Institute, Amsterdam.

Ugarriza, JE \& Caluwaerts, D (eds) 2014, Democratic Deliberation in Deeply Divided Societies, Palgrave Macmillan, London.

United Nationalities Federal Council 2011, The Position Statement of the United Nationalities Federal Council (UNFC) on Peace in the Country United Nationalities Federal Council, United Nationalities Federal Council, Scribd.com.

United Nations 2008, United Nations Declaration on the Rights of Indigenous Peoples, United Nations, p. 18.

United Nations Development Programme 2007, Constitution-making in Nepal: Report of a Conference Organized by the Constitution Advisory Support Unit, UNDP, 3-4 March 2007 United Nations Development Programme (Nepal), United Nations Development Programme (Nepal), Kathmandu.

United Nations Development Programme 2008, Designing the Federal State in Nepal: Report of a Conference, 26-29 February 2008 United Nations Development Programme (Constitutional Advisory Support Unit) \& German Technical Cooperation, United Nations Development Programme (Constitutional Advisory Support Unit) \& German Technical Cooperation, Kathmandu. 
Upadhyay, A 2015, 'Analysis: A combination of factors made 4-party deal possible', The Kathmandu Post, 10 June 2015. Available from: http://kathmandupost.ekantipur.com/news/2015-06-10/analysis-a-combination-offactors-made-4-party-deal-possible.html. [12 June 2015].

Upadhyay, A \& Bhattarai, KD 2014, 'If there's a push for conservative constitution, there'll be strong resistance', eKantipur, 22 December 2014. Available from: http://www.ekantipur.com/2014/12/22/interview/if-theres-a-push-for-conservativeconstitution-therell-be-strong-resistance/399342.html. [23 December 2014].

Uyangoda, J 2005, 'Ethnic conflict, the state and the tsunami disaster in Sri Lanka', Inter-Asia Cultural Studies, vol. 6, no. 3, pp. 341-352.

Uyangoda, J 2010a, 'Ethnic conflict and the civil war in Sri Lanka', in P Brass, (ed) Routledge Handbook of South Asian Politics, pp. 291-302. Routledge, Oxon.

Uyangoda, J 2010b, 'Sri Lanka in 2009: from civil war to political uncertainities', Asian Survey, vol. 50, no. 1, pp. 104-11.

Verma, YP 1981, Nepal: Progress and Problems 1972-80, Pratibha Verma, Kathmandu.

Vollen, K 2008, 'The System of Representation for the Constituent Assembly Elections in Nepal: An assessment and suggestions for future elections', University of Oslo. Available from: http://www.uio.no/english/research/interfaculty-researchareas/democracy/news-and-events/events/conferences/2010/papers/VollanSystemOfRepresentationNepal-2008.pdf.

Wallis, J 2014, Constitution Making during State Building, Cambridge University Press, Cambridge and New York.

Walton, MJ 2008, 'Ethnicity, Conflict, and History in Burma: The Myths of Panglong', Asian Survey, vol. 48, no. 6, pp. 889-910.

Walton, MJ 2012, Politics in the Moral Universe: Burmese Buddhist Political Thought, thesis, University of Washington, Washington, Political Science.

Walton, MJ 2013, 'The 'Wages of Burman-ness': Ethnicity and Burman Privilege in Contemporary Myanmar', Journal of Contemporary Asia, vol. 43, no. 1, pp. 1-27.

Walton, MJ \& Hayward, S 2014, Contesting Buddhist Narratives Democratization, Nationalism, and Communal Violence in Myanmar East West Center, Honolulu.

Watts, RL 1999, Comparing federal systems, 2nd edn, Published for the School of Policy Studies, Queen's University by McGill-Queen's University Press, Montreal; London.

Welhengama, G \& Pillay, N 2013, 'Minorities' claim to secession by virtue of the right to selfdetermination: Asian perspectives with special reference to Kosovo and Sri Lanka', Nordic Journal of International Law, vol. 82, no. 2, pp. 249-282.

Welikala, A 2004, Fiscal and Financial Arrangement in a Federal Sri Lanka: Some Issues for Discussion, Centre for Policy Alternatives, Colombo.

Weller, M \& Wolff, S (eds) 2005, Autonomy, self-governance and conflict resolution: innovative approaches to institutional design in divided societies, Routledge, London; New York.

Weng, L 2015, 'Mongla Rebels say 'Full Control' of Region Brings Development', The Irrawaddy, 30 April 2015. Available from: http://www.irrawaddy.org/multimediaburma/mongla-rebels-say-full-control-of-region-brings-development.html. [2 May 2015].

Weng, L 2016, 'Ethnic Armed Group Leaders Discuss Formation of a Burman State', The Irrawaddy, 27 July 2016. Available from: http://www.irrawaddy.com/burma/ethnicarmed-group-leaders-discuss-formation-of-a-burman-state.html. [28 July 2016].

Whelpton, J 2005, A history of Nepal, Cambridge University Press, Cambridge and New York. Wickramasinghe, N 2010, 'Sri Lanka's Independence: Shadows over a colonial graft', in P Brass, (ed) Routledge Handbook of South Asian Politics, pp. 41-51. Routledge, Oxon. 
Wickremesinghe, R 2015, 'Ranil: Let's Promote Consensus - Sujata Jayawardena Memorial Oration 2015', Daily Mirror, 14 December 2016. Available from: http://www.dailymirror.lk/99287/ranil-let-s-promote-consensus. [14 December 2016].

Wigneswaran, CV 2016, 'Constitutional Reforms: A Brief Survey Of Our Past and Present', Colombo Telegraph, 18 January 2016. Available from: https://www.colombotelegraph.com/index.php/constitutional-reforms-a-briefsurvey-of-our-past-present/.

Wijeratne, A 2016, 'Veddah Chief wants Community's recognition', Ceylon Today, 8 March 2016. Available from: http://www.ceylontoday.lk/51-120464-news-detail-veddahchief-wants-communitys-recognition.html. [8 March 2016].

Wijeyeratne, RDS 2007, 'Rethinking Sri Lanka's Constitutional Present: Buddhism, the Asokan Personality and the Galactic Polity', Social Analysis, vol. 51, no. 1, pp. 156-178.

Wikramasinghe, N 2006, Sri Lanka in the Modern Age, Hurst and Company, London.

Win, K, Han, UM \& Hlaing, UT 2011, Myanmar Politics 1958-62, vol. II, Committee for the Compilation of Historical Facts, Ministry of Culture Historical Research Centre, Publications Committee, Yangon.

Win, TL 2016, 'Tu Ja: Lack of Ethnic MPs is 'Serious Weakness' in Parliament', The Irrawaddy, 14 January 2016. Available from: http://www.irrawaddy.com/interview/tu-ja-lack-ofethnic-mps-is-serious-weakness-in-parliament.html. [14 January 2016].

Win, ZM \& Khine, TA 2016, 'Aung San Suu Kyi Wants Amendment to Make Myanmar a Federal Democratic Union', Radio Free Asia, 18 April 2016, [21 June 2016].

Wolff, S 2009, 'Complex Power-sharing and the Centrality of Territorial Self-governance in Contemporary Conflict Settlements', Ethnopolitics, vol. 8, no. 1, pp. 27-45.

Wucherpfennig, J, Weidmann, N-C, Girardin, L, Cederman, L-E \& Wimmer, A 2011, 'Politically relevant ethnic groups across space and time: Introducing the GeoEPR dataset', Conflict Management and Peace Studies, vol. 28, no. 5, pp. 323-427.

Yadav, RB 2010, 'Towards an Inclusive, Secular and Federal Constitution"', in B Adhikari, (ed) Nepal: Design Options for the Constitution, pp. 1-2. Nepal Constitutional Foundation, Kathmandu.

Young, I 2002, Inclusion and Democracy, Oxford University Press, Oxford.

Zaw, HN 2015, "History May Blame Those Who Refuse to Hold Talks", The Irrawaddy, 21 April 2015. Available from: http://www.irrawaddy.org/interview/history-may-blamethose-who-refuse-to-hold-talks.html. [24 April 2015].

Zaw, HN \& Naing, SY 2016, 'Second 'Panglong' Conference to be Held in August', The Irrawaddy, 28 June 2016. Available from:

http://www.irrawaddy.com/burma/second-panglong-conference-held-august.html. [28 June 2016].

Zaw, M 2016, 'Taung Yoe survey aims to boost lobby for ethnic affairs minister', Myanmar Times, 15 July 2016. Available from: http://www.mmtimes.com/index.php/nationalnews/mandalay-upper-myanmar/21417-taung-yoe-survey-aims-to-boost-lobby-forethnic-affairs-minister.html. [17 July 2016].

Zaw, N 2015, 'Lower House Approves Two 'Race and Religion' Bills', The Irrawaddy, 20 March 2015. Available from: http://www.irrawaddy.org/burma/lower-house-approves-tworace-and-religion-bills.html. [23 March 2015].

Zheng, Y 2007, 'China's de facto federalism', in B He, B Galligan \& T Inoguchi, (eds), Federalism in Asia, pp. 213-241. Edward Elgar, Cheltenham, UK.

Ziblatt, D 2004, 'Rethinking the Origins of Federalism: Puzzle, Theory, and Evidence from Nineteenth-Century Europe', World Politics, vol. 57, no. 1, pp. 70-98.

Ziblatt, D 2006, Structuring the State: The Formation of Italy and Germany and the Puzzle of Federalism, Princeton University Press, Princeton. 
Zuhair, A 2016, Dynamics of Sinhala Buddhist Ethno-Nationalism in Post-War Sri Lanka, April 2016 Centre for Policy Alternatives, Centre for Policy Alternatives, Colombo. 


\section{Appendix 1: List of meetings and events}

\section{A1.1 Myanmar}

\section{A1.1.1 Meetings}

\begin{tabular}{|c|c|c|}
\hline Date & Name & Designation, organization, location \\
\hline $04 / 12 / 2014$ & Dr Alan Smith & $\begin{array}{l}\text { Head of Ethnic Peace Resource Centre, and } \\
\text { Principal Consultant to the Myanmar Peace } \\
\text { Support Initiative, Yangon }\end{array}$ \\
\hline $05 / 12 / 2014$ & $\begin{array}{l}\text { Dr Andrew Ngun Kung } \\
\text { Lian }\end{array}$ & $\begin{array}{l}\text { Presidential Advisor \& Peace Negotiator, } \\
\text { Myanmar Peace Centre, Yangon }\end{array}$ \\
\hline $08 / 12 / 2014$ & U Tin Oo & $\begin{array}{l}\text { Vice Chairperson and co-founder of the } \\
\text { National League for Democracy, former } \\
\text { military general, Yangon }\end{array}$ \\
\hline $15 / 12 / 2014$ & [Liaison officer] & $\begin{array}{l}\text { PaO National Liberation Organization, } \\
\text { Taunggyi }\end{array}$ \\
\hline $16 / 12 / 2014$ & $\begin{array}{l}\text { Sai Maung Tin, Sai Hla } \\
\text { Maung, Sai Eik Aye, } \\
\text { Nang Than Than Shwe } \\
\text { and Sai Kyaw Maung }\end{array}$ & $\begin{array}{l}\text { Member of Parliament, and committee } \\
\text { members, Shan Nationalities Democratic } \\
\text { Party, Taunggyi }\end{array}$ \\
\hline $18 / 12 / 2014$ & U Soe Aung & $\begin{array}{l}\text { Danu Literature, Culture and Regional } \\
\text { Development Association, Taunggyi }\end{array}$ \\
\hline $18 / 12 / 2014$ & Major Sai Oo, plus two & $\begin{array}{l}\text { Restoration Council of Shan State / Shan } \\
\text { State Army South, Taunggyi }\end{array}$ \\
\hline $19 / 12 / 2014$ & Sai Latt & $\begin{array}{l}\text { Research Director, Pyidaungsu Institute, } \\
\text { Yangon }\end{array}$ \\
\hline $23 / 23 / 2014$ & Major Saw Sheesho & $\begin{array}{l}\text { Karen National Union / Karen National } \\
\text { Liberation Army, Hpa'an }\end{array}$ \\
\hline $23 / 12 / 2014$ & $\begin{array}{l}\text { Thein Aing, Man Aung } \\
\text { Pyi Soe and Naw Yuzana } \\
\text { Wah }\end{array}$ & $\begin{array}{l}\text { President, Vice President and advisor, Plone- } \\
\text { Swar Democratic Party, Hpa'an }\end{array}$ \\
\hline $24 / 12 / 2014$ & Nan Say Wah & $\begin{array}{l}\text { Member of Parliament, Plone-Swar } \\
\text { Democratic Party; Social and Development } \\
\text { Union of Myanmar, Hpa'an }\end{array}$ \\
\hline $26 / 12 / 2014$ & Nai Win Hla & $\begin{array}{l}\text { Director in-charge, New Mon State Party / } \\
\text { New Mon Liberation Army, Mawlamyine }\end{array}$ \\
\hline $26 / 12 / 2014$ & $\begin{array}{l}\text { Dr Minh Soe Lin, Naing } \\
\text { Ye Zaw, Sai Lin }\end{array}$ & $\begin{array}{l}\text { General Secretary and Central Committee } \\
\text { members, Mon National Party, Mawlamyine }\end{array}$ \\
\hline 29/12/2014 & Shwe Thein & Chair of the Land Core Group, Yangon \\
\hline 08/03/2016 & Aung Naing Oo & $\begin{array}{l}\text { Director Peace Dialogue Programme, } \\
\text { Myanmar Peace Centre }\end{array}$ \\
\hline 09/08/2016 & Dr Khin Zaw Win & Director, Tampada Institute, Yangon \\
\hline $10 / 10 / 2016$ & Prof. Thida Thun & $\begin{array}{l}\text { Head of International Relations, University of } \\
\text { Mandalay, Mandalay }\end{array}$ \\
\hline
\end{tabular}


A1.1.2 Events / seminars

\begin{tabular}{|l|l|l|}
\hline Date & Event & Participants \\
\hline $03 / 12 / 2014$ & $\begin{array}{l}\text { Myanmar Peace Support } \\
\text { Initiative liaison, Yangon }\end{array}$ & $\begin{array}{l}\text { Donors, NGOs and the Myanmar Peace } \\
\text { Centre }\end{array}$ \\
\hline $05 / 12 / 2014$ & $\begin{array}{l}\text { Federalism in Asia seminar } \\
\text { (co-presenter), Mandalay }\end{array}$ & $\begin{array}{l}\text { Academics, students and civil society } \\
\text { representatives }\end{array}$ \\
\hline $08 / 12 / 2014$ & $\begin{array}{l}\text { Federalism in Asia seminar } \\
\text { (co-presenter), Lashio }\end{array}$ & $\begin{array}{l}\text { Political parties, cultural associations, } \\
\text { youth groups and civil society } \\
\text { representatives }\end{array}$ \\
\hline
\end{tabular}

\section{A1.2 Nepal}

A1.2.1 Meetings

\begin{tabular}{|c|c|c|}
\hline Date & Name & Designation, organization, location \\
\hline $17 / 08 / 2010$ & Keshav Raj Pandey & $\begin{array}{l}\text { Department of General Administration, } \\
\text { Government of Nepal, Kathmandu }\end{array}$ \\
\hline $18 / 08 / 2010$ & Budhi Bahadur Karki & $\begin{array}{l}\text { Centre for Constitutional Dialogue, UNDP, } \\
\text { Kathmandu }\end{array}$ \\
\hline $28 / 08 / 2010$ & Yagya Bikram Shahi & $\begin{array}{l}\text { Office for the High Commissioner for } \\
\text { Human Rights, Kathmandu }\end{array}$ \\
\hline $14 / 09 / 2010$ & Sharmilla Karki & $\begin{array}{l}\text { President, Jagaran Nepal; General } \\
\text { Secretary, NGO Federation of Nepal, } \\
\text { Kathmandu }\end{array}$ \\
\hline $14 / 09 / 2010$ & Ashoda Timsina & $\begin{array}{l}\text { Board member, Federation of Nepal } \\
\text { Journalists, Kathmandu }\end{array}$ \\
\hline $16 / 09 / 2010$ & Suvash Darnal & $\begin{array}{l}\text { Managing Director, Samata Foundation, } \\
\text { Kathmandu }\end{array}$ \\
\hline $17 / 09 / 2010$ & Kaushal Kumar Singh & $\begin{array}{l}\text { President, Other Backward Class } \\
\text { Federation, Kathmandu }\end{array}$ \\
\hline $22 / 09 / 2010$ & Prakash A. Raj & $\begin{array}{l}\text { Vice President, Nepal Council of World } \\
\text { Affairs, Kathmandu }\end{array}$ \\
\hline $07 / 10 / 2010$ & Krishna Sunar & Dalit NGO Federation, Kaski \\
\hline $12 / 11 / 2010$ & Malla K Sundar & $\begin{array}{l}\text { Maoist member of the Constituent } \\
\text { Assembly; General Secretary, National } \\
\text { Coalition Against Racial Discrimination; } \\
\text { Founding member of National Federation } \\
\text { of Indigenous Nationalities; Patron Newa } \\
\text { National Front, Kathmandu }\end{array}$ \\
\hline $16 / 11 / 2010$ & Dr Om Gurung & $\begin{array}{l}\text { Head of School of Anthropology, } \\
\text { Tribhuvan University; Former General } \\
\text { Secretary, Nepal Federation of } \\
\text { Indigenous Nationalities, Kathmandu }\end{array}$ \\
\hline $18 / 11 / 2010$ & Hari Bishwakarma & $\begin{array}{l}\text { Dalit Studies and Development Centre, } \\
\text { Kathmandu }\end{array}$ \\
\hline $20 / 11 / 2010$ & $\begin{array}{l}\text { Assoc. Prof. Dr. Balkrishna } \\
\text { Mahubang }\end{array}$ & $\begin{array}{l}\text { Tribhuvan University (Demography); } \\
\text { Former General Secretary of Nepal } \\
\text { Federation of Indigenous Nationalities, } \\
\text { Kathmandu }\end{array}$ \\
\hline
\end{tabular}




\begin{tabular}{|l|l|l|}
\hline Date & Name & Designation, organization, location \\
\hline $24 / 11 / 2010$ & Ganesh Biskwakarma & $\begin{array}{l}\text { President, Rastriya Dalit Network, } \\
\text { Kathmandu }\end{array}$ \\
\hline $08 / 09 / 2014$ & Rohan Edrisinha & $\begin{array}{l}\text { International Programme Manager, } \\
\text { Support to Participatory Constitution } \\
\text { Building, UNDP, Kathmandu }\end{array}$ \\
\hline $08 / 09 / 2014$ & Madhev Kumar Nepal & $\begin{array}{l}\text { Senior Leader, Communist Party of Nepal } \\
\text { (United Marxist Leninist), former prime } \\
\text { minister, member of Constituent } \\
\text { Assembly, Kathmandu }\end{array}$ \\
\hline $09 / 09 / 2014$ & Lal Babu Yadav & $\begin{array}{l}\text { Associate Professor, Political Science, } \\
\text { Tribhuvan University, Kathmandu }\end{array}$ \\
\hline $10 / 09 / 2014$ & Suriya Dhungel & $\begin{array}{l}\text { Presidential Advisor } \\
\text { Nepali Congress member of the } \\
\text { Constituent Assembly, member of the } \\
\text { Constitution Drafting Committee, Foreign } \\
\text { Minister }\end{array}$ \\
\hline $10 / 09 / 2014$ & Dr Prakash Mahat & $\begin{array}{l}\text { Vice Chairman, Communist Party of Nepal } \\
\text { (Maoist), former prime minister, member } \\
\text { of the Constituent Assembly, Kathmandu }\end{array}$ \\
\hline $11 / 09 / 2014$ & Dr Baburam Bhattarai & $\begin{array}{l}\text { Advocate and senior leader of } \\
\text { Communist Party of Nepal (Maoist) }\end{array}$ \\
\hline $09 / 03 / 2016$ & Khim Lal Devkota &
\end{tabular}

\section{A1.2.2 Events}

\begin{tabular}{|l|l|l|}
\hline Date & Event & Participants \\
\hline $17 / 08 / 2010$ & $\begin{array}{l}\text { Practical implications of } \\
\text { Autonomous Regions and } \\
\text { Special Regions }\end{array}$ & $\begin{array}{l}\text { Constituent Assembly members, political } \\
\text { advisors, academics and civil society } \\
\text { representatives }\end{array}$ \\
\hline $\mathbf{1 8 / 0 8 / 2 0 1 0}$ & $\begin{array}{l}\text { Federalism Dialogue in } \\
\text { proposed Newa Province } \\
\text { Jadan Province: Managing } \\
\text { Viability and Diversity }\end{array}$ & $\begin{array}{l}\text { Cocal level political party members } \\
\text { Constituent Assembly members, political } \\
\text { advisors, academics and civil society } \\
\text { representatives }\end{array}$ \\
\hline $02 / 09 / 2010$ & $\begin{array}{l}\text { Non-territorial federalism: } \\
\text { options for Dalit, Muslims } \\
\text { and other scattered } \\
\text { communities } \\
\text { (presenter) }\end{array}$ & $\begin{array}{l}\text { Constituent Assembly members, political } \\
\text { advisors, academics and civil society } \\
\text { representatives, especially those from } \\
\text { Dalit and Muslim communities }\end{array}$ \\
\hline Provincial Parliament: & Variations & $\begin{array}{l}\text { Constituent Assembly members, political } \\
\text { advisors, academics and civil society } \\
\text { representatives }\end{array}$ \\
\hline $16 / 09 / 2010$ & $\begin{array}{l}\text { Managing the Transition to } \\
\text { Federal Units }\end{array}$ & $\begin{array}{l}\text { Constituent Assembly members, political } \\
\text { advisors, academics and civil society } \\
\text { representatives }\end{array}$ \\
\hline $29 / 09 / 2010$ & $\begin{array}{l}\text { Balancing Identity and } \\
\text { Viability }\end{array}$ & $\begin{array}{l}\text { Constituent Assembly members, political } \\
\text { advisors, academics and civil society } \\
\text { representatives }\end{array}$ \\
\hline & &
\end{tabular}




\begin{tabular}{|l|l|l|}
\hline Date & Event & Participants \\
\hline 06/10/2010 & $\begin{array}{l}\text { Non-territorial federalism } \\
\text { for Dalits and Muslims, } \\
\text { Kaski } \\
\text { (presenter) }\end{array}$ & Dalit NGO Federation, Western Region \\
\hline $19 / 11 / 2010$ & $\begin{array}{l}\text { Ethnic federalism and non- } \\
\text { territorial federalism, } \\
\text { Nepalgunj, (presenter) }\end{array}$ & Tharu Indigenous Federation \\
\hline $19 / 11 / 10$ & $\begin{array}{l}\text { Non-territorial federalism } \\
\text { for Muslims, Nepalgunj, } \\
\text { (presenter) }\end{array}$ & Fatima Foundation \\
\hline $19 / 11 / 10$ & $\begin{array}{l}\text { Non-territorial federalism } \\
\text { for Dalits, Nepalgunj, } \\
\text { (presenter) }\end{array}$ & $\begin{array}{l}\text { Dalit NGO Federation, Far Western } \\
\text { Region }\end{array}$ \\
\hline $9-10 / 09 / 14$ & $\begin{array}{l}\text { Federalism in Asia } \\
\text { workshop (co-convenor), } \\
\text { Kathmandu }\end{array}$ & $\begin{array}{l}\text { Constituent Assembly members, political } \\
\text { advisors, academics and civil society } \\
\text { representatives }\end{array}$ \\
\hline
\end{tabular}

\section{A1.3 Sri Lanka}

\section{A1.3.1 Meetings}

\begin{tabular}{|c|c|c|}
\hline Date & Name & Designation, organization, location \\
\hline $19 / 11 / 2015$ & Dr Asanga Welikala & $\begin{array}{l}\text { Lecturer in constitutional law, University } \\
\text { of Edinburgh }\end{array}$ \\
\hline $19 / 11 / 2015$ & Lionel Guruge & $\begin{array}{l}\text { Director Community Outreach, Centre for } \\
\text { Policy Alternatives, former founding } \\
\text { member JVP party }\end{array}$ \\
\hline 20/11/2015 & Nizam Kariapper & $\begin{array}{l}\text { General Secretary Sri Lankan Muslim } \\
\text { Congress, Mayor Kalmuni, Director Urban } \\
\text { Housing Authority, Attorney, Colombo }\end{array}$ \\
\hline 20/11/2015 & Prof Jayadeva Uyangoda & $\begin{array}{l}\text { Professor of Political Science, University } \\
\text { of Colombo, member of the Prime } \\
\text { Minister's Advisory Committee on } \\
\text { Constitutional Reform }\end{array}$ \\
\hline $20 / 11 / 2015$ & Rohan Edrisinha & $\begin{array}{l}\text { Founder of Centre for Policy Alternatives, } \\
\text { member of the Prime Minister's Advisory } \\
\text { Committee for Constitutional Reform, } \\
\text { Colombo }\end{array}$ \\
\hline $22 / 11 / 2015$ & Manohara De Silva & $\begin{array}{l}\text { Attorney, President's Counsel, Law } \\
\text { Commissioner, Colombo }\end{array}$ \\
\hline $23 / 12 / 2015$ & S Thavarajah & $\begin{array}{l}\text { Opposition Leader of the Northern } \\
\text { Province, Eelam People's Democratic } \\
\text { Party, Jaffna }\end{array}$ \\
\hline $24 / 12 / 2015$ & Varaythara Perumul & $\begin{array}{l}\text { First (and only) Chief Minister of the } \\
\text { North-Eastern Province, Jaffna }\end{array}$ \\
\hline $25 / 11 / 2015$ & $\begin{array}{l}\text { Selvarajah Kajendren } \\
\text { Mannivanan }\end{array}$ & $\begin{array}{l}\text { Attorney and Coordinator of the Tamil } \\
\text { National People's Front, Jaffna }\end{array}$ \\
\hline
\end{tabular}




\begin{tabular}{|l|l|l|}
\hline Date & Name & Designation, organization, location \\
\hline $25 / 11 / 2015$ & Dr Thayalan Ambayalan & $\begin{array}{l}\text { Local surgeon, long-time community } \\
\text { leader and spokesperson, academic, and } \\
\text { advisor to education ministry, Jaffna }\end{array}$ \\
\hline $26 / 11 / 2015$ & C.V. Wigneswaran & $\begin{array}{l}\text { Chief Minister of the Northern Province, } \\
\text { ITAK party, former Justice of the Supreme } \\
\text { Court, Jaffna }\end{array}$ \\
\hline $01 / 12 / 2015$ & $\begin{array}{l}\text { Dr Paisakothy } \\
\text { Saravanamuttu }\end{array}$ & $\begin{array}{l}\text { Executive Director, Centre for Policy } \\
\text { Alternatives, Colombo }\end{array}$ \\
\hline $012 / 2015$ & $\begin{array}{l}\text { Dr Jayampatthy } \\
\text { Wickremaratne }\end{array}$ & $\begin{array}{l}\text { UNPSP party, member of parliament, } \\
\text { member of the parliamentary steering } \\
\text { committee and other parliamentary } \\
\text { committees for constitutional reform, } \\
\text { former head of the Sri Lanka Institute for } \\
\text { Constitutional Development }\end{array}$ \\
\hline $03 / 12 / 2015$ & Dr Jehan Perrera & $\begin{array}{l}\text { Executive Director, National Peace } \\
\text { Council, Colombo }\end{array}$ \\
\hline $03 / 12 / 2015$ & Gehan Gunatilleke & $\begin{array}{l}\text { Research Director, Verite Institute; } \\
\text { Advocate, Colombo }\end{array}$ \\
\hline
\end{tabular}

\section{A1.3.2 Events}

\begin{tabular}{|l|l|l|}
\hline Date & Event & Participants \\
\hline $17 / 11 / 2015$ & $\begin{array}{l}\text { Constitutional Reform, } \\
\text { Sabaragamuwa University } \\
\text { of Sri Lanka, Ratnapura }\end{array}$ & $\begin{array}{l}\text { Civil society organizations, academics, } \\
\text { students }\end{array}$ \\
\hline $23 / 11 / 2015$ & $\begin{array}{l}\text { All Island Community } \\
\text { Political Solutions } \\
\text { Conference, Jaffna }\end{array}$ & Political parties, civil society organizations \\
\hline $01 / 12 / 2015$ & $\begin{array}{l}\text { Citizen's Initiative for } \\
\text { Constitutional Change, } \\
\text { Colombo }\end{array}$ & Civil society organizations \\
\hline $04 / 05 / 2015$ & $\begin{array}{l}\text { International Conference } \\
\text { on Social Sciences, } \\
\text { University of Colombo, } \\
\text { Colombo }\end{array}$ & Academics, students \\
\hline
\end{tabular}




\section{Appendix 2: Data and coding}

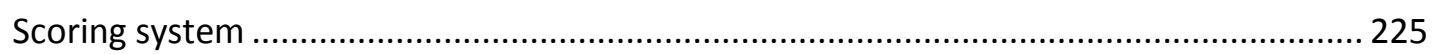

Notes for coding across time series in the summary sheet ........................................... 232

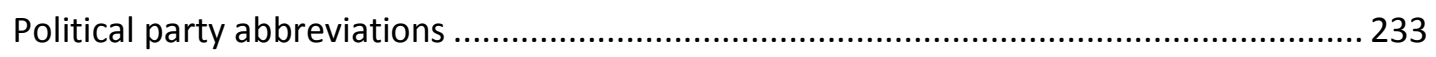

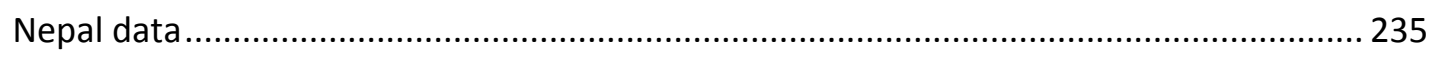

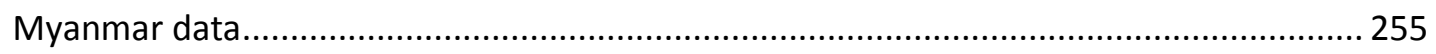

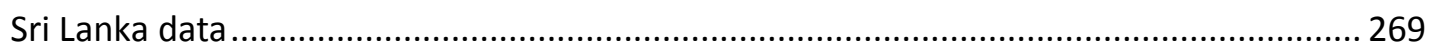




\section{A2.1 Scoring system}

Table A1: Indicators, measures, criteria and instructions

\begin{tabular}{|c|c|c|c|c|c|}
\hline Indicator & Measure & Reference & Criteria & Score & Coding instructions \\
\hline \multirow[t]{9}{*}{ Autonomy } & \multirow{5}{*}{$\begin{array}{l}\text { Extent of central } \\
\text { authority }\end{array}$} & \multirow{5}{*}{$\begin{array}{l}\text { F1 - } \\
\text { Federalism }\end{array}$} & Unlimited power to direct units & -4 & \multirow[t]{4}{*}{ Sum all, up to -4 maximum } \\
\hline & & & $\begin{array}{l}\text { Center can override or alter powers, units or boundaries } \\
\text { unilaterally }\end{array}$ & -1 & \\
\hline & & & $\begin{array}{l}\text { Center can override units' legislation (or must approve, but } \\
\text { without obligation) }\end{array}$ & -1 & \\
\hline & & & $\begin{array}{l}\text { Center can appoint, approve, revoke a unit's leaders, or similar } \\
\text { (e.g. dissolve provincial legislatures) }\end{array}$ & -1 & \\
\hline & & & Center can take power during an emergency or similar & 0 & Not scored, data collection only \\
\hline & \multirow[t]{4}{*}{$\begin{array}{l}\text { Scope of unit's } \\
\text { autonomy }\end{array}$} & \multirow[t]{4}{*}{ F2 - Federalism } & $\begin{array}{l}\text { Legislative \& executive, including law } \& \text { order; taxation } \& \\
\text { revenue; land \& natural resources; and, education \& language }\end{array}$ & 4 & \multirow{3}{*}{$\begin{array}{l}\text { One score only (not summed) } \\
\text { Add or subtract } 0.5 \text { for each } \\
\text { listed significant power grouping } \\
\text { covered or not }\end{array}$} \\
\hline & & & $\begin{array}{l}\text { Scope of powers narrow (i.e. missing above functions; } \\
\text { administrative only; or absent executive or legislative) }\end{array}$ & 2 & \\
\hline & & & $\begin{array}{l}\text { Levels of government only mentioned in constitution (with or } \\
\text { without accompanying purposes or principles) }\end{array}$ & 1 & \\
\hline & & & Legislative decentralization or autonomy acts made & 0 & Not scored, data collection only \\
\hline \multirow[t]{3}{*}{ Constitutionalism } & \multirow[t]{3}{*}{ Constitutionalism } & \multirow[t]{3}{*}{ F3 - Federalism } & $\begin{array}{l}\text { Rigid constitution, requires super majority or referendum to } \\
\text { change }\end{array}$ & 1 & \multirow[t]{3}{*}{ Sum all } \\
\hline & & & $\begin{array}{l}\text { Independent or balanced approach to resolving interjurisdictional } \\
\text { disputes }\end{array}$ & 1 & \\
\hline & & & Independent court interprets constitution & 1 & \\
\hline \multirow[t]{2}{*}{ Interdependence } & \multirow[t]{2}{*}{ Bicameralism } & \multirow[t]{2}{*}{ F4 - Federalism } & $\begin{array}{l}\text { Units are represented in a bicameral legislature where each } \\
\text { house has broadly similar powers }\end{array}$ & 3 & \multirow{2}{*}{$\begin{array}{l}\text { Units are assessed as the } \\
\text { highest level units, not including } \\
\text { autonomous zones, special } \\
\text { regions or local government, } \\
\text { which are covered separately }\end{array}$} \\
\hline & & & $\begin{array}{l}\text { Units or ethnic groups are represented in the legislature - but } \\
\text { either the lower house is superior, or there is only one house }\end{array}$ & 1 & \\
\hline
\end{tabular}




\begin{tabular}{|c|c|c|c|c|c|}
\hline Indicator & Measure & Reference & Criteria & Score & Coding instructions \\
\hline & & & $\begin{array}{l}\text { Units or ethnic group has a veto right over matters affecting } \\
\text { autonomy or cultural rights }\end{array}$ & 1 & $\begin{array}{l}\text { Add one to above score if this } \\
\text { right is incorporated }\end{array}$ \\
\hline & \multirow{3}{*}{$\begin{array}{l}\text { Legislative / } \\
\text { executive } \\
\text { relations }\end{array}$} & \multirow[t]{3}{*}{$\begin{array}{l}\text { C1 - } \\
\text { Consociational }\end{array}$} & $\begin{array}{l}\text { Parliamentary system (executive drawn from and accountable to } \\
\text { parliament) }\end{array}$ & 2 & \multirow{3}{*}{$\begin{array}{l}\text { One score (not summed) } \\
\text { Hybrid systems (e.g. Sri Lanka } \\
\text { post 1978, Myanmar 2008) } \\
\text { score } 1.5\end{array}$} \\
\hline & & & $\begin{array}{l}\text { Presidential system (democratically elected president vested with } \\
\text { executive power) }\end{array}$ & 1 & \\
\hline & & & $\begin{array}{l}\text { Unelected head of state with executive power (including military, } \\
\text { single-party system, monarch) }\end{array}$ & 0 & \\
\hline \multirow{9}{*}{ Units } & \multirow{5}{*}{$\begin{array}{l}\text { Basis of units } \\
\text { (identity / } \\
\text { territory) }\end{array}$} & \multirow{5}{*}{ E1 - Ethnicity } & $\begin{array}{l}50 \% \text { or more of the units are for minority ethnic groups (i.e. have } \\
\text { a unit named after them, or they are the majority), but there are } \\
\text { no special rights }\end{array}$ & 3 & \multirow{5}{*}{$\begin{array}{l}\text { A single score for the basis of } \\
\text { units (not summed) } \\
\text { Special rights are political } \\
\text { prerogatives guaranteeing } \\
\text { leadership of units, or other } \\
\text { important roles, to a given } \\
\text { ethnic group }\end{array}$} \\
\hline & & & $\begin{array}{l}\text { One or more (up to 50\%) of the units are for minority ethnic } \\
\text { groups (i.e. a unit is named after them, or they are the majority), } \\
\text { but there are no special rights }\end{array}$ & 2 & \\
\hline & & & $\begin{array}{l}\text { Units are based on a mixture of territorial and identity-based } \\
\text { criteria (major ethnic group(s) are consolidated within a single } \\
\text { boundary without creating a majority group, with or without } \\
\text { ethnic naming), or are local units designed to cluster ethnicities }\end{array}$ & 1 & \\
\hline & & & Units are based on territorial criteria only & 0 & \\
\hline & & & $\begin{array}{l}\text { Units are designed to avoid consolidating regional (identity- } \\
\text { based) minorities }\end{array}$ & -1 & \\
\hline & \multirow[t]{3}{*}{ Sub-unit level } & \multirow[t]{3}{*}{ E2 - Ethnicity } & $\begin{array}{l}\text { Includes regional / local autonomous areas / self-administered } \\
\text { zones with constitutionally defined powers }\end{array}$ & 3 & \multirow[t]{3}{*}{ Additional points } \\
\hline & & & $\begin{array}{l}\text { Includes regional / local autonomous areas / self-administered } \\
\text { zones with constitutionally defined territories or communities }\end{array}$ & 2 & \\
\hline & & & $\begin{array}{l}\text { Includes ability to create regional / local autonomous areas / self- } \\
\text { administered zones }\end{array}$ & 1 & \\
\hline & $\begin{array}{l}\text { Levels of } \\
\text { government }\end{array}$ & E3 - Ethnicity & $\begin{array}{l}\text { Four or more levels of government (not including above sub-unit } \\
\text { level. Instead local, village level etc.) }\end{array}$ & 1 & $\begin{array}{l}\text { A single score only - not } \\
\text { summed (i.e. difference }\end{array}$ \\
\hline
\end{tabular}




\begin{tabular}{|c|c|c|c|c|c|}
\hline Indicator & Measure & Reference & Criteria & Score & Coding instructions \\
\hline & & & $\begin{array}{l}\text { Three levels of government (not including above sub-unit level. } \\
\text { Instead local, village level etc.) }\end{array}$ & 1 & $\begin{array}{l}\text { between } 3 \text { and } 4 \text { levels not } \\
\text { reflected in score) }\end{array}$ \\
\hline Asymmetry & $\begin{array}{l}\text { Degree of } \\
\text { asymmetry }\end{array}$ & E4 - Ethnicity & $\begin{array}{l}\text { Certain (ethnic) units are more represented in the center than } \\
\text { other units }\end{array}$ & 1 & Sum all \\
\hline \multirow[t]{5}{*}{ Representation } & \multirow{5}{*}{$\begin{array}{l}\text { Identity } \\
\text { elements of } \\
\text { representative } \\
\text { mechanisms }\end{array}$} & \multirow[t]{5}{*}{$\begin{array}{l}\text { C2 - } \\
\text { Consociational }\end{array}$} & $\begin{array}{l}\text { Seats or other positions are reserved specifically for ethnic } \\
\text { groups }\end{array}$ & 1 & Sum all \\
\hline & & & $\begin{array}{l}\text { Proportional representation is used (score 1) or used extensively } \\
\text { or in multiple institutions (score } 2 \text { ) }\end{array}$ & 2 & $\begin{array}{l}\text { If threshold is greater than } 5 \% \text {, } \\
\text { or PR is limited to less than } 40 \% \\
\text { of seats (if parallel), score } 1\end{array}$ \\
\hline & & & $\begin{array}{l}\text { Mixed-member electorates, electoral delineation or direct } \\
\text { appointments used to further identity-based representation }\end{array}$ & 1 & $\begin{array}{l}\text { Electoral delineation criteria } \\
\text { apply when constituencies can } \\
\text { be drawn to reflect clustered } \\
\text { ethnic communities }\end{array}$ \\
\hline & & & $\begin{array}{l}\text { No explicit or specific measures for identity or proportional based } \\
\text { representation }\end{array}$ & 0 & \\
\hline & & & No representation & -2 & \\
\hline \multirow[t]{5}{*}{ Cultural rights } & \multirow[t]{5}{*}{$\begin{array}{l}\text { Extent of Cultural } \\
\text { Rights }\end{array}$} & \multirow[t]{4}{*}{$\begin{array}{l}\text { C3 - } \\
\text { Consociational }\end{array}$} & $\begin{array}{l}\text { A variety of language and religious institutions are institutionally } \\
\text { supported }\end{array}$ & 1 & Sum all, includes legislative acts \\
\hline & & & $\begin{array}{l}\text { There is the ability to make and apply personal laws (such as for } \\
\text { religion and family law) }\end{array}$ & 1 & $\begin{array}{l}\text { May be pre-existing rights not } \\
\text { accorded via constitution }\end{array}$ \\
\hline & & & $\begin{array}{l}\text { Ethnic groups are recognised and have (non-territorial) } \\
\text { institutional autonomy }\end{array}$ & 1 & $\begin{array}{l}\text { E.g. right to develop language } \\
\text { and culture, right to natural } \\
\text { resources }\end{array}$ \\
\hline & & & $\begin{array}{l}\text { Individual rights and freedoms are protected, guaranteed / } \\
\text { discrimination banned }\end{array}$ & 0 & Not scored, data collection only \\
\hline & & & A national religion and/or language are prescribed & -1 & Sum all \\
\hline
\end{tabular}




\begin{tabular}{|c|c|c|c|c|c|}
\hline Indicator & Measure & Reference & Criteria & Score & Coding instructions \\
\hline & \multirow[t]{2}{*}{$\begin{array}{l}\text { Assimilative } \\
\text { aspects }\end{array}$} & \multirow[t]{2}{*}{$\begin{array}{l}\text { C4 - } \\
\text { Consociational }\end{array}$} & $\begin{array}{l}\text { There are explicit restrictions on important identity-based rights } \\
\text { (e.g. religious freedom), or formalized integration }\end{array}$ & -1 & \\
\hline & & & $\begin{array}{l}\text { There is formal institutionalized identity-based } \\
\text { disenfranchisement, discrimination, repression, dispossession }\end{array}$ & -1 & \\
\hline \multirow[t]{7}{*}{$\begin{array}{l}\text { Federalism } \\
\text { behaviors }\end{array}$} & Units & BF1 - Federalism & Increase or decrease in the number of units & \multicolumn{2}{|c|}{$\begin{array}{l}\text { Proportional increase or decrease in number } \\
\text { (e.g. from } 14 \text { to } 16=0.14(2 / 14) ; 5 \text { to } 2=-0.6(- \\
3 / 5)\end{array}$} \\
\hline & \multirow[t]{2}{*}{ Powers } & \multirow[t]{2}{*}{ BF2 - Federalism } & $\begin{array}{l}\text { Addition or subtraction of substantive but minor powers from the } \\
\text { units }\end{array}$ & 0.2 & $\begin{array}{l}\text { Per event (or negative score), } \\
\text { excluding for example deletion } \\
\text { of obsolete power - OR - }\end{array}$ \\
\hline & & & $\begin{array}{l}\text { Addition or subtraction of substantive major powers from the } \\
\text { units }\end{array}$ & 0.5 & $\begin{array}{l}\text { As above. Major means } \\
\text { revenue/taxation; natural } \\
\text { resources/land; } \\
\text { education/language; } \\
\text { police/security }\end{array}$ \\
\hline & Dissolution & BF3 - Federalism & Dissolution of a unit, or its legislature or executive & -0.5 & Per event \\
\hline & Disallowance & BF4 - Federalism & Disallowance or legislating over a unit's legislation & -0.25 & \\
\hline & \multirow[t]{2}{*}{ Major } & \multirow[t]{2}{*}{ BF6 - Federalism } & $\begin{array}{l}\text { State of emergency, or rule without a constitution, for more than } \\
\text { one year }\end{array}$ & \multicolumn{2}{|c|}{$\begin{array}{l}\text { Suspension of federal score consistent with } \\
\text { the extent of suspension of federal powers }\end{array}$} \\
\hline & & & Secession event & -2 & \\
\hline \multirow[t]{3}{*}{$\begin{array}{l}\text { Consociational } \\
\text { behaviors }\end{array}$} & \multirow[t]{3}{*}{ Executive } & \multirow[t]{3}{*}{$\begin{array}{l}\text { BC1 - } \\
\text { Consociational }\end{array}$} & $\begin{array}{l}\text { Units or identity groups are represented in the executive via a } \\
\text { consensus government }\end{array}$ & 4 & $\begin{array}{l}\text { All major parties / groups are } \\
\text { included in Cabinet }\end{array}$ \\
\hline & & & $\begin{array}{l}\text { Units or identity groups are represented in the executive via a } \\
\text { multiparty coalition, including ethnic parties, in an oversized } \\
\text { Cabinet }\end{array}$ & 3 & $\begin{array}{l}\text { Oversized means more parties } \\
\text { are included in Cabinet than is } \\
\text { required to have a majority }\end{array}$ \\
\hline & & & $\begin{array}{l}\text { Units or identity groups are represented in the executive via a } \\
\text { multiparty coalition, including ethnic parties, in a minimal Cabinet }\end{array}$ & 2 & $\begin{array}{l}\text { Minimal means that only parties } \\
\text { required to make a majority are } \\
\text { included }\end{array}$ \\
\hline
\end{tabular}




\begin{tabular}{|c|c|c|c|c|c|}
\hline Indicator & Measure & Reference & Criteria & Score & Coding instructions \\
\hline & & & $\begin{array}{l}\text { Identity groups are represented in the executive via multiethnic } \\
\text { parties }\end{array}$ & 1 & \\
\hline & & & Single party (system) or other authoritarian style executive & 0 & \\
\hline & Proportionality & $\begin{array}{l}\mathrm{BC} 2- \\
\text { Consociational }\end{array}$ & $\begin{array}{l}\text { Proportionality in legislature - parties (seats versus share of } \\
\text { votes) }\end{array}$ & $\begin{array}{l}10 / \\
\text { Gallagher } \\
\text { Index }\end{array}$ & $\begin{array}{l}\text { Only incorporates parties which } \\
\text { won a seat, or have more than } \\
1 \% \text { of the vote } \\
\text { (see Lijphart 1999: 145) }\end{array}$ \\
\hline & \multirow[t]{2}{*}{$\begin{array}{l}\text { Segmented } \\
\text { autonomy }\end{array}$} & $\begin{array}{l}\text { BC3 - } \\
\text { Consociational }\end{array}$ & $\begin{array}{l}\text { Empowerment of ethnic groups to exercise autonomy over } \\
\text { cultural matters (e.g. education) if not pre-existing in constitution }\end{array}$ & 1 & \\
\hline & & $\begin{array}{l}\mathrm{BC3}- \\
\text { Consociational }\end{array}$ & $\begin{array}{l}\text { Removal or centralization of cultural matters (e.g. nationalizing } \\
\text { language) }\end{array}$ & -1 & \\
\hline & Veto & $\begin{array}{l}\text { BC4 - } \\
\text { Consociational }\end{array}$ & Exercise of minority veto & 2 & \\
\hline \multirow[t]{2}{*}{$\begin{array}{l}\text { Ethnicity in units } \\
\text { behaviors }\end{array}$} & \multirow[t]{2}{*}{ Ethnicity } & BE1 - Ethnicity & $\begin{array}{l}\text { Realignment, addition or merging of units to increase the } \\
\text { ethnicity incorporated into demarcation }\end{array}$ & 1 & Or negative as the case may be \\
\hline & & BE2 - Ethnicity & $\begin{array}{l}\text { Addition of powers, representation or other asymmetries aligning } \\
\text { with ethnicity }\end{array}$ & 1 & Or negative as the case may be \\
\hline \multirow{8}{*}{ OTHER } & \multirow{5}{*}{ Conflict } & \multirow{5}{*}{ O1 - Other } & Insurgency - two or more units, up to $50 \%$ of the country & -2 & \\
\hline & & & Insurgency - confined to one unit & -1 & \\
\hline & & & $\begin{array}{l}\text { Violent widespread riots, protests, displacement (not as part of } \\
\text { insurgencies) }\end{array}$ & 0.5 & \\
\hline & & & Ceasefire - ends insurgency (temporarily) & 0.5 & Of score for relevant insurgency \\
\hline & & & Peace Agreement - ends insurgency (permanently) & 1 & Of score for relevant insurgency \\
\hline & \multirow[t]{2}{*}{ Regime change } & \multirow[t]{2}{*}{ O2-Other } & Democratic & 1 & \\
\hline & & & Undemocratic & -1 & \\
\hline & Economic & O3 - Other & Major marketisation or opening up of economy & 1 & \\
\hline
\end{tabular}




\begin{tabular}{|c|c|c|c|c|c|}
\hline Indicator & Measure & Reference & Criteria & Score & Coding instructions \\
\hline & & & Economic crisis, or restrictive reforms leading to crisis & -1 & \\
\hline & \multirow[t]{2}{*}{ External } & \multirow[t]{2}{*}{ O4 - Other } & Natural or manmade disaster & 1 & $\begin{array}{l}\text { Extensive and with nation-wide } \\
\text { impacts }\end{array}$ \\
\hline & & & Major changes in international environment or relations & 2 & $\begin{array}{l}\text { For example, intervention of } \\
\text { neighboring country }\end{array}$ \\
\hline & \multirow[t]{5}{*}{ Party system } & \multirow[t]{5}{*}{ O5 - other } & Single party or authority system (ethnic) & -2 & \multirow{5}{*}{$\begin{array}{l}\text { As at each year, or the system in } \\
\text { place for the most of each } \\
\text { calendar year where more than } \\
\text { one system existed } \\
\text { Mixed systems may be scored at } \\
+/-0.5\end{array}$} \\
\hline & & & Single party or authority system (multi-ethnic) & -1 & \\
\hline & & & Multiparty (dominant ethnicity based) & 0 & \\
\hline & & & Multiparty (multiethnic) & 1 & \\
\hline & & & Multiparty (ethnic) & 2 & \\
\hline Democratization & & Dem & $\begin{array}{l}\text { DEMOC variable in Polity Project's Political Regime } \\
\text { Characteristics and Transitions, } 1800-2015 \text { dataset }\end{array}$ & 1 to 10 & (Marshall et al 2015) \\
\hline \multirow[t]{3}{*}{$\underline{\text { Secession risk }}$} & Conflict & SR1 & Extent of country controlled by armed groups & Ref $01 / 2$ & Conflict score (01) divided by 2 \\
\hline & $\begin{array}{l}\text { Ethnic } \\
\text { homogeneity }\end{array}$ & SR2 & Ethnic homogeneity of existing or prospective unit & 0 to 2 & $\begin{array}{l}\text { No majority groups (0), majority } \\
\text { groups (1) or group(s) with more } \\
\text { than } 90 \% \text { of population in given } \\
\text { area (2) }\end{array}$ \\
\hline & $\begin{array}{l}\text { International } \\
\text { influence }\end{array}$ & SR3 & Conducive international environment & 0 or 2 & $\begin{array}{l}\text { No international support (0), } \\
\text { international environment } \\
\text { supportive (1), international } \\
\text { actors actively support (2) }\end{array}$ \\
\hline \multirow[t]{3}{*}{$\begin{array}{l}\text { Infrastructural } \\
\text { capacity }\end{array}$} & Negotiating & IC1 & Presence and type of political organization & 0 to 3.5 & $\begin{array}{l}\text { Sum of: ethnic parties (0.5) } \\
\text { armed groups (1), non-partisan } \\
\text { representative body (2) }\end{array}$ \\
\hline & Administrative & IC2 & Presence and type of regional administrative capacity & 0 to 2.5 & $\begin{array}{l}\text { Sum of: quasi-federal (0.5), } \\
\text { federal (1), parallel } \\
\text { administration (2) }\end{array}$ \\
\hline & Accountability & DC1 & Accountability (executive is accountable to the legislature) & 1 & Sum all \\
\hline
\end{tabular}




\begin{tabular}{|c|c|c|c|c|c|}
\hline Indicator & Measure & Reference & Criteria & Score & Coding instructions \\
\hline \multirow[t]{5}{*}{$\begin{array}{l}\text { Deliberative } \\
\text { conditions }\end{array}$} & & & & & $\begin{array}{l}\text { Score half for hybrid or mixed } \\
\text { arrangements }\end{array}$ \\
\hline & Local levels & DC2 & $\begin{array}{l}\text { Strong local government (three or four levels of constitutionally } \\
\text { secure government) }\end{array}$ & 1 & \\
\hline & $\begin{array}{l}\text { Multiethnic } \\
\text { parties }\end{array}$ & DC3 & $\begin{array}{l}\text { Multiethnic political parties provide semi-detached forum } \\
\text { (multiethnicity required at the center (e.g. by electoral laws)) }\end{array}$ & 1 & \\
\hline & Inclusivity & DC4 & $\begin{array}{l}\text { Inclusivity is required of central institutions (proportionality and } \\
\text { additional reservations) }\end{array}$ & 1 & $\begin{array}{l}\text { Not including political parties, } \\
\text { which are covered under DC3 }\end{array}$ \\
\hline & Reciprocity & DC5 & $\begin{array}{l}\text { Electoral system includes incentives for parties to appeal across } \\
\text { ethnic groups (e.g. transferable votes) }\end{array}$ & 1 & \\
\hline
\end{tabular}


A2.1.1 Notes for coding across time series in the summary sheet

- All formal institutional scores continue from year to year unless not implemented, legislation revoked or replaced, or constitution amended, replaced or abrogated (such as in a military coup or state of emergency). This applies to F1-4, E1-4 and C1-4. Nonimplementation by passive means is scored three years after formal institutionalization.

- Behavioral scores are:

- continuing and coded relative to the last score, rather than incorporating the score for that year per se. For example, if in 1948 the score was 3 and in 1949 the score was 5 , then the number entered into the summary sheet at 1949 is 2 , so that the total is 5 . This applies to BF1, BC1\&2; or

- continuing and cumulative, such that each score is maintained over each year and new scores are added or subtracted to that continuing total, as the case may be. This applies to BE1\&2

- one-off - such that the score is coded in the year it occurs and that score lapses the subsequent year, except in special specified circumstances. This applies to most BF items (BF2-6), BC3\&4.

- Other scores are: $\mathrm{O1}$ - continuing and coded relative to the last score, 02-4 - one-off, and 05 , where a score is provided for the system as at that year.

- The year(s) in which a multi-year event is scored is with reference to 30 June of each year. For example, if an executive was moved from a single to multiple party executive in April, then the multiparty score is applied for that year. If it occurred in November, the multiparty score is applied for the following year only.

- Secession risk, infrastructural capacity and deliberative conditions are scored at key points or events (e.g. a new constitution, external intervention) and scores can continue until updated. This applies to SR1-3, IC1 \& DC1-5. 


\section{A2.2 Political party abbreviations}

Table A2: Political party abbreviations - Nepal

\begin{tabular}{|c|c|}
\hline Abbreviation & Party name \\
\hline AN & Akhanda Nepal \\
\hline BSP & Bahujan Samaj Party \\
\hline CBREP & Chure Babar Rashtriya Ekata Party \\
\hline CPN (M) & Communist Party of Nepal (Maoists) \\
\hline CPN (ML) & Communist Party of Nepal (Marxist-Leninist) \\
\hline CPN (U) & Communist Party of Nepal (Unified) \\
\hline DJP & Dalit Janajati Party \\
\hline FSP & Federal Socialist Party \\
\hline JJN & Jana Jagaran Party \\
\hline KRM & Khambuwan Rashtriya Morchan \\
\hline MJAFN & Madhesi Janakar Adhikar Forum, Nepal \\
\hline MJAFN (L) & Madhesi Janakar Adhikar Forum, Nepal (Loktantrik) \\
\hline $\operatorname{MJF}(\mathrm{G})$ & Madeshi Janadikar Forum (Gantantrik) \\
\hline MJAF & Madhesi Jana Adhikar Forum \\
\hline MSPN & Madheshi Samata Party Nepal \\
\hline $\mathrm{NC}$ & Nepali Congress \\
\hline $\mathrm{NCP}(\mathrm{P} / \mathrm{ML})$ & Nepal Communist Party (Prajatantrik / Marxist-Leninist) \\
\hline NCP & Nepal Communist Party \\
\hline NCP (UML) & Nepal Communist Party (United Marxist Leninist) \\
\hline NCP (UML) & Nepal Communist Party (United Marxist-Leninist) \\
\hline NMKP & Nepal Majdur Kisan Party \\
\hline NPD & Nepal Pariwar Dal \\
\hline NRGP & Nepal Rastravadi Gorkha Parishad \\
\hline NRP & Nepa Rastriya Party \\
\hline NSP & Nepal Sadbhavana Party \\
\hline NSP-A & Nepal Sadbhavana Party (Ananda) \\
\hline NWPP & Nepal Workers Peasant Party \\
\hline PM & Prajatantrik Mahasabha \\
\hline RJMN & Rastriya Jana Morcha Nepal \\
\hline RJMP & Rastriya Jana Mukti Party \\
\hline RJP & Rastriya Janamukti Party \\
\hline RMBSP & Rashtriya Madhesh Bahujan Samajwadi Party \\
\hline RPP & Rastriya Prajatantra Party \\
\hline $\operatorname{RPP}(\mathrm{A})$ & Nepal Praja Parishad (Archarya) \\
\hline $\operatorname{RPP}(\mathrm{C})$ & Rastriya Prajatantra Party (Chand) \\
\hline $\operatorname{RPP}(\mathrm{M})$ & Nepal Praja Parishad (Mishra) \\
\hline $\operatorname{RPP}(\mathrm{T})$ & Rastriya Prajatantra Party (Thapa) \\
\hline RPPN & Rastriya Prajatantra Party \\
\hline SJMN & Samyukta Jana Morcha Nepal \\
\hline SJP & Samajwadi Janata Party \\
\hline SLMM & Samyukta Loktantrik Madhesi Morcha \\
\hline SLRM & Sanghiya Loktantrik Rastriya Manch \\
\hline SP & Sadbhavana Party \\
\hline SPP & Samyukta Prajatantra Party \\
\hline SSP & Sanghiya Sadhbhawana Party \\
\hline TMLP & Terai Madhesh Loktantric Party \\
\hline TMSP & Terai Madhe Sadbhawana Party \\
\hline TTPN & Taruhat Terai Party Nepal \\
\hline
\end{tabular}


Table A3: Political party abbreviations - Myanmar

\begin{tabular}{|l|l|}
\hline Abbreviation & Party name \\
\hline AFPFL & Anti-fascist People's Freedom League \\
\hline ANP & Arakan National Party \\
\hline CPB & Communist Party of Burma \\
\hline KYO & Karen Youth Organisation \\
\hline MNP & Mon National Party \\
\hline NDF & National Democratic Force \\
\hline NLD & National League for Democracy \\
\hline NUP & National Unity Party \\
\hline RNDP & Rakhine Nationalities Development Party \\
\hline SLORC & State Law and Order Council \\
\hline SNLD & Shan Nationalities League for Democracy \\
\hline SNDP & Shan Nationalities Democratic Party \\
\hline USDP & Union Solidarity and Development Party \\
\hline
\end{tabular}

Table A4: Political party abbreviations - Sri Lanka

\begin{tabular}{|c|c|}
\hline Abbreviation & Party name \\
\hline ACMC & All Ceylon Makkal Conference \\
\hline ACTC & All Ceylon Tamil Congress \\
\hline BLP & Bolshevik-Leninist Party \\
\hline $\mathrm{CIC}$ & Ceylon Indian Congress \\
\hline CWC & Ceylon Workers Congress \\
\hline DNF & Democratic National Movement \\
\hline DVJP & Desha Vimukthi Janatha Pakshaya \\
\hline EPDP & Eelam People's Democratic Party \\
\hline ITAK & Illankai Tamil Arasu Kachchi \\
\hline JHU & Jathika Hela Urumaya \\
\hline JVP & Jathika Vimukti Peramuna \\
\hline LP & Labor Party \\
\hline LSSP & Lanka Sama Samaja Party \\
\hline MEP & Mahajana Eksath Peramuna \\
\hline NFF & National Freedom Front \\
\hline NUA & National Unity Alliance \\
\hline PA & People's Alliance \\
\hline SLF & Sinhala Language Front \\
\hline SLFP & Sri Lanka Freedom Party \\
\hline SLFSP & Sri Lanka Freedom Socialist Party \\
\hline SLMC & Sri Lankan Muslim Congress \\
\hline SLMP & Sri Lanka Mahajana Party \\
\hline SU & Sinhala Urumaya \\
\hline TELO & Tamil Eelam Liberation Organisation \\
\hline TNA & Tamil National Alliance \\
\hline UF & United Front \\
\hline UNFGG & United National Front for Good Governance \\
\hline UNP & United National Party \\
\hline UPFA & United People's Freedom Alliance \\
\hline USA & United Socialist Alliance \\
\hline VLSSP & Vilplavakari Lanka Sama Samaja Party \\
\hline
\end{tabular}


A2.3 Nepal data 
Table A5: Nepal constitutions

\begin{tabular}{|c|c|c|c|c|c|c|c|c|c|c|}
\hline Measure & Baseline - pre1948 & $\mathrm{S}$ & 1948 & $\mathrm{~S}$ & 1951 & $\mathrm{~s}$ & 1959 & $\mathrm{~S}$ & 1962 & $\mathrm{~s}$ \\
\hline $\begin{array}{l}\text { F1 - Extent of } \\
\text { central authority }\end{array}$ & Rana Oligarchy & -4 & $\begin{array}{l}\text { A46-47 - king can assume } \\
\text { all powers in emergency; } \\
\text { A34 - king can block } \\
\text { consideration of any Bill; } \\
\text { A19 - scope of authority is } \\
\text { subject to the center \& } \\
\text { higher level region }\end{array}$ & -4 & Absolute & -4 & $\begin{array}{l}\text { Absolute - see for } \\
\text { example A63, A10, } \\
\text { A42, A55 }\end{array}$ & -4 & Absolute & -4 \\
\hline $\begin{array}{l}\text { F2 - Scope of } \\
\text { unit's autonomy }\end{array}$ & $\mathrm{n} / \mathrm{a}$ & 0 & $\begin{array}{l}\text { A19 - Panchayats have } \\
\text { education, welfare and } \\
\text { the prosperity of the } \\
\text { people and the territory } \\
\text { under their charge, } \\
\text { including justice, water } \\
\text { supply, basic education - } \\
\text { implementation only }\end{array}$ & 2 & $\begin{array}{l}\text { A6 - Majesty to take } \\
\text { steps to establish } \\
\text { Village Panchayats }\end{array}$ & 1 & No units & 0 & $\begin{array}{l}\text { A30-32- } \\
\text { Establishment of } \\
\text { Village, Local and } \\
\text { Regional Panchayat, } \\
\text { general purpose role } \\
\text { only. }\end{array}$ & 1 \\
\hline $\begin{array}{l}\text { F3 - } \\
\text { Constitutionalism }\end{array}$ & Nil & 0 & $\begin{array}{l}\text { A67 - judicial committee } \\
\text { of legislature to resolve } \\
\text { disputes and interpret } \\
\text { constitution (semi- } \\
\text { independent); A68 - } \\
\text { review to be held to } \\
\text { consider changes (King to } \\
\text { implement) }\end{array}$ & 1 & $\begin{array}{l}\text { Interim Act only (see } \\
\text { preamble); } \\
\text { otherwise King } \\
\text { decides } \\
\text { interpretation, } \\
\text { changes etc. }\end{array}$ & 0 & $\begin{array}{l}\text { A53 - two-thirds } \\
\text { majority required; A54 } \\
\text { - Supreme Court } \\
\text { interprets (but A57 - } \\
\text { appointed by king at } \\
\text { his discretion }\end{array}$ & 1.5 & $\begin{array}{l}\text { A82 - king can } \\
\text { unilaterally amend } \\
\text { constitution; A71 - } \\
\text { Supreme Court } \\
\text { jurisdiction extends to } \\
\text { fundamental rights } \\
\text { only }\end{array}$ & 0 \\
\hline $\begin{array}{l}\text { F4 - } \\
\text { Bicameralism }\end{array}$ & $\mathrm{n} / \mathrm{a}$ & 0 & $\begin{array}{l}\text { A22 / Sch A - } 36 \text { of } \\
\text { seventy seats in upper } \\
\text { chamber comprised on } \\
\text { Panchayat } \\
\text { representatives }\end{array}$ & 3 & $\begin{array}{l}\text { A34 - Advisory } \\
\text { Assembly to have } \\
\text { members appointed } \\
\text { by king as } \\
\text { representative of } \\
\text { regions, classes and } \\
\text { interests }\end{array}$ & 1 & $\mathrm{n} / \mathrm{a}$ & 0 & $\begin{array}{l}\text { A34 - National } \\
\text { Panchayat includes } \\
\text { representatives (reps) } \\
\text { of Zonal Assembly (and } \\
\text { some appointed } \\
\text { members) }\end{array}$ & 1 \\
\hline
\end{tabular}




\begin{tabular}{|c|c|c|c|c|c|c|c|c|c|c|}
\hline Measure & Baseline - pre1948 & $\mathrm{S}$ & 1948 & $\mathrm{~S}$ & 1951 & $\mathrm{~S}$ & 1959 & $\mathrm{~S}$ & 1962 & $\mathrm{~S}$ \\
\hline $\begin{array}{l}\text { C1 - Legislative } \\
\text { executive } \\
\text { relations }\end{array}$ & $\begin{array}{l}\text { Unelected Rana } \\
\text { oligarchy }\end{array}$ & 0 & $\begin{array}{l}\text { A7 - executive a mix of } \\
\text { representatives of Ranas, } \\
\text { king and Panchayats } \\
\text { (elected) - with at least } \\
\text { two from elected } \\
\text { legislature - but A6 -are } \\
\text { subordinate to the king }\end{array}$ & 0.5 & $\begin{array}{l}\text { A58(a) - Advisory } \\
\text { Assembly may seek } \\
\text { resignation of } \\
\text { executive, but } \\
\text { decision subject to } \\
\text { king; A25-27 - } \\
\text { executive appointed } \\
\text { by and responsible } \\
\text { to king in whom } \\
\text { executive power is } \\
\text { vested }\end{array}$ & 0 & $\begin{array}{l}\text { A13 - PM appointed by } \\
\text { king, must have } \\
\text { confidence of } \\
\text { legislature, Ministers } \\
\text { appointed on } \\
\text { recommendation of } \\
\text { PM }\end{array}$ & 2 & $\begin{array}{l}\text { Part } 7 \text { - executive } \\
\text { power vested in king }\end{array}$ & 0 \\
\hline $\begin{array}{l}\text { E1 - Basis of units } \\
\text { (identity / } \\
\text { territory) }\end{array}$ & $\mathrm{n} / \mathrm{a}$ & 0 & $\begin{array}{l}\text { Panchayats incorporate } \\
\text { identity where } \\
\text { territorially clustered }\end{array}$ & 1 & $\begin{array}{l}\text { A6: Majesty to take } \\
\text { steps to establish } \\
\text { Village Panchayats - } \\
\text { accounts for identity } \\
\text { where territorially } \\
\text { clustered }\end{array}$ & 1 & $\mathrm{n} / \mathrm{a}$ & 0 & $\begin{array}{l}\text { S30-32 - Establishment } \\
\text { of Village, Local and } \\
\text { Regional Panchayats, } \\
\text { general purpose role } \\
\text { only - accounts for } \\
\text { identity where } \\
\text { clustered }\end{array}$ & 1 \\
\hline $\begin{array}{l}\text { E2 - Sub-units } \\
\text { (autonomous } \\
\text { zones) }\end{array}$ & $\mathrm{n} / \mathrm{a}$ & 0 & $\mathrm{n} / \mathrm{a}$ & 0 & $\mathrm{n} / \mathrm{a}$ & 0 & $\mathrm{n} / \mathrm{a}$ & 0 & $\mathrm{n} / \mathrm{a}$ & 0 \\
\hline $\begin{array}{l}\text { E3 - Local } \\
\text { government (no. } \\
\text { of levels) }\end{array}$ & $\mathrm{n} / \mathrm{a}$ & 0 & $\begin{array}{l}\text { Three - A16-22 - state } \\
\text { legislature; Zilla } \\
\text { Panchayats; Gram and } \\
\text { Nagar Panchayats }\end{array}$ & 1 & $\begin{array}{l}\text { Two - center and } \\
\text { local }\end{array}$ & 0 & One & 0 & $\begin{array}{l}\text { S30-32 - } \\
\text { Village/Municipalities } \\
\text { (thousands), Local (75) } \\
\text { and Regional (14) } \\
\text { Panchayats }\end{array}$ & 2 \\
\hline $\begin{array}{l}\text { E4 - Degree of } \\
\text { asymmetry }\end{array}$ & $\mathrm{n} / \mathrm{a}$ & 0 & $\begin{array}{l}\text { A16-22 - Village (Gram) } \\
\text { Panchayats less } \\
\text { autonomous that town } \\
\text { (Nagar) Panchayat }\end{array}$ & 0 & $\mathrm{n} / \mathrm{a}$ & 0 & $n / a$ & 0 & $\mathrm{n} / \mathrm{a}$ & 0 \\
\hline $\begin{array}{l}\mathrm{C} 2 \text { - Inclusivity } \\
\text { and } \\
\text { proportionality }\end{array}$ & Nil & 0 & $\begin{array}{l}\text { A16 - 5-15 members } \\
\text { voted by adults with } \\
\text { necessary qualifications }\end{array}$ & 1 & $\begin{array}{l}\text { A34-Advisory } \\
\text { Assembly General to } \\
\text { have members }\end{array}$ & 0 & $\begin{array}{l}\text { A24-House of Reps } \\
\text { electoral division } \\
\text { delineation to take }\end{array}$ & 1 & $\begin{array}{l}\text { No explicit means; } \\
\text { FPTP in single-member }\end{array}$ & 0 \\
\hline
\end{tabular}




\begin{tabular}{|c|c|c|c|c|c|c|c|c|c|c|}
\hline Measure & Baseline - pre1948 & $\mathrm{S}$ & 1948 & $\mathrm{~S}$ & 1951 & $\mathrm{~S}$ & 1959 & $\mathrm{~S}$ & 1962 & $\mathrm{~S}$ \\
\hline & & & $\begin{array}{l}\text { (effectively multi- } \\
\text { member districts), and } \\
\text { section } 22 / \text { Sch } A \text { which } \\
\text { provides for mix of } \\
\text { elected reps (being } \\
\text { Panchayat reps), and } \\
\text { appointed interests }\end{array}$ & & $\begin{array}{l}\text { appointed by the } \\
\text { king as } \\
\text { representative of } \\
\text { regions, classes and } \\
\text { interests - for } \\
\text { purpose of advising } \\
\text { on new constitution }\end{array}$ & & $\begin{array}{l}\text { account of diversity of } \\
\text { inhabitants (among } \\
\text { other things), but FPTP } \\
\text { - A19 - senate, half } \\
\text { elected by House of } \\
\text { Reps by PR system, } \\
\text { half appointed }\end{array}$ & & $\begin{array}{l}\text { constituencies (see } \\
\text { Nohlen et al 2001) }\end{array}$ & \\
\hline $\begin{array}{l}\text { C3 - Extent of } \\
\text { cultural rights } \\
\text { and freedoms }\end{array}$ & & 0 & $\begin{array}{l}\text { A4 - gives some basic } \\
\text { freedoms }\end{array}$ & 0 & $\begin{array}{l}\text { A15: ban on } \\
\text { discrimination; A14: } \\
\text { equality before the } \\
\text { law }\end{array}$ & 0 & $\begin{array}{l}\text { A4-5: Equality \& } \\
\text { discrimination bans; }\end{array}$ & 0 & $\begin{array}{l}\text { A10, } 11 \text { - } \\
\text { discrimination bans, } \\
\text { equality, freedoms etc. }\end{array}$ & 0 \\
\hline $\begin{array}{l}\text { C4 - Assimilating } \\
\text { aspects }\end{array}$ & $\begin{array}{l}\text { Formalized } \\
\text { identity-based } \\
\text { discrimination } \\
\text { through Royal } \\
\text { Decree }\end{array}$ & -2 & $\mathrm{n} / \mathrm{a}$ & 0 & none specified & 0 & $\begin{array}{l}\text { A70 - Nepali as } \\
\text { national language; A5 - } \\
\text { regard to religious } \\
\text { tradition \& ban on } \\
\text { conversions }\end{array}$ & -2 & $\begin{array}{l}\text { A3 - Hindu state; A4 } \\
\text { Nepali as national } \\
\text { language, A6 other } \\
\text { Hindu iconography; A8 } \\
\text { - ability to terminate } \\
\text { citizenship } \\
\end{array}$ & -4 \\
\hline & & -6 & & 5.5 & & -1 & & $\begin{array}{c}- \\
1.5 \\
\end{array}$ & & -2 \\
\hline
\end{tabular}




\begin{tabular}{|c|c|c|c|c|c|c|c|c|}
\hline Measure & 1967 Amendments & $S$ & 1990 & $S$ & 2007 (interim) & $S$ & 2015 & $S$ \\
\hline $\begin{array}{l}\text { F1 - Extent of } \\
\text { central authority }\end{array}$ & As per 1962 & -4 & Absolute & -4 & Absolute & -4 & $\begin{array}{l}\text { A232 - Government may issue } \\
\text { directives, President may dissolve } \\
\text { institutions in some } \\
\text { circumstances; A234 - Inter- } \\
\text { Provincial Council for dispute } \\
\text { resolution }\end{array}$ & -2 \\
\hline $\begin{array}{l}\text { F2 - Scope of unit's } \\
\text { autonomy }\end{array}$ & $\begin{array}{l}\text { A18-19 - principles of } \\
\text { Panchayat system added }\end{array}$ & 2 & $\begin{array}{l}\text { A104 and 46(1) - mentions Local } \\
\text { Authorities }\end{array}$ & 1 & $\begin{array}{l}\text { A138/9 - provides for federal } \\
\text { system and local governance }\end{array}$ & 1 & $\begin{array}{l}\text { Part } 5 \text { and associated schedules } \\
\text { set out division of powers for } \\
\text { provincial and local levels }\end{array}$ & 4 \\
\hline $\begin{array}{l}\text { F3 - } \\
\text { Constitutionalism }\end{array}$ & No change & 0 & $\begin{array}{l}\text { A116 - 2/3 majority required; } \\
\text { A88(2) - Supreme Court has } \\
\text { jurisdiction in relation to courts }\end{array}$ & 2 & $\begin{array}{l}\text { A148 - amendment requires 2/3 } \\
\text { majority; A102/7 - Supreme } \\
\text { Court has jurisdiction }\end{array}$ & 2 & $\begin{array}{l}\text { A274 - 2/3 majority required for } \\
\text { amendment; A295 - provision for } \\
\text { a federal commission and } \\
\text { provincial and other level } \\
\text { amendments; A114 - jurisdiction } \\
\text { of Supreme Court only re } \\
\text { fundamental rights; A234 - } \\
\text { Interstate Council for dispute } \\
\text { resolution established but } \\
\text { numbers weighted to center }\end{array}$ & 1 \\
\hline F4 - Bicameralism & $\begin{array}{l}\text { A33 - Zonal Assembly } \\
\text { comprises representatives of } \\
\text { the lower level Panchayats } \\
\text { (added) }\end{array}$ & 2 & $\begin{array}{l}\text { A46(1)(c) Local authorities and } \\
\text { regions represented in the } \\
\text { upper house }\end{array}$ & 3 & $\mathrm{n} / \mathrm{a}$ & 0 & $\begin{array}{l}\text { A86 - } 56 \text { of } 59 \text { members of upper } \\
\text { house provincial and local level } \\
\text { representatives; A275 - consent of } \\
\text { provinces to changes to provinces } \\
\text { required }\end{array}$ & 4 \\
\hline $\begin{array}{l}\mathrm{C} 1 \text { - Legislative } \\
\text { executive relations }\end{array}$ & $\begin{array}{l}\text { Part } 7(26) \text { - introduction of } \\
\text { PM and Cabinet from } \\
\text { national legislature, but still } \\
\text { responsible to king } \\
\text { (50\% score) }\end{array}$ & 1.5 & $\begin{array}{l}\text { A36 - Prime Minister } \\
\text { (commanding majority) and } \\
\text { Cabinet appointed from } \\
\text { legislature }\end{array}$ & 2 & $\begin{array}{l}\text { A38 - PM appointed on } \\
\text { consensus of seven major } \\
\text { parties and Maoists, or two } \\
\text { third majority of Parliament }\end{array}$ & 2 & $\begin{array}{l}\text { A75-76 - Council of Ministers has } \\
\text { executive power and appointed by } \\
\text { PM commanding majority of } \\
\text { house }\end{array}$ & 2 \\
\hline
\end{tabular}




\begin{tabular}{|c|c|c|c|c|c|c|c|c|}
\hline Measure & 1967 Amendments & $S$ & 1990 & $S$ & 2007 (interim) & $S$ & 2015 & $S$ \\
\hline $\begin{array}{l}\text { E1 - Basis of units } \\
\text { (identity / } \\
\text { territory) }\end{array}$ & No change & 1 & $\begin{array}{l}\text { A104 and 46(1) - Local } \\
\text { Authorities incorporate identity } \\
\text { where territorially clustered }\end{array}$ & 1 & Not yet delineated & 0 & $\begin{array}{l}\text { Mixture of territorial and identity- } \\
\text { based criteria (see Report of the } \\
\text { CRSDSP } 2010 \text { for example) }\end{array}$ & 1 \\
\hline $\begin{array}{l}\text { E2 - Sub-units } \\
\text { (autonomous } \\
\text { zones) }\end{array}$ & $\mathrm{n} / \mathrm{a}$ & 0 & $\mathrm{n} / \mathrm{a}$ & 0 & $\mathrm{n} / \mathrm{a}$ & 0 & $\begin{array}{l}\text { A56 provision for autonomous } \\
\text { regions to be created }\end{array}$ & 1 \\
\hline $\begin{array}{l}\text { E3 - Local } \\
\text { government (no. of } \\
\text { levels) }\end{array}$ & As per 1962 & 2 & $\begin{array}{l}\text { Four levels of government (as } \\
\text { per 1962), though none } \\
\text { constitutionally empowered }\end{array}$ & 2 & $\begin{array}{l}\text { (At least) three levels of } \\
\text { government to be established } \\
\text { (see above) }\end{array}$ & 1 & $\begin{array}{l}\text { Three levels of government } \\
\text { (center, provinces and local level) }\end{array}$ & 1 \\
\hline $\begin{array}{l}\text { E4 - Degree of } \\
\text { asymmetry }\end{array}$ & $\mathrm{n} / \mathrm{a}$ & 0 & $\mathrm{n} / \mathrm{a}$ & 0 & $\mathrm{n} / \mathrm{a}$ & 0 & $\mathrm{n} / \mathrm{a}$ & 0 \\
\hline $\begin{array}{l}\mathrm{C} 2 \text { - Inclusivity and } \\
\text { proportionality }\end{array}$ & $\begin{array}{l}\text { A35 - National Panchayat - } \\
\text { only people registered in } \\
\text { government-sponsored class } \\
\text { \& professional organizations } \\
\text { (for peasants, laborers, } \\
\text { students, women, former } \\
\text { military personal \& college } \\
\text { graduates) }\end{array}$ & 1 & $\begin{array}{l}\text { A46(1) - out of } 60 \text { member } \\
\text { upper house, } 35 \text { are elected via } \\
\text { proportional representation, } 15 \\
\text { appointed by the king on basis } \\
\text { of expertise, and fifteen elected } \\
\text { at the local level by local level } \\
\text { officials }\end{array}$ & 2 & $\begin{array}{l}\text { A45 - Legislature/Constituent } \\
\text { Assembly to include nominated } \\
\text { representatives of otherwise } \\
\text { excluded identity groups; A63 - } \\
\text { proportional representation, } \\
\text { and requirement for parties to } \\
\text { be proportional }\end{array}$ & 3 & $\begin{array}{l}\text { Mixed / parallel - A84 - 165/110 } \\
\text { FPTP/PR with special minority } \\
\text { representation provision; A176 - } \\
\text { Provincial legislatures 60/40 } \\
\text { FPTP/PR, with special provision for } \\
\text { minority representation; } \\
\text { A222/223 - local level multi- } \\
\text { member }\end{array}$ & 3 \\
\hline $\begin{array}{l}\text { C3 - Extent of } \\
\text { cultural rights and } \\
\text { freedoms }\end{array}$ & As per 1962 & 0 & $\begin{array}{l}\text { A19 - right to religious freedoms } \\
\text { (less conversions \& within } \\
\text { tradition); A6 - Nepali as official } \\
\text { language, others as national } \\
\text { languages; A18 - right to } \\
\text { preserve \& promote language \& } \\
\text { culture, and for primary } \\
\text { education in mother tongue; } \\
\text { A10 - equality; A11 - } \\
\text { discrimination ban }\end{array}$ & 3 & $\begin{array}{l}\text { A3 - secular, multiethnic state; } \\
\text { A5 - all mother-tongues } \\
\text { national languages, but official } \\
\text { business still in Nepali; A17 right } \\
\text { to education in mothertongue; } \\
\text { A2,13-14 - equality, } \\
\text { discrimination bans etc.; A23 - } \\
\text { right to religious freedom } \\
\text { (qualified); A34-35 directives for } \\
\text { proportionality and positive } \\
\text { discrimination }\end{array}$ & 3 & $\begin{array}{l}\text { A3 - multiethnic etc, A6/7 } \\
\text { provides for multiple national and } \\
\text { official languages, Part } 3 \text { - } \\
\text { standard rights and freedoms; A4 } \\
\text { - secular but privileging Hinduism, }\end{array}$ & 2.5 \\
\hline
\end{tabular}




\begin{tabular}{|c|c|c|c|c|c|c|c|c|}
\hline Measure & 1967 Amendments & $\mathrm{s}$ & 1990 & $\mathrm{~s}$ & 2007 (interim) & $\mathrm{s}$ & 2015 & $\mathrm{~s}$ \\
\hline $\begin{array}{l}\text { C4 - Assimilating } \\
\text { aspects }\end{array}$ & As per 1962 & -3 & $\begin{array}{l}\text { A4 - prescribes as (multiethnic) } \\
\text { Hindu state; A6 - Nepali as } \\
\text { official language, others as } \\
\text { national languages; A27 - king as } \\
\text { symbol of Nepali nationality but } \\
\text { adherent of Aryan culture and } \\
\text { Hindu religion; citizenship rules } \\
\text { have effect that more than } 3 \\
\text { million (mostly Madheshis) } \\
\text { cannot get citizenship }\end{array}$ & -3 & $\mathrm{~N} / \mathrm{a}$ & 0 & $\begin{array}{l}\text { A4 - ancient religions - i.e. } \\
\text { Hinduism - has priority place, and } \\
\text { conversions banned }\end{array}$ & -2 \\
\hline TOTAL & & 2.5 & & 9 & & 8 & & 15.5 \\
\hline
\end{tabular}

Sources: (The Constitution of Nepal 1962; The Constitution of Nepal 1990; Constitution of Nepal 2015; Constitution of the Kingdom of Nepal 1959; Interim Constitution of Nepal 2063 (2007); Interim Government of Nepal Act 1951; Whelpton 2005; Constitution of Nepal 1948) 
Table A6: Nepal elections and party proportionality (1948-2016)

\begin{tabular}{|c|c|c|c|c|c|c|c|c|c|c|c|c|c|c|c|c|}
\hline & ELECTIONS & 1959 & & & & & 1991 & & & & & 1994 & & & & \\
\hline Designation & PARTIES & Votes & $\begin{array}{l}\text { Votes } \\
\% \\
\end{array}$ & Seats & $\begin{array}{l}\text { Seats } \\
\%\end{array}$ & $\begin{array}{l}\text { Deviati } \\
\text { on }^{2}\end{array}$ & Votes & $\begin{array}{l}\text { Votes } \\
\% \\
\end{array}$ & $\begin{array}{l}\text { Seat } \\
\mathrm{s}\end{array}$ & $\begin{array}{l}\text { Seats } \\
\%\end{array}$ & $\begin{array}{l}\text { Deviati } \\
\text { on }^{2}\end{array}$ & Votes & $\begin{array}{l}\text { Votes } \\
\% \\
\end{array}$ & Seats & $\begin{array}{l}\text { Seats } \\
\%\end{array}$ & $\begin{array}{l}\text { Deviati } \\
\text { on }^{2}\end{array}$ \\
\hline Mixed & Nepali Congress & 666,898 & 37.2 & 74 & 67.9 & 942.49 & $2,752,452$ & 39.5 & 110 & 53.7 & 201.64 & $2,545,287$ & 34.5 & 83 & 40.5 & 36.00 \\
\hline Pahadi & NRGP & 305,118 & 17.1 & 19 & 17.4 & 0.09 & & & & & & & & & & \\
\hline Pahadi & SPP & 177,408 & 9.9 & 5 & 4.6 & 28.09 & & & & & & & & & & \\
\hline Pahadi & NCP & 129,142 & 7.2 & 4 & 3.7 & 12.25 & & & & & & & & & & \\
\hline Pahadi & PM & 59,896 & 3.3 & 2 & 1.8 & 2.25 & & & & & & & & & & \\
\hline Pahadi & NPP (M) & 59,820 & 3.3 & 1 & 0.9 & 5.76 & & & & & & & & & & \\
\hline Pahadi & $\operatorname{NPP}(\mathrm{A})$ & 53,038 & 3 & 0 & 0 & & & & & & & & & & & \\
\hline Ethnic-Madheshi & Terai Congress & 36,107 & 2 & 0 & 0 & & & & & & & & & & & \\
\hline Mixed & CPN (UML) & & & & & & $2,040,102$ & 29.3 & 69 & 33.7 & 19.36 & $2,532,601$ & 31.9 & 88 & 42.9 & 121.00 \\
\hline Ethnic-Madheshi & SJMN & & & & & & 351,904 & 5 & 9 & 4.3 & 0.49 & 100,285 & 1.4 & 0 & 0 & \\
\hline Pahadi & NSP & & & & & & 298,610 & 4.3 & 6 & 2.9 & 1.96 & 265,847 & 3.6 & 3 & 1.5 & 4.41 \\
\hline Pahadi/Newar & $\operatorname{RPP}(C)$ & & & & & & 478,604 & 6.9 & 3 & 1.5 & 29.16 & & & & & \\
\hline Mixed & NCP (P/ML) & & & & & & 177,323 & 2.5 & 2 & 1 & 2.25 & & & & & \\
\hline Mixed & NMKP & & & & & & 91,335 & 1.3 & 2 & 1 & 0.09 & 75,072 & 1 & 4 & 2 & 1.00 \\
\hline Pahadi/Newar & $\operatorname{RPP}(\mathrm{T})$ & & & & & & 392,499 & 5.6 & 1 & 0.5 & 26.01 & & & & & \\
\hline Pahadi/Newar & RPP & & & & & & & & & & & $1,367,148$ & 18.5 & 20 & 9.8 & 75.69 \\
\hline Pahadi/Newar & RJMN & & & & & & 34,509 & 0.5 & 0 & 0 & & & & & & \\
\hline Pahadi/Newar & RJMP & & & & & & & & & & & 79,996 & 1.1 & 0 & 0 & 1.21 \\
\hline & Independents & & & & & & 303,723 & 4.4 & 3 & 1.5 & & 471,324 & 6.4 & 7 & 3.4 & \\
\hline TOTALS & & & & 105 & & & & & 205 & & & & & 205 & & \\
\hline $\begin{array}{l}\text { Gallagher index (G) } \\
\text { (Disproportionality) }\end{array}$ & & & & & & 22.26 & & & & & 10.04 & & & & & 4.24 \\
\hline SCORE (10/GI) (Pro & portionality) & & & & & 0.45 & & & & & 1.00 & & & & & 2.36 \\
\hline SCORE adjusted & & & & & & 0.45 & & & & & 0.55 & & & & & 1.36 \\
\hline
\end{tabular}




\begin{tabular}{|c|c|c|c|c|c|c|c|c|c|c|c|c|c|c|c|c|}
\hline & ELECTIONS & 1999 & & & & & 2008 & & & & & 2013 & & & & \\
\hline Designation & PARTIES & Votes & $\begin{array}{r}\text { Vote } \\
\text { s\% } \\
\end{array}$ & Seats & $\begin{array}{r}\text { Seats } \\
\% \\
\end{array}$ & $\begin{array}{r}\text { Deviat } \\
\text { ion }^{2} \\
\end{array}$ & Votes & $\begin{array}{r}\text { Vote } \\
\text { s\% }\end{array}$ & Seats & $\begin{array}{r}\text { Seats } \\
\% \\
\end{array}$ & $\begin{array}{r}\text { Deviat } \\
\text { ion }^{2} \\
\end{array}$ & Votes & $\begin{array}{r}\text { Votes } \\
\% \\
\end{array}$ & Seats & $\begin{array}{r}\text { Seats } \\
\% \\
\end{array}$ & $\begin{array}{r}\begin{array}{r}\text { Deviat } \\
\text { ion }^{2}\end{array} \\
\end{array}$ \\
\hline Mixed & $\begin{array}{l}\text { Nepali } \\
\text { Congress }\end{array}$ & $\begin{array}{r}3,214,7 \\
86\end{array}$ & 37.2 & 111 & 54.1 & $\begin{array}{r}285.6 \\
1\end{array}$ & $\begin{array}{r}461877 \\
3\end{array}$ & 21.9 & 115 & 19.1 & 7.94 & $\begin{array}{r}511335 \\
3\end{array}$ & 27.63 & 196 & 34.09 & 41.74 \\
\hline Pahadi & NRGP & & & & & & & & & & & & & & & \\
\hline Pahadi & SPP & & & & & & & & & & & & & & & \\
\hline Pahadi & NCP & & & & & & & & & & & & & & & \\
\hline Pahadi & PM & & & & & & & & & & & & & & & \\
\hline Pahadi & NPP (M) & & & & & & & & & & & & & & & \\
\hline Pahadi & $\operatorname{NPP}(A)$ & & & & & & & & & & & & & & & \\
\hline $\begin{array}{l}\text { Ethnic- } \\
\text { Madheshi }\end{array}$ & Terai Congress & & & & & & & & & & & & & & & \\
\hline Mixed & CPN (UML) & $\begin{array}{r}2,734,5 \\
68\end{array}$ & 31.6 & 71 & 34.6 & 9.00 & $\begin{array}{r}441243 \\
4\end{array}$ & 21.0 & 108 & 18.0 & 8.98 & $\begin{array}{r}473169 \\
9\end{array}$ & 25.56 & 175 & 30.43 & 23.72 \\
\hline $\begin{array}{l}\text { Ethnic- } \\
\text { Madheshi }\end{array}$ & SJMN & 74,669 & 0.9 & 1 & 0.5 & 0.16 & & & & & & & & & & \\
\hline Pahadi & NSP & 278,435 & 3.2 & 5 & 2.4 & 0.64 & & & & & & & & & & \\
\hline Pahadi/Newar & $\operatorname{RPP}(\mathrm{C})$ & 295,812 & 3.4 & 0 & 0 & & & & & & & & & & & \\
\hline Mixed & NCP (P/ML) & 567,760 & 6.6 & 0 & 0 & & & & & & & & & & & \\
\hline Mixed & NMKP & 48,685 & 0.6 & 1 & 0.5 & 0.01 & & & & & & & & & & \\
\hline Pahadi/Newar & $\operatorname{RPP}(\mathrm{T})$ & 902,328 & 10.4 & 11 & 5.4 & 25.00 & & & & & & & & & & \\
\hline Pahadi/Newar & RPP & & & & & & 187203 & 0.9 & 4 & 0.5 & 0.15 & 498547 & 2.69 & 13 & 2.26 & 0.19 \\
\hline Pahadi/Newar & RJMN & 121,426 & 1.4 & 5 & 2.4 & 1.00 & & & & & & & & & & \\
\hline Pahadi/Newar & RJMP & 94,860 & 1.1 & 0 & 0 & & & & & & & & & & & \\
\hline & Independents & 251,930 & 2.9 & 0 & 0 & & 123619 & 0.6 & 2 & 0.3 & & 107764 & & 2 & & \\
\hline Multiethnic & CPN (M) & & & & & & $\begin{array}{r}628972 \\
3\end{array}$ & 29.9 & 239 & 38.1 & 67.46 & $\begin{array}{r}304887 \\
1\end{array}$ & 16.47 & 80 & 13.91 & 6.55 \\
\hline $\begin{array}{l}\text { Ethnic- } \\
\text { Madheshi }\end{array}$ & MJAFN & & & & & & $\begin{array}{r}131248 \\
1\end{array}$ & 6.2 & 54 & 9.0 & 7.53 & 420429 & 2.27 & 10 & 1.74 & 0.28 \\
\hline $\begin{array}{l}\text { Ethnic- } \\
\text { Madheshi }\end{array}$ & MJAFN (L) & & & & & & & & & & & 558455 & 3.02 & 14 & 2.43 & 0.34 \\
\hline $\begin{array}{l}\text { Ethnic- } \\
\text { Madheshi }\end{array}$ & TMLP & & & & & & 684517 & 3.3 & 21 & 3.5 & 0.06 & 353029 & 1.91 & 11 & 1.91 & 0.00 \\
\hline Pahadi & CPN (ML) & & & & & & 411741 & 2.0 & 9 & 1.5 & 0.21 & 228391 & 1.23 & 5 & 0.87 & 0.13 \\
\hline $\begin{array}{l}\text { Ethnic- } \\
\text { Madheshi }\end{array}$ & SP & & & & & & 341603 & 1.6 & 9 & 1.5 & 0.02 & 274201 & 1.48 & 6 & 1.04 & 0.19 \\
\hline Ethnic & 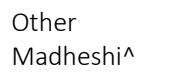 & & & & & & 148408 & 0.7 & 4 & 0.7 & 0.00 & & & & & \\
\hline
\end{tabular}




\begin{tabular}{|c|c|c|c|c|c|c|c|c|c|c|c|c|c|c|c|c|}
\hline & ELECTIONS & 1999 & & & & & 2008 & & & & & 2013 & & & & \\
\hline Designation & PARTIES & Votes & $\begin{array}{r}\text { Vote } \\
\text { s\% }\end{array}$ & Seats & $\begin{array}{r}\text { Seats } \\
\% \\
\end{array}$ & $\begin{array}{r}\text { Deviat } \\
\text { ion }^{2} \\
\end{array}$ & Votes & $\begin{array}{r}\text { Vote } \\
\text { s\% }\end{array}$ & Seats & $\begin{array}{r}\text { Seats } \\
\%\end{array}$ & $\begin{array}{r}\text { Deviat } \\
\text { ion }^{2}\end{array}$ & Votes & $\begin{array}{r}\text { Votes } \\
\%\end{array}$ & Seats & $\begin{array}{r}\text { Seats } \\
\%\end{array}$ & $\begin{array}{r}\text { Deviat } \\
\text { ion }^{2}\end{array}$ \\
\hline Ethnic & Other ethnic ${ }^{\wedge \wedge}$ & & & & & & 321397 & 1.5 & 6 & 1.0 & 0.28 & & & & & \\
\hline Pahadi/multi & Other & & & & & & $\begin{array}{r}127136 \\
1\end{array}$ & 6.0 & 30 & 5.0 & 1.10 & & & & & \\
\hline Pahadi/Newar & RPPN & & & & & & & & & & & 883276 & 4.77 & 24 & 4.17 & 0.36 \\
\hline Ethnic & FSP & & & & & & & & & & & 229957 & 1.24 & 5 & 0.87 & 0.14 \\
\hline $\begin{array}{l}\text { Ethnic - } \\
\text { Madheshi }\end{array}$ & $\begin{array}{l}\text { Other } \\
\text { Madheshi* }\end{array}$ & & & & & & & & & & & 429705 & 2.32 & 9 & 1.57 & 0.57 \\
\hline Ethnic & Other ethnic** & & & & & & & & & & & 417569 & 2.26 & 9 & 1.57 & 0.48 \\
\hline Pahadi/multi & Other*** & & & & & & & & & & & 609912 & 3.30 & 16 & 2.78 & 0.26 \\
\hline TOTALS & & & & 205 & & & $\begin{array}{r}210451 \\
98\end{array}$ & & 601 & & & 18508770 & & 575 & & \\
\hline \multicolumn{2}{|c|}{$\begin{array}{l}\text { Gallagher index (GI) } \\
\text { (Disproportionality) }\end{array}$} & & & & & 11.95 & & & & & 1.99 & & & & & 4.57 \\
\hline \multicolumn{2}{|c|}{ SCORE (10/GI) (Proportionality) } & & & & & 0.84 & & & & & 5.02 & & & & & 2.19 \\
\hline \multicolumn{2}{|c|}{ SCORE adjusted } & & & & & -1.52 & & & & & 4.18 & & & & & -2.83 \\
\hline
\end{tabular}

^NSP, CBREP; ^^RJP, DJP NRP; *RMBSP, TMSP, MJF (G) SSP, MSPN; **RJP, TTPN, DJP, KRMN, NRP, SLRM; ***CPN (U), NWPP, RJMN, NPD, JJP, SJP

Sources: (Nohlen, Grotz \& Hartmann 2001a; Citizens Committee for Clean Election 2014; Election Commission Nepal 2016) 
Table A7: Nepal legislature ethnic proportionality (1999, 2008, 2013)

\begin{tabular}{|c|c|c|c|c|c|c|c|c|c|c|}
\hline & $\begin{array}{l}\text { Proportion of } \\
\text { population } \\
(\%)\end{array}$ & $\begin{array}{l}\text { 1999- } \\
\text { Seats }\end{array}$ & $\begin{array}{l}1999-\% \text { of } \\
\text { total seats }\end{array}$ & Proportionality & $\begin{array}{l}2008 \text { total } \\
\text { seats }\end{array}$ & $\begin{array}{l}2008-\% \text { of } \\
\text { seats }\end{array}$ & Proportionality & 2013 & $\begin{array}{l}2013-\% \text { of } \\
\text { total seats }\end{array}$ & Proportionality \\
\hline $\begin{array}{l}\text { Bahun- } \\
\text { Chhetri }\end{array}$ & 28.8 & & & & 201 & 35 & 1.2 & 236 & 41 & 1.4 \\
\hline Dalit & 12.7 & 4 & 1.5 & 0.1 & 49 & 9 & 0.7 & 40 & 7 & 0.6 \\
\hline Janajati* & 37 & 56 & 21.2 & 0.6 & 170 & 30 & 0.8 & 195 & 34 & 0.9 \\
\hline Madheshi** & 20.5 & 46 & 17.4 & 0.8 & 155 & 27 & 1.3 & 104 & 18 & 0.9 \\
\hline TOTAL & & 265 & & & 575 & & & & 575 & \\
\hline
\end{tabular}

*including Terai Janajati, **not including Muslim or Terai Dalit, Proportionality>1=overrepresented 
Table A8: Nepal legislature ethnic proportionality - detailed (2013)

\begin{tabular}{|lrr|}
\hline \multicolumn{1}{|c}{ Ethnicity } & FPTP & \% of pop \\
\hline Bahun & 75 & 12.18 \\
Chhetri & 43 & 16.6 \\
Madheshi & 24 & 20.05 \\
Tharu & 19 & 6.56 \\
Yadav & 16 & 3.98 \\
Newar & 13 & 4.99 \\
Thakuri & 8 & 1.61 \\
Rai & 6 & 2.34 \\
Limbu & 6 & 1.97 \\
Gurung & 6.46 \\
Muslim & 5 & 4.39 \\
Tamang & 5 & 5.81 \\
Magar & 4 & 7.12 \\
Sanyasi/Dashnami & 4 & 0.86 \\
Ghale & 3 & 0.09 \\
Sherpa & 2 & 0.43 \\
Chhantyal & 2 & 0.04 \\
Kami & 2 & 4.75 \\
Sunuwar & 1 & 0.14 \\
Thakali & 1 & 0.05 \\
Other Janajati / Dalit & 1 & 5.5 \\
\hline
\end{tabular}

FPTP= First Past the Post $\mathrm{PR}=$ Proportional Representation

Sources: (Citizens Committee for Clean Election 2014; Nepali 2008; Lawoti 2010; Malik et al. 2009, p. 431) 
Table A9: Nepal executives - parties and type

\begin{tabular}{|c|c|c|c|c|c|}
\hline Years & Prime Minister & Party(s) & No. of parties & Classification & Score \\
\hline $1948-50$ & Rana & Ranas, & 1 & $\mathrm{n} / \mathrm{a}$ & 0 \\
\hline 1951 & Rana & Five Ranas and five Nepali Congress & 2 & $\mathrm{n} / \mathrm{a}$ & 0 \\
\hline 1952 & MP Koirala & Nepali Congress plus independents & 2 & Oversized & 3 \\
\hline 1953-55 & & RPP (NC offshoot/royalists) & 1 & Minimum & 0 \\
\hline 1956 & KI Singh & NC offshoot & 1 & Minimum & 0 \\
\hline $1957-58$ & & Council of Advisors & 1 & $\mathrm{n} / \mathrm{a}$ & 0 \\
\hline 1959 & BP Koirala & Nepali Congress & 1 & Minimum & 0 \\
\hline 1960-89 & & Partyless Panchayat & 1 & Single & 0 \\
\hline 1990-91 & KP Bhattarai & Nepali Congress \& United Leftist Front & 2 & Oversized & 3 \\
\hline 1991-94 & GP Koirala & Nepali Congress & 1 & Minimum & 1 \\
\hline 1994-95 & MM Adhikari & CPN (UML) & 1 & Minority & 1 \\
\hline 1996 & SB Dueba & Nepali Congress, RPP \& NSP & 3 & Oversized & 3 \\
\hline 1997 & LB Chand & RPP \& CPN (UML) & 2 & Minimum & 2 \\
\hline 1997-98 & SB Thapa & RPP \& NC & 2 & Minimum & 2 \\
\hline 1998-99 & GP Koirala & $\begin{array}{l}\text { Minority government of NC (12/04/1998) which was later joined by NCP(ML), the } \\
\text { latter split off from CPN (UML) in early 1998. The NCP (ML) later left the government } \\
\text { and was replaced by CPN (UML) and NSP (23/12/1998). }\end{array}$ & $1,2,3$ & Minimum & 1.5 \\
\hline 1999 & KP Bhattarai till 2000 then GP Koirala & NC & 1 & Minimum & 1 \\
\hline 2000-01 & GP Koirala & NC & 1 & Minimum & 1 \\
\hline 2002 & SB Dueba & NC & 1 & Minimum & 1 \\
\hline 2003 & LB Chand & partyless & 1 & $\mathrm{n} / \mathrm{a}$ & 0 \\
\hline 2004-05 & SB Dueba & $\begin{array}{l}\text { NC, NCP (ML), RPP, NSP, CPN (UML) (who were appointed by and representing the king } \\
\text { / not elected) }\end{array}$ & 6 & Oversized & 3 \\
\hline 2006 & King & King & 1 & $\mathrm{n} / \mathrm{a}$ & 0 \\
\hline 2006-2007 & GP Koirala & NC, CPN (UML), RPP, CPN-ML, NSP-A, Maoists, Madheshi Morcha & 8 & Consensus & 4 \\
\hline 2008 & PK Dahal & Maoists, CPN (UML), MPRF, + small parties & $3+$ & Oversized & 3 \\
\hline $2009-10$ & MK Nepal & NC, CPN (UML), MJAF, plus small parties & $3+$ & Minimum & 2 \\
\hline 2011 & J Khanal & CPN (UML), Maoists & 2 & Minimum & 2 \\
\hline 2012 & B Bhattarai & Maoists, SLMM (7-parties alliance) & 8 & Minimum & 2 \\
\hline 2013 & KR Regmi & National consensus technocratic government & 0 & Consensus & 4 \\
\hline 2014-15 & S Koirala & NC, CPN (UML) & 2 & Minimum & 2 \\
\hline 2015-16 & KP Oli & CPN (UML), Maoists, RPPN, MJAFN, BSP, MSPN, Rastriya Janamorcha & 7 & Minimum & 2 \\
\hline
\end{tabular}


Table A10: Nepal executive ethnic proportionality (August 2016)

\begin{tabular}{|l|l|l|}
\hline Name & Party & Ethnicity \\
\hline Mr. Khadga Prasad Sharma Oli & Communist Party of Nepal (Unified Marxist-Leninist) & BC \\
Mr. Kamal Thapa & Rastriya Prajatantra Party Nepal & BC \\
Mr. Bijaya Gachchhadar & Madheshi Jana Adhikar Forum Nepal (Loktantrik) & M \\
Mr. Top Bahadur Rayamajhi & Unified Communist Party of Nepal (UCPN) (Maoist) & BC \\
Mr. Bhim Rawal & Communist Party of Nepal (Unified Marxist-Leninist) & BC \\
Mr. Chitra Bahadur K.C. & Rastriya Janamorcha & BC \\
Mr. C. P. Mainali & Communist Party of Nepal (ML) & BC \\
Mr. Shakti Basnet & UCPN (Maoist) & BC \\
Mr. Bishnu Poudel & Communist Party of Nepal (UML) & BC \\
Mr. Agni Kharel & Communist Party of Nepal (UML) & BC \\
Mr. Som Prasad Pandey & Communist Party of Nepal (UML) & BC \\
Mr. Satya Narayan Mandal & Communist Party of Nepal (UML) & Newar \\
Mr. Sherdhan Rai & Communist Party of Nepal (UML) & Rai \\
Mr. Ananda Prasad Pokhrel & Communist Party of Nepal (UML) & BC \\
Mr. Ram Kumar Subba & Rastriya Prajatantra Party Nepal & \\
Mr. Rekha Sharma & UCPN (Maoist) & Limbu \\
Mr. Shanta Manavi & Communist Party of Nepal (UML) & BC \\
Mr. Haribol Gajurel & UCPN (Maoist) & BC \\
Mr. Giriraj Mani Pokhrel & UCPN (Maoist) & BC \\
Mr. Agni Sapkota & UCPN (Maoist) & BC \\
Mr. Ganeshman Pun & UCPN (Maoist) & BC \\
Mr. Umesh Yadav & UCPN (Maoist) & Magar \\
Mr. Ram Janam Chaudhary & MJAFN (Loktantrik) & M \\
Mr. Bishwendra Paswan & Bahujan Samajwadi (Shakti) Party & M \\
Mr. Meghraj Nepali & Madhesh Samata Party Nepal & Dalit \\
Mr. Mo. Mustak Aalam & Communist Party of Nepal (UML) & Dalit \\
Mr. Bikram Bahadur Thapa & Rastriya Prajatantra Party Nepal & Muslim \\
Mr. Kunti Kumari Shahi & Rastriya Prajatantra Party Nepal & BC \\
Mr. Dinesh Shrestha & Rastriya Prajatantra Party Nepal & BC \\
Mr. Biraj Bista & Rastriya Prajatantra Party Nepal & Newar \\
Source: (Office of the Prime Ministerand Council of Ministers 2016) & \\
\hline
\end{tabular}

\begin{tabular}{|c|c|c|c|c|}
\hline (July 2016) & No. & $\begin{array}{l}\text { Pop\% } \\
\text { (2001) }\end{array}$ & $\begin{array}{l}\text { Proportion } \\
\text { of Cabinet }\end{array}$ & $\begin{array}{l}\text { Proportio- } \\
\text { nality }\end{array}$ \\
\hline Bahun/Chhetri & 19 & 28.5 & $63 \%$ & 2.21 \\
\hline Dalit & 2 & 12.7 & $7 \%$ & 0.55 \\
\hline Madheshi (Hindu caste groups) & 3 & 20.5 & $10 \%$ & 0.49 \\
\hline Newar & 2 & 5.5 & $7 \%$ & 1.82 \\
\hline Rai & 1 & 2.3 & $3 \%$ & 1.30 \\
\hline Magar & 1 & 7.1 & $3 \%$ & 0.42 \\
\hline Muslim & 1 & 4.2 & $3 \%$ & 0.71 \\
\hline Limbu & 1 & 1.3 & $3 \%$ & 2.38 \\
\hline Total & 30 & & & \\
\hline Janajati total & 5 & 37 & $17 \%$ & 0.46 \\
\hline \multicolumn{5}{|l|}{ Proportionality $>1=$ overrepresented } \\
\hline Number of parties in Cabinet & & 7 & & \\
\hline $\begin{array}{l}\text { Number of seats held by parties in } \\
\text { Cabinet }\end{array}$ & & 303 & (minimum) & \\
\hline $\begin{array}{l}\text { Cabinet } \\
\text { Number of parties in legislature }\end{array}$ & & 31 & & \\
\hline $\begin{array}{l}\text { Proportion of seats in legis. by Cabinet } \\
\text { parties }\end{array}$ & & 50.08 & & \\
\hline Proportion of parties in Cabinet & & 22.58 & & \\
\hline
\end{tabular}

$\mathrm{BC}=$ Bahun Chhetri

$\mathrm{M}=$ Madheshi 
Table A11: Nepal event summary table (1945-2016)

\begin{tabular}{|c|c|}
\hline Year & Change / event \\
\hline 1945 & (Baseline - Rana oligarchy) \\
\hline 1947 & Widespread anti-Rana protests, organized by Nepali National Congress \\
\hline 1948 & New constitution, established by the Ranas, but never properly implemented \\
\hline 1950 & $\begin{array}{l}\text { Start of anti-Rana armed struggle by Nepali National Congress aligned insurgents. Ends in } 1951 \\
\text { with agreement to form coalition government }\end{array}$ \\
\hline 1951 & $\begin{array}{l}\text { New constitution, quasi-federal monarchy for a transition to democracy } \\
\text { Regime change to constitutional monarchy } \\
\text { Nepali Congress form government with independents (scored at 1952) } \\
\text { Indian troops invited three times to arrest rebels and repress protests (post new government) } \\
\text { Agreement process facilitated by India (Delhi Accord) and caused by division in political elite and } \\
\text { Indian policy (whose influence was possible via the withdrawal of the British) }\end{array}$ \\
\hline 1953 & Local Panchayats established \\
\hline 1956 & Introduction of Nepali as the national language \\
\hline 1959 & $\begin{array}{l}\text { New constitution, regime change to unitary democracy } \\
\text { New government abolishes Rajayuta system which enabled formerly independent rajas (in central } \\
\text { and west) to control territories in return for an annual tribute } \\
\text { National Democratic Front formed to organize protests against government reforms }\end{array}$ \\
\hline 1960 & King seizes power, declares state of emergency, suspends constitution and bans political parties \\
\hline 1961 & Insurgencies form and fighting lasts approximately one year (more than 100 killed) \\
\hline 1962 & $\begin{array}{l}\text { New constitution, quasi-federal monarchy, state of emergency lifted } \\
\text { Fourteen development regions established }\end{array}$ \\
\hline 1963 & $\begin{array}{l}\text { Country Code } 1963 \text { bans caste \& religious discrimination, and recognises customary law of certain } \\
\text { Indigenous groups }\end{array}$ \\
\hline 1964 & Citizenship Act disenfranchises Madheshis and Land Reform Act imposes ceilings on holdings \\
\hline 1967 & $\begin{array}{l}\text { Constitutional amendments expand Panchayat system and introduce a parliamentary executive, } \\
\text { accountable to the king }\end{array}$ \\
\hline 1973 & Military action to put down student protests and democracy activities \\
\hline 1974 & Protests and unrest continues with assassination and hijacking attempts \\
\hline 1975 & $\begin{array}{l}\text { Constitutional changes, creates government appointed committee to vet and nominate candidates, } \\
\text { and removed class organizations from the Rastriya Panchayat }\end{array}$ \\
\hline 1979 & $\begin{array}{l}\text { Economic crisis, leads to widespread protests and pressure for democratic reform } \\
\text { Two democratic fighters hung, leads to further student protests and deployment of army }\end{array}$ \\
\hline 1980 & $\begin{array}{l}\text { Constitutional changes, following a referendum, introduce direct election of the national-level } \\
\text { Panchayat and election and responsibility of the prime minister to the national-level Panchayat } \\
\text { Direct election of Panchayat in mostly single member districts, though some were dual member }\end{array}$ \\
\hline 1982 & Decentralization Act gives more Panchayats more power and control over local civil service \\
\hline 1985 & Currency devaluation and large World Bank loan \\
\hline 1989 & $\begin{array}{l}\text { Economic crisis following border trade disagreements with India } \\
\text { Widespread protests }\end{array}$ \\
\hline 1990 & $\begin{array}{l}\text { Jana Andolan (People's Uprising) } \\
\text { New democratic unitary constitution }\end{array}$ \\
\hline 1991 & Reservation policies commence following census \\
\hline 1992 & Violent protests regarding a border agreement with India, police shoot 12 \\
\hline 1993 & Further protests, police shoot 24 \\
\hline 1995 & Police atrocities in western Nepal contributes to rise of Maoists \\
\hline 1996 & Maoist rebel insurgency commences \\
\hline 1999 & Khumbuwan insurgency commences, lasts until 2002 \\
\hline 2002 & $\begin{array}{l}\text { State of emergency declared, political parties arrested, crackdown on Maoists } \\
\text { Hill and Madheshi people riot in opposition }\end{array}$ \\
\hline 2005 & $\begin{array}{l}\text { State of emergency ends, rights restored } \\
\text { Jana Andolan II (People's Uprising), brings state to a standstill and Maoist rebels align with political } \\
\text { parties to end monarchy and sign the Comprehensive Peace Agreement }\end{array}$ \\
\hline 2006 & Legislature restored as a single house \\
\hline 2007 & Interim constitution established to guide new constitution-making process \\
\hline 2008 & $\begin{array}{l}\text { Madheshi uprising (large protests in the Terai) } \\
\text { Election for Constituent Assembly and restoration of democracy }\end{array}$ \\
\hline
\end{tabular}




\begin{tabular}{|c|c|}
\hline Year & Change / event \\
\hline & $\begin{array}{l}\text { First amendment to the interim constitution declares Nepal to be a federal secular democratic } \\
\text { republic }\end{array}$ \\
\hline 2015 & $\begin{array}{l}\text { Major earthquakes cause devastation and large loss of life } \\
\text { New federal constitution enacted } \\
\text { Riots in Terai in response to new constitution }\end{array}$ \\
\hline 2016 & $\begin{array}{l}\text { First amendment to the } 2015 \text { constitution broadens scope and application of proportionality } \\
\text { requirements }\end{array}$ \\
\hline
\end{tabular}

Key sources: (Whelpton 2005; International Crisis Group 2007; United Nations Development Programme 2007; B. Karki 2014; Malik et al. 2009; Gellner 2007) 
Table A12: Nepal summary (1945-2016)

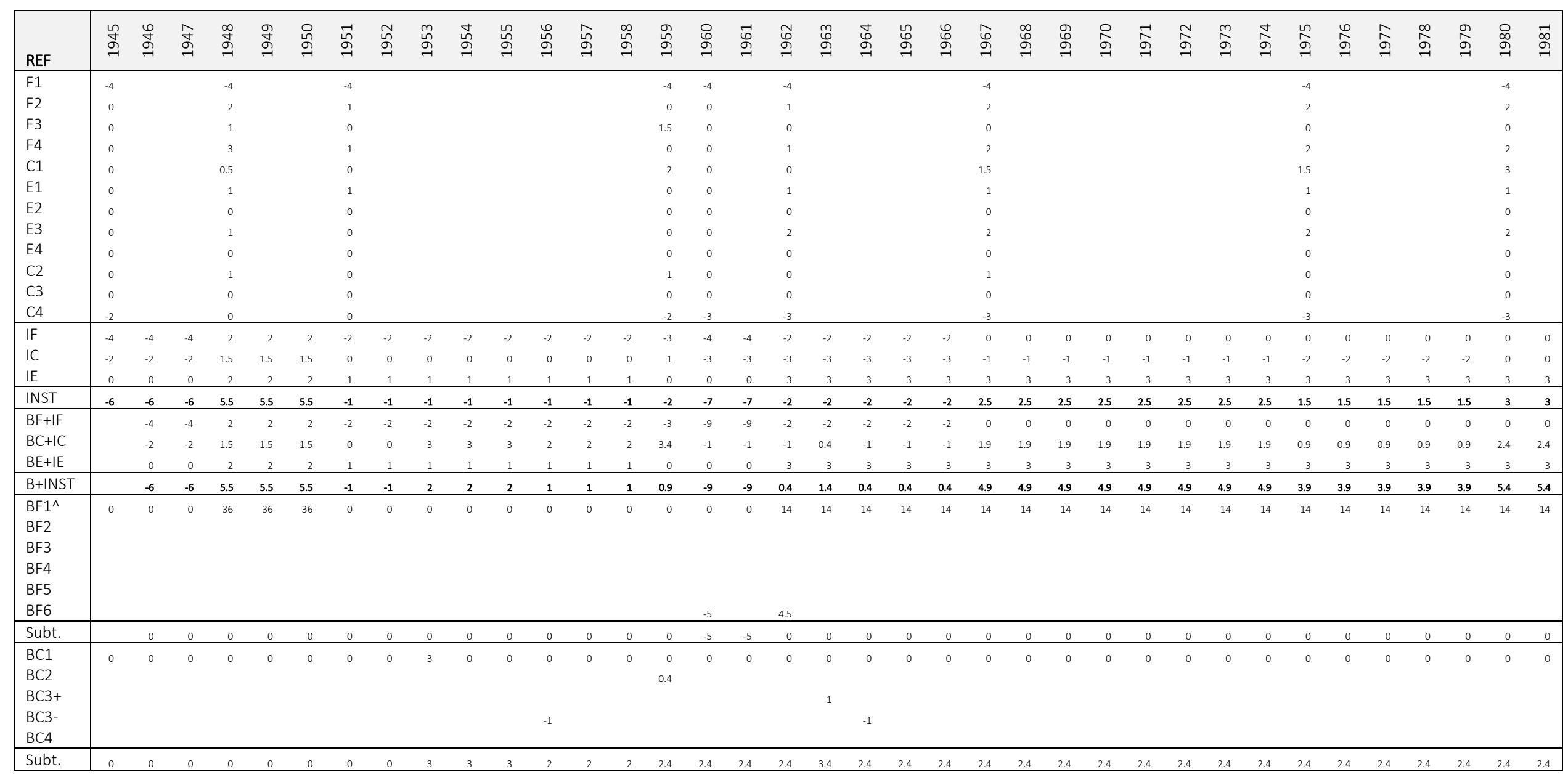




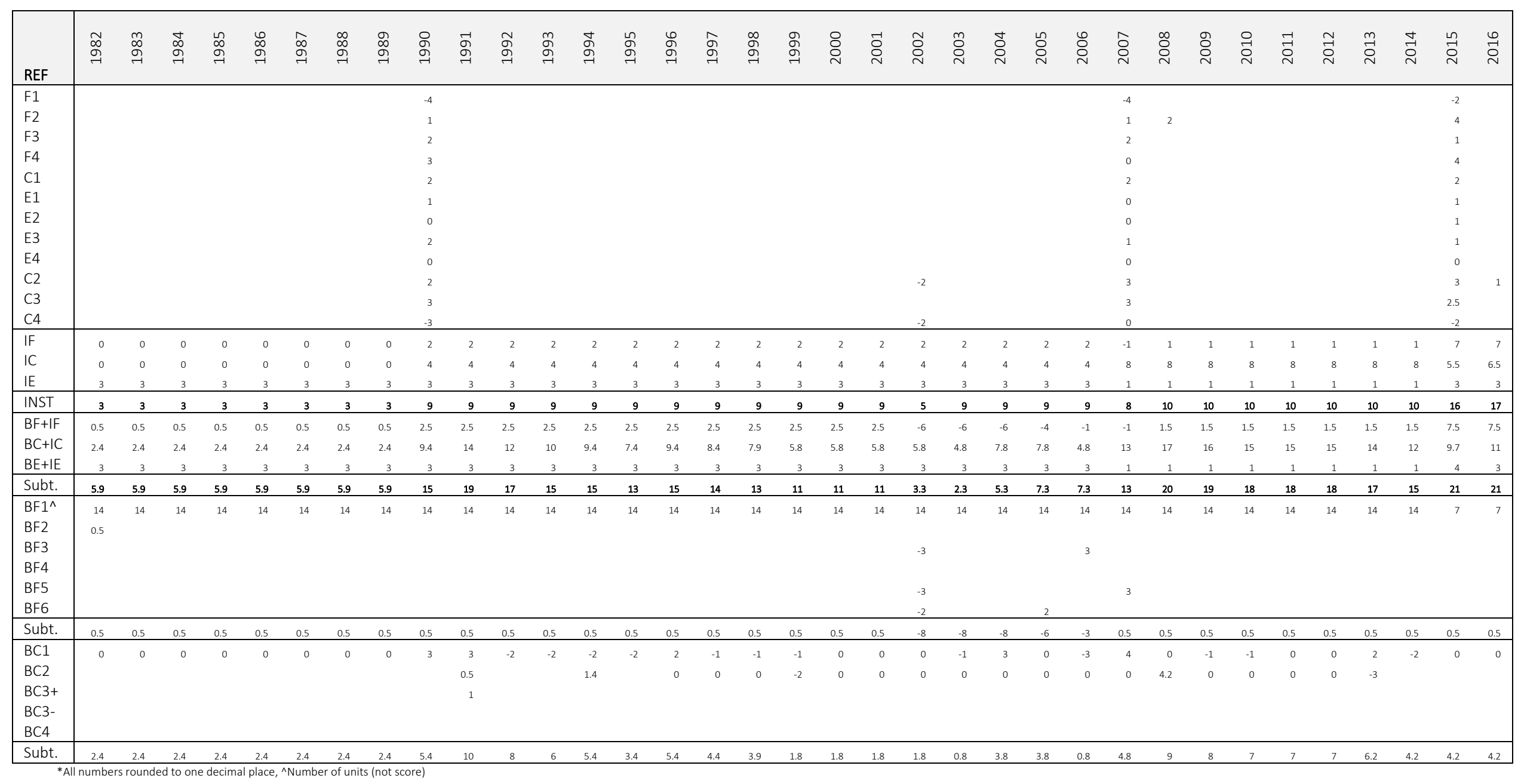


Table A13: Nepal - Other variables and sequencing factors summary (1945-2016)

\begin{tabular}{|c|c|c|c|c|c|c|c|c|c|c|c|c|c|c|c|c|c|c|c|c|c|c|c|c|c|c|c|c|c|c|c|c|c|c|c|c|}
\hline REF & $\underset{f}{\stackrel{\text { f }}{\sigma}}$ & & 今 & $\begin{array}{l}\infty \\
\text { जे }\end{array}$ & ఫ్ & 吕 & 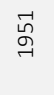 & స్ & 足 & 鹃 & 㞫 & $\begin{array}{l}\stackrel{\leftrightarrow}{\sigma} \\
\stackrel{\sigma}{\sigma}\end{array}$ & 名 & 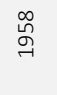 & 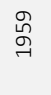 & $\begin{array}{l}\circ \\
\stackrel{\circ}{\sigma}\end{array}$ & $\begin{array}{l}\vec{ه} \\
\stackrel{\sigma}{\sigma}\end{array}$ & $\begin{array}{l}\widetilde{\sigma} \\
\text { హ}\end{array}$ & 足 & 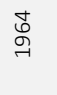 & 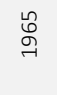 & $\begin{array}{l}\text { ஜ } \\
\stackrel{\sigma}{\sigma}\end{array}$ & $\begin{array}{l}\widehat{ᄋ} \\
\stackrel{\sigma}{\sigma}\end{array}$ & $\begin{array}{l}\infty \\
\stackrel{\leftrightarrow}{\sigma}\end{array}$ & $\begin{array}{l}\text { ᄋ్ } \\
\stackrel{\sigma}{\sigma}\end{array}$ & مे & $\vec{\sigma}$ & 余 & 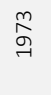 & 离 & $\begin{array}{l}\stackrel{n}{\sigma} \\
\stackrel{\sigma}{7}\end{array}$ & $\begin{array}{l}0 \\
\stackrel{9}{7}\end{array}$ & 犬ิ & $\begin{array}{l}\infty \\
\stackrel{-}{9}\end{array}$ & $\begin{array}{l}\stackrel{\Omega}{2} \\
\text { مे }\end{array}$ & $\begin{array}{l}\infty \\
\stackrel{\leftrightarrow}{\rightarrow}\end{array}$ \\
\hline \multicolumn{37}{|c|}{ OTHER INTERACTING } \\
\hline $\mathrm{O} 1$ & & & -1 & & & -2 & -2 & & & & & & & & -1 & & -2 & -2 & & & & & & & & & & & -1 & -1 & & & & & -1 & \\
\hline $\mathrm{O} 2$ & & & & & & & 1 & & & & & & & & & -1 & & & & & & & & & & & & & & & & & & & & \\
\hline 03 & & & & & & & & & & & & & & & & & & & & & & & & & & & & & & & & & & & -1 & \\
\hline 04 & & & & & & & 1 & & & & & & & & & & & & & & & & & & & & & & & & & & & & & \\
\hline 05 & -2 & -2 & -2 & -2 & -2 & -2 & 0 & 0 & 0 & 0 & 0 & 0 & 0 & 0 & 0 & 0 & 0 & -2 & -2 & -2 & -2 & -2 & -2 & -2 & -2 & -2 & -2 & -2 & -2 & -2 & -2 & -2 & -2 & -2 & -2 & -2 \\
\hline Dem & & & & 0 & 0 & 0 & 0 & 0 & 0 & 0 & 0 & 0 & 1.3 & 2.7 & 4 & 0 & 0 & 0 & 0 & 0 & 0 & 0 & 0 & 0 & 0 & 0 & 0 & 0 & 0 & 0 & 0 & 0 & 0 & 0 & 0 & 0 \\
\hline \multicolumn{37}{|c|}{ Secession risk \& Infrastructural Capacity } \\
\hline SR1 & 0 & 0 & 0.5 & 0 & 0 & 1 & 1 & 0 & 0 & 0 & 0 & 0 & 0 & 0 & 0.3 & 0 & 1 & 1 & 0 & 0 & 0 & 0 & 0 & 0 & 0 & 0 & 0 & 0 & 0.3 & 0.3 & 0 & 0 & 0 & 0 & 0.3 & 0 \\
\hline SR2 & 0 & 0 & 0 & 0 & 0 & 0 & 0 & 0 & 0 & 0 & 0 & 0 & 0 & 0 & 0 & 0 & 0 & 0 & 0 & 0 & 0 & 0 & 0 & 0 & 0 & 0 & 0 & 0 & 1 & 1 & 1 & 1 & 1 & 1 & 1 & 0 \\
\hline SR3 & 0 & 0 & 2 & 2 & 2 & 2 & 2 & 0 & 0 & 0 & 0 & 0 & 0 & 0 & 0 & 0 & 0 & 0 & 0 & 0 & 0 & 0 & 0 & 0 & 0 & 0 & 0 & 0 & 1 & 1 & 1 & 1 & 1 & 1 & 1 & 0 \\
\hline Subt. & 0 & 0 & 2.5 & 2 & 2 & 3 & 3 & 0 & 0 & 0 & 0 & 0 & 0 & 0 & 0.3 & 0 & 1 & 1 & 0 & 0 & 0 & 0 & 0 & 0 & 0 & 0 & 0 & 0 & 2.3 & 2.3 & 2 & 2 & 2 & 2 & 2.3 & 0 \\
\hline IC & 0 & 0 & 0 & 0 & 0 & 0 & 0 & 0 & 0.5 & 0.5 & 0.5 & 0.5 & 0.5 & 0.5 & 0.5 & 0.5 & 0.5 & 0.5 & 0.5 & 0.5 & 0.5 & 0.5 & 0.5 & 0.5 & 0.5 & 0.5 & 0.5 & 0.5 & 0.5 & 0.5 & 0.5 & 0.5 & 0.5 & 0.5 & 0.5 & 0.5 \\
\hline \multicolumn{37}{|c|}{ Deliberative conditions } \\
\hline DC1 & & & & & & & 0 & & & & & & & & 0.5 & & & 0 & & & & & & & & & & & & & & & & & & 1 \\
\hline DC2 & & & & & & & 1 & & & & & & & & 0 & & & 1 & & & & & & & & & & & & & & & & & & 1 \\
\hline DC3 & & & & & & & 0 & & & & & & & & 0 & & & 0 & & & & & & & & & & & & & & & & & & 0 \\
\hline DC4 & & & & & & & 0 & & & & & & & & 0 & & & 0 & & & & & & & & & & & & & & & & & & 0 \\
\hline DC5 & & & & & & & 0 & & & & & & & & 0 & & & 0 & & & & & & & & & & & & & & & & & & 0 \\
\hline Subt. & & & & & & & 1 & & & & & & & & 0.5 & & & 1 & & & & & & & & & & & & & & & & & & 2 \\
\hline
\end{tabular}




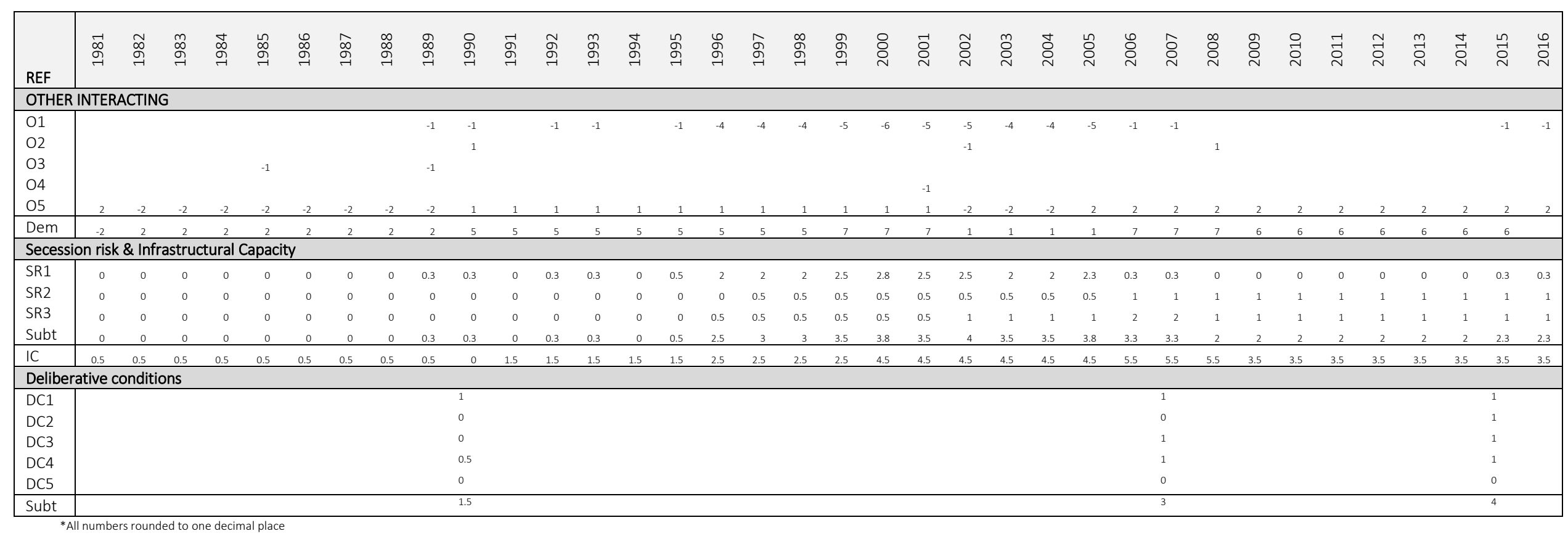

${ }^{*}$ All numbers rounded to one decimal place 
A2.4 Myanmar data 
Table A14: Myanmar constitutions

\begin{tabular}{|c|c|c|c|c|c|c|c|c|c|c|}
\hline Measure & Baseline - (1935) & $\mathrm{s}$ & 1947 & $\mathrm{~s}$ & 1962 & $\mathrm{~s}$ & 1974 & $S$ & 2008 & $\mathrm{~s}$ \\
\hline $\begin{array}{l}\text { F1 - Extent of } \\
\text { central authority }\end{array}$ & $\begin{array}{l}\text { A6 - Governor chooses } \\
\text { Ministers }\end{array}$ & -4 & $\begin{array}{l}\text { A94 - emergency intervention } \\
\text { powers; A156 - President } \\
\text { approves state bill, but is obliged } \\
\text { to unless constitutional issues; } \\
\text { A160 - President appoints Heads } \\
\text { of States on recommendation of } \\
\text { Prime Minister; A96 - ensures } \\
\text { certain revenue goes to the states }\end{array}$ & 1.5 & $\begin{array}{l}\text { The Revolutionary Council, } \\
\text { which is the supreme } \\
\text { authority of the Party, has } \\
\text { absolute authority }\end{array}$ & -4 & $\begin{array}{l}\text { A28 - "Local autonomy under } \\
\text { central leadership is the } \\
\text { structure of the State"; A39 - } \\
\text { (Central) Parliament can } \\
\text { amend etc state boundaries, } \\
\text { after "ascertaining the } \\
\text { wishes" of the relevant state; } \\
\text { A76 - emergency } \\
\text { intervention powers }\end{array}$ & -4 & $\begin{array}{l}\text { A261 - President } \\
\text { nominates Chief Minister \& } \\
\text { State Parliament cannot } \\
\text { refuse; A40A/411 - } \\
\text { Emergency intervention } \\
\text { powers; A279 - Self- } \\
\text { administered areas } \\
\text { subordinate to states and } \\
\text { Union; A198 - Legislative } \\
\text { hierarchy - state laws } \\
\text { invalid if inconsistent with } \\
\text { central laws; A262(I) - Chief } \\
\text { Minister responsible to } \\
\text { President }\end{array}$ & -3 \\
\hline $\begin{array}{l}\text { F2 - Scope of } \\
\text { unit's autonomy }\end{array}$ & $\begin{array}{l}\text { Split of country into } \\
\text { Ministerial Burma and } \\
\text { Frontier Areas } \\
\text { administered separately } \\
\text { - see Schedule } 2 \text { for } \\
\text { specifics }\end{array}$ & 1 & $\begin{array}{l}\text { Sch } 3 \text { - } 7 \text { main areas including } \\
\text { taxation, education, security } \\
\text { (including judicial), local govt, but } \\
\text { little natural resources (there is a } \\
\text { requirement to consult relevant } \\
\text { state minister re extractives) }\end{array}$ & 3.5 & Units abolished & 0 & $\begin{array}{l}\text { Ch } 10 \text { establishes 'People's } \\
\text { Councils' at each level of govt } \\
\text { tasked within administration } \\
\text { only; Ch } 7 \text { provides for unit } \\
\text { and sub-unit judicial system }\end{array}$ & 2 & $\begin{array}{l}\text { A11C - each level of govt } \\
\text { has all three branches; Sch } \\
2 / 3 \text { - relatively weak set of } \\
\text { powers, but including } \\
\text { taxation, some natural } \\
\text { resources }\end{array}$ & 2.5 \\
\hline $\begin{array}{l}\text { F3 - } \\
\text { Constitutionalism }\end{array}$ & n/a British legislation & 0 & $\begin{array}{l}\text { A208 requires a 2/3 majority for } \\
\text { constitutional change and gives } \\
\text { units right to veto particular } \\
\text { changes; A199 also gives ability to } \\
\text { create new states but needs } \\
\text { approval of affected units; A135 } \\
\text { gives Supreme Court power to } \\
\text { resolve disputes }\end{array}$ & 3 & No constitution & 0 & $\begin{array}{l}\text { A53 - simple procedure for } \\
\text { amendment, Party is } \\
\text { supreme; A39 - Parliament } \\
\text { may amend, add, change } \\
\text { names etc. of the states / } \\
\text { divisions }\end{array}$ & 0 & $\begin{array}{l}\text { A46 - Constitutional } \\
\text { tribunal for dispute } \\
\text { resolution; } 75 \% \text { majority } \\
\text { required to change } \\
\text { constitution; A226 - Union } \\
\text { govt may decide matters of } \\
\text { dispute between } \\
\text { jurisdictions re non- } \\
\text { constitutional matters; } \\
\text { A299 - President appoints } \\
\text { head of court, little right of } \\
\text { refusal by Parliament }\end{array}$ & 1.5 \\
\hline F4 - Bicameralism & $\mathrm{Nil}$ & 0 & $\begin{array}{l}\text { Yes, see Ch IX - Members of the } \\
\text { Chamber of Nationalities join }\end{array}$ & 3 & $\mathrm{n} / \mathrm{a}$ & 0 & $\begin{array}{l}\text { n/a however, A64 - Council of } \\
\text { State includes members from }\end{array}$ & 1 & $\begin{array}{l}\text { A141 - Each state and } \\
\text { division, and self- }\end{array}$ & 3 \\
\hline
\end{tabular}




\begin{tabular}{|c|c|c|c|c|c|c|c|c|c|c|}
\hline Measure & Baseline - (1935) & $S$ & 1947 & $S$ & 1962 & $S$ & 1974 & $S$ & 2008 & $S$ \\
\hline & & & $\begin{array}{l}\text { together according to where from } \\
\text { to form the State Councils }\end{array}$ & & & & $\begin{array}{l}\text { each state and division (taken } \\
\text { from among representatives } \\
\text { in the central Parliament) }\end{array}$ & & $\begin{array}{l}\text { administered areas (SAA) } \\
\text { represented in upper } \\
\text { house (at } 12 \text { each with } 1 \\
\text { for each SAA) }\end{array}$ & \\
\hline $\begin{array}{l}\text { C1 - Legislative } \\
\text { executive } \\
\text { relations }\end{array}$ & Parliamentary & 2 & Parliamentary & 2 & Military rule & 0 & Presidential & 1 & $\begin{array}{l}\text { Hybrid presidential (but } \\
\text { voted for by Parliament, } \\
\text { and with some Ministers } \\
\text { from legislature) }\end{array}$ & 1.5 \\
\hline $\begin{array}{l}\text { E1 - Basis of units } \\
\text { (identity / } \\
\text { territory) }\end{array}$ & $\begin{array}{l}\text { Split of country into } \\
\text { Ministerial Burma and } \\
\text { Frontier Areas } \\
\text { administered separately } \\
\text { - see Schedule } 2 \text { for } \\
\text { specifics }\end{array}$ & 1 & $\begin{array}{l}\text { Includes ethnic states (Shan, } \\
\text { Kachin and Kayah, ethnic special } \\
\text { divisions (Chin Hill \& Arakan Hills), } \\
\text { and a Burmese core, each with } \\
\text { different rights and } \\
\text { representative arrangements. } \\
\text { States have special powers, } \\
\text { Burma proper is governed by the } \\
\text { center (See A2-7) }\end{array}$ & 3 & Units abolished & 0 & $\begin{array}{l}\text { A31 - Seven ethnic states and } \\
\text { seven Bamar divisions }\end{array}$ & 3 & $\begin{array}{l}\text { Seven ethnic states and } \\
\text { seven Bamar divisions, no } \\
\text { special rights }\end{array}$ & 3 \\
\hline $\begin{array}{l}\text { E2 - Sub-units } \\
\text { (autonomous } \\
\text { zones) }\end{array}$ & $\begin{array}{l}\text { No specific mechanisms } \\
\text { re units or similar }\end{array}$ & 0 & $\begin{array}{l}\text { A91 provides for regional } \\
\text { autonomy through delegation to } \\
\text { representative bodies as defined } \\
\text { by law }\end{array}$ & 1 & $n / a$ & 0 & $\mathrm{n} / \mathrm{a}$ & 0 & $\begin{array}{l}\text { A56 - Self-administered } \\
\text { areas (which have different } \\
\text { powers and different } \\
\text { representation in upper } \\
\text { house (1 } 1 \text { v 12) (see A141) }\end{array}$ & 3 \\
\hline $\begin{array}{l}\text { E3 - Local } \\
\text { government (no. } \\
\text { of levels) }\end{array}$ & $n / a$ & 0 & $\mathrm{n} / \mathrm{a}$ & 0 & $n / a$ & 0 & $\begin{array}{l}\text { A29 - Four levels of } \\
\text { government; }\end{array}$ & 1 & $\begin{array}{l}\text { Local administrative bodies } \\
\text { have several mentions, no } \\
\text { powers }\end{array}$ & 0.5 \\
\hline $\begin{array}{l}\text { E4 - Degree of } \\
\text { asymmetry }\end{array}$ & $\begin{array}{l}\text { Two separate forms of } \\
\text { territory (see Sch 2) - } \\
\text { basically the hill and } \\
\text { plains division }\end{array}$ & 2 & $\begin{array}{l}\text { Shan State has more substantial } \\
\text { powers and representation than } \\
\text { Kachin \& Kayah states, and there } \\
\text { are special divisions with lessor } \\
\text { powers }\end{array}$ & 3 & $\mathrm{n} / \mathrm{a}$ & 0 & nil & 0 & $\begin{array}{l}\text { A9a - specifies all states } \\
\text { and divisions are equal }\end{array}$ & 0 \\
\hline $\begin{array}{l}\mathrm{C} 2 \text { - Inclusivity } \\
\text { and } \\
\text { proportionality }\end{array}$ & $\begin{array}{l}\text { Sch } 3-25 \text { of } 132 \text { seats in } \\
\text { House of Reps reserved } \\
\text { for particular identity }\end{array}$ & 2 & $\begin{array}{l}\text { Ethnic \& regional groups } \\
\text { guaranteed a certain number of } \\
\text { Parliamentary seats (e.g. A166); }\end{array}$ & 1 & $\mathrm{Nil}$ & 0 & $\begin{array}{l}\text { A176 - FPTP with some multi- } \\
\text { member districts, depending } \\
\text { on size }\end{array}$ & 1 & $\begin{array}{l}\text { A276(I) - National races } \\
\text { over a certain population } \\
\text { must be appointed to the }\end{array}$ & 1 \\
\hline
\end{tabular}




\begin{tabular}{|c|c|c|c|c|c|c|c|c|c|c|}
\hline Measure & Baseline - (1935) & $\mathrm{s}$ & 1947 & $\mathrm{~s}$ & 1962 & $\mathrm{~s}$ & 1974 & $\mathrm{~s}$ & 2008 & $\mathrm{~s}$ \\
\hline & $\begin{array}{l}\text { groups, but also } \\
\text { provision (A4) to } \\
\text { delineate boundaries for } \\
\text { election of identity- } \\
\text { based representatives; } \\
\text { Sch 3: A10 \& } 11 \text { - provide } \\
\text { for proportional voting, } \\
\text { appointment in Senate }\end{array}$ & & $\begin{array}{l}182 \text { seats were elected in two- } \\
\text { member constituencies (TMC) on } \\
\text { a non-communal basis, } 56 \text { of } \\
\text { these TMC were uncontested. } 24 \\
\text { seats were reserved for the Karen } \\
\& 4 \text { for Anglo-Burmans }\end{array}$ & & & & & & $\begin{array}{l}\text { Leading Body in the Self } \\
\text { Administered Zones. Also - } \\
\text { state / division Parliaments } \\
\text { elect national (minority) } \\
\text { race representatives to } \\
\text { serve as Ministers in the } \\
\text { Cabinet (e.g. A391, A375) }\end{array}$ & \\
\hline $\begin{array}{l}\text { C3 - Extent of } \\
\text { cultural rights and } \\
\text { freedoms }\end{array}$ & $\begin{array}{l}\text { A8(c) - Governor to } \\
\text { safeguard rights of } \\
\text { minorities }\end{array}$ & 0 & $\begin{array}{l}\text { A22 recognizes other religions } \\
\text { and bans discrimination, with A20 } \\
\text { providing freedom of religion (by } \\
\text { amendment in } 1954 \text { - not scored } \\
\text { here) }\end{array}$ & 0 & Not protected & 0 & $\begin{array}{l}\text { A21 - freedom of religion, } \\
\text { culture, language etc. (for the } \\
\text { 'national races'); A147 - } \\
\text { equality before the law; }\end{array}$ & 0 & $\begin{array}{l}\text { A3 - recognizes multi- } \\
\text { races; A22 - Union to assist } \\
\text { to develop national races' } \\
\text { language, culture etc.; } \\
\text { A347/8 - equality and basic } \\
\text { individual freedoms and } \\
\text { protections }\end{array}$ & 1 \\
\hline $\begin{array}{l}\text { C4 - Assimilating } \\
\text { aspects }\end{array}$ & $\begin{array}{l}\mathrm{n} / \mathrm{a} \text { though English } \\
\text { requirements }\end{array}$ & -2 & $\begin{array}{l}\text { A21 - Buddhism gets 'special } \\
\text { position' }\end{array}$ & -2 & Policy based & 0 & $\begin{array}{l}\text { A102 - Burmese language of } \\
\text { the courts, though others } \\
\text { may be used; A152 - } \\
\text { Burmese is the common } \\
\text { language of education } \\
\text { though others may be } \\
\text { taught; A153 - relevant } \\
\text { cultural freedoms qualified } \\
\text { by need to protect national } \\
\text { unity }\end{array}$ & -2 & $\begin{array}{l}\text { A36 - Buddhism given } \\
\text { foremost place; Bamar } \\
\text { (Myanmar) is official } \\
\text { language }\end{array}$ & -2 \\
\hline TOTAL & & 2 & & 16 & & -4 & & 3 & & 12 \\
\hline
\end{tabular}

Sources: (Constitution of the Republic of the Union of Myanmar 2008; The Constitution of the Union of Burma 1947; The Constitution of the Union of Burma 1974; Government of Burma Act 1935) 
Table A15: Myanmar elections and party proportionality (1947-2016)

\begin{tabular}{|c|c|c|c|c|c|c|c|c|c|c|c|c|c|c|c|c|}
\hline \multirow[b]{2}{*}{ Designation } & \multirow{2}{*}{$\begin{array}{l}\text { ELECTIONS } \\
\text { PARTIES }\end{array}$} & \multicolumn{5}{|l|}{1947} & \multicolumn{5}{|l|}{2010} & \multicolumn{5}{|c|}{2015 Lower House } \\
\hline & & Votes & $\begin{array}{l}\text { Vote } \\
\text { s\% }\end{array}$ & Seats & $\begin{array}{l}\text { Seats } \\
\%\end{array}$ & $\begin{array}{l}\text { Deviati } \\
\text { on }^{2}\end{array}$ & Votes & $\begin{array}{l}\text { Votes } \\
\%\end{array}$ & Seats & $\begin{array}{l}\text { Seats } \\
\%\end{array}$ & $\begin{array}{l}\text { Deviati } \\
\text { on }^{2}\end{array}$ & Votes & $\begin{array}{l}\text { Votes } \\
\%\end{array}$ & Seats & $\begin{array}{l}\text { Seats } \\
\%\end{array}$ & $\begin{array}{l}\text { Deviati } \\
\text { on }^{2}\end{array}$ \\
\hline Bamar & AFPFL & $1,755,000$ & 83.57 & 173 & 82.4 & 1.37 & & & & & & & & & & \\
\hline Bamar & CPB & 126,000 & 6.00 & 7 & 3.3 & 7.29 & & & & & & & & & & \\
\hline Ethnic & KYO & 109,000 & 5.19 & 19 & 9 & 14.51 & & & & & & & & & & \\
\hline Ethnic & $\begin{array}{l}\text { Independent } \\
\text { Karen }\end{array}$ & & & 5 & & & & & & & & & & & & \\
\hline Bamar & Independent & & & & & & & & & & & & & & & \\
\hline & Bamar & & & 4 & & & & & & & & & & & & \\
\hline Ethnic & $\begin{array}{l}\text { Others } \\
\text { (nominal*) }\end{array}$ & 110,000 & & 2 & & & & & & & & & & & & \\
\hline Bamar / multi & NLD & & & & & & & & & & & $\begin{array}{r}1279456 \\
1\end{array}$ & 57.06 & 255 & 58 & 0.88 \\
\hline Bamar / multi & NUP & & & & & & $4,060,802$ & 19.44 & 12 & 2.73 & 279.22 & & & & & \\
\hline Ethnic & SNLD & & & & & & & & & & & 352,914 & 1.57 & 12 & 2.7 & 1.28 \\
\hline Bamar / multi & USDP & & & & & & 11858125 & 56.76 & 259 & 58.86 & 4.41 & $\begin{array}{r}6,341,92 \\
0\end{array}$ & 28.28 & 30 & 6.8 & 461.39 \\
\hline Ethnic & RNDP & & & & & & 599,008 & 2.87 & 9 & 2.05 & 0.67 & & & & & \\
\hline Ethnic & Others ethnic & & & & & & & & 19 & 4.32 & & & & & & \\
\hline Bamar / multi & NDF & & & & & & $1,483,329$ & 7.1 & 8 & 1.82 & 27.88 & & & & & \\
\hline Ethnic & $\begin{array}{l}\text { SNDP } \\
\text { Military }\end{array}$ & & & & & & 508,780 & 2.44 & $\begin{array}{r}18 \\
110\end{array}$ & $\begin{array}{r}4.09 \\
25\end{array}$ & 2.72 & & & 110 & 25 & \\
\hline Ethnic & ANP & & & & & & & & & & & 490,664 & 2.19 & 12 & 2.7 & 0.26 \\
\hline Ethnic & $\begin{array}{l}\text { Others ethnic } \\
\text { Cancelled due to }\end{array}$ & & & & & & & & & & & & & 14 & 6.3 & \\
\hline TOTALS & insurgencies & & & & & & 22421123 & & $\begin{array}{r}5 \\
440\end{array}$ & & & $\begin{array}{r}2242362 \\
9\end{array}$ & & $\begin{array}{r}7 \\
440\end{array}$ & 1.6 & \\
\hline $\begin{array}{l}\text { Gallagher inde } \\
\text { Disproportiona }\end{array}$ & & & & & & 3.40 & & & & & 62.98 & & & & & 115.95 \\
\hline SCORE (10/GI) & roportionality & & & & & 2.94 & & & & & 0.16 & & & & & 0.09 \\
\hline SCORE adjuste & & & & & & 2.94 & & & & & 0.16 & & & & & -0.07 \\
\hline
\end{tabular}

*average number of votes per seat X 11 (total number of votes unavailable)

**1990 results not recorded above as parliament did not form. NLD received 59.9\% of the vote, NUP 21.2, SNLD 1.7\%, USDP $1.5 \%$

Sources: (Nohlen, Grotz \& Hartmann 2001a; International Crisis Group 2015; Myanmarelections.org 2016; ALTSEAN Burma 2010) 
Table A16: Myanmar legislature ethnic proportionality (2010)

\begin{tabular}{|c|c|c|c|c|c|c|c|c|c|c|c|c|}
\hline 2010 & $\begin{array}{l}\text { Lower House } \\
\text { seats } \%\end{array}$ & $\begin{array}{l}\text { Upper House } \\
\text { seats \% }\end{array}$ & Total seats & Total seats \% & $\begin{array}{l}\text { Proport- } \\
\text { ionality }\end{array}$ & Military \% & $\begin{array}{l}\text { Seats by } \\
\text { parties only }\end{array}$ & $\begin{array}{l}\text { Seats by } \\
\text { party only \% }\end{array}$ & $\begin{array}{l}\text { Seats by } \\
\text { major parties }\end{array}$ & $\begin{array}{l}\text { Major } \\
\text { parties \% }\end{array}$ & $\begin{array}{l}\text { Seats by } \\
\text { party type }\end{array}$ & $\begin{array}{l}\text { Party type } \\
\% .\end{array}$ \\
\hline Bamar & 71.7 & 64.5 & 456 & 69.3 & 1.02 & 87.9 (146) & 310 & 63.01 & 310 & 72.77 & 426 & 86.59 \\
\hline Ethnic & 28.3 & 35.5 & 202 & 30.7 & 0.96 & $12.1(20)$ & 182 & 36.99 & 116 & 27.23 & 66 & 13.41 \\
\hline Total & & & 658 & & & & 492 & & 426 & & & \\
\hline
\end{tabular}

Sources: (Egreteau 2014) plus Table A15; Proportionality>1=overrepresented 
Table A17: Myanmar executives - parties and type

\begin{tabular}{|r|l|l|c|c|}
\hline \multicolumn{1}{|l|}{ Years } & Prime Minister / President & Party(s) & No. of \\
parties
\end{tabular}

Sources: (Nohlen, Grotz \& Hartmann 2001a; President's Office 2016) 
Table A18: Myanmar executive ethnic proportionality (August 2016)

\begin{tabular}{|l|l|l|}
\hline Name & Party & Ethnicity \\
\hline Aung San Suu Kyi & National League for Democracy & Bamar \\
Aung Thu & National League for Democracy & Bamar \\
Ye Aung, Lt. Gen. & Military & Bamar \\
Than Myint & National League for Democracy & Bamar \\
Win Khaing & Independent & Karen \\
Sein Win, Lt. Gen. & Military & Bamar \\
Myo Thein Gyi & Independent & Bamar \\
Aung San Suu Kyi & National League for Democracy & Bamar \\
Pe Zin Tun & Independent & Bamar \\
Naing Thet Lwin & Mon National Party & Mon \\
Myint Htwe & Independent & Bamar \\
Kyaw Swe, Lt. & & \\
Gen. & Military & Bamar \\
Ohn Maung & Independent & Bamar \\
Khin Maung Cho & Independent & Bamar \\
Pe Myint & Independent & Rakhine \\
& Union Solidarity and Development & \\
Thein Swe & Party & Bamar \\
Ohn Win & Independent & Bamar \\
Kyaw Win & National League for Democracy & Bamar \\
& Union Solidarity and Development & \\
Aung Ko & Party & Bamar \\
Win Myat Aye & National League for Democracy & Bamar \\
Kyaw Tint Swe & Independent & Bamar \\
Thant Sin Maung & National League for Democracy & Bamar \\
Maw Than & Independent & Bamar \\
Htun Htun Oo & Independent & Bamar \\
\hline Source: (President S Office 2016) & \\
\hline
\end{tabular}

\begin{tabular}{|l|r|r|r|r|}
\hline Ethnicity & No. & Pop \% & $\begin{array}{r}\text { Proportion } \\
\text { of Cabinet }\end{array}$ & Proportionality \\
\hline Bamar & 21 & 68 & 87.5 & 1.29 \\
Mon & 1 & 2 & 4.2 & 2.08 \\
Rakhine & 1 & 4 & 4.2 & 1.04 \\
Karen & 1 & 7 & 4.2 & 0.60 \\
\hline
\end{tabular}

Proportionality $>1=$ overrepresented

Source: (President's Office 2016) 
Table A19: Myanmar event summary table (1945-2016)

\begin{tabular}{|c|c|}
\hline Year & Change / event \\
\hline 1945 & (Baseline - Government of Burma Act 1935) \\
\hline 1947 & $\begin{array}{l}\text { New constitution, democratic federalism, four units and a Bamar core } \\
\text { Muslim leaders in Arakan rebel demanding an Islamic state in their region }\end{array}$ \\
\hline 1948 & $\begin{array}{l}\text { Independence } \\
\text { Citizenship limited to those peoples arriving before } 1823 \\
\text { Conflict with Karen National Union and Communist Party of Burma commence }\end{array}$ \\
\hline 1949 & Kachin and Mon forces commence rebellion \\
\hline 1950 & $\begin{array}{l}\text { Emergency Provision Act provides for } 20 \text {-year jail terms for inciting unrest and 'disturbing the } \\
\text { peace and tranquillity of the state' } \\
\text { Kuomintang enters Burma from China and sets up base }\end{array}$ \\
\hline 1951 & Karen Special Division upgraded to State \\
\hline 1953 & Legislation passes to nationalize and redistribute land to peasants to farm \\
\hline 1954 & Buddhism given special position in the constitution \\
\hline 1955 & Communist Party of Burma seeks to abandon armed struggle and become a political party \\
\hline 1958 & Military assumes power following request from Prime Minister. Constitution remains in operation \\
\hline 1960 & $\begin{array}{l}\text { Democracy restored and election are held with Bamar candidates' dominant } \\
\text { Border agreement with China heralds period of good relations }\end{array}$ \\
\hline 1961 & $\begin{array}{l}\text { Constitution amended to make Buddhism the state religion } \\
\text { Kachin Independence Army commences insurgency }\end{array}$ \\
\hline 1962 & $\begin{array}{l}\text { Military seizes power after coup, immediately abolishes ethnic states' and establishes socialism } \\
\text { Communist Part of Burma internal coup and resumes armed struggle }\end{array}$ \\
\hline 1964 & Three groups merge to become Shan State Army, intensifying conflict in Shan State \\
\hline 1965 & Military's four cuts program commences \\
\hline 1967 & $\begin{array}{l}\text { Following cultural revolution, relations with China sour, Kuomintang launches assaults, and there } \\
\text { are anti-Chinese protests and institutional discrimination }\end{array}$ \\
\hline 1968 & China formally supports Communist Party of Burma rebellion \\
\hline 1973 & Lahu become militarily organized (no score change) \\
\hline 1974 & $\begin{array}{l}\text { New constitution, creates quasi-federalism within a single-party system } \\
\text { Military violently represses workers' protests, causalities result }\end{array}$ \\
\hline 1975 & $\begin{array}{l}\text { Opposition National Democratic Front formed by regionally-based minority groups, who mounted } \\
\text { guerrilla insurgencies (no score change) }\end{array}$ \\
\hline 1978 & $\begin{array}{l}\text { Anti-Muslim riots and army brutality - over 200,000 fled across the border; army blames Muslims } \\
\text { (Bengalis/Rohingyas) }\end{array}$ \\
\hline 1982 & $\begin{array}{l}\text { Burma Citizenship Law updates } 1948 \text { legislation, targeting and excluding returning Rohingyas, and } \\
\text { creates three categories of citizenship, including an associate citizenship category }\end{array}$ \\
\hline 1986 & China withdraws support for Communist Party of Burma \\
\hline 1987 & $\begin{array}{l}\text { Currency devaluation and economic crises } \\
\text { Mass protests and anti-government riots }\end{array}$ \\
\hline 1988 & $\begin{array}{l}\text { Peoples' uprising following economic crisis, violently crushed } \\
\text { Military seizes power after coup } \\
\text { Chin army begins fighting a low-level rebellion } \\
\text { Democratic elections held, but results not honored }\end{array}$ \\
\hline 1989 & $\begin{array}{l}\text { Communist Party of Burma breaks up and communist rebellion ends } \\
\text { Multiple ceasefires signed, mostly with former communist groups including United Wa State Army, } \\
\text { Shan State Army and Kachin Independence Army }\end{array}$ \\
\hline 1991 & $\begin{array}{l}\text { Anti-Muslim riots, hundreds of thousands flee across the border, continues into } 1992 \\
\text { Three further ceasefires }\end{array}$ \\
\hline 1993 & $\begin{array}{l}\text { Development of Border Areas and National Races Law - enforces integration } \\
\text { Constitutional Convention commences } \\
\text { Mong Tai army commences insurgency }\end{array}$ \\
\hline 1994 & $\begin{array}{l}\text { Kachin Independent Army (KIA) agreed to stop fighting. Hostilities were resumed } 17 \text { years later. } \\
\text { Three other ceasefires signed including with New Mon State Party and Karenni National } \\
\text { Progressive Party }\end{array}$ \\
\hline 1995 & $\begin{array}{l}\text { Particularly intense fighting with Karen National Union (government forces overran its stronghold } \\
\text { at Manerplaw and forced people to take refuge in Thailand) }\end{array}$ \\
\hline 1996 & $\begin{array}{l}\text { Khun Sa, an opium trafficker in command of some 15,000 Shan troops, surrenders (not scored) } \\
\text { Military jails supporters of Aung San Suu Kyi in a bid to block a pro-democracy meeting }\end{array}$ \\
\hline
\end{tabular}




\begin{tabular}{|l|l|}
\hline Year & Change / event \\
\hline 1997 & Four minor groups sign ceasefires \\
\hline 2002 & One minor group signs ceasefire \\
\hline 2003 & $\begin{array}{l}\text { Banking crisis } \\
\text { Constitutional Convention resumes, but working off SLORC's basic principles }\end{array}$ \\
\hline 2006 & $\begin{array}{l}\text { Legislature restored, but as a single house } \\
\text { Shan State Army signs ceasefire (unscored as already having a ceasefire) }\end{array}$ \\
\hline 2008 & $\begin{array}{l}\text { Peoples' Uprising (Saffron Revolution) } \\
\text { Two relatively minor groups sign ceasefires (not scored) }\end{array}$ \\
\hline 2009 & $\begin{array}{l}\text { Cyclone Nargis } \\
\text { New constitution, drafted by military government passed in referendum. Re-establishes fourteen } \\
\text { units, and adds six self-administered areas }\end{array}$ \\
\hline 2010 & $\begin{array}{l}\text { Border Guard Forces established among some ceasefire groups, but other decline to participate } \\
\text { Democratic election, boycotted by main opposition parties including National League for }\end{array}$ \\
\hline 2011 & $\begin{array}{l}\text { Fighting resumes with Kachin Independence Army } \\
\text { Bi-election, National League for Democracy stand and overwhelmingly win most available seats } \\
\text { Six parties/insurgent groups sign ceasefires, including New Mon State Party, Restoration Council of } \\
\text { Shan State, Karen National Union (KNU) and Shan State Progress Party (Shan State Army - North) } \\
\text { (all except for KNU had existing ceasefires in place) }\end{array}$ \\
\hline 2012 & $\begin{array}{l}\text { Race and religion bills passed, and voting rights of Rohingyas (white card holders) removed } \\
\text { Democratic election, National League for Democracy clear winners } \\
\text { New fighting breaks out in Shan State } \\
\text { National ceasefire framework signed, but no new groups covered and conflict in Shan, Kachin \& } \\
\text { Arakan states continue }\end{array}$ \\
\hline $\begin{array}{l}\text { National League for Democracy assumes government, commence series of '21 st century Panglong' } \\
\text { conferences }\end{array}$ \\
\hline (Silersten 1977; Smith 1991; Taylor 2009; Sadan 2009; Lintner 19g9; Kivmaki \& Pasch 2009;
\end{tabular}

Key sources: (Silverstein 1977; Smith 1991; Taylor 2009; Sadan 2009; Lintner 1999; Kivimaki \& Pasch 2009;

Szajkowski 2004) 
Table A20: Myanmar summary (1945-2016)

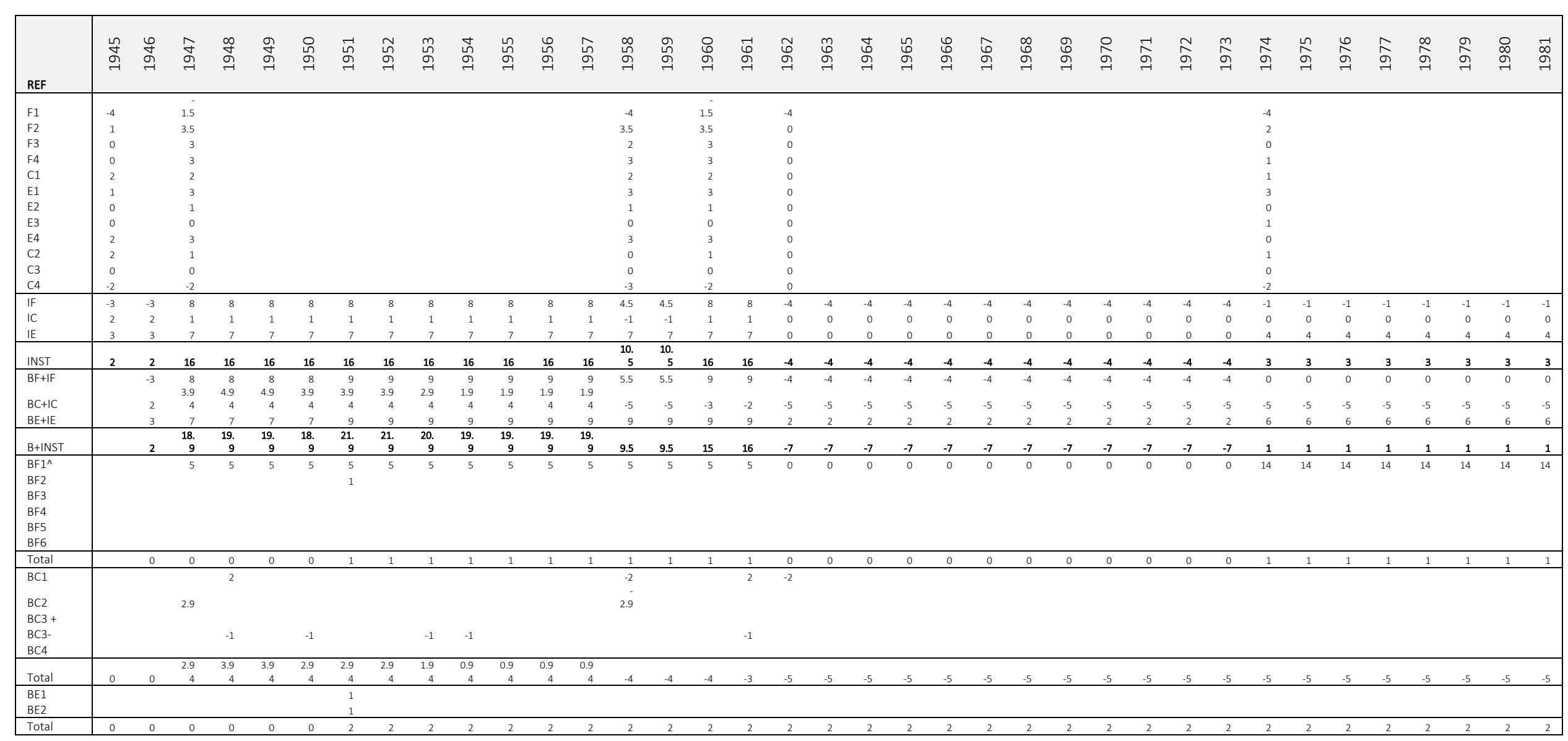




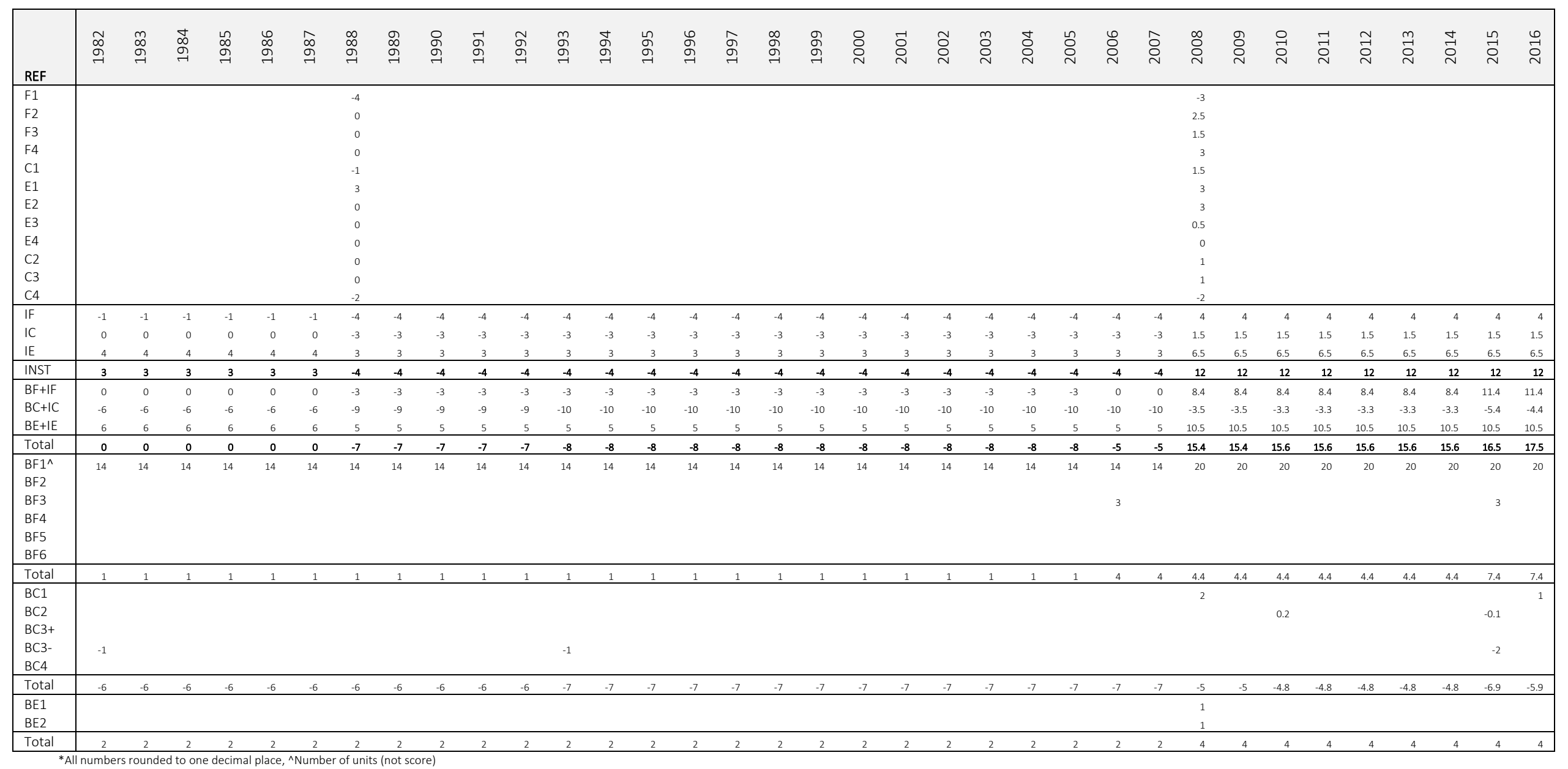

Table A21: Myanmar - Other variables and sequencing factors summary (1945-2016) 


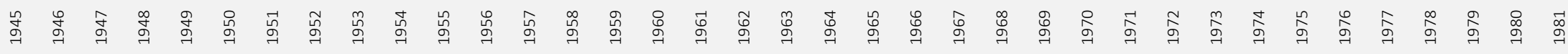

\begin{tabular}{ll} 
REF & \\
\hline OTHER INTERACTING
\end{tabular}

OTHER INTERACTING

$\mathrm{O} 1$
$\mathrm{O} 2$

$\mathrm{O} 3$

04

O5

\begin{tabular}{l|llllllllllllllllllllllllllllllllllll}
\hline Dem & 8 & 8 & 8 & 8 & 8 & 8 & 8 & 8 & 8 & 8 & 8 & 8 & 8 & 8 & 0 & 0 & 0 & 0 & 0 & 0 & 0 & 0 & 0 & 0 & 0 & 0 & 0 & 0 & 0 & 0 & 0 & 0 & 0 & 0 \\
\hline Secession risk \& Infrastructural Capacity & & & & & & & & & & & & &
\end{tabular}

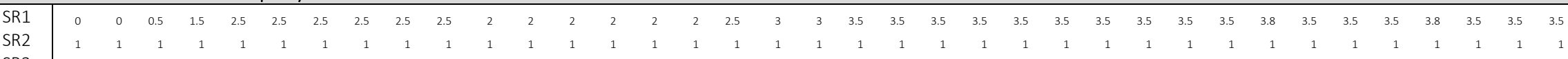

\begin{tabular}{l|lllllllllllllllllllllllllllllllllllllllllllllll} 
SR3 & 1 & 1 & 1 & 1 & 1 & 1 & 1 & 1 & 1 & 1 & 1 & 1 & 1 & 1 & 1 & 1 & 1 & 1 & 1 & 1 & 1 & 1 & 1 & 1 & 1 & 1 & 1 & 1 & 1 & 1 & 1 & 1 & 1 & 1 & 1 & 1 & 1 \\
Subt & 1 & 1 & 1 & 1 & 1 & 2 & 2 & 2 & 2 & 2 & 2 & 2 & 2 & 2 & 2 & 1 & 1 & 1 & 1 & 1 & 1 & 1 & 1 & 2 & 2 & 2 & 2 & 2 & 2 & 2 & 2 & 2 & 2 & 2 & 2 & 2 & 2
\end{tabular}

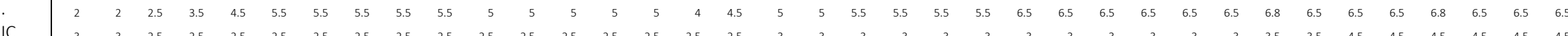
\begin{tabular}{|l|lllllllllllllllllllllllllllllllllllll} 
IC & 3 & 3 & 2.5 & 2.5 & 2.5 & 2.5 & 2.5 & 2.5 & 2.5 & 2.5 & 2.5 & 2.5 & 2.5 & 2.5 & 2.5 & 2.5 & 2.5 & 3 & 3 & 3 & 3 & 3 & 3 & 3 & 3 & 3 & 3 & 3 & 3 & 3.5 & 3.5 & 4.5 & 4.5 & 4.5 & 4.5 & 4.5 & 4.5 \\
\hline Deliberative conditions
\end{tabular}

DC1

$\mathrm{DC2}$

DC3

DC4

DC5

\begin{tabular}{|c|c|c|}
\hline 1 & 0 & 0 \\
\hline 0 & 0 & 0.5 \\
\hline 0 & 1 & 1 \\
\hline 1 & 0 & 0 \\
\hline 0 & 0 & 0 \\
\hline
\end{tabular}




\begin{tabular}{|c|c|c|c|c|c|c|c|c|c|c|c|c|c|c|c|c|c|c|c|c|c|c|c|c|c|c|c|c|c|c|c|c|c|c|c|c|}
\hline REF & 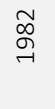 & $\stackrel{\infty}{\stackrel{\infty}{न}}$ & 离 & $\stackrel{\text { }}{\stackrel{\infty}{\rightarrow ~}}$ & $\begin{array}{l}\stackrel{\infty}{\infty} \\
\stackrel{\rightarrow}{-}\end{array}$ & & $\begin{array}{l}\alpha \\
\alpha \\
o \\
a\end{array}$ & & 兽 & 号 & 굥 & ๙ू & ঐ్ & హ్ & 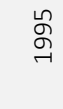 & Љু & ब్ & 只 & ஓ్ & ঃ্ণি & $\vec{ర}$ & ర్ & @ి & ఫ্ণ & 亗 & 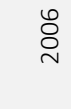 & ఫે & $\stackrel{\infty}{\stackrel{్}{े}}$ & ஓें & 요 & $\bar{c}$ & & ָ̃ & $\stackrel{m}{\stackrel{n}{\sim}}$ & 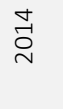 & 岂 \\
\hline \multicolumn{37}{|c|}{ OTHER INTERACTING } \\
\hline $\begin{array}{l}01 \\
02\end{array}$ & -7 & -7 & & -7 & -7 & 7.5 & 7. & & -4 & -4 & $\begin{array}{l}-4 \\
-1\end{array}$ & 4.5 & -4 & -1 & -1 & -1 & -1 & -1 & -1 & -1 & -1 & -1 & -1 & -1 & -1 & -1 & 1.5 & -1 & -1 & $\begin{array}{l}-1 \\
0.5\end{array}$ & & 2 & -1 & -1 & -1 & -2 \\
\hline 03 & & & & & & -1 & & & & & & & & & & & & & & & & & -1 & & & & & & & & & & & & & \\
\hline 04 & & & & & 1 & & & & 1 & & & & & & & & & & & & & & & & & & & -1 & & & & & & & & \\
\hline 05 & -2 & -2 & -2 & -2 & -2 & -2 & $=$ & & -2 & 2 & -2 & -2 & -2 & -2 & -2 & -2 & -2 & -2 & -2 & -2 & -2 & -2 & -2 & -2 & -2 & -2 & -2 & -2 & -2 & 1.5 & 1. & 5 & .5 & 1.5 & 1.5 & 1.5 \\
\hline De & & & & & & & & & & & & & & & & & & & & & & & & & & & & & & & & & & & & \\
\hline \multicolumn{37}{|c|}{ Secession risk \& Infrastructural Capacity } \\
\hline SR1 & 3.5 & 3.5 & & 3.5 & 3.5 & 3.8 & 3.8 & & 2 & 2 & 2 & 2.3 & 2 & 0.5 & 0.5 & 0.5 & 0.5 & 0.5 & 0.5 & 0.5 & 0.5 & 0.5 & 0.5 & 0.5 & 0.5 & 0.5 & 0.8 & 0.5 & 0.5 & 0.5 & & 1 & .5 & 0.5 & 0.5 & 1 \\
\hline SR2 & 1 & 1 & & 1 & 1 & 1 & & & 1 & 1 & 1 & 1 & 1 & 1 & 1 & 1 & 1 & 1 & 1 & 1 & 1 & 1 & 1 & 1 & 1 & 1 & 1 & 1 & 1 & 1 & & 1 & 1 & 1 & 1 & 1 \\
\hline SR3 & 2 & 2 & 2 & 2 & 2 & 1 & & & 1 & 1 & 1 & 1 & 1 & 1 & 1 & 1 & 1 & 1 & 1 & 1 & 1 & 1 & 1 & 1 & 1 & 1 & 1 & 1 & 1 & 。 & & 0 & 0 & 0 & 0 & 0 \\
\hline subt & & & & & & & & & & & & & & & & & & & & & & & & & & & & & & & & & & & & \\
\hline IC & 6.5 & 6.5 & 6.5 & 6.5 & $\begin{array}{l}6.5 \\
4.5\end{array}$ & $\begin{array}{l}.58 \\
4.5\end{array}$ & $\begin{array}{l}5.8 \\
3.5\end{array}$ & & .5 & $\begin{array}{r}4.5 \\
3\end{array}$ & $\begin{array}{r}4.5 \\
3.5 \\
\end{array}$ & $\begin{array}{l}4.3 \\
3.5 \\
\end{array}$ & 3.5 & $\begin{array}{l}2.5 \\
3.5 \\
\end{array}$ & $\begin{array}{l}2.5 \\
3.5 \\
\end{array}$ & $\begin{array}{l}2.5 \\
3.5 \\
\end{array}$ & $\begin{array}{l}2.5 \\
3.5 \\
\end{array}$ & $\begin{array}{l}2.5 \\
3.5 \\
\end{array}$ & $\begin{array}{l}2.5 \\
3.5\end{array}$ & $\begin{array}{l}2.5 \\
3.5\end{array}$ & $\begin{array}{l}2.5 \\
3.5\end{array}$ & $\begin{array}{l}2.5 \\
3.5\end{array}$ & $\begin{array}{l}2.5 \\
3.5 \\
3.5\end{array}$ & $\begin{array}{l}2.5 \\
3.5\end{array}$ & $\begin{array}{l}2.5 \\
3.5\end{array}$ & $\begin{array}{l}2.5 \\
3.5\end{array}$ & $\begin{array}{l}2.8 \\
3.5\end{array}$ & $\begin{array}{r}2.5 \\
4 \\
\end{array}$ & 2.5 & 1.5 & & & 5 & $\begin{array}{r}1.5 \\
5\end{array}$ & $\begin{array}{l}1.5 \\
5\end{array}$ & \\
\hline \multirow{2}{*}{\multicolumn{37}{|c|}{ Deliberative conditions }} \\
\hline DC1 & & & & & & & & & & & & & & & & & & & & & & & & & & & & 1 & & & & & & & & \\
\hline DC2 & & & & & & & & & & & & & & & & & & & & & & & & & & & & 0 & & & & & & & & \\
\hline DC3 & & & & & & & & & & & & & & & & & & & & & & & & & & & & 1 & & & & & & & & \\
\hline DC4 & & & & & & & & & & & & & & & & & & & & & & & & & & & & 1 & & & & & & & & \\
\hline DC5 & & & & & & & & & & & & & & & & & & & & & & & & & & & & 0 & & & & & & & & \\
\hline & & & & & & & & & & & & & & & & & & & & & & & & & & & & & & & & & & & & \\
\hline
\end{tabular}


A2.5 Sri Lanka data 
Table A22: Sri Lanka constitutions

\begin{tabular}{|c|c|c|c|c|c|c|c|c|c|c|}
\hline Measure & Baseline (1931) & $\mathrm{s}$ & 1948 & $\mathrm{~s}$ & 1972 & $\mathrm{~s}$ & 1978 & $\mathrm{~s}$ & 1987 Amendments & $\mathrm{s}$ \\
\hline $\begin{array}{l}\text { F1 - Extent of } \\
\text { central authority }\end{array}$ & Colonial & -4 & $\begin{array}{l}\text { A4 - Governor-General has any } \\
\text { powers etc. as UK wishes to } \\
\text { ascribe, but still subject to } \\
\text { constitution }\end{array}$ & -4 & $\begin{array}{l}\text { A2 - "Sri Lanka is a unitary } \\
\text { state" }\end{array}$ & -4 & $\begin{array}{l}\text { A2 - "Sri Lanka is a unitary } \\
\text { state" }\end{array}$ & -4 & $\begin{array}{l}\text { A154B(2) - Provincial } \\
\text { Governors appointed by } \\
\text { President, (but should act } \\
\text { on advice of Chief Minister } \\
\text { (154B(8)(d)); A154J - pre- } \\
\text { emptive emergency } \\
\text { intervention powers; \& } \\
154 N \text { if center considers } \\
\text { that province can't govern; } \\
\text { 154M - powers of } \\
\text { Provincial Council from \& } \\
\text { subject to Parliament, } \\
\text { which can amend with 2/3 } \\
\text { majority; Governor must } \\
\text { approve legislation, has } \\
\text { financial roles, may } \\
\text { dissolve Councils; } \\
\text { President may issue } \\
\text { directives \& confer powers } \\
\text { on center }\end{array}$ & -3 \\
\hline $\begin{array}{l}\text { F2 - Scope of } \\
\text { unit's autonomy }\end{array}$ & $\begin{array}{l}\mathrm{n} / \mathrm{a} \text { - note some } \\
\text { provincial structure } \\
\text { existed but was of little } \\
\text { practical consequence }\end{array}$ & 0 & $\begin{array}{l}\text { Provinces are mentioned in A41 } \\
\text { but not empowered }\end{array}$ & 1 & $\begin{array}{l}\text { Provinces mentioned in } \\
\text { A78(2), but only incidently }\end{array}$ & 1 & $\begin{array}{l}\text { A5 / Sch } 2 \text { sets out } \\
\text { administrative districts }\end{array}$ & 1 & $\begin{array}{l}\text { A154P - Provincial judicial } \\
\text { system; Sch } 8 \text { - List of } \\
\text { powers, including } \\
\text { concurrent. List includes } \\
\text { police, education, land, } \\
\text { health, taxes but not key } \\
\text { natural resources, nor a } \\
\text { provincial public service }\end{array}$ & 4 \\
\hline $\begin{array}{l}\text { F3- } \\
\text { Constitutionalism }\end{array}$ & Subject to British & 0 & $\begin{array}{l}\text { Judiciary subject to confidence of } \\
\text { legislature; A52(2) - } \\
\text { Constitutional change processes } \\
\text { not explicit }\end{array}$ & 0 & $\begin{array}{l}\text { A44 - National Assembly } \\
\text { can amend or replace } \\
\text { constitution with } 2 / 3 \\
\text { majority; Judiciary } \\
\text { interprets constitution but } \\
\text { subordinate to legislature }\end{array}$ & 1 & $\begin{array}{l}\text { A118 - Supreme Court has } \\
\text { jurisdication over } \\
\text { constitutional matters; Ch } \\
12 \& 13 \text { provide general } \\
\text { amendment procedures, } \\
\text { with a referendum for certain }\end{array}$ & 1 & $\begin{array}{l}\text { Adds A154A(3) - enables } \\
\text { merging/co-administration } \\
\text { of provinces; Center } \\
\text { retains rights to direct, } \\
\text { overrule etc. in lieu of } \\
\text { dispute resolution }\end{array}$ & 1 \\
\hline
\end{tabular}




\begin{tabular}{|c|c|c|c|c|c|c|c|c|c|c|}
\hline Measure & Baseline (1931) & $\mathrm{s}$ & 1948 & $\mathrm{~S}$ & 1972 & $\mathrm{~s}$ & 1978 & $\mathrm{~s}$ & 1987 Amendments & S \\
\hline & & & & & & & $\begin{array}{l}\text { changes; Judiciary } \\
\text { subordinate to legislature; } \\
\text { A84 provides for a } \\
\text { constitutional process to } \\
\text { enact unconstitutional laws; } \\
\text { A16 protects pre-existing } \\
\text { unconstitutional laws; A80(3) } \\
\text { prevents people challenging } \\
\text { laws on basis of inconsistency }\end{array}$ & & & \\
\hline F4 - Bicameralism & $\mathrm{n} / \mathrm{a}$ & 0 & $\begin{array}{l}\text { Yes, but not representative of } \\
\text { units (Part III) }\end{array}$ & 1 & Nil & & Nil & & Nil & 0 \\
\hline $\begin{array}{l}\text { C1 } \text { - Legislative } \\
\text { executive } \\
\text { relations }\end{array}$ & Parliamentary & 2 & Parliamentary & 2 & $\begin{array}{l}\text { Presidential hybrid } \\
\text { (Cabinet appointed from } \\
\text { within legislature) }\end{array}$ & 1.5 & $\begin{array}{l}\text { Presidential hybrid (Cabinet } \\
\text { appointed from within } \\
\text { legislature) }\end{array}$ & 1.5 & As per 1978 & 1.5 \\
\hline $\begin{array}{l}\text { E1 - Basis of units } \\
\text { (identity / } \\
\text { territory) }\end{array}$ & $n / a$ & 0 & $\begin{array}{l}\text { Units include Northern and } \\
\text { Eastern provinces dilineated to } \\
\text { account for Tamil identity (see } \\
\text { A41(2)) }\end{array}$ & 2 & As per 1948 & 2 & As per 1948 & 2 & As per 1948 & 2 \\
\hline $\begin{array}{l}\text { E2 - Sub-units } \\
\text { (autonomous } \\
\text { zones) }\end{array}$ & $\mathrm{n} / \mathrm{a}$ & 0 & $\mathrm{n} / \mathrm{a}$ & 0 & $n / a$ & 0 & $n / a$ & 0 & $n / a$ & 0 \\
\hline $\begin{array}{l}\text { E3 - Local } \\
\text { government (no. } \\
\text { of levels) }\end{array}$ & $n / a$ & 0 & $n / a$ & 0 & $\begin{array}{l}\text { Numerous mentions of } \\
\text { Local Authorities, no fixing } \\
\text { of units or powers }\end{array}$ & 0 & $\begin{array}{l}\text { Numerous mentions of Local } \\
\text { Authorities, no fixing of units } \\
\text { or powers }\end{array}$ & 0 & $\begin{array}{l}\text { Local Authorities numerous } \\
\text { mentions and subordinate } \\
\text { to Provincial Councils }\end{array}$ & 0 \\
\hline $\begin{array}{l}\text { E4 - Degree of } \\
\text { asymmetry }\end{array}$ & $\mathrm{n} / \mathrm{a}$ & 0 & $\begin{array}{l}\text { see A11 \& A41 (discussed under } \\
\text { representation) }\end{array}$ & 0 & $\begin{array}{l}\text { A78(4) - some groups have } \\
\text { special representation and } \\
\text { state acknowledges group } \\
\text { rights (A16(2)) and has a } \\
\text { duty to assist development } \\
\text { of languages and cultures } \\
\text { (A16(7)) }\end{array}$ & 0 & n/a & 0 & $\mathrm{Nil}$ & 0 \\
\hline $\begin{array}{l}\mathrm{C} 2 \text { - Inclusivity } \\
\text { and } \\
\text { proportionality }\end{array}$ & $\begin{array}{l}\text { Proportional } \\
\text { representation used in } \\
\text { communal based }\end{array}$ & 2 & $\begin{array}{l}\text { A8-9 - Lower house is 50/50 } \\
\text { FPTP/Appointed, Senate fully PR; } \\
\text { (by amendment in 1954); A11 - }\end{array}$ & 3 & $\begin{array}{l}\text { A78(4): enables an } \\
\text { electoral district to be } \\
\text { delineated so as to give a }\end{array}$ & 0 & $\begin{array}{l}\text { PR voting system (but } \\
\text { threshold at } 12 \% \text { ) }\end{array}$ & 1 & PR voting system continues & 1 \\
\hline
\end{tabular}




\begin{tabular}{|c|c|c|c|c|c|c|c|c|c|c|}
\hline Measure & Baseline (1931) & $\mathrm{s}$ & 1948 & $\mathrm{~s}$ & 1972 & $\mathrm{~s}$ & 1978 & $\mathrm{~s}$ & 1987 Amendments & $\mathrm{s}$ \\
\hline & $\begin{array}{l}\text { representation prior to } \\
1931 \text { and then de-facto } \\
\text { during immediate pre- } \\
\text { independence period }\end{array}$ & & $\begin{array}{l}\text { establishes separate Indian } \\
\text { [Plantation Tamil] and Pakistani } \\
\text { [Muslim] electorates for upper } \\
\text { house. Electoral boundaries } \\
\text { otherwise would ensure Tamil } \\
\text { representation, and number such } \\
\text { that in theory, constitutional } \\
\text { change would not occur without } \\
\text { Sinhala and Tamil agreement; } \\
\text { S41(4) - division of electoral } \\
\text { districts to account for any } \\
\text { communities and diversity }\end{array}$ & & $\begin{array}{l}\text { particular and different } \\
\text { (identity-based) } \\
\text { community a } \\
\text { representative in } \\
\text { Parliament, but still all } \\
\text { FPTP - hence score } \\
\text { negated }\end{array}$ & & & & & \\
\hline $\begin{array}{l}\text { C3 - Extent of } \\
\text { cultural rights and } \\
\text { freedoms }\end{array}$ & $\begin{array}{l}\text { Personal laws, and use of } \\
\text { local languages enabled } \\
\text { by the British during } \\
\text { colonial period }\end{array}$ & 1 & $\begin{array}{l}\text { A29 - religious and other } \\
\text { freedoms guaranteed }\end{array}$ & 0 & $\begin{array}{l}\text { A9, A11 provide for use of } \\
\text { Tamil in official matters; } \\
\text { A18 - fundamental right } \\
\text { and individual protections } \\
\text { standard, but former A29 } \\
\text { removed }\end{array}$ & 0 & $\begin{array}{l}\text { Ch } 4 \text { provides for Sinhala as } \\
\text { official language \& Tamil as a } \\
\text { national; Ch } 3 \text { - standard } \\
\text { protections of individual } \\
\text { rights; A27(5)(6) protect } \\
\text { against discrimination and } \\
\text { provide for equality }\end{array}$ & 1 & $\begin{array}{l}\text { A2/18 - Tamil also an } \\
\text { official language, but } \\
\text { preferencing of Sinhala in } \\
\text { formal institutions } \\
\text { continues }\end{array}$ & 1 \\
\hline $\begin{array}{l}\text { C4 - Assimilating } \\
\text { aspects }\end{array}$ & $n / a$ & 0 & $\mathrm{n} / \mathrm{a}$ & 0 & $\begin{array}{l}\text { A6 - Buddhism given } \\
\text { 'foremost place' and "duty } \\
\text { of the state to protect and } \\
\text { foster"; A7 - Sinhala as the } \\
\text { national language }\end{array}$ & -2 & $\begin{array}{l}\text { A6 - Buddhism given } \\
\text { 'foremost place' and "duty of } \\
\text { the state to protect and } \\
\text { foster" }\end{array}$ & -2 & As per 1978 & -2 \\
\hline TOTAL & & 1 & 0 & 5 & 0 & $\begin{array}{r}- \\
0.5\end{array}$ & 0 & 1.5 & 0 & 5.5 \\
\hline
\end{tabular}

Sources: (Constitution of the Republic of Sri Lanka (Ceylon) 1972; The Constitution of the Democratic Socialist Republic of Sri Lanka 1978; Thirteenth Amendment to the Constitution of the Republic of Sri Lanka 1987; Special Commission on the Ceylon Constitution 2008 [1928]; Ceylon Constitution Order in Council 1946; Ceylon Independence Act 1947) 
Table A23: Sri Lanka elections and party proportionality (1947-2016)

\begin{tabular}{|c|c|c|c|c|c|c|c|c|c|c|c|c|c|c|c|c|}
\hline & ELECTIONS & 1947 & & & & & 1952 & & & & & 1960 & & & & \\
\hline Designation & PARTIES & Votes & $\begin{array}{r}\text { Vote } \\
\text { s\% } \\
\end{array}$ & Seats & $\begin{array}{r}\text { Seats } \\
\% \\
\end{array}$ & $\begin{array}{r}\text { Deviati } \\
\text { on }^{2}\end{array}$ & Votes & $\begin{array}{r}\text { Votes } \\
\% \\
\end{array}$ & Seats & $\begin{array}{r}\text { Seats } \\
\% \\
\end{array}$ & $\begin{array}{r}\text { Deviati } \\
\text { on }^{2}\end{array}$ & Votes & $\begin{array}{r}\text { Votes } \\
\% \\
\end{array}$ & Seats & $\begin{array}{r}\text { Seats } \\
\% \\
\end{array}$ & $\begin{array}{r}\text { Deviati } \\
\text { on }^{2}\end{array}$ \\
\hline Sinhala & $\begin{array}{l}\text { UNP/UNF/UNF } \\
\text { GG }\end{array}$ & 751,432 & 39.8 & 42 & 44.2 & 19.36 & $1,026,005$ & 44.1 & 54 & 56.8 & 161.29 & $1,144,166$ & 37.6 & 30 & 19.9 & 313.29 \\
\hline Sinhala & LLSP/USA & 204,020 & 10.8 & 10 & 10.5 & 0.09 & 305,133 & 13.1 & 9 & 9.5 & & 224,995 & 7.4 & 12 & 7.9 & \\
\hline Sinhala & BLP & 113,193 & 6 & 5 & 5.3 & 0.49 & - & - & & & & & & & & \\
\hline Sinhala & CP / VLSSP & 70,331 & 3.7 & 3 & 3.2 & 0.25 & 134,528 & 5.8 & 4 & 4.2 & 2.56 & 90,219 & 3 & 4 & 2.6 & 0.16 \\
\hline Sinhala & Labor Party & 38,932 & 2.1 & 1 & 1.1 & 1.00 & 27,096 & 1.2 & 1 & 1.1 & 0.01 & & & & & \\
\hline Tamil & Tamil Congress & 82,499 & 4.4 & 7 & 7.4 & 9.00 & 64,512 & 2.8 & 4 & 4.2 & 1.96 & & 1.5 & 1 & 0.7 & \\
\hline UC Tamil & $\mathrm{ClC}$ & 72,230 & 3.8 & 6 & 6.3 & 6.25 & & & & & & & & & & \\
\hline Sinhala & SLFP/PA/UPFA & & & & & & 361,250 & 15.5 & 9 & 9.5 & 36.00 & $1,022,171$ & 33.6 & 75 & 49.7 & 259.21 \\
\hline Tamil & FP/ITAK/TNA & & & & & & 45,331 & 1.9 & 2 & 2.1 & 0.04 & 213,733 & 7 & 16 & 10.6 & 12.96 \\
\hline Sinhala & MEP & & & & & & & & - & - & & 106,816 & 3.5 & 3 & 2 & 2.25 \\
\hline Muslim & SLMC & & & & & & & & & & & & & & & \\
\hline Tamil & $\begin{array}{l}\text { TULF } \\
\text { USA }\end{array}$ & & & & & & & & & & & & & & & \\
\hline Sinhala & JVP & & & & & & & & & & & & & & & \\
\hline & NUA & & & & & & & & & & & & & & & \\
\hline UC Tamil & CWC & & & & & & & & & & & & & & & \\
\hline Tamil & TELO & & & & & & & & & & & & & & & \\
\hline Tamil & EPDP & & & & & & & & & & & & & & & \\
\hline Sinhala & SU & & & & & & & & & & & & & & & \\
\hline UC Tamil & SCTC & & & & & & & & & & & & & & & \\
\hline TOTALS & & & & 74 & & & & & 83 & & & & & 141 & & \\
\hline \multicolumn{2}{|c|}{ Average deviation from 1 squared } & & & & & 5.2 & & & & & 33.6 & & & & & 117.7 \\
\hline \multirow{2}{*}{\multicolumn{2}{|c|}{$\begin{array}{l}\text { Gallagher index (GI) } \\
\text { (Disproportionality) }\end{array}$}} & & & & & & & & & & & & & & & \\
\hline & & & & & & 4.3 & & & & & 10.0 & & & & & 17.1 \\
\hline \multicolumn{2}{|c|}{ SCORE (10/GI) (Proportionality) } & & & & & 2.3 & & & & & 1.0 & & & & & 0.58 \\
\hline \multicolumn{2}{|c|}{ SCORE (10/GI) - adjusted } & & & & & 2.3 & & & & & -1.3 & & & & & -0.4 \\
\hline
\end{tabular}




\begin{tabular}{|c|c|c|c|c|c|c|c|c|c|c|c|c|c|c|c|c|}
\hline & ELECTIONS & 1970 & & & & & 1977 & & & & & 1989 & & & & \\
\hline Designation & PARTIES & Votes & $\begin{array}{r}\text { Vote } \\
\text { s\% } \\
\end{array}$ & Seats & $\begin{array}{r}\text { Seats } \\
\%\end{array}$ & $\begin{array}{r}\text { Deviati } \\
\text { on }^{2} \\
\end{array}$ & Votes & $\begin{array}{r}\text { Votes } \\
\% \\
\end{array}$ & Seats & $\begin{array}{r}\text { Seats } \\
\%\end{array}$ & $\begin{array}{r}\text { Deviati } \\
\text { on }^{2} \\
\end{array}$ & Votes & $\begin{array}{r}\text { Votes } \\
\% \\
\end{array}$ & Seats & $\begin{array}{r}\text { Seats } \\
\%\end{array}$ & $\begin{array}{r}\text { Deviati } \\
\text { on }^{2} \\
\end{array}$ \\
\hline Sinhala & $\begin{array}{l}\text { UNP/UNF/UNFG } \\
\text { G }\end{array}$ & $1,892,525$ & 37.9 & 17 & 11.3 & 707.56 & $3,179,221$ & 50.9 & 140 & 83.3 & 1049.76 & $2,838,005$ & 50.7 & 125 & 55.6 & 24.01 \\
\hline $\begin{array}{l}\text { Sinhala } \\
\text { Sinhala }\end{array}$ & $\begin{array}{l}\text { LLSP/USA } \\
\text { BLP }\end{array}$ & 433,224 & 8.7 & 19 & 12.6 & 15.21 & 225,317 & 3.6 & & & & $2,000,005$ & . & 125 & 年 & t. \\
\hline Sinhala & $\mathrm{CP} / \mathrm{VLSSP}$ & 169,199 & 3.4 & 6 & 4 & 0.36 & 123,856 & 2.0 & & & & & & & & \\
\hline Sinhala & Labor Party & & & & & & & & & & & & & & & \\
\hline $\begin{array}{l}\text { Tamil } \\
\text { UC Tamil }\end{array}$ & $\begin{array}{l}\text { Tamil Congress } \\
\mathrm{ClC}\end{array}$ & 115,567 & 2.3 & 3 & 2 & 0.09 & & & & & & & & & & \\
\hline Sinhala & SLFP/PA/UPFA & $1,839,979$ & 36.9 & 91 & 60.3 & 547.56 & $1,855,331$ & 29.7 & 8 & 4.8 & 620.01 & $1,785,369$ & 31.9 & $67 \%$ & 29.9 & 4.00 \\
\hline Tamil & FP/ITAK/TNA & 245,727 & 4.9 & 13 & 8.6 & 13.69 & & & & & & & & & & \\
\hline Sinhala & MEP & & & & & & & & & & & & 3 & 3 & 1.3 & 2.89 \\
\hline Muslim & SLMC & & & & & & & & & & & & & 4 & 1.8 & \\
\hline Tamil & TULF & & & & & & 421,488 & 6.8 & 18 & 10.7 & 15.21 & 202,016 & 3.6 & 10 & 4.4 & 0.64 \\
\hline & USA & & & & & & & & & & & $\begin{array}{l}188,594 \\
160271\end{array}$ & 3.4 & 3 & 1.3 & 4.41 \\
\hline Sinhala & $\begin{array}{l}\text { JVP } \\
\text { NUA }\end{array}$ & & & & & & & & & & & 160,271 & 2.9 & - & & \\
\hline UC Tamil & CWC & & & & & & & & 1 & 0.6 & & & & & & \\
\hline Tamil & TELO & & & & & & & & & & & & & & & \\
\hline Tamil & EPDP & & & & & & & & & & & & & & & \\
\hline Sinhala & SU & & & & & & & & & & & & & & & \\
\hline UC Tamil & SCTC & & & & & & & & & & & & & & & \\
\hline TOTALS & & & & 149 & & & 21045198 & & 167 & & & & & & & \\
\hline \multicolumn{2}{|c|}{ Average deviation from 1 squared } & & & & & 214.1 & & & & & 561.66 & & & & & 7.2 \\
\hline \multicolumn{2}{|c|}{$\begin{array}{l}\text { Gallagher index (GI) } \\
\text { (Disproportionality) }\end{array}$} & & & & & 25.3 & & & & & 29.0 & & & & & 4.2 \\
\hline \multirow{2}{*}{\multicolumn{2}{|c|}{ SCORE (10/GI) (Proportionality) }} & & & & & 0.4 & & & & & 0.3 & & & & & 2.4 \\
\hline & & & & & & -0.2 & & & & & -0.1 & & & & & 2.0 \\
\hline
\end{tabular}




\begin{tabular}{|c|c|c|c|c|c|c|c|c|c|c|c|c|c|c|c|c|}
\hline & ELECTIONS & 2000 & & & & & 2010 & & & & & 2015 & & & & \\
\hline Designation & PARTIES & Votes & $\begin{array}{r}\text { Vote } \\
\text { s\% }\end{array}$ & Seats & $\begin{array}{r}\text { Seats } \\
\% \\
\end{array}$ & $\begin{array}{r}\text { Deviati } \\
\text { on }^{2}\end{array}$ & Votes & $\begin{array}{r}\text { Votes } \\
\% \\
\end{array}$ & Seats & $\begin{array}{r}\text { Seats } \\
\% \\
\end{array}$ & $\begin{array}{r}\text { Deviati } \\
\text { on }^{2}\end{array}$ & Votes & $\begin{array}{r}\text { Votes } \\
\% \\
\end{array}$ & Seats & $\begin{array}{r}\text { Seats } \\
\% \\
\end{array}$ & $\begin{array}{r}\text { Deviati } \\
\text { on }^{2} \\
\end{array}$ \\
\hline $\begin{array}{l}\text { Sinhala } \\
\text { Sinhala } \\
\text { Sinhala } \\
\text { Sinhala } \\
\text { Sinhala } \\
\text { Tamil } \\
\text { UC Tamil }\end{array}$ & $\begin{array}{l}\text { UNP/UNF/UNFG } \\
\text { G } \\
\text { LLSP/USA } \\
\text { BLP } \\
\text { CP / VLSSP } \\
\text { Labor Party } \\
\text { Tamil Congress } \\
\text { CIC }\end{array}$ & $3,477,770$ & 40.2 & 89 & 39.6 & 0.36 & $2,357,057$ & 29.34 & 60 & 26.67 & 7.15 & $5,098,916$ & 45.66 & 106 & 47.11 & 2.11 \\
\hline Sinhala & SLFP/PA/UPFA & $3,900,901$ & 45.1 & 107 & 47.6 & 6.25 & $4,848,388$ & 60.33 & 144 & 64.00 & 13.47 & $4,732,664$ & 42.38 & 95 & 42.22 & 0.02 \\
\hline $\begin{array}{l}\text { Tamil } \\
\text { Sinhala }\end{array}$ & $\begin{array}{l}\text { FP/ITAK/TNA } \\
\text { MEP }\end{array}$ & & & & & & 233,190 & 2.9 & 14 & 6.22 & 11.04 & 515,963 & 4.62 & 16 & 7.11 & 6.21 \\
\hline $\begin{array}{l}\text { Muslim } \\
\text { Tamil }\end{array}$ & $\begin{array}{l}\text { SLMC } \\
\text { TULF } \\
\text { USA }\end{array}$ & 106,033 & 1.2 & 5 & 2.2 & & & & & & & 44,193 & 0.4 & 1 & 0.44 & 0.00 \\
\hline Sinhala & JVP & 518,774 & 6 & 10 & 4.4 & 2.56 & 441,251 & 5.49 & 7 & 3.11 & 5.66 & 543,944 & 4.87 & 6 & 2.67 & 4.85 \\
\hline UC Tamil & $\begin{array}{l}\text { NUA } \\
\text { CWC }\end{array}$ & 197,983 & 2.3 & 4 & 1.8 & 0.25 & & & & & & & & & & \\
\hline $\begin{array}{l}\text { Tamil } \\
\text { Tamil }\end{array}$ & $\begin{array}{l}\text { TELO } \\
\text { EPDP }\end{array}$ & & & $\begin{array}{l}3 \\
4\end{array}$ & $\begin{array}{l}1.3 \\
1.8\end{array}$ & & & & & & & 33,481 & 0.3 & 1 & 0.44 & 0.02 \\
\hline Sinhala & SU & & & 1 & & & & & & & & & & & & \\
\hline $\begin{array}{l}\text { UC Tamil } \\
\text { TOTALS }\end{array}$ & SCTC & & & 1 & & & & & & & & & & & & \\
\hline \multicolumn{2}{|c|}{ Average deviation from 1 squared } & & & & & 2.36 & & & & & 9.33 & & & & & 2.2 \\
\hline \multicolumn{2}{|c|}{$\begin{array}{l}\text { Gallagher index (GI) } \\
\text { (Disproportionality) }\end{array}$} & & & & & 2.2 & & & & & 4.3 & & & & & 2.6 \\
\hline \multicolumn{2}{|c|}{ SCORE (10/GI) (Proportionality) } & & & & & 4.6 & & & & & 2.3 & & & & & 3.9 \\
\hline \multicolumn{2}{|c|}{ SCORE (10/GI) - adjusted } & & & & & 2.2 & & & & & -2.3 & & & & & 1.6 \\
\hline
\end{tabular}

*UC= Upcountry

Sources: (Nohlen, Grotz \& Hartmann 2001a; Department of Elections 2016) 
Table A24: Sri Lanka legislature ethnic proportionality (2000-2015)

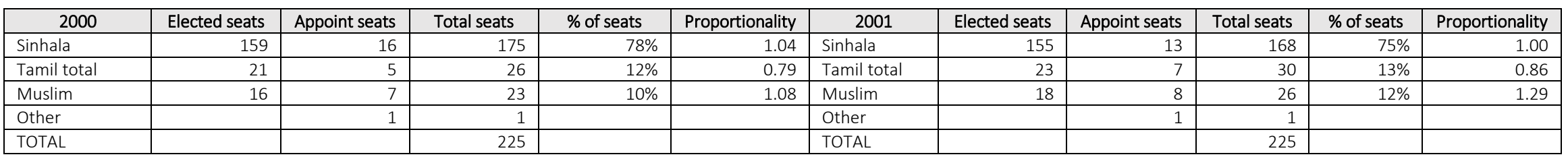

\begin{tabular}{|c|c|c|c|c|c|c|c|c|c|c|c|}
\hline 2004 & Elected seats & Appoint seats & Total seats & $\%$ of seats & Proportionality & 2010 & Elected seats & Appoint seats & Total seats & $\%$ of seats & Proportionality \\
\hline Sinhala & 152 & 14 & 166 & $74 \%$ & 0.99 & Sinhala & 159 & 21 & 180 & $80 \%$ & 1.07 \\
\hline Tamil total & 29 & 7 & 36 & $16 \%$ & 1.05 & Tamil total & 22 & 5 & 27 & $12 \%$ & 0.79 \\
\hline Muslim & 15 & 7 & 22 & $10 \%$ & 1.08 & Muslim & 15 & 3 & 18 & $8 \%$ & 0.86 \\
\hline Other & & 1 & 1 & & & Other & & & & & \\
\hline
\end{tabular}

\begin{tabular}{|l|r|r|r|r|r|r|}
\hline \multicolumn{1}{|c|}{2015} & Elected seats & Appoint seats & Total seats & \% of seats & Proportionality & $\begin{array}{c}\text { Proport. of } \\
\text { population }\end{array}$ \\
\hline Sinhala & 153 & 20 & 173 & $77 \%$ & 1.03 & 74.9 \\
\hline Tamil total* & 24 & 4 & 28 & $12 \%$ & 0.79 & 15.2 \\
\hline Muslim & 17 & 5 & 22 & $10 \%$ & 1.08 & 9.3 \\
\hline UC Tamil & 6 & 0 & 6 & $3 \%$ & 0.73 & 4.1 \\
\hline Other & 1 & & 1 & & & \\
\hline TOTAL & 196 & 29 & 225 & & & \\
\hline
\end{tabular}

*includes Upcountry (UC) Tamils

Proportionality $>1=$ overrepresented

Sources: (The Parliament of Sri Lanka 2016; Jayakody 2015; Kalambi 2015; Kotelawala 2015) 
Table A25: Sri Lanka executives - parties and type

\begin{tabular}{|c|c|c|c|c|c|}
\hline Years & Prime Minister & Party(s) & No. of parties & Classification & Score \\
\hline 1947-52 (March) & DS Senanayake & United National Party (UNP), All Ceylon Tamil Congress & 2 & Minimum & 2 \\
\hline $1952-53$ (Sept) & Dudley Senanayake & UNP & 1 & Minimum & 0 \\
\hline 1953-1956 (April) & John Kotelawala & UNP & 1 & Minimum & 0 \\
\hline 1956-1959 (Sep) & SWRD Bandaranaike & Sri Lanka Freedom Party (SLFP), Sinhala Language Front, VLSSP (MEP coalition) & 3 & Minimum & 0 \\
\hline 1959-1960 & W Dahanyake & SLFP, SLF, VLSSP (MEP Coalition) & 3 & Minimum & 0 \\
\hline (Mar-July) 1960 & Dudley Senanayake & UNP, Federal Party & 2 & Re-election & \\
\hline 1960-1965 (Mar) & Sirimavo Bandranaike & SLFP & 1 & Minimum & 0 \\
\hline 1965-1970 (May) & Dudley Senanayake & UNP, ITAK, Tamil Congress, MEP, JVP, SLFSP) & 6 & Oversized & 3 \\
\hline 1970-1977 (July) & Sirimavo Bandranaike & United Front (UF), coalition of SLFP, LSSP and the Communist Party & 3 & Oversized & 3 \\
\hline 1977-1988 (Dec) & JR Jayawardene & UNP & 1 & Minimum & 0 \\
\hline 1988-1993 (May) & R Premadasa & UNP, Ceylon Worker Congress (CWC) & 2 & Oversized & 3 \\
\hline 1993-1994 (Nov) & DB Wijetunga & UNP, CWC & 2 & Oversized & 3 \\
\hline 1994-2005 (Nov) & Chandrika Kumaratunga & People's Alliance (SLFP, DVJP, LSSP, SLMP, EPDP, SLMC) (+1 other later) & 8 & Oversized & 3 \\
\hline 2005-2015 & M Rajapakse & United People's Freedom Alliance (SLFP + 8), SLMC, Jathika Hela Urumaya, EPDP & 12 & Minimum / Oversized & 2.5 \\
\hline 2015 - & MR Siresena & United National Front for Good Governance (UNP+11), SLFP, SLMC, ACMC, NFF, CWC & $17+$ & Oversized / consensus & 3.5 \\
\hline
\end{tabular}

Sources: (Malik et al. 2009, p. 336; Nohlen, Grotz \& Hartmann 2001a; Horowitz 2000 [1985], pp. 379-386) 
Table A26: Sri Lanka executive ethnic proportionality (August 2016)

\begin{tabular}{|c|c|c|}
\hline Name & Party & Ethnicity \\
\hline M Siresena & Sri Lanka Freedom Party (SLFP) & Sinhala \\
\hline Ranil Wickremesinghe & United National Party (UNP) & Sinhala \\
\hline Vajira Abeywardena & UNP & Sinhala \\
\hline John Amaratunga & UNP & Sinhala \\
\hline Mahinda Amaraweera & SLFP & Sinhala \\
\hline Sarath Amunugama & SLFP & Sinhala \\
\hline Thalatha Atukorale & UNP & Sinhala \\
\hline Rishad Bathiudeen & All Ceylon Makkal Congress & Muslim \\
\hline Ranjith Madduma Bandara & UNP & Sinhala \\
\hline Nimal Siripala de Silva & SLFP & Sinhala \\
\hline Palani Digambaran & National Union of Workers & UC Tamil \\
\hline Duminda Dissanayake & SLFP & Sinhala \\
\hline Navin Dissanayake & UNP & Sinhala \\
\hline S. B. Dissanayake & SLFP & Sinhala \\
\hline Harin Fernando & UNP & Sinhala \\
\hline Sarath Fonseka & Democratic Party & Sinhala \\
\hline Daya Gamage & UNP & Sinhala \\
\hline Mano Ganesan & Democratic People's Party & UC Tamil \\
\hline Rauff Hakeem & Sri Lankan Muslim Congress & Muslim \\
\hline M. H. A. Haleem & UNP & Muslim \\
\hline P. Harrison & UNP & Sinhala \\
\hline Kabir Hashim & UNP & Muslim \\
\hline Dayasiri Jayasekara & SLFP & Sinhala \\
\hline CB Jayasinghe & UNP & Sinhala \\
\hline Akila Viraj Kariyawasam & UNP & Sinhala \\
\hline Ravi Karunanayake & UNP & Sinhala \\
\hline Gayantha Karunatileka & UNP & Sinhala \\
\hline Lakshman Kiriella & UNP & Sinhala \\
\hline Faiszer Musthapha & SLFP & Muslim \\
\hline S. B. Nawinne & UNP & Sinhala \\
\hline Gamini Jayawickrama Perera & UNP & Sinhala \\
\hline Sajith Premadasa & UNP & Sinhala \\
\hline Susil Premajayantha & SLFP & Sinhala \\
\hline Wijeyadasa Rajapakshe & UNP & Sinhala \\
\hline Arjuna Ranatunga & Democratic National Movement & Sinhala \\
\hline Champika Ranawaka & Jathika Hela Uramaya & Sinhala \\
\hline Sagala Ratnayaka & UNP & Sinhala \\
\hline Mahinda Samarasinghe & SLFP & Sinhala \\
\hline Mangala Samaraweera & UNP & Sinhala \\
\hline Rajitha Senaratne & Democratic National Movement & Sinhala \\
\hline John Senewiratne & SLFP & Sinhala \\
\hline Ranjith Siyambalapitiya & SLFP & Sinhala \\
\hline Gamini Vijithamuni Soysa & SLFP & Sinhala \\
\hline D. M. Swaminathan & UNP & Tamil \\
\hline Chandima Weerakkody & SLFP & Sinhala \\
\hline Anura Priyadharshana Yapa & SLFP & Sinhala \\
\hline
\end{tabular}




\begin{tabular}{|l|r|r|r|}
\hline Per ethnicity & No. in Cabinet & \% of population & Proportionality \\
\hline Sinhala & 38 & 74.9 & 1.12 \\
Tamil & 1 & 11.1 & 0.18 \\
Muslim & 5 & 9.3 & 1.18 \\
Upcountry Tamil & 2 & 4.1 & 0.98 \\
Total & 46 & 100 & 1.00 \\
\hline
\end{tabular}

Sources: (The Parliament of Sri Lanka 2016; Office of the Cabinet of Ministers 2016)

Proportionality $>1=$ overrepresented 
Table A27: Sri Lanka event summary table (1945-2016)

\begin{tabular}{|c|c|}
\hline Year & Change / event \\
\hline 1945 & (Baseline - 1931 - the Donoughmore Constitution) \\
\hline 1946 & $\begin{array}{l}\text { Ceylon Constitution Order in Council (Soulbury Constitution) (scored at } 1947 \text { with independence } \\
\text { Act). Unitary, but continues colonial provincial boundaries (nine administrative units) }\end{array}$ \\
\hline 1947 & $\begin{array}{l}\text { Ceylon Independence Act, constitutional order comes into effect } \\
\text { Elections held for new independence parliament }\end{array}$ \\
\hline 1948 & $\begin{array}{l}\text { Ceylon Citizenship Act } 1948 \text { passed, disenfranchising to Upcountry Tamils (11-12\% of the } \\
\text { population) } \\
\text { Tamil Congress splits, Federal Party formed }\end{array}$ \\
\hline 1949 & Passage of Ceylon Parliamentary Elections Act 1949 (further disenfranchises Upcountry Tamils) \\
\hline 1951 & $\begin{array}{l}\text { Constitution amended to provide special seats in Parliament for Indian and Pakistani people (1st } \\
\text { Amendment) }\end{array}$ \\
\hline 1953 & First Sinhalese resettlement scheme commences in North and East \\
\hline 1956 & $\begin{array}{l}\text { Official Language Act and related legislation makes Sinhala the language of education } \\
\text { Tamils protest and anti-Tamil riots ensue }\end{array}$ \\
\hline 1957 & $\begin{array}{l}\text { Bandaranaike-Chelvanayakam Pact agrees to language reforms and establishment of regional } \\
\text { councils - not implemented (abrogated 1958) }\end{array}$ \\
\hline 1958 & $\begin{array}{l}\text { Tamil Language (Special Provisions) Act } 1958 \text { (but not properly implemented) } \\
\text { Further Tamil protests re language leads to further anti-Tamil riots } \\
\text { State of emergency declared, lasts less than one year }\end{array}$ \\
\hline 1959 & $\begin{array}{l}\text { President Bandarainake is assassinated by a Buddhist Monk, state of emergency declared, lasts less } \\
\text { than three months }\end{array}$ \\
\hline 1961 & $\begin{array}{l}\text { Official Language Act implemented, Federal Party protests in North and East, state of emergency } \\
\text { declared }\end{array}$ \\
\hline 1962 & Attempted military coup against government \\
\hline 1963 & State of emergency lifted \\
\hline 1964 & $\begin{array}{l}\text { Agreement with India gives a minority of Upcountry Tamils citizenship but majority returned to } \\
\text { India }\end{array}$ \\
\hline 1965 & $\begin{array}{l}\text { Senanayake-Chelvanayagam pact agrees to make Tamil a 'language of administration' and to } \\
\text { establish district councils - not implemented }\end{array}$ \\
\hline 1966 & $\begin{array}{l}\text { Tamil Language (Special Provision) Act } 1958 \text { implemented, though never fully } \\
\text { Indian / Pakistan communal seats in Senate provisions ceased (see } 1^{\text {st }} \text { Amendment) }\end{array}$ \\
\hline 1970 & $\begin{array}{l}\text { Ban on Tamil media } \\
\text { S Bandarainake commences economic reforms, including nationalisation of industries }\end{array}$ \\
\hline 1971 & $\begin{array}{l}\text { Higher education reforms make it more difficult for Tamils to enter university and civil service } \\
\text { Janathā Vimukthi Peramuṇa (JVP) insurgency begins, lasts three years }\end{array}$ \\
\hline 1972 & New republican constitution, changes name to Sri Lanka, unitary and democratic \\
\hline 1974 & $\begin{array}{l}\text { Agreement between India and Sri Lanka re citizenship for Upcountry Tamils (not scored) } \\
\text { Violence between police and Tamils in Jaffna (not scored) }\end{array}$ \\
\hline 1975 & Assassination of Jaffna mayor (not scored) \\
\hline 1976 & $\begin{array}{l}\text { Tamil United Liberation Front resolve to establish separate state (not scored) } \\
\text { Liberation Tigers of Tamil Eelam (LTTE) formed (not scored) }\end{array}$ \\
\hline 1977 & $\begin{array}{l}\text { State of emergency lifted and ban on JVP party removed } \\
\text { Free market reforms, sale of govt enterprises, creation of free-trade zone, deregulation; foreign } \\
\text { investment incentives (1977-79) } \\
\text { Calls for separate state for Tamils leads to anti-Tamil riots, which continue through } 1978\end{array}$ \\
\hline 1978 & New constitution, changes from Parliamentary to Presidential (hybrid) system \\
\hline 1979 & Prevention of Terrorism Act passed and used to target and exclude Tamils \\
\hline 1981 & $\begin{array}{l}\text { District Development Committees established (administrative roles only) } \\
\text { State deploys violence against Tamils in Jaffna. Shortlived state of emergency }\end{array}$ \\
\hline 1982 & $\begin{array}{l}\text { Referendum for continuation of government for additional term without election } \\
\text { Sri Lanka seeks to renege on remaining obligations under citizenship agreements with India (not } \\
\text { scored) }\end{array}$ \\
\hline 1983 & $\begin{array}{l}\text { Constitution amended to prohibit violation of territorial integrity with effect of disenfranchising } \\
\text { Tamils (and leaving them unrepresented until 1989) } \\
\text { 'Black July' LTTE launch ambush and deadly anti-Tamil riots follow. Start of full scale civil war. } \\
\text { (India actively support Tamil insurgents) } \\
\text { Nation-wide state of emergency }\end{array}$ \\
\hline
\end{tabular}




\begin{tabular}{|c|c|}
\hline Year & Change / event \\
\hline 1985 & Thimpu peace talks held between LTTE and state, no agreement \\
\hline 1987 & $\begin{array}{l}\text { Indo Lanka Accord and } 13^{\text {th }} \text { Amendment to the constitution creates quasi-federalism } \\
\text { Indian troops stationed in north of country and engage with LTTE }\end{array}$ \\
\hline 1988 & $\begin{array}{l}\text { 14th Amendment to the constitution lowers threshold for proportional representation system, and } \\
\text { bans advocacy of separatism, } 16^{\text {th }} \text { Amendment 'clarifies' language provisions } \\
\text { Northern and Eastern Provinces merged } \\
\text { Legislation empowers Governors to assume provincial financial responsibilities } \\
\text { Grant of Citizenship to Stateless Persons Act passed enabling Upcountry Tamils to apply for } \\
\text { citizenship }\end{array}$ \\
\hline 1989 & $\begin{array}{l}\text { 16th Amendment to the Constitution makes Tamil and Sinhala both official languages of } \\
\text { administration and legislation } \\
\text { Ceasefire between LTTE and Government, lasts until 1990, Indian troops depart, state of } \\
\text { emergency lifted }\end{array}$ \\
\hline 1990 & $\begin{array}{l}\text { Dissolution of North Eastern Provincial Council } \\
\text { Ceasefire broken, and tens of thousands of Muslims driven out of Northern Province }\end{array}$ \\
\hline 1991 & Law and order and land powers not devolved as per constitution (score negated) \\
\hline 1993 & President assassinated by LTTE (not scored) \\
\hline 1995 & $\begin{array}{l}\text { Government announces proposal to further devolve power to provinces (not scored) } \\
\text { Ceasefire agreed between Government and LTTE but lasting only from Jan to April } 1994\end{array}$ \\
\hline 1998 & State of emergency amidst intense fighting and terrorism activities \\
\hline 2001 & State of emergency lifted \\
\hline 2002 & Ceasefire between LTTE and Government with Norwegian mediation \\
\hline 2004 & Boxing Day Tsunami \\
\hline 2006 & $\begin{array}{l}\text { Supreme Court rules merger of Northern and Eastern Provinces (in 1988) to be unconstitutional } \\
\text { Ceasefire breaks down }\end{array}$ \\
\hline 2008 & $\begin{array}{l}\text { Elected councillors restored to Eastern Province } \\
\text { North Central and Sabaragamuwa Provincial Councils dissolved }\end{array}$ \\
\hline 2009 & $\begin{array}{l}\text { Government declares 'complete victory' over LTTE } \\
\text { Elected councillors restored to Northern Province }\end{array}$ \\
\hline 2010 & $18^{\text {th }}$ Amendment further empowers President \\
\hline 2013 & $\begin{array}{l}\text { Divi Neguma Act } 2013 \text { establishes central department with responsibilities that overlap the powers } \\
\text { of Provincial Councils }\end{array}$ \\
\hline 2015 & $\begin{array}{l}\text { Common presidential candidate Siresena adopted platform to abolish executive presidency, wins } \\
\text { election. Good governance coalition formed } \\
19^{\text {th }} \text { Amendment restores independence of judiciary }\end{array}$ \\
\hline 2016 & Parliament turned into a Constitutional Assembly to prepare a new constitution \\
\hline
\end{tabular}

Key sources: (Centre for Poverty Analysis 2016; DeVotta 2004; Wickramasinghe 2010; Malik et al. 2009; Oberst

1988; Uyangoda 2010a; Welikala 2004; Edrisinha et al. 2008b) 
Table A28: Sri Lanka summary (1945-2016)

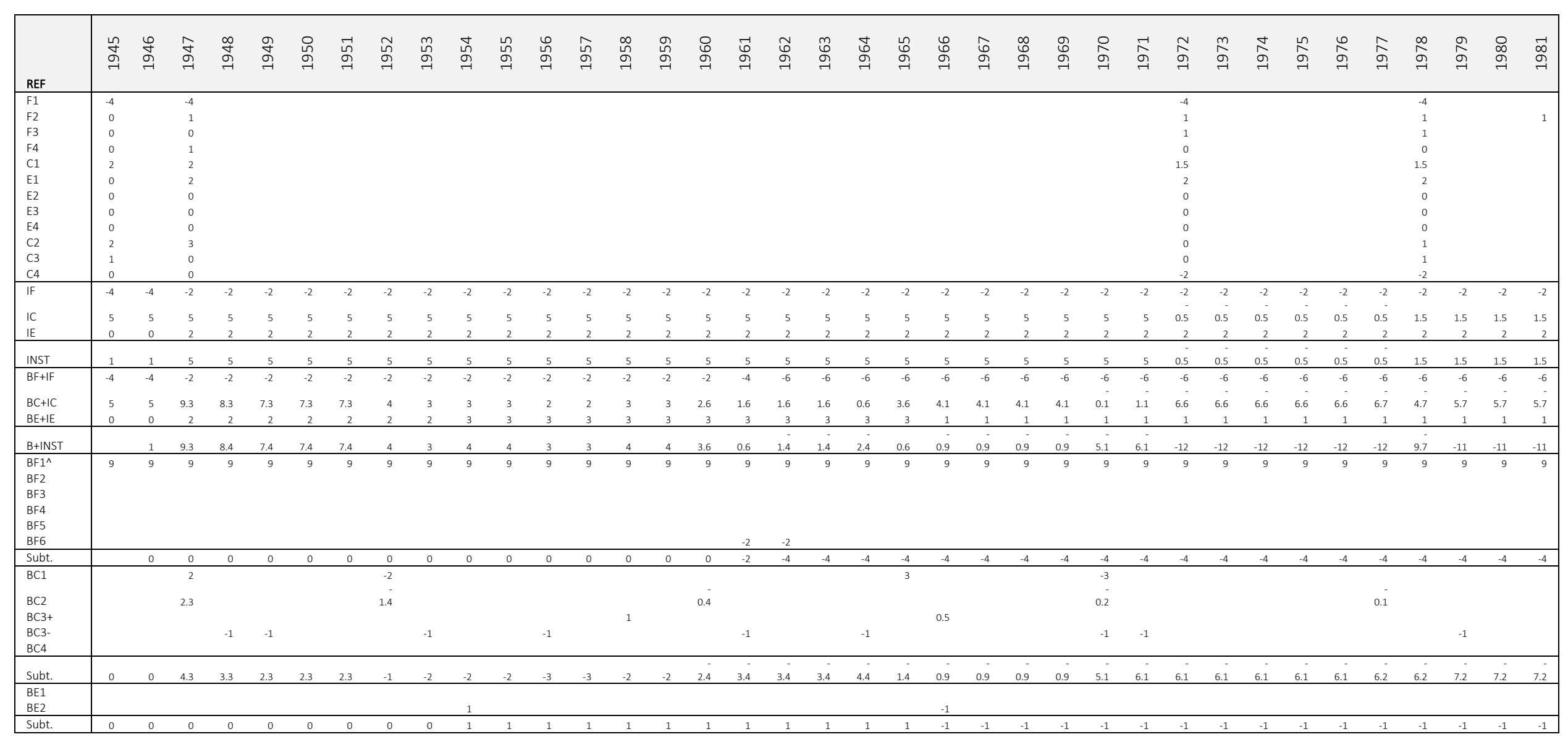




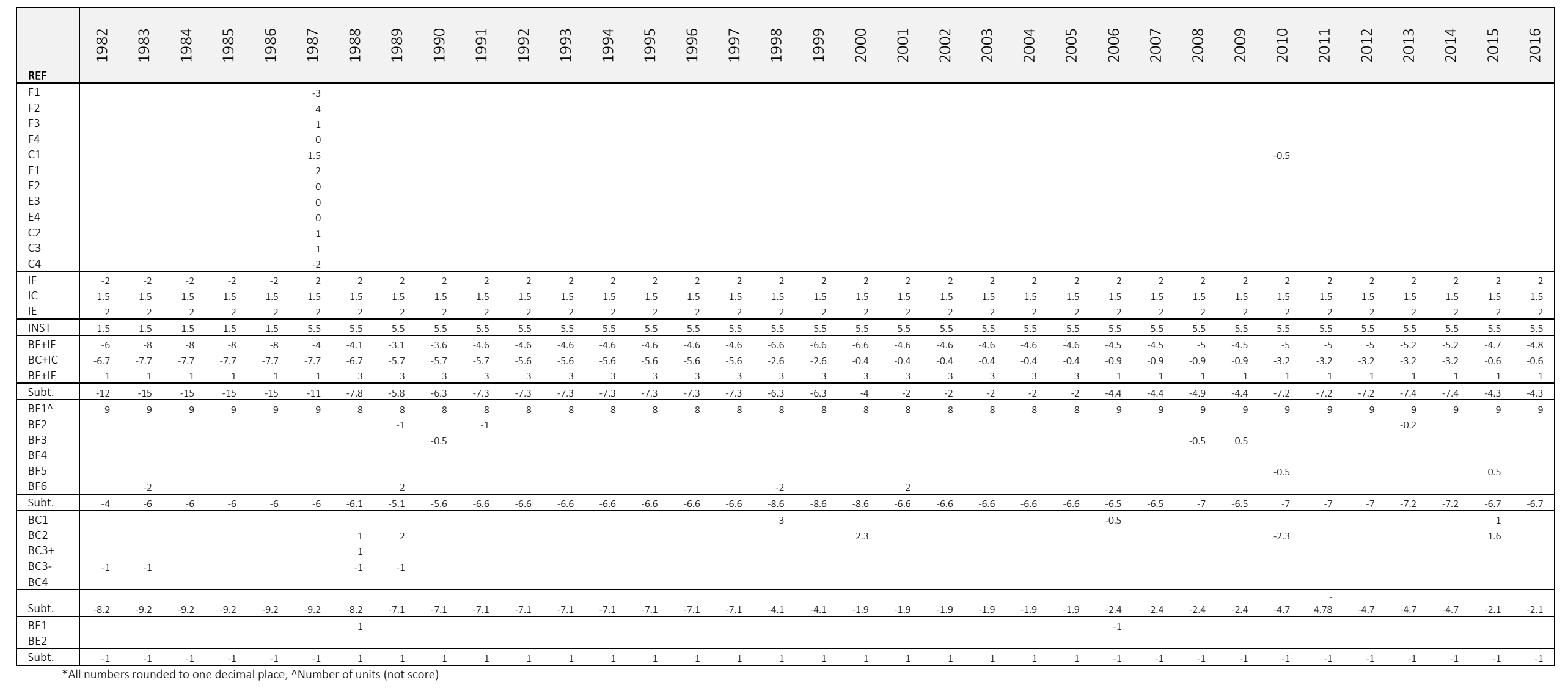


Table A29: Sri Lanka - Other variables and sequencing factors summary (1945-2016)

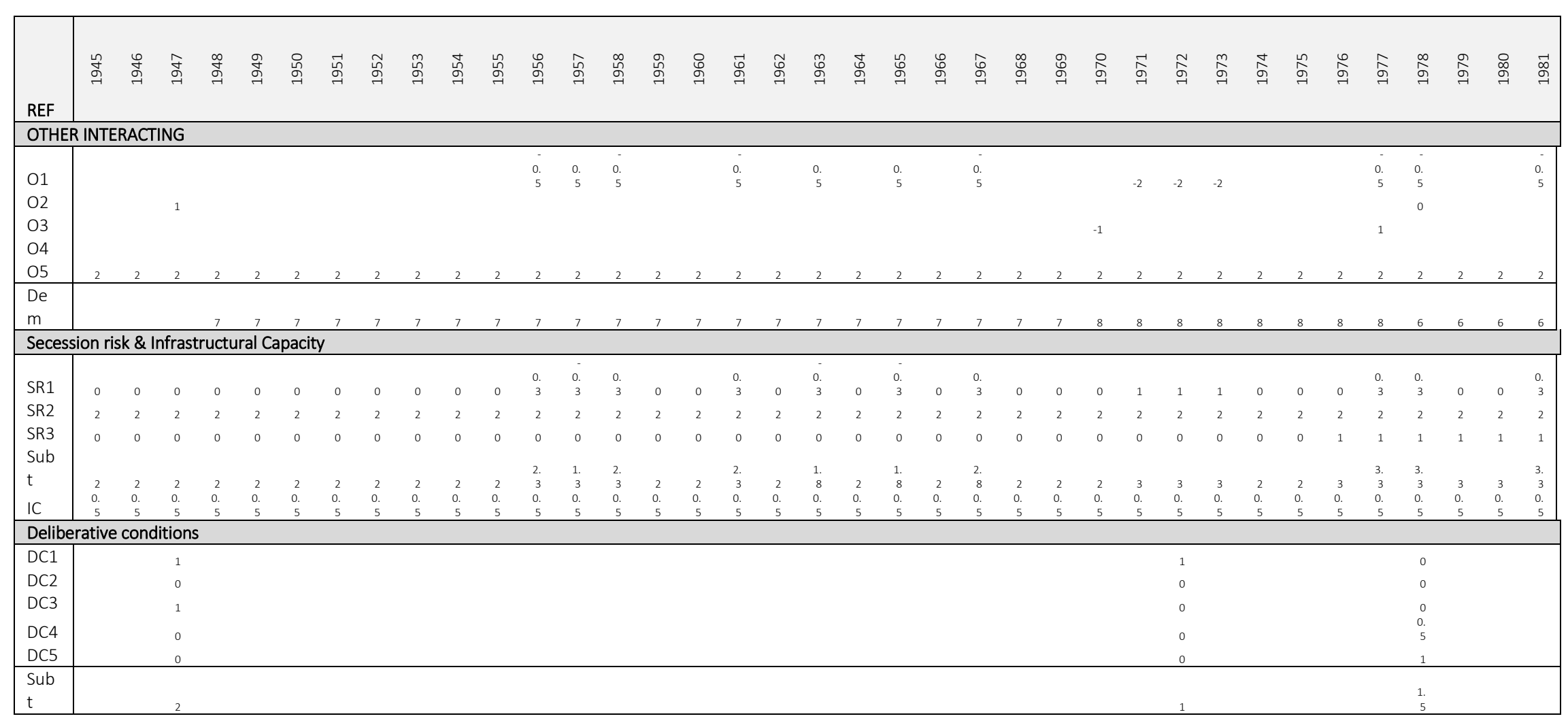




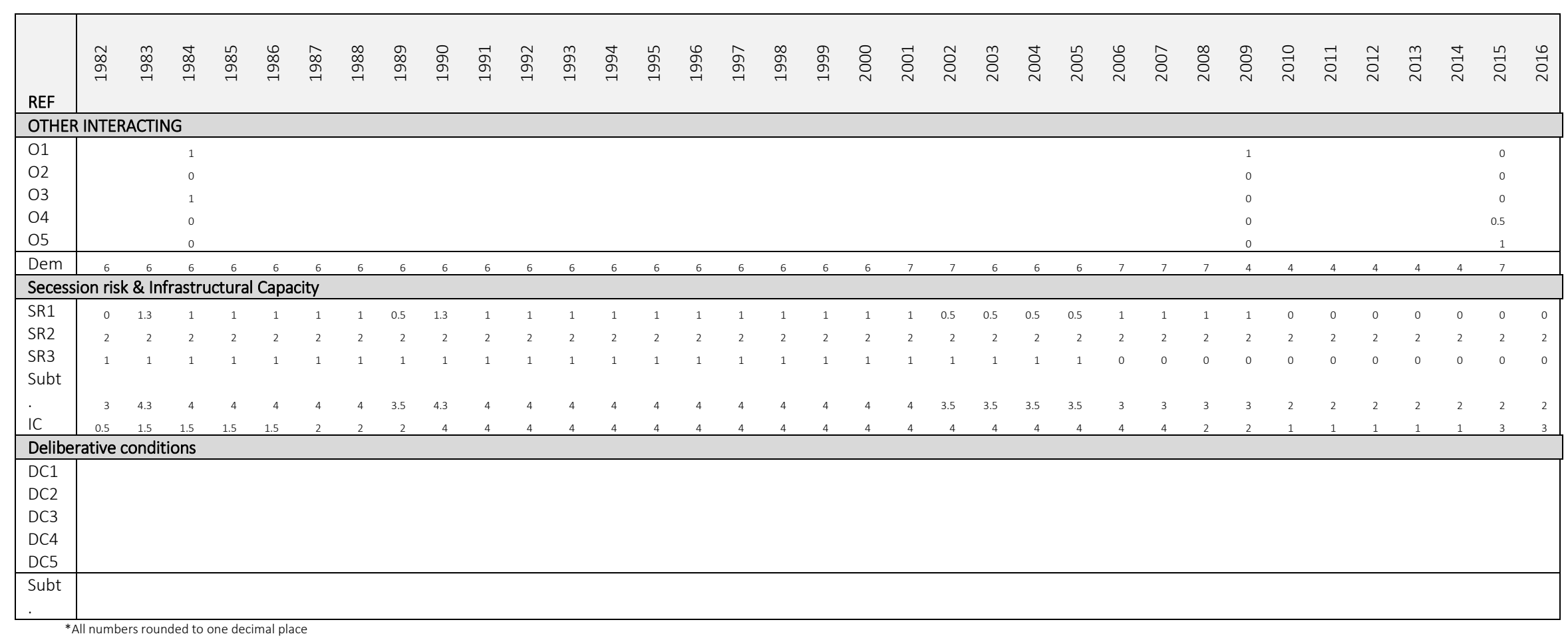




\section{Appendix 3: Media data from Nepal's federalism debate}

\begin{tabular}{|c|c|c|c|c|}
\hline $\begin{array}{l}\text { Preferred type of } \\
\text { federalism }\end{array}$ & Rationale & $\begin{array}{l}\text { Name and position / } \\
\text { association }\end{array}$ & Date & Source \\
\hline Territorial & $\begin{array}{l}\text { States based on river basins, with ethnic regions } \\
\text { within those states as part of a four-tier model }\end{array}$ & $\begin{array}{l}\text { Alok Bohara, Professor, } \\
\text { University of New } \\
\text { Mexico }\end{array}$ & $\begin{array}{l}\text { 4-10 July } \\
2008\end{array}$ & $\begin{array}{l}\text { 'Cooperative Federalism', Nepali } \\
\text { Times, Issue } 407\end{array}$ \\
\hline Territorial & $\begin{array}{l}\text { Ethnic federal states will ultimately lead to the } \\
\text { corrosion of Nepalese identity, united strength, } \\
\text { and harmony, as each shall fight for supremacy }\end{array}$ & Bishnu Pathak, PhD & $\begin{array}{l}14 \text { July } \\
2008\end{array}$ & $\begin{array}{l}\text { 'Work toward Federalism in Nepal } \\
\text { Appears More Complex than the Peace } \\
\text { Accord and Constituent Assembly', } \\
\text { Conflict Study Center, Situation Update } \\
73\end{array}$ \\
\hline $\begin{array}{l}\text { Combination of } \\
\text { territorial and ethnic }\end{array}$ & $\begin{array}{l}\text { Population, economic viability, geography, } \\
\text { ethnicity, history, administrative viability - } \\
\text { should respond to ethnic and regional } \\
\text { grievances }\end{array}$ & $\begin{array}{l}\text { Minendra Rijal, Nepali } \\
\text { Congress leader }\end{array}$ & $\begin{array}{l}20 \mathrm{Dec} \\
2008\end{array}$ & $\begin{array}{l}\text { 'Federalism but how?', Nepali Times } \\
\text { (website) }\end{array}$ \\
\hline Territorial & Geographical viability & $\begin{array}{l}\text { Ratneshworlal Kayastha, } \\
\text { Madheshi Janadhikar } \\
\text { Forum }\end{array}$ & $\begin{array}{l}20 \mathrm{Dec} \\
2008\end{array}$ & $\begin{array}{l}\text { 'Federalism but how?', Nepali Times } \\
\text { (website) }\end{array}$ \\
\hline Ethnic & $\begin{array}{l}\text { The four bases of identity (ethnicity, language, } \\
\text { culture and geography) }\end{array}$ & $\begin{array}{l}\text { Shanker Pokhrel, CPN- } \\
\text { UML }\end{array}$ & $\begin{array}{l}20 \mathrm{Dec} \\
2008\end{array}$ & $\begin{array}{l}\text { 'Federalism but how?', Nepali Times } \\
\text { (website) }\end{array}$ \\
\hline Ethnic & $\begin{array}{l}\text { Economically viable, but addressing the 'ground } \\
\text { reality' of identity politics }\end{array}$ & $\begin{array}{l}\text { Shankar Sharma, } \\
\text { Economist }\end{array}$ & $\begin{array}{l}20 \mathrm{Dec} \\
2008 \\
\end{array}$ & $\begin{array}{l}\text { 'Federalism but how?', Nepali Times } \\
\text { (website) }\end{array}$ \\
\hline Ethnic & $\begin{array}{l}\text { Must address the socio-political issue of identity } \\
\text { politics }\end{array}$ & $\begin{array}{l}\text { Balkrishna Mabuhang, } \\
\text { Assoc. Prof, Tribhuvan } \\
\text { University }\end{array}$ & $\begin{array}{l}20 \mathrm{Dec} \\
2008\end{array}$ & $\begin{array}{l}\text { 'Federalism but how?', Nepali Times } \\
\text { (website) }\end{array}$ \\
\hline
\end{tabular}




\begin{tabular}{|c|c|c|c|c|}
\hline $\begin{array}{l}\text { Preferred type of } \\
\text { federalism }\end{array}$ & Rationale & $\begin{array}{l}\text { Name and position / } \\
\text { association }\end{array}$ & Date & Source \\
\hline $\begin{array}{l}\text { Combination of } \\
\text { territorial and ethnic }\end{array}$ & $\begin{array}{l}\text { Four cooperative federal states, } 13 \text { regions and } \\
4000 \text { village/urban centers }\end{array}$ & $\begin{array}{l}\text { Alok Bohara, Professor, } \\
\text { University of New } \\
\text { Mexico }\end{array}$ & $\begin{array}{l}20 \mathrm{Dec} \\
2008\end{array}$ & $\begin{array}{l}\text { 'Federalism but how?', Nepali Times } \\
\text { (website); and }\end{array}$ \\
\hline Territorial & $\begin{array}{l}\text { Nepal is hyper-pluralistic nation. Dividing along } \\
\text { ethnic lines is virtually impossible }\end{array}$ & $\begin{array}{l}\text { Dr Ambika P Adhikari, } \\
\text { Arizona State University }\end{array}$ & $\begin{array}{l}29 \text { July } \\
2009\end{array}$ & $\begin{array}{l}\text { 'Federalism in Nepal: Quo Vadis?', } \\
\text { Opinion Piece, MyRepublica }\end{array}$ \\
\hline Territorial & $\begin{array}{l}\text { States should be north to south, ethnic basis } \\
\text { will be divisive, there are no calls for ethnic } \\
\text { federalism here }\end{array}$ & $\begin{array}{l}\text { Pitamber Dhakal } \\
\text { Uddhav Pyakurel } \\
\text { Arjun Bahadur Airi } \\
\text { Pabitra Shahi } \\
\text { Kagendra Thapa } \\
\text { Sajnu Sing Bishwakarma } \\
\text { Prem Bahadur Thapa } \\
\text { Shobha BK }\end{array}$ & $\begin{array}{l}20-26 \text { Nov } \\
2009\end{array}$ & $\begin{array}{l}\text { 'If the constitution isn't written on } \\
\text { time, Maoists will be to blame', Nepali } \\
\text { Times, Issue } 477\end{array}$ \\
\hline $\begin{array}{l}\text { Territorial with } \\
\text { Karnali province }\end{array}$ & $\begin{array}{l}\text { Should be based on geography and availability } \\
\text { of natural resources }\end{array}$ & $\begin{array}{l}\text { German Nepali, Dalit } \\
\text { activist, Karnali Zone }\end{array}$ & $\begin{array}{l}11-17 \text { Dec } \\
2009\end{array}$ & $\begin{array}{l}\text { 'Constitution supplement: } \\
\text { Autonomous Karnali', Nepali Times, } \\
\text { Issue } 480\end{array}$ \\
\hline Territorial & $\begin{array}{l}\text { States should incorporate hill, mountain and } \\
\text { Terai regions; Nepali national sentiment } \\
\text { shouldn't be fragmented }\end{array}$ & $\begin{array}{l}\text { Nanadraj Dhital, } \\
\text { Disabled Rehabilitation } \\
\text { \& Development Centre }\end{array}$ & $\begin{array}{l}\text { 11-17 Dec } \\
2009\end{array}$ & $\begin{array}{l}\text { 'Constitution supplement: } \\
\text { Autonomous Karnali', Nepali Times, } \\
\text { Issue } 480\end{array}$ \\
\hline Ethnic & $\begin{array}{l}\text { Recognition of ethnic provinces is an implicit } \\
\text { affirmation of the equal status of every ethnic } \\
\text { group. It is to legitimize egalitarian multiplicity }\end{array}$ & Pramod Mishra & $\begin{array}{l}24 \\
\text { December } \\
2009\end{array}$ & $\begin{array}{l}\text { 'Don't Gift Ethnic Federalism', } \\
\text { eKantipur }\end{array}$ \\
\hline $\begin{array}{l}\text { Ethnic but not the } 14 \\
\text { State model }\end{array}$ & $\begin{array}{l}\text { Demands one state for Madheshi (14 State } \\
\text { proposal splits in two) }\end{array}$ & $\begin{array}{l}\text { Mahendra Yadav, } \\
\text { Chairman, Madheshi } \\
\text { Janadhikar Forum }\end{array}$ & $\begin{array}{l}20 \text { Jan } \\
2010\end{array}$ & $\begin{array}{l}\text { 'MJF express reservation over } 2 \text { states } \\
\text { in Tarai', eKantipur }\end{array}$ \\
\hline
\end{tabular}




\begin{tabular}{|c|c|c|c|c|}
\hline $\begin{array}{l}\text { Preferred type of } \\
\text { federalism }\end{array}$ & Rationale & $\begin{array}{l}\text { Name and position / } \\
\text { association }\end{array}$ & Date & Source \\
\hline $\begin{array}{l}\text { Ethnic but not the } 14 \\
\text { State model }\end{array}$ & $\begin{array}{l}\text { Does not provide a Limbuwan State; forces } \\
\text { together other groups. }\end{array}$ & $\begin{array}{l}\text { Rajya Parisad, Sanghiya } \\
\text { Limbuwan }\end{array}$ & $\begin{array}{l}22 \text { Jan } \\
2010\end{array}$ & $\begin{array}{l}\text { 'Limbuwan, Khumbuwan furious over } \\
\text { federal provinces', eKantipur }\end{array}$ \\
\hline $\begin{array}{l}\text { Ethnic but not the } 14 \\
\text { State model }\end{array}$ & $\begin{array}{l}\text { Does not provide a Khumbuwan State (contrary } \\
\text { to prior agreement) }\end{array}$ & $\begin{array}{l}\text { Khumbuwan Rastriya } \\
\text { Morcha }\end{array}$ & $\begin{array}{l}22 \text { Jan } \\
2010\end{array}$ & $\begin{array}{l}\text { 'Limbuwan, Khumbuwan furious over } \\
\text { federal provinces', eKantipur }\end{array}$ \\
\hline $\begin{array}{l}\text { Ethnic but not the } 14 \\
\text { State model }\end{array}$ & $\begin{array}{l}\text { Demands one state for Madheshi (14 State } \\
\text { proposal splits in two) }\end{array}$ & $\begin{array}{l}\text { Laxman Tharu, Taruhat } \\
\text { Struggle Committee }\end{array}$ & $\begin{array}{l}27 \text { Jan } \\
2010\end{array}$ & $\begin{array}{l}\text { 'MJF, Tharuhat strike five-pt deal to } \\
\text { fight for single state', eKantipur }\end{array}$ \\
\hline Territorial & $\begin{array}{l}\text { Giving privileges to ethnic groups will not solve } \\
\text { problems }\end{array}$ & $\begin{array}{l}\text { Raj Kaji Maharjan, UCPN } \\
\text { (Maoist) }\end{array}$ & $\begin{array}{l}29 \text { Jan }-4 \\
\text { Feb } 2010\end{array}$ & $\begin{array}{l}\text { 'Constitution Supplement: There are } \\
\text { caste systems within all ethnic } \\
\text { communities', Nepali Times, Issue } 487\end{array}$ \\
\hline Territorial & $\begin{array}{l}\text { The contributions of Muslims should be } \\
\text { acknowledged too }\end{array}$ & $\begin{array}{l}\text { Kaushar Shah, Muslim } \\
\text { Association }\end{array}$ & $\begin{array}{l}29 \text { Jan }-4 \\
\text { Feb } 2010\end{array}$ & $\begin{array}{l}\text { 'Constitution Supplement: There are } \\
\text { caste systems within all ethnic } \\
\text { communities', Nepali Times, Issue } 487\end{array}$ \\
\hline Territorial & $\begin{array}{l}\text { No caste is dominant everywhere; there should } \\
\text { be even natural resources }\end{array}$ & $\begin{array}{l}\text { Narayan Koju, Nepal } \\
\text { Workers Peasant Party }\end{array}$ & $\begin{array}{l}29 \text { Jan }-4 \\
\text { Feb } 2010\end{array}$ & $\begin{array}{l}\text { 'Constitution Supplement: There are } \\
\text { caste systems within all ethnic } \\
\text { communities', Nepali Times Issue } 487\end{array}$ \\
\hline Territorial & Provinces should be based on natural resources & Nirmal Pode (Dalit) & $\begin{array}{l}29 \text { Jan }-4 \\
\text { Feb } 2010\end{array}$ & $\begin{array}{l}\text { 'Constitution Supplement: There are } \\
\text { caste systems within all ethnic } \\
\text { communities', Nepali Times Issue } 487\end{array}$ \\
\hline Ethnic (14 States) & $\begin{array}{l}\text { Ethnic groups should receive autonomy; Dalits } \\
\text { do not need a province, only special privileges }\end{array}$ & $\begin{array}{l}\text { Tilak Pariyar, CA } \\
\text { member, UCPN (Maoist) }\end{array}$ & $\begin{array}{l}12-18 \mathrm{Feb} \\
2010\end{array}$ & $\begin{array}{l}\text { 'Constitution Supplement: Dalit } \\
\text { liberation within ethnic provinces', } \\
\text { Nepali Times, Issue } 489\end{array}$ \\
\hline Ethnic (14 States) & $\begin{array}{l}\text { Multi-ethnic alliances will emerge, as the } \\
\text { minority status of each group will prevent } \\
\text { discrimination }\end{array}$ & $\begin{array}{l}\text { Prashant Jha, Journalist, } \\
\text { (Madheshi) }\end{array}$ & $\begin{array}{l}12-18 \text { Feb } \\
2010\end{array}$ & $\begin{array}{l}\text { Federal Realities, Nepali Times, Issue } \\
489\end{array}$ \\
\hline
\end{tabular}




\begin{tabular}{|c|c|c|c|c|}
\hline $\begin{array}{l}\text { Preferred type of } \\
\text { federalism }\end{array}$ & Rationale & $\begin{array}{l}\text { Name and position / } \\
\text { association }\end{array}$ & Date & Source \\
\hline Territorial & $\begin{array}{l}\text { Ethnic states not possible with such diversity. } \\
\text { There should be Himal (3), Hilly }(7 / 8) \text { and Terai } \\
\text { (3) regions }\end{array}$ & $\begin{array}{l}\text { Lyarkal Lama, CPN-UML, } \\
\text { CA member, Yolmu }\end{array}$ & $\begin{array}{l}12-18 \mathrm{Feb} \\
2010\end{array}$ & $\begin{array}{l}\text { 'Constitution Supplement: Liberation } \\
\text { without oppression' Nepali Times, } \\
\text { Issue } 489\end{array}$ \\
\hline Territorial & $\begin{array}{l}\text { Imperative for multi-ethnic states to engineer } \\
\text { an accommodative structure }\end{array}$ & $\begin{array}{l}\text { Dr Bipin Adhikari, } \\
\text { Constitutional law expert }\end{array}$ & $\begin{array}{l}25 \text { Feb } \\
2010\end{array}$ & 'Identity Politics', eKantipur \\
\hline Territorial (6 States) & $\begin{array}{l}\text { Promotes only ethnicity at expense of } \\
\text { geography, population, economic capacities } \\
\text { and natural resources; will invite conflict }\end{array}$ & $\begin{array}{l}\text { Laxmi Pariyar, CA } \\
\text { member, Nepali } \\
\text { Congress, Udaypur } \\
\text { (Dalit) }\end{array}$ & $\begin{array}{l}26 \text { Feb }-4 \\
\text { March } \\
2010\end{array}$ & $\begin{array}{l}\text { 'Constitution Supplement: Ethnic } \\
\text { Federalism will invite conflict'. Nepali } \\
\text { Times, Issue } 491\end{array}$ \\
\hline Ethnic (14 States) & $\begin{array}{l}\text { Addresses concerns of all communities; done on } \\
\text { the basis of resources }\end{array}$ & $\begin{array}{l}\text { Bhupendra Chemjong, } \\
\text { President, Federation of } \\
\text { Indigenous People }\end{array}$ & $\begin{array}{l}16-22 \text { April } \\
2010\end{array}$ & $\begin{array}{l}\text { 'Constitution Supplement: } \\
\text { Hong Kong Speaks out', Nepali Times, } \\
\text { Issue } 498\end{array}$ \\
\hline Territorial (6 States) & Risk of secession if too many states & $\begin{array}{l}\text { Kamal Poudel, } \\
\text { Intellectual }\end{array}$ & $\begin{array}{l}16-22 \text { April } \\
2010\end{array}$ & $\begin{array}{l}\text { 'Constitution Supplement: } \\
\text { Hong Kong Speaks out', Nepali Times, } \\
\text { Issue } 498\end{array}$ \\
\hline Ethnic (14 States) & $\begin{array}{l}\text { As long as they ensure rights of marginalized; } \\
\text { expense is not an issue }\end{array}$ & $\begin{array}{l}\text { Nanda Changshu, } \\
\text { Secretary, Kirant } \\
\text { Yakthung Chumlung }\end{array}$ & $\begin{array}{l}16-22 \text { April } \\
2010\end{array}$ & $\begin{array}{l}\text { 'Constitution Supplement: } \\
\text { Hong Kong Speaks out', Nepali Times, } \\
\text { Issue } 498\end{array}$ \\
\hline $\begin{array}{l}\text { Ethnic with } \\
\text { autonomous regions } \\
\text { for each scheduled } \\
\text { ethnic group }\end{array}$ & $\begin{array}{l}\text { Gives rights, can bring the backward } \\
\text { communities to the table }\end{array}$ & $\begin{array}{l}\text { Bhakta Dura, Advisor, } \\
\text { Dura Society }\end{array}$ & $\begin{array}{l}\text { 16-22 April } \\
2010\end{array}$ & $\begin{array}{l}\text { 'Constitution Supplement: } \\
\text { Hong Kong Speaks out', Nepali Times, } \\
\text { Issue } 498\end{array}$ \\
\hline Territorial (6 States) & $\begin{array}{l}\text { Majority of ethnic people of proposed provinces } \\
\text { live elsewhere. Will create additional social } \\
\text { cleavages }\end{array}$ & $\begin{array}{l}\text { Bhim Thapa Magar, } \\
\text { former general } \\
\text { secretary, Magar } \\
\text { Association }\end{array}$ & $\begin{array}{l}16-22 \text { April } \\
2010\end{array}$ & $\begin{array}{l}\text { 'Constitution Supplement: } \\
\text { Hong Kong Speaks out', Nepali Times, } \\
\text { Issue } 498\end{array}$ \\
\hline
\end{tabular}




\begin{tabular}{|c|c|c|c|c|}
\hline $\begin{array}{l}\text { Preferred type of } \\
\text { federalism }\end{array}$ & Rationale & $\begin{array}{l}\text { Name and position / } \\
\text { association }\end{array}$ & Date & Source \\
\hline Territorial (6 States) & Everyone should be treated equally & $\begin{array}{l}\text { Rita Gurung, Deputy } \\
\text { Secretary, Tamu Tyohyul }\end{array}$ & $\begin{array}{l}16-22 \text { April } \\
2010\end{array}$ & $\begin{array}{l}\text { 'Constitution Supplement: } \\
\text { Hong Kong Speaks out', Nepali Times, } \\
\text { Issue } 498\end{array}$ \\
\hline Ethnic (14 States) & $\begin{array}{l}\text { We favor coexistence (and will run the } \\
\text { province) }\end{array}$ & $\begin{array}{l}\text { Abichandra Ingnam, } \\
\text { General Secretary, } \\
\text { Limbuwan National } \\
\text { Liberation Front }\end{array}$ & $\begin{array}{l}16-22 \text { April } \\
2010\end{array}$ & $\begin{array}{l}\text { 'Constitution Supplement: } \\
\text { Hong Kong Speaks out', Nepali Times, } \\
\text { Issue } 498\end{array}$ \\
\hline Ethnic & $\begin{array}{l}\text { The country should be secular and the } \\
\text { provinces should be ethnic }\end{array}$ & $\begin{array}{l}\text { Tashi Shyahngo } \\
\text { Gurungseni CPN-UML, } \\
\text { Mustang }\end{array}$ & $\begin{array}{l}30 \text { April - } \\
6 \text { May } \\
2010\end{array}$ & $\begin{array}{l}\text { 'We lost our identity by writing } \\
\text { "Gurung"', Nepali Times, Issue } 500 .\end{array}$ \\
\hline Territorial & $\begin{array}{l}\text { Too many ethnic groups, and model doesn't } \\
\text { account for ecology adequately }\end{array}$ & Govinda Das Shrestha & $\begin{array}{l}7-13 \text { May } \\
2010\end{array}$ & $\begin{array}{l}\text { 'Ecology based provinces', Nepali } \\
\text { Times, Issue } 501\end{array}$ \\
\hline Territorial & $\begin{array}{l}\text { The diversity of Nepal means that it is not } \\
\text { possible to have a majority ethnic group in any } \\
\text { single province }\end{array}$ & $\begin{array}{l}\text { Pramod Jaiswa, Centre } \\
\text { for South Asian Studies, } \\
\text { Jawaharlal Nehru } \\
\text { University }\end{array}$ & $\begin{array}{l}14 \text { July } \\
2014\end{array}$ & $\begin{array}{l}\text { 'Federalism and Nepal: Internal } \\
\text { Differences, Himalayan Frontier, } \\
\text { \#4563, Institute of Peace and Conflict } \\
\text { Studies }\end{array}$ \\
\hline Ethnic & $\begin{array}{l}\text { Only 'identity inclusive' federalism can provide } \\
\text { equal rights for marginalized communities. } \\
\text { They should be based on single identity }\end{array}$ & $\begin{array}{l}\text { Nagendra Kumal, } \\
\text { Chairman, Nepal } \\
\text { Federation of Indigenous } \\
\text { Nationalities }\end{array}$ & $\begin{array}{l}25 \text { August } \\
2014\end{array}$ & $\begin{array}{l}\text { 'That Janajatis want 'ethnic states' is } \\
\text { baseless propaganda', eKantipur, Oped } \\
\text { Interview }\end{array}$ \\
\hline Territorial & $\begin{array}{l}\text { Generally opposed to federalism but emphasis } \\
\text { should be on geographical integration }\end{array}$ & Bihari K Shrestha & $\begin{array}{l}22-28 \text { Aug } \\
2014\end{array}$ & $\begin{array}{l}\text { 'Federal Fundamentalism: Question } \\
\text { the merits of federalism and you are } \\
\text { committing blasphemy', Nepali Times, } \\
\text { Comment }\end{array}$ \\
\hline Mixed & $\begin{array}{l}\text { A mix is inevitable it is only a question of } \\
\text { emphasis }\end{array}$ & $\begin{array}{l}\text { Narayan Mayandar, } \\
\text { Consultant }\end{array}$ & $\begin{array}{l}6 \text { Sept } \\
2014\end{array}$ & $\begin{array}{l}\text { Imagined divide: When it comes to } \\
\text { federalism, identity and capability }\end{array}$ \\
\hline
\end{tabular}




\begin{tabular}{|c|c|c|c|c|}
\hline $\begin{array}{l}\text { Preferred type of } \\
\text { federalism }\end{array}$ & Rationale & $\begin{array}{l}\text { Name and position / } \\
\text { association }\end{array}$ & Date & Source \\
\hline & & & & $\begin{array}{l}\text { cannot be either/or bases', eKantipur } \\
\text { (editorial) }\end{array}$ \\
\hline $\begin{array}{l}\text { Mixed but primarily } \\
\text { ethnic }\end{array}$ & $\begin{array}{l}\text { Identity and capability as criteria but } \\
\text { incorporating a majority community, so that } \\
\text { they can have a greater say }\end{array}$ & $\begin{array}{l}\text { CPN-Maoist Vice } \\
\text { Chairman, Narayan Kaji } \\
\text { Shrestha }\end{array}$ & $\begin{array}{l}9 \text { Sept } \\
2014\end{array}$ & $\begin{array}{l}\text { 'Federalism is not a magic bullet. It } \\
\text { cannot solve everything', MyRepublica }\end{array}$ \\
\hline Ethnic & $\begin{array}{l}\text { Unspecified (want 'single identity-based } \\
\text { federalism') }\end{array}$ & $\begin{array}{l}\text { CPN-Maoist led 33-party } \\
\text { bloc }\end{array}$ & $\begin{array}{l}15 \text { Sept } \\
2014\end{array}$ & $\begin{array}{l}\text { 'Identity basis for federalism', } \\
\text { eKantipur, Top Stories }\end{array}$ \\
\hline $\begin{array}{l}\text { Mixed but primarily } \\
\text { territorial }\end{array}$ & $\begin{array}{l}\text { Considering the diversity and population of the } \\
\text { Madhesh }\end{array}$ & Nepali Congress & $\begin{array}{l}6 \text { Oct } \\
2014\end{array}$ & $\begin{array}{l}\text { 'NC moots equal provinces for Tarai } \\
\text { and hills', eKantipur, Top Stories }\end{array}$ \\
\hline Territorial & $\begin{array}{l}\text { Divide on the basis of population, named after } \\
\text { major rivers with integration a key element - six } \\
\text { states }\end{array}$ & $\begin{array}{l}\text { Yagya B. Karki, Member } \\
\text { Nepal Planning } \\
\text { Commission }\end{array}$ & $\begin{array}{l}22 \text { Oct } \\
2014\end{array}$ & $\begin{array}{l}\text { 'Federalism and State Restructuring: A } \\
\text { better way to create provinces', The } \\
\text { Himalayan Times, page } 5\end{array}$ \\
\hline Territorial & $\begin{array}{l}\text { Ethnic provinces may lead to fragmentation } \\
\text { (wants six provinces) }\end{array}$ & $\begin{array}{l}\text { General Secretary of the } \\
\text { CPN-UML, Ishwor } \\
\text { Pokhrel }\end{array}$ & $\begin{array}{l}25 \text { Oct } \\
2014\end{array}$ & $\begin{array}{l}\text { 'No need for more than six provinces: } \\
\text { Pokhrel', eKantipur }\end{array}$ \\
\hline Territorial & $\begin{array}{l}\text { Population too mixed for ethnic provinces, } \\
\text { which would be a slippery slope of conflict and } \\
\text { 'economic ruin'. Wants five North/South } \\
\text { provinces }\end{array}$ & $\begin{array}{l}\text { Ram C Archarya, } \\
\text { Economist }\end{array}$ & $\begin{array}{l}31 \text { Oct } \\
2014\end{array}$ & $\begin{array}{l}\text { 'Ethnic federalism defies the principles } \\
\text { of democracy, efficiency, and } \\
\text { inclusiveness', eKantipur, Opinion }\end{array}$ \\
\hline Ethnic & $\begin{array}{l}\text { Not specified, wants previous agreements and } \\
\text { CA } 1 \text { proposal implemented }\end{array}$ & $\begin{array}{l}\text { Upendra Yadav, Chair of } \\
\text { Madheshi Janadhikar } \\
\text { Forum }\end{array}$ & $\begin{array}{l}3 \mathrm{Nov} \\
2014\end{array}$ & $\begin{array}{l}\text { 'NC, UML, RPP federation model not } \\
\text { acceptable: Yadav', eKantipur, Top } \\
\text { Stories }\end{array}$ \\
\hline
\end{tabular}




\begin{tabular}{|c|c|c|c|c|}
\hline $\begin{array}{l}\text { Preferred type of } \\
\text { federalism }\end{array}$ & Rationale & $\begin{array}{l}\text { Name and position / } \\
\text { association }\end{array}$ & Date & Source \\
\hline Mixed & $\begin{array}{l}\text { Nepal multi-ethnic and multi-lingual and so } \\
\text { ethnic states and priorities are not possible - } \\
\text { basis must be identity and viability }\end{array}$ & $\begin{array}{l}\text { Narayan Kaji Shrestha, } \\
\text { Vice-Chairman, UCPN } \\
\text { (Maoist) }\end{array}$ & $\begin{array}{l}3 \mathrm{Nov} \\
2014\end{array}$ & $\begin{array}{l}\text { 'Federate on the basis of both identity } \\
\text { and capability', eKantipur, Interview }\end{array}$ \\
\hline Territorial & $\begin{array}{l}\text { North-south alignment is most optimal for } \\
\text { development purposes }\end{array}$ & $\begin{array}{l}\text { Dr Shekar Koirala, Nepali } \\
\text { Congress Central } \\
\text { Committee }\end{array}$ & $\begin{array}{l}19 \text { Jan } \\
2015\end{array}$ & $\begin{array}{l}\text { 'Five disputed districts could be } \\
\text { governed by Centre', eKantipur, } \\
\text { Interview }\end{array}$ \\
\hline Mixed & $\begin{array}{l}\text { Able to create more inclusive structures while } \\
\text { safeguarding territorial integrity - as per } \\
\text { existing CA agreed criteria }\end{array}$ & $\begin{array}{l}\text { Lok Raj Bhajaral, author } \\
\text { and former professor }\end{array}$ & $\begin{array}{l}26 \text { Jan } \\
2015\end{array}$ & $\begin{array}{l}\text { 'Federalism is a political issue to be } \\
\text { decided by political actors', eKantipur, } \\
\text { Interview, }\end{array}$ \\
\hline Territorial & $\begin{array}{l}\text { There are too many ethnic groups in Nepal to } \\
\text { make ethnic federalism practical }\end{array}$ & $\begin{array}{l}\text { Jhalanath Khanal, CPN- } \\
\text { UML senior leader }\end{array}$ & $\begin{array}{l}23 \text { April } \\
2015\end{array}$ & $\begin{array}{l}\text { 'Federalism on ethnic line not possible: } \\
\text { Khanal', eKantipur }\end{array}$ \\
\hline Territorial & Ethnic federalism will spread disharmony & $\begin{array}{l}\text { Yogesh Bhattrai, CPN- } \\
\text { UML Secretary }\end{array}$ & $\begin{array}{l}24 \text { April } \\
2015\end{array}$ & $\begin{array}{l}\text { 'Lying is Dahal's second nature: Yogesh } \\
\text { Bhattarai', eKantipur }\end{array}$ \\
\hline $\begin{array}{l}\text { Ethnic (Madhesh } \\
\text { provinces) }\end{array}$ & $\begin{array}{l}\text { Need own province to safeguard rights and end } \\
\text { discrimination - a Madhesh province will not } \\
\text { separate the country }\end{array}$ & $\begin{array}{l}\text { Laxman Lal Karna, } \\
\text { Sadbhavana Party Co- } \\
\text { chairman }\end{array}$ & $\begin{array}{l}16 \text { July } \\
2015\end{array}$ & $\begin{array}{l}\text { 'Weekly Interview: No more bad } \\
\text { checks. We want hard cash this time', } \\
\text { MyRepublica }\end{array}$ \\
\hline Ethnic & $\begin{array}{l}\text { Provinces should have key ethnic, linguistic, } \\
\text { geographical, cultural and historical aspects } \\
\text { taken into consideration }\end{array}$ & $\begin{array}{l}\text { Nagendra Kumal, } \\
\text { Chairman, Nepal } \\
\text { Federation of Indigenous } \\
\text { Nationalities }\end{array}$ & $\begin{array}{l}24 \text { July } \\
2015\end{array}$ & $\begin{array}{l}\text { 'Janajati MPs press for equality, } \\
\text { inclusiveness', eKantipur, Top Stories }\end{array}$ \\
\hline Territorial & $\begin{array}{l}\text { Economic strength is the key element for truly } \\
\text { autonomous states and should be prioritized }\end{array}$ & Dr Matthias Hartwig & 7 Aug 2015 & $\begin{array}{l}\text { 'Weekly interview: five states ideal for } \\
\text { Nepal, MyRepublica }\end{array}$ \\
\hline
\end{tabular}




\begin{tabular}{|l|l|l|l|l|}
\hline $\begin{array}{l}\text { Preferred type of } \\
\text { federalism }\end{array}$ & Rationale & $\begin{array}{l}\text { Name and position / } \\
\text { association }\end{array}$ & Date & Source \\
\hline $\begin{array}{l}\text { Mixed but primarily } \\
\text { territory }\end{array}$ & $\begin{array}{l}\text { Hill, mountain and Terai are critical to all } \\
\text { Nepalis, though identity should also be factored } \\
\text { in as it is important }\end{array}$ & $\begin{array}{l}\text { Geja Sharma Wagle, } \\
\text { security sector expert }\end{array}$ & $\begin{array}{l}\text { 2 Sept } \\
2015\end{array}$ & $\begin{array}{l}\text { Weekly interview: there was no need } \\
\text { to deploy the army', MyRepublica }\end{array}$ \\
\hline
\end{tabular}

$\mathrm{CA}=$ Constituent Assembly 


\section{Appendix 4 - Quantitative analysis for variable selection}

\section{A4.1 Hypotheses}

The proposition that is explored through this quantitative study is based on the theoretical framework described in Chapters 1 and 3, in particular the rival theories outlined in Chapter 1.3. The study is used to inform the selection of variables for further analysis. The proposition is that:

Asian states with a high diversity of distinct ethnic groups are likely to accommodate their minority ethnic groups, if they have experienced considerable internal conflict. State religions will affect the decision in Buddhist states, which are more likely to repress the conflict and ethnic group demands. It is of little relevance whether or to what extent the state is democratic, or whether it is a post-colonial state, notwithstanding that Malaysia, Pakistan and India created territorial federal systems around the time of independence.

The hypotheses to test and refine this proposition are:

$\mathrm{H}_{1}$ : $\quad$ Ethnic, language and religious diversity is positively related with the extent to which an Asian state accommodates its ethnic groups;

$\mathrm{H}_{2}$ : Internal conflict moderates the relationship between diversity and the accommodation of ethnic groups, specifically, the greater the extent of conflict the greater the extent of accommodation;

$\mathrm{H}_{3}$ : The degree of democratization (regime type) mediates the relationship between diversity and accommodation, but the effect is not significant;

$\mathrm{H}_{4}$ : The legacy of post-colonialism has no significant effect on the extent to which an Asian State accommodates its ethnic groups;

$\mathrm{H}_{5}$ : A country's religious cultures is related to the extent to which an Asian State will accommodate its ethnic groups. In particular, a Buddhist culture is unlikely to accommodate extensively.

The unit of analysis is countries and the target population is countries in Asia. The sample is countries from East Asia, South Asia and South-East Asia, not including East Timor, the Maldives and Papa New Guinea, for which sufficient information was not available. It does not include the Middle East, Pacific Islands or Central Asian republics. There are 22 observations. Because the population size is small and it forms part of broader research focussing on Asia, non-probability convenience sampling approach was utilized, focussing on the region of interest, where there is considerable pressure to accommodate minority ethnic groups and accessible information.

Ethnic groups are considered here to be ethnic, language or religious groups, although in terms of the broader qualitative study, this is expanded to include caste groups. Ethnic groups are operationalized in terms of diversity (which is an independent variable). Although the diversity measures may compound, an average across dimensions is used due to the overlap (between ethnicity and language for example). Other variables are discussed in the next section. 
A further parameter is that the period for which conflict and accommodation is considered relevant for the study is the post WWII period, because many of the countries only have their incarnation as a modern-nation state after this period. It is acknowledged that the sample and population size are small and so the quantitative outcomes are of limited value. Hence the need to supplement with qualitative analysis.

\section{A4.2 Variables}

The dependent variable for each hypothesis is the degree of accommodation, operationalized in terms of autonomy, inclusion, recognition and repression(-). The author has constructed an index for the purpose of the design and initial testing of the model.

The index uses four dimensions, or facts, each of which are measured using ordinal scales (as below). The Accommodation variable is continuous/interval, as constructed from four ordinal measures. Internal validity was measured by finding the alpha value. The scale reliability co-efficient was approximately 0.5 , which is not satisfactory. However, the four dimensions measure different aspects of accommodation which may or may not be in place regardless of the presence of other aspects. Further, the scores accord generally with the author's knowledge of this subject matter. Hence the index was not adjusted on account of the alpha test. The scoring system for the four dimensions are:

Repression ( 0 = violent repression of identity groups; 1 = political repression; 2 = nil)

Inclusion ( 0 = mostly dominant and discriminated groups; 1 = dominant groups, but also groups that are partners and autonomous; 2 = mostly shared power);

Language ( 0 = no minority languages officially recognized; 2 = some recognized)

Autonomy $(0$ = no autonomous regions; 2 = special autonomy arrangements; 4 = federal)

Autonomy is the most meaningful forms of accommodation and that which is generally demanded by minority ethnic groups in Asia, so it is given the highest weight.

Existing measures were considered. For example, the GeoEPR database (Wucherpfennig et al. 2011) was considered for use as the sole measure. However, it was rejected as it classes ethnic groups as having regional autonomy, when in many cases that autonomy is in fact very weak and more akin to decentralization (such as for many groups in Indonesia), or not genuinely implemented and rejected by the group itself (e.g. Tamils in Sri Lanka). It has instead been used a factor in the index to measure inclusion. Other sources are listed in the codebook at Table A34. Information is from 2007-2014 and updated as far as practical.

It should also be noted that autonomy is considered on the basis of formal institutional structures, rather than accounting for behavoral elements. See Table A34 for scores.

Independent and control variables are:

Diversity, which relates to ethnic, linguistic and religious diversity and is operationalized using the ethno-linguistic fractionalization index (Alesina et al. 2003). Diversity is an independent variable in hypotheses 1, 2 and 3 and a control variable in hypothesis 4. 
Conflict, which is intended to capture internal conflicts largely focussed on ethnic group and autonomy issues. It is operationalized using a war coding source and considering the number and length of intra-state wars (Sarkees \& Wayman 2010). Conflict is a mediator variable in hypothesis 2 .

Democratization, which concerns the extent to which democratic practices and ideals are institutionalized and practiced in a country. It is operationalized using a preexisting index established by the Economist Intelligence Unit, which measures factors such as elections, rule of law and civil liberties (Economist Intelligence Unit 2013). Democratization is an independent variable in hypothesis 3 and a control variable in hypothesis 1 .

State formation, which concerns whether a country is post-colonial, independent through secession from another Asian state, or existed as an independent state preWWII. It is a dummy variable, used as an independent variable in hypothesis 4 and a control variable in hypothesis 1 .

Secularization, which is the degree to which a countries institutional system favours a particular religion. It is operationalized based on whether a countries' constitution or basic law(s) recognise an official religion. It is an independent variable for hypothesis 5 .

Religion, which is the dominant religion or culture within the particular country, based on information from the CIA Fact Book (Central Intelligence Agency 2007). It is an independent variable for hypothesis 5 .

Variables 1 to 3 use interval/continuous measures, variables 4, 5 and 6 are nominal and were re-coded to dummy variables when used or trialled as control or other variables when testing hypotheses 1 through 4 . A reliability and validity test of the indicators has not been undertaken as they are all existing publicly available indexes or categorical variables, other than the Accommodation variable (discussed above). Table A30 provides details on the indicators as per each observation. Full details including scoring system and sources are available in the codebook at A35. 
Table A30: Observations and indicators

\begin{tabular}{|c|c|c|c|c|c|c|c|c|}
\hline $\begin{array}{l}\text { Observ. } \\
\text { No. }\end{array}$ & Country & Diversity (index) & $\begin{array}{l}\text { Conflict, internal } \\
\text { (length/1000) }\end{array}$ & $\begin{array}{l}\text { Democracy } \\
\text { (index) }\end{array}$ & $\begin{array}{l}\text { State formation } \\
\text { (type) }\end{array}$ & $\begin{array}{l}\text { (Constitutional) } \\
\text { Secularization }\end{array}$ & (Primary) Religion & $\begin{array}{l}\text { Accommodation } \\
\text { score }\end{array}$ \\
\hline 1 & Bangladesh & 1.2 & 0.0 & 5.86 & Secession & No & Muslim & 2 \\
\hline 2 & Bhutan & 5.3 & 0.0 & 4.82 & Post-colonial & No & Buddhist & 1 \\
\hline 3 & Brunei & 4.4 & 0.0 & 1.00 & Post-colonial & No & Muslim & 2 \\
\hline 4 & Cambodia & 1.7 & 1.9 & 4.60 & Post-colonial & No & Buddhist & 4 \\
\hline 5 & China & 3.2 & 3.0 & 3.00 & Pre-war & Yes & Confucian/Secular & 5.5 \\
\hline 6 & India & 5.2 & 7.2 & 7.69 & Post-colonial & Yes & Hindu & 10 \\
\hline 7 & Indonesia & 5.8 & 7.6 & 6.82 & Post-colonial & No & Muslim & 5.5 \\
\hline 8 & Japan & 1.9 & 0.0 & 8.08 & Pre-war & Yes & Buddhist & 2 \\
\hline 9 & Korea Nth & 1.8 & 0.0 & 1.08 & Post-colonial & Yes & Buddhist & 2 \\
\hline 10 & Korea Sth & 2.2 & 0.0 & 8.06 & Post-colonial & Yes & Buddhist & 2 \\
\hline 11 & Laos & 5.7 & 3.8 & 2.21 & Post-colonial & Yes & Buddhist & 3 \\
\hline 12 & Malaysia & 6.2 & 0.0 & 6.49 & Post-colonial & No & Muslim & 8 \\
\hline 13 & Mongolia & 2.7 & 0.0 & 6.51 & Pre-war & No & Buddhist & 4 \\
\hline 14 & Myanmar & 4.0 & 8.6 & 2.76 & Post-colonial & No & Buddhist & 6.5 \\
\hline 15 & Nepal & 5.1 & 3.6 & 4.77 & Pre-war & Yes & Hindu & 9 \\
\hline 16 & Pakistan & 6.0 & 2.5 & 4.64 & Post-colonial & No & Muslim & 9 \\
\hline 17 & Philippines & 4.6 & 13.7 & 6.41 & Post-colonial & Yes & Christian & 5 \\
\hline 18 & Singapore & 4.8 & 0.0 & 5.92 & Secession & Yes & Confucian/Secular & 6 \\
\hline 19 & Sri Lanka & 4.5 & 9.2 & 5.69 & Post-colonial & No & Buddhist & 2 \\
\hline 20 & Taiwan & 4.9 & 0.0 & 7.57 & Secession & Yes & Buddhist & 3 \\
\hline
\end{tabular}




\begin{tabular}{|c|c|c|c|c|c|c|c|c|}
\hline $\begin{array}{l}\text { Observ. } \\
\text { No. }\end{array}$ & Country & Diversity (index) & $\begin{array}{l}\text { Conflict, internal } \\
\text { (length/1000) }\end{array}$ & $\begin{array}{l}\text { Democracy } \\
\text { (index) }\end{array}$ & $\begin{array}{l}\text { State formation } \\
\text { (type) }\end{array}$ & $\begin{array}{l}\text { (Constitutional) } \\
\text { Secularization }\end{array}$ & (Primary) Religion & $\begin{array}{l}\text { Accommodation } \\
\text { score }\end{array}$ \\
\hline 21 & Thailand & 4.6 & 0.7 & 6.25 & Pre-war & No & Buddhist & 1 \\
\hline 22 & Vietnam & 3.3 & 3.1 & 3.29 & Post-colonial & Yes & Confucian/Secular & 2 \\
\hline
\end{tabular}


As with any quantitative study, it was necessary to reduce down the complexity and multitude of factors impacting, or potentially impacting, on a country's decision to accommodate. There are many problems with the choices made above. Many data sets and sources were investigated and rejected, such as the social regulation of religion, the number of internal conflicts and the abovementioned GeoEPR dataset. Some of the most notable problems are that it doesn't account for the time at which the decision to accommodate / provide autonomy was made; it doesn't distinguish between, or exclude, conflicts that were not related to ethnic issues (affecting validity of this measure); and, it doesn't include a variable related to regime changes.

\section{A4.3 Analysis}

\section{A4.3.1 Correlation}

The first step of analysis was to test multicolinearity between all the variables. A pairwise correlation approach was used, notwithstanding that the data set is complete and so the choice between casewise and pairwise is somewhat irrelevant, using a pairwise correlation enables the significance level to be estimated. A 90\% confidence interval was used, because of the small sample size. The full results are available in Appendix 3.

Other than in relation to the correlation between dummy variables providing indicators of the same measure (e.g. Religion) (and a correlation between Conflict and Christian states, of which there is only one), the only statistically significant correlation between independent variables was between Conflict and the post-colonial category of the State Formation variable. Further, there were only three statistically significant correlations between independent and dependent variables, being between Diversity and Accommodation, and between Hinduism and Buddhist categories of the Religion variable, and Accommodation. Buddhist was negatively correlated, and Hindu positively. They were also the only substantively significant correlations (higher than $r>0.35$ ). These results support Hypotheses 1 and 5 .

When plotting the relationship between Diversity and Accommodation on a scattergram and finding the regression line, the nature of the relationship becomes more apparent (see Figure 1 below). Having a high level of diversity does not mean that a country is likely to accommodate their minority identity groups, but having a low level of diversity means that they are less likely to. This is further considered through multivariate regression analysis. 
Figure A1: Relationship between Diversity and Accommodation

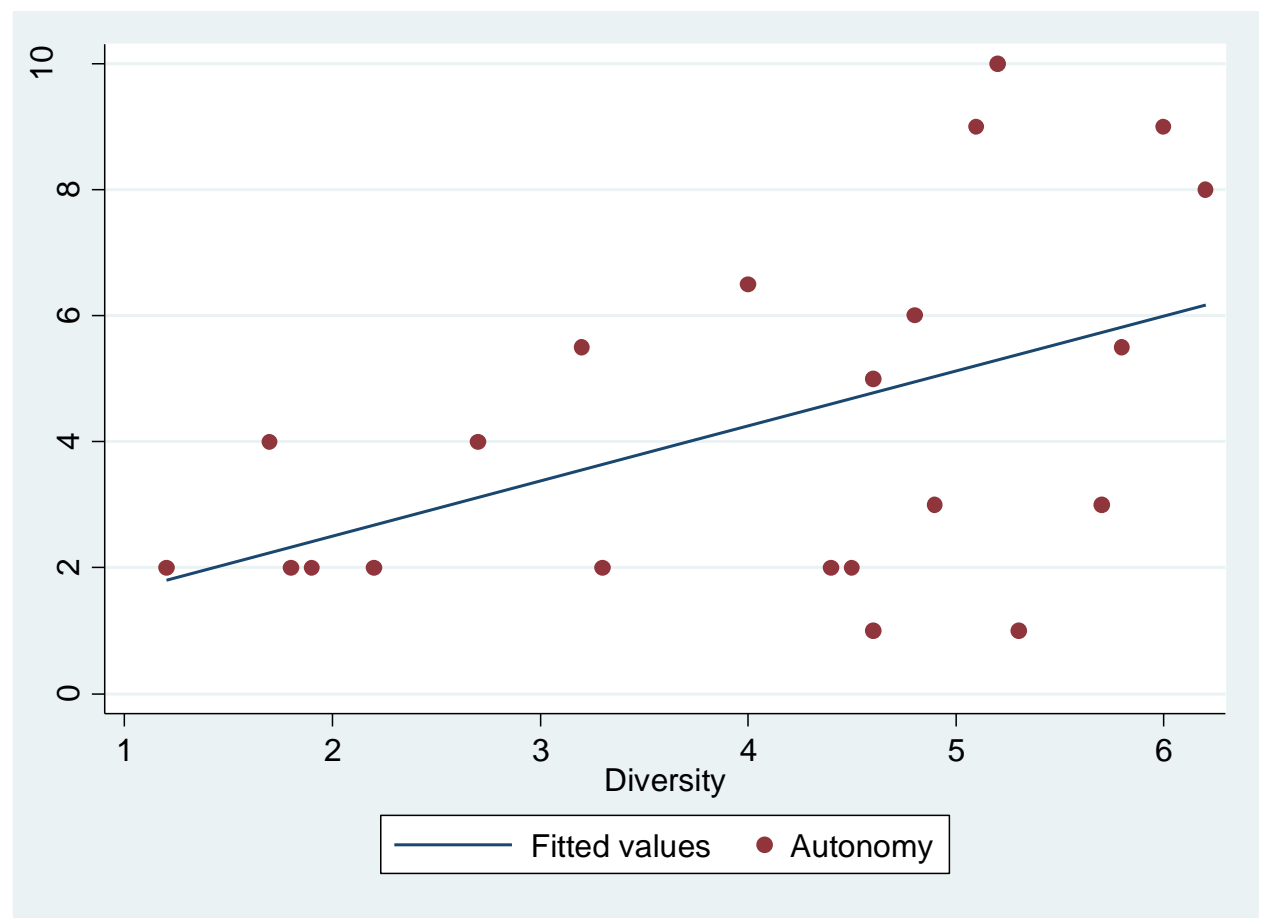

\section{A4.3.2 Diversity and accommodation}

Multiple regression analyses were undertaken to test the significance of Diversity $\left(\mathrm{H}_{1}\right)$ using Conflict, Democracy and State Formation as control variables. As mentioned, there were 22 observations and although there are only four variables, the use of dummy variables for analysis purposes provides for 16 degrees of freedom. Religion and Constitutional Secularism were removed from the analysis as Constitutional Secularism was found to have no impact and Religion had too few observations falling in each category so as to blur the results. A $90 \%$ confidence interval was used and the estimation method was Ordinary Least Squares. The null hypothesis is $\mathrm{H}_{0}$ : $\mathrm{B}_{\text {Diversity }} \leq 0$. A number of tests were also run and some adjustments to data made. These are discussed below.

The regression analysis found Diversity was a statistically and substantively significant predictor of Accommodation when controlling for other factors. Those other factors, State Formation, Conflict and Democracy were found not to be statistically significant, although prewar states could be said to have a substantively significant positive relationship with Accommodation. 
Table A31: Regression analysis results for Diversity and Accommodation

\begin{tabular}{|l|l|l|}
\hline Variable & Co-efficient & $\mathbf{P}>\mathbf{t} \mid$ \\
\hline Diversity & 0.797 & 0.066 \\
\hline Conflict & 0.164 & 0.353 \\
\hline Post-colonial (SF) & -0.305 & 0.878 \\
\hline Prewar (SF) & 0.570 & 0.779 \\
\hline Democracy & 0.097 & 0.747 \\
\hline Constant & 0.147 & 0.958 \\
\hline
\end{tabular}

The model explained approximately $30 \%$ of the variance ( $R 2=0.2956)$, although the model itself was not reliable with $P>F=0.2962$. Hence several tests were run. Initially it was considered that the independent variables may be affecting each other, noting though the lack of correlation amongst them as discussed above. A variance inflation test was performed, and there was no substantive relation found across the independent variables.

Next tests for heteroskedasticity were conducted. A variable for residuals (e) and a scatterplot were created. This showed a random distribution. Next a Breusch-Pagan / CookWeisberg test for heteroskedasticity was conducted using the fitted values of the dependent variable. Heteroskedasticity did not appear to be present (Prob>Chi=0.07). It was also checked whether the residuals were normally distributed. As per Figure 2 below, the residuals were normally distributed considering the number of observations.

Figure A2: Distribution of error term

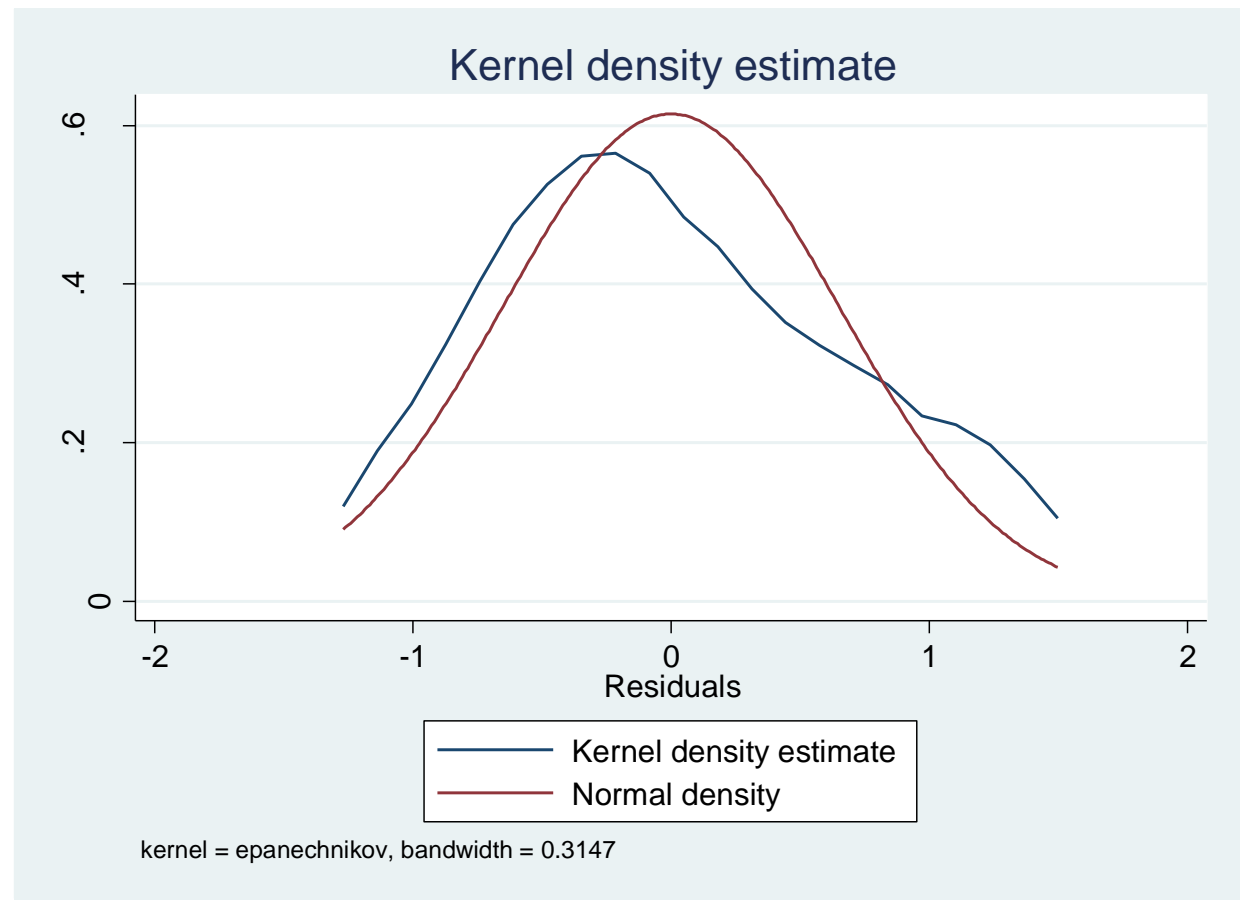

The distribution of the dependent variable was also tested for. Again, given the small number of observations, the dependent variable was normally distributed (see Figure A3). 
Figure A3: Distribution of the dependent variable

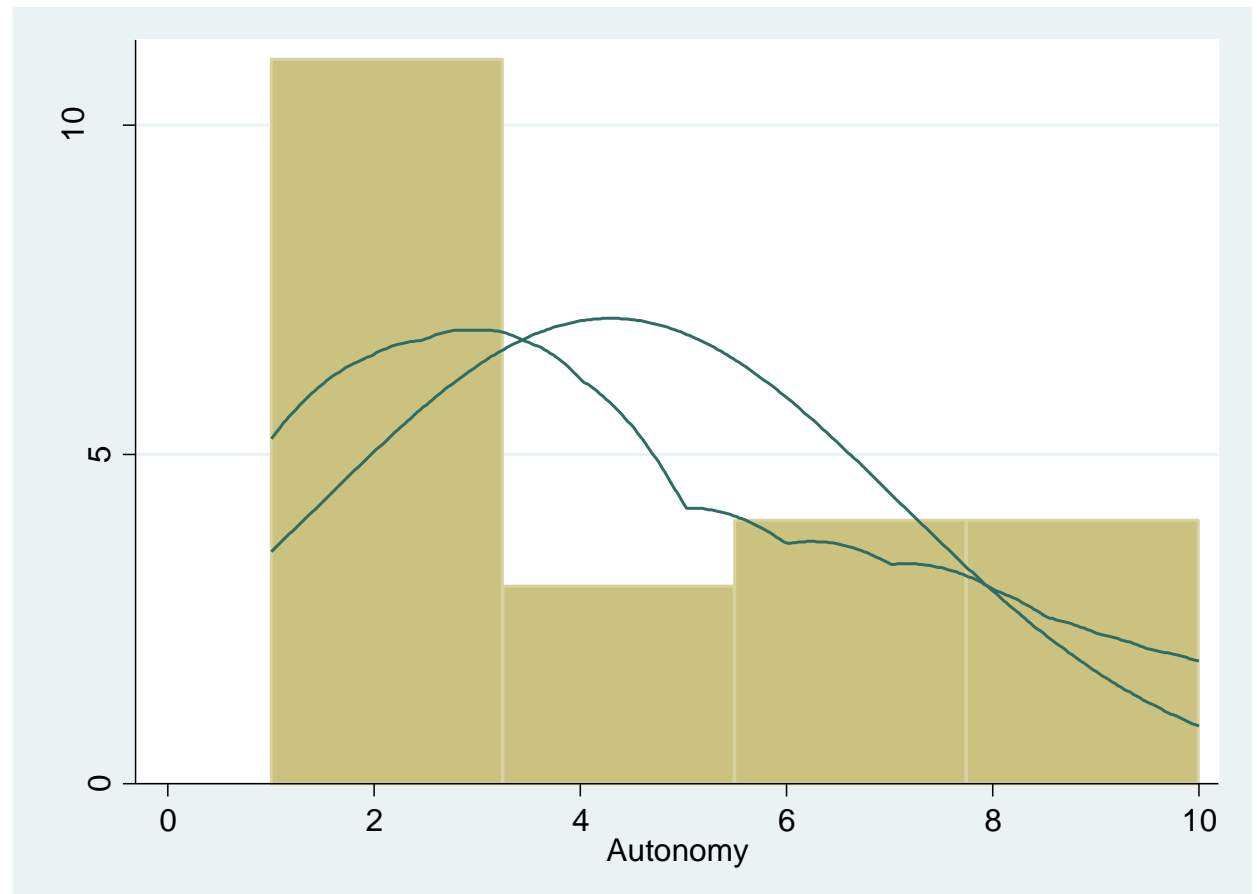

Next a specification test was run to ensure that the relationship between the variables was linear, which was confirmed. Finally, an OV Test was run to check for omitted variables, and none were identified. It was thereby concluded that the null hypothesis can be rejected and that Diversity is positively related to Accommodation. Further, it appears likely that the role of State Formation is insignificant (Hypothesis 4).

A test for outliers was also conducted by predicting the yhat, residual and rstandard (zscores). There were a number of high residuals $(>2)$, which was not surprising given the small number of observations. The most significant outliers were India, which scored highly on the dependent variable scale and was under predicted by 4.08 , and Thailand, which was over predicted by -4.10 . Given the next three most significant outliers are Nepal, Bhutan and Sri Lanka, it may be that Buddhism and Hinduism are significant factors, as per Hypothesis 5, with Buddhism decreasing the degree of accommodation and Hinduism increasing (see discussion below).

\section{A4.3.3 The role of conflict}

It is hypothesized (2) that Conflict has a moderating effect on Diversity and that Conflict will make it more likely that a country with high diversity will accommodate its minority identity groups. To test this hypothesis, the Null Hypothesis is $\mathrm{H}_{0}$ : DivCon>0, where DivCon is the moderating variable. A new variable, DivCon was created by multiplying Diversity by Conflict, and a regression analysis was run. The results are presented in Table 3 below. 
Table A32: Regression results for Conflict moderating Diversity

\begin{tabular}{|l|l|l|l|}
\hline Independent Variable & Dependent Variable & Co-efficient & $\mathbf{P}>|\mathbf{t}|$ \\
\hline Diversity & Accommodation & 0.737 & 0.115 \\
Conflict & & 0.027 & 0.977 \\
DivCon (moderator) & & 0.024 & 0.903 \\
\hline
\end{tabular}

Given these results, although not statistically significant, it is enough to reject the Null Hypothesis and support the alternative hypothesis that Conflict has a moderating effect on Diversity. Specifically, every increase of one point/degree in conflict will increase the impact of Diversity on the degree to which an Asian State will accommodate its minority identity groups, by 0.024 , to such that for a value of Conflict at 2, the effect of Diversity on Accommodation would be $0.785(0.737+(2 * 0.24))$, holding other factors constant.

It was surprising that Conflict was found to be so insignificant, especially with respect to its relationship to Diversity (see $5 b)$ ). However, there are apparent explanations. When interrogating the data, it can be seen that there are three countries that have high scores for Conflict and Diversity, but which did not have high levels of Accommodation, namely Vietnam, Laos and Cambodia. Each of these had significant internal conflict that involved external forces (the US) and which did not always relate to identity group demands. Hence these types of conflicts are not likely to contribute to accommodation. Further, Malaysia had no internal conflict, but did accommodate. This can be explained by the post-colonial process and imposition of federalism by the withdrawing British. Nonetheless, if the data is adjusted to discount conflicts in Vietnam, Laos and Cambodia there is little difference, probably due to Malaysia (and perhaps Pakistan and Bangladesh). Removing all these anomalous cases would bring the integrity of the model into question.

\section{A4.3.4 The role of democracy}

It is hypothesized that Democracy (and hence regime type) has a mediating effect on Diversity $\left(\mathrm{H}_{4}\right)$, such that a higher degree of Democracy will amplify the effect on Accommodation of Diversity. First the relationship between Diversity and Accommodation was confirmed as positively correlated and statistically significant. The relationship between Diversity and Democracy was positively correlated but was neither substantively significant, nor statistically significant. The coefficient of Diversity was only 0.09 less when coupled with the mediating variable, or an effect of approximately $1 \%$ holding other factors constant, and, as mentioned the effect of Diversity on Democracy was insignificant, which is in keeping with the hypothesis. However, given the lack of statistical significance, one cannot take much from the results. 
Table A33: Regression results for Democracy mediating Diversity

\begin{tabular}{|l|l|l|l|}
\hline Independent Variable & Dependent Variable & Co-efficient & $\mathbf{P}>|\mathbf{t}|$ \\
\hline Diversity & Accommodation & 0.875 & 0.022 \\
\hline Diversity & Democracy & 0.031 & 0.847 \\
\hline Diversity & Accommodation & 0.866 & 0.010 \\
Democracy & & 0.141 & 0.564 \\
\hline
\end{tabular}

\section{A4.3.5 Religion, secularization and accommodation}

Analyses of variance and covariance was undertaken using one-way and two-way ANOVA methods to test the effect of religion and constitutional secularization on the extent of accommodation. The Null Hypothesis is that the mean scores across religions are equal $\left(\mathrm{H}_{0}\right.$ : $\mathrm{u}_{1}=\mathrm{u}_{2}=\mathrm{u}_{3}=\mathrm{u}_{4}=\mathrm{u}_{5}$ ). The results are informative but must be treated with caution given the small sample size, the limited number of observations in certain categories and the lack of controlled factors.

Firstly, a one-way ANOVA test was run using Religion and its five given categories/factors (Buddhist, Confucian/Secular, Muslim, Hindu and Christian). The results were as anticipated, with Buddhism having the lowest mean at 3.23, followed by (in increasing order), Confucian/Secularism, Muslim, Christian and Hindu. The model appears robust with higher mean squares across groups (16.84) as compared to within groups (5.68), a relatively uniform standard deviation (where population numbers allowed relevance) and $p<0.05$. Therefore, the null hypothesis was rejected and the hypothesis supported.

Figure A4: Graphical representation of relationship between religion and accommodation

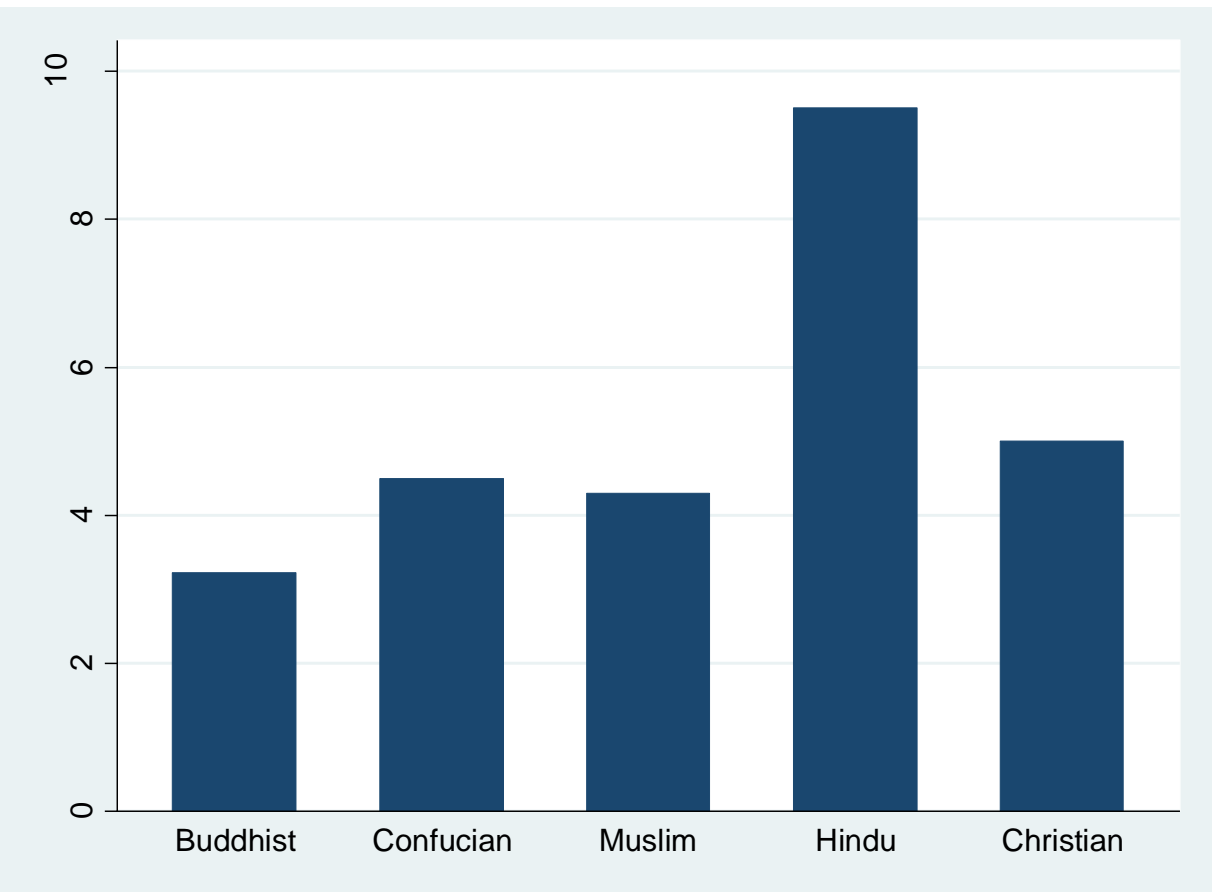


When it comes to Secularism, the one-way ANOVA test showed little difference between secular and non-secular states generally with each category having a similar mean (4.1 to 4.5), while $p<0.075$. A two-way ANOVA test was then run, to see whether Secularism interacted with Religion in any kind of influential way. The results reaffirmed that constitutional secularism was not substantively significant and it did not combine in any meaningful way, though the model remained robust $(P<0.058)$. If anything, secularism had the opposite effect to that expected whereby Buddhist states that had shown a reluctance to accommodate appeared more likely to accommodate if they were non-secular (a mean of 3.8 versus 2.3). In any case, the results of the ANOVA test indicate that certain religious cultures are less likely to accommodate than others, in particular Buddhism, while Hindu cultures have shown a willingness to accommodate to a high degree. Key results are summarized in the Table A33.

Table A33: ANOVA test results summary

\begin{tabular}{|l|l|l|l|l|l|l|l|l|l|}
\hline \multirow{2}{*}{ Religion } & \multicolumn{4}{l}{ Mean } & \multicolumn{4}{l|}{ Standard Deviation } & \multicolumn{3}{l|}{ Frequency } \\
\cline { 2 - 10 } & Unsp. & Non-S & Sec & Unsp. & Non-S & Sec & Unsp. & Non-S & Sec \\
\hline Buddhist & 3.2 & 3.8 & 2.3 & 2.3 & 2.7 & 0.5 & 11 & 7 & 4 \\
\hline Confucian/Secular & 4.5 & - & 4.5 & 2.2 & - & 2.2 & 3 & - & 3 \\
\hline Muslim & 4.3 & 4.6 & 3.0 & 3.2 & 3.4 & 0.0 & 5 & 4 & 1 \\
\hline Hindu & 9.5 & - & 9.5 & 0.7 & - & 0.7 & 2 & - & 2 \\
\hline Christian & 5.0 & - & 5.0 & 0.0 & - & 0.0 & 1 & - & 1 \\
\hline
\end{tabular}

(Unsp = unspecified; Non-s = Non-secular; Sec = Secular, as per the countries' constitution).

\section{A4.4 Summary}

The model developed to predict the degree of accommodation does not appear adequate to draw any strong generalization. The low number of observations and the lack of statistically significant independent variables suggests that the conditions which lead to a state to accommodate are too complex, interrelated and endogenous for a quantitative approach.

In any case, all of the results were consistent with the hypotheses, a number of interesting observations can be made and one generalization appears possible. That is, Hypothesis 1 , that a high level of diversity increases the likelihood that a state will accommodate their minority identity groups. In particular, if there is a low level of diversity, repression or at least non-accommodation would appear likely. A possible explanation is that the higher the diversity the less likely there is to be secession. This will be investigated further.

It can be observed that conflict does appear to have a moderating effect on diversity, that is it appears to make it more likely that a country will accommodate its ethnic groups on account. However, the result is much smaller than expected, though there are explanations available. Qualitative analysis of the role of conflict would surely draw a stronger conclusion, given that many autonomous arrangements are agreed in direct response to conflict (e.g. the Philippines and Mindanao, and Indonesia and Aceh). The results this suggest a data validity 
problem, or simply a variety of other factors combining in different ways with conflict to elicit different responses.

Further, it can be observed that democracy seems to have a positive mediating effect on diversity although again this is insignificant. This observation would run contrary to common explanations for the lack of accommodation in Asia, because the level of democracy as well as the mode of state formation (e.g. whether by secession or through the withdrawal of colonial masters) appear to have little influence over the extent to which a state accommodates its ethnic groups. This would support Hypotheses 3 and 4.

Finally, with relation to Hypothesis 5, it would appear that religious culture in a state has a strong bearing on the degree of accommodation, in particular, if the state is predominantly Buddhist, accommodation will be low, and if it is Hindu, accommodation will be high. However, it does appear that the secularization of the state (as in the constitution) is irrelevant. 
Table A34: Factors and scores for dependent variable

\begin{tabular}{|l|l|l|l|l|l|}
\hline Country & Repression & Language & Inclusion & Autonomy & Score \\
\hline Bangladesh & 2 & 0 & 0 & 0 & 2 \\
\hline Bhutan & 1 & 0 & 0 & 0 & 1 \\
\hline Brunei & 2 & 0 & 0 & 0 & 2 \\
\hline Cambodia & 2 & 0 & 2 & 0 & 4 \\
\hline China & 0 & 0 & 1.5 & 2 & 5.5 \\
\hline India & 2 & 2 & 2 & 4 & 10 \\
\hline Indonesia & 1 & 0 & 1.5 & 2 & 5.5 \\
\hline Japan & 2 & 0 & 0 & 0 & 2 \\
\hline Korea North & 2 & 0 & 0 & 0 & 2 \\
\hline Korea South & 2 & 0 & 0 & 0 & 2 \\
\hline Laos & 2 & 0 & 2 & 0 & 3 \\
\hline Malaysia & 2 & 0 & 2 & 0 & 8 \\
\hline Mongolia & 2 & 0 & 2 & 0 & 4 \\
\hline Myanmar & 1 & 0 & 1.5 & 4 & 6.5 \\
\hline Nepal & 2 & 1 & 2 & 4 & 9 \\
\hline Pakistan & 2 & 2 & 1 & 4 & 9 \\
\hline Philippines & 2 & 0 & 1 & 2 & 5 \\
\hline Singapore & 2 & 2 & 0 & 0 & 3 \\
\hline Sri Lanka & 0 & 0 & 0 & 0 & 2 \\
\hline Taiwan & 2 & 0 & 0 & 0 & 2 \\
\hline Thailand & 0 & 0 & 0 & 0 & 2 \\
\hline Vietnam & 2 & 0 & 0 & 2 & 2 \\
\hline
\end{tabular}


Table A35: Codebook

\begin{tabular}{|c|c|c|c|c|}
\hline Variable & Indicator & Description & Code & Reference \\
\hline Diversity & $\begin{array}{l}\text { Ethnic } \\
\text { fractionalizati } \\
\text { on }\end{array}$ & $\begin{array}{l}\text { Average of ethnic, } \\
\text { language and religious } \\
\text { diversity } \\
\text { fractionalization index }\end{array}$ & 0 to 10 & $\begin{array}{l}\text { (Alesina et al. } \\
2003 \text { ) }\end{array}$ \\
\hline Conflict & $\begin{array}{l}\text { Length of } \\
\text { internal } \\
\text { conflict }\end{array}$ & $\begin{array}{l}\text { Combined length of } \\
\text { internal conflict in days } \\
\text { since } 1944 \text {, divided by } \\
1000\end{array}$ & 0 to 15 & $\begin{array}{l}\text { (Sarkees \& } \\
\text { Wayman 2010) }\end{array}$ \\
\hline Democracy & $\begin{array}{l}\text { Democracy } \\
\text { index }\end{array}$ & $\begin{array}{l}\text { Weighted average of } \\
\text { factors such as } \\
\text { presence of free and } \\
\text { fair elections }\end{array}$ & 0 to 10 & $\begin{array}{l}\text { (Economist } \\
\text { Intelligence Unit } \\
2013 \text { ) }\end{array}$ \\
\hline \multirow[t]{3}{*}{ State formation } & \multirow[t]{3}{*}{ Origin of State } & \multirow{3}{*}{$\begin{array}{l}\text { Based on whether state } \\
\text { was formed via } \\
\text { decolonisation or } \\
\text { secession, post world } \\
\text { war II, or existed prior } \\
\text { to that war }\end{array}$} & $\begin{array}{l}0=\text { other } \\
1=\text { secession }\end{array}$ & \multirow{3}{*}{$\begin{array}{l}\text { (Central } \\
\text { Intelligence } \\
\text { Agency 2007) }\end{array}$} \\
\hline & & & $\begin{array}{l}0=\text { other } \\
1=\text { postcolonia } \\
I\end{array}$ & \\
\hline & & & $\begin{array}{l}0=\text { other } \\
1=\text { pre-war }\end{array}$ & \\
\hline $\begin{array}{l}\text { Secularization } \\
\text { (ConstSecul) }\end{array}$ & $\begin{array}{l}\text { Constitutional } \\
\text { Secularization }\end{array}$ & $\begin{array}{l}\text { Whether or not a State } \\
\text { religion is recognized in } \\
\text { the country's } \\
\text { constitution }\end{array}$ & $\begin{array}{l}0=\text { Yes } \\
1=\text { No }\end{array}$ & $\begin{array}{l}\text { (Pew Templeton } \\
\text { Global Religious } \\
\text { Futures Project } \\
\text { 2012) }\end{array}$ \\
\hline \multirow[t]{5}{*}{ Religion } & \multirow{5}{*}{$\begin{array}{l}\text { Dominant } \\
\text { state religion } \\
\text { or culture }\end{array}$} & \multirow{5}{*}{$\begin{array}{l}\text { Categorical } \\
\text { identification of the } \\
\text { dominant state religion } \\
\text { or culture in terms of } \\
\text { percentage of people } \\
\text { subscribing to that } \\
\text { particular religion or } \\
\text { culture }\end{array}$} & $\begin{array}{l}0=\text { other } \\
1=\text { Buddhist }\end{array}$ & \multirow{5}{*}{$\begin{array}{l}\text { (Central } \\
\text { Intelligence } \\
\text { Agency 2007) }\end{array}$} \\
\hline & & & $\begin{array}{l}0=\text { other } \\
\text { 1=Confucian/ } \\
\text { secular }\end{array}$ & \\
\hline & & & $\begin{array}{l}0=\text { other } \\
1=\text { Muslim }\end{array}$ & \\
\hline & & & $\begin{array}{l}0=\text { other } \\
1=\text { Hindu }\end{array}$ & \\
\hline & & & $\begin{array}{l}0=\text { other } \\
1=\text { Christian }\end{array}$ & \\
\hline $\begin{array}{l}\text { Accommodatio } \\
\text { n (DVAccom) }\end{array}$ & $\begin{array}{l}\text { Accommodati } \\
\text { on of minority } \\
\text { identity } \\
\text { groups }\end{array}$ & $\begin{array}{l}\text { Whether and to what } \\
\text { extent a State has } \\
\text { accommodated its } \\
\text { minority identity } \\
\text { groups, based on } \\
\text { measures of repression, } \\
\text { recognition, inclusion \& } \\
\text { autonomy. }\end{array}$ & 0 to 10 & $\begin{array}{l}\text { (Central } \\
\text { Intelligence } \\
\text { Agency 2007) } \\
\text { (He, Galligan \& } \\
\text { Inoguchi 2007) } \\
\text { (Malik et al. } \\
\text { 2009) } \\
\text { (Wucherpfennig } \\
\text { et al. 2011) }\end{array}$ \\
\hline
\end{tabular}


Table A36: Variable correlation

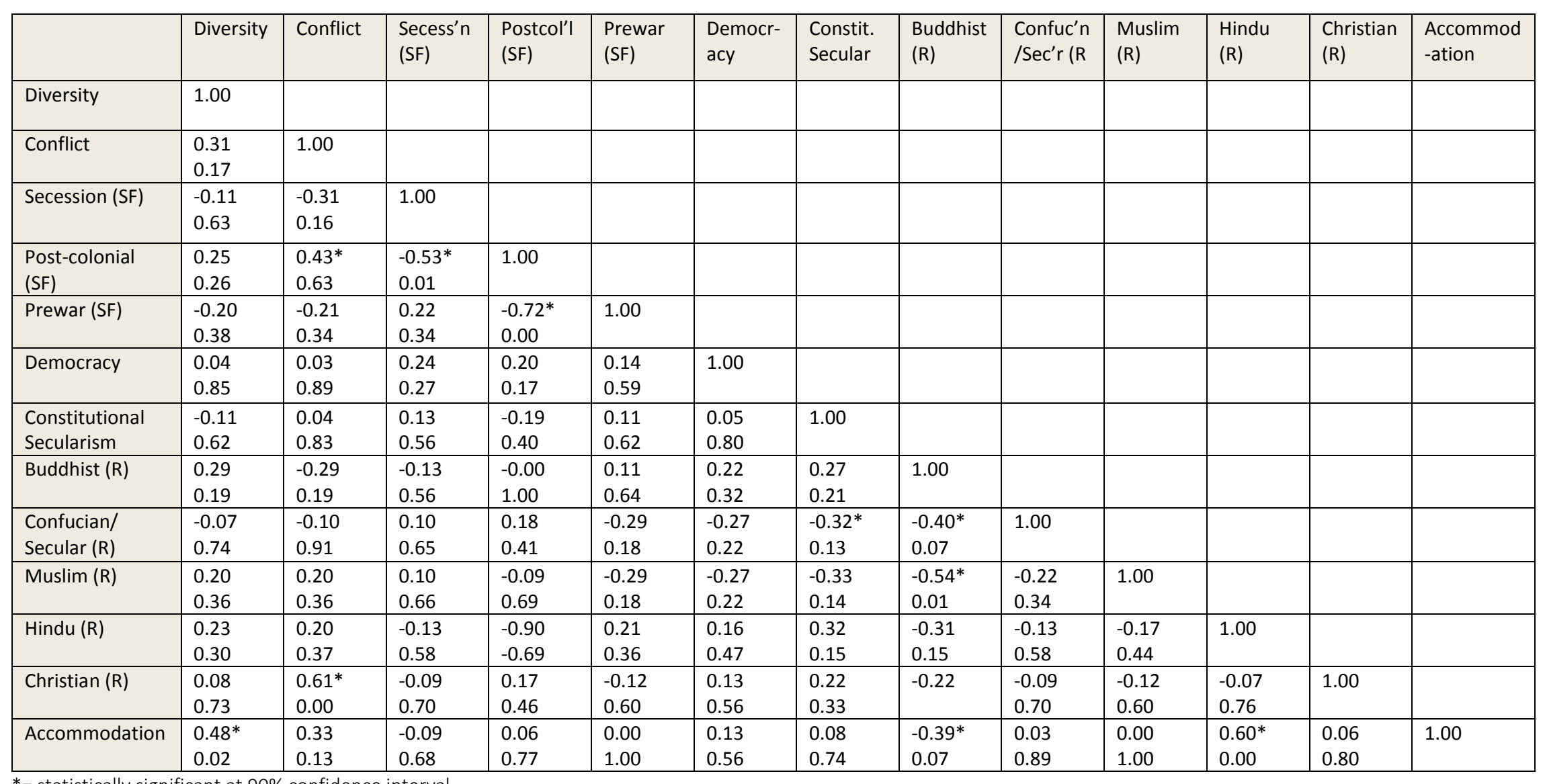

$*$ = statistically significant at $90 \%$ confidence interval 
[back page] 
